Antike Mythologie in christlichen Kontexten der Spätantike 


\section{Millennium-Studien}

zu Kultur und Geschichte

des ersten Jahrtausends $\mathbf{n}$. Chr.

\section{Millennium Studies}

in the culture and history

of the first millennium C.E.

Herausgegeben von / Edited by

Wolfram Brandes, Alexander Demandt,

Helmut Krasser, Hartmut Leppin,

Peter von Möllendorff, Karla Pollmann

\section{Band 54}




\section{Antike Mythologie in christlichen Kontexten der Spätantike}

Herausgegeben von

Hartmut Leppin

DE GRUYTER 
Diese Publikation wurde im Rahmen des an der Bayerischen Staatsbibliothek durchgeführten und durch das Bundesministerium für Bildung und Forschung geförderten Vorhabens 16TOA021 Reihentransformation für die Altertumswissenschaften (,Millennium Studien“) mit Mitteln des DFG-geförderten Projekts Fachinformationsdienst Altertumswissenschaften - Propylaeum im Open Access bereitgestellt.

\section{(cc) BY-NC-ND}

Dieses Werk ist lizenziert unter der Creative Commons Attribution-NonCommercial-NoDerivatives 4.0 International Lizenz. Weitere Informationen finden Sie unter http://creativecommons.org/licenses/by-nc-nd/4.0/.

Die Bedingungen der Creative-Commons-Lizenz gelten nur für Originalmaterial. Die Wiederverwendung von Material aus anderen Quellen (gekennzeichnet mit Quellenangabe) wie z.B. Schaubilder, Abbildungen, Fotos und Textauszüge erfordert ggf. weitere Nutzungsgenehmigungen durch den jeweiligen Rechteinhaber.

ISBN 978-3-11-040043-4

e-ISBN (PDF) 978-3-11-040495-1

e-ISBN (EPUB) 978-3-11-040506-4

ISSN 1862-1139

\section{Library of Congress Cataloging-in-Publication Data}

A CIP catalog record for this book has been applied for at the Library of Congress.

\section{Bibliografische Information der Deutschen Nationalbibliothek}

Die Deutsche Nationalbibliothek verzeichnet diese Publikation in der Deutschen

Nationalbibliografie; detaillierte bibliografische Daten sind im Internet

über http://dnb.dnb.de abrufbar.

(C) 2015 Walter de Gruyter GmbH, Berlin/München/Boston

Druck und Bindung: $\mathrm{CPI}$ books $\mathrm{GmbH}$, Leck

@) Gedruckt auf säurefreiem Papier

Printed in Germany

www.degruyter.com 


\section{Vorwort}

Dieser Band ist hervorgegangen aus einer Tagung zu demselben Thema, die in Frankfurt am Main im November 2012 stattfand. Möglich wurde sie wie auch die Erarbeitung des Bandes dank einer großzügigen Unterstützung durch ein KoselleckProjekt der Deutschen Forschungsgemeinschaft.

Das Thema des Sammelbandes ist von großer Breite. Es konnte daher nicht Ziel des Unternehmens sein, Vollständigkeit zu erlangen. Vielmehr ging es darum, den Facettenreichtum des Gegenstandes sichtbar zu machen, indem Vertreter unterschiedlicher Disziplinen und Forschungsansätze ins Gespräch gebracht wurden. Das sollte auch der vorliegende Band spiegeln. Da er mithin interdisziplinär angelegt ist, wurde in der Zitierweise keine Einheitlichkeit angestrebt, sondern eine Übersetzbarkeit der Angaben in andere Fächerkulturen.

Die Tagung und der Band wären ohne die Unterstützung zahlreicher Beteiligter nicht möglich gewesen. $\mathrm{Zu}$ danken ist für die redaktionelle Arbeit vor allem Marius Kalfelis M.A., ferner Sebastian Bauer und Sophie Röder und Serena Pirrotta für die souveräne Betreuung im Verlag. Das Register wurde erstellt durch Sebastian Bauer.

Frankfurt am Main, im Mai 2014 



\section{Inhalt}

Vorwort - V

Einleitung: Antike Mythologie in christlichen Kontexten der Spätantike - 1

Claudia Schindler

Pagane Mythen - christliche Herrscher. Mythos und Mythologie in den politischen Dichtungen Claudians - 19

Domenico Accorinti

Nonnos und der Mythos: Heidnische Antike aus christlicher Perspektive - 43

Ulrich Schmitzer

Sidonius Apollinaris - unfruchtbare Muse oder Erneuerung der Poesie im Zeichen des Mythos? - 71

Christian Schäfer

„Scheinbare Extravaganz“. Pagane und christliche Platoniker über die Wunderlichkeit des Mythos — 93

Winrich Löhr

Christliche Bischöfe und klassische Mythologie in der Spätantike — 115

Henrike Maria Zilling

Die Mimesis des Heros: Pagane Helden in christlicher Deutung - 139

Mischa Meier

Herakles - Herakleios - Christus. Georgios Pisides und der kosmorhýstes — 167

Fabienne Jourdan

Orpheus and 'Orphism' in the Christian Literature (in Greek) of the First Five Centuries - 193

Clifford Ando

Mythistory: The Pre-Roman Past in Latin Late Antiquity — 207

Jörg Rüpke

Geteilte und umstrittene Geschichten: Der Chronograph von 354 und die Katakombe an der Via Latina - 221 
VIII — Inhalt

Sarah Bassett

"Curious Art": Myth, Sculpture, and Christian Response in the World of Late Antiquity 239

Troels Myrup Kristensen

Dressed in Myth: Mythology, Eschatology, and Performance on Late Antique Egyptian Textiles — 263

Abstracts -297

Abkürzungen (Editionen, Zeitschriften, Reihen, Nachschlagewerke) — 303

Personenregister -309

Register der Orte, Länder und Völkerschaften — 317 


\section{Einleitung: Antike Mythologie in christlichen Kontexten der Spätantike ${ }^{1}$}

In eine christliche Gefangenschaft sei der klassische Mythos während der Spätantike geraten. Zwar habe das Christentum ihn geduldet, doch: Solche Liberalität war die Schautoleranz der konsolidierten Macht. Mit so drastischen Worten beschreibt Hans Blumenberg in einem eindringlichen Aufsatz die Zäsur, die nach seiner Deutung die Christianisierung der Römischen Welt für die Geschichte des Mythos bedeutete. ${ }^{2}$ Die Zeit der Renaissance erscheint bei solchen Prämissen als Epoche der Befreiung für die alten Götter.

Diese Einschätzung gab der Philosoph an einem prominenten Ort, nämlich in dem 1971 erschienenen Sammelband Terror und Spiel, herausgegeben von Manfred Fuhrmann, dessen Ziel es laut Untertitel war, Probleme der Mythenrezeption zu behandeln. Er war ein Tagungsband der in Deutschland höchst einflussreichen Arbeitsgruppe Poetik und Hermeneutik, in der sich Vertreter verschiedener Fächer regelmäßig trafen, um ein zentrales Thema der Geisteswissenschaften unter interdisziplinären Gesichtspunkten zu beleuchten. $\mathrm{Zu}$ den Teilnehmern zählten neben Hans Blumenberg viele weitere bedeutende Gelehrte, etwa die Literaturwissenschaftler Wolfgang Iser und Hans Robert Jauß, der Religionswissenschaftler Jacob Taubes, der Historiker Reinhart Koselleck und aus den Altertumswissenschaften Forscher wie die Latinisten Manfred Fuhrmann und Reinhart Herzog oder der Althistoriker Christian Meier.

Die daraus resultierenden Sammelbände, gerade die älteren, sind zum Teil bis heute Standardwerke geblieben, und das zu Recht. ${ }^{3}$ Dies gilt auch für das genannte

1 Dieser Essay versucht den Ertrag des Sammelbandes zu profilieren; Literaturhinweise können nur exemplarisch sein und verstehen sich eher als Ergänzungen zu den umfänglichen Hinweisen in den Einzelbeiträgen des Bandes.

2 Hans Blumenberg, Wirklichkeitsbegriff und Wirkungspotential des Mythosbegriffs, in: Manfred Fuhrmann (Hg.), Terror und Spiel. Probleme der Mythenrezeption (Poetik und Hermeneutik 4), München $1990^{2}$, 11-66; s. die Diskussion der Teilnehmer dazu ibid., 527-547 und Hans Robert Jauß, Allegorese, Remythisierung und neuer Mythos. Bemerkungen zur christlichen Gefangenschaft der Mythologie im Mittelalter, ibid., 187-209. - Zu Blumenberg allgemein vgl. etwa Elizabeth Brient, The Immanence of the Infinite: Hans Blumenberg and the Threshold to Modernity, Washington, D.C. 2002; Franz Josef Wetz, Hans Blumenberg zur Einführung (Zur Einführung 289), Hamburg $2004^{2}$ (insbes. 100 -114 zum Mythos); Felix Heidenreich, Mensch und Moderne bei Hans Blumenberg, München 2005 (insbes. 67-74); Oliver Müller, Sorge um die Vernunft. Hans Blumenbergs phänomenologische Anthropologie, Paderborn 2005 (insbes. 177-181); Nadia Sels, The Function of Irony in Mythical Narratives. Hans Blumenberg and Homer's Ludicrous Gods, in: Wim M. J.van Binsbergen/Eric Venbrux (Hg.), New Perspectives on Myth. Proceedings of the Second Annual Conference of the International Association for Comparative Mythology, Ravenstein 19.-21. August 2008 (Papers in Intercultural Philosophy and Transcontinental Comparative Studies 5), Nimwegen 2010, 409-426.

3 Zu erwähnen wäre etwa Hans Robert Jauß (Hg.), Nachahmung und Illusion (Poetik und Hermeneutik 1), München 1964; Wolfgang Iser (Hg.), Immanente Ästhetik, ästhetische Reflexion: Lyrik als Paradigma 
Buch, das für die Behandlung der Mythenrezeption weiterhin unverzichtbar ist und zumal in den Literaturwissenschaften anregend wirkt. Daher wird dieser Band, der zugleich eine bestimmte Phase der Forschung eindrucksvoll repräsentiert, hier zum Ausgangspunkt der Einleitung genommen, obwohl er schon vor geraumer Zeit erschienen ist. ${ }^{4}$ Zudem erscheint die Auseinandersetzung mit dem plastischen Bild der christlichen Gefangenschaft des Mythos schon deswegen lohnend, weil es in seinen Vorannahmen so aufschlussreich ist. Denn der dogmatischen Ungebundenheit und Plastizität der Mythologie werden der dogmatische Ernst des Christentums und seine Unduldsamkeit gegenübergestellt. ${ }^{5}$

Blickt man auf die weiteren Beiträge jenes Bandes, so lassen sich zwei Subtexte beobachten: zum einen der eines krassen Gegensatzes zwischen Christentum und Heidentum, zum anderen der Versuch, dem Ganzen eine politische Dimension abzugewinnen, indem man eine moderne Begrifflichkeit, Ausdrücke wie Liberalität oder Toleranz, den antiken Gegebenheiten überstülpt. In beiden Punkten wird man heute vorsichtiger sein: Weder gelten die Entitäten Heidentum und Christentum als festgefügt noch wird man so unbefangen Begriffe der modernen politischen Kommunikation auf eine ältere Epoche übertragen, wie das in den siebziger Jahren geschah.

Charakteristisch für Blumenbergs Verständnis der Problematik erscheint folgende Passage: Die christliche Apologetik hat ihn (sc. den Mythos) ebenso mißverstanden, als sie - in absoluter Ernsthaftigkeit gegenüber den Widersprüchen der Mythologie und ihrer Frivolität - dort im Grunde den Konkurrenten sah, der wegen des vermeintlichen Gehaltes an ,Lehre، auszuschalten und dessen Stelle einzunehmen war, während doch in Wirklichkeit es nur die an den Gehalten der Mythologie praktizierte Liberalität gewesen ist, die als bleibend konkurrierende Unterströmung bis tief in die Renaissance und Neuzeit hinein dem Christentum als der Form des dogmatischen Ernstes und absoluter Verbindlichkeit den kontrastierenden Modus des Denkens und Sprechens darbot. Bezeichnend ist die empirisch schlicht unzutreffende Behauptung: Die Liberalität der

der Moderne (Poetik und Hermeneutik 2), München 1966; Hans Robert Jauß (Hg.), Die nicht mehr schönen Künste: Grenzphänomene des Ästhetischen (Poetik und Hermeneutik 3), München 1968.

4 Blumenberg hat diese Überlegungen später in sein großangelegtes Projekt der Arbeit am Mythos eingehen lassen, das das Thema in einer anthropologischen Dimension entfaltet, s. idem, Arbeit am Mythos, Frankfurt a. M. zuerst 1979; zur Einordnung dieser Arbeit etwa Ada Neschke-Hentschke, Rez. zu Hans Blumenberg: Arbeit am Mythos, Zeitschrift für philosophische Forschung 37 (1983), 448 - 453, die insbes. 450 den universalen Anspruch des Blumenberg'schen Mythosbegriffs kritisiert. Zur problematischen Entgegensetzung von Mythos und Dogma etwa Enno Rudolph, Mythos - Logos - Dogma. Eine Auseinandersetzung mit Hans Blumenberg, in: Oswald Bayer (Hg.), Mythos und Religion. Interdisziplinäre Aspekte, Stuttgart 1990, 58-79. Zur Kontextualisierung innerhalb der philosophischen Diskussionen zum Mythos Jörg Villwock, Mythos und Rhetorik. Zum inneren Zusammenhang zwischen Mythologie und Metaphorologie in der Philosophie Hans Blumenbergs, Philosophische Rundschau 32 (1985), 68-91.

5 Schon kritisiert von Jacob Taubes, Der dogmatische Mythos der Gnosis, in: Fuhrmann (s. Anm. 2), 145-156. Vgl. auch die Diskussion zu Blumenberg ibid., 527-547. 
Mythologie überlebte nur in den Übungsstücken der Rhetorik. ${ }^{6}$ Niemand wird heute daran zweifeln, dass das Überleben auf einer viel breiteren Grundlage erfolgte.

Bezogen auf die Spätantike, liegt verschiedenen Beiträgen jenes Bandes ferner eine Phasenmodell zugrunde, das vor allem ein kurz zuvor erschienener Aufsatz des Latinisten Manfred Fuhrmann entfaltet hatte: Fuhrmann vertrat die Auffassung, dass nach einer Zeit der Konfrontation im 5. Jahrhundert die christlichen und die heidnischen Eliten einen Kompromiss geschlossen hätten, der es erlaubt habe, bei Verzicht auf die traditionellen Kulte innerhalb bestimmter poetischer Gattungen die antike Mythologie zu tolerieren. ${ }^{7}$ Die Frage reduzierte sich also auf den gewiss wichtigen Aspekt der Elitenkonkurrenz, die den Mythos vor der Vernichtung bewahrte. Die Akzeptanz des Mythos wird dann zu einem Machterweis des Christentums. Fuhrmanns Blick richtete sich im Wesentlichen auf die lateinische Literatur und traf gar nicht das ganze Feld der außerliterarischen Präsenz von Mythologie. Und auch an jenen Debatten der Arbeitsgruppe Poetik und Hermeneutik nahm kein Archäologe teil, der Fuhrmanns Bild hätte korrigieren können; welche Bedeutung aber archäologische Quellen für diese Fragen haben, wird gerade im vorliegenden Band deutlich.

Es ist leicht, die Schwächen von Positionen zu markieren, die vor mehr als 40 Jahren formuliert wurden; darum geht es hier auch nicht. Ihre Wiedergabe soll vielmehr verdeutlichen, wie sich die Forschung der letzten Jahrzehnte entwickelt hat und dass dabei ein Thema erörtert wird, dessen Bedeutung über den Kreis der Spätantikespezialisten hinausreicht. Jeder Gang in ein Kunstmuseum führt eindrucksvoll die unbestreitbare Tatsache vor Augen, dass der Mythos in der christlichen Welt und auch in der säkularisierten kraftvoll überlebt hat. ${ }^{8}$ Doch auch außerhalb der bildungsbürgerlichen Provinz ist die Präsenz von Mythen bis in die Gegenwart hinein beachtlich. Um nur einige willkürlich zusammengegoogelte Beispiele zu nennen: Das sächsische Lößnitz rühmt

6 Blumenberg (s. Anm. 2), 20 und 21.

7 Manfred Fuhrmann, Die lateinische Literatur der Spätantike. Ein literarhistorischer Beitrag zum Kontinuitätsproblem, Antike \& Abendland 13 (1967), 56 - 79, 76f. sowie mit ähnlichen Formulierungen, aber bezogen auf die Mythen: idem, Die antiken Mythen im christlich-heidnischen Weltanschauungskampf der Spätantike, Antike \& Abendland 36 (1990), 138-151; vgl. idem, Rom und die Spätantike. Porträt einer Epoche, München u.a. 1994, 57. Zum Bild des Kompromisses s. Blumenberg (s. Anm. 4), 388; idem (s. Anm. 2).

8 Sehr vieles wird erschlossen bei Maria Moog-Grünewald (Hg.), Mythenrezeption. Die Antike Mythologie in Literatur, Musik und Kunst von den Anfängen bis zur Gegenwart (DNP Suppl.-Bd. 5), Stuttgart/Weimar 2008 (mit geschickt arrangierter Auswahlbibliographie); viele Hinweise in http:// www.oeaw.ac.at/kal/mythos/bibliomythos.pdf; reiches Material zur Präsenz von antiken Mythen in der Gegenwart in der Art, wie in den nächsten Sätzen geschildert, bei http://c2 m.free.fr/al/mytho.htm (abgerufen am 29.03.2014, 12:27). Udo Reinhardt, Der antike Mythos. Ein systematisches Handbuch (Rombach-Wissenschaften Paradeigmata 14), Freiburg/Br. 2011 vermittelt einen reichhaltigen, persönlich gefärbten Überblick, der knapp (409-413) auf christliche Kontexte eingeht; Hugo Rahner, Griechische Mythen in christlicher Deutung, Basel $1984^{4}$ will anders, als der Titel vielleicht suggeriert, keine systematische Darlegung bieten, sondern deutet das Verhältnis von Mythos und Christentum im Sinne einer christlichen Symboltheologie, die den Mythos - durchaus im Sinne mancher antiker Theologen - als Vorklang des Christentums auffasst. 
sich eines Gesundheits- und Fitnessclubs namens Apollo; ${ }^{9}$ Hercules ist eine beliebte Gestalt in Computerspielen, die sogar einen Helden-Parcours bieten, ${ }^{10}$ und auf ein Hotel namens Diana stößt man in fast jeder Stadt.

Nicht nur die antiken Mythologeme sind ubiquitär, auch der Begriff des Mythos ist beliebt - oder ist es das Wort? Ihm eignet jedenfalls eine proteushafte Vielfalt der Erscheinungsformen: Ganze Zeitalter und Denkweisen können als mythologisch bezeichnet werden; man findet Mythen in den verschiedensten Kulturen, in der Literatur wie auch im Alltag. Fast alles und fast jeder kann $\mathrm{zu}$ einem Mythos werden, ein Fußballverein wie ein Fernsehstar, so suggeriert es der Alltagsgebrauch des Wortes. Es kommt sogar zu interessanten Verschränkungen dreier verschiedener Wirklichkeitskonzepte, nämlich der Wissenschaft, des Wunderglaubens und der Mythologie, wie in der folgenden Zeitungsüberschrift: Forscher entlarven Hartz-IV-Wunder als Mythos. ${ }^{11}$ Mythos kann für etwas Bewundernswertes stehen, das eine gewisse historische Dauer hat, aber auch für das Falsche. Dem Christentum werden Mythen zugesprochen, doch kann es auch wie bei Hans Blumenberg als Welt des Dogmas und damit als Gegenentwurf zur mythologischen Weltsicht interpretiert werden.

Mehr Präzision fordert der wissenschaftliche Sprachgebrauch, doch hier lässt sich ebenfalls eine bemerkenswerte Spannbreite der Begriffsverwendung feststellen. Aleida und Jan Assmann grenzen angesichts der vielfältigen Bedeutungsschattierungen sieben Begriffe voneinander $a b$, die sie etwas technizistisch jeweils mit dem Kürzel $M$ und einer Ziffer versehen: ${ }^{12} M$ 1: Mythos als überwundenes Stadium kulturhistorischer Entwicklung; M 2: Mythos als zeitbedingte Einkleidung einer an sich zeitlosen Wahrheit, die etwa durch Allegorese erschlossen werden kann; M 3: Mythos als in weitester Auffassung sinnstiftende Erzählung; M 4: Mythen des Alltags, als Leitbilder, die kollektives Handeln und Erleben prägen; M 5: Mythos als narrativer Begriff, der im Sinne der aristotelischen Poetik Anfang, Mitte und Ende einer Erzählung betont; M 6: Literarischer Mythos, also Mythen, die ständig in der künstlerischen Verarbeitung umgeschrieben werden (hier wäre Entsprechendes für die bildende Kunst zu sagen, die aber nicht im Blick der Autoren ist); M 7: der Mythos im Sinne der großen Erzählungen, die einzelne formulieren; als ein Beispiel geben die Assmanns Friedrich Nietzsches Lehre von der ewigen Wiederkehr. Für die Beiträge des vorliegenden Bandes sind dabei insbesondere M 1-3 und M 6 bedeutsam, wenn man dieser

9 http://www.fitnessapollo.de, abgerufen am 06.02.2014, 12:24.

10 http://www.mogelpower.de/cheats/Hercules-_PC_488.html, abgerufen am 29.03.2014, 12:32.

11 Die Welt vom 03.02.2014 (http://www.welt.de/wirtschaft/article124489299/Forscher-entlarvenHartz-IV-Wunder-als-Mythos.html, abgerufen am 06.02. 2014 um 13:46).

12 Aleida u. Jan Assmann, Handbuch religionswissenschaftlicher Grundbegriffe 4 (1998), 179 - 200, s. v. Mythos, insbes. 179-181; s. ferner Walter Burkert/Axel Horstmann, Historisches Wörterbuch der Philosophie 6 (1984), 281-318, s.v. Mythos, Mythologie (ausführlicher: Axel Horstmann, Der Mythosbegriff vom frühen Christentum bis zur Gegenwart, Archiv für Begriffsgeschichte 23 [1979], 7-54; 197245); Fritz Graf u. a., DNP 8 (2000), 633 - 650, s.v. Mythos; Christine Schmitz/Francesco Zanella/Susanne Heydasch-Lehmann, RAC 25 (2013), 471-516, s.v. Mythos. 
Einteilung überhaupt folgen will. Arbeitspraktisch scheint es mir eher sinnvoll zu sein, eine relativ allgemeine Definition zu wählen, die aber unseren erfahrungsgesättigten Intuitionen entspricht: Mythen waren kollektiv bedeutsame, durch Tradition bekannte Erzählungen von Göttern und Heroen oft in ihrer Interaktion mit Menschen; auf jeden Fall haben es die Mythen der Antike, wie sie hier behandelt werden, mit personal gedachten Gestalten zu tun. ${ }^{13}$

Die Mythen sind allerdings nicht nur narrativ im Kontext der antiken Götterwelt zu sehen; sie gehörten auch in den Zusammenhang religiöser Kulte, die an bestimmten Orten über Jahrhunderte praktiziert wurden, auf der Grundlage oft sehr unterschiedlicher Varianten des Mythos, denen häufig ein aitiologischer Charakter zukam. Auf zahlreichen öffentlichen Kunstwerken, auch auf Münzen sah man mythische Bilder; für die lokale Identität gerade der Städte im Osten besaßen sie eine herausragende Bedeutung. ${ }^{14}$

Mythischen Motiven begegnete man so an verschiedenen sozialen Orten in unterschiedlicher Weise; die Allgegenwart der Mythen war gerade für die römische Kaiserzeit prägend: ${ }^{15}$ Man erblickte sie in Gestalt von Werken der bildenden Kunst auf öffentlichen Plätzen und in Privathäusern, man las über sie in der Literatur, man verfolgte sie namentlich bei den populären Pantomimen auf der Bühne und selbst in den mythischen Scharaden der Arena, man begegnete ihnen als einer literarischen Form der Philosophie, man zelebrierte ihre Tradition in Kulthandlungen. Unterschiede gab es sicherlich von Ort zu Ort: So hatte in Athen die Mythologie gewiss eine andere Sichtbarkeit und ein anderes Publikum als in Mainz bzw. Mogontiacum; auch literarische Milieus konnten je nach Region unterschiedlich sein.

Mythische Darstellungen besaßen offenbar durchaus auch Bedeutung für die Bewältigung der Kontingenz von Lebenskrisen: Als die Körperbestattung sich seit dem beginnenden 2. Jahrhundert wieder ausbreitete, wurden zahlreiche Sarkophage gefertigt. Hier sah man Mythen, die auf die Freuden und Pflichten des Lebens, aber auch und insbesondere auf den Tod beziehbar waren, mit so unterschiedlichen Motiven wie

\footnotetext{
13 Assmann/Assmann (s. Anm. 12) definieren aus religionswissenschaftlicher Perspektive den Mythos im allgemeinsten Sinne als den einer Gruppe vorgegebenen Fundus an Bildern und Geschichten (179). Doch scheint mit für die Behandlung speziell der Antike der personale Aspekt definitorisch wichtig zu sein.

14 Aus der reichen Literatur Tanja Scheer, Mythische Vorväter. Zur Bedeutung griechischer Heroenmythen im Selbstverständnis kleinasiatischer Städte (Münchener Arbeiten zur Alten Geschichte 7), München 1993; Ruth Lindner, Mythos und Identität. Studien zur Selbstdarstellung kleinasiatischer Städte in der römischen Kaiserzeit (Schriften der Wissenschaftlichen Gesellschaft an der JohannWolfgang-Goethe-Universität, Geisteswissenschaftliche Reihe 9), Stuttgart 1994; Bahadir Yildirim, Identities and Empire. Local Mythology and the Self-Representation of Aphrodisias, in: Barbara E. Borg (Hg.), Paideia. The World of the Second Sophistic (Millennium Studies 2), Berlin/New York 2008², $23-$ 52.

15 Paul Zanker/Björn Christian Ewald, Mit Mythen leben. Die Bilderwelt der römischen Sarkophage, München 2004, insbes. $37 \mathrm{f}$.
} 
Alkestis, Dionysos, Hippolytos oder den Niobiden. ${ }^{16}$ Insofern spricht einiges dafür, dass Mythen auch in nicht-christlichen Kontexten durchaus mit Fragen persönlicher Religiosität zu tun hatten.

Doch mit solchen Aussagen muss man vorsichtig sein. Was sah, las und hörte man denn, wenn es um Mythen ging? Wie wurden die Mythen perzipiert? Wem galten sie als religiös gehaltvoll? Maß man ihnen Bedeutung bei oder handelte es sich um eingeschliffene Floskeln und Ornamente, bei deren Verwendung man sich nichts dachte? Einfache Antworten darauf werden sich nicht finden, denn die Wahrnehmung der Mythen war gewiss kontextabhängig. Auch der Einzelne konnte einen Mythos je nach Situation ganz unterschiedlich wahrnehmen, sei es dass er über ihn beim Hören einer Persiflage lachte, dass er zu ihm aufblickte, wenn er ihn kunstvoll dargestellt fand, oder angesichts eines Sarkophags die Erinnerung an seine Sterblichkeit erfuhr. Im 3. Jahrhundert scheint sich in manchen Bereichen die Präsenz des Mythos verringert zu haben. Doch muss man dies keineswegs allein auf das Christentum zurückführen. ${ }^{17}$

Scheinbar liegt es auf der Hand, dass das Christentum kein unbefangenes Verhältnis zum Mythos haben konnte, wie auch immer er sich darstellte und wahrgenommen wurde. Er handelte von Göttern, in denen die Christen allenfalls Dämonen erblicken konnten, und er war in seinen wandelbaren Narrationen weit entfernt vom antiken Christentum, das sich in den ersten Jahrhunderten nach Christus zu einer Religion verbindlicher, verschriftlichter oder zumindest verbindlich fixierbarer Dogmen entwickeln sollte. Doch sollte man nicht vergessen, dass anfangs eine große Beweglichkeit und Vielfalt der Erzählungen über Jesus und über die Apostel bestand, wie bereits ein kurzer Blick in die apokryphe Tradition, aber eigentlich schon in die vier Evangelien lehrt. Gleichwohl äußerten Christen, zumal die Apologeten, fundamentale Kritik am Mythos, dessen Erzählungen in ihrer Widersprüchlichkeit und teils auch Obszönität sich nur allzu leicht lächerlich machen ließen.

Aber das Verhältnis von Christen zu Mythologischem lässt sich nicht über einen Leisten schlagen, zumal bereits von jüdischen Autoren verschiedene Formen des Umgangs mit dem Mythos erprobt worden waren. ${ }^{18}$ Denn zu jeder Zeit ist die Rede von „dem“ Christentum fragwürdig, da das antike Christentum nicht weniger vielfältig war

16 Dazu liegt schon eine reiche Literatur vor, s. nur etwa die mit einem reichen Repertorium versehene Synthese für die Stadt Rom Zanker/Ewald (s. Anm. 15).

17 S. für die Sarkophage, wo seit 220/30 die Zahl mythischer Darstellungen deutlich zurückgeht, Zanker/Ewald (s. Anm. 15), 255-263, ohne dass dies alle Bereiche der bildenden Kunst beträfe. Ibid., 262 ziehen sie die Möglichkeit eines christlichen Einflusses in Erwägung, erklären aber selbst, dass es dafür keinen Beleg gibt; zu Beginn des 3. Jahrhunderts wäre er kaum zu erwarten, da die Christen noch nicht in die Zentren der Gesellschaft vorgedrungen waren.

$18 \mathrm{Zu}$ Recht betont von René Bloch, Moses und der Mythos: Die Auseinandersetzung mit der griechischen Mythologie bei jüdisch-hellenistischen Autoren (Supplements to the Journal for the Study of Judaism 145), Leiden/Boston 2011. - Nicht behandelt werden kann hier die Rolle mythologischer Themen in jüdischen Bildwerken, wo sie seit dem 3. Jahrhundert immer wieder auftauchen, s. Lee I. Levine, Visual Judaism in Late Antiquity. Historical Contexts of Jewish Art, New Haven 2012, etwa 81f., $126-128,227,317-319,398,452$. 
als die Welt der Mythologie. In vielen der religiösen Äußerungen, die mit dem schwer zu definierenden Begriff der Gnosis bezeichnet werden und deren Anhänger sich zumindest in Teilen als christlich verstanden, spielten Mythen, die sich von den anderen antiken jedoch in Namensform und Erzählweise erheblich unterscheiden konnten, eine wie auch immer näher zu bestimmende, aber doch wesentliche Rolle. ${ }^{19}$ Gerade das könnte die Ablehnung, die dem Mythos bei anderen Christen entgegenschlug, befeuert haben. Für noch andere Christen wiederum, namentlich solche, die von der syrischen Kultur geprägt waren, waren die Mythen auch kulturell fremd. Im Gegensatz dazu wurden Christen, die ihre Sozialisierung in einer griechisch-römischen Umwelt erfahren hatten, mit Mythen groß; die Gebildeteren befassten sich im Unterricht intensiv mit ihnen. Bedeutsamkeit maßen allerdings wohl alle Christen dem Mythos bei, da er eben sichtbar für das religiös Andere, das Heidnische, stand. Auch das konnte ganz unterschiedlich aufgenommen werden: Während die einen Christen auf scharfe Konflikte mit dem setzten, was sie als heidnisch definierten, pflegten andere ein entspannteres Verhältnis zur Tradition.

Es ist daher bemerkenswert, dass im Prozess der Christianisierungen zwar die Kulte allmählich erloschen, die Mythen aber nicht untergingen. Eine Schlüsselepoche, die das Überleben der Mythologie möglich machte, bildete gewiss die Spätantike, mit der sich dieser Sammelband beschäftigt. Denn es war jene Epoche, in der das Christentum sich als Religion der Kaiser, der Eliten, der Gesellschaft insgesamt durchsetzte und schließlich alle Diskurse zu beherrschen schien. Und doch traf man in allen Phasen der Spätantike vielerorts auf mythologische Themen: Sie waren sichtbar bei öffentlich aufgestellten Kunstwerken und als Teil der Ausstattung privater Anwesen, lesbar in Texten, die dem Schulunterricht dienten, aber auch in solchen, die neu verfasst wurden, ausgedeutet in philosophischen Schriften, aber auch in theologischen Werken.

19 Zur Eigenart der Grundstruktur gnostischer Mythen s. Carsten Colpe, RAC 11 (1981), 537-659, s.v. Gnosis II (Gnostizismus), insbes. 635-639; ferner Walter Burkert, Kritiken, Rettungen und unterschwellige Lebendigkeit griechischer Mythen zur Zeit des frühen Christentums, in: Raban von Haehling (Hg.), Griechische Mythologie und frühes Christentum. Die antiken Götter und der eine Gott, Darmstadt 2005, 173-193, hier: 189-193. Hans Jonas spricht in seinem klassischen Werk (Gnosis und spätantiker Geist, Göttingen 1964ㄴ) von einer mythologischen Gnosis, der der erste, viel später erst ergänzte Band gewidmet ist. Akzentuiert wird die Rolle des Mythos von Taubes (s. Anm. 5); vgl. die Diskussion insbesondere zur Problematik des dort verwendeten Mythosbegriffs in: Fuhrmann (s. Anm. 2), 579 - 591. Die Diskussion ist weiter offen, zumal der Gnosisbegriff selbst sich als immer schwieriger erweist; vgl. Christoph Markschies, Die Gnosis, München 2010³ als pointierte Positionierung zugunsten der Verwendung des Begriffs der Gnosis Birger A. Pearson, Gnosticism and Christianity in Roman and Coptic Egypt, London u. a. 2004 (zur mythischen Dimension 205-207); ferner Antti Marjanen, ,Gnosticism‘, in: Susan Ashbrook Harvey/David G. Hunter (Hg.), The Oxford Handbook of Early Christian Studies, Oxford 2008, 203-220 (konziser Forschungsüberblick); einen theoretischen Neuansatz bietet Johann E. Hafner, Selbstdefinition des Christentums. Ein systemtheoretischer Zugang zur frühchristlichen Ausgrenzung der Gnosis, Freiburg u.a. 2003. 
Das christianisierte Reich konnte Mythologisches mithin zumindest ertragen. Unbestreitbar ist, dass sich für Mythen weiterhin sehr unterschiedliche Auffassungen anboten und dass auch Christen sie keineswegs einheitlich wahrnahmen. Als ein Beispiel sei auf die Ausstattung des Hippodroms von Konstantinopel mit mythologischen Kunstwerken durch Constantin den Großen hingewiesen, die BASSETT in diesem Band als Teil einer bewussten kaiserlichen Repräsentation interpretiert, mit der Constantin der Große die Ursprünge der Stadt in Erinnerung ruft und Sieghaftigkeit evoziert. Christliche Quellen machten sich darauf ihren je eigenen Reim: Während Euseb von Caesarea, der Bischof aus der Provinz, meint, dass durch die Aufstellung der Kunstwerke das Heidentum der Lächerlichkeit preisgegeben worden sei (Vita Constantini 3,54,2f.), sieht Sokrates, der hauptstädtische Kirchenhistoriker, in ihrer Verwendung im Hippodrom zwar eine Schwächung des Heidentums, doch auch einen Schmuck für die Stadt $(1,16,3)$ und ganz analog ist die Interpretation des Sozomenos, eines ebenfalls in der Hauptstadt wirkenden Kirchenhistorikers; auch bei ihm werden die Werke ästhetisiert (2,5,3f.).

Schon dieses Beispiel eines prominenten Ortes zeigt: Es kann nicht darum gehen, eine lineare Untergangs- oder Überlebensgeschichte der antiken Mythologie zu erzählen, sondern man hat es mit einer Vielfalt von Umgangsweisen, von Aneignungsprozessen zu tun, die in der spätantiken Gesellschaft möglich waren. ${ }^{20}$ Gerade die Pluralität, die Polyphonie der Spätantike hat die Forschung der letzten Jahrzehnte ja mit aller Deutlichkeit herausgearbeitet, und sie bestätigt sich auch in den Beiträgen dieses Bandes. Es wäre daher überaus spannend, eine Geschichte der Präsenz von Mythologie in Rom zu schreiben, die bewusst den Einschnitt der sogenannten Constantinischen Wende überbrücken würde. ${ }^{21}$

Das aber ist gegenwärtig nicht zu leisten. Dieser Sammelband zielt lediglich auf eine, indes überaus wichtige Phase der „Arbeit am Mythos“ in der mediterranen Tradition, eben auf die Phase der Christianisierung im spätantiken Reich, ${ }^{22}$ und es geht

20 Zum Begriff der Aneignung etwa Marian Füssel, Die Kunst der Schwachen. Zum Begriff der „Aneignung“ in der Geschichtswissenschaft, Sozial.Geschichte 21,3 (2006), 7-28 (Überblick zur Anwendung in der neueren Geschichte, vor allem bezogen auf Gegenstände); Dietmar Rothermund (Hg.), Aneignung und Selbstbehauptung. Antworten auf die europäische Expansion, München 1999, insbes. 4-9. Rémi Brague, Inclusion et digestion. Deux modèles d'appropriation culturelle, in: Philippe Capelle/Geneviève Hébert/Marie-Dominique Popelard (Hg.), Le Souci du passage. Hommage à Jean Greisch, Paris 2003, 77-96 = idem, Au moyen du moyen âge. Philosophies médiévales en chrétienté, judaïsme et islam, Paris 2006, 187-204, unterscheidet die beiden im Titel genannten Formen der Aneignung. Inclusion bewahre die Andersartigkeit des Gegenstandes, während die digestion den Gegenstand völlig verinnerliche, so dass er seine Unabhängigkeit verliere. Letzteres scheint Blumenberg zu unterstellen, doch dürfte inclusion die christliche Form der Aneignung des Mythos treffender beschreiben.

21 Anknüpfen könnte man in manchem an Jean Pépin, Mythe et allégorie. Les origines grecques et les contestations judéo-chrétiennes, Paris $1976^{2}$.

22 Für die frühere Geschichte des Christentums s. die Beiträge in Raban von Haehling (Hg.), Griechische Mythologie und frühes Christentum. Die antiken Götter und der eine Gott, Darmstadt 2005. Hier wird die Vielfalt der Aneignungsprozesse bereits sichtbar. 
um die griechisch-römische Mythologie in ihren vielfältigen Erscheinungsformen. Seine Beiträge untersuchen exemplarisch, wie der Mythos sich in christlichen Kontexten darbot. Damit stellt sich zugleich die Frage, warum, wo und wie der Mythos überleben konnte - und ob er dazu nur als Gefangener imstande war. Überdies ist zu erörtern, inwieweit sich unterschiedliche Phasen des Umgangs mit dem Mythos bestimmen lassen.

Hier versucht der vorliegende Band ein breiteres Panorama zu bieten. Vollständigkeit kann und will er dabei keineswegs beanspruchen - insbesondere fehlt der umfassende Bereich des Verhältnisses von Mythologie und Urbanistik fast vollständig. ${ }^{23}$ Nicht behandelt wird die Kleinkunst, etwa Öllampen ${ }^{24}$ oder Glasgerät ${ }^{25}$; auch die reichhaltigen Mosaiken werden hier nicht erörtert. Relativ wenig berücksichtigt sind ferner die Inschriften - um nur einige Beispiele für Lücken zu nennen. ${ }^{26}$ Es geht nicht darum, das Thema abzuschließen, sondern darum, den Forschungsstand zu verdeutlichen und weiterzuführen. Was in dem Band behandelt ist, vermittelt gleichwohl, so die Hoffnung, ein aufschlussreiches und anregendes Bild der Vielfalt im Umgang mit dem Mythos in der Spätantike.

Da die Verwendung von antiken Mythen in einem hohen Maße an Konventionen von Gattungen und Medien gebunden war, ist dieser Sammelband nicht nach mythologischen Motiven gegliedert und ordnet die Beiträge auch nicht chronologisch, sondern eben nach Medien und Gattungen, in denen Mythen vorkommen. Auf diese Weise können Verbindungen sichtbar werden, aber auch Ungleichzeitigkeiten zwischen Medien und Gattungen, die erklärungsbedürftig sind.

Das Epos und die Dichtung überhaupt haben in diesem Kontext seit jeher besonders große Aufmerksamkeit auf sich gezogen, da hier mythologische Elemente deutlich hervortraten, und zwar selbst wenn Autoren oder Adressaten in einen christlichen Zusammenhang gehören. Wie erwähnt, hat Fuhrmann die Entwicklung des Epos zum Ausgangspunkt der Geschichte des Mythos in der Spätantike genommen.

Mehrere Beiträge dieses Bandes befassen sich mit dieser Gattung: Am Beispiel des vieldiskutierten, um 400 aktiven Dichters Claudian zeigt CLAUDIA SCHINDLER auf, dass der Gebrauch der Mythen in der Poesie durchaus mit christlichen Vorstellungen bis hin

\footnotetext{
23 Etwa Angelos Chaniotis, Myths and Contexts in Aphrodisias, in: Ueli Dill/Christine Walde (Hg.), Antike Mythen. Medien, Transformationen und Konstruktionen, Berlin/New York 2009, 313-338.

24 John Lund, Motifs in Context. Christian Lamps, in: Jens Fleischer/Niels Hannestad/Marjatta Nielsen u.a. (Hg.), Late Antiquity. Art in Context = Acta Hyperborea 8 (2001), 199-214, der in verschiedenen Gattungen der materiellen Kultur Nordafrikas einen Übergang von heidnischen zu christlichen Motiven zu Beginn des 5. Jahrhunderts beobachtet; Arja Karivieri, Mythological Subjects on Late Roman Lamps and the Persistence of Classical Tradition, ibid., 179-198.

25 Jutta Dresken-Weiland, Bilder im Grab und ihre Bedeutung im Kontext der Christianisierung der frühchristlichen Welt, AnTard 19 (2011), 63-78, 73-78 zu Zwischengoldgläsern.

26 Wichtige Beobachtungen zur Verbindung von Inschrift und Kunstwerk bei Georgios Deligiannakis, Christian Attitudes towards Pagan Statuary: The Case of Anastasius of Rhodes, Byz 78 (2008), 142-158 (mit zahlreichen Literaturhinweisen), der betont, dass Kunstwerke Gegenstände ästhetischer Erfahrung und städtischen Stolzes blieben.
} 
zur Mythenkritik konform gehen kann. Ja, die Mythen werden in den entscheidenden, politischen Aspekten durch die Akteure der Jetztzeit überboten. So gesehen, kann Claudians Umgang mit dem Mythos, obwohl er in seiner Dichtung so prominent ist, nachgerade herabsetzend klingen. Zugleich bieten die Mythen namentlich der panegyrischen Dichtung einen Stoff, der aus spezifisch christlichen Texten nicht gewonnen werden konnte, da der Mythos breiter bekannt und anerkannt war.

Domenico ACCORINTI verdeutlicht am Beispiel des im 5. Jahrhundert wirkenden Epikers Nonnos, wie unterschiedlich das Nebeneinander von heidnisch qualifizierten Dionysiaka und christlicher Paraphrase des Johannes-Evangeliums ausgelegt werden konnte. Er selbst betont, dass das Verhältnis von beidem nicht als kontrastiv gesehen werden muss, dass vielmehr gewichtige Elemente beiden epischen Texten gemeinsam sind, vor allem das Motiv von Tod und Auferstehung, so dass ein Deutungsangebot entsteht, dank dem die heidnische und die christliche Tradition kompatibel werden, gerade weil die beiden Richtungen nicht als gegensätzlich erscheinen. Zugleich sieht AcCORINTI in den Dionysiaka einen Hinweis auf die Überlegenheit der christlichen Auferstehungslehre gegenüber heidnischen Vorstellungen zur Widererweckung von Toten, so dass im mythologischen Epos die christliche Tradition für die Leser, die in der Lage sind, die intertextuellen Bezüge wahrzunehmen, das Ältere überbieten würde.

UlRICH SCHMitzer behandelt den dichtenden Senator Sidonius Apollinaris, der um 470 zum Bischof von Clermont geweiht wurde. Er stellt fest, dass sowohl in seiner Panegyrik als auch in seiner Kleindichtung mythologische Motive eine stärkere Rolle spielen als in früheren Werken der Gattungen, und zwar auch dann, wenn diese wie ein kaiserlicher Panegyricus im öffentlichen Raum dargeboten wurden. Allerdings verloren sie ihre Brisanz. Schmitzer spricht von einer Einkapselung der paganen Gedankenwelt. Diese sei - hier zeigt sich eine Gemeinsamkeit mit ScHINDLERs Deutung indes weiterhin unverzichtbar gewesen, um etwa in der Panegyrik bestimmte Dinge zum Ausdruck zu bringen. Auch in der Kleindichtung bediente man sich daher gerne und ohne Scheu des Wissensspeichers, den die Mythen bildeten. Ihre Präsenz war eine poetische Option, kein religiöses Bekenntnis.

CHRISTIAN SchäFer untersucht einen Bereich, in dem Christentum und Heiden eine gemeinsame Grundlage hatten: platonisch inspirierte Denkweisen. Hier ist die Bewertung des Mythos oft gerade nicht etwas Trennendes; vielmehr ist beiden Traditionen gemeinsam, dass sie „wunderliche“ Elemente am Mythos feststellen: Die heidnische Mythenkritik wird vom Christentum aufgenommen, doch entwickelt sie sich auch weiter. Zumal am Beispiel des in der Zeit Julian Apostatas (361-363) wirkenden Sal(l)ustios wird erkennbar, wie die Deutung des Mythos sich angesichts der Herausforderung des Christentums entwickelt. Der Gedanke der (scheinbaren) Unpassendheit des Mythos, die auf Platon selbst zurückgeht, wird erneuert und der Mythos gerade den Gebildeten unter seinen Verächtern nahegebracht. Umgekehrt wirkt die platonische Mythendeutung auf die christliche Interpretationsweise biblischer Erzählungen zurück. Gerade auf diesem Feld tritt die Verschränkung christlicher und heidnischer Positionen bei der Arbeit am Mythos deutlich hervor: Weder steht das 
spätantike Heidentum hilflos-erstarrt da, noch sind die Christen gegenüber dem anderen verschlossen. Die Arbeit am Mythos schreitet lebendig fort.

Explizit christliche Texte kamen bei bestimmten Fragen auch nicht leicht am Mythos vorbei: WINRICH LöHR beleuchtet die Rolle, die Mythologeme bei christlichen Bischöfen der Spätantike spielen. Sie erscheinen nicht mehr als Gegenstand einer leidenschaftlichen Polemik: Zum einen gelten sie als Ausdruck einer überwundenen Phase, zum anderen als Bildungsgut, aber unter der Voraussetzung, dass sie neutralisiert sind, dass sie nicht als Figuren eines Glaubens verstanden werden. Damit konnten die Bischöfe indes, hier treffen die Überlegungen sich mit ScHÄFERs Ausführungen, an heidnische Auffassungen anschließen, da die mythischen Gestalten für viele gerade nicht die religiöse Bedeutung hatten, die Christen jenen der Bibel beimaßen. Die entscheidende Frage war vielmehr, inwieweit sie zur Sittlichkeit ermunterten. Die mythologischen Themen konnten als Ausdruck des gemeinsamen Codes der Gebildeten Akzeptanz finden, indem man zugleich die Überlegenheit der christlichen Lehre betonte: Christentum und Heidentum wurden in dieser Deutung durch curriculare Hierarchisierung integriert, womit die Mythen letztlich ihren heidnischen Charakter im Sinne eines unauflöslichen Gegensatzes zum Christentum einbüßten und den christlichen Lehren gewissermaßen vorgeschaltet waren.

An Erich Auerbachs Literaturtheorie anknüpfend fragt HENRIKE ZILLING danach, inwieweit die christlichen Helden auf heidnische Heroen referieren. Dafür verweist sie auf Motivähnlichkeiten zwischen antiken Heroen und den christlichen der Evangelien, aber besonders auch der Märtyrerberichte. Die Geschichte des frühen Christentums wird so $\mathrm{zu}$ einer Geschichte von Helden, die figural mit den klassischen Heroen verbunden sind, wobei zugleich Jesus Christus so viele Besonderheiten aufweist, dass er trotz aller Gemeinsamkeiten mit einem klassischen Heros eine Gestalt sui generis bleibt. Besonders deutlich werden die Gemeinsamkeiten im Vergleich zwischen Herakles und dem Märtyrerbischof Polykarp. Mythos und Martyrium erscheinen hier in einer Kontinuität. Ferner können Mythen dazu dienen, Verhaltensweisen von Christen zu begründen. In dieser Deutung werden Teile des Mythos somit von Christen gleichsam vereinnahmt.

Herakles spielt noch im 7. Jahrhundert eine bedeutende Rolle, wie MischA MEIER zeigt. Der Rekurs auf Herakles und seine Leistungen erlaubt es dem Kaiser Herakleios (610-641), sich an Christus anzunähern. Hier sind Mythos und Christentum nicht nur koexistent, sondern sie verstärken sich gegenseitig. Relativ subtile Anspielungen genügten in der Zeit, als das Reich vollständig christianisiert erscheint, um den Mythos zu evozieren. So wird Herakles erneut zu einem wichtigen Element der kaiserlichen Selbstdarstellung, wenngleich in ganz andere Manier als unter Commodus und den Tetrarchen. Die fortwährende Adaptabilität des Mythos - MEIER spricht sogar von einer „Herakles-Mode“ - wird hier überaus deutlich.

Einer weiteren mythischen Gestalt widmet sich FABIEnNE JoURdan, indem sie die Aneignung des Orpheus-Mythos durch Christen untersucht, die sehr unterschiedlich erfolgen konnte: Dieser Mythos hatte eine besondere Bedeutung, da Orpheus von vielen Christen als Begründer der griechischen Religion insgesamt aufge- 
fasst wurde. Er konnte einerseits deswegen denunziert werden, doch wird ihm auch eine Hinwendung zum Monotheismus zugeschrieben, so dass er auch als Vorbild für Konversion zu dienen vermag. Doch selbst wenn Orpheus positiv gesehen wurde, näherten die Christen sich ihm im Modus der Überbietung, da eben die Hinwendung zum Christentum der entscheidende Schritt war.

Clifford ANDo widmet sich den Mythen der Vor- und Frühgeschichte Roms, die in der Spätantike wohlbekannt waren. Jetzt aber wurden sie angesichts der Herausforderung durch das jüdisch-christliche Narrativ im Sinne einer Geschichte verstanden, die historischer Kohärenz bedurfte. Bei den Kommentatoren zur frühen römischen Geschichte ist daher ein Streben nach Systematisierung feststellbar, das einem Plutarch etwa fehlte. Insofern verwandeln diese Autoren Mythos in eine Narration nach Art der Historiographie. Der Mythos erweist sich weiterhin als veränderlich und kann so ohne weiteres in christlichen wie nicht-christlichen Kontexten weiterleben.

Durch eine Behandlung literarischer wie archäologischer Quellen verdeutlicht JöRG RÜPKE die Möglichkeit eines Nebeneinanders von Christlichem und Heidnischem in ganz verschiedenen Medien, womit die binäre Gegenüberstellung von beidem im Sinne eines Weltanschauungskampfes, wie man in der Zeit der Ideologien (Karl Dieter Bracher) gerne sagte, in Frage gestellt wird. RüPKE wählt den Kalender von 354 als ein Zeugnis einer senatorischen Haltung aus, die über den üblichen Konflikten steht. Vor diesem Hintergrund wird auch die Präsenz mythologischer Motive in den Katakomben an der Via Latina, die aus der gleichen Zeit stammen, verständlich. Überhaupt scheinen die Akteure dieses Milieus das Verhältnis von Heidentum und Christentum nicht primär als konflikthaft gesehen und mythische Themen nicht notwendig religiös interpretiert zu haben.

SARAH BASSETT erörtert den Umgang mit der klassischen Kunst im spätantiken Konstantinopel, dem Neuen Rom. Sie betont die anhaltende Präsenz von Statuen mit mythologischen Themen. In Konstantinopel wurden Statuen sogar in einem bestimmten System gezielt an öffentlichen Plätzen aufgestellt. Vor allem evozierten sie die mythische Tradition über Konstantinopels Ursprünge in Rom und damit indirekt in Troja. Im 5. Jahrhundert, als die Zahl der kaiserlichen Portraits wuchs, wurden mythologische Ensembles verstärkt in privaten Zusammenhängen präsentiert. Hier beschwor man nicht mehr die mythische Tradition der Stadt herauf, vielmehr rief man die frühere religiöse Bedeutung vieler Statuen sowie ihren kunsthistorischen Rang in Erinnerung; doch wurden sie auch zusammen mit Gestalten von wilden Lebewesen präsentiert, damit exotisiert, vielleicht auch gedemütigt, wobei zugleich auch ihr ästhetischer Rang in Erscheinung treten konnte. Von apologetischer Verdammung entwickelte sich die christliche Haltung gegenüber mythologischen Statuen zu institutionalisierter Akzeptanz.

Eine selten genutzte Quelle behandelt Troels MYRuP KRISTENSEN: ägyptische Textilien, die man in Gräbern gefunden hat. Diese Objekte haben den Vorzug, dass sie nicht in die Welt der Eliten gehören - KRISTENSEN spricht bei den Nutzern vorsichtig von middle classes - und eine in großen Mengen produzierte Ware darstellen, ähnlich wie etwa Öllampen. Auch bei den Textilien wird ein Nebeneinander klassischer, nicht 
spezifisch ägyptischer mythologischer und christlicher Motive sichtbar; auch hier ist davon auszugehen, dass der Mythos nicht als unchristlich definiert, sondern als ein Teil der eigenen Kultur aufgefasst wurde, den die Aneignung christlicher Motive nicht zwingend affizierte. Denn diese Textilien wurden nicht nur als schöne Objekte gesehen, sondern als Element der Selbstdarstellung im Tode, wobei die Verwendung eines mythischen Motivs keineswegs zwingend bedeutet, dass der Besitzer damit über seine religiöse Identität Auskunft geben wollte. Das bedeutet zugleich, dass die Zuordnung von Gräbern zum Christentum und Heidentum nicht möglich ist. Gemeinsame kulturelle Prägungen blieben von der Definition des Mythos als heidnisch, die manche Theologen propagierten, unberührt.

Die Beiträge des Sammelbandes machen, so fragmentarisch das Bild noch ist, verschiedenes deutlich: Aufgelöst hat sich das Paradigma einer Mythologie, die zwar Plastizität besaß, aber letztlich selbstreferentiell war. Vielmehr wird die Mythologie in einer Vielfalt von Verwendungsweisen gesehen, im modernen Universitätsjargon gesprochen: in ihrer Anschlussfähigkeit. Es kommt darauf an, wo, wann und wem Mythologisches begegnet. Daraus ergeben sich vielfältige Möglichkeiten der Aneignung. Es gibt daher auch keine lineare Entwicklung des Niedergangs oder Bedeutungsverlusts des Mythos, sondern verschiedene Modi der Rekontextualisierung.

Dabei ist auch ein quellenkritisches Problem zu berücksichtigen: Die Überlieferungsgeschichte führte dazu, dass literarische Quellen bewusst selektiert wurden, und zwar im Sinne christlicher Vorstellungen, die auf eine Abgrenzung vom Heidentum setzten - auch wenn manches andere überlebt hat. Wenn man sich in einem Gedankenexperiment vorstellt, dass nur die archäologische Überlieferung erhalten geblieben wäre, so hätte man weitaus stärker den Eindruck eines Nebeneinanders von Christlichem und Heidnischem - wenn man überhaupt diese Kategorien als das zentrale Interpretament wählen würde. ${ }^{27}$ Man würde zudem feststellen müssen, dass auch noch mindestens bis zum ausgehenden 4. Jahrhundert Kunstwerke mit mythologischem Gehalt produziert wurden. ${ }^{28}$

Die in der bildenden Kunst besonders sichtbare Verbindbarkeit von mythischen und christlichen Themen ist auch anderswo greifbar. Was sind die Gründe für das Überleben? Hier lassen sich nur einige vorläufige Überlegungen anstellen: Für die Bewohner antiker Städte, die weiterhin fortwährend auf Kunstwerke der klassischen Tradition trafen, mochte die Koexistenz von Mythischem und Christlichem einfach ein selbstverständlicher Teil ihrer Lebenswelt gewesen sein. Derartige Dispositionen

27 Die relative Schnelligkeit des Übergangs für die funerären Zusammenhänge betont Dresken-Weiland (s. Anm. 25), wobei es im 3. Jahrhundert auch zu einem pragmatischen Nebeneinander kam: Anscheinend wurden auf Sarkophage mit herkömmlichen Motiven Deckel mit Jonas-Darstellungen gelegt.

28 Marianne Bergmann, Chiragan, Aphrodisias, Konstantinopel. Zur mythologischen Skulptur der Spätantike (Palilia 7), Wiesbaden 1999; Christiane Vorster, Spätantike Bildhauerwerkstätten in Rom. Beobachtungen zur Idealskulptur in der nachkonstantinischen Zeit, JDAI 127/8 (2012/3), 393-498. 
tauchen aber in Schriftquellen typischerweise nicht auf, da sie eben nicht reflektiert wurden.

Ferner bedurfte gerade eine Gesellschaft, die sich religiös so radikal wandelte wie die spätantike, vermutlich neutraler Räume, um eine inklusive Kommunikation zu ermöglichen und damit den Zusammenhalt zumal der religiös so diversen Eliten zu bewahren: ${ }^{29}$ Über bestimmte Dinge, und das betrifft sowohl die politische Ordnung als auch die Selbstdarstellung von Eliten, ließ sich offenbar besser sprechen, wenn man traditionelle, weithin bekannte und akzeptierte Themen wählte, die auch wenn sie mythologisch waren, nicht als religiös distinktiv begriffen werden mussten.

Möglicherweise wäre noch eine weitere Voraussetzung dafür zu berücksichtigen, dass der klassische Mythos die Christianisierungen in verschiedenen Bereichen der Gesellschaft überleben konnte: In der Antike entwickelte man, wie ScHÄFER verdeutlicht, früh ein reflexives Verhältnis zu Mythen, nahm sie also nicht einfach hin, sondern durchdachte sie, überformte sie auch, spielte sogar mit ihnen, so dass sie leicht vom religiösen Kontext ablösbar waren. Noch stärker als für Griechenland gilt dies für Rom, wohin viele griechische Mythen transponiert worden waren, so dass sie ihren örtlichen Bezug verloren, teils auch einen neuen fanden. Das bewirkte auch die von Blumenberg beschworene hohe Plastizität des Mythos, seine Ungeeignetheit zur Markierung von Ketzern und Apostaten, die dazu führte, dass man einen falschen Gebrauch dieser Erzählungen schwerlich zu denunzieren vermochte - und da konnten am Ende auch Christen sich seiner bedienen. ${ }^{30}$

Ferner wird darüber nachzudenken sein, wie hilfreich die binäre Unterscheidung zwischen Heidentum und Christentum überhaupt ist, die eine einseitige Perspektive vermittelt, gerade weil sie von manchen theologischen Texten der Antike favorisiert wurde. Denn es gab christliche Gruppen, die auf Abgrenzung setzten und die in der Überlieferung sehr präsent sind. Doch bildeten sich auch andere Gruppen: Einiges spricht dafür, dass für manche Christen gerade der Eliten das, was andere Christen als heidnisch verwarfen, als Altbekanntes erträglich war, während Heiden Christliches, also zunächst einmal Neuartiges, nur schwer akzeptieren konnten.

Offenbar war der Mythos auch religionsübergreifend wichtig für die Konstitution der Eliten, insofern als Mythenkenntnis ein Mittel der Statusdistinktion bildete. Es gab starke Gruppen von konsensorientierten Akteuren, von center-Christians und center-pagans, wie sie kürzlich genannt wurden. ${ }^{31}$ Die antike paideia, der kein spezifisch christliches Schulwesen gegenüberstand, vermittelte den Gebildeten jenseits aller sonstigen Differenzen einen gemeinsamen Code, der besonders in der Dichtung sichtbar wurde und für den Mythisches unverzichtbar war - das Bildungswesen hatte ja nie der religiösen Unterweisung gedient. Insofern bedeutet die religiöse Neutralisierung des Mythos hier den Normalzustand. Julian sollte mit seinen religiös getönten

29 Hartmut Leppin, Christianisierungen im Römischen Reich: Überlegungen zum Begriff und zur Phasenbildung, ZAC 16 (2012), 245-276, 259-265.

30 Blumenberg (s. Anm. 2), 17.

31 Alan Cameron, The Last Pagans of Rome, Oxford 2011. 
Forderungen an die Rhetoren, dass sie hinter den Inhalten der von ihnen unterrichteten Texte zu stehen hätten, ein isolierter Einzelfall bleiben. ${ }^{32}$

Mir scheint es aufgrund des Gesagten hilfreich, heuristisch nach mindestens drei Formen des christlichen Umgangs mit Mythen zu differenzieren, die sich übrigens nicht wechselseitig ausschließen: Gerade die frühen christlichen Autoren stellen den falschen Mythos der christlichen Wahrheit entgegen. Mythos wurde hier nachgerade zu einem Gegenstand der Polemik und Abgrenzung. Das konnte geschehen, indem man, an die hergebrachte Mythenkritik seit Xenophanes von Kolophon und Platon anknüpfend, Mythen als kindisch, widersprüchlich oder frivol abtat, aber auch in euhemeristischer Weise als Überhöhung historischer Geschehnisse entlarvte, um zu bekräftigen, dass allein der christliche Gott Verehrung verdiente. Diese Haltung löste da, wo Christen Gewalt anwandten, bisweilen Handlungen aus, die das mythologische Werk depotenzierten: über die Kennzeichnung von Kunstwerken mit einem Kreuz ${ }^{33}$ bis hin zu deren physischer Vernichtung und in Einzelfällen zu Versuchen der Eliminierung von Mythen aus dem Bildungsbetrieb. Gerade diese Form der bisweilen durchaus auch physischen Arbeit am Mythos belegt indes, wie ernst die Kraft des Mythos von einigen genommen wurde. Doch verloren diese zerstörerischen Formen des Umgangs, wie es scheint, in der Spätantike an Bedeutung.

Eine andere Form des christlichen Umgangs mit Mythen war ihre Neutralisierung in religiöser Hinsicht. Indem man - und dieses „man“ schließt auch Bischöfe ein (LöHR) - sie als kulturell notwendiges, wenngleich der christlichen Botschaft unterlegenes Bildungswissen einordnete oder als ästhetische Phänomene betrachtete, gar musealisierte (BASSETT), erleichterte man ihre Integration in eine christliche Welt; die Allegorese, die sich schon unter heidnischen Philosophen und Mythographen entwickelt hatte, war dazu ein probates Mittel. ${ }^{34}$ Ein plastisches Bild wählt SCHMITZER, laut dem eine Einkapselung nötig war, um die Mythologie ihrer Brisanz zu berauben. Umgekehrt sah ein bekennender Heide wie Kaiser Julian sofort die Gefahr, die für seine religiöse Position aus einer solchen Haltung zum Mythos folgte und ereiferte sich über Christen, die ohne religiöse Anteilnahme klassische Texte lehrten. ${ }^{35}$

Eine dritte Form, die sich mit der zweiten überlappt, wäre die der Aneignung von Mythen, indem man deutlich machte, wie überlegen das Christentum gegenüber der Mythologie war, die so eine Stufe zum wahren Verständnis des Christentums bilden

32 Grundlegend aufgrund der Einbeziehung seiner umfänglichen älteren Forschungen Alan Cameron, Poetry and Literary Culture in Late Antiquity, in: Simon Swain/Mark Edwards (Hg.), Approaching Late Antiquity. The Transformation from Early to Late Empire, Oxford 2004, 327-354. Zu Julians sog. Rhetorenedikt s. Cod. Theod. 13,13,5 mit Jul., Ep. 61c (Bid.) und die völlige Ablehnung durch den differenziert über den Kaiser urteilenden Ammianus Marcellinus 22,10,7; 25,4,20.

33 Aber auch mit dieser Kennzeichnung konnten sich unterschiedliche Deutungen verbinden, s. Troels Myrup Kristensen, Miraculous Bodies. Christian Viewers and the Transformation of ,Pagan`Sculpture in Late Antiquity, in: Stine Birk/Birte Poulsen (Hg.), Patrons and Viewers in Late Antiquity (Aarhus Studies in Mediterranean Antiquity 10), Aarhus 2012, 31-66.

34 Grundlegend Pépin (s. Anm. 21).

35 Jul., Ep. 61c (Bid.). 
konnte - in diesem Sinne deutet im vorliegenden Band ACCORINTI die Dionysiaka des Nonnos, aber auch ScHINDLER Claudian und BASSETT den Umgang mit bildender Kunst. Oder aber man deutete, auch hier bot sich die Methode der Allegorese an, etwas vordergründig Unwahres wie die mythischen Erzählungen als verhüllte Wahrheit und bezog so Mythen auf das Christentum. Die Aneignung wurde dadurch erleichtert, dass viele Mythen christlichen Narrationen ähnelten, wie ZILLING herausarbeitet. ${ }^{36}$

Andererseits kann in einer Welt, in der das Christentum immer mehr dominierte, die Hervorhebung der Mythen bei Nicht-Christen Ausdruck eines offensiven Traditionsbewusstseins sein, das sich gerade dem Christentum verweigerte und auf die Unterscheidung davon wert legte. Philosophisch überhöht werden konnte dies, indem man wie in der neuplatonischen Interpretation die Mythen als legitime Fiktion verstand. Die religiöse Aufladung des Mythos durch manche christliche Polemiker wurde von Heiden übernommen; doch blieb dies eine Erscheinung, die wohl nur eine Minderheit betraf. ${ }^{37}$

Wenn der Umgang des Christentums mit Themen der Mythologie keineswegs einheitlich war, so ergibt sich daraus eine naheliegende Schlussfolgerung: Es war nicht nur die Adaptabilität des Mythos, die sein Überleben sicherte, sondern auch die Vielfalt des Christentums, die dazu beitrug. So wie es verschiedene Christentümer gab, gab es auch verschiedene Umgangsweisen mit dem Mythos. Man wird zudem stärker als früher die Gemeinsamkeiten von Christen und Heiden hervorheben, so die Allgegenwart eines Platonismus in den gebildeten Milieus oder die strukturellen Ähnlichkeiten zwischen heidnischen und christlichen Narrationen, auf die verschiedene Beiträge hingewiesen haben. Möglicherweise wäre es aufschlussreich, in Hinblick auf das Verhältnis zum Mythos einen Vergleich zwischen der griechisch-römischen und denjenigen christlichen Kulturen durchzuführen, deren Schriftlichkeit nicht auf dem klassischen Kanon aufbaute, namentlich der syrischen, aber das kann hier nicht geschehen.

Was die zeitliche Gliederung angeht, so bestätigt sich das von Manfred Fuhrmann entwickelte Phasenmodell, allerdings lediglich für den Bereich der Literatur. Hier verfestigt sich der Eindruck, dass im 5. Jahrhundert der Mythos eine stärkere Präsenz hatte als im 4. Jahrhundert, besonders deutlich in der Gattung des Epos. Diese Entwicklung mag insofern paradox erscheinen, als um die Wende zum 5. Jahrhundert das Christentum Dominanz entwickelte; doch scheint in eben dieser Zeit paideia wieder an Bedeutung für die Statusdistinktion der weitgehend sich zum Christentum bekennenden Eliten gewonnen zu haben, so dass mythologische Themen nicht religiös, sondern intellektuell distinktiv waren. Es mochte angesichts der Überlegenheit des Christentums auch schwierig anmuten, den Mythos als gefährlich zu beschreiben. In dieser Zeit genügte es in der Elitenkommunikation offenbar, andeutungsweise Hin-

36 In diesem Band Zilling, jüngst Anna Ferrari, La rilettura cristiana dei miti pagani, AnTard 19 (2011), $209-222$.

37 Zur Übersetzung von Fremdwahrnehmung in Selbstwahrnehmung im spätantiken Heidentum Hartmut Leppin, Zum Wandel des spätantiken Heidentums, Millennium 1 (2004), 59 - 81. 
weise auf Mythen zu geben, deren Verständnis man voraussetzen durfte; SCHMITZER betont, dass dies auf spätere Renaissancen vorauswies.

Im Epos des 6. Jahrhunderts scheinen mythologische Motive hingegen einen Rückgang erlebt zu haben. ${ }^{38}$ In dieser Zeit, der Epoche des totalisierenden christlichen Diskurses, ändert sich anscheinend auch sonst vieles: Die Zahl mythologischer Darstellungen verringerte sich offenbar nicht nur im Epos, sondern auch auf Textilien, also in einer ganz anderen Welt, aber erneut gilt: Die Entwicklung verläuft nicht linear. Denn unter Herakleios gewannen, wie MEIER verdeutlicht, mythologische Elemente eine ganz neue Bedeutung für die kaiserliche Selbstdarstellung.

Daraus ergibt sich eines ganz deutlich: Christentum und die Aneignung mythologischer Themen schließen sich nicht aus. Ein Nebeneinander war, wie RüPKE zeigt, schon im 4. Jahrhundert möglich, und es blieb auch so. Welcher Bildsprache man sich bediente, hing ab von der Funktion des Mediums und der Zielgruppe, aber gewiss auch von persönlichen Präferenzen von Schöpfern oder Auftraggebern. Vieles bleibt im Dunkeln, aber die Vorstellung einer fundamentalen Opposition von Christentum und Mythos setzt eine religiöse Eindeutigkeit des Mythos voraus, die es in den Augen vieler Zeitgenossen offenbar nicht besaß.

Doch wird man hier weitere Differenzierungen anbringen müssen: Bedeutung behielten gewiss auch regionale Unterschiede. Orte pflegten auf ihre jeweilige Art mythische Traditionen, wie ANDo für Rom und BASSETT für Konstantinopel verdeutlicht. Man könnte dann auch über die Frage einer Sonderstellung Ägyptens reflektieren, wie sie aus KRISTENSENs Beitrag erhellen mag. Es wäre also zu überlegen, ob das Nebeneinander christlicher und nicht-christlicher Motive, das man hier feststellt, eine Besonderheit dieser Landschaft war oder aber den besonderen Erhaltungsbedingungen in Hinblick auf Textilien in der Gegend zu verdanken ist. ${ }^{39}$

Blickt man weiter nach Westen, so spricht die umfänglich erhaltene Dichtung dafür, dass das Vandalenreich mit seiner blühenden lateinischen Literatur ebenfalls eine Sonderstellung einnahm; erinnert sei an Namen wie den des Poeten Dracontius und den des im Mittelalter außerordentlich einflussreichen Mythographen Fulgentius, der vermutlich in diesen Kontext gehört. ${ }^{40}$ Überdies wird man soziale Unterschiede in

38 Claudia Schindler, Per carmina laudes. Untersuchungen zur spätantiken Verspanegyrik von Claudian bis Coripp (Beiträge zur Altertumskunde 253), Berlin/New York 2009.

39 Zum Nebeneinander von Christlichem und Heidnischem in der ägyptischen Literatur Leslie S. B. MacCoull, Dioscorus of Aphrodito. His Work and his World (The Transformation of the Classical Heritage 16), Berkeley 1988, besonders plastisch das Gedicht H5, 9-31. - Regionale Unterschiede bei der Dekoration von Öllampen zwischen Nordafrika und Athen stellt Lund (s. Anm. 24), 205 f. fest.

40 Roswitha Simons, Dracontius und der Mythos. Christliche Weltsicht und pagane Kultur in der ausgehenden Spätantike (Beiträge zur Altertumskunde 186), München u.a. 2005, insbes.95-114, zeigt unterschiedliche Formen des Umgangs mit Mythen bei einer grundsätzlichen, oft aggressiven Ablehnung; vgl. Doreen Selent, Allegorische Mythenerklärung in der Spätantike. Wege zum Werk des Dracontius (Litora classica 2), Rahden/Westf. 2011, die den Begriff der Allegorie für Dracontius fruchtbar macht und für die Neukontextualisierung der Mythen den Begriff der „Transmythologisierung“ vorschlägt (zu Fulgentius 49-55); John Chance, Medieval Mythography. From Roman North Africa to the 
den Blick nehmen müssen, die über die Feststellung der Bedeutung von Mythen für die soziale Distinktion der Eliten hinausgehen, denn auch in anderen Schichten scheint der Mythos seine Präsenz bewahrt zu haben: Das Beispiel der Textilien spricht dafür, dass auch middle classes sich von Mythen affizieren ließen. Zudem ist zu berücksichtigen, inwieweit eine mythisch inspirierte Bildsprache oder Narration auch außerhalb der Eliten oral weiterleben konnte, etwa in Zaubersprüchen und Beschwörungsformeln. ${ }^{41}$

Doch bei allen Differenzierungen: In den klassischen Mythen war eine symbolische Tradition gespeichert, die sich immer neuen Aneignungsprozessen erschloss. Der Mythos insgesamt ließ sich von den Christen nicht fangen, mochten auch Teile unter Verschluss geraten. In der Renaissance öffneten sich ganz andere Türen, doch keine führte zurück in die alte, klassische Welt des Mythos, sondern zu neuen Formen der Aneignung, die bis heute kein Ende gefunden haben.

School of Chartres, A.D. 433-1177, 2 Bde., Gainesville/Flor. 2001 erörtert eindringlich die vielfältigen Formen des Umgangs mit dem Mythos in lateinischer Spätantike und Mittelalter; s. Bd. 1, 95-128 zu Fulgentius.

41 Etwa David Frankfurter, The Laments of Horus in Coptic. Myth, Folklore and Syncretism in Late Antique Egypt, in: Ueli Dill/Christine Walde (Hg.), Antike Mythen. Medien, Transformationen und Konstruktionen. Fritz Graf zum 65. Geburtstag, Berlin/New York 2009, 229-247. 


\section{Pagane Mythen - christliche Herrscher. Mythos und Mythologie in den politischen Dichtungen Claudians}

Kaum eine Frage hat die Forschungen zu Claudian so kontinuierlich und so intensiv beschäftigt wie diejenige nach der Konfession dieses Dichters, ${ }^{1}$ der, wahrscheinlich aus dem ägyptischen Alexandria stammend, ${ }^{2}$ seit 395 n.Chr. als Hofdichter in den Diensten des weströmischen Kaiserhofes stand. Dabei scheint die Sachlage auf den ersten Blick unzweifelhaft. Nach den Zeugnissen zweier christlicher Zeitgenossen war Claudian kein Christ: „Ohne Verbindung zum christlichen Glauben“, a Christi nomine alienus, hat Augustinus sein Werk im fünften Buch seines Gottesstaates genannt, ${ }^{3}$ einen „unbekehrbaren Heiden“, paganus pervicacissimus, gar der Historiker Orosius. ${ }^{4}$ Die überlieferten Dichtungen Claudians scheinen ihnen Recht zu geben: Nicht nur wählt sich Claudian für sein Epos De raptu Proserpinae einen dezidiert nichtchristlichen Stoff, nicht nur lassen seine Carmina minora mit Ausnahme des häufig als unecht erachteten Gedichts De salvatore ${ }^{5}$ keinerlei Bezüge zum Christentum erkennen. Auch die politischen Dichtungen, die Claudian zwischen 395 und 404 für hohe Würdenträger und Angehörige des weströmischen Kaiserhofs verfasste, blenden das Christentum vollständig aus. „Es ist“, so schreibt Siegmar Döpp, ,als ob es für den politischen Dichter Claudian das Christentum nicht gäbe; vielmehr könnte man aus seinen Werken den Eindruck gewinnen, das Heidentum lebe mit ungebrochener Kraft fort“ “ ${ }^{6}$ Der älteren Claudian-Forschung galt der Dichter daher gern als ,ausgemachter Heide“ und als ,letzter großer Dichter des paganen Roms‘. Alan Cameron überschreibt ein

1 Zuletzt: H. Harich-Schwarzbauer, Dokumentation, Historisierung, gelehrte Andeutung und spielerische Erhaltung: Zur literarischen Repräsentation philosophischer Diskurse bei Claudius Claudianus, in: Th. Fuhrer (Hrsg.), Die christlich-philosophischen Diskurse der Spätantike: Texte, Personen, Institutionen, Stuttgart 2008, 347-362. Einen ausführlichen Forschungsüberblick gibt S. Döpp, Zeitgeschichte in Dichtungen Claudians, Wiesbaden 1980 (Hermes ES 43), 24-41; C. Moreschini, Paganus pervicacissimus? Religione e ,filosofia‘ in Claudiano, in: W.-W. Ehlers, F. Felgentreu, S. H. Wheeler (Hrsg.), Aetas Claudianea, München - Leipzig 2004, 57-77, 57-59.

2 Die ägyptische Herkunft Claudians wurde bezweifelt von P. G. Christiansen, Claudian - a Greek or a Latin, Scholia 6 (1997), 79-95; überzeugend für eine Herkunft des Dichters aus dem Osten wieder B. Mulligan, The Poet From Egypt? Reconsidering Claudian's Eastern Origin, Philologus 151 (2007), 285 310 (erneuter Widerspruch von P. G. Christiansen/D. Christiansen, Claudian. The Last Great Pagan Poet, AntCl 78 [2009], 133-144).

3 Aug. civ. 5,68.

4 Oros. hist. 7,35.

5 Vgl. P. Fargues, Claudien. Etudes sur sa poésie et son temps, Paris 1933, $159 \mathrm{f}$.

6 Döpp (s. Anm. 1), 25f. Ähnlich H. L. Levy, Themes of Encomium and Invective in Claudian, TAPA 89 (1958), 336-347, 345: „Claudian writes as if the old Roman state religion were in full bloom throughout the Empire.“ 
Kapitel seiner Monographie provokant mit dem Titel „The Pagan at a Christian Court“7 und zuletzt haben Peder G. Christiansen und David Christiansen 2009 Claudian als „The Last Great Pagan Poet“ tituliert. ${ }^{8}$ Die neuere Forschung hat indes nachgewiesen, dass diese Einschätzung weitaus problematischer ist, als es zunächst den Anschein hat. ${ }^{9}$ Fakt ist zwar, dass Claudian in seinen Dichtungen auf explizite Bezüge zum Christentum verzichtet. Ebenso evident ist jedoch, dass er fast zehn Jahre lang als offizieller Hofdichter in den Diensten des Honorius, eines Sohnes des christianissimus imperator Theodosius, und seines vandalischen Heermeisters und Vormunds Stilicho gewirkt hat und für seine poetischen Leistungen sogar mit einer Statue auf dem Trajansforum geehrt wurde, deren Sockelinschrift erhalten ist. Wie hat man sich also das offensichtliche Miteinander von paganen ${ }^{10}$ Dichtungen und christlichen Auftraggebern zu erklären? Sind Claudians Gedichte und die Tatsache, dass er mit ihnen über ein Jahrzehnt die öffentliche Meinung entscheidend prägte, ein Zeichen für die religiöse Toleranz Stilichos, wie frühe Claudian-Forscher wie Theodor Birt und Santo Mazzarino meinen ${ }^{11}$ Sollten Claudians Gedichte die heidnische Senatsaristokratie für Stilicho gewinnen? - dies die Vermutung von Harry Levy. ${ }^{12}$ Oder war Claudian ein „höfischer Scheinchrist“, so Wolfgang Schmid, ${ }^{13}$ der unter dem Deckmantel christlicher Konfession unbeirrt an seinen paganen Vorstellungen festhielt und diese in seinen Dichtungen kommunizierte?

Um es kurz zu machen: Ich glaube, dass es - gerade bei der Art von hochoffizieller, in vielfältige Traditionen eingebundener und verschiedensten Interessen verpflichteter Auftragsdichtung, die Claudian betreibt ${ }^{14}$ - extrem schwierig ist, aus seinen Dichtungen Rückschlüsse über seine persönliche religiöse Gesinnung abzuleiten, zumal neuere Untersuchungen gezeigt haben, dass zum einen das Verhältnis von Christen-

7 A. Cameron, Claudian. Poetry and Propaganda at the Court of Honorius, Oxford 1970, 189.

8 Christiansen/Christiansen (s. Anm. 2), 133-144.

9 Für die folgende Diskussion vgl. auch Döpp (s. Anm. 1), 24-41; C. Schindler, Claudians pagane Götter. Tradition und Innovation in der spätantiken Panegyrik, Gym 115 (2008), 331-345, 333- 335.

10 Der Begriff „pagan“, von christlichen Autoren zur Abgrenzung der eigenen Lehren geprägt, wird hier rein deskriptiv und wertneutral verwendt. Vgl. auch P. Gemeinhardt, Das lateinische Christentum und die pagane Bildung, Tübingen 2007, $21 \mathrm{f}$.

11 Th. Birt, De moribus christianis quantum Stilichonis aetate in aula imperatoria occidentali valuerint disputatio, Marburg 1885, xxiii; S. Mazzarino, La politica religiosa di Stilicone, Rendiconti/Istituto Lombardo, Accademia di Scienze e Lettere, Classe di Lettere, Scienze morali e storiche 71 (1938), 235262, hier: 245 f.; ähnlich Harich-Schwarzbauer (s. Anm. 1), 350.

12 Levy (s. Anm. 6).

13 W. Schmid, s.v. Claudianus I, RAC 3 (1957), 152-167, 160; Cameron (s. Anm. 7), 216.

14 Zur generischen Einordnung der Gedichte vgl. P. L. Schmidt, Politik und Dichtung in der Panegyrik Claudians, Konstanz 1976 (Konstanzer Universitätsreden 55); H. Hofmann, Überlegungen zu einer Theorie der nichtchristlichen Epik der lateinischen Spätantike, Philologus 132 (1988), 101-159; C. Schindler, Per carmina laudes. Untersuchungen zur spätantiken Verspanegyrik von Claudian bis Coripp, Berlin u.a. 2009 (Beiträge zur Altertumskunde 253); zuletzt G. Müller, Lectiones Claudianeae. Studien zu Poetik und Funktion der politisch-zeitgeschichtlichen Dichtungen Claudians, Heidelberg 2011 (Bibliothek der Klassischen Altertumswissenschaften, NF, 2. Reihe). 
tum und Kaisertum prinzipiell sehr viel komplexer ist, als es auf den ersten Blick erscheint, ${ }^{15}$ dass zum anderen der Umgang von Christen und Nichtchristen (die man ohnehin nicht dichotomisch trennen kann $)^{16}$ in vielen Bereichen kein kämpferisches Gegeneinander sein musste und dass pagane Traditionen in der Kunst, der Literatur und in der Philosophie mindestens bis ins fünfte Jahrhundert hinein weit verbreitet waren, ${ }^{17}$ so dass es nicht erstaunlich ist, dass ein prominenter Vertreter des Christentums wie Ambrosius seine Predigten mit antiken Mythologemen schmückte. ${ }^{18}$

Wie eine ganze Reihe anderer Claudian-Forscher glaube ich weiterhin, dass der Versuch, ein ,Glaubensbekenntnis‘ des Dichters zu ergründen, zum Verständnis seiner Dichtungen allenfalls begrenzt beizutragen vermag. ${ }^{19}$ Die Frage sollte meines Erachtens nicht lauten, ob Claudian ein ,Heide‘, ein ,Christ“ oder gar ein „höfischer Scheinchrist“ gewesen ist. Viel eher sollte man, wie es in der neueren Claudian-Forschung vermehrt geschieht, fragen, was den Hofdichter des theodosianischen Herrscherhauses bewogen haben kann, gerade in einem christlichen Kontext an achristlichen, aus dem gesamten Reservoir paganer Bildung gespeisten Dichtungen festzuhalten. Die Tendenz geht zumeist dahin, diese Frage mit dem Hinweis auf einen gewissen Traditionalismus Claudians zu beantworten: Pagane Elemente wie die Mythologie, so Cameron, „had long since become merely decorative“.${ }^{20}$ Die spätantiken Eliten seien in der paganen Bildungstradition erzogen worden, mit der zu brechen einem Dichter nicht ohne weiteres möglich gewesen sei. ${ }^{21}$

Doch lässt sich meines Erachtens mit dem Verweis auf pagane Bildungstraditionen die fast schon programmatisch achristliche Ausrichtung von Claudians Dichtungen nur zum Teil erklären. Am Beispiel der Verwendung eines Kristallisations-

15 Vgl. H. Leppin, Kaisertum und Christentum in der Spätantike. Überlegungen zu einer unwahrscheinlichen Synthese, in: A. Fahrmeir, A. Imhausen (Hrsg.), Die Vielfalt normativer Ordnungen. Konflikte und Dynamik in historischer und ethnologischer Perspektive, Frankfurt am Main 2013, 197 223.

16 Vgl. H. Leppin, Christianisierungen im Römischen Reich: Überlegungen zum Begriff und zur Phasenbildung, ZAC 16 (2012), 247-278, 249; 260.

17 Vgl. W. Liebeschuetz, Pagan Mythology in the Christian Empire, International Journal of the Classical Tradition 2 (1995), 193-208; Leppin (s. Anm. 16), $263 \mathrm{f}$.

18 Vgl. Cameron (s. Anm. 7), 199.

19 Aufschlussreich sind etwa die Ergebnisse von Harich-Schwarzbauer (s. Anm. 1), 360, zu Claudians hellenistischer Sozialisation in Alexandria im Umfeld der Neuplatoniker, die sie anhand der philosophischen Diskurse bei Claudian nachweist, wobei sie sich allerdings zu Claudians, Christentum nicht positioniert.

20 Cameron (s. Anm. 7), 199.

21 Vgl. zu dieser Forschungsdiskussion Schindler (s. Anm. 9), 335 (mit weiterführender Literatur). Für die Bedeutung der paganen Bildungstraditionen für die spätantike Elite außerdem Liebeschuetz (s. Anm. 17), $194 \mathrm{f}$. 
punktes vermeintlich paganer Gesinnung in Claudians politischen Dichtungen, des Mythos, ${ }^{22}$ möchte ich daher im Folgenden zeigen,

(1) dass gerade der Mythos bei Claudian im Kontext des Herrscherlobs eine wichtige Funktion übernimmt, die von christlichen Stoffen in dieser Form nicht geleistet werden kann, ${ }^{23}$

(2) dass Claudians Verwendung des Mythos nicht so sehr von Verehrung und Hochachtung gegenüber den paganen Kulturgütern zeugt als dass sie vielmehr eine kritische, beinahe schon destruktive Haltung des Dichters erkennen lässt,

(3) und schließlich, dass Claudians Rekurse auf den Mythos christliche Empfindungen nicht verletzen, sondern vielfach sogar mit ihnen konform gehen und bisweilen sogar dezidiert an die Mythenkritik christlicher Autoren anknüpfen.

\section{I. „Mythische Geographie“: Der Mythos als Bestandteil der römischen Literatur- und Kulturtradition}

Obgleich Mythologisches in Claudians politischen Dichtungen eine wichtige Rolle spielt, handelt es sich bei diesen Werken nicht um „mythologische“ Dichtungen im eigentlichen Sinn. Nicht Figuren des Mythos stehen im Mittelpunkt der Darstellung, sondern Persönlichkeiten der Zeitgeschichte, die als Adressaten der Gedichte teils nach den Vorgaben der rhetorischen Panegyrik verherrlicht, teils zu Protagonisten einer Handlung gemacht werden. ,Mythologisch' sind Claudians Panegyriken und Invektiven nur insofern, als sowohl die Protagonisten und ihre Gegenspieler als auch ihre Lebenswirklichkeit durch so gut wie alle politischen Dichtungen hindurch ${ }^{24}$ mit Gegebenheiten oder Figuren des Mythos in Verbindung gebracht werden. Dies geschieht zum Teil nur beiläufig und implizit. So wird die reale Welt in Claudians politischen Epen konsequent von mythischen Völker- und Ortsnamen überformt: Die Goten erscheinen stets ethnologisch unkorrekt als Getae, der Po heißt in Anspielung auf die PhaethonSage Eridanus. ${ }^{25}$ Häufig verbindet Claudian in seinen Gedichten mit geographischen

22 Der Mythendefinition von Chr. Schmitz, F. Zanella, S. Heydasch-Lehmann, s.v. Mythos, RAC 25 (2013), 471-516, 474, folgend, verstehe ich Mythen als „Erzählungen über Götter und Heroen“, vor allem in ihrer Manifestation als Narrative in literarisch-ästhetischen Diskursen.

23 Zur Unverzichtbarkeit des mythischen Stoffes s. Schmitzer in diesem Band.

24 Die Referenzdichte auf Mythologisches ist in den Gedichten etwa gleich hoch. Eine Ausnahme ist der Panegyricus für das Konsulat von Mallius Theodorus, der nur einen einzigen Verweis auf den Mythos enthält (283-295) - dies wohl deswegen, weil hier sehr stark auf die philosophischen Interessen des Mallius Theodorus abgehoben wird.

25 Z.B. Gild. 37; Stil. 1,111 (Getae); OlProb 259; III Cons. Hon. 123 (Eridanus); IV Cons. Hon. 508 (Res Pandioniae). Vgl. C. Schindler, Tradition-Transformation-Innovation. Claudians Panegyriken und das Epos, in: W.-W. Ehlers, F. Felgentreu, S. H. Wheeler (Hrsg.), Aetas Claudianea, München - Leipzig 2004, $16-37,21$. 
Angaben Hinweise auf ein mythisches Ereignis, um diesen Ort zu lokalisieren. So wird das ,Ende der Welt‘ in der Invektive gegen Rufin unter Verweis auf die odysseische Nekyia bestimmt: Fern im äußersten Gallien, am Rande des Ozeans, gebe es einen Ort, wo Odysseus nach der Überlieferung mit einem Blutopfer das Volk der Toten beschworen habe: ubi fertur Ulixes / sanguine libato populum movisse silentem (Ruf. 1,124f.). Zweifellos sind derartige Verweise auf den Mythos den generischen Konventionen der epischen Dichtung geschuldet, in denen Claudians Dichtungen stehen. ${ }^{26}$ Insbesondere die mythischen Ortsnamen sind dabei Gemeingut der Bildungstradition. Sie gehören dem Buchwissen der ,klassischen“ Antike an, einem Buchwissen, das „von jeder kultischen Bindung abgelöst“ ${ }^{“ 27}$ ist und dessen Spuren sich dementsprechend noch bei Venantius Fortunatus finden, wenn dieser die Hölle als Tartarus, den Himmel als Olympus und Jupiter als Tonans bezeichnet. ${ }^{28}$

Bei Claudian hat die ,mythische Geographie، jedoch eine wichtige Funktion, die sich besonders dort manifestiert, wo der Dichter in Verbindung mit geographischen Angaben in einer katalogartigen Aufzählung verschiedene Mythologeme präsentiert. Im zweiten Buch der Invektive gegen Eutrop zum Beispiel widmet er sich ausführlich der Landschaft Phrygien, die er als reiches und kulturträchtiges Land vorstellt (Eutr. 2,238-273). Phrygien ist nicht nur der Ursprung von Kultur und Sprache, sondern auch Schauplatz verschiedener mythologischer Ereignisse (Eutr. 2,255-261):

Hic cecidit Lyciis iactata paludibus olim 255 tibia, foedatam cum reddidit unda Minervam, hic et Apollinea victus testudine pastor suspensa memores inlustrat pelle Celaenas. quattuor hic magnis procedunt fontibus amnes auriferi; nec miror aquas radiare metallo, 260 quae totiens lavere Midan.

Hier fiel zu Boden die Flöte, die einst in die lykischen Sümpfe geschleudert wurde, als die Woge Minerva entstellt zurückwarf, hier macht der Hirte, von Apollons Lyra bezwungen, mit aufgehängter Haut Kelainai berühmt, das die Erinnerung an ihn bewahrte. Hier ergießen sich aus großen Quellen vier Gold führende Ströme, und ich wundere mich nicht, dass Wasser vom Goldglanz schimmern, die so oft den Midas badeten. ${ }^{29}$

Drei Mythen sind es, die der Dichter, gegliedert durch hic - hic - hic, mit Phrygien in Verbindung bringt: Es ist das Land, in dem Minerva aus Zorn über ihr entstelltes Spiegelbild ihre Flöte ins Wasser warf, Marsyas im Wettstreit dem Apoll unterlag und dessen goldschimmernde Flüsse auf den mythischen König Midas weisen. Abgesehen davon, dass die ausführliche Ekphrasis Phrygiens als Ganze die Schilderung der an-

26 Vgl. C. Ware, Claudian and the Roman Epic Tradition, Cambridge 2012, 42- 44.

27 Vgl. Schmitz (s. Anm. 22), 474.

28 Ven. Fort. laud. Mar. 140; 207; 329 (Tartarus); 259 (Olympus).

29 Alle Übersetzungen der lateinischen Zitate stammen von der Verfasserin. 
stehenden Kriegshandlungen retardiert, ${ }^{30}$ ist für den ,mythologischen` Teil noch ein anderer Aspekt entscheidend. Alle drei Mythologeme werden dem Rezipienten in extremer Verrätselung geboten. Schon die äußerst knappen Hinweise auf Minerva und Midas erschließen sich nur demjenigen, der den Verlauf des Mythos kennt. Ohne Vorkenntnisse unverständlich bleibt die in suspensa pelle $(2,258)$ liegende Anspielung auf die Häutung des Marsyas, zumal dieser nicht einmal mit seinem Namen, sondern lediglich als Apollinea victus testudine pastor $(2,257)$ eingeführt wird. Um die Verrätselung in all ihren Details zu entschlüsseln, ist eine gute Kenntnis der literarischen Prätexte erforderlich: Die Minerva-Anspielung wird erst nach der Lektüre von Ovids Fasti, die Marsyas- und Midas-Anspielungen nach der Lektüre seiner Metamorphosen verständlich. ${ }^{31}$ Der mythologische Katalog von In Eutropium erfordert also fundierte Literaturkenntnisse. Der Rückverweis auf Ovid ist dabei viel mehr als ein intellektuelles Spiel. Die Ovid-Reminiszenzen weisen Phrygien als literarische Landschaft aus und reklamieren sie als einen Teil der römischen Literaturtradition, in der Gestalten der antiken Literatur ihre Heimat haben: Es geht dem Dichter nicht primär um die Inhalte des Mythos, sondern darum, die Literatur- und Kulturtradition zu evozieren, in denen diese mythischen Begebenheiten tradiert werden. Indem der Dichter nun das reale Phrygien in einen Erinnerungsort ovidischer Mythen verwandelt, reklamiert er es als genuin römisches Gebiet ${ }^{32}$ - ein Aspekt, der die Plünderung dieser blühenden Kulturlandschaft durch die barbarischen Goten, die der Dichter im Anschluss an die Topothesie in dem Satz talem tum Phrygiam Geticis populatibus uri / permisere dei (2,274f.) lapidar zum Ausdruck bringt, umso illegitimer erscheinen lässt. Die Goten plündern nicht irgendeine Provinz im fernen Kleinasien, sie bedrohen die Kulturschätze der römischen Welt. Letztlich steht der Mythos also für römische Literatur, die römische Literatur für eine kulturelle Vormachtstellung, aus der sich die Gebietsansprüche ganz natürlich ergeben. Mit den Inhalten des eben erst zur Staatsreligion erklärten Christentums, die noch kein allgemeines Kulturgut sind und noch nicht einmal über eine allgemeine Akzeptanz verfügen, lässt sich eine ähnlich schlagkräftige Argumentation nicht führen.

\section{Der Mythos als Chiffre in politischen Diskursen}

Sehr viel häufiger noch als die Verknüpfung von Geographica mit mythischen Begebenheiten ist die direkte Gegenüberstellung von Protagonisten aus Claudians Gedichten mit mythologischen Figuren in Form von Synkriseis, wie sie die panegyrische

30 Vgl. H. Schweckendiek, Claudians Invektive gegen Eutrop (In Eutropium), Hildesheim u.a. 1992, 206.

31 Ov. met. 6,382-400 (Marsyas); fast. 6,693-710 (Minerva/Marsyas); met. 11,85-193 (Midas).

32 Eine ähnliche Funktion hat der Katalog griechischer Berge und Kultstätten in III Cons. Hon. 111-118. 
Theorie vorschreibt. ${ }^{33}$ Auch hier liefert der Mythos - anders als christliche Stoffe - in mehrfacher Hinsicht ein reichhaltiges Reservoir für die Herrscherlegitimation. Was die Auswahl der Stoffe angeht, ist zu beobachten, dass Claudian regelmäßig auf Mythen zurückgreift, die bereits vor seiner Zeit im politischen Diskurs Chiffren für Macht und Einflussnahme sind. Diese Chiffren werden innerhalb von Claudians dichterischem Werk mehrfach wiederholt und dadurch als feste Bilder etabliert: Olybrius und Probinus, Honorius und Arcadius und die beiden Theodosii erscheinen als Castor und Pollux: ${ }^{34}$ Das mythische Brüderpaar verkörpert bereits in früheren politischen Kontexten das Ideal der concordia und wird vor allem in der julisch-claudischen Dynastie verschiedentlich mit Thronerben in Beziehung gesetzt, z. B. dadurch, dass diese in gemeinsamen Tempeln verehrt werden. ${ }^{35}$

Relativ häufig sind in Claudians politischen Dichtungen Verweise auf Hercules, ${ }^{36}$ dessen Verbindung zur römischen Staatsmacht sich schon auf Münzprägungen des ersten vorchristlichen Jahrhunderts findet, der als Hercules Augustus oder Hercules Augusti für den Schutz des römischen Kaisers zuständig war, ${ }^{37}$ der in der Spätantike durch die Dynastie der Herculii ${ }^{38} \mathrm{zu}$ besonderer Prominenz aufstieg und auch in den Panegyrici Latini immer wieder als Referenz-Held herangezogen wird. ${ }^{39}$ Die Bezwingung der Giganten und anderer erdgeborener Ungeheuer schließlich, die bei Claudian wiederholt als Bild für die Überwindung externer Gegner verwendet wird, ${ }^{40}$ begegnet seit der spätarchaischen Zeit in Literatur und Kunst als Chiffre für den Sieg über die barbarische Bedrohung. ${ }^{41}$ Die verschiedenen Bilder vom Sturz des Phaethon und der Rettung der Welt durch Sol $^{42}$ implizieren nicht nur die verbreiteten allegorischen

33 Zum Begriff der Synkrisis, ihren Formen und ihrer Verwendung vgl. F. Focke, Synkrisis, Hermes 58 (1923), 327-368; L. Pernot, La rhétorique de l'eloge dans le monde gréco-romain, Bd. 2, Paris 1993, 690 698.

34 OlProb. 236-244; Gild. 213-222; IV Cons. Hon. 206-211.

35 Vgl. B. Poulsen, The Dioscuri and Ruler Ideology, SO 66 (1991), 119-146, bes. 123-125.

36 Ruf. 1,283-296; IV Cons. Hon. 132; 532-538; Stil. 1,143-147; Get. 377-379.

37 Vgl. M. Clauss, Kaiser und Gott. Herrscherkult im römischen Reich, München - Leipzig 2001, 281.

38 Z.B. Paneg. Lat. XI(III),3,2-3; vgl. W. Derichs, Herakles, Vorbild des Herrschers in der Antike, Diss. Köln 1950, 108f.; M. Mause, Die Darstellung des Kaisers in der lateinischen Panegyrik, Stuttgart 1994, 69; F. Kolb, Herrscherideologie in der Spätantike, Berlin 2001, 167-171.

39 Vgl. XII Panegyrici Latini, rec. brevique adnotatione critica instruxit R. A. B. Mynors, Oxford 1964, 294 (Index nominum s. v. Hercules). Auch in der nachantiken Herrscherlegitimation sind Verweise auf Hercules häufig, vgl. W. Sparn, Hercules Christianus. Mythographie und Theologie in der frühen Neuzeit, in: W. Killy (Hrsg.), Mythographie der frühen Neuzeit. Ihre Anwendung in den Künsten, Wiesbaden 1984, 73-107; J. Berger, Hercules - Held zwischen Tugend und Hybris. Ein europäischer Erinnerungsort der frühen Neuzeit?, in: I. Dingel, M. Schnettger (Hrsg.), Auf dem Weg nach Europa. Deutungen, Visionen, Wirklichkeiten, Göttingen 2010, 79-106; s. auch Meier in diesem Band.

40 III Cons. Hon. 152-162; IV Cons. Hon. 108; 532-538; Stil. 1,303-308; Get. 61-66; praef. VI Cons. Hon. 17-18.

41 F. Graf, A. Ley, s.v. Giganten, DNP 4 (1998), 1066-1069 (mit weiterführender Literatur).

42 IV Cons. Hon. 62-69; VI Cons. Hon. 165-177; 185-192. 
Deutungen des Mythos als kosmische Katastrophe, ${ }^{43}$ sondern auch die Gleichsetzung des Herrschers oder gar der Stadt Rom mit dem Sonnengott, der bis ins Jahr 325 auf Münzprägungen erscheint. ${ }^{44}$

Insbesondere diejenigen mythologischen Figuren, die in Claudians Panegyriken mehrfach zum Vergleich herangezogen werden, sind also durch Vorverwendungen in den verschiedensten politischen Kontexten und Medien fest etabliert, so dass ihr Erscheinen für die Rezipienten beinahe schon Signalwirkung gehabt haben dürfte. Dabei waren möglicherweise nicht einmal primär die Implikationen der ursprünglichen mythologischen Figur entscheidend, sondern ihre Rezeption und ihre Geläufigkeit in bestimmten politischen Kontexten: Wenn Claudian die weströmischen Würdenträger mit Hercules, den Dioskuren und Sol parallelisiert, macht er im Bewusstsein des Rezipienten hinter diesen mythischen Figuren immer frühere Herrscher sichtbar, die ebenfalls als Hercules, als Dioskuren oder als Sol gewürdigt worden waren. Die politische Botschaft, die sich mit bestimmten Gestalten und Ereignissen des Mythos verband, war offensichtlich so stark, dass sie Claudian bewogen hat, im Kontext seiner politischen Dichtungen an ihnen festzuhalten. Dies war ihm umso leichter möglich, als sämtliche mythologische Figuren, die in seinen Gedichten als Chiffren für politische Macht auftreten, nachweislich in christlichen Diskursen sanktioniert sind: Hercules wurde zwar von christlichen Autoren auf der einen Seite kritisiert, weil es ihm nicht gelungen sei, seine Leidenschaften $\mathrm{zu}$ besiegen, auch wird seine Unzucht verurteilt: ${ }^{45}$ Diese Seite seiner Persönlichkeit bleibt in Claudians Gedichten ausgespart. Andererseits gibt es Stimmen, die Hercules durchaus als tugendhaften Helden sehen, der am Scheideweg die richtige Wahl trifft. In den Stromata des Clemens von Alexandria erscheint er gar zusammen mit Alexander als Muster eines vernünftigen und göttlichen Herrschers. ${ }^{46}$ Boethius befasst sich in seiner Consolatio philosophiae ausführlich mit den Arbeiten des Hercules (cons. 4,7,13-35); als letzte Arbeit wird das Tragen des Himmelsgewölbes genannt. Mit ihr ist eine Aufforderung an die Tapferen verbunden, dem Beispiel des Hercules zu folgen und sich den Himmel zu verdienen. ${ }^{47}$ Wenn Claudian im ersten Buch von In Rufinum Stilichos Taten an den Taten des Hercules misst (1,283-296) oder in den Laudes Stilichonis Stilicho, der die politische Verantwortung bereitwillig übernimmt, mit Hercules vergleicht, der sich von Atlas das Himmelsgewölbe auf die Schultern laden lässt (1,143-147), dann mussten diese Vergleiche für christliche Rezipienten nicht unbedingt anstößig wirken, sondern konnten sogar positiv konnotiert sein. Die Gigantomachie ist ebenfalls ein

43 M. Hillgruber, Der Phaethon-Mythos als Gegenstand kosmologischer Spekulationen, Gym 102 (1995), 481-496.

44 Vgl. G. H. Halsberghe, The Cult of Sol Invictus, Leiden 1972, $169 \mathrm{f}$.

45 Angaben nach A. J. Malherbe, s.v. Herakles, RAC 14 (1988), 559-583, 574-581.

46 Clem. Al. Strom. 1,158,3.

47 Boeth. cons. 4,7,29-35: ultimus caelum labor inreflexo / sustulit collo pretiumque rursus / ultimi caelum meruit laboris. / Ite nunc, fortes, ubi celsa magni / ducit exempli via. Cur inertes / terga nudatis? superata tellus / sidera donat. Vgl. Schmitz (s. Anm. 22), $505 \mathrm{f}$. 
traditionelles Bild für politischen Umsturz. Sie ist im Herrscherlob fest etabliert, so dass nicht nur Claudian, sondern auch Eusebios in der Vita Constantini und Panegyriker mit einem nachgewiesenermaßen christlichen Hintergrund wie Sidonius Apollinaris und Coripp an ihr festhalten. ${ }^{48}$ Eine ähnlich positive Bewertung erfahren die Dioskuren: Bei Ennodius werden sie zusammen mit anderen mythischen Freundespaaren als Beispiele für Freundestreue angeführt, ${ }^{49}$ sie werden ferner mit Peter und Paul sowie mit Kosmas und Damian analogisiert und sogar unter die christlichen Märtyrer aufgenommen. ${ }^{50}$ Gerade die Konvergenz pagan-antiker und christlicher Deutungsmöglichkeiten prädestiniert mythische Figuren wie die Dioskuren, Hercules und die Giganten als panegyrische Vergleichsobjekte.

Am deutlichsten sind die Parallelen und Überlagerungen schließlich im Falle der Figur Apolls. Spätestens seit der Schlacht von Actium ist dieser Gott an die politischen Erfolge Roms gebunden. So beruft sich auch ein anonymer Panegyricus auf Konstantin auf den Schutzgott Apoll. ${ }^{51}$ Es ist daher nicht erstaunlich, dass Claudian Apoll mehrfach in Vergleichen heranzieht..$^{52}$ Besonders signifikant ist der Mythos von Apoll als Sieger über die Python-Schlange, den bereits Lucan in seiner Pharsalia auf zeitgeschichtliche Ereignisse bezieht. ${ }^{53}$ Claudian hat dieses Mythologem insgesamt dreimal verwendet: Im Panegyricus auf Olybrius und Probinus findet er sich innerhalb eines Vergleiches der von Proba angefertigten Konsulatsroben mit den Gewändern, die Latona für ihre Zwillinge Apollo und Diana webt (OlProb. 186-189), im Panegyricus auf das vierte Konsulat des Honorius in Verbindung mit dem Giganten-Mythos (IV Cons. Hon. 532-538). Die längste Version bietet die Praefatio zum ersten Buch von In Rufinum. Nachdem der Dichter den Mythos ausführlich referiert hat, beschließt er die Ausführungen mit einer Übertragung der mythischen Ereignisse auf die aktuelle Situation (Ruf. praef. 1,15-18):

\section{Nunc alio domini telis Pythone perempto convenit ad nostram sacra caterva lyram, qui stabilem servans Augustis fratribus orbem iustitia pacem, viribus arma regit.}

Nun, da ein neuer Python durch die Geschosse des Herrschers bezwungen, kommt die heilige Schar zum Klang meiner Lyra zusammen -

48 Euseb. Vit. Const. 1,5,1; Sidon. carm. 6,23-26; Coripp. Ioh. 1,451-459; 5,156f.; 6,658-660, vgl. J.-U. Andres, Das Göttliche in der Johannis des Corippus: Antike Götterwelt und christliche Wertvorstellung im Widerstreit?, Trier 1997, 23-27.

49 Ennod. Epist. 1,9: nobis, si placet in novellum usum maiorum exempla revocare, potius Pyladis et Orestis, Nisi et Euryali, Pollucis et Castoris, si nihil his clandestinorum actuum decerpit obscenitas, convenit gratiae meminisse vel fidei.

50 W. Kraus, s.v. Dioskuren, RAC 3 (1957), 1122-1138, 1333-1138.

51 Paneg. Lat. VI(VIII),21,4-22,1.

52 IV Cons. Hon. 132-136; Stil. 3,58-62; VI Cons. Hon. 26-38.

53 Lucan. 7,148. 
des Herrschers, der dauerhaft den Erdkreis bewahrt für die Kaiser-Brüder und mit Gerechtigkeit den Frieden wahrt, mit Stärke die Waffen schwingt.

Auffällig an dieser Übertragung ist eine gewisse Asymmetrie: Rufin erscheint als „neuer Python“ (alio Pythone, 15), als Reinkarnation des mythischen Untiers. Sein Bezwinger Stilicho hingegen ist kein ,neuer Apoll‘, sondern wird in seiner aktuellen politischen Funktion als dominus, der als Vormund für Honorius und Arcadius (servans Augustis fratribus orbem, 17) die Welt im Frieden wie im Krieg lenkt, eingeführt. Bei näherer Betrachtung erweist sich diese Asymmetrie als Kunstgriff: Zum einen markiert die unmittelbare Identifikation Rufins mit der Python-Schlange die Größe und Irrationalität der Bedrohung, die von dem oströmischen praefectus praetorio ausgeht. Der Dichter bereitet so schon hier Rufins Diffamierung als Ziehsohn der Furie Allecto vor, mit der er das erste Buch von In Rufinum eröffnen wird. Zum anderen lässt sich, was den symbolischen Gehalt angeht, in die Apollo-Python-Geschichte sehr viel leichter noch als in andere Mythen ein christlicher Subtext hineinlesen. Wie Isabella Gualandri gezeigt hat, ${ }^{54}$ weist die Praefatio zum ersten Rufin-Buch auffällige Übereinstimmungen mit Eusebs Vita Constantini auf. Dort wird berichtet, dass Konstantin über dem Eingang des Palasts ein Bildnis von sich als Schlangenbezwinger anbringen ließ; die Schlange steht nach Eusebs eigener Interpretation für den Dämon, der die Kirche angegriffen hat. ${ }^{55}$ Spätere Herrscher machten sich diese Ikonographie ebenfalls $\mathrm{zu}$ eigen, so dass für die christlichen Rezipienten von Claudians Dichtungen in der Apollo-Python-Episode ein christlicher Subtext mitschwingen konnte. ${ }^{56}$ In der Gestalt der Python-Schlange repräsentiert Rufin somit das Dämonische und das ultimativ Böse. Stilicho hingegen, der dominus, wird zu einem neuen Konstantin: Der mythische Drachentöter Apoll avanciert also zunächst zu einem christlichen Herrscher und wird schließlich zu Stilicho, der das Erbe des christianissimus imperator Theodosius vollkommen zu Recht antritt.

\section{Der Mythos als Grundlage für panegyrische Überbietung}

Claudian begnügt sich in vielen Fällen jedoch nicht damit, die Taten und Verhaltensweisen seiner Protagonisten mit den Taten und Verhaltensweisen mythischer Figuren gleichzusetzen. Die Synkrisis mit einer mythischen Figur bildet für ihn, wie

54 Vgl. I. Gualandri, Alio ... Pythone perempto: Tracce „costantiniane“ nell' In Rufinum di Claudiano, in: P. Arduini (Hrsg.), Studi offerti ad A. Perutelli, Bd. 2, Rom 2008, 71-80, 72-75.

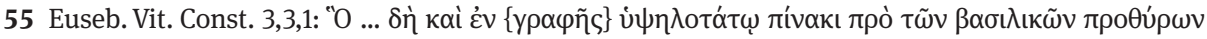

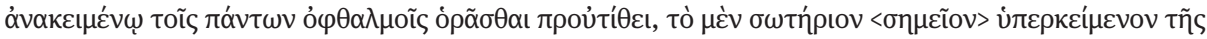

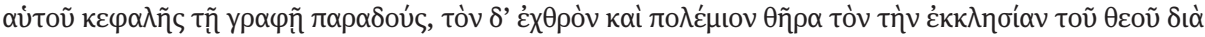

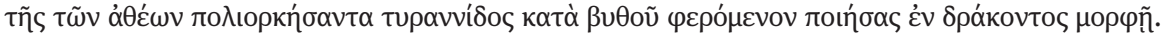

56 Vgl. Gualandri (s. Anm. 54), 76. 
verschiedentlich bemerkt wurde, ${ }^{57}$ oftmals nur den Ausgangspunkt für eine steigernde Überbietung - auch dies ist ein Vorteil, den der Mythos gegenüber biblischen Stoffen hat. Insbesondere Stilicho wird konsequent als Persönlichkeit gezeigt, die in ihren Handlungen den Figuren des Mythos überlegen ist. Siegmar Döpp weist darauf hin, dass der „panegyrische Topos der Überbietung“ bereits in den Silven des Statius angelegt und überhaupt „in der Panegyrik besonders beliebt“ gewesen sei. ${ }^{58}$ Claudian setzt den Typus des überbietenden Vergleichs allerdings sehr viel konsequenter und elaborierter ein als seine Vorgänger. Er bedient sich dabei häufig der „synkrisis analitica“, in der, wie Isabella Gualandri zeigt, einzelne Aspekte in minutiösen Vergleichen herausgearbeitet werden, um beim Rezipienten den Eindruck einer Objektivität zu erzeugen. ${ }^{59}$ Überbietungen des Mythos sind bei Claudian nicht nur ungleich häufiger als bei früheren Panegyrikern, „der mythologische Vergleich hat bei Claudian den Gipfel seiner Entwertung erreicht“ “. ${ }^{60}$ Das vielzitierte Diktum von der superata vetustas, ${ }^{61}$ die angesichts der Großtaten Stilichos schweigen soll, zeigt, dass der Dichter sich seiner Strategie durchaus bewusst ist und sie auch seinem Rezipienten bewusst machen möchte.

Die einfachste Form der Überbietung besteht darin, den Gepriesenen und sein Verhalten mit dem Verhalten einer oder mehrerer mythologischer Figuren zu konfrontieren, um ihn abschließend als qualitativ oder quantitativ überlegen zu erweisen. So dient etwa im Bellum Geticum eine Abfolge von mythischen Begebenheiten dem Dichter dazu, die Ankunft Stilichos in dem von Goten bedrohten Italien zu bewerten (Get. 438-449):

creditur Herculeis lucem renovasse lacertis

femina dilecti fatis impensa mariti;

et iuvenem spretae laniatum fraude novercae

non sine Circaeis Latonia reddidit herbis;

Cretaque, si verax narratur fabula, vidit

Minoum rupto puerum prodire sepulchro, quem senior vates avium clangore repertum gramine restituit; mirae nam munere sortis

dulcia mella necem, vitam dedit horridus anguis:

at tuus adventus non unum corpus ab umbris,

sed tot communi populos sub morte iacentes

totaque Tartareis e faucibus oppida traxit.

57 Z.B. Fargues (s. Anm. 5), 211f.; Döpp (s. Anm. 1), 35 f.

58 Döpp (s. Anm. 1), 36. Zur Überbeitung der mythologischen Vergangenheit durch die christliche Gegenwart s. Accorinti in diesem Band.

59 I. Gualandri, Aspetti della synkrisis nella poesia latina tardoantica: Claudiano, in: G. Hinojo Andrés, J. C. Fernández Corte (Hrsg.), Munus quaesitum meritis. Homenaje a Carmen Codoñer, Salamanca 2007, 445-453, 446.

60 R. Herzog, Die allegorische Dichtkunst des Prudentius, München 1966 (Zetemata 42), 131.

61 Claud. Ruf. 1,283: taceat superata vetustas; ähnlich bereits OlProb. 197 f.: talem nulla refert antiquis pagina libris / nec Latiae cecinere tubae nec Graia vetustas. 
Man glaubt, dass durch Hercules' Arme die Frau das Licht der Welt erneut erblickt hat, die sich geopfert hat für das Schicksal ihres geliebten Mannes; und den jungen Mann, der zerrissen worden war durch den Betrug der verschmähten Stiefmutter, gab (aber nicht ohne die Kräuter der Kirke) Latonia dem Leben zurück. Und Kreta, wenn die Geschichte, die man erzählt, tatsächlich wahr ist, sah den Sohn des Minos aus dem aufgebrochenen Grab hervortreten - ihn, den der greise Seher durch Vogelgeschrei fand und mit Heilkraut ins Leben zurückholte: Denn durch das Geschenk eines wundersamen Schicksals gab süßer Honig ihm den Tod, gab das Leben ihm eine schreckliche Schlange. Doch deine Ankunft hat nicht einen Toten aus dem Schattenreich erlöst, sondern so viele Völker, die unter einem gemeinsamen Tod dalagen, und so viele Städte aus dem Rachen des Tartarus befreit.

Grundlage für die Gegenüberstellung ist ein mythologisches Trikolon aus Hercules, Diana und dem kaum bekannten und namentlich nicht genannten Polyidus. Der Dichter ruft zunächst in überaus gelehrter Verknappung, aber mit einer stark emotionalen Färbung seiner Darstellung, die Taten dieser Personen in Erinnerung: Hercules holte Alcestis aus der Unterwelt zurück, „die sich für das Schicksal ihres geliebten Mannes geopfert hat“ (dilecti fatis impensa mariti, 439), Diana den Hippolytus, „der durch den Betrug der verschmähten Stiefmutter zerrissen worden war“ (spretae laniatum fraude novercae, 440), Polyidus den Glaucus, „,dem durch das Geschenk eines wundersamen Schicksals süßer Honig den Tod und eine schreckliche Schlange das Leben gab" (mirae nam munere sortis / dulcia mella necem, vitam dedit horridus anguis, $445 \mathrm{f}$.). ${ }^{62}$ Diese Verweise auf die bewegenden Schicksale der Geretteten werten einerseits die Leistungen der mythischen Unterweltsfahrer auf und inszenieren Stilichos Mission gegen die Goten als eine Art Katabasis, zumal die Goten im Folgenden sogar explizit mit dem Rachen des Tartarus (Tartareis faucibus, 449) gleichgesetzt werden. Andererseits meldet der Dichter bereits im Laufe der Erzählung durch die Formulierungen creditur (438) und si verax narratur fabula (442) Zweifel an der Glaubwürdigkeit der Überlieferung an und wertet Dianas Leistung durch den Hinweis ab, dass sie ohne Kirkes Zauberkräuter (non sine Circaeis herbis, 440) nicht hätte vollbracht werden können. Durch at scharf gegen die mythologische Überlieferung abgesetzt ist schließlich die Tat des Stilicho, wobei der Dichter die Emotionalität der Mythen mit dem Aspekt der schieren Masse aussticht: Stilichos Ankunft habe nicht nur eine einzige Person (non unum corpus, 447), sondern ganz Völkerschaften (tot communi populos sub morte iacentes, 448) noch vor ihrem Ableben dem sicheren Tod entrissen und zahlreiche Städte vor dem Untergang gerettet (totaque Tartareis e faucibus oppida traxit, 449). Die prosaische Ausdrucksweise des Stilicho-Abschnittes, aus der nur die Formulierung Tartareis e faucibus herausfällt, desavouiert den Mythos zusätzlich: Wäh-

62 Polyidus wurde von Minos ausgeschickt, um dessen verschwundenen Sohn Glaucus aufzuspüren. Er fand Glaucus in einem Weinkeller vor, ertrunken in einem Honigfass, und wurde von Minos mit dem Auftrag, den Sohn wieder lebendig zu machen, in dem Weinkeller eingesperrt. Als eine Schlange in den Keller eindrang, wurde sie von Polyidus getötet. Daraufhin erschien eine zweite Schlange, die ein Heilkraut mitbrachte, das die getötete Schlange wieder zum Leben erweckte. Mit diesem Heilkraut machte Polyidus dann den Minos-Sohn wieder lebendig. Der sehr entlegene Mythos ist bei Apollod. Bibl. 3,3,1-2 und (in einer Variation für Aesculapius anstelle von Polyidus) bei Hyg. Fab. 136 überliefert. 
rend dieser seinen Effekt aus seiner Emotionalität und aus der kunstvollen poetischen Darstellung zieht, wirken Stilichos Leistungen per se.

Es kommt jedoch noch etwas hinzu. Überbietende Synkriseis wie diese sind paganen wie christlichen Rezipienten, wie gesagt, aus der panegyrischen Tradition geläufig. Speziell der Vergleich mit mythischen Unterweltsfahrern ist sogar mit einer nahezu identischen Motivik und Gedankenführung in einer Rede des Libanius an Theodosius zu finden, an die sich manche von Claudians Rezipienten noch erinnert haben mögen (Libanius or. 20,8 Bd. 2, 424 f. Foerster):

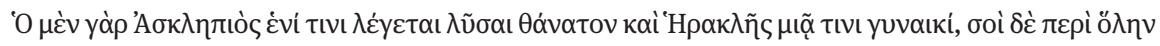

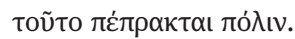

Asklepios soll einen Mann vom Tod erlöst haben und Herakles eine Frau - du aber hast dies hinsichtlich der ganzen Stadt vollbracht! ${ }^{63}$

Motiv und Durchführung des Vergleiches sind so ähnlich, dass der Rekurs unmittelbar erkennbar ist, auch wenn die Reihenfolge vertauscht ist, der Verweis auf Hippolytus fehlt und Asklepios an der Stelle des Polyidus steht: Hier zeigt sich noch einmal, dass es dem Dichter nicht um die Mythologeme an sich geht, sondern wiederum um die implizite Gleichsetzung Stilichos mit dem christianissimus imperator Theodosius.

Aber auch aus christlicher Sicht ist der Einsatz von überbietenden Synkriseis wie der eben besprochenen noch aus anderen Gründen nicht nur unanstößig, sondern sogar begrüßenswert: Einmal deswegen, weil die Demontage der mythologischen Figuren und Ereignisse zur Schwächung des paganen Mythos beiträgt und gerade die paganen Jenseitsmythen den christlichen Autoren schon lange ein Dorn im Auge waren, ${ }^{64}$ zum anderen deswegen, weil es sich bei der Synkrisis auch um eine christliche Argumentationsform handelt, mit der schon Origenes in seiner Schrift Contra Celsum die Überlegenheit Josephs über den griechischen Helden Bellerophon nachgewiesen hatte. ${ }^{65}$ Wenn Claudian die mythologische Synkrisis als Mittel der Überbietung einsetzt, rückt er also den Herrscher in die Nähe biblischer Figuren: Seine Überlegenheit über Figuren des Mythos hat Stilicho nicht nur mit Theodosius, sondern auch mit Figuren wie Joseph gemeinsam.

\section{Die Fiktionalität der Mythos}

Eine weitere Strategie der panegyrischen Überbietung, die in Claudians Gedichten in immer neuen Variationen zur Anwendung kommt, besteht darin, die Fiktionalität mythischer Begebenheiten gegen den Wahrheitsgehalt der zeitgeschichtlichen Ereignisse auszuspielen. Die Kritik am mangelnden Wahrheitsgehalt des Mythos hat in

63 Die Stelle ist verzeichnet bei H. Schroff (Hrsg.), Claudians Gedicht vom Gotenkrieg, Berlin 1927, 64. Ein ähnliches Bild findet sich auch bei Libanius or. 13,42 Bd. 2, 77 f. Foerster.

64 Vgl. Schmitz (s. Anm. 22), 503 f.

65 Origenes Cels. 4,46; vgl. Schmitz (s. Anm. 22), 503. 
der Antike eine lange, bis auf die ,lügenden Musen` in Hesiods Theogonie (27f.) zurückreichende Tradition, die vor allem im philosophischen Schrifttum kultiviert wurde und den christlichen Schriftstellern zahlreiche Anknüpfungspunkte bot. ${ }^{66}$ Augustin gelten Stoffe der Aeneis als poetica figmenta (civ. 18,15) oder als poetica vanitas (civ. 19,12), „den mythischen Erfindungen der Dichter setzt er den wahrhaftigen christlichen Gott entgegen“, ${ }^{67}$ und das christliche Verdikt setzt sich bis zu den figmenta poetarum des Mittelalters hinein fort, die man in allegorischer Lesart gleichwohl weitertradierte. ${ }^{68}$

Auf der anderen Seite ist es auch in der panegyrischen Tradition üblich, sich vom Mythos zu distanzieren, indem man ihn als „Tradition“ oder als „Bericht der Dichter“ markiert; ${ }^{69}$ die Normativität des Mythos steht dabei jedoch außer Frage. In Claudians Dichtung treffen sich diese Argumentationsmuster. Verschiedentlich distanziert sich der Erzähler durch unpersönliche Wendungen wie cantatur (Eutr. 1,290), einschränkende Formulierungen fabula, seu verum, canitur (Stil. 3,231) oder, wie in dem oben besprochenen Beispiel, durch si verax narratur fabula (Get. 442) von seinen mythologischen Gegenständen; einmal schiebt er die Fiktionen den ,alles übersteigernden Musen“ (augentibus omnia Musis: VI Cons. Hon. 475) zu. Die ausführlichste und komplexeste Konfrontation von mythischer Fiktion und panegyrischer ,Realität‘ findet sich zu Beginn des Bellum Geticum. ${ }^{70}$ Dieses Gedicht setzt - einigermaßen überraschend $^{71}$ - mit einem ausführlichen Referat der Leistungen des Tiphys, des Steuermanns der Argo, bei der Durchfahrt durch die Symplegaden ein. Tiphys’ herausragende Leistung wird allerdings bereits in den ersten Versen wieder relativiert: Die Symplegaden-Durchfahrt gelang nur mit göttlicher Beteiligung (post numina, 4) und mit einem - wenngleich nur kleinen - Schaden für das Schiff (tenui damno, 5). ${ }^{72}$ Schon in Vers 6 wird der Mythos durch ein fertur in seiner Glaubwürdigkeit grundsätzlich in

66 Vgl. M. Fuhrmann, Die antiken Mythen im christlich-heidnischen Weltanschauungskampf der Spätantike, Antike und Abendland 36 (1990), 138-151, 141 f.; Schmitz (s. Anm. 22), 492 - 494 (auch zum Folgenden).

67 Schmitz (s. Anm. 22), 493.

68 Vgl. L. Gompf, Figmenta poetarum, in: A. Önnerfors u.a. (Hrsg.), Literatur und Sprache im europäischen Mittelalter. Festschrift für K. Langosch, Darmstadt 1973, 53-62.

69 Vgl. Pernot (s. Anm. 33), 763.

$70 \mathrm{Zu}$ der gesamten Stelle ausführlich C. Schindler, Claudians Argonautica. Zur Darstellung und Funktion des Mythos zu Beginn des Epos De bello Getico (1-35), in: A. Harder, M. Cuypers (Hrsg.), Beginning from Apollo. Studies in Apollonius Rhodius and the Argonautic Tradition, Leuven - Paris Dudley, MA 2005, 107-123.

71 Vgl. I. Gualandri, „Solus post numina Tiphys“.Variazioni claudianee sul tema della nave Argo (Bell. Get. 1-35), in: L. Castagna, Ch. Riboldi (Hrsg.), Amicitiae templa serena: Studi in onore di Giuseppe Aricáo, Bd. 1, Mailand 2008, 753-776, 755.

72 Der Versuch von Gualandri (s. Anm. 71), 761-764, diese Einschränkungen mit der aktuellen Politik Stilichos abzugleichen, scheint mir in der panegyrischen Situation, in der es ja um eine konsequente Überhöhung des Gepriesenen geht, nicht ganz treffend. 
Frage gestellt und in Vers 10 mit einer rhetorischen Frage vollends zurückgestuft (Get. 11-14): ${ }^{73}$

\section{[...] quod si ardua Tiphyn \\ navis ob innocuae meritum sic gloria vexit, quae tibi pro tanti pulso discrimine regni \\ sufficient laudes, Stilicho?}

Wenn nun stolzer Ruhm den Tiphys dafür in den Himmel hob, dass er ein Schiff unversehrt bewahrte, welche Ehrungen werden dann für dich dafür, dass du die Gefahr von einem so großen Reich abgewehrt hast, hinreichend sein, Stilicho?

Hier lenkt der Dichter unter Verwendung der alten Metapher vom „Staatsschiff“74 von der realen Argo auf den römischen Staat über, um Stilichos Überlegenheit zu erweisen. Seinen poetischen Vorgängern wirft er zugleich vor, durch übermäßiges Lob mythischer Großtaten falsche Maßstäbe gesetzt zu haben, die es ihm schwer machten, den wahren Helden Stilicho angemessen zu loben: Wenn schon Tiphys unsterblichen Ruhm dafür erntete, ein einziges (reales) Schiff durch die Symplegaden manövriert zu haben, so führt der Dichter aus, welche Würdigungen sind dann noch den Leistungen Stilichos angemessen, der ja das Staats-Schiff ,Römisches Reich` vor dem Untergang gerettet habe? Im Folgenden wird die panegyrische Aussage noch weiter gesteigert, indem der Dichter die Zweifel an dem Wahrheitsgehalt des Mythos, die er in der Symplegaden-Episode durch fertur bereits angedeutet hatte, konkretisiert: Die Berichte vom Argonautenzug zögen ihre Wirkung vor allem aus den Aufbauschungen der Dichter (Get. 14-27):

\section{[...] licet omnia vates}

in maius celebrata ferant ipsamque secandis

Argois trabibus iactent sudasse Minervam

nec nemoris muti iunxisse carentia sensu

robora, sed caeso Tomarii Iovis augure luco

arbore praesaga tabulas animasse loquaces;

plurima sed quamvis variis miracula monstris

ingeminent teneras vincturo carmine mentes,

Harpyiasque truces insopitisque refusum tractibus aurati custodem velleris anguem et iuga taurorum rapidis ambusta favillis et virides galeis sulcos fetasque novales

Martis et in segetem crescentia semina belli:

nil veris aequale dabunt. [...]

Mögen auch die Dichter alles, was sie feiern, größer machen als es ist, und stolz verkünden, dass Minerva selbst beim Schneiden der Argo-Planken Schweiß vergossen und nicht gefühlloses Eichenholz eines stummen Hains zusammengefügt, sondern den weissagenden Hain des Tomari-

73 Vgl. Herzog (s. Anm. 60), 132.

74 Vgl. I. Gualandri, Aspetti della tecnica compositiva in Claudiano, Mailand - Varese 1968, 66. 
schen Jupiter gefällt und mit dem schicksalskündenden Baum die Schiffsplanken beseelt habe, dass sie sprechen konnten: Mögen sie auch noch so viele Wunder und verschiedene Monster aufhäufen, die in einem epischen Gedicht leichtgläubige Gemüter zu fesseln vermögen, trotzige Harpyien, eine Schlange, die sich in niemals schlafenden Windungen als Wächterin eines Goldenen Vlieses rekelt, Stiergespanne, ringsum angesengt von glühender Asche, Ackerfurchen, grün von Helmen und die menschenschwangere Areswiese, und zu einer Saat aufkeimende Samen des Krieges: Sie werden nichts aufbieten können, das der Wahrheit ebenbürtig ist.

Auch wenn die Dichter alles aufböten, um die Prominenz des Mythos zu steigern Minervas göttliche Hilfe beim Bau der Argo, der sprechende Kielbalken aus dem Holz der Dodonäischen Eiche, verschiedene Monster wie die Harpyien, eine niemals schlafende Schlange, feuerschnaubende Stiere und aus dem Boden wachsende Erdgeborene: Gegen die wahren Leistungen Stilichos haben sie keine Chance: nil veris aequale dabunt (27). Der Dichter stellt hier das mythologische Dichten an sich in Frage und verbannt es auf eine niedrigere Kulturstufe, indem er durch die Formulierung teneras vincturo carmine mentes (21) die Rezipienten mythologischer Dichtungen als unbedarfte Kinder entlarvt. Durch den ,mythologischen Beginn' des Bellum Geticum wird die Erwartung des Rezipienten bewusst getäuscht: Der Mythos von der Argo, der in der früheren römischen Literatur, etwa in den Argonautica des Valerius Flaccus, als mythische Chiffre für historische Großtaten verwendet worden war, ${ }^{75}$ erweist sich in dem spätantiken Kontext als gänzlich ungeeignet. Dass wir uns nicht in einem ProsaPanegyricus, sondern in einem formal als Epos ausgewiesenen Text befinden, verschärft die Abgrenzung: Der Dichter markiert hier sehr klar, dass er bei allem formalen Traditionalismus nicht gewillt ist, an gängige episch-mythologische Traditionen anzuknüpfen, sondern im Gegenteil einen radikalen Bruch zu provozieren bereit ist. Der Mythos ist zwar vielleicht noch ein normativer Referenzpunkt für die gebildeten Rezipienten Claudians, um die Leistungen Stilichos besser einordnen zu können: Er muss aber den Großtaten der spätantiken Elite ebenso weichen, wie das mythologische Epos den politischen Dichtungen Claudians Platz machen muss. Die programmatische Aussage an der Spitze des Gedichts lässt sich außerdem auf alle weiteren Mythologica im Bellum Geticum (und vielleicht sogar in allen weiteren Gedichten Claudians) übertragen: Mythische Darstellungen sind stets mit dem Makel der Fiktionalität behaftet.

\section{Mythenkritik und Destruktion „klassischer“ Mythen in Claudians politischen Dichtungen}

Dass Claudian in seinen Panegyriken insgesamt nicht eine nostalgische Wiederbelebung des Mythos, sondern sogar eine dezidierte Abkehr von den mythischen Stoffen

75 Vgl. E. Burck, Die Argonautica des Valerius Flaccus, in: ders. (Hrsg.), Das römische Epos, Darmstadt 1979, 208-253, 211; Schindler (s. Anm. 70), 120. 
anstrebt, zeigt sich besonders deutlich an den Stellen, an denen er nicht nur die Überlegenheit der Protagonisten über die mythischen Helden erweist und auf die Fiktionalität des Mythos abhebt, sondern einen mythischen Prätext, der in der allgemeinen Wahrnehmung als positiv oder zumindest als neutral wahrgenommen wird, durch eine Umdeutung ins Negative in Frage stellt. Dies geschieht zum Teil implizit, wie zum Beispiel im ersten Buch der Laudes Stilichonis (1,318-324):

non ego dilectu, Tyrii sed vomere Cadmi

tam subitas acies concepto dente draconis

exiluisse reor: Dircaeis qualis in arvis

messis cum proprio mox bellatura colono

cognatos strinxit gladios, cum semine iacto

terrigenae galea matrem nascente ferirent

armifer et viridi floreret milite sulcus.

\begin{abstract}
Nicht, so glaube ich, durch Aushebung, sondern aus der Furche der Pflugschar des tyrischen Kadmos sind aus Drachenzahn so plötzlich Schlachtreihen hervorgesprungen. Wie in den dirkäischen Gefilden die Saat, die bald mit ihrem eigenen Sämann Krieg führen sollte, die blutsverwandten Schwerter zückte, als nach der Aussaat Erdgeborene mit entstehendem Helm ihre Mutter schlugen und von frisch emporgesprossenem Soldaten die waffentragende Furche prangte.
\end{abstract}

Ausgangspunkt für den Vergleich ist die Schnelligkeit, mit der es Stilicho gelang, die Truppen für den Kampf gegen die Bedrohungen aus dem Osten und dem Westen zu sammeln. Diese unglaubliche Geschwindigkeit deute, so die persönliche Auffassung des Dichters, nicht auf eine normale Truppenaushebung (dilectus, 1,318) hin, sondern darauf, dass die Soldaten der thebanischen Drachensaat des Kadmos (vomere Cadmi, 1,318) entsprungen seien - ein Bild, das anschließend in sieben Versen breit ausgemalt wird. Gerade die Tatsache, dass dieses Bild eher märchenhaft und auch ohne weiteren Hinweis des Dichters als fiktional zu identifizieren ist, überhöht Stilichos Leistung: Seine realen Erfolge sind so verblüffend, dass der Dichter nur an ein mythisches Mirakel glauben kann. Der Verweis auf die Gründung Thebens, der in der KadmosGeschichte mitschwingt, könnte zudem die auf die ,Neugründung' Roms durch Stilicho hinweisen, die Claudian am Schluss des ersten Buches explizit formuliert hat. ${ }^{76}$

Auch hier bedient sich der Dichter also zunächst der Normativität des Mythos, um seinen Rezipienten die Größe von Stilichos Erfolgen vor Augen zu führen. Doch davon abgesehen wird schnell deutlich, dass die Geschwindigkeit, mit der die Truppen parat stehen, der einzige Punkt ist, in dem Kadmos' und Stilichos Heer sich gleichen. Denn Kadmos' Sparten sind, wie der Dichter im Folgenden ausführt, eine „Saat, die bald mit ihrem eigenen Sämann Krieg führen sollte“, messis cum proprio mox bellatura colono (1,321), sie ziehen „blutsverwandte Schwerter“, cognatos gladios (1,322), mit denen sie sich gegenseitig bekriegen und sogar auf ihre eigene Mutter einschlagen: cum semine iacto / terrigenae galea matrem nascente ferirent (1,323f.). Das schnelle Emporwachsen

76 Vgl. Claud. Stil. 1,370-385. 
der thebanischen Sparten ist somit vollkommen sinnlos, da es zu einem blutigen Bruderkrieg führt, bei dem es, wie Claudians Publikum bekannt gewesen sein dürfte, nur wenige Überlebende gab. Die Variante des Mythos, dass die Sparten auch gegen Kadmos kämpfen, ist ungewöhnlich und vor Claudian nicht belegt; ${ }^{77}$ er hat sie möglicherweise selbst erfunden, um die Situation noch weiter zuzuspitzen. Die Wendung cognatos gladios $(1,322)$ zitiert überdies die Wendung cognatas acies am Beginn von Lucans Pharsalia $(1,4)$ und ruft dadurch zugleich die Erinnerung an die römischen Bürgerkriege des ersten vorchristlichen Jahrhunderts auf - zumal bereits Lucan den Mythos von Kadmos' Drachensaat (allerdings innerhalb des Jason-Mythos) als Bild für den römischen Bürgerkrieg herangezogen hat (Lucan. 4,549-556); zwischen diesem Bild und Claudians Schilderung lassen sich zahlreiche Übereinstimmungen feststellen. ${ }^{78}$

Stilicho hingegen führt einen legitimen Krieg, den er vorher vom Senat hat genehmigen lassen: non ante fretis exercitus astitit ultor / ordine quam prisco censeret bella senatus (Stil. 1,326f.). Gegenüber dieser ausgefeilten und von der Tradition sanktionierten Rechtlichkeit, der Honorius' Heermeister sich fügt, erscheint der thebanische Mythos von den einander bekriegenden Sparten primitiv: Er gehört einer Epoche an, die im ausgehenden vierten Jahrhundert längst überwunden ist, wie Claudian selbst es im Bellum Gildonicum den älteren Theodosius formulieren lässt: ne consanguineis certetur comminus armis, / ne, precor. haec trucibus Thebis, haec digna Mycenis (286f.). Bruderkriege sind Thebens und Mykenes, aber nicht Roms würdig. Den Gepriesenen zeichnet also aus, dass er die positiven Aspekte des Mythos tradiert, die negativen hingegen überwindet.

Sogar noch einen Schritt weiter geht Claudian im Panegyricus auf das sechste Konsulat des Honorius. Er rekapituliert hier die Aggressionen und Usurpationen von Alarich und Gildo gegen Honorius' Vater Theodosius; doch nun könne der Vater sich seines gerechtfertigten Zornes erinnern und genießen, dass beide Aggressoren ihre gerechte Strafe erhalten hätten (VI Cons. Hon. 113-121):

\footnotetext{
ense Thyestiadae poenas exegit Orestes, sed mixtum pietate nefas dubitandaque caedis gloria materno laudem cum crimine pensat; pavit Iuleos inviso sanguine Manes Augustus, sed falsa pii praeconia sumpsit in luctum patriae civili strage parentans: at tibi causa patris rerum coniuncta saluti bellorum duplicat laurus, isdemque tropaeis reddita libertas orbi, vindicta parenti.
}

Mit dem Schwert vollstreckte Orestes die Strafe über den Thyestes-Sohn, doch seinem Frevel war die Erfüllung der Sohnespflicht beigemischt und zweifelhaft der Ruhm für die Mordtat, wenn er

77 Vgl. U. Keudel, Poetische Vorläufer und Vorbilder in Claudians De consulatu Stilichonis. Imitationskommentar, Göttingen 1979 (Hypomnemata 26), $56 \mathrm{f}$.

78 Vgl. Keudel (s. Anm. 77), 57. 
mit einem Verbrechen an der Mutter den Ruhm wägt. Es nährte Augustus die Manen Caesars mit dem Blut seiner Feinde, doch falsch tat er seinen ehrfurchtsvollen Respekt kund, indem er Sühne übte mit Bürgerblut zur Trauer des Vaterlandes. Doch dir verdoppelt die Sache des Vaters, verbunden mit Rettung des Staates, den Kriegslorbeer, und durch dieselben Siegeszeichen wurde dem Erdkreis die Freiheit zurückgegeben und Rache dem Vater.

An dieser Stelle illustrieren zwei Beispiele, dass es dem Sohn nicht selten zufällt, für seinen ermordeten Vater Rache nehmen zu müssen: Der Dichter nennt zuerst Orestes, der seine Mutter Klytaimnestra erschlug, um den Mord an seinem Vater zu rächen, dann Octavian (Augustus, 117), der mit den Bürgerkriegen die Ermordung seines Adoptivvaters sühnen wollte. Die Verbindung von Orestes und Augustus ist traditionell: Michael Dewar vermutet, dass Claudian hier ein Legitimationsmuster der augusteischen Propaganda aufnimmt, mit dem Orestes' Muttermord Octavians grausames Vorgehen gegen die Caesar-Mörder rechtfertigte. ${ }^{79}$ Claudian benutzt die beiden Bilder jedoch nicht, wie man es vielleicht erwarten könnte, um Honorius in die Traditionslinie Orestes - Octavian einzureihen. Im Gegenteil: Orestes habe sich, so führt er aus, mit dem Ruhm, seinen Vater gerächt zu haben, zugleich die Bürde des Muttermordes aufgeladen, seine Tat sei somit ein mit Sohnespflicht vermischter Frevel, der Ruhm, den er für den Mord davontrage, zweifelhaft: mixtum pietate nefas dubitandaque caedis / gloria (114f.). Noch vernichtender fällt die Kritik an Octavian aus: Dieser habe unter dem Deckmantel einer falschen pietas gehandelt (falsa pii praeconia sumpsit, 117) und die Welt in einen gefährlichen Bürgerkrieg gestürzt: in luctum patriae civili strage parentans (118). Gegen diese beiden Negativ-Exempla wird Honorius positiv abgesetzt: Er habe die Angelegenheiten, die seinen Vater betrafen, mit dem allgemeinen Wohl verbunden und so seinen Kriegsruhm verdoppelt: at tibi causa patris rerum coniuncta saluti / bellorum duplicat laurus (119f.), mit der Rache für den Vater sei die Befreiung des Erdkreises einhergegangen: reddita libertas orbi, vindicta parenti (121). An die Stelle von nefas, crimen und einer dubitanda gloria, von invisus sanguis, luctus und civilis strages in den Beispielen von Orestes und Octavian treten auf Seiten des Honorius die juristisch und ethisch einwandfreie causa patris, die salus rerum und schließlich libertas. Die Rechtlichkeit von Stilichos Handeln wird gegen die Primitivität des Mythos abgegrenzt; Octavian, der mythenkonform handelte, wird ebenfalls politische Unreife attestiert. In Honorius' Handeln hingegen sind persönliche Emotionen und Allgemeinwohl nicht mehr diametral entgegengesetzt, sondern bilden eine Einheit: Der Herrscher überwindet die Unzulänglichkeiten und Fehler nicht nur seines mythischen, sondern auch seines politischen Vorgängers.

79 M. Dewar, Claudian, Panegyricus de sexto consulatu Honorii Augusti, Oxford 1996, 138. Grundlegend zu Orestes und Augustus T. Hölscher, Augustus and Orestes, Travaux du Centre d'archéologie méditerranéenne de l'Académie Polonaise des sciences 30. Études et Traveaux 15 (1990), 164-168; zuletzt S. Tilg, Augustus and Orestes. Two Literary Clues, CQ 58 (2008), 368- 370 (mit einem Überblick über die frühere Literatur). 
Jedoch nicht allein die thebanischen Sparten, Orestes und Octavian-Augustus werden in Claudians Panegyriken einer harschen Kritik unterzogen. In seiner Destruktion der historischen und mythischen Traditionen macht der Dichter nicht einmal vor dem römischen Nationalhelden Aeneas halt. Im ersten Buch der Laudes Stilichonis würdigt er Stilichos Erfolge gegen die Westgoten und die Bastarner, die die Ermordung von dessen Vorgänger Promotus übermütig gemacht habe (Stil. 1,94-108):

\section{[...] quis enim Visos in plaustra feroces \\ reppulit aut saeva Promoti caede tumentes \\ Bastarnas una potuit delere ruina? \\ Pallantis iugulum Turno moriente piavit \\ Aeneas, tractusque rotis ultricibus Hector \\ irato vindicta fuit vel quaestus Achilli: \\ tu neque vaesano raptas venalia curru \\ funera nec vanam corpus meditaris in unum \\ saevitiam: turmas equitum peditumque catervas \\ hostilesque globos tumulo prosternis amici; \\ inferiis gens tota datur. nec Mulciber auctor \\ mendacis clipei fabricataque vatibus arma \\ conatus iuvere tuos: tot barbara solus \\ milia iam pridem miseram vastantia Thracen \\ finibus exiguae vallis conclusa tenebas.}

Denn wer hat die wilden Westgoten zu ihren Wagen zurückgetrieben oder hat es vermocht, die Bastarner, die aufmüpfig geworden waren nach dem grausamen Mord an Promotus, in einer Niederlage zu vernichten? Pallas' durchgeschnittene Kehle sühnte Aeneas mit Turnus’ Tod, und Hektor, von den rächenden Wagenrädern mitgeschleift, war dem zornigen Achill Rache - oder sogar bares Geld! Du, Stilicho, reißt weder verkäufliche Leichen im Wahnsinn mit deinem Streitwagen fort noch ersinnst du ergebnislose Grausamkeit gegen einen einzigen Leichnam: Reiterschwadrone, Formationen von Fußtruppen und ganze feindliche Heerscharen streckst du nieder dem Grab deines Freundes: Ein ganzes Volk wird den Unterirdischen übereignet. Und nicht Vulkan war der Schöpfer eines Lügen-Schildes und nicht Waffen, die von Dichtern fabriziert wurden, unterstützten deine Unternehmungen: Allein hast du so viele tausende Barbaren, die schon seit langem das unglückliche Thrakien verwüsteten, in einem engen Tal eingeschlossen und dort festgehalten.

Zwei Verweise auf prominente mythische Helden, Aeneas und Achill, veranschaulichen in typischer Überbietungstopik Stilichos Leistung. ${ }^{80}$ Die Berichterstattung des Erzählers ist hierbei zunächst neutral: Aeneas habe, so führt er aus, Pallas’ Ermordung mit dem Tod des Turnus gesühnt, und auch der geschleifte Hektor sei Gegenstand von Achills Rache gewesen: Pallantis iugulum Turno moriente piavit / Aeneas tractusque rotis ultricibus Hector / irato (sc. Achilli) vindicta fuit (1,97-99). In den folgenden Ausführungen wechselt der Tonfall: Achill, so macht der Erzähler in einem nachgeschobenen vel quaestus Achilli $(1,100)$ deutlich, ging es mit der Ermordung Hektors nicht nur um Rache, vindicta, sondern vor allem um schnöden Gewinn - eine An- 


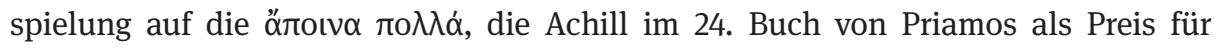
Hektors Leiche entgegennimmt. ${ }^{81}$ Im Folgenden verkehrt sich die Darstellung vollends ins Negative, indem materielle und unkontrollierte emotionale Aspekte zunehmend Oberhand gewinnen: Achills Wagen wird zu einem vaesanus currus, die Leiche Hektors zu corpora venalia, die Ermordung des Kriegsgegners zu einer vana saevitia. Achills Taten fungieren nur noch als Negativfolie, gegen die sich Stilicho abheben kann, wie das dreimalige neque - nec - nec zeigt. Schließlich werden Stilichos Leistungen denen Achills gegenübergestellt: Am Grab seines Freundes habe Stilicho Reiterschwadronen und Scharen von Fußtruppen hingestreckt (turmas equitum peditumque catervas:1,102) und dem ermordeten Promotus sogar ein ganzes Volk als Totengabe dargebracht: inferiis gens tota datur (1,104). Im Folgenden wechselt die Darstellung auf eine andere Ebene, auf der der Dichter wiederum den Topos von der Fiktionalität des Mythos aufruft. Anders als die mythischen Helden habe Stilicho nicht über einen von Vulcanus gefertigten Lügen-Schild (mendax clipeus, vgl. 1,105) und über Waffen verfügt, die ohnehin nur der Phantasie der Dichter entsprungen seien (fabricata vatibus arma: 1,105), sondern sei allein gegen Tausende von Barbaren angetreten: tot barbara solus / milia ... conclusa tenebas (1,106-108). Zu der quantitativen Überbietung - ein Toter gegen ein ganzes Volk - kommt eine qualitative: Der Mythos, ohnehin ein Lügengespinst der Dichter mit moralisch fragwürdigen und ohne göttliche Hilfe kaum kampffähigen Helden, verblasst angesichts der Leistungen Stilichos. Die Benennung Vulcans mit dem urrömischen Namen Mulciber $(1,107),{ }^{82}$ die Bezeichnung des Schildes als clipeus $(1,108)^{83}$ und vielleicht sogar die Bezeichnung der Dichter als vates $(1,108)$ legen es zudem nahe, vor allem den letzten Teil der Mythendestruktion auch auf Aeneas und seine Darstellung durch Vergil zu beziehen. Hier zeigt sich deutlich, dass nicht einmal mehr die nationalrömische mythische Vergangenheit für den Dichter einen Eigenwert besitzt, sondern lediglich noch ein Referenzpunkt für eine Gegenwart ist, die von dem einzig echten und wahren Helden, von Stilicho, überstrahlt wird. Mit Stilicho, das ist die Stoßrichtung dieses wie vieler anderer mythologischer Vergleiche Claudians, bricht ein Zeitalter an, das die pagane Mythologie Griechenlands und Roms hinter sich lässt und ihrer nicht mehr bedarf.

Dass die Demaskierung des Mythos als Repräsentation einer primitiven Frühzeit mit verdrehten, längst nicht mehr gültigen Wert- und Normvorstellungen christlichen Normen insgesamt nicht zuwiderläuft, ist unzweifelhaft. Speziell die Demontage der wichtigsten epischen Helden Achill und Aeneas berührt sich jedoch ausdrücklich mit christlicher Mythenkritik. Lactanz hatte im fünften Buch seiner Divinae institutiones das Bild des pius Aeneas systematisch destruiert. Im Rahmen seiner Reflexionen über Gerechtigkeit hatte er nachgewiesen, dass Aeneas das Epitheton pius nicht verdient habe. Der Held, den der Dichter nämlich selber als „Mann von hervorragender

81 Hom. Il. 24,555f.

82 J. Scherf, s.v. Mulciber, DNP 8 (2000), $457 \mathrm{f}$.

83 Unmittelbar zur Bezeichnung von Aeneas' neugeschmiedetem Schild Verg. Aen. 8,447; 8,625; 8,729. 
Frömmigkeit“, als insignem pietate virum ausweise, habe nach dem Tod des Pallas Gefangene gemacht, die er als Menschenopfer darbringen wollte; außerdem habe er dem Turnus die erflehte Gnade verweigert (Lact. inst. 5,10): ${ }^{84}$

quid quod bonus Aeneas haud aspernanda precantis trucidauit? adiuratus enim per eundem patrem et spes surgentis Iuli, nequaquam pepercit

furiis accensus et ira.

quisquamne igitur hunc putet aliquid in se uirtutis habuisse, qui et furore tamquam stipula exarserit et manium patris per quem rogabatur oblitus iram frenare non quierit? nullo igitur modo pius, qui non tantum non repugnantes, sed etiam precantes interemit.

Was ist damit, dass „der treffliche Aeneas Leute“ umbrachte, die „nicht zu Verachtendes erbaten“? Beschworen nämlich bei demselben Vater und „der Hoffnung des aufwachsenden Iulus“, gewährte er keineswegs Schonung, „von Wüten entflammt und vom Zorne“. Könnte also irgendwer glauben, dass dieser einen Funken von Anstand (virtus) in sich gehabt habe, der in Raserei wie ein Strohhalm aufloderte und die Manen des Vaters, bei dem er gebeten wurde, vergaß und seinen Zorn nicht zügeln konnte? In keinster Weise ist also einer fromm (pius), der nicht nur Menschen, die sich nicht wehrten, tötete, sondern sogar solche, die um Gnade baten.

Aeneas, so führt Lactanz aus, sei „wie ein Strohhalm in Raserei entbrannt“ (furore velut stipula exarsit) und habe seinen Zorn nicht zügeln können (iram frenare), er, der sogar um Gnade Flehende getötet habe, könne nicht pius genannt werden. Das Vergil-Zitat furiis accensus et ira aus den Schlussversen der Aeneis (Aen. 12,946) deutet darauf hin, dass Lactanz hier vor allem an die Tötung des Turnus denkt. Vor dem Hintergrund dieser Kritik erscheint die claudianische Formulierung Pallantis iugulum Turno moriente piavit / Aeneas $(1,97)$ in einem etwas anderen Licht: Die Tötung des Turnus war trotz des Verbums piare, das den Aeneas gegenüber Achill zunächst positiv zu konturieren scheint, kein Akt der pietas. Die Adjektive ultrix (1,98), iratus (1,99) und vaesanus (1,100), mit denen Claudian im weiteren Verlauf seiner Ausführungen das Verhalten des Achill belegt, entsprechen der lactanzischen Mythenkritik, indem sie den ungesunden furor des epischen Helden verurteilen.

Wenn Claudian dann dem Stilicho bescheinigt, er habe sich eben nicht zu „eitler Grausamkeit“, vana saevitia (1,101f.), hinreißen lassen, sondern vielmehr turmas equitum peditumque catervas / hostilesque globos (1,102f.) dem Begräbnis seines Freundes dargebracht, und wenn er im Folgenden von den marodierenden Barbarenhorden spricht, die Stilicho allein bezwungen habe (tot barbara solus / milia iam pridem miseram vastantia Thracen, 1,106f.), dann liefert er nicht nur eine quantitative Überbietung des Mythos, sondern entlastet Stilicho von jeglicher Kritik, einen Krieg geführt zu haben, der gegen christliche Normen verstößt: Stilicho tritt an zu einem

84 Zur christlichen, resp. lactanzischen Vergilkritik vgl. A. Wlosok, Der Held als Ärgernis: Vergils Aeneas, Würzburger Jahrbücher für die Altertumswissenschaft NF 8 (1982), 9-21; dies., Zwei Beispiele frühchristlicher ,Vergilrezeption'. Polemik (Lact. div. inst. 5,10) und Usurpation (Or. Const. 19-21), in: V. Pöschl (Hrsg.), 2000 Jahre Vergil, Wiesbaden 1983, 63-86; J. Walter, Pagane Texte und Wertvorstellungen bei Lactanz, Göttingen 2006 (Hypomnemata 165), 123. 
Krieg gegen einen an sich überlegenen äußeren Feind (hostiles globos, 1,104), mit dem er ein ihm widerfahrenes Unrecht rächt; er tut nur das, was er aus Gründen der Staatsräson tun muss und führt auch nach dem Konzept Augustins ein bellum iustum. ${ }^{85}$ Claudian erweist seinen Protagonisten also an dieser Stelle als fähigen Feldherrn und als moralisch integre Figur, die sich in ihrem Verhalten zu den christlichen Normen konform verhält. An die Stelle des längst obsoleten pius Aeneas tritt ein pius Stilicho - auch dies ein Hinweis auf die neue Zeit, die unter seiner Vormundschaft anbricht.

\section{Ergebnisse}

Kehren wir abschließend zum Ausgangspunkt unserer Untersuchung zurück. Die Integration paganer Mythen in Claudians politische Dichtungen, das haben die Betrachtungen meines Erachtens deutlich gezeigt, ist kein Hinweis auf eine pagane Gesinnung Claudians. Vielmehr kann man beobachten, dass der Dichter den Mythos, der für seine nichtchristlichen und seine christlichen Rezipienten gleichermaßen Bestandteil der Bildungstradition ist, in vielfältiger Weise funktionalisiert und in den Dienst seiner panegyrischen Aussagen stellt. Er tut dies, ohne gegen christliche Normen zu verstoßen: Sei es, indem er aus einer mythischen Geographie aktuelle Herrschaftsansprüche ableitet, die spätantiken Herrscher mit mythologischen Chiffren belegt oder die Adressaten seiner Gedichte durch konsequentes Überbieten der mythischen Vorgaben überhöht.

Claudians zahlreiche Verweise auf den Mythos dienen somit nicht dazu, die Normativität der mythischen Welt zu tradieren und dem Rezipienten als ein idealtypisches Paradigma vor Augen zu führen. Vielmehr zieht der Dichter eine klare Grenze zwischen der mythischen Vergangenheit und der zeitgeschichtlichen Realität, um auf dieser Basis die mythischen Figuren und Ereignisse gegen die Figuren und Ereignisse seiner Gedichte auszuspielen. Die Adressaten von Claudians Gedichten stehen über dem Mythos und vermögen seine Exemplarität und Normativität durch ihr vorbildliches Verhalten auf Dauer sogar zu ersetzen. Davon, dass Claudian „chantait avec trop de ferveur la mythologie“, wie Émilienne Demougeot es formuliert hat, ${ }^{86} \mathrm{kann}$ also keine Rede sein; auch sind „Claudians glutvolle Epen ... mit ihrem mythologischen Prunk“ weit davon entfernt, „ein einziger Triumph des Paganismus“ zu sein, wie Manfred Fuhrmann im Anschluss an Wolfgang Schmid schreibt. ${ }^{87}$ Es geht Claudian gerade nicht darum, den Mythos zu stabilisieren, sondern darum, auf der Ebene der

85 Aug. quaest. hept. 6,10: iusta autem bella ea definiri solent quae ulciscuntur iniurias, si qua gens vel civitas, quae bello petenda est, vel vindicare neglexerit quod a suis inprobe factum est vel reddere quod per iniurias ablatum est. Zum bellum iustum als Topos der Panegyrik Mause (s. Anm. 38), $189 \mathrm{f}$.

86 E. Demougeot, De l'unité à la division de l'empire romain (395-410). Essai sur le gouvernement impérial, Paris 1951, 288.

87 W. Schmid, s.v. Claudian, LAW, 638-640, 639; zustimmend Fuhrmann (s. Anm. 66), 145. 
literarischen Darstellung einen Paradigmenwechsel zu propagieren: den Wechsel vom ,mythischen` zum ,politischen' Helden, der des mythischen Vorbilds nicht mehr bedarf und dessen Handeln keinerlei Widersprüche zu christlichen Norm- und Wertvorstellungen aufweist. Die Beibehaltung paganer Mythen und das vorübergehende Akzeptieren der normativen Kraft, die von ihnen ausgeht, ist dabei für Claudian paradoxerweise das Mittel der Wahl, den in der paganen Tradition erzogenen Rezipienten diesen Paradigmenwechsel anzuzeigen. 


\title{
Nonnos und der Mythos: Heidnische Antike aus christlicher Perspektive
}

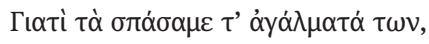 \\ yı

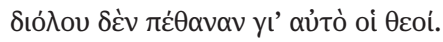 \\ (Konstantin Kavafis, 'I $\omega v ı$ เóv) \\ Zum Gedenken an \\ Bernard Gerlaud (1939-2010)
}

\section{Das Thema: „Wie gingen die Christen mit dem Mythos um?“}

„Antike Mythologie in christlichen Kontexten der Spätantike“, so lautet das interessante Thema, das sich diese internationale Frankfurter Tagung vorgenommen hat, in unterschiedlichen Aspekten zu behandeln. Einerseits scheint dies eine glückliche Fortsetzung der Reihe von wertvollen Vorträgen zu sein, die im Wintersemester 20032004 am Lehrstuhl für Alte Geschichte der Rheinisch-Westfälischen Technischen Hochschule Aachen abgehalten wurde und eine bedeutende Sammlung, „Griechische Mythologie und frühes Christentum“, hervorgebracht hat. ${ }^{1}$ Andererseits erinnert der Titel der Konferenz an das Werk von Hugo Rahner, „Griechische Mythen in christlicher Deutung“, einen Meilenstein in der vergleichenden Religionsgeschichte. ${ }^{2}$ Diese Problematik betrifft eine der 101 wichtigsten Fragen, die Ulrike und Jörg Rüpke versucht haben, in ihrem schönen Büchlein „Götter und Mythen der Antike“ zu beantworten: „Wie gingen die Christen mit dem Mythos um?“ Obwohl es, wie die Autoren selbst einräumen, schwierig ist, eine Antwort auf diese Frage zu geben, ${ }^{3}$ müssen wir aber, und das ist die Absicht dieser Konferenz, die komplexen Gründe für die anhaltende Lebendigkeit und Wirkung der antiken Mythologie in der christlichen Spätantike verstehen.

1 R. von Haehling (Hrsg.), Griechische Mythologie und frühes Christentum (Darmstadt 2005). Ich danke Professor Hartmut Leppin herzlich für die Einladung zu dieser Tagung. Ihm verdanke ich auch die deutsche Übersetzung einiger Zitate.

2 H. Rahner, Griechische Mythen in christlicher Deutung [1945]. Mit 11 Abbildungen und einem Geleitund Schlüsselwort von A. Rosenberg (Basel ${ }^{2} 1985$ ).

3 U. Rüpke/J. Rüpke, Die 101 wichtigsten Fragen. Götter und Mythen der Antike (München 2010) 38. 


\section{Der Dichter Nonnos von Panopolis: Forschungsstand}

Aus dieser Perspektive ist der Fall des Dichters Nonnos von Panopolis (ca. 400 - 470),

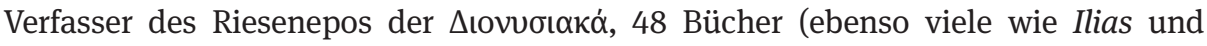

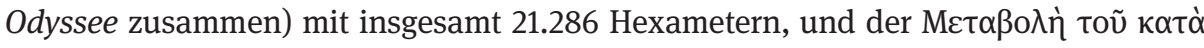

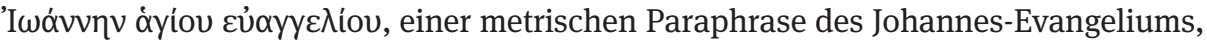
21 Bücher mit insgesamt 3660 Hexametern, paradigmatisch. Ob Nonnos Heide oder Christ war, ist seit langer Zeit umstritten. Diese Aporie, es dreht sich um die problematische Koexistenz von Dionysiaka und Paraphrase, das eine ein mythologisches Epos, das andere ein christliches Gedicht, wurde von Margarete Riemschneider am Ende ihres „Im Garten Claudias“ (1970), eines historischen Romans, der vom Leben des Nonnos inspiriert war, eindringlich vorgetragen. Denn die Autorin lässt das Manuskript der Paraphrase, das nach dem Tod des Dichters in seiner Bibliothek verstaubte, zu einem Rätsel für die Nachfahren der Gelehrten werden:

Die Paraphrasen des Johannesevangeliums verstaubten in seiner Bibliothek.

Die Gelehrten vieler Jahrhunderte haben sich seither den Kopf darüber zerbrochen, wer sie geschrieben haben könnte. Dem Stil nach Nonnos. Aber der Dichter der Dionysiaka?

Ein Heide ${ }^{4}$

Es sind nun mehr als vierzig Jahre seit der Erscheinung des Buches von Riemschneider vergangen, das zwar äußerst verdienstvoll für die Nonnos-Studien ist, ${ }^{5}$ doch niemand könnte - zumindest glaube ich das - ihre abschließende Behauptung teilen: „Niemals hätte ein Christ die ,Dionysiaka' schreiben können.“6

Lassen Sie mich jedoch die Hauptpunkte der Religion und Kultur des Nonnos, die ich vor kurzem im Artikel für das „Reallexikon für Antike und Christentum“ behandelt habe, zusammenfassen. ${ }^{7}$ In der Vergangenheit wurden besonders zwei Lösungen für die scheinbare Unvereinbarkeit von Dionysiaka und Paraphrase vorgeschlagen: 1) Nonnos war, wie Synesios, Claudianus, Dracontius, Ausonius, Sidonius Apollinaris, Palladas, Agathias und die Rhetoren der Schule von Gaza (Prokopios, Chorikios, Aeneas), ein Vertreter des heidnisch-christlichen religiösen Synkretismus der Spät-

4 M. Riemschneider, Im Garten Claudias. Kulturgeschichtlicher Roman über den letzten großen Dichter der Antike (Leipzig 1970) 207.

5 Vgl. M. Riemschneider, Der Stil des Nonnos, in: J. Irmscher (Hrsg.), Aus der byzantinistischen Arbeit der DDR, 1 (Berlin 1957) 46-70; dies., Die Rolle Ägyptens in den Dionysiaka des Nonnos, in: P. Nagel (Hrsg.), Probleme der koptischen Literatur. Tagungsmaterialien der II. koptologischen Arbeitskonferenz des Instituts für Byzantinistik der Martin-Luther-Universität Halle-Wittenberg am 12. und 13. Dezember 1966 (Halle 1968) 73-83.

6 Riemschneider (s. Anm. 4) 210; vgl. D. Hernández de la Fuente, Nonnus' Paraphrase of the Gospel of John: Pagan Models for Christian Literature, in: J. P. Monferrer-Sala (Hrsg.), Eastern Crossroads. Essays on Medieval Christian Legacy (Piscataway, NJ 2007) 169-190, hier 173 Anm. 22.

7 D. Accorinti, Art. Nonnos von Panopolis, in: RAC 25 (2013) 1107-1129, hier 1111-1113. 
antike (Golega); ${ }^{8}$ 2) Nach der Abfassung der Dionysiaka trat Nonnos zum Christentum über und verfasste die Paraphrase (Bogner, Keydell). ${ }^{9}$

Gegenwärtig wird in der Forschung die Bekehrungsthese abgelehnt, da man meint, dass Nonnos Christ gewesen sein müsse (Cameron), ${ }^{10}$ und es scheint wahrscheinlich, dass die beiden Werke eine kulturelle Äußerung des synkretistischen Milieus von Panopolis sind, was durch archäologische Zeugnisse gestützt wird. ${ }^{11}$ Insbesondere haben „Dionysos der Erlöser“ (1985), eine Studie von Wiktor A. Daszewski über die spätantiken Bodenmosaiken aus Nea-Paphos (4. Jh.), in der der Autor eine monotheistische Deutung des Bildkomplexes im ,Haus des Aion“ vorschlug, und „Dionysus und Christus“ (1992), ein Artikel von Dietrich Willers zur Religionszugehörigkeit des Dichters von Panopolis, in der Nonnosforschung eine große Resonanz hervorgerufen. ${ }^{12}$ Diese Beiträge haben in der Tat zu der Annahme geführt, dass der Held des nonnianischen Epos als ein erlösender Gott interpretiert werden kann. ${ }^{13}$ Doch

8 J. Golega, Studien über die Evangeliendichtung des Nonnos von Panopolis. Ein Beitrag zur Geschichte der Bibeldichtung im Altertum (Breslau 1930) $80 \mathrm{f}$.

9 H. Bogner, Die Religion des Nonnos von Panopolis, Philologus 89 (1934) 320 - 333. R. Keydell, Art. Nonnos (Nr. 15), in: RE 17.1 (1936) 904-920, hier 905, 910 f., $915 \mathrm{f}$.

10 A. Cameron, Poets and Pagans in Byzantine Egypt, in: R. S. Bagnall (Hrsg.), Egypt in the Byzantine World 300 - 700 (Cambridge/New York 2007) 21-46, hier 36-38, 43 f.

11 L. Miguélez Cavero, Poems in Context. Greek Poetry in the Egyptian Thebaid 200 - 600 AD (Berlin/ New York 2008) 191-263. Zu Panopolis und Schenute von Atripe (ca. 347-465), Abt von zwei Männerklöstern und einem Frauenkloster in Panopolis, vgl. M. Westerhoff, „[...] die hellenischen Herzen, die unter euch sind“ - Schenute und die ,Hellenen“ in seinem Traktat Contra Origenistas, in: S. G. Vashalomidze/L. Greisiger (Hrsg.), Der Christliche Orient und seine Umwelt. Gesammelte Studien zu Ehren Jürgen Tubachs anläßlich seines 60. Geburtstags (Wiesbaden 2007) 87-96, bes. 87-89 (für ein PDF dieses Artikels danke ich dem Autor); H.-J. Cristea, Schenute von Atripe: Contra Origenistas. Edition des koptischen Textes mit annotierter Übersetzung und Indizes einschließlich einer Übersetzung des 16. Osterfestbriefs des Theophilus in der Fassung des Hieronymus (ep. 96) (Tübingen 2011) 111-122; A. G. Lopez, Shenoute of Atripe and the Uses of Poverty. Rural Patronage, Religious Conflict, and Monasticism in Late Antique Egypt (Berkeley/Los Angeles/London 2013) 19-26.

12 W. A. Daszewski, Dionysos der Erlöser. Griechische Mythen im spätantiken Cypern (Mainz 1985). D. Willers, Dionysos und Christus - ein archäologisches Zeugnis zur ,Konfessionsangehörigkeit‘ des Nonnos, MH 49 (1992) 141-151.

13 G.W. Bowersock, Hellenism in Late Antiquity (Ann Arbor 1990) 44: „If there is any trace in this work [Dionysiaka] of the Christian empire in which it took shape, it is in the redemptive role of Dionysus“; 4950: „Publishing the mosaic at New Paphos for the first time, the Polish archaeologist Wiktor Daszewski entitled his work, Dionysos der Erlöser, ,Dionysus the Redeemer.' He could not have chosen a better title to suggest the soteriological aspects of the god." S. McNally, Syncretism in Panopolis? The evidence of the ,Mary Silk، in the Abegg Stiftung, in: A. Egberts/B. P. Muhs/J. van der Vliet (Hrsg.), Perspectives on Panopolis. An Egyptian Town from Alexander the Great to the Arab Conquest (Leiden/Boston/Köln 2002) 145-164, hier 147: „One scholar [D. Willers] has argued that Nonnos’ writings show at the same time a genuine reverence for both Christ and Dionysos.“ Vgl. P. Talloen, From Pagan to Christian: Religious Iconography in Material Culture from Sagalassos, in: L. Lavan/M. Mulryan (Hrsg.), The Archaeology of Late Antique ,Paganism“ (Leiden/Boston 2011) 575 - 607, hier 578: „[O]ne deity in particular appears to have been the focus of much attention in Sagalassos and throughout the eastern Mediterranean during the 4th c. A.D., namely Dionysus. His popularity is attested both in literary sources 
bereits ein Jahr nach der Veröffentlichung des Buches von Daszewski erschien die Erwiderung Johannes Deckers mit dem provokativen Titel „Dionysos der Erlöser?“ (1986), der zufolge die dionysische Ikonographie der Mosaikbilder neutral ist: „Das Mosaikbild im ,Haus des Aion“ ist keine heidnische Ikone!“14 Aber die monotheistische Interpretation des Dionysos-Mosaiks aus dem ,Haus des Aion“ wurde kürzlich von Elizabeth Kessler-Dimin wieder unterstützt. Sie sieht dies als ein Zeichen dafür, dass die heidnischen Religionen in der Spätantike noch lebendig waren. ${ }^{15}$

Im Gegensatz zu dem, was Hans Bogner und Rudolf Keydell vorausgesetzt hatten, hat Francis Vian eine religionslose Interpretation der Dionysiaka geliefert: 1) Das Interesse des Nonnos am orphisch-eleusinischen Ritual und an den dionysischen Mysterien sei nur oberflächlich; 2) Die Dionysiaka enthielten keine Heilstheologie, denn „Dionysos n'est pas un Rédempteur au sens chrétien du terme“, und daher wolle Nonnos Dionysos nicht Christus gleichstellen; 3) Die Dionysiaka ließen sich als ein Kapitel der Universalgeschichte ( Peisander von Laranda, 3. Jh. n. Chr., Verfasser der

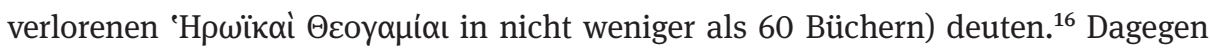
denkt Daria Gigli Piccardi, dass die „Christianisierung des Dionysos“ das Ziel des Nonnos sei, ${ }^{17}$ und Enrico Livrea schlägt eine typologische Deutung der Dionysiaka vor: Dionysos sei die Vorankündigung eines rettenden Gottes. ${ }^{18}$ Nach Wolfgang Liebe-

(most notably the Dionysiaca of Nonnus of Panopolis) and material culture, and perhaps reflects his rising position in the pagan pantheon at that time. Indeed, Dionysus may have been promoted as an alternative to Christ, facilitated by their shared characteristics of miraculous birth, mystery cult and divine resurrection."

14 J. G. Deckers, Dionysos der Erlöser? Bemerkungen zur Deutung der Bodenmosaiken im ,Haus des Aion“ in Nea-Paphos auf Cypern durch W. A. Daszewski, RQ 81 (1986) 145-172, hier 161, vgl. 167: „Wie falsch es ist, von der Darstellung ,heidnischer` Götter und Heroen auf Objekten dieses Bereichs [des privaten Luxus' und Daseinsgenusses] auf die Religion ihrer Benutzer zu schließen, zeigen am besten die Reliefs der kostbaren Silbergeräte der Christin Proiecta, auf denen sich um die Venus marina Nereiden, Seekentauren und Amorini fröhlich tummeln.“

15 E. Kessler-Dimin, Tradition and Transmission. Hermes Kourotrophos in Nea Paphos, Cyprus, in: G. Gardner/K. L. Osterloh (Hrsg.), Antiquity in Antiquity. Jewish and Christian Pasts in the Greco-Roman World (Tübingen 2008) 255 - 280. Für eine ähnliche strittige Interpretation eines Mosaiks s. R. Talgam/Z. Weiss, The Mosaics of the House of Dionysos at Sepphoris, Excavated by E. M. Meyers, E. Netzer, and C. L. Meyers (Jerusalem 2004) 127-131.

16 F. Vian, Théogamies et sotériologie dans les Dionysiaques de Nonnos, JS (juillet-décembre 1994) 197-233, hier 224 = ders., L'épopée posthomérique. Recueil d'études, édité par D. Accorinti (Alessandria 2005) 513-550, hier 541.

17 D. Gigli Piccardi, Nonno di Panopoli, Le Dionisiache. Introduzione, traduzione e commento, I (Canti I-XII) (Mailand 2003) 66-83, hier 82.

18 E. Livrea, Nonno di Panopoli, Parafrasi del Vangelo di S. Giovanni. Canto B. Introduzione, testo critico, traduzione e commento (Bologna 2000) 72-76; kritisch gegenüber dieser Lesart ist P. F. Beatrice, Art. Nonno di Panopoli, in: A. Di Berardino (Hrsg.), Nuovo dizionario patristico e di antichità cristiane (Genua/Mailand 22007) II, 3530 - 3533, hier 3531. F. Jourdan, Dionysos dans le Protreptique de Clement d'Alexandrie. Initiations dionysiaques et mystères chrétiens, RHR 223 (2006) 265-282 hat recht überzeugend dargelegt, dass, im Gegensatz zu Orpheus, „Clément d'Alexandrie ne propose pas de voir 
schuetz, dem Autor des Beitrags „The Use of Pagan Mythology in the Christian Empire with Particular Reference to the Dionysiaca of Nonnus“ (1996), könnte Nonnos in den Dionysiaka auch eine apologetische Haltung gegen die heidnische Mythologie einnehmen. Doch sein Riesenepos erweist sich als „a kind of encyclopedia“ (vergleichbar mit Macrobius, Martianus Capella, Johannes Lydos, Johannes Malalas). ${ }^{19}$

Die Neutralität der klassischen Kultur zwischen dem 5. und 7. Jh., die sich nicht mit dem Christentum verschmelzen ließ, sondern neben diesem gedanklich einherging, wird von Anthony Kaldellis, Pierre Chuvin und Alan Cameron auch in Bezug auf Nonnos betont: Es sei falsch, einige Werke als Auswirkung des zeitgenössischen Lebens anzusehen oder, um Camerons „The Last Pagans of Rome“ zu zitieren,

if a forty-eight-book work entirely dedicated to Dionysus in a highly classicizing style turns out to have no real pagan content or purpose, Dionysiac scenes in traditional domestic contexts like silver plate and textiles are best read as decorative rather than devotional. ${ }^{20}$

Auch wenn die Dionysiaka nur ,Literatur‘ wären, ohne Beziehung zwischen Text und Kontext, was ich kaum glaube, ${ }^{21}$ ist es dennoch ebenso möglich, dass die antiken Leser dem Gedicht eine symbolisch-allegorische Bedeutung beimaßen, sodass das gebildete, christliche wie heidnische Publikum, das der Adressat der beiden Werke gewesen sein muss, die Kontrastimitation in der Paraphrase selbst (z. B. Christus/Dionysos oder Christus/Hermes) finden konnte. ${ }^{22}$

Von diesem Standpunkt aus ist das neue Buch Robert Shorrocks „The Myth of Paganism“ (2011) ein origineller Beitrag zum besseren Verständnis der Welt des

en Dionysos une préfiguration du Dieu chrétien. [...] Le païens cultivés en effet établissaient d'euxmêmes ce parallèle, et ce parfois pour denoncer la vanité de la figure christique“ (274).

19 W. Liebeschuetz, The Use of Pagan Mythology in the Christian Empire with Particular Reference to the Dionysiaca of Nonnus, in: P. Allen/E. M. Jeffreys (Hrsg.), The Sixth Century - End or Beginning? (Brisbane 1996) 75-91, bes. 82-88.

20 A. Kaldellis, Hellenism in Byzantium. The Transformations of Greek Identity and the Reception of the Classical Tradition (Cambridge 2007) 174-178. P. Chuvin, Chronique des derniers païens. La disparition du paganisme dans l'Empire romain, du règne de Constantin à celui de Justinien (Paris ${ }^{3} 2009$ ) 367-370; ders., Revisiting Old Problems: Literature and Religion in the Dionysiaca, in: K. Spanoudakis (Hrsg.), Nonnus of Panopolis in Context. Poetry and Cultural Milieu in Late Antiquity with a Section on Nonnus and the Modern World (Berlin/New York 2014) 3-18, bes.12-18. A. Cameron, The Last Pagans of Rome (Oxford 2011) 698-706, hier 701. Vgl. F. Graf, Myth in Christian Authors, in: K. Dowden/N. Livingstone (Hrsg.), A Companion to Greek Mythology (Malden, MA/Oxford 2011) 319-338, bes. 328 f.

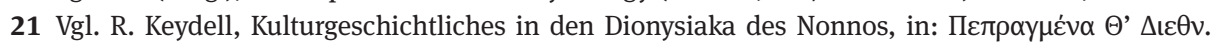

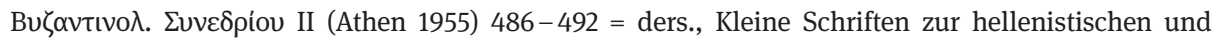
spätgriechischen Dichtung (1911-1976), zusammengestellt von W. Peek (Leipzig 1982) 516-522.

22 Zum Zielpublikum des Dichters s. Th. A. Schmitz, Nonnos und seine Tradition, in: St. Alkier/R. B. Hays (Hrsg.), Die Bibel im Dialog der Schriften (Tübingen/Basel 2005) 195-216, hier 215f.; S. Matzner, Christianizing the Epic - Epicizing Christianity: Nonnus' Paraphrasis and the Old-Saxon Heliand in a Comparative Perspective. A study in the Poetics of Acculturation, Millennium 5 (2008) 111-145, hier 142f.; G. Agosti, Greek Poetry, in: S. F. Johnson (Hrsg.), The Oxford Handbook of Late Antiquity (New York 2012) 361-404, hier 380-382. 
Nonnos und zur Überwindung der irreführenden Gegenüberstellung der beiden Werke, Dionysiaka und Paraphrase: Nonnos' Schwanken zwischen Heidentum und Christentum, der klassischen und der christlichen Kultur, drückt die zwei dichterischen Tendenzen in der spätantiken Literatur aus, das heißt, die Möglichkeit zu entscheiden, ob man ,Musendichter‘ oder ,Dichter Christi“ sein will, und dies soll nicht so sehr als eine Gegenüber-, sondern vielmehr als eine Nebeneinanderstellung der zwei Sphären, deren Verhältnis nicht durch eine Trennungslinie bestimmt ist, betrachtet werden. ${ }^{23} \mathrm{Zu}$ Recht hat Shorrock zur Nebeneinanderstellung des Christlichen und des Dionysischen in Nonnos angemerkt:

Nonnus' transformation of the story of Christ into Classical epic is no mere literary exercise. The juxtaposition of the Paraphrase with the world of Dionysus and the Dionysiaca has elucidated a complex web of correspondences and points of intersection. The text of the Paraphrase, drawing on the rich seam of Dionysiac imagery already present in John's Gospel, encourages us to reflect on the intersection between Christ and the figure of Dionysus and his world. The Paraphrase does not present a simple mapping of Dionysiac imagery onto Christian; nor does it provide us with any neat conclusions about the relationship between Classical tradition and the Christian world. At the heart of the relationship between these two spheres lies an essential, one might say Dionysiac, instability - a disturbing (yet exhilarating) refusal to dictate and determine meaning. ${ }^{24}$

\section{Nonnos und der Mythos}

Hinsichtlich des Gebrauchs des Mythos bei Nonnos gibt es noch keine allgemeine Untersuchung wie die von Vappu Pyykkö über die griechischen Mythen bei Basileios von Kaisareia, Gregorios von Nazianzos, Gregorios von Nyssa und Johannes Chrysostomos (1991), obwohl uns die wichtige Monographie von Pierre Chuvin, „Mythologie et géographie dionysiaques“ (1991), und einzelne Beiträge zu verschiedenen mythologischen Themen wie beispielsweise Keydells „Mythendeutung in den Dionysiaka des Nonnos“ (1961) zur Verfügung stehen. ${ }^{25}$ Eine solche Untersuchung wäre wünschenswert und würde zweifellos durch die Verwendung des „Index général des noms propres“, welchen die Budé-Ausgabe der Dionysiaka bereitgestellt hat, erleichtert werden. ${ }^{26}$ Nun stimmt es zwar, dass eine umfassende Behandlung des Themas fehlt, aber wir können dennoch behaupten, dass die Haltung des Nonnos sich sowohl von der

23 R. Shorrock, The Myth of Paganism. Nonnus, Dionysus and the World of Late Antiquity (London 2011), bes. 13-48, 120 -123; vgl. die Besprechung von S. Bär, Plekos 14 (2012) 95-105.

24 Shorrock (s. Anm. 23) 78.

25 V. Pyykkö, Die griechischen Mythen bei den großen Kappadokiern und bei Johannes Chrysostomos (Turku 1991). P. Chuvin, Mythologie et géographie dionysiaques. Recherches sur l'œuvre de Nonnos de Panopolis. Préface d'E. Will (Clermont-Ferrand 1991). R. Keydell, Mythendeutung in den Dionysiaka des Nonnos, in: G. Radke (Hrsg.). Gedenkschrift für G. Rohde (Tübingen 1961) 105-114 = ders., Kleine Schriften (s. Anm. 21) 523-532.

26 Nonnos de Panopolis, Les Dionysiaques, XIX. Index général des noms propres, établi par F. Vian et M.-Ch. Fayant (Paris 2006). 
Intransigenz gegenüber dem Heidentum der Apologeten als auch von den moralischen Absichten des Fulgentius (5.-6. Jh.), des Verfassers der Mythologiae, unterscheidet. ${ }^{27}$ Vielleicht ist seine Annäherung an den Mythos mit der des Dracontius zu vergleichen, wenn wir die Bemerkungen Roswitha Simons aufnehmen wollen:

Die Verarbeitung und Darstellung von Mythen ist für Dracontius wie auch für andere Autoren der ausgehenden Spätantike nicht mehr problematisch, sie muß nicht gerechtfertigt werden. Die Mythen sind ein Kulturgut wie anderes paganes philosophisches Gedankengut auch, das integriert ist in ein christlich bestimmtes Weltbild. ${ }^{28}$

\section{Das Motiv des nekrophilen Inders (Dion. 35.21-78) und der Penthesileiamythos}

Eine der Episoden der Dionysiaka, die am stärksten die Bearbeitungsweise des Mythos im Werk des Nonnos verdeutlicht, ist das Motiv des nekrophilen Inders im 35. Buch (21-78), ${ }^{29}$ das von der Liebe post mortem des Achilleus zu Penthesileia, der Amazonenkönigin, die den Trojanern zu Hilfe kam und von Achilleus getötet wurde, inspiriert ist. ${ }^{30}$ Diesem Thema, das dem homerischen Epos fremd ist und Gegenstand der verlorenen Aithiopis des Arktinos von Milet war, begegnet man in der Literatur und in der Ikonographie seit der archaischen Epoche, und es ist weit verbreitet. Die ausführlichste Darstellung der Penthesileia-Geschichte findet sich, wie gut bekannt ist, bei Quintus von Smyrna (3. Jh. n. Chr.) im ersten Buch der Posthomerica (538-781). Doch in den spätantiken Mosaiken ist das Motiv wenig belegt, trotz zahlreicher literarischer Zeugnisse, die seit dem Hellenismus die erotische Komponente akzentuiert haben. ${ }^{31}$ Nonnos überträgt den Penthesileiamythos, dessen berühmteste Rezeption in

27 Dazu E. Albu, Fulgentius the Mythoclast: Cooling Pagan Passions in Christian Late Antiquity, Electronic Antiquity 14 (2010-2011) 83-96; É. Wolff/Ph. Dain (Hrsg.), Fulgence, Mythologies (Villeneuve d'Ascq 2013) $18-21$.

28 R. Simons, Dracontius und der Mythos. Christliche Weltsicht und Pagane Kultur in der ausgehenden Spätantike (Leipzig 2005) 368.

29 Ausg.: H. Frangoulis/B. Gerlaud, Nonnos de Panopolis, Les Dionysiaques, XII, Chants XXXV et XXXVI. Texte établi, traduit et commenté par H. F. avec la collaboration de B. G. (Paris 2006).

30 F. Schwenn, Art. Penthesileia, in: RE, Suppl.-Bd. 7 (1940) 868-875, hier 872-874. E. Berger, Art. Penthesileia, in: LIMC 7.1 (1994) 296-305. Zur Rezeption des Amazonenmotivs s. C. Reinle, Exempla weiblicher Stärke? Zu den Ausprägungen des mittelalterlichen Amazonenbildes, HZ 270 (2000) 1-38; S. Andres, Le Amazzoni nell'immaginario occidentale. Il mito e la storia attraverso la letteratura (Pisa 2001); ders., Le Amazzoni nordiche tra localizzazioni geografiche e appropriazioni mitiche, Classiconorroena 29 (2011) 5-93 (url: http://www.tema.unina.it/index.php/Classnorr/article/view/849/ 1526); C. Schubert/A. Weiß, Amazonen zwischen Griechen und Skythen. Gegenbilder in Mythos und Geschichte (Berlin/New York 2013).

31 G. Arrigoni, Pentesilea e Marcia Elice. La bellezza dell'Amazzone come ricordo d'amore, Archeologia Classica 33 (1981) [1984] 253-272, hier 256f. F. Ghedini, Achille, eroe ambiguo' nella produzione 
der Neuzeit das gleichnamige Drama von Heinrich von Kleist (1808) ist, ${ }^{32}$ auf eine jungfräuliche Bakchantin aus dem Gefolge des Dionysos. ${ }^{33}$ Während des Massakers der Bassariden, das am Anfang des Buches beschrieben wird (1-20), hat ein anonymer Inder eine der Bakchantinnen tödlich mit dem Speer durchbohrt. Von ihrer nackten

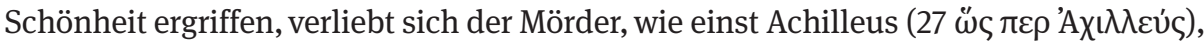
in die Sterbende und er hätte sich mit der von ihm getöteten Bakchantin geschlechtlich vereint, hätte er keine Furcht vor dem Zorn des Königs Deriades gehabt (21-35a):

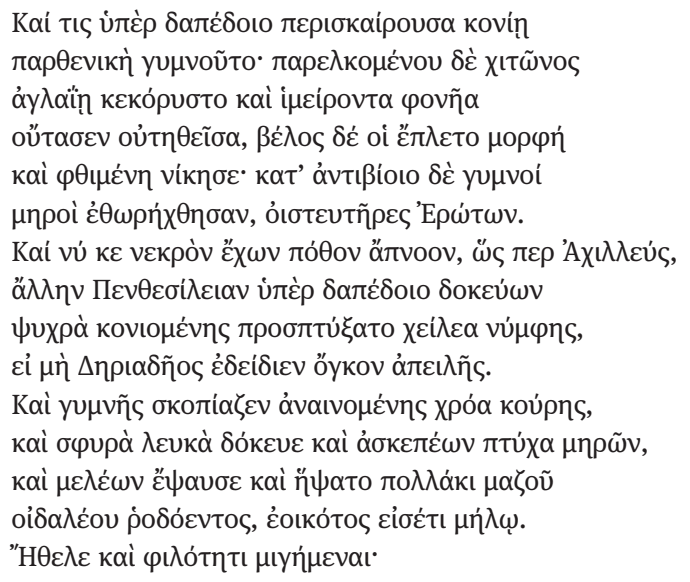

Eine der Bakchen, die über den Boden hin rollte, entblößte | dabei die Glieder. Ihr Unterkleid rutschte zur Seite, mit ihrer | Schönheit als Waffe verwundete, selber verwundet, sie ihren | Mörder durch wildes Verlangen. Ihr wurde die Schönheit zum Treffer, | sterbend errang sie den Sieg. Die nackten Schenkel durchbohrten | gleichsam mit Pfeilen den Gegner, Schützen, die Liebe erweckten. | Beinahe hätte der Inder, verliebt in die Tote, am Boden, | wie einst Achilleus, aufs neue Penthesileia vor Augen, | innig die kalten Lippen des Mädchens geküßt, das im Staube | lag. Doch er stockte aus banger Furcht vor der Weisung des Königs, | schaute nur auf das nackte Mädchen, das ihm versagt war, | sah auf die hellen Knöchel, den Winkel zwischen den Hüften, | tastete über die Glieder, ergriff mehr als einmal die straffen, | rosigen Brüste, so lieblich wie Äpfel. Verlangen nach einer | Liebesvereinigung wollte ihn überwältigen. ${ }^{34}$

Schließlich, frustriert von seiner sinnlosen Sehnsucht (35b-36), hält der Inder eine längere Rede (37-77), in die Nonnos die Prosopopöie der verstorbenen Bakchantin einfügt (49b-53a), und setzt seinen Weg fort (78):

musiva tardo antica, AnTard 5 (1997) 239-264, hier 258-260. G. Agosti, Nonno di Panopoli, Le Dionisiache, III (Canti XXV-XXXIX) (Mailand 2004; ${ }^{3}$ 2013) 562-564. Frangoulis/Gerlaud (s. Anm. 29) 5f. 32 Vgl. B. Greiner, Art. Penthesileia, in: M. Moog-Grünewald (Hrsg.), Mythenrezeption. Die antike Mythologie in Literatur, Musik und Kunst von den Anfängen bis zur Gegenwart = DNP, Suppl.-Bd. 5 (Stuttgart/Weimar 2008) 557-562, hier $560 \mathrm{f}$.

33 Penthesileia wird bei Nonnos nur in Buch 35 erwähnt.

34 Übers.: D. Ebener, Nonnos, Werke, I: Leben und Taten des Dionysos I-XXXII. II: Leben und Taten des Dionysos XXXIII-XLVIII; Nachdichtung des Johannesevangeliums (Berlin 1985) II, 32f. 
ó $\psi \varepsilon \dot{~} \delta \varepsilon \dot{~} \kappa \alpha ́ \mu \nu \omega v$

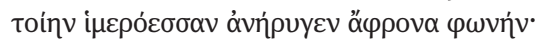

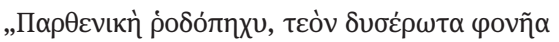

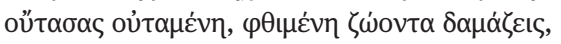

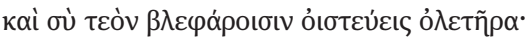

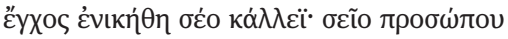

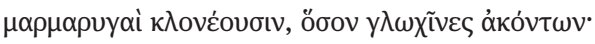

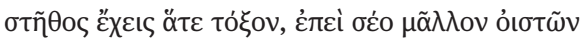

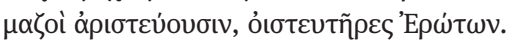

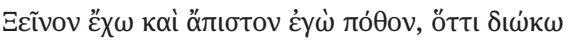

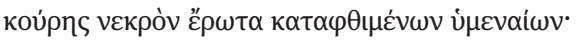

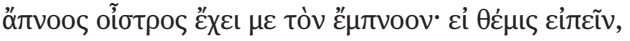

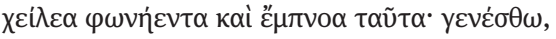

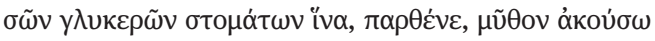

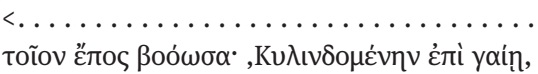

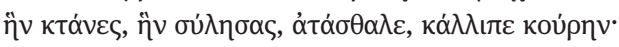

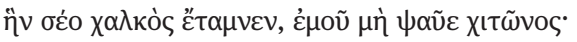

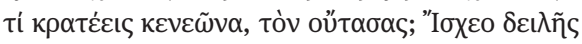

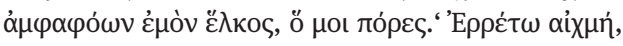

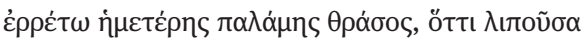

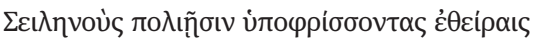

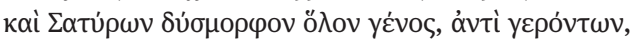

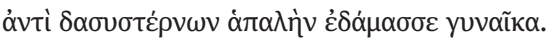

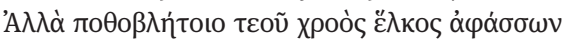

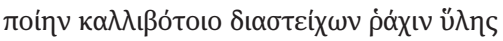

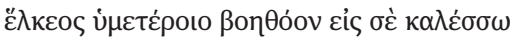

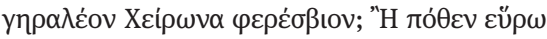

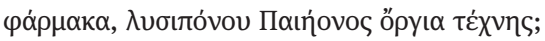

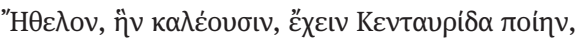

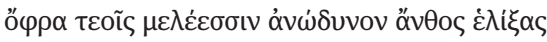

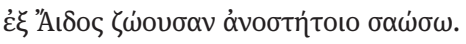

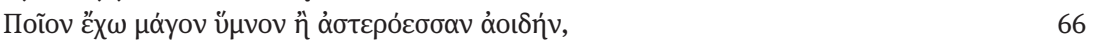

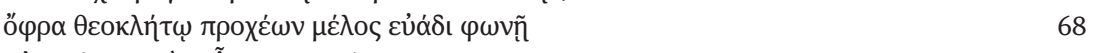

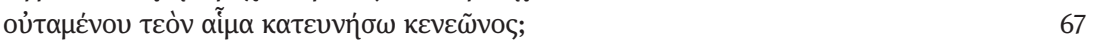

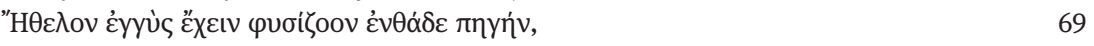

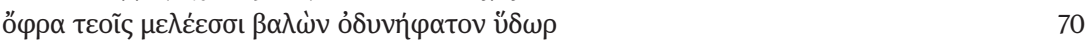

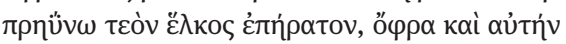

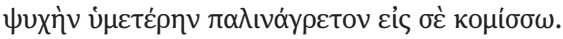

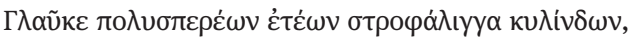

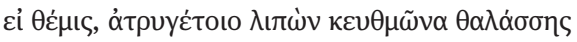

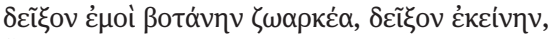
ท்

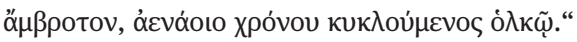

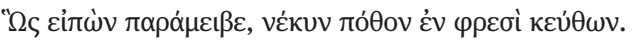

Schließlich | stieß er, mit Anstrengung, Worte hervor, voll Sehnsucht, doch sinnlos: | „Mädchen mit rosigen Armen, verwundet, verwundest du deinen | unglücklich liebenden Mörder, bezwingst den Lebenden sterbend, | triffst mit den Blicken den, der dich totschlug. Besiegte doch deine | Schönheit die Lanze des Feindes. Dein herrlich strahlendes Antlitz | schreckt und erschüttert nicht minder als Spitzen von Speeren. Dein Busen | wirkt wie ein Bogen, da deine Brüste, Schützin der 
Liebe, | stärkere Kraft entfalten als Pfeile. Mich drängt ein Verlangen, | unerhört, seltsam und gar nicht zu glauben. Ich liebe ein Mädchen, | aber die Liebe erstarb, die Vermählung wurde zunichte. | Mich, den noch Lebenden, stachelt ein Lebloses. Dürfte ich wünschen, | sollten die starren Lippen, beseelt, zu sprechen beginnen, | wollte ich Worte aus deinem lieblichen Munde vernehmen, | etwa die folgenden: ,Fort von dem Mädchen, du gottloser Frevler, | das du erschlugst und beraubtest und über den Erdboden wälztest! | Rühre nicht an mein Gewand, nachdem mich dein Schwert erst zerfleischte! | Rühre den Körper nicht an, den du trafest! Betaste die Wunde | nicht, die du mir so furchtbar geschlagen!'Verflucht hier die Waffe, | hier auch verflucht die schamlose Faust: Sie traf nicht Silene, | deren Leiber von gräßlichen Haarzotten starren, nicht Satyrn, | diese abscheulichen Wesen, nicht Greise, nicht haarige Brüste, | sie überwältigte ohne Mitleid ein Mädchen, ein zartes! | Aber betaste ich deinen verwundeten Leib, den ich liebe - | welche Gebirge voll waldiger Triften muß ich durchstreifen, | einen betagten Cheiron als lebenspendenden Pfleger | deiner Wunde gewinnen zu können? Wo finde ich Mittel, | Paians geheime Arzneien, die Schmerzen zu stillen vermögen? | Hätte ich doch zu meiner Verfügung das ,Kraut der Kentauren': | Lindernde Blüten wollte um deinen Körper ich winden, | dich aus dem Hades, dem keiner entrinnt, zum Leben befreien! | Was für ein Zauberlied stimme ich an, welch Lied der Gestirne, | um im Bakchantengesang die Götter um Hilfe zu flehen, | heilend das Blut, das deiner Wunde entströmt, noch zu stillen? | Hätte ich neben mir doch den Quell, der Leben uns spendet: | gleich übersprühen wollte ich dich mit dem lindernden Wasser, | stillen die Schmerzen deiner verehrungswürdigen Wunde, | damit die Seele in deinen Körper zurückkehren lassen! | Glaukos, du Lenker des Umlaufs so zahlreicher Jahre, verlasse, | bitte, den tiefen Schlund des ruhelos wogenden Meeres, | zeig mir das lebenbewahrende Kraut, ja, ebendasselbe, | das an die Lippen du einstmals dir setztest, um ewiges Leben | jetzt zu genießen, im Zuge der Zeiten auf immer zu kreisen!“ | Damit verließ er die Tote, die Liebe zu ihr tief im Herzen. ${ }^{35}$

Diese ,missglückte Nekrophilie‘, die in der Vergangenheit mehr als einen Zweifel über die Persönlichkeit des Dichters aufgeworfen hat, ${ }^{36}$ gehört zur Kategorie der ,BeinaheEpisode', die von Heinz-Günther Nesselrath untersucht wurde, ${ }^{37}$ und zeigt, dass Nonnos einer Version des Mythos folgt, die von Eustathios von Thessalonike (ca.1110 -

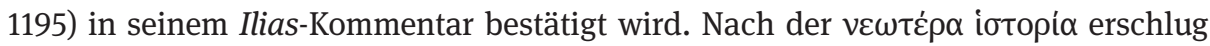

35 Übers.: Ebener (s. Anm. 34) $33 \mathrm{f}$.

36 Keydell (s. Anm. 9) 916: „Die Knabenliebe wird hier zum letztenmal in griechischer Dichtung behandelt, aber auch Nekrophilie $(35,27)$, sadistische $(34,226 \mathrm{ff}$.) und masochistiche $(16,38)$ Züge finden sich. Sicher ist diese Erotik nicht literarisch, sondern hat ihre Wurzeln in der Persönlichkeit des

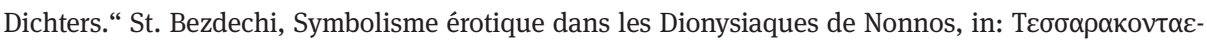

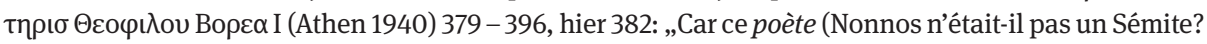

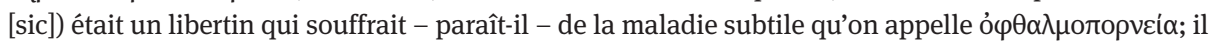
s'est vautré, à ce qu'il semble, dans toutes les orgies d'une débauche imaginaire“; 390: „Les lignes cidessus [Dion. $35.21 \mathrm{ff}$.], qui n'admettent pas d'autre interprétation, constituent une preuve évident que l'œuvre de Nonnos est une mine pour ceux qui veulent trouver dans la littérature l'illustration des symptomes du domaine de ce que Krafft-Ebing appelait psychopatia sexualis.“

37 H.-G. Nesselrath, Ungeschehenes Geschehen. ,Beinahe-Episoden“ im griechischen und römischen Epos von Homer bis zur Spätantike (Stuttgart 1992) 71: „In einer der makabersten Szenen des ganzen Werkes (XXXV 21 ff.) hätte sich ein Inder an einer von ihm getöteten Bakchantin fast der Nekrophilie hingegeben, und selbst nach dem auch hier erfolgenden кaí vv $\kappa \varepsilon-\varepsilon i$ rń braucht er noch eine längere Rede (37-78), um sich von diesem Gelüst loszureißen.“ 
Achilleus den Thersites mit einem Faustschlag, weil dieser ihm die Wollust ( $\lambda \alpha y v \varepsilon i ́ \alpha)$ gegenüber dem Leichnam Penthesileias vorgeworfen hatte:

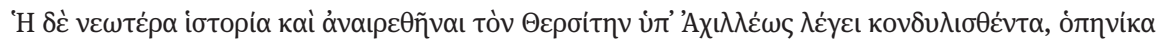

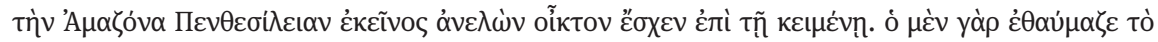

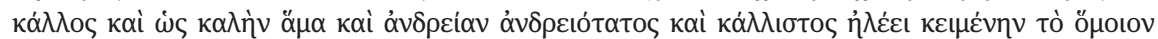

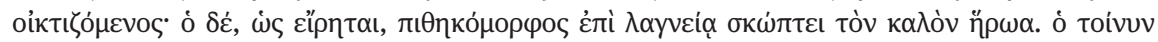

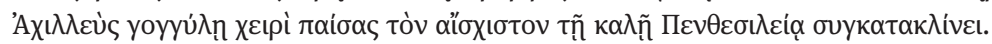

Die jüngere Version berichtet, dass Thersites von Achill auch mit einem Fausthieb getötet worden sei, als er, nachdem er die Amazone Penthesileia getötet hatte, Mitleid für die tot Daliegende zeigte. Er nämlich bestaunte die Schönheit und hatte Mitleid mit der Schönen und zugleich Tapferen als der Schönste und Tapferste, wobei er die Gemeinsamkeit beklagte. Der aber (sc. Thersites), in seiner Affengestalt, verspottet den schönen Helden wegen seiner Wollust. Achill nun schlägt den Elendsten mit der geballten Faust und legt ihn neben die schöne Penthesileia. ${ }^{38}$

Bis vor kurzem haben die Gelehrten, wie zu erwarten war, ihre Aufmerksamkeit auf den ,makaber-krankhaften` Aspekt dieser Episode gerichtet. Auf der einen Seite wurde betont, dass die nonnianische Beschreibung des Todes der Bakchantin ,est aux antipodes de celle du poète des Posthomériques, qui se veut décente et morale“. ${ }^{39}$ Auf der anderen Seite wurde die ausgefeilte Ethopöie des Inders, die an Libanius' Progymnasmata erinnert, als „un divertimento letterario raffinato, elegante e più che malizioso“ gekennzeichnet. ${ }^{40}$ Aber diese Lesarten versäumen es, den Zweck dieser skan-

38 Eustath. zu Hom., Il. 2.220 (I, 317.19-25 van der Valk); vgl. schol. zu Soph., Phil. 445; schol. zu

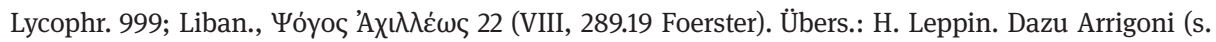
Anm. 31) 268-270; E. Magnelli, Note a frammenti di Sotade, Seminari romani di cultura graeca 11 (2008) 299-313, hier 307 Anm. 41; s. auch R. Schmiel, The Amazon Queen. Quintus of Smyrna, Book 1, Phoenix 40 (1986) 185-194, hier 193.

39 Frangoulis/Gerlaud (s. Anm. 29) 5 mit Anm. 14. An dieser Stelle verweist man auf F. Vian, Quintus de Smyrne, La suite d'Homère, I, Livres I-IV (Paris 1963) 11: „Un autre souci majeur de Quintus est celui de la moralité. Il insiste sur la pudeur de la vierge guerrière, sur son souci de mourir avec décence, comme Iphigénie. Rien de trouble non plus dans les sentiments d'Achille, alors que le roman prétendait qu'il s'était uni à la défunte; Thersite lui-même ne fait aucune allusion à cette fable malgré la violence de ses invectives. Ce respect des convenances a conduit le poète à débarrasser la légende de ses accrétions romanesques et à retrouver la simplicité du récit cyclique. La passion d'Achille demeure muette ou du moins ses pensées ne sont-elles rapportées que très brièvement et au style indirect; ainsi sont évités la préciosité et le bel esprit que la rhétorique et la poésie de l'époque impériale ont cultivés avec tant de plaisir.“ Vgl. G. Massimilla, Aỉó́s negli occhi e sul volto: riflessioni su due temi ricorrenti nella poesia greca, Incontri triestini di filologia classica 10 (2010-2011) 233-254, hier 244.

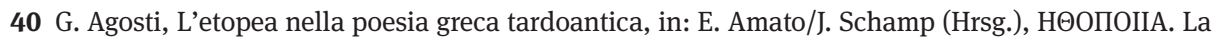
représentation de caractères entre fiction scolaire et réalité vivante à l'époque impériale et tardive (Freiburg/Salerno 2005) 34-60, hier 48, vgl. 59, wo Agosti die Stelle des Nonnos (Dion. 35.37-47) mit

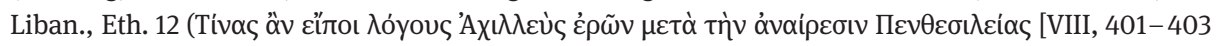

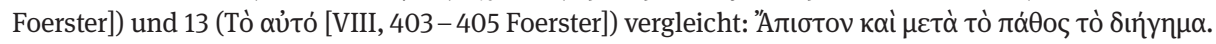

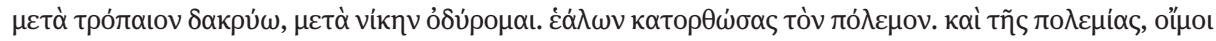

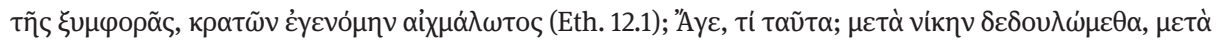

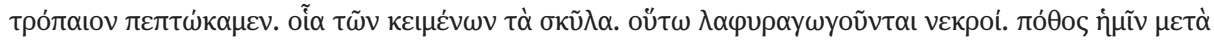


dalösen Wiederverwendung des Mythos von Achilleus und Penthesileia bei einem christlichen Dichter wie Nonnos zu verstehen. Immerhin kann man sich vorstellen, dass Nonnos den Mythos allegorisch-symbolisch lesen will. Es genügt hier zu er-

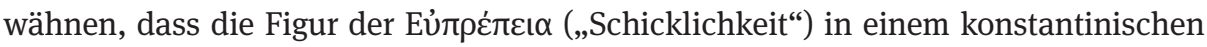
Mosaik aus Shahba-Philippopolis, das von Janine Balty beschriebenen wurde, die peinliche homerische Szene der Liebe von Ares und Aphrodite (Od. 8.285-295) zu rechtfertigen strebt. ${ }^{41}$ Aber ich glaube nicht, dass hier das Penthesileia-Motiv auf die angebliche Symbolik des Sieges der Liebe über den Tod und der Unsterblichkeitshoffnung auf einigen Sarkophagen anspielen könnte. ${ }^{42}$ Eine solche Auslegung wurde von Fernand Missonnier für eine anonyme Grabinschrift aus Rom aus dem 2. -3. Jh. n. Chr. vorgeschlagen..$^{43}$ In diesem Epigramm ,wird die Verstorbene Marcia Helike von ihrem Gatten als zu Lebzeiten schön wie Aphrodite und im Tode schön wie eine Amazone gepriesen, die als Tote noch mehr Liebe weckte als die Lebende“ “.44

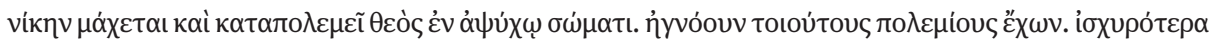

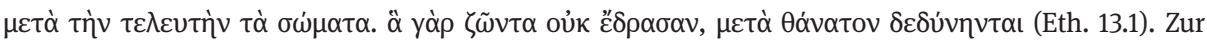
Mythologie als Quelle für die byzantinischen rhetorischen Übungen vgl. I. Taxidis, Die Episode des Palamedes in den byzantinischen Progymnasmata, BZ 102 (2009) 731-737.

41 J. Balty, Mosaïques antiques de Syrie (Brüssel 1977) 44-69; ders., Les mosaïques de ShahbaPhilippopolis. Chronologie, Ateliers, Commanditaires, Annales archéologiques arabes syriennes 41 (1997) 49-61. Vgl. Ch. Körner, Philippus Arabs. Ein Soldatenkaiser in der Tradition des antoninischseverischen Prinzipats (Berlin/New York 2002) 220 -222; G. Agosti, Due note sulla convenienza di Omero, in: A. Marcone (Hrsg.), Società e cultura in età tardoantica. Atti dell'incontro di studi, Udine 2930 maggio 2003 (Florenz 2004) 38-57, hier 38-51.

42 P. Zanker/B. Ch. Ewald, Mit Mythen leben. Die Bilderwelt der römischen Sarkophage (München 2004) $285-288$.

43 F. Missonnier, Sur la signification littéraire du mythe d'Achille et Penthésilée (à propos d'un fragment de bas-relief inédit), Mélanges d'archéologie et d'histoire 49 (1932) 111-131, hier 126f. zu IG XIV 1839 = Kaibel, Ep. Gr. 727; Cougny, Anth. Gr. App. II 612; Peek GVI 1164; Peek GG 392; Moretti, IGUR III 1268. Vgl. H. Brandenburg, Meerwesensarkophage und Clipeusmotiv. Beiträge zur Interpretation römischer Sarkophagreliefs, JDAI 82 (1967) 195-245, hier 220 f. mit Anm. 81; Arrigoni (s. Anm. 31) 271; G. Agosti, Epigrammi lunghi nella produzione epigrafica tardoantica, in: A. M. Morelli (Hrsg.), Epigramma longum. Da Marziale alla tarda antichità. From Martial to Late Antiquity, Atti del Convegno internazionale, Cassino, 29-31 maggio 2006, II (Cassino 2008) 663-692, hier 673.

44 A. Fendt, Schön und stark wie eine Amazone - zur Konstruktion eines antiken Identifikationsmodells. Amazonendarstellungen auf einem Achill-Penthesilea-Sarkophag als Bilder für Vorstellungen von Weiblichkeit im 3. Jh. n.Chr., in: N. Sojc (Hrsg.), Neue Fragen, neue Antworten. Antike Kunst als

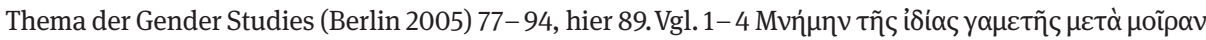

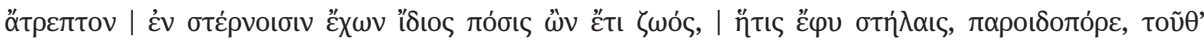

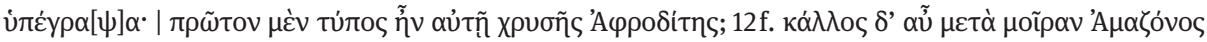

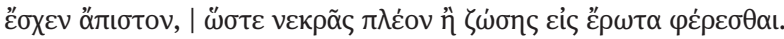




\section{Nonnos und die Drusianageschichte der Johannesakten (63-86)}

Ein anderer Schlüssel zur Auslegung der gesamten Episode wird stattdessen durch die anregende Lektüre des Appendix „De la virginité des Bacchantes“, den Bernard Gerlaud seiner Ausgabe der Bücher 33-34 der Dionysiaka hinzufügte, empfohlen. ${ }^{45}$ Unter Berücksichtigung der verschiedenen Stellen im Epos des Nonnos stellt Gerlaud fest, dass die Bakchantinnen als $\pi \alpha \rho \theta \varepsilon ́ v o ı ~ \varphi v y o ́ \delta \varepsilon \mu \nu \iota^{46}$ alles tun, um ihre Jungfräulichkeit/Keuschheit zu bewahren: Unter dem Schutz der schrecklichen Schlangen entkommen sie den trunkenen Satyrn (12.382-393) und weibertollen Indern (15.75; 17.190; 34.208; 35.18) gleichermaßen. ${ }^{47}$ Gerlaud ist sich sehr wohl bewusst, dass die literarische und ikonographische Tradition des Mänadismus mehrdeutig ist, weil Laszivität und Mäßigkeit sich abwechseln: Der Dionysoskult selbst beachtet die $\pi \alpha \rho \theta \varepsilon v i ́ \alpha$ (vgl. Diod. Sic. 4.3.2f.). ${ }^{48}$ Allerdings ist er auch davon überzeugt, dass das Beharren eines christlichen Dichters wie Nonnos auf der Jungfräulichkeit der Bakchantinnen im Leben und nach dem Tode wie im Fall der Protagonistin dieser Episode

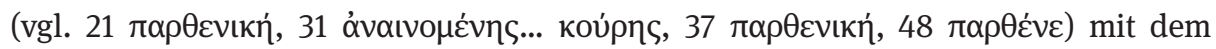
Einfluss des Enkratismus erklärt werden kann. ${ }^{49}$ Diese Form der extremen Askese (Enthaltsamkeit von Fleisch, Wein, Geschlechtsverkehr), die Tatian der Syrer im 2. Jh. vertrat, radikalisierte die Verherrlichung der Jungfräulichkeit als ethisches Ideal. Trotz der Verurteilung des Enkratismus durch Theodosius II. (428) hielt sich die Häresie in den asketisch-monastischen Kreisen. ${ }^{50}$ Es ist auch erwähnenswert, dass der Enkratismus Berührungspunkte mit dem Dionysismus hat. ${ }^{51}$ Wenn wir dem Zeugnis des Epiphanius von Salamis glauben dürfen, berichtete Severus, ein Anhänger der Sekte, der später als Tatian gelebt haben muss (Eus., H.E. 4.29.4f.), dass die Weinrebe aus dem Samen des Teufels in Schlangengestalt erschaffen sei. ${ }^{52}$ Weiterhin ist es angebracht,

45 B. Gerlaud, Nonnos de Panopolis, Les Dionysiaques, XI, Chants XXXIII-XXXIV (Paris 2005) 244258.

46 G. D’Ippolito, Studi Nonniani. L'epillio nelle Dionisiache (Palermo 1964) 86-114. D. Hernández de la Fuente, ,Bakkhos Anax‘. Un estudio sobre Nono de Panópolis (Madrid 2008) 86-97.

47 Gerlaud (s. Anm. 45) $245 \mathrm{f}$.

48 Gerlaud (s. Anm. 45) 246-252.

49 Gerlaud (s. Anm. 45) 252f. Zur weiblichen Askese im spätantiken Ägypten s. R. Krawiec, Shenoute and the Women of the White Monastery. Egyptian Monasticism in Late Antiquity (Oxford/New York 2002); E. Wipszycka, L’ascétisme féminin dans l'Égypte de l'Antiquité Tardive: Topoi littéraires et formes d'ascèse, in: H. Melaerts/L. Mooren (Hrsg.), Le rôle et le statut de la femme en Égypte hellénistique, romaine et byzantine, Actes du colloque international, Bruxelles - Leuven 27-29 Novembre 1997 (Paris/Löwen/Sterling, VA 2002) 355-396.

50 M. Zellentin, Rabbinic Parodies of Jewish and Christian Literature (Tübingen 2011) 86-94.

51 Gerlaud (s. Anm. 45) 253.

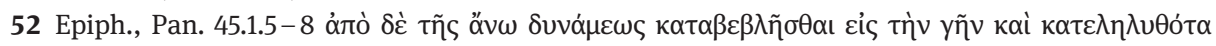

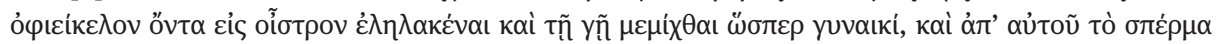

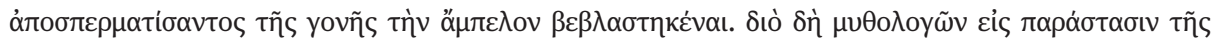


darauf hinzuweisen, dass Nonnos durch die Romanliteratur der apokryphen Apostelgeschichten, die eine sehr starke enkratitische Tendenz haben, beeinflusst sein könnte. Neben der Polymorphie Christi (Act. Jo. 88-93), die mit der des Dionysos zu vergleichen ist (Dion. 45.119-121 Hom., Hymn. Dion. 7.2f.), finden wir in den apokryphen Akten auch die Geschichten von keuschen Jungfrauen wie Drusiana aus den Johannesakten, Thekla aus den Paulus- bzw. Theklaakten ${ }^{53}$ oder Mygdonia und Tertia

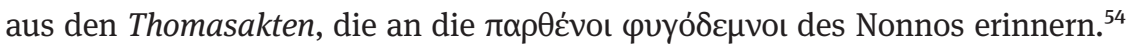

In den Johannesakten, die in Ägypten, am ehesten in Alexandrien, kurz nach 150 n. Chr. anzusetzen sind, ${ }^{55}$ wird von Drusiana (63-86), der keuschen Gemahlin des Andronikos von Ephesus, die den gewünschten Tod findet, um der leidenschaftlichen Liebe des jungen Kallimachos zu entkommen, erzählt. ${ }^{56}$ Nach ihrem Tod besticht Kallimachos den Verwalter des Andronikos namens Fortunatus mit Geld, um Drusianas Leichnam zu schänden. Aber in dem Augenblick, in dem Kallimachos sich im Begriff befindet, die Verstorbene zu vergewaltigen, tötet eine Schlange den Verwalter und macht den jungen Mann bewegungsunfähig:

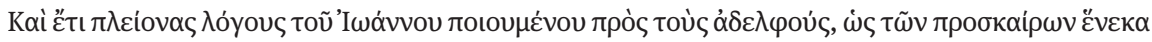

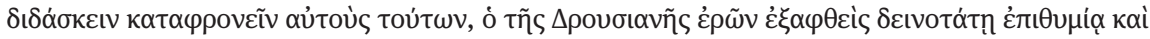

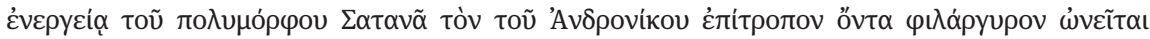

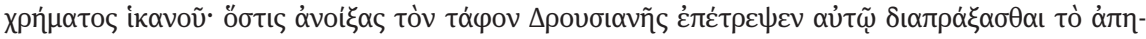

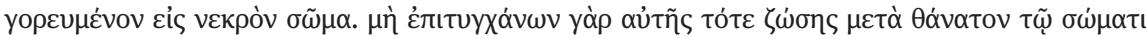

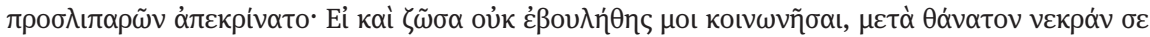

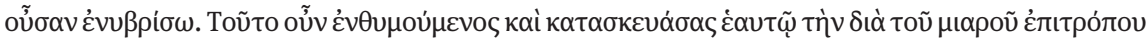

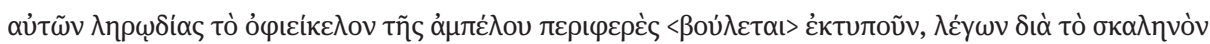

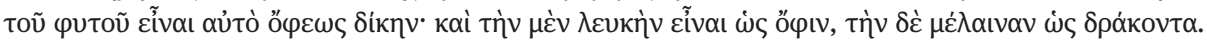

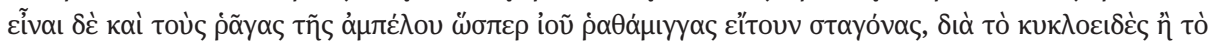

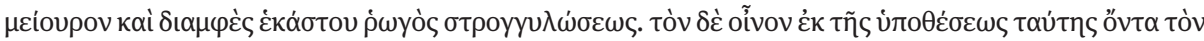

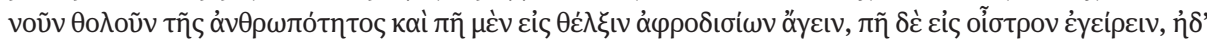

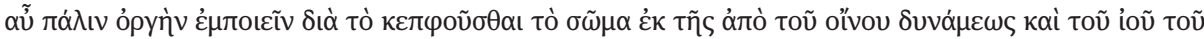

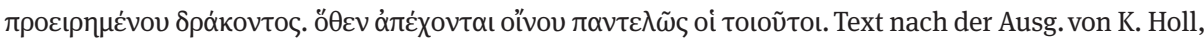
Epiphanius (Ancoratus und Panarion), II, Panarion Haer. 34-64 (Leipzig 1922; 2., bearb. Auflage herausgegeben von J. Dummer, Berlin 1980) $199 \mathrm{f}$.

53 J. N. Bremmer, Magic, Martyrodom and Women's Liberation in the Acts of Paul and Thecla, in: ders. (Hrsg.), The Apocryphal Acts of Paul and Thecla (Kampen 1996) 36-59; J. W. Barrier, Ascetism in the Acts of Paul and Thecla's Beatitudes. The Coptic Heidelberg Papyrus as an Exegetical Test Case, in: H.-U. Weidemann (Hrsg.), Asceticism and Exegesis in Early Christianity. The Reception of New Testament Texts in Ancient Ascetic Discourses, with an Introduction by E. A. Clark (Göttingen/Bristol, CT 2013) $163-185$.

54 Gerlaud (s. Anm. 45) 253f.Vgl. S. Petersen, „Zerstört die Werke der Weiblichkeit!“ Maria Magdalena, Salome und andere Jüngerinnen Jesu in christlich-gnostischen Schriften (Leiden/Boston/Köln 1999) $325-333$.

55 E. Junod/J.-D. Kaestli, Le dossier des ,Actes de Jean', in: ANRW 2.25.6 (Berlin/New York 1988) 4293 4362, hier $4353 \mathrm{f}$.

56 Ausg.: E. Junod/J.-D. Kaestli, Acta Iohannis, I-II (Turnhout 1983) I, 253-293. J. N. Bremmer, Drusiana, Cleopatra, and Some Other Women in the Acts of John, in: A.-J. Levine, with M. M. Robbins (Hrsg.), A Feminist Companion to the New Testament Apocrypha (London/New York 2006) 77-87. 


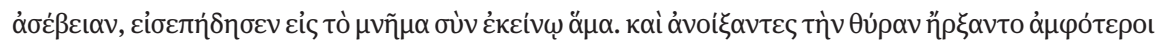

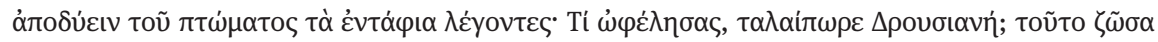

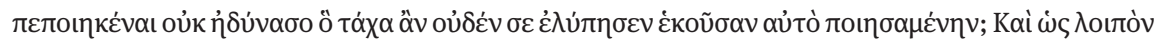

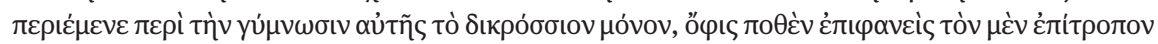

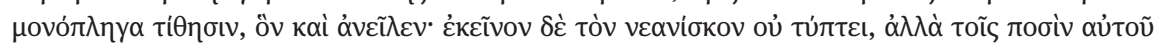

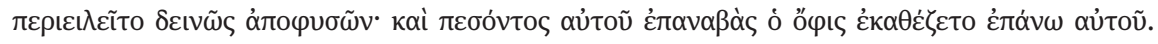

Und während Johannes noch mehr Worte an die Brüder richtete, um sie der vergänglichen Dinge wegen zu belehren, daß sie diese verachteten, bestach der Liebhaber der Drusiana, erfaßt von schrecklichster Begierde und dem Wirken des vielgestaltigen Satans, mit einer erklecklichen Summe den geldgierigen Verwalter des Andronikos. Der öffnete die Grabkammer der Drusiana und gewährte es ihm, das Versagte an dem toten Leib zu vollführen. Denn da er sie, als sie (noch) lebte, nicht gewonnen hatte, ließ er nach ihrem Tod nicht ab von ihrem Leib und sprach: „Wenn du auch als Lebende nicht mit mir verkehren wolltest, so will ich dich doch nach dem Tode als Leichnam schänden." Das hatte er im Sinn, und nachdem er seine gottlose Tat vermittelst des ruchlosen Verwalters in die Wege geleitet hatte, stürmte er zusammen mit diesem zum Grab. Und als sie die Tür geöffnet hatten, begannen sie beide, dem Leichnam die Totengewänder auszuziehen, indem sie sagten: „Was hat es dir genützt, unglückliche Drusiana? Hättest du nicht, als du noch lebtest, dieses tun können, was dich schwerlich betrübt hätte, hättest du es freiwillig getan?“ Und als nurmehr allein das Hemd ihre Blöße bedeckte, erschien von irgendwoher eine Schlange, versetzte dem Verwalter einen einzigen Biß (und) tötete ihn (so) auch. Jenen jungen Mann jedoch biß sie nicht; vielmehr wand sie sich schrecklich zischend um seine Füße, und als er hinfiel, begab sich die Schlange hinauf (auf ihn) und ließ sich auf ihm nieder. ${ }^{57}$

Die Drusiana der Johannesakten zeigt, wie Gerlaud herausarbeitet, auffallende Über-

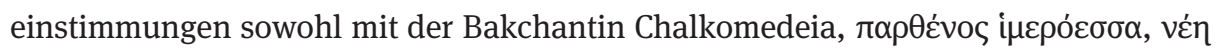

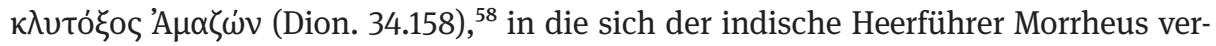
liebt (B. 33-35), als auch mit der jungfräulichen Bakchantin unserer Episode, mit der der nekrophile Inder Geschlechtsverkehr haben möchte:

Ainsi, dans les Actes de Jean, 63-86, on trouve l'édifiante histoire de la vierge Drusiana: malgré des menaces de mort, elle se refuse à son époux; ,elle aimait mieux mourir que de commettre cette horreur“ [Act. Jo. $63 \sim$ Dion. 33.319f.]. Par la suite, elle „demande à Dieu de la faire mourir pour échapper aux assiduités d'un amant [ Dion. 33.341-345, 379f.]. Elle meurt en effet; l'amant réussit... à pénétrer dans le tombeau de Drusiana afin de souiller son cadavre [ Dion. 35.21-78]. Un serpent s'enroule aux pieds de l'amant et l'empêche d'exécuter ses desseins." Ce serpent salvateur, qui n'a évidemment rien de satanique, rappelle le serpent dionysiaque qui protège la virginité des Bacchantes en général et de Chalcomédé en particulier [ Dion. 33.366 -369; 35.199222]. ${ }^{59}$

57 Act. Jo. 70 f. (Junod/Kaestli [s. Anm. 56] I, 263-267); Übers.: W. Schneemelcher, Neutestamentliche Apokryphen in deutscher Übersetzung, II: Apostolisches. Apokalypsen und Verwandtes (Tübingen $\left.{ }^{6} 1997\right) 181$.

58 Zum Wort 'A $\mu \alpha \zeta \dot{\omega} v$ bei Nonnos s. Gerlaud (s. Anm. 45) 10.

59 Gerlaud (s. Anm. 45) 255. Vgl. V. Giraudet, Virginity at Stake: Greek Novels, Apocryphal Acts of the Apostles, and the Dionysiaca of Nonnus Panopolitanus, in: M. P. Futre Pinheiro/J. Perkins/R. Pervo (Hrsg.), The Ancient Novel and Early Christian and Jewish Narrative: Fictional Intersections (Groningen 2012) 49-64. 
Gerlaud hat zweifellos Recht, wenn er bemerkt, dass das Schlangenmotiv und die Nekrophilieszene der Johannesakten ${ }^{60}$ sich in den Dionysiaka widerspiegeln. Doch weil er sich ausschließlich auf das Résumé der Geschichte von Drusiana aus einem alten Artikel von Georges Blond, „Les Encratites et la vie mystique“ (1952), ${ }^{61}$ beschränkt, gelingt es ihm nicht, eine vergleichende Analyse zu entwickeln, um insgesamt zu einem Verständnis des Motivs des nekrophilen Inders zu gelangen, was auch andere bisher versäumt haben.

In dieser langen Geschichte der Johannesakten, die von Junod und Kaestli als ein Paar mit der verlorenen Geschichte von Drusiana und Andronikos angesehen wird, ${ }^{62}$ gibt es nämlich, zusätzlich zur Keuschheit ${ }^{63}$ ein weiteres beherrschendes Thema: die Auferstehung. Erst wird Kallimachos von Johannes durch ein Gebet wiedererweckt und bekehrt (75-78); dann erweckt Johannes auch Drusiana (79f.); endlich wird auch Fortunatus von Drusiana wieder zum Leben erweckt, aber er will sich nicht bekehren und kehrt zu den Toten zurück (82f.). ${ }^{64}$

Kehren wir nun wieder zu unserer Diskussion der Penthesileia-Episode zurück, die wie eine mise-en-abyme des Romans von Morrheus und Chalkomedeia (B. 33-35) wirkt, deren Leitmotiv die Überlegenheit der Liebe (Aphrodite/Chalkomedeia) über den Krieg (Ares/Morrheus) ist. ${ }^{65}$ Die Episode ist in zwei verschieden große Abschnitte unterteilt. Der erste, der einen narrativen Charakter hat (23-26), dreht sich um die nackte, auf dem Boden sterbende Bakchantin. Mit den Waffen der Schönheit, ein Topos, den schon Claudianus in der griechischen Gigantomachie (2.43-54) verwendet, ${ }^{66}$ erregt sie bei dem Inder eine fleischliche Begierde. Diese Nekrophilie, die sich einem makabren Voyeurismus anschließt (28, 31f.), wird von Nonnos sehr stark betont. ${ }^{67}$ Doch dieses Verhalten wird gleichzeitig getadelt: Der Dichter bezeichnet die Sehnsucht des Inders nach der toten Bakchantin als ő $\varphi \rho \omega \nu$ (36), „sinnlos“. Nun wird dieses Adjektiv in der Paraphrase verwendet, um die Worte der Juden, die Christus

60 Dazu J. Spittler, Animals in the Apocryphal Acts of the Apostles. The Wild Kingdom of Early Christian Literature (Tübingen 2008) 110 - 116 (,The Snake That Stopped the Necrophiliac“).

61 G. Blond, Les Encratites et la vie mystique, in: Mystique et Continence. Travaux scientifiques du VII ${ }^{e}$ congrès international d'Avon (Paris 1952) 117-130, hier 124 f.; vgl. Gerlaud (s. Anm. 45 ) 255 Anm. 4. 62 Junod/Kaestli (s. Anm. 56) II, 541: „Seul le cycle qui racontait l'affrontement entre Drusiane et Andronicus devait avoir une dimension comparable. Notre récit faisait sans doute pendant à ce cycle perdu, avec lequel il possède plusieurs analogies. Ensemble, ils devaient constituer les deux volets d'une sorte de ,roman de Drusiane'.“

63 T. Onuki, Heil und Erlösung. Studien zum Neuen Testament und zur Gnosis (Tübingen 2004) 298300.

64 J. Perkins, Roman Imperial Identities in the Early Christian Era (London/New York 2009) 147-149. 65 Agosti (s. Anm. 31) 460-471. Gerlaud (s. Anm. 45) 15-33. Frangoulis/Gerlaud (s. Anm. 29) 5. H. Frangoulis, Du roman à l'épopée. Influence du roman grec sur les Dionysiaques de Nonnos de Panopolis (Besançon 2014) 38-42.

66 Agosti (s. Anm. 31) 562f. Frangoulis/Gerlaud (s. Anm. 29) 116f.

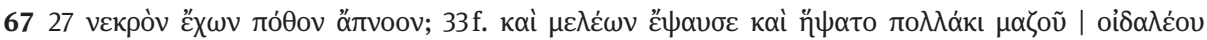

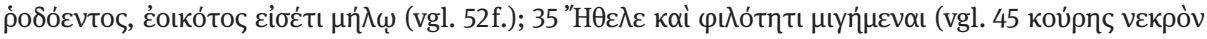

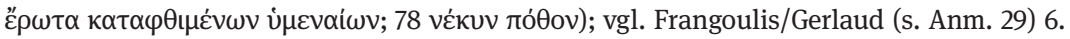


ablehnen, zu stigmatisieren. ${ }^{68}$ Dies ist ein Beweis, dass das Wort eine starke negative Konnotation in der Penthesileia-Episode aufweisen kann. Müssen wir daher auch von einer nicht ,neutralen“ Lesart der Liebe des Achilleus zur Penthesileia sprechen? ${ }^{69}$ Warum wollte Nonnos die Nekrophilie behandeln? Ein seltenes Thema in der griechischen Literatur, ${ }^{70}$ aber außerordentlich aktuell, wenn man bedenkt, dass im Jahr 2012 Gerüchte über eine Legalisierung der Nekrophilie in Ägypten auf der Grundlage einer Fatwa (2011) des marokkanischen Scharia-Gelehrten Zamzami Abdul Bari verbreitet wurden: Ehemännern soll es erlaubt werden, Geschlechtsverkehr mit ihren toten Frauen innerhalb von sechs Stunden nach dem Tod zu haben. ${ }^{71}$

Die Antwort auf diese Fragen könnte nun im zweiten Abschnitt der Episode, der langen Rede des Inders (37-77), gefunden werden. Diese Rede zeigt eine dreiteilige Struktur:

(A) 37-46a: Paradoxer Sieg der Bakchantin über ihren Mörder, der von einem selt-

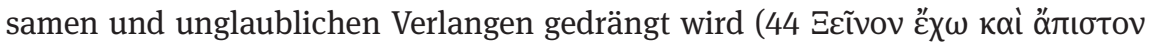

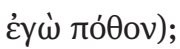

(B) 46b-53a: Prosopopöie der verstorbenen Bakchantin, die dem Inder den Vergewaltigungsversuch vorwirft;

(C) 53b-77: Bedauern des Inders $(53 b-57)$ und sein Wunsch, die Bakchantin mit Cheiron (58-61a), Paian (61b f.), dem „Kraut der Kentauren“ (63-65), einem Zauberlied (66-68-67), der Lebensquelle (69-72), sowie dem „lebenbewahrenden Kraut“ des Glaukos (73-77) zu heilen und wieder zum Leben zu erwecken.

Die Sorgfalt, mit der Nonnos die Rede des Inders verfasste, war bereits Gegenstand einer rhetorisch-stilistischen Analyse. Dabei wurde auch die Existenz eines numerischen Gleichgewichts in jedem der drei Teile der Rede festgestellt. ${ }^{72}$ Ebenso wurden auf der thematischen Ebene einige Parallelen ausgemacht, sowohl innerhalb des Buches

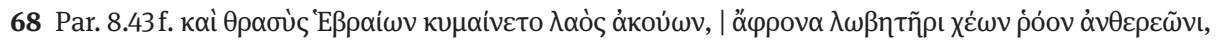

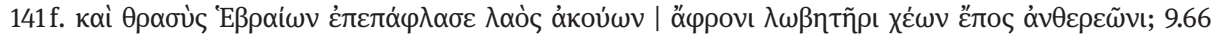

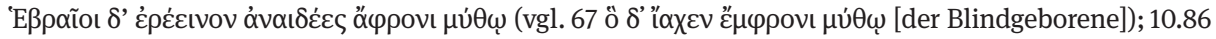

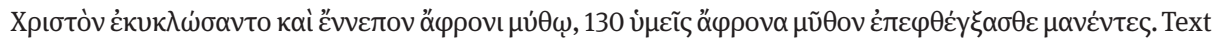
nach der Ausg. von A. Scheindler, Nonni Panopolitani Paraphrasis S. Evangelii Ioannei, accedit S. Evangelii textus et index verborum (Lipsiae 1881).

69 Vgl. M. Fantuzzi, Achilles in Love. Intertextual Studies (Oxford 2012) 283-286, hier 286: „That in the end, after long torment, reason prevails over passion and the Indian soldier observes Deriades' prohibition of sex with the enemy, is most probably, first of all, a piece of evidence of the fact that Nonnus remained a Christian, despite his inclination to explore the dialogue between classical and Christian views of the world, and to confront in particular their stances about potentially disturbing issues such as the power of sexuality.“

70 Agosti (s. Anm. 31) 565. Frangoulis/Gerlaud (s. Anm. 29) 6. A. Aggrawal, Necrophilia. Forensic and Medico-legal Aspects (Boca Raton, FL 2011) 4-7.

71 S. url: http://www.moroccoboard.com/news/5238-fatwa-necrophilia-religiously-acceptable-prac tice-in-islam; url: http://www.moroccoworldnews.com/2012/04/36995/egypt-alleged-measure-to-al low-necrophilia-a-pure-hoax/.

72 Frangoulis/Gerlaud (s. Anm. 29) 6 f. 
35 als auch mit anderen Büchern der Dionysiaka: z. B. die oben genannte Überlegenheit der Aphrodite über Ares (37-43 168-173), die Prosopopöie der verstorbenen Bakchantin (46b - 53a 11.318 - 324) oder die gelehrte Liste von Heilungsmethoden (58 - 77 17.357-377; $29.100-103,153-161,264-275) .{ }^{73}$ Es sind auch diejenigen, die den Akzent auf die Ähnlichkeiten zwischen dem „Quell, der Leben uns spendet“ und die Bakchantin heilen und wieder erwecken könne (69-72), und einigen prägnanten Ausdrücken, die Nonnos in der Paraphrase benutzte, um das „lebendige“ Wasser der Samariterin und das „schmerzstillende“ Wasser des Heilbades von Bethesda zu be-

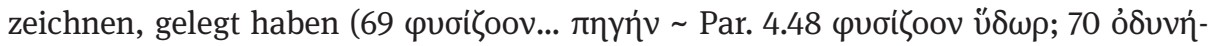
$\varphi \alpha \tau o v$ v̌ $\delta \omega \rho=$ Par. 5.10). ${ }^{74}$

Aber es fehlt, wie schon gesagt, ein tiefergehendes Verständnis für das Motiv des nekrophilen Inders. Dieses können wir erreichen, wenn wir den Vergleich mit der Drusianageschichte der Johannesakten (63-86) ausführlich behandeln. Diese Erzählung gab der Dichterin Hrotsvit von Gandersheim (um 935-nach 973) den Stoff zu ihrem Schauspiel Calimachus oder Resuscitatio Drusianę et Calimachi (BHL 4325), dessen Argumentum lautet:

qui eam non solum vivam sed etiam prę tristicia atque execratione illiciti amoris in domino mortuam plus iusto amavit unde morsu serpentis male periit sed precibus sancti Iohannis apostoli una cum Drusiana resuscitatus in Christo est renatus.

Der liebte sie nicht nur im Leben, sondern vor Trauer und angesichts des Fluchs einer unstatthaften Liebe auch, nachdem sie im Herrn gestorben war, mehr als angemessen, weswegen er durch einen Schlangenbiss elend starb, aber durch die Gebete des heiligen Apostels Johannes zusammen mit Drusiana wieder auferweckt und in Christus wiedergeboren wurde. ${ }^{75}$

Die Auferweckung der toten Drusiana durch den Evangelisten Johannes ist auch eine der Szenen aus dem Leben des Heiligen, die viele Künstler, einschließlich des soge-

73 Agosti (s. Anm. 31) 565 - 570. Frangoulis/Gerlaud (s. Anm. 29) 118-121. Zu den Heilkräutern vgl. W. Speyer, Der heilkundige Hippozentaur, Alexander der Große und Hippokrates. Ein neuer Text über die erste Offenbarung der Heilpflanzen, in: J. Dalfen/K. Forstner/M. Fussl/W. Speyer (Hrsg.), Symmicta Philologica Salisburgensia, Festschrift G. Pfligersdorffer (Rom 1980) 171-183 = ders., Frühes Christentum im antiken Strahlungsfeld. Ausgewählte Aufsätze (Tübingen 1989) 292-304.

74 G. Agosti, Nonno di Panopoli, Parafrasi del Vangelo di San Giovanni. Canto quinto. Introduzione, edizione critica, traduzione e commento (Florenz 2003) $58 \mathrm{f}$.

75 Ausg.: Hrotsvit, Opera Omnia, edidit W. Berschin (München/Leipzig 2001) 177-194, hier 177. Übers.: H. Leppin.Vgl. M. Giovini, A nugace in castum: l'itinerario salvifico di Callimaco, adulescens innamorato di Rosvita, Mediaevalia 28 (2007) 137-164; H. Scheck, Reform and Resistance. Formations of Female Subjectivity in Early Medieval Ecclesiastical Culture (Albany, NY 2008) 157-160; S. L. Wailes, Hrotsvit’s Plays, in: P. R. Brown/S. L. Wailes (Hrsg.), A Companion to Hrotsvit of Gandersheim (fl. 960). Contextual and Interpretive Approaches (Leiden/Boston 2012) 121-145, hier 124-130, 139f.; M. A. Zampelli, The Necessity of Hrotsvit: Evangelizing Theatre, ebd., 147-199, hier 171-179. 
nannten Meisters der Augustiner-Kreuzigung (Tafelgemälde, Bayerisches Nationalmuseum, München, um 1380 -1390), inspiriert haben. ${ }^{76}$

\section{Das Thema der Auferstehung}

Nun ist es leicht zu erkennen, dass von den drei Teilen der Rede des Inders der dritte (C $=24 \mathrm{Vv} .1 / 2)$ der ausgedehnteste ist. In diesem wird das Thema der Auferstehung in 20 Versen (58-77), fast der Hälfte der gesamten Rede, ${ }^{77}$ durch die Verwendung von Ausdrücken im Verhältnis zum Lebens- und Unsterblichkeitsmotiv entwickelt. ${ }^{78}$ Die Liste von Heilungsmethoden, die als eine „énumération hétéroclite, faite sans souci de vraisemblance“ gedacht wurde, ${ }^{79}$ ist kein reines Füllsel, sondern spricht für eine wohlbedachte Absicht des Nonnos. Wenn wir nun bedenken, dass die verschiedenen Heilungs- und Erweckungsmethoden, um die Bakchantin aus dem Hades zurück zu

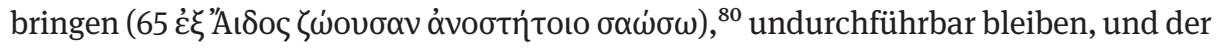

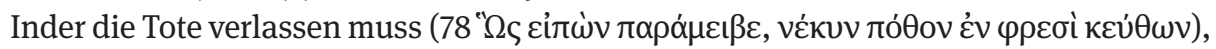
so ist es selbstverständlich, auch an die Auferweckung der toten Drusiana in den Johannesakten zu denken. Wenn man bedenkt, dass die Johannesakten, vielleicht ein Werk eines „chrétien d'origine païenne et converti de fraîche date“ ${ }^{81}$ dem aus Heiden und Christen gemischten Publikum des Nonnos bekannt gewesen sein müssten, ist es wahrscheinlich, dass der Dichter durch eine Anspielung auf den Mythos von Achilleus

76 H. Krauss/E. Uthemann, Was Bilder erzählen. Die klassischen Geschichten aus Antike und Christentum in der abendländischen Malerei (München ${ }^{6} 2011$ ) 338. D. Preyß, „Die Auferweckung der Drusiana und die Kreuzigung Christi“ - kunsthistorische und maltechnische Untersuchungen zu zwei Tafelgemälden des 14. Jahrhunderts aus dem Bayerischen Nationalmuseum in München, in: H. Nogossek/D. Popp (Hrsg.), Beiträge zur Kunstgeschichte Ostmitteleuropas, Bd. 13 (Marburg 2001) 61-73. 77 Nach dem V. 48 ist eine Lücke zu verzeichnen, s. Frangoulis/Gerlaud (s. Anm. 29) 7 Anm. 23, 118. 78 R. García-Gasco Villarrubia, Orfeo y el Orfismo en las Dionisíacas de Nono, Diss. (Madrid 2007) 148 156 („El rescate del Hades: 35.37-78“). Zu den Vorstellungen des Unsterblichkeitsglaubens in den Inschriften s. M. Obryk, Unsterblichkeitsglauben in den griechischen Versinschriften (Berlin/Boston 2012).

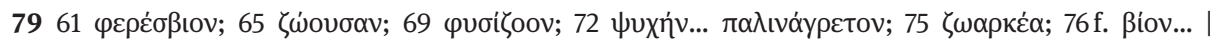

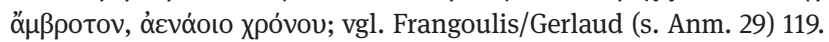

80 Zum Begriff s. Dion. 11.304-307, 30.155, 34.332f.; Par. 2.104-107, 5.94-99 (dazu Agosti [s. Anm. 74] 461 f.), 108-112. Vgl. J. N. Bremmer, Don't Look Back. From the Wife of Lot to Orpheus and Eurydice, in: E. Noort/E. J. C. Tigchelaar (Hrsg.), Sodom's Sin. Genesis 18-19 and Its Interpretation (Leiden/Boston 2004) $49-67=$ ders., Greek Religion and Culture, the Bible and the Ancient Near East (Leiden/Boston 2008) 117-132.

81 Junod/Kaestli (s. Anm. 55) 4353: „On prêtera volontiers à l'auteur les traits d'un chrétien d'origine païenne et converti de fraîche date. Il a embrassé la foi en Jésus avec enthousiasme et conviction, mais sa conception de Dieu et de la vie religieuse demeure fortement influencée par un courant spiritualiste bien présent dans la foi païenne des II et $\mathrm{III}^{\mathrm{e}}$ siècles. Sans doute appartient-il à une classe cultivée qui s'est ralliée au christianisme sans abandonner l'idéal religieux qui était le sien avant sa conversion“; vgl. 4355: „ils [Act. Jo.] représentent une tentative d'intégrer le christianisme au sein d'un courant monothéiste et spirituel qui traverse la foi païenne aux II et III $^{\mathrm{e}}$ siècles.“ 
und Penthesileia die Episode der Bakchantin und des nekrophilen Inders im Gegensatz zu der Drusianageschichte aufgebaut hat: Gegenüber den Wunderheilungen der heidnischen Antike, die den Toten nicht wieder zum Leben erwecken können, stehen die Auferstehung Christi und der Glaube der Menschen, welche, wie Johannes und Drusiana, Wunder in dessen Namen bewirken. ${ }^{82}$ Als das gebildete Publikum des Nonnos die Rede des Inders hörte, konnte es darin auch eine bedeutungsvolle Kontrastimitation Christus/Asklepios erkennen, in welcher Christus als wahrer Heiland und wahrer Arzt dargestellt wird..$^{83}$

Und es ist kein Zufall, dass Theodoret von Kyrrhos (393-nach 460), ein Zeitgenosse des Nonnos, den Konflikt Christus/Asklepios am Ende seiner Schrift ${ }^{\circ} \mathrm{\lambda} \lambda \lambda \eta \nu \iota \kappa \tilde{\omega} \nu$

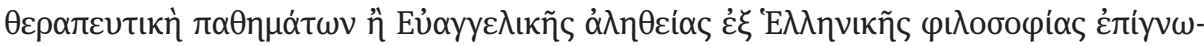
$\sigma \iota \varsigma$, der „Heilung der hellenischen Krankheiten oder Wiedererkennen der Wahrheit des Evangeliums aus der hellenischen Philosophie“ (12.96-98), reflektiert:

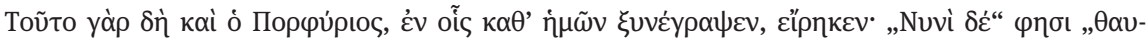

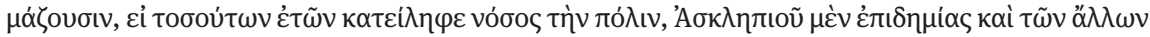

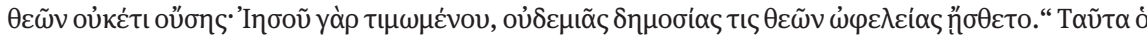

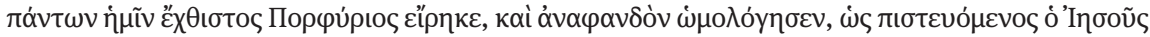

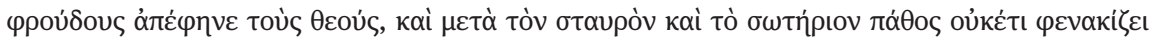

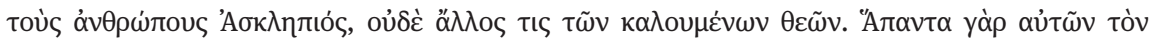

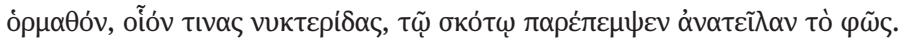

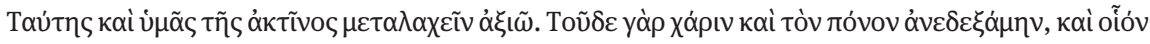

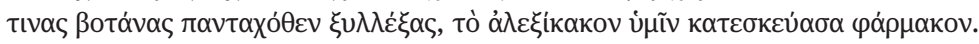

Das sagte auch Porphyrios in der Schrift gegen uns: „Jetzt aber“, sagt er, „wundern sie sich, wenn eine Krankheit über so viele Jahre die Stadt erfasst hat, wo Asklepios und die anderen Götter sich nicht mehr dort aufhalten. Als Jesus nämlich verehrt wurde, konnte niemand irgendeinen öffentlichen Nutzen der Götter wahrnehmen“. Das hat Porphyrios gesagt, der uns doch von allen am feindseligsten gesonnen ist, und damit offen eingestanden, dass Jesus, wenn man an ihn glaubt,

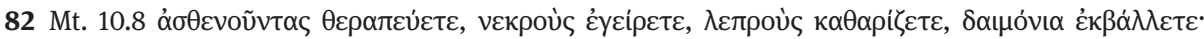

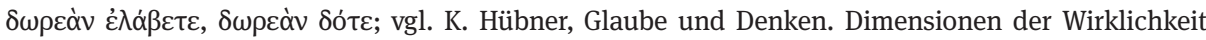
(Tübingen 2004) 191.

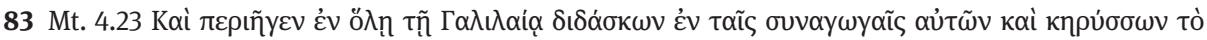

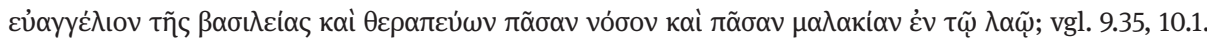
Zum Problem D. Knipp, ,Christus Medicus ' in der frühchristlichen Sarkophagskulptur. Ikonographische Studien zur Sepulkralkunst des späten vierten Jahrhunderts (Leiden/Boston/Köln 1998); M. Dörnemann, Krankheit und Heilung in der Theologie der frühen Kirchenväter (Tübingen 2003) 162; F. Steger, Asklepiosmedizin. Medizinischer Alltag in der römischen Kaiserzeit (Stuttgart 2004) 100; Ch. Schulze, Medizin und Christentum in Spätantike und frühem Mittelalter (Tübingen 2005) 15f. Anm. 3; Th. de Bruyn, Appeals to Jesus as the one „Who Heals Every Illness and Every Infirmity“ (Matt 4:23, 9:35) in Amulets in Late Antiquity, in: L. Di Tommaso/L. Turcescu (Hrsg.), The Reception and Interpretation of the Bible in Late Antiquity, Proceedings of the Montréal Colloquium in Honour of Charles Kannengiesser, 11-13 October 2006 (Leiden/Boston 2008) 65-81; L. M. Jefferson, The Staff of Jesus in Early Christian Art, Religion and the Arts 14 (2010) 221-251, hier 229 (mit Anm. 14), 234; ders., Superstition and the Significance of the Image of Christ Performing Miracles in Early Christian Art, in: J. Baun/A. Cameron/M. Edwards/M. Vinzent (Hrsg.), Studia Patristica. Volume XLIV: Archaeologica, Arts, Iconographica, Tools, Historica, Biblica, Theologica, Philosophica, Ethica (Löwen 2010) 15-20, hier $17 \mathrm{f}$. 
die Götter als wirkungslos erwiesen hat, und nach dem Kreuz und dem heilbringenden Leid täuscht Asklepios nicht mehr die Menschen noch ein anderer der sogenannten Götter. Ihren ganzen Schwarm nämlich hat wie irgendwelche Fledermäuse in die Dunkelheit das aufgegangene Licht zurückgeschickt.

Ich wünsche, dass ihr an diesem Glanz teilhabt. Deswegen habe ich auch die Mühe auf mich genommen und, indem ich gleichsam irgendwelche Pflanzen überall gesammelt habe, habe ich für euch das übelabwehrende Heilmittel zubereitet. ${ }^{84}$

Zugleich aber scheint Nonnos auch die Perspektive des Verfassers der 'H $\mathrm{\lambda} \lambda \eta \nu \iota \kappa \tilde{\omega} \nu$

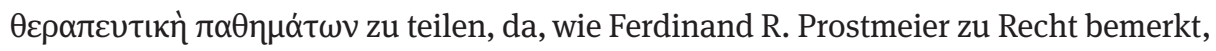
„Theodorets Apologie belegt, dass die christliche Literatur der Spätantike sich nicht als etwas völlig Neues gegenüber der heidnischen Literatur darstellt. Sie ist vielmehr in Anknüpfung und Auseinandersetzung mit ihr entstanden und damit auch vor diesem Hintergrund zu bewerten. “85

Nun ist es durchaus möglich, dass die missglückte Erweckung der Bakchantin einen impliziten Verweis auf die Botschaft der christlichen Auferstehung enthält sowie auch auf den Unterschied zwischen Christus und den heidnischen Göttern wie Herakles, Asklepios und Dionysos, denen die christlichen Apologeten wie Justin und Theophilos von Antiochia eine Erweckung und eine Himmelfahrt zuschrieben. ${ }^{86}$

\begin{abstract}
84 P. Canivet, Théodoret de Cyr, Thérapeutique des maladies helléniques. Texte critique, introduction, traduction et notes, I-II (Paris 1958), hier II, 446. Übers.: H. Leppin. Bezüglich dieser Stelle Theodorets und des Phänomens der Kontrastimitation in Nonnos vgl. G. Agosti, Usurper, imiter, communiquer: le dialogue interculturel dans la poésie grecque chrétienne de l'Antiquité tardive, in: N. Belayche/J.-D. Dubois (Hrsg.), L'oiseau et le poisson. Cohabitations religieuses dans les mondes grec et romain (Paris 2011) 275-299, hier 294-296.
\end{abstract}

85 F. R. Prostmeier, Christliche Paideia. Die Perspektive Theodorets von Kyrrhos, RQ 100 (2005) 1-29, hier 27. Zum alternativen Titel seines Werkes vgl. die Einleitung Canivets zu Théodoret de Cyr (s. Anm. 84) I, 50 f.: „Critique des erreurs grecques, oui, mais ,connaissance‘ ou plutôt ,compréhension“ de la verité à partir des philosophes grecs. Il reste donc à recueillir les bribes de pensée qui ont survécu au tri impitoyable, pour les confronter à l'enseignement de l'Écriture, afin d'établir que ce qu'il y a de meilleur chez les philosophes se retrouve identiquement dans l'enseignement des Apôtres; mieux, que les philosophes ont entrevu dans la pénombre ce que l'Évangile mettra en pleine lumière. On montrera ainsi que le mystère chrétien est d'une certaine façon intérieur à la pensée grecque dans ce qu'elle a de plus élevé, et qu'il est au terme de l'effort qui a mené les philosophes vers le vrai“; A. Schwab, Thales von Milet in der frühen christlichen Literatur. Darstellungen seiner Figur und seiner Ideen in den griechischen und lateinischen Textzeugnissen christlicher Autoren der Kaiserzeit und Spätantike (Berlin/Boston 2012) 258; Y. Papadogiannakis, Christianity and Hellenism in the Fifth-Century Greek East. Theodoret's Apologetics Against the Greeks in Context (Washington, D.C. 2012) 31-51. Für die

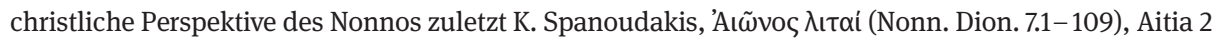
(2012) (e.-Veröff., url: http://aitia.revues.org/505).

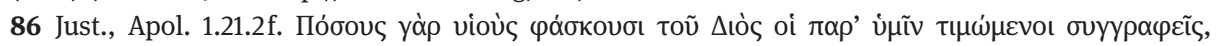

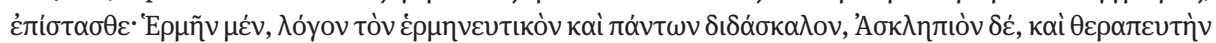

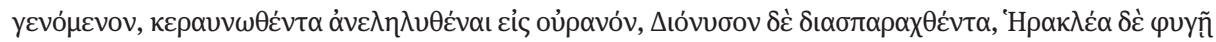

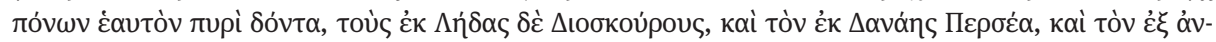

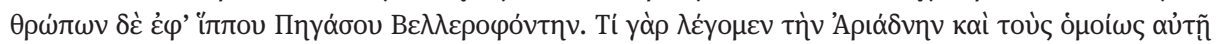

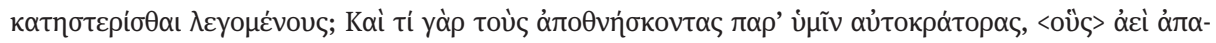


Tatsächlich hat das paulinische Konzept der Auferstehung Jesu als Beginn der endzeitlichen Totenerweckung (Act. 17.31 f.; 1 Cor. 15.20) keine Entsprechung in der heidnischen Antike. ${ }^{87}$ Allerdings kann auch ein gewisses Interesse des Autors an heidnischen ,Auferstehungen' vorausgesetzt werden. Es genügt in diesem Zusammenhang etwa daran zu erinnern, dass Epiphanius von Salamis im Kapitel 85 seines Werkes Ancoratus („Der Festgeankerte“), in dem er die Auferstehung des Fleisches behandelt, ${ }^{88}$ schreibt, dass er über die heidnischen Auferstehungserzählungen erstaunt ist:

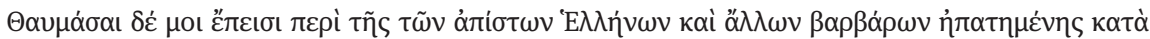

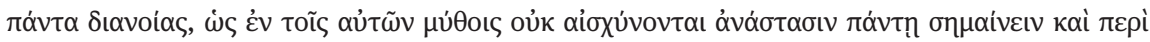

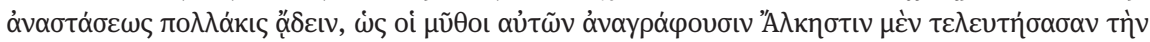

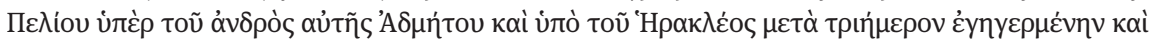

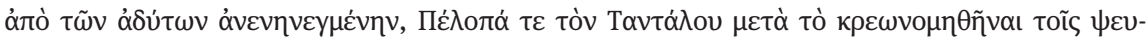

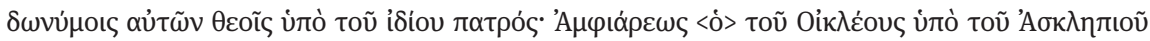

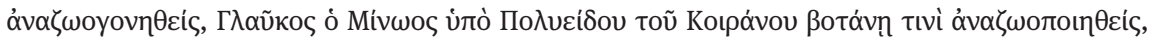

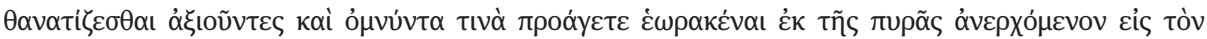

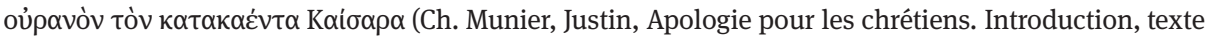

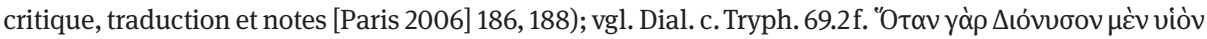

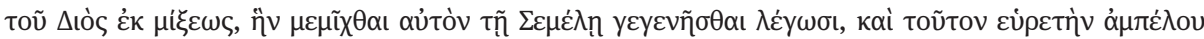

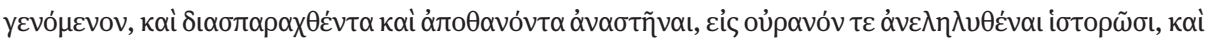

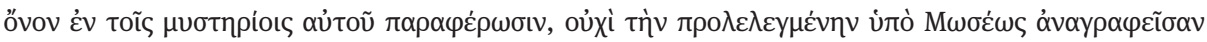

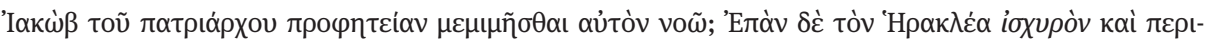

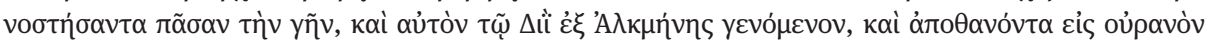

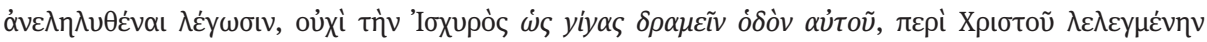

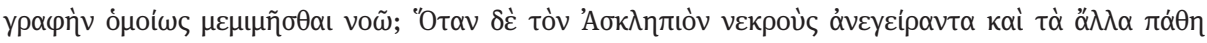

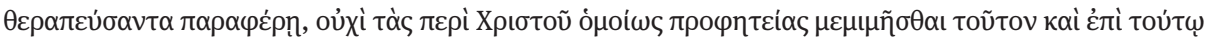
$\varphi \eta \mu \mathrm{i}$ (Ph. Bobichon, Justin Martyr, Dialogue avec Tryphon. Édition critique, I [Freiburg 2003] 372, 374);

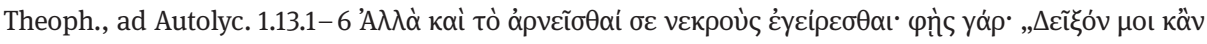

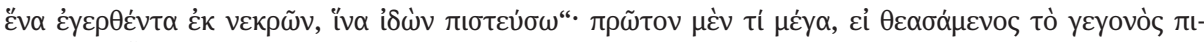

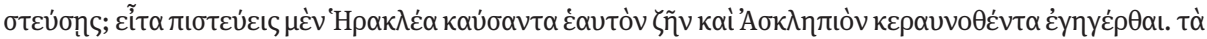

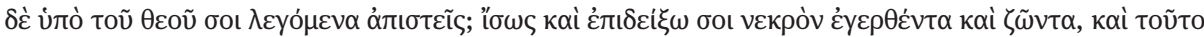

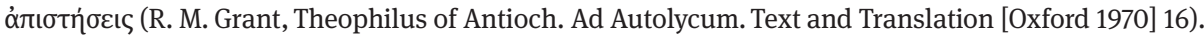
Dazu C. Walker Bynum, The Resurrection of the Body in Western Christianity, 200-1336 (New York 1995) 29-31; D. Zeller, Hellenistische Vorgaben für den Glauben an die Auferstehung Jesu?, in: R. Hoppe/U. Busse (Hrsg.), Von Jesus zum Christus. Christologische Studien. Festgabe für Paul Hoffmann zum 65. Geburtstag (Berlin/New York 1998) 71-91, hier 77; D. Ø. Endsjø, Greek Resurrection Beliefs and the Success of Christianity (New York 2009) 58f., 101; F. Massa, Tra la vigna e la croce. Dioniso nei discorsi letterari e figurativi cristiani (II - IV secolo) (Stuttgart 2014) 89-99. Zur Heraklesinterpretation s. in diesem Sammelband auch Zilling und Meier.

87 Zeller (s. Anm. 86) 90: „Die Auferstehung Jesu als Anfang der endzeitlichen Totenerweckung ist jüdisch konzipiert, sprengt aber schon die apokalyptischen Vorstellungen des Judentums. Als solche hat sie in der griechisch-römischen Antike keine Entsprechung." Zum Thema der Auferweckung und Auferstehung im koptischen Liber Bartholomaei s. M. Westerhoff, Auferstehung und Jenseits im koptischen „Buch der Auferstehung Jesu Christi, unseres Herrn“ (Wiesbaden 1999) 282-285; anders als J.-D. Kaestli und P. Cherix (5./6. Jh.) nimmt der Author eine Datierung des $L B$ in das 8. oder 9. Jh. vor, s. $226 \mathrm{f}$. 88 Dazu O. Kösters, Die Trinitätslehre des Epiphanius von Salamis. Ein Kommentar zum ,Ancoratus‘ (Göttingen 2003) 308-312; zum Problem der Datierung des Ancoratus (374) vgl. ebd., 80 - 88. 


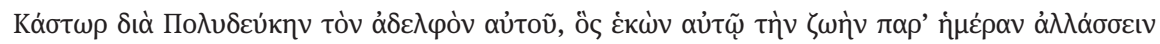

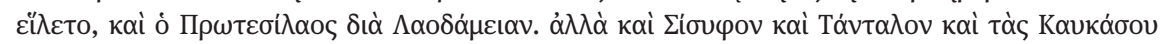

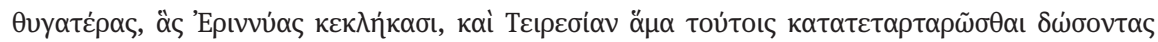

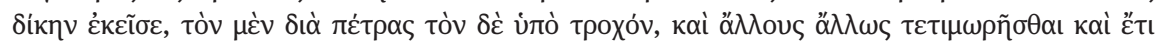

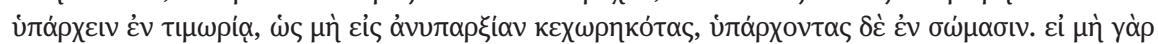

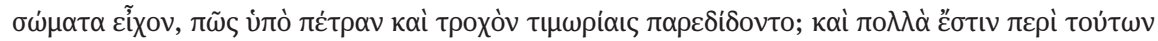

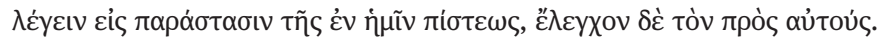

Staunen nämlich überkommt mich über den in jeder Hinsicht verfehlten Gedanken der ungläubigen Heiden und anderer Barbaren, da sie in ihren Mythen sich nicht scheuen, allenthalben von einer Auferstehung zu berichten und oft eine Auferstehung zu besingen, wie ihre Mythen überliefern, dass Alkestis, die Tochter des Pelias, die für ihren Gatten Admet gestorben war, von Herakles nach drei Tagen auferweckt und aus der Unterwelt geholt worden sei, ebenso Pelops, der Sohn des Tantalos, nachdem er den angeblichen Göttern als Fleischportion vom eigenen Vater aufgetischt worden war. Amphiaraos, der Sohn des Oikles wurde von Asklepios wieder lebendig gemacht, Glaukos, der Sohn des Minos, von Polyeidos, dem Sohn des Koiranos, mit einer Pflanze zum Leben erweckt, Kastor durch seinen eigenen Bruder Polydeukes, der sich freiwillig dafür entschieden habe, mit ihm täglich das Leben zu wechseln, und Protesilaos durch Laodameia. Aber auch Sisyphos und Tantalos und die Töchter des Kaukasos, die Erinnyen heißen, und Tereisias sollen zusammen mit den anderen in den Tartaros geworfen worden sein, um ihre Strafe zu büßen, der eine durch einen Felsbrocken, der andere an einem Rad; andere seien anders bestraft worden und unterlägen weiter der Strafe und da sie nicht in die Nicht-Existenz gekommen seien, seien sie körperlich existent. Wenn sie nämlich keine Körper hätten, wie könnten sie dann einem Fels und einem Rad in ihren Strafen ausgeliefert sein? Und viel wäre über sie zu sagen zur Darlegung unseres Glaubens und als Beweis gegen sie. ${ }^{89}$

Als Beispiele einer Anastasis im Mythos nennt der Bischof von Salamis neben Alkestis, Pelops, Amphiaraos, Kastor und Protesilaos auch Glaukos, den Sohn des Minos und der Pasiphaë, der in einem Honigfass starb und vom Seher Polyeidos mit einem Zauberkraut ins Leben zurückgeholt wurde, wie Apollodorus (Bibl. 3.3.1f.) und Hyginus (Fab. 136) ausführlich erklären. ${ }^{90}$ Es ist eben ein gleichnamiger Glaukos, ein Meeresgott, der die mythologische Aufzählung in der Rede des nekrophilen Inders schließt (73-77). Dieser war ein Fischer (oder Jäger) aus Anthedon (Böotien), der als Sohn des Polybos oder des Anthedon, des Kopeus oder des Poseidon galt. Als er ein wunderbares Kraut aß, wurde er unsterblich und sprang ins Meer, wie Glaukos selbst, der Geliebte der Skylla, in den Metamorphosen Ovids (13.904-968, 14.1-74), die ein

89 Ausg.: Holl (s. Anm. 52) I, 105f. Übers.: H. Leppin.

$90 \mathrm{Zu}$ dieser kretischen Legende s. M. Corsano, Glaukos. Miti greci di personaggi omonimi (Rom 1992)

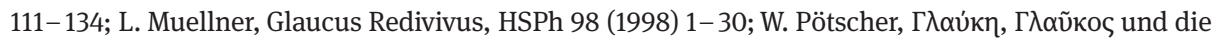
Bedeutung von y^avkós, RhM 141 (1998) 97-111, hier 101. Für das Auferstehungsmotiv im Glaukosmythos vgl. R. Gaedechens, Art. Glaukos, Nr. 9 [Sohn des Minos], in: W. H. Roscher (Hrsg.), Ausführliches Lexikon der griechischen und römischen Mythologie 1.2 (Leipzig 1886-1890) 1686-1688, hier

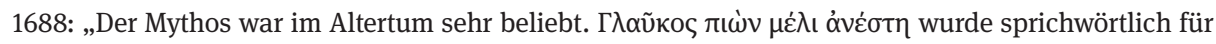
solche, die für tot ausgegeben waren und wieder ans Licht kamen (Apostol. in den Paroem. Graeci 2, Cent. 5, 48 mit euhemeristicher Deutung wie beim Palaephat. c. 27).“ $\mathrm{Zu}$ den drei verschiedenen Glaukos-Mythen s. zuletzt M.-C. Beaulieu, The Myths of the Three Glauci, Hermes 141 (2013) 121-141. 
Gedicht von Ezra Pound inspiriert haben, erzählt. ${ }^{91}$ Es ist wahrscheinlich, wie schon bemerkt wurde, dass Nonnos in diesem Kontext das Unsterblichkeitsmotiv des Glaukos von Anthedon mit dem Auferstehungsmotiv des Glaukos, des Sohnes des Minos, kombiniert hat. ${ }^{92}$ Nun könnte, obwohl der Sohn des Minos in den Dionysiaka niemals erwähnt wird, die Tradition, nach welcher Polyidos den Glaukos durch die Berührung mit einem Wunderkraut (demselben, mit der die von Polyidos getötete Schlange von einer anderen Schlange wieder zum Leben erweckt wurde) wiederbelebt hatte, in der Geschichte der Auferstehung der Schlange und des Tylos reflektiert sein. Die Erzählung dieser lydischen Legende, die Nonnos in Dion. 25.524-552 ausführlich schildert, ${ }^{93}$ weist offensichtliche thematische und sprachliche Parallelen ${ }^{94}$ zur Auferweckung des Lazarus in der Paraphrase (11.158-180 Jo. 11.43f.) auf. ${ }^{95}$

Dies beweist wieder einmal, wie zentral das Motiv des Todes und der Auferstehung für Nonnos ist. Dieser Aspekt wird auch von Shorrock aufgeführt. ${ }^{96}$ Bei diesem Schluss geht er von einer Beobachtung Glen Bowersocks aus. Dieser hat in seinem Buch „Fiction as History“ (1994) gezeigt, dass die weite Verbreitung des Motivs der Auferstehung des Fleisches in der Literatur der Kaiserzeit durch die Geschichte der Evangelien beeinflusst wurde:

Among the most conspicuous features of the fiction of the Roman empire, not only the prose romances but the mythological confections as well, is resurrection after death in the original body. Much of the time the resurrection is explained by theatrical and often bloody deaths that turn out

91 Ein Überblick bei Corsano (s. Anm. 90) 11-37. Zur Ovids Erzählung s. G. M. Masselli, Glauco, dio ,in erba'. Da Publio Ovidio Nasone a Ercole Luigi Morselli (Foggia 2011) 31-51. Pounds „An Idyl for Glaucus“ wurde 1909 in Personae veröffentlicht, vgl. P. Th. M. G. Liebregts, Ezra Pound’s „An Idyl for Glaucus“, Journal of Modern Literature 19 (1994) 171-178.

92 Frangoulis/Gerlaud (s. Anm. 29) 121.

93 Chuvin (s. Anm. 25) 106-111; vgl. R. Lindner, Mythos und Identität. Studien zur Selbstdarstellung kleinasiatischer Städte in der römischen Kaiserzeit (Stuttgart 1994) 131f.

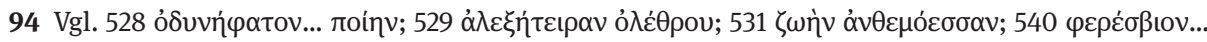

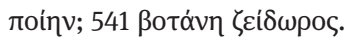

95 F. Vian, Nonnos de Panopolis, Les Dionysiaques, IX, Chants XXV-XXIX (Paris 1990) 40: „ [...] les affinités entre les histoires de Glaucos et de Tylos sont évidentes et il est probable que ce sont les Lydiens influencés par la culture grecque qui ont inséré la fable crétoise dès l'époque archaïque dans leurs traditions nationales“; 41: , [...] l'épyllion rapporte un miracle à rapprocher de la résurrection de Lazare. On note des similitudes formelles avec le ch. XI de la Paraphrase ainsi qu'avec une épigramme anonyme de date incertaine [A.P. 1.49]." Vgl. Agosti (s. Anm. 31) 124f., 132f.; Hernández la Fuente (s. Anm. 46) 183-192; Shorrock (s. Anm. 23) 51, 97f.; K. Spanoudakis, The Resurrections of Tylus and Lazarus in Nonnus of Panopolis (Dion. XXV, 451-552 and Par. $\Lambda$ ), in: D. Lauritzen/M. Tardieu (Hrsg.), Le voyage des légendes. Hommages à Pierre Chuvin (Paris 2013) 191-208; ders., The Shield of Salvation: Dionysus' Shield in Nonnus' Dionysiaca 25.380 - 572, in: Spanoudakis (s. Anm. 20) 333-371, bes. $334-$ 344, 354-358.

96 Shorrock (s. Anm. 23) 97-100. Dazu vgl. schon Hernández de la Fuente (s. Anm. 46) 183-205 („Resurreciones dionísiacas“); ders., Parallels between Dionysos and Christ in Late Antiquity: Miraculous Healings in Nonnus' Dionysiaca, in A. Bernabé/M. H. de Jáuregui/A. I. Jiménez San Cristóbal/R. M. Hernández (Hrsg.), Redefining Dionysos (Berlin/Boston 2013) 464-487, bes. 479-483. 
not to have been deaths at all. The Scheintod, as the Germans call it, the „apparent death,“ allows for all the excitement and tragedy of extinction and resurrection without unduly straining the credulity of the reader. ${ }^{97}$

Denn welchen Sinn und Bedeutung hat die Rede des nekrophilen Inders im 35. Buch der Dionysiaka? Man könnte meinen, dass sie auf die Auferstehung des Leibes, ein umstrittenes Thema in der christlichen Spätantike, verweise. ${ }^{98}$ Anders aber als bei Justin, Theophilos von Antiochia und Epiphanios von Salamis werden die Analogien zwischen Heiden- und Christentum nur kryptisch angedeutet. ${ }^{99}$ Aus dieser Perspektive ist es anzunehmen, dass Nonnos eine Verbindung zwischen „dem lebenbewahrenden

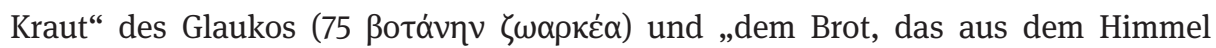
herabstieg“, dem lebendigen Brot Christi, ${ }^{100}$ hergestellt hat.

\section{Die ,Passion“ der Bakchantin als Gegenpart der Passion Christi}

Am Ende seines Appendix „De la virginité des Bacchantes“ betonte Gerlaud, dass das Lob der Jungfräulichkeit ein gemeinsames Thema für Heidentum und Christentum

97 G. W. Bowersock, Fiction as History. Nero to Julian (Berkeley/Los Angeles 1994) 99-119 („Resurrection“), hier 99, vgl. 113 („The widespread use of the resurrection motif in many forms of Roman imperial fictional writing - erotic romance, hagiography, mythological revisionism, and satire - suggests an unusually great interest in this subject, far beyond any interest documented for earlier periods“) und 115f. (,Peregrinus after death appeared before him [a serious and reliable old gentleman] garbed in white and crowned with olive [Lucianus, Peregr. 40]. There is an unmistakable echo here of the Gospel narratives, although the white clothes belong in that story to the angelic messenger or messengers who proclaim the risen Christ. In the earliest account, that of Mark, Mary Magdalene and two other women encounter a young man in Jesus's tomb clothed in a long white garment [Mc. 16.5]“). $98 \mathrm{Vgl}$. T. Fuhrer, Körperlichkeit und Sexualität in Augustins autobiographischen und moraltheoretischen Schriften, in: B. Feichtinger/H. Seng (Hrsg.), Die Christen und der Körper. Aspekte der Körperlichkeit in der christlichen Literatur der Spätantike (München/Leipzig 2004) 173-188, hier 183-185; Perkins (s. Anm. 64) 92-94. Zu den Darstellungen von frühchristlichen Totenerweckungen s. C. Nauerth, Vom Tod zum Leben. Die christlichen Totenerweckungen in der spätantiken Kunst (Wiesbaden 1980). Die Auferstehung des Fleisches und die Auferweckung von den Toten dagegen werden nur selten in Grabinschriften thematisiert, s. J. Dresken-Weilandt, Die Auferstehung des Fleisches in den frühchristlichen Grabinschriften, in: T. Nicklas/F. V. Reiterer/J. Verheyden, in collaboration with H. Braun (Hrsg.), The Human Body in Death and Resurrection (Berlin/New York 2009) 371-389.

99 Zum Begriff ,Kryptochristianismus‘ s. K. Smolak, ,Kryptochristianismen` in spätantiker paganer Hymnik?, Acta Archaeologica Academiae Scientiarum Hungaricae 44 (2004) 341-355.

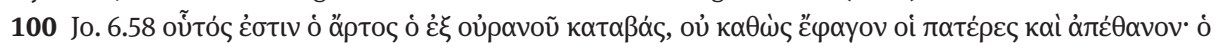

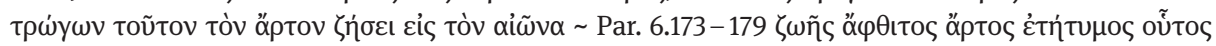

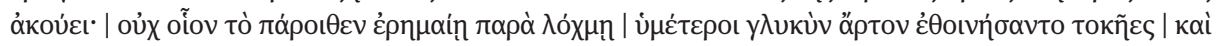

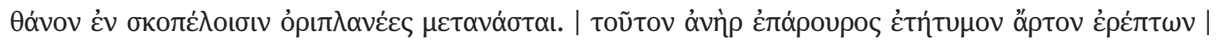

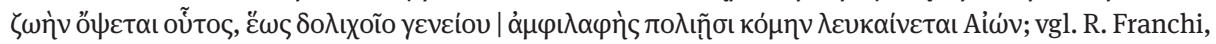
Nonno di Panopoli, Parafrasi del Vangelo di San Giovanni. Canto sesto. Introduzione, testo, traduzione e commento (Bologna 2013) 130-138, 467-470. 
war, und er schloss nicht aus, dass Nonnos die Bakchantinnen als Virgines Bacchi nach dem Vorbild der Virgines Christi sehen könne: Dies ist ein weiterer Hinweis darauf, dass der Dichter der Dionysiaka und der Paraphrase eher Kontinuität als Bruch zwischen der klassischen und der christlichen Kultur in der Spätantike wahrnahm. ${ }^{101}$ Wir können Gerlaud folgen, aber es ist auch notwendig zu erkennen, wie Nonnos, ein Christ, imstande war, durch seine Auslegung des Mythos die zwei Sphären zu verknüpfen. Ohne diese Perspektive würden die Worte, die die von der Lanze durchbohrte Bak-

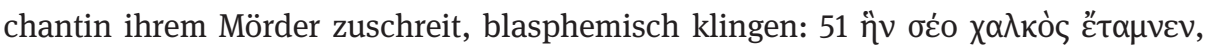

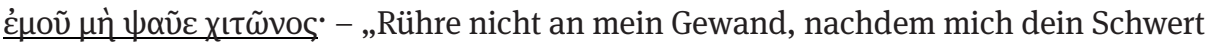
erst zerfleischte!"“102

Daran könnte ein intelligenter Leser eine Verfremdung der Szene des Noli me tangere sehen, in der Jesus Maria von Magdala erscheint, wie es sich aus dem Vergleich mit Par. 20.72b-75, wo Nonnos das zweite Hemistich der Dion. 35.51 ändert, ${ }^{103}$ abzeichnet:

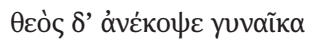

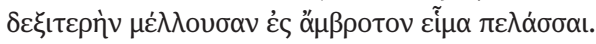

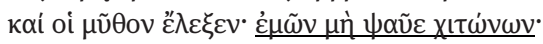

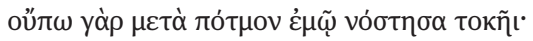

[Maria] streckte die Rechte nach seinem | Göttergewand. Er wehrte sie ab und rief ihr die Worte | warnend entgegen: „Rühr nicht an meine Gewänder! Noch kehrte | ich nach dem Tode nicht heim zu meinem Vater." ${ }^{\text {104 }}$

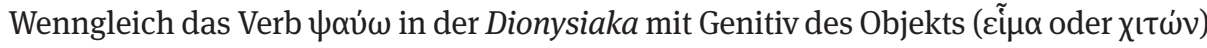
in ähnlichen Gewaltkontexten verwendet wird, ${ }^{105}$ kommt der Negativsatz der beiden Halbverse nicht vor. Angesichts der wahrscheinlichen Priorität der Paraphrase ${ }^{106}$ scheint es demnach, dass Nonnos das Noli me tangere des Johannesevangeliums an die Prosopopöie der Bakchantin angepasst haben könnte, um eine Analogie zwischen dem Christlichen und dem Heidnischen hervorheben zu können, das heißt zwischen: (A) dem Tod Christi, der am Kreuz von einer Lanze an der Seite durchbohrt wurde

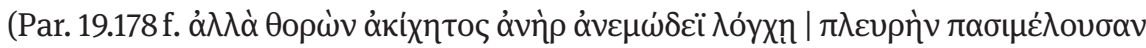

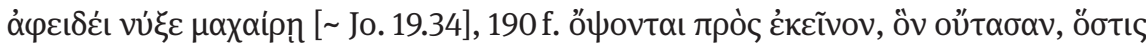

101 Gerlaud (s. Anm. 45) 255-258. Zur religiösen Koexistenz in der griechischen und römischen Welt s. die verschiedenen Aufsätze in Belayche/Dubois (s. Anm. 84).

102 Übers.: Ebener (s. Anm. 34) II, 33.

103 D. Accorinti, Nonno di Panopoli, Parafrasi del Vangelo di S. Giovanni. Canto XX. Introduzione, testo critico, traduzione e commento (Pisa 1996) 186.

104 Übers.: Ebener (s. Anm. 34) II, 404.

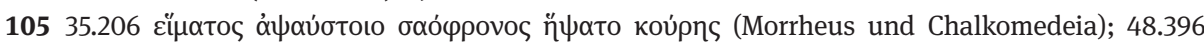

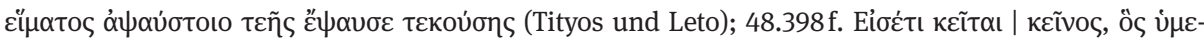

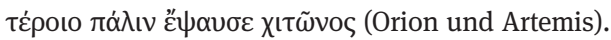

106 F. Vian, MAPTY $\Sigma$ chez Nonnos de Panopolis: étude de sémantique et de chronologie, REG 110 (1997) $143-160$ = ders., L'épopée posthomérique (s. Anm. 16) 565-584. 


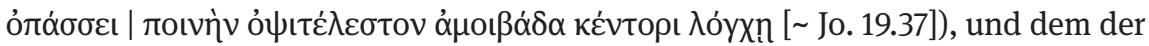

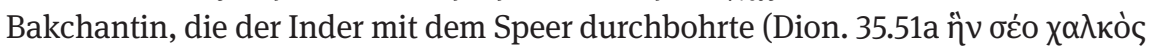

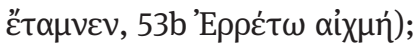

(B) der Erscheinung des auferstandenen Jesus vor Maria aus Magdala (Par. 20.61b - 83 [ Jo. 20.14-18]) und der Prosopopöie der verstorbenen Bakchantin an den Inder (Dion. 35.49b-53a).

In diesem Sinne könnte auch die ,Passion“ der Bakchantin in ein christliches Weltbild integriert und als Gegenpart der Passion Christi lesbar werden. Dieses ,heidnischchristliche Experiment', um den Titel eines neuen Buches von Hartmut Leppin zu variieren, ${ }^{107}$ wäre nicht verwunderlich, wenn man bedenkt, dass Nonnos, wie Konstantinos Spanoudakis überzeugend gezeigt hat, die Ikariosgeschichte (Dion. 47.1264) auf dem Hintergrund der Passion Christi entwickelt hat. ${ }^{108}$ Eben dies bezeugt die Tatsache, dass der Märtyrertod eine Brücke zwischen dem Dionysischen und dem Christlichen sein konnte.

107 H. Leppin, Justinian. Das christliche Experiment (Stuttgart 2011).

108 K. Spanoudakis, Icarius Jesus Christ? Dionysiac Passion and Biblical Narrative in Nonnus' Icarius Episode (Dion. 47, 1-264), WSt 120 (2007) 35-92. Vgl. Ph. Bourgeaud, Dionysos, the Wine and Ikarios. Hospitality and Danger, in: R. Schlesier (Hrsg.), A Different God? Dionysos and Ancient Polytheism (Berlin/Boston 2011) 161-172, hier 169. 



\title{
Ulrich Schmitzer
}

\section{Sidonius Apollinaris - unfruchtbare Muse oder Erneuerung der Poesie im Zeichen des Mythos?}

\author{
Forte pater superum prospexit ab aethere terras: \\ ecce viget quodcumque videt; mundum reparasse \\ aspexisse fuit; solus fovet omnia nutus. \\ Iamque ut conveniant superi, Tegeaticus Arcas \\ nunc plantis, nunc fronte volat, vix contigit arva \\ et toto descendit avo, mare, terra vel aer \\ indigenas misere deos. Germane Tonantis, \\ prime venis, viridi qui Dorida findere curru \\ suetus in attonita spargis cito terga serenum; \\ umentes Nymphas Phorcus comitatur ibique \\ glaucus, Glauce, venis, vatum et certissime Proteu, \\ certus eras. Longo veniunt post ordine divi:
}

Zufällig blickte der Göttervater vom Himmel auf die Erde herab. Siehe da, alles ist rege und bewegt sich, was auch immer er sieht. Die Welt angesehen zu haben, hieß, sie wiederhergestellt zu haben. Ein einziges Nicken belebt alles. Und damit die Götter nun zusammenkommen, fliegt der Arkadier aus Tegea bald mittels seiner Schuhe, bald mittels seines Flügelhutes auf der Stirn. Und kaum erreichte er die Fluren und stieg ganz von seinem Großvater Atlas herab, da schickten Meer, Erde und Luft ihre eigenen Götter. Du, Bruder des Donnerers, kommst als erster, der du mit grünem Wagen Doris, die Meeresflut, zu teilen pflegst und schnell über deren erstaunten Rücken heitere Ruhe verteilst. Phorcus, begleitet die feuchten Nymphen, und dort kommst du, Glaucus, und du, der untrüglichste aller Seher, Proteus, warst es sicher. Und in langer Reihe kommen danach die Götter ...1

In der Tat kommen dann die von Merkur, dem arkadischen Götterboten, herbeigerufenen Bacchus, Mars, Hercules, Venus, Ceres, Diana, Iuno, Minerva, Cybele, Saturn, Apollo, Pan, Faunus, die Satyrn, Castor und Pollux, Perseus, Vulcan, Tiphys und schließlich der vergöttlichte Romulus. Sie alle finden sich mit Jupiter zur einer Ratsversammlung zusammen, zu einer Götterversammlung, wie sie die antike Literatur seit der Ilias kennt und wie sie im lateinischen Bereich durch Ennius, Vergil und Ovid zum konstitutiven erzählerischen Bauelement des Epos wurde. ${ }^{2}$ Das transferiert das con-

1 Sidon. carm. 7,17-29 - Sidonius ist zitiert nach Sidoine Apollinaire, text établi et traduit par André Loyen, 3 Bände, Paris 1960 - 1970; wichtig auch wegen der Sachanmerkungen Sidonius, Poems and Letters, with an English Translation, Introduction, and Notes by W. B. Anderson, 2 Bände, London/ Cambridge, Mass. 1936/1965. Forschungsbericht von Silvia Condorelli, Prospettive Sidoniane. Venti anni di studi su Sidonio Apollinare (1982-2002), Bollettino di studi latini 33 (2003), 140-174.

2 Siehe Markus Janka, Wenn Götterväter zürnen ...: von Zeus und Aigisth zu Jupiter, Augustus und Lykaon, Hermes 127 (1999), 345-355. Eine (weitgehend unkommentierte) Zusammenstellungen der Bezüge auf frühere Dichter (aus der Wortebene) findet sich bei Robert E. Colton, Some Literary Influences on Sidonius Apollinaris, Amsterdam 2000. 
cilium deorum aus der epischen Narration in das durch einen Herrscher und dessen Lob qua Analogie zum Göttervater bestehende Kraftfeld. ${ }^{3}$ Und noch einen wesentlicheren Unterschied gibt es: Der Verfasser dieser Verse lebt anders als seine großen Vorgänger in einer Umwelt, in der das pagane Denken seine Selbstverständlichkeit verloren hatte, in der auch die staatlichen Würdenträger längst zu Christen geworden waren - was auch immer das im Einzelfall konkret bedeuten mochte. Der soeben vorgestellte Textausschnitt ${ }^{4}$ ist auch keineswegs das Produkt etwa heimlich ausgelebter paganer Nostalgie, sondern öffentlich und in hochpolitischem Kontext situiert, handelt es sich doch um den Panegyricus, den der junge Sidonius Apollinaris am 1. Januar 456 auf Avitus ${ }^{5}$ zum Antritt von dessen Kaiserkonsulat in Rom hielt. ${ }^{6}$ Sidonius war sogar in offizieller Mission unterwegs, hatten ihn doch die Städte seiner Heimat Gallien entsandt, um den Kontakt mit Avitus - gleichfalls Gallier und sogar der Schwiegervater des Sidonius - aufrecht zu erhalten und möglichst davon zu profitieren. Es liegt aufgrund dieser Konstellation die Vermutung nahe, dass Sidonius vernünftigerweise mit einer wohlwollenden Aufnahme seiner Verse, also auch mit der Referenz auf den paganen Mythos, rechnen konnte. ${ }^{7}$ Wie aber passen heidnische Götter, die in ihrem Rat über die richtige Besetzung des Herrscheramtes entscheiden und natürlich (wie ex post deutlich wird) die richtige Wahl treffen, zu einem christlichen Kaiser?

Bevor wir dem weiter nachgehen, sei zunächst ein kurzer Blick auf Sidonius Apollinaris und dessen Biographie geworfen. Sidonius ${ }^{8}$ wurde ca. 430 in Gallien geboren ${ }^{9}$ und gehörte einer bedeutenden aristokratischen Familie an, ${ }^{10}$ durch die Heirat

3 Antonella Bruzzone, Il „,concilium deorum“ nella poesia panegiristica latina da Claudiano a Sidonio Apollinare, in: Anna Maria Taragna (Hrsg.), La poesia tardoantica e medievale. Atti del II convegno internazionale di studi, Perugia, 15-16 novembre 2001, Alessandria 2004, 129-141, bes. 135 f.

4 Vgl. auch Claudia Schindler, Per carmina laudes. Untersuchungen zur spätantiken Verspanegyrik von Claudian bis Coripp, Berlin/New York 2009 (Beiträge zur Altertumskunde 253), 182-198, 186, Anm. 55 zur schwierigen Textkonstitution in carm. 7,20 (Tegeaticus Arcas vs. Tegeaticus ales).

5 Kurzer Überblick bei Klaus-Peter Johne, Avitus [1], DNP 2 (1997), 372.

6 Alexander Demandt, Geschichte der Spätantike. Das Römische Reich von Diocletian bis Justinian, München 1998, 142; zu Sidonius und Rom siehe Ralf Behrwald, Das Bild der Stadt Rom im 5. Jh. Das Beispiel des Sidonius Apollinaris, in: Therese Fuhrer (Hrsg.), Rom und Mailand in der Spätantike, Berlin 2011, 283-302.

7 Zur politischen Situation, in der Panegyricus vorgetragen wurde, siehe Hagith S. Sivan, Sidonius Apollinaris, Theodoric II, and Gothic-Roman Politics from Avitus to Anthemius, Hermes 117 (1989), 8594 sowie Andrew Gillett, Envoys and Political Communication in the Late Antique West, 411-533, Cambridge 2003, 84-112; außerdem immer noch André Loyen, Recherches historiques sur les Panégyriques de Sidoine Apollinaire, Paris 1942, 35- 58.

8 Vgl. immer noch die Tabelle in Courtenay E. Stevens, Sidonius Apollinaris and his Age, Oxford 1933, XIIIf.; umfassend zum politischen Rahmen und der weltlichen und kirchlichen Laufbahn Jill Harries, Sidonius Apollinaris and the Fall of Rome AD 407-485, Oxford 1994, bes. 75 - 81 (zu Sidonius und Avitus in Rom).

9 Vgl. Helga Botermann, Wie aus Galliern Römer wurden. Leben im Römischen Reich, Stuttgart 2005, 382- 417. 
mit Papanilla, der Tochter des Avitus, wurde sein sozialer Status weiter aufgewertet. Er genoss eine sehr umfangreiche Erziehung, die ihn mit den klassischen lateinischen Autoren aufs engste vertraut machte. ${ }^{11}$ Er unterstützte zunächst - wie eingangs festgehalten - den weströmischen Kaiser Avitus, später dessen Nachfolger Maiorianus, die beide zeittypisch rasch ums Leben kamen. Danach zog sich Sidonius in den 60er Jahren des 5. Jahrhunderts ins Privatleben zurück, bis er 467 abermals der Bitte seiner gallischen Mitbürger folgte und nach Rom, zum jetzigen Kaiser Anthemius, reiste, um Schutz vor der Bedrohung Galliens durch die Westgoten zu erbitten. Dies war die Zeit, in der auch in Gallien die administrativen Strukturen geradezu erdbebenartig zusammenbrachen, und als Sidonius ca. 468 zurückkehrte, sah er sich gezwungen, das Bischofsamt von Clermont ${ }^{12} \mathrm{zu}$ übernehmen, um damit nicht so sehr geistlich denn politisch zu wirken und den vordrängenden Westgoten entgegenzutreten. Das war keineswegs von dauerhaftem Erfolg gekrönt, vielmehr war v.a. die Stadt Clermont bedrohlichen Angriffen und langandauernden Belagerungen ausgesetzt. Sidonius starb mitten in diesen Wirren irgendwann in den 480er Jahren. ${ }^{13}$ Er hinterließ ein nicht nur angesichts der Zeitumstände außerordentlich umfangreiches literarisches Werk, das 147 Briefe in neun Büchern ${ }^{14}$ umfasst sowie eine nach carmina maiora und carmina minora gegliederte Gedichtsammlung. Die carmina maiora enthalten die panegyrischen hexametrischen Poeme (wie den eingangs anzitierten Panegyricus auf Avitus) samt ihren Begleitgedichten. Die carmina minora stammen aus Sidonius' vorepiskopaler Lebensphase und sind deutlich als ein zusammengehöriges Gedichtbuch markiert und schließen mit einem Abschiedsgedicht an das Buch, einem Propempticon.

Sidonius gehört also zur aristokratischen Elite Galliens, ${ }^{15}$ wie es sich etwa eine Generation früher auch über Ausonius aus Bordeaux ${ }^{16}$ sagen lässt. Er hatte eine

10 Siehe generell Patrizia Mascoli, Gli Apollinari. Per la storia di una famiglia tardoantica, Bari 2010, bes. $23-33$.

11 Knappe Bemerkungen bei Botermann (s. Anm. 9), 403f.; vgl. auch generell Johannes Christes, Richard Klein, Christoph Lüth (Hrsgg.), Handbuch der Erziehung und Bildung in der Antike, Darmstadt 2006 (jeweils die Kapitel zur Spätantike); außerdem Ágnes T. Horváth, The Education of Sidonius Apollinaris in the Light of his Citations, Acta classica Universitatis Scientiarum Debreceniensis 36 (2000), 151-162; Pierre Riché, La survivance des écoles publiques en Gaule au Ve siècle, Le Moyen Age 63 (1957), 421- 436 (auch zu Sidonius’ späterer bildungspolitischer Tätigkeit); zuletzt generell Edwad Watts, Education: Speaking, Thinking, and Socializing, in: Scott Fitzgerald Johnson (Hrsg.), The Oxford Handbook of Late Antiquity, Oxford 2012, 467-486.

12 Vgl. auch Joop van Waarden, Sidonio Apollinare, poeta e vescovo, VetChr 48 (2011), 99-113.

13 Das Epitaph (aufbewahrt im Musée Bargonin, Clermont-Ferrand) ist bequem mit Abbildung und Transkription zugänglich unter www.sidoniusapollinaris.nl (Sektion: Texts, Links \& More).

14 Zur Bedeutung der Briefe des Sidonius als Mittel des geistigen Widerstandes gegen die Goten und die Rolle der traditionellen Bildung dabei siehe Oliver Overwien, Kampf um Gallien. Die Briefe des Sidonius Apollinaris zwischen Literatur und Politik, Hermes 137 (2009), 93-117.

15 Vgl. Scott McGill, Latin Poetry, in: Scott Fitzgerald Johnson (Hrsg.), The Oxford Handbook of Late Antiquity, Oxford 2012, 340f. zum literarischen Leben in Gallien. 
sorgfältige Ausbildung genossen, die keineswegs die klassischen Bildungsautoren allen voran den (kommentierten ${ }^{17}$ ) Vergil - zugunsten der christlichen Glaubenstrakte in den Regalen verstauben ließ. Für Sidonius ist vielmehr die in den kanonischen Werken der Literatur repräsentierte Geschichte des Imperium Romanum und die zugrunde liegenden Werte ein wesentlicher Faktor seines Denkens, so dass durch diese Romanitas auch die Götter aus der Zeit der römischen Größe zumindest als Teil der Tradition darin ihren Platz fanden. ${ }^{18}$

Doch die alte, biographistisch angehauchte Frage nach der „Authentizität“ von Literatur, also von der Identität der Persönlichkeit des Verfassers mit den tragenden Gedanken seiner Werke, führt(e) nicht selten zu einer negativen ästhetischen Bewertung von Sidonius' Dichtungen. ${ }^{19}$ C. E. Stevens beispielsweise, der vor achtzig Jahren eine prinzipiell immer noch hilfreiche Sidonius-Monographie verfasste, urteilt unmissverständlich über die zu Beginn zitierte Passage:

This is very uninspired writing. It is worse than mere padding, it is very bad padding ... Even the account of Rome's past, which is not pointless, is so over-elaborated that ... it fails in its effect and the point of contrast is lost. Yet, with all its fault, this poem, the first of his that is preserved, is in some ways the best that Sidonius ever wrote. ${ }^{20}$

Das ist eine sehr deprimierende Diagnose, die im Grunde genommen diesen gesamten Beitrag in seiner Berechtigung in Frage stellt. Demnach hätte es der politisch und kirchenpolitisch erfolgreiche, hoch gebildete Sidonius nicht vermocht, aus diesen Voraussetzungen ein auch nur halbwegs überzeugendes Ergebnis zu generieren. Das impliziert zugleich ein generelles Verdikt über die literarischen Potentiale dieser Zeit. Die Autoren können nicht mehr aus Eigenem Größe erreichen, sondern nur noch - wie der Mond das Sonnenlicht - literarisch wie politisch Großes reflektieren:

It is a notable fact about Sidonius' poetry, and indeed a commentary on his mind, that he could not create heroic figures. He could only write up to a noble subject, but he could not himself ennoble it. ${ }^{21}$

16 Jüngste Zusammenfassung bei Joachim Gruber, D. Magnus Ausonius, Mosella. Kritische Ausgabe, Übersetzung, Kommentar, Berlin/Boston 2013 (Texte und Kommentare 42), 9-13; vgl. auch dessen Zusammenstellungen unter http://joachimgruber.userweb.mwn.de/ausonius.html.

17 Zuletzt Alan Cameron, The Last Pagans of Rome, Oxford 2011, 567-626.

18 Vgl. Lynette Watson, Representing the Past, Redefining the Future: Sidonius Apollinaris' Panegyrics of Avitus and Anthemius, in: Mary Whitby (Hrsg.), The Propaganda of Power. The Role of Panegyric in Late Antiquity, Leiden/Boston/Köln 1998, 177-198, bes. 191-195; außerdem Frank-Michael Kaufmann, Studien zu Sidonius Apollinaris, Frankfurt am Main et al. 1995, 81-105.

19 Der Illustration für diese traditionelle Position halber sei das Urteil in Teuffels „philologischem Reichskursbuch“ zitiert: „Der begabteste Vertreter der Strebsamkeit und Formgewandtheit, aber auch der Gedankenarmut und Phrasenhaftigkeit der gallisch römischen Literatur der Zeit ist C. Sollius Apollinaris Sidonius ...“ (Wilhelm Teuffel, Geschichte der römischen Literatur, Leipzig 1870, 967).

20 Stevens (s. Anm. 8), 32f.

21 Stevens (s. Anm. 8), 33. 
Noch gut siebzig Jahre später urteilt Gernot Krapinger im Neuen Pauly nicht wesentlich freundlicher:

\begin{abstract}
Weder in den Briefen noch in den Gedichten entfernt sich S. in Wortschatz, Flexionssystem und Syntax weit von seinen Vorbildern Statius, Ovidius, Vergilius, Horatius, Claudianus ..., Silius ... Italicus und Ausonius bzw. für die Prosa Plinius, Symmachus ... und Cicero ... Die übermäßige Verwendung von Alliterationen, Homoioteleuta, Paronomasien und Klangspielereien ist dem Gesamtwerk ebenso eigen wie der Hang zu längeren Perioden, Hyperbolen und Synekdochen, Metonymien und Periphrasen (... eine ,späte Nachwirkung des Asianismus'). S. fußt stark auf paganem Bildungsgut, seine Zugehörigkeit zur christl. Kirche kommt selten zum Tragen, an einer denkerischen Auseinandersetzung zw. christl. und nichtchristl. Positionen ist er nicht interessiert. Auch philos. oder theologische Dispute sind seine Sache nicht, dazu ist seine Freude am Konkreten, Anschaulichen und Polit.-Praktischen zu ausgeprägt. ${ }^{22}$
\end{abstract}

Sidonius, so scheint es, hat noch nicht so recht Anteil an der generellen Neubewertung der spätantiken Literatur gewonnen, in deren Gefolge die Eigenständigkeit gegenüber aus klassizistischen Paradigmen abgeleiteten Deszendenzmodellen betont wurde und ein Claudian, aber auch ein Ausonius wieder unter die Autoren gezählt wird, deren sich die Latinistik nicht zu schämen braucht. Demnach ist die Qualitätsproblematik auch unter der hier verfolgten Fragestellung alles andere als marginal, entscheidet sich doch daran, ob die Präsenz des Mythos bei Sidonius als dysfunktionale Einsprengsel oder als Teil eines umfassenden poetischen Konzepts auf der Höhe der Zeit zu bewerten ist. ${ }^{23} \mathrm{Ob}$ sich draus eventuell sogar eine generelle Rehabilitation des Sidonius ableiten lässt (oder nicht), wird sich noch zeigen.

Die Untersuchung dieser Frage vollzieht sich auf zwei (unterschiedlich ausführlich dargestellten) Ebenen: Im Bereich der „großen“, Politisches betreffenden Literatur war durch den „Staatsdichter“ Claudian den Weg bereitet, als er schon am Ende des 4. Jahrhunderts den traditionellen Götterapparat - und mit ihm die Götterversammlung - literarisch rettete und selbst für dezidiert christliche Herrscher ganz und gar akzeptabel machte. Demnach ist es keine literarische Revolution, dass Sidonius sich des paganen mythologischen Apparats bedient, sogar wenn er die Götterinvokation gegenüber Claudian noch deutlich ausweitet. ${ }^{24}$ Dieser Befund gilt auch dann, wenn Claudia Schindler recht hat und Claudian im Vergleich zu seinen Vorgängern aus augusteischer Zeit und früher Kaiserzeit die Rolle der Götter gegenüber den menschlichen Protagonisten erheblich beschnitten hat, um auf diese Weise die Herrscher stärker hervorzuheben, als es in der paganen Tradition der Fall gewesen war; ${ }^{25}$ denn die schiere

22 Gernot Krapinger, Sidonius Apollinaris, DNP 11 (2001), 522 f., hier: 523.

23 Siehe auch den Beitrag in diesem Band von Winrich Löhr, Christliche Bischöfe und klassische Mythologie in der Spätantike (mit Blick auf Augustinus und v. a. den griechischen Sprachraum).

24 Schindler (s. Anm. 4), 185-187.

25 Claudia Schindler, Claudians „pagane“ Götter. Tradition und Innovation in der spätantiken Panegyrik, Gym 115 (2008), 331-345; außerdem generell Schindler (s. Anm. 4) zur antiken Verspanegyrik (ohne spezielles Interesse an der pagan-christlichen Thematik); zu Sidonius' panegyrischen Dichtungen für Maiorianus (und deren mythologischen Elementen) siehe Severin Koster, Princeps und 
Möglichkeit der Präsenz des paganen Apparats und dessen literarische Etablierung ist doch ein starkes Zeichen für die folgenden Dichter. Offenbar ist es nach dem Ende der tatsächlichen ideologischen Auseinandersetzungen, die noch weite Strecken des 4. Jahrhunderts prägten, nun möglich, panegyrisches Schreiben in der traditionellen Form fortzuführen, ohne dass die Geehrten daran Anstoß genommen hätten (das ist ein wichtiges Indiz dafür, dass zumindest die Zeitgenossen den Versuch als gelungen angesehen haben, denn der Unwille eines verunglückt gepriesenen Herrschers wäre der weiteren Karriere gewiss nicht förderlich gewesen).

Liest man die solcherart entstandene Literatur nur mit der Intention, daraus Glaubensaussagen des Verfassers - und zwar hundertprozentig authentische - zu gewinnen, dann kann man wohl zu einem Ergebnis kommen, wie es Alan Cameron provozierend formuliert:

If all we had from the pen of Sidonius Apollinaris was his imperial panegyrics, and we knew nothing about his life beyond these poems, it might well have been argued that he was pagan. ${ }^{26}$

Ein solches Resultat zeigt natürlich die Absurdität der zugrundeliegende Fragestellung, eine Frage, die man u. a. an die als „Namenschristen“ apostrophierten Claudian und Ausonius gerichtet hatte. ${ }^{27}$ Und so ist es nur konsequent, wenn die neuere Forschung über die spätantike Literatur diese uralte Erkundigung nach dem Verhältnis von persönlicher Religiosität ${ }^{28}$ und literarischem Anspruch ad acta legt. ${ }^{29}$

Vielleicht ist das Fortbestehen der traditionellen panegyrischen (oder allgemeiner: literarischen) Form vergleichbar mit dem Fortbestand der römischen Repräsentationsbauten. Der Palatin wurde nicht als Herrschersitz aufgegeben (wenn denn der römische Kaiser tatsächlich einmal in Rom war), mochte er sich auch auf die paganen Helden Euander, Aeneas und Romulus zurückführen. Auch die Stadt Rom insgesamt wurde nicht von den sichtbaren Resten des Heidentums gereinigt, die Tempel blieben

poeta in Lyon (Sidon. carm. 3, 4, 13), in: Udo Kindermann, Wolfgang Maaz, Fritz Wagner (Hrsgg.), Festschrift für Paul Klopsch, Göppingen 1988, 293-307.

26 Cameron (s. Anm. 17), 206; eher vermittelnd ist neuerdings wieder Jaclyn Maxwell, Paganism and Christianization, in: Scott Fitzgerald Johnson (Hrsg.), The Oxford Handbook of Late Antiquity, Oxford 2012, 849-875.

27 Das ist im Grunde genommen das große Thema von Cameron (s. Anm. 17) passim. Zu Ausonius siehe auch Joachim Gruber, Plekos 15 (2013), 91-95 (Rez. von Paul Dräger, Ausonius: Sämtliche Werke, Bd. 1, Trier 2012), hier: 94 mit Anm. 7 zur Frage nach dem Verhältnis des Ausonius zum Christentum (mit weiterer Literatur).

28 Für den griechischen Bereich stellt sich ja ein vergleichbares Problem für Nonnos: Zur Erklärung des Nebeneinanders von christlichen und paganen Werken ist man immer wieder auf biographistische Modelle ausgewichen; vgl. den Beitrag von Domenico Accorinti in diesem Band.

29 In grundsätzlich vergleichbarer Weise stellt auch Jörg Rüpke (Geteilte und umstrittene Geschichten: Der Chronograph von 354 und die Katakombe an der via Latina - in diesem Band) die „binäre Opposition“ Heidentum vs. Christentum zugunsten einer „neue[n] Perspektive auf den Stellenwert der Religion innerhalb der spätantiken Gesellschaft sowie die komplexe Beschaffenheit von Religion“ in Frage. 
im Zentrum stehen - selbst der der Venus und Roma -, und niemand störte sich daran, allenfalls Prudentius. Die Taliban-Lösung, die gewaltsame Auslöschung aller Spuren einer unliebsamen Vergangenheit (wie im Artilleriebeschuss der Buddha-Statuen von Bamiyan in Afghanistan 2001), war weder im urbanen Raum des Westens (auf dem Land konnte es anders aussehen) noch in der Literatur eine tatsächliche Option. Die pagane Gedankenwelt wird gleichsam eingekapselt und damit ihrer Brisanz beraubt, da sie eine öffentliche Funktion zu erfüllen hat, für die das Christentum keinen wirklichen Ersatz bieten konnte. ${ }^{30}$ Umgekehrt musste sich der gallische Landsmann des Sidonius, Ausonius aus Bordeaux, sich nicht ganz ein Jahrhundert zuvor durchaus um Freiraum mühen, wie aus der Debatte mit seinem Verwandten Paulinus von Nola, ${ }^{31}$ aber auch implizit aus dem Cento nuptialis ablesen lässt, indem er sich gegen naivchristliche Usurpation Vergils im Cento der Proba verwahrte.

Doch lässt sich der anhand der panegyrischen Dichtung und deren spezifischen Bedingungen $^{32}$ erhobene Befund einer selbstverständlichen Instrumentalisierung des Mythos einfach auf andere poetische Formen, auf die Persönliches behandelnde Kleindichtung z. B., übertragen und damit generalisieren? Denn wesentlich brisanter als in der Großdichtung scheint die Präsenz des Paganen in der Kleindichtung, die sich viel stärker als eine persönliche Dichtung geriert, bekenntnishaft erscheint und vermeintlich einen Blick auf den Autor selbst freigibt. ${ }^{33}$ Um darüber genaueren Aufschluss $\mathrm{zu}$ erhalten, sei jetzt der Blick auf das bereits genannte Gedichtbuch der carmina minora ${ }^{34}$ gerichtet und hier wiederum exemplarisch auf das carmen $9 .{ }^{35}$

Dieses Gedicht trägt die Widmung des gesamten Buches an Magnus Felix, ${ }^{36}$ der 469 als Praefectus Praetorio Galliarum belegt ist, also an einen Angehörigen der gallorömischen Elite. Mit einer solchen Dedikation stellt sich Sidonius in eine lange Reihe von Buchanfängen in der lateinischen Dichtung. Der erste Beleg findet sich bei Catull

30 Zur Unverzichtbarkeit des mythischen Stoffes s. Schindler in diesem Band.

31 Siehe David Amherdt, Ausone et Paulin de Nole: correspondance. Introduction, texte latin, traduction et notes, Bern et al. 2004, 23-25.

32 Die (tages-)politische Bedeutung der Panegyrici verbietet es, den dort verwendeten Götterapparat nur als fiktionales Bildungsgut zu sehen (wie in anderen Bereichen, dazu den Beitrag von Löhr in diesem Band), vielmehr muss es eine Harmonie von Form und Inhalt gegeben haben.

33 Siehe prinzipiell Martin Hose, Das lyrische Ich und die Biographie des Lyrikers. Überlegungen zu einem alten Problem und seinem Nutzen, in: Markus Schauer, Gabriele Thome (Hrsgg.), Altera Ratio. Klassische Philologie zwischen Subjektivität und Wissenschaft. Festschrift für Werner Suerbaum zum 70. Geburtstag, Stuttgart 2003, 42-61.

34 Siehe den Überblick bei Condorelli (s. Anm. 1), 163-164; Willy Schetter, Zur Publikation der Carmina minora des Apollinaris Sidonius, Hermes 120 (1992), 343-363 = in: ders., Kaiserzeit und Spätantike. Kleine Schriften 1957-1992, Wiesbaden 1994, 236 - 256 (hiernach zitiert), hier: 256: Das ursprüngliche Gedichtbuch enthielt demnach alle Gedichte bis auf carm. 22 und 23 und wurde um 462 publiziert. 35 Zum Aufbau siehe Stefania Santelia, Le dichiarazioni del poeta. Il carme IX di Sidonio Apollinare, Invigilata lucernis 20 (1998), 229 - 254; angekündigt ist ein Kommentar der Verfasserin zu den gesamten carmina minora; siehe www.sidoniusapollinaris.nl (Sektion: „Bibliography: in preparation/in press“). 36 PLRE 2, 463f.; Dirk Henning, Periclitans res publica. Kaisertum und Eliten in der Krise des weströmischen Reiches 454/5-493 n.Chr., Wiesbaden 1999, 91; Kaufmann (s. Anm. 18), 306-308. 
im carmen 1, gerichtet an Cornelius (Nepos): cui dono lepidum novum libellum ...? Corneli tibi: Eine Gedichtsammlung wird in einem solchen Verfahren nicht zuletzt durch ihren Adressaten nobilitiert. Während allerdings Catull seine Kleindichtung privaten Inhalts auch in einer auf wenige Verse konzentrierten Form vorstellt, ist das bei Sidonius ganz anders, wenn er sich von der politisch-panegyrischen Großdichtung abwendet. Denn wohl schreibt er (carm. 9,9-13): ${ }^{37}$

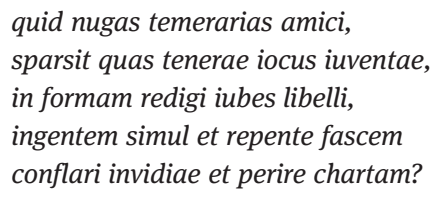

Was befiehlst du, die verstandeslosen Kleinigkeiten des Freundes, die der Scherz der zarten Jugend ausstreute, in die Gestalt eines kleinen Buches zu bringen, und zugleich plötzlich ein riesiges Bündel an Neid zu schnüren und das Papier zu verderben.

Sidonius greift mit nugae und libellus sowie charta Catullische Themenwörter auf, die im ersten Gedicht des Neoterikers seine Position und die seines patronus markierten. ${ }^{38}$ Obendrein ist das gesamte Gedicht im Hendecasyllabus gehalten, einem durch Catull prominent gemachten Metrum. ${ }^{39}$ In diese Übernahme der neoterischen Gedankenwelt gehört auch das Auftreten des Neids - den ФӨóvoৎ hatte Kallimachos mit einem Fußtritt hinausbefördert ${ }^{40}$ - sowie die Charakterisierung solcher poetischer Bemühungen als Jugenddichtungen, unabhängig vom tatsächlichen Lebensalter bei der Entstehung der Gedichte. ${ }^{41}$ Denn spätestens seit den biographischen Schemata zu Vergil beginnt eine Dichterlaufbahn in der Jugend mit geringen Gedichten nach Art des Catalepton, um sich dann mit fortschreitendem Alter über Bukolik und Georgik zu den epischen Höhen der Aeneis zu erheben. ${ }^{42}$

Was Sidonius allerdings grundlegend von seinem neoterischen Vorgänger unterscheidet, ist das Fehlen von brevitas (trotz des Diminutivs libellus). Vielmehr war auch den zitierten Versen bereits eine ausführliche Würdigung von Felix' Rang, insbesondere seines Familienstandes vorausgegangen. Offenbar ist es eben nicht mehr

37 Vgl. Santelia (s. Anm. 35), 239 zu weiteren Anspielungen auf Catull und Martial.

38 Auch iubes gehört zur Terminologie des literarischen patronus-cliens-Verhältnisses wie bei Prop. 1,3, vgl. auch die haud mollia iussa des Maecenas in Verg. georg. 3,40.

39 Siehe auch Jesús Hernández Lobato, „Sterilis Camena“. El Carmen 9 de Sidonio Apolinar o la muerte de la poesia, ACME 63 (2010), 97-133, hier: 98.

40 Severin Koster, Kallimachos als Apollonpriester, in: ders., Tessera. Sechs Beiträge zur Poesie und poetischen Theorie der Antike, Erlangen 1983 (Erlanger Forschungen A,30), 9-23.

41 Vgl. Ulrich Schmitzer, Jakob Baldes Batrachomyomachie, Paideia 66 (2011), 491-518, hier: 495 zu ähnlichen Verfahren bei Jakob Balde, der die „leichte“ Batrachomyomachie zu einem Jugendgedicht erklärte, unabhängig vom tatsächlichen Entstehungszeitpunkt.

42 Vgl. zuletzt Ulrich Schmitzer, Strategien der Selbstkanonisierung bei Ovid, in: ders. (Hrsg.), Enzyklopädie der Philologie. Themen und Methoden der Klassischen Philologie heute, Göttingen 2013 (Vertumnus 11), 51-81, bes. 51f. 
opportun, eine solche lobende Erwähnung in catullischer Knappheit vorzunehmen. Die geänderten Usancen hätten das als ungebührlich schroff erscheinen lassen, auch im Rahmen von personaler Dichtung war jetzt Ausführlichkeit oder gar Exuberanz nötig. Der Rekurs auf die frühere römische Dichtung, personifiziert in Catull, ist also bei aller stilistisch-poetologischen Aufgeladenheit des Vokabulars in erster Linie durch Thematik und damit verbundene Stilhöhe gewonnene Aussage über Kleindichtung, nicht durch den Umfang. Dennoch hat Sidonius bei allen Unterschieden damit einen die traditionelle lateinische Dichtung aufgreifenden Rahmen gesetzt, der nicht nur die Form, sondern auch die damit verbundenen Inhalte in den Focus rückt. Die Fortsetzung bewegt cum grano salis sich in den von der kallimacheisch inspirierten Dichtung vorgezeichneten Bahnen, indem Sidonius mit der Wegmetapher ${ }^{43}$ die Neuartigkeit seines Tuns unterstreicht.

Der Hauptteil des Gedichts, der gut 300 Verse umfasst, bringt jedoch schon zu Beginn eine Überraschung. Denn Sidonius nennt keineswegs, was er auf dieser poetologischen Basis nun eigentlich dichten möchte, sondern was er nicht zum Thema macht. Diese Priamelreihe ist eine ins Gigantische gesteigerte kallimacheische recusatio, ${ }^{44}$ die mit einer klaren Absage an traditionelle Stoffe einsetzt (carm. 9,16-18):

Non nos currimus aggerem vetustum

nec quicquam invenies ubi priorum

antiquas terat orbitas Thalia.

Wie laufen nicht einen alten Weg ${ }^{45}$ entlang und du wirst nichts finden, wo Thalia die alten Wagenspuren der Früheren durchfurcht.

Thalia ist generell die Muse der leichten und kleinen Dichtung, spätestens seitdem Vergil seine 6. Ekloge ebenfalls mit dem Anspruch auf Neuartigkeit eingeleitet hatte: Prima Syracusio dignata est ludere versu ... nostra Thalia. Sie bezeichnet abermals Stilhöhe und generisches Milieu, nicht mit exakter Zuweisung das yévoৎ der Komödie, und führt damit wiederum ins kallimacheische Gedankengut.

Sidonius beginnt die Reihe des als Stoff Abgelehnten mit fremden Ländern und Völkern (19-37), kommt sodann in gleitendem Übergang zu den großen militärischen Leistungen von Marathon und den Thermopylen bis zu Alexander bei Gaugamela - er bietet also dezidiert keine Zeitgeschichte, sondern kanonisierte, als exemplum taugliche und noch dazu klassische griechische Historie. Sie wäre das genuine Thema von Historiographie oder in unserem Kontext historischer Epik, in jedem Fall von hoch auf der Skala literarischer Dignität angesiedelten Gattungen. Von da geht Sidonius

43 Walter Wimmel, Kallimachos in Rom. Die Nachfolge seines apologetischen Dichtens in der Augusteerzeit, Wiesbaden 1960 (Hermes Einzelschriften 16), 103-111.

44 Lobato (s. Anm. 39), 109 mit konzentriertem Überblick über die negativ gewürdigten Dichter.

45 Für agger in der Bedeutung von via strata, „Straße, Weg“, siehe ThLL 1, s.v. agger, 1309,17-56 (seit Vergil und vor allem in der Spätantike). 
noch einen Schritt weiter zurück, in die Grauzone zwischen Geschichte und Mythos (carm. 9,65-75):

\begin{abstract}
Non vectos Minyas loquente silva dicam Phasiaco stetisse portu, forma percita cum ducis Pelasgi molliret rabidos virago tauros, nec tum territa, cum suus colonus post anguis domiti satos molares armatas tremebundus inter herbas florere in segetem stuperet hostem et pugnantibus hinc et hinc aristis supra belliferas madere glaebas culmosos viridi cruore fratres.
\end{abstract}

Ich will nicht davon künden, dass die Minyer, die mit dem sprechenden Baum des Waldes fuhren, im Hafen des Phasis Halt machten, während die Heldenjungfrau, bestrickt von der Schönheit des pelasgischen Anführers, die wilden Stiere besänftigte und auch dann nicht erschrocken war, als der von ihr zum Bauern Gemachte die Zähne der zahmen Schlange säte und zitternd mitten unter den bewaffneten Trieben staunte, dass der Feind zur Saat erblühte und dass, während die Ähren hierhin und dorthin kämpften, über den kriegsbringenden Schollen die halmgestaltigen Brüder vom grünen Blut trieften.

In preziösen Wendungen umreißt Sidonius die Grundzüge der Argonautensage, wie sie Apollonios Rhodios, Varro Atacinus und Valerius Flaccus in epischer Breite entwickelt hatten. Das ist gewissermaßen die Mutter aller Epen, da schon die homerische Odyssee die Fahrt der Argo und die damit verbundene kulturstiftende Leistung der Nautik als

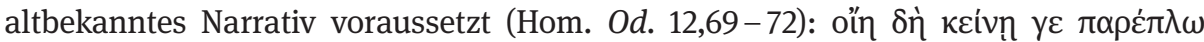

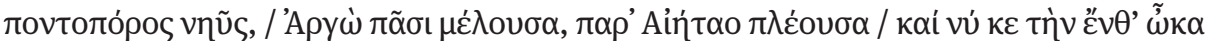

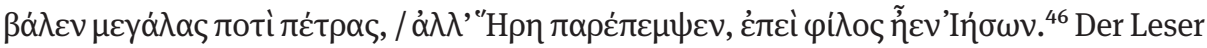
weiß allerdings noch nicht genau, wohin das nun führen wird, denn die Argonauten können sowohl für menschliche Großtaten stehen - und damit an die zuvor genannten militärischen Leistungen anknüpfen - oder mit chronologischer Inversion aus der Welt der Historie in den Mythos überleiten. Es wird sich zeigen, dass Letzteres der Fall ist.

Indem Sidonius die Argonautenerzählung prominent unter die abgelehnten Themen einreiht, schließt er sich zugleich an das Vergils Proömium zum 3. GeorgicaBuch an, der ebenfalls die Argonautensage, repräsentiert durch den Hylas-Mythos, zur Definition seines poetischen Programms ex negativo genutzt hatte (Verg. georg. 3,3-9): ${ }^{47}$

46 „Einzig ein meerbefahrendes Schiff fuhr dort vorbei: Argo, die alle in den Erzählungen beschäftigt, als sie von Aietes wegfuhr. Und auch sie hätte die Woge dort schnell an die großen Felsen geworfen, doch Hera geleitete sie vorbei, weil ihr Jason lieb war (Übers. von Wolfgang Schadewaldt).“

47 Siehe zum komplexen kallimacheischen Hintergrund und zur recusatio-Thematik zusammenfassend Virgil, Georgics, Vol. 2: Books III-IV, ed. by Richard F. Thomas, Cambridge 1988, z. St. 
cetera, quae vacuas tenuissent carmine mentes, omnia iam vulgata: quis aut Eurysthea durum aut inlaudati nescit Busiridis aras? cui non dictus Hylas puer et Latonia Delos Hippodameque umeroque Pelops insignis eburno, acer equis? temptanda via est, qua me quoque possim tollere humo victorque virum volitare per ora.

Alles Übrige, was im Gedicht die aufnahmebereiten Sinne fesseln, ist längst allgemein bekannt: Wer kennt nicht den harten Eurystheus oder die Altäre des ruhmlosen Busiris? Wem hat man nicht schon vom Knaben Hylas erzählt und vom Delos der Latona, von Hippodame und Pelops, berühmt wegen seiner Elfenbeinschulter, tollkühn zu Pferde. Ich muss einen Weg versuchen, auf dem auch ich mich von der Erde erheben kann und siegreich meinen Flug durch die Münder der Männer nehme.

Durch die Referenz auf Vergil wir für den kundigen Leser zugleich die Opposition „obsoleter Stoff vs. Innovation“ (also die Ablehnung bereits ad nauseam traktierter Stoffe) aufgerufen, die Sidonius überlagert durch die inhaltliche Frage nach abzulehnenden Mythen, die er in einer langen Reihe anschließt - nota bene: nach Mythen, nicht dem Mythos an sich. Von einer solchen prinzipiellen Verweigerung ist das gesamte Gedicht hindurch (und auch sonst) nicht die Rede. Allerdings hat Sidonius durch den Beziehungsrahmen bereits eine bestimmte Lesererwartung geweckt. Doch es dauert noch eine ganze Weile, bis entschieden ist, ob sie auch eingelöst (oder enttäuscht) werden wird.

Denn zunächst schließt sich mit ähnlichem Umfang wie für die Argonauten der Hinweis auf die Gigantomachie an (carm. 9,76-93) - ebenfalls ein traditionelles großepisches Thema ${ }^{48}$-, bevor mit erneut gesuchter Artistik die Taten des Hercules folgen, die ebenfalls bei Vergil kurz erwähnt sind (Vergils Busiris ist wohl Sidonius' hospes, Eurystheus ist der Auslöser für die Taten des Hercules; carm. 9,94-100):

Non hic Herculis excolam labores, cui sus, cerva, leo, Gigas, Amazon, hospes, taurus, Eryx, aves, Lycus, fur, Nessus, Libs, iuga, poma, virgo, serpens, Oete, Thraces equi, boves Hiberae, luctator fluvius, canis triformis portatusque polus polum dederunt.

Ich will hier nicht die Arbeiten des Hercules ausbreiten, dem Schwein (Eber), Hirschkuh, Löwe, Gigant, Amazone, Gastfreund, Stier, Eryx, Vögel, Lycus, der Dieb, Nessus, der Libyer, das Joch, der Apfel, die Jungfrau, die Schlage, Oete, die Thrakischen Pferde, die spanischen Rinder, der kämpfende Fluss, der dreigestaltige Hund und der getragene Himmel den Himmel gaben.

48 Philip Hardie, Virgil's Aeneid. Cosmos and Imperium, Oxford 1986 ist immer noch die beste Auseinandersetzung mit diesem Thema. 
Ob polus hier als Ausdruck für die Apotheose verwendet wurde, um das christlich konnotierte caelum zu vermeiden, ist immerhin eine Überlegung wert. Es wäre ein Indiz für eine literarische Konfliktvermeidungsstrategie. Wichtiger ist aber für Sidonius sicher die Assoziation mit dem höchsten Punkt des Himmelsgewölbes und das Polyptoton polus/polum, wofür er einen ganzen Vers aufwendet: Die aus den Taten resultierende Apotheose erhält mehr Raum als die sie letztlich herbeiführenden Taten je für sich. Sidonius kann nicht weniger als dreiundzwanzig um Hercules zentrierte Sagen in sechs Versen (eventuell ein numerisches Spiel mit den kanonischen zwölf Taten) unterbringen. ${ }^{49}$

Ein solche umfassende und zugleich aufs äußerste komprimierte Zusammenstellung der kanonischen und unkanonischen Taten ${ }^{50}$ des Hercules ist kein punktueller Einfall des Sidonius. In einem anderen Metrum, im Hexameter, und eine anderen Kontext, einem Hochzeitsgedicht auf ein ohne jeden Zweifel christliches Brautpaar aus der gallischen Aristokratie, ${ }^{51}$ versucht er sich im Rahmen der carmina minora noch einmal daran, indem er Hercules in die Ekphrasis von Festgewändern einreiht (carm. 15,135-145): ${ }^{52}$
Amphitryoniadi surgebat tertia vestis:
parvulus hic gemino cinctus serpente novercae
inscius arridet monstris ludumque putando
insidias dum nescit amat, vultuque dolentis
exstingui deflet quos ipse interficit angues.
Praeterea sparsis sunt haec subiecta figuris,
sus, leo, cerva, gigas, taurus, iuga, Cerberus, hydra,
hospes, Nessus, Eryx, volucres, Thrax, Cacus, Amazon,
Cres, fluvius, Libs, poma, Lycus, virgo, polus, Oete.
Hoc opus, et si quid superest, quod numina vestit,
virgineae posuere manus.

Dem Amphitryonsprössling galt das dritte Gewand: Noch ganz klein, umwunden von den beiden Schlangen der Stiefmutter, lacht dieser unwissend die Ungeheuer an und, da er es für ein Spiel hält, liebt er die Nachstellungen, solange er sie nicht kennt, und mit der Miene eines Trauernden beweint er, dass die Schlangen, die er selbst getötet hat, nun ausgelöscht sind. Außerdem ist unter die verstreuten Gestalten dies eingefügt: Das Schwein, der Löwe, die Hirschkuh, der Gigant, der

49 Siehe auch Michael Roberts, The Jeweled Style. Poetry and Poetics in Late Antquity, Ithaca/London 1989, 59-61 über die Beliebtheit solcher kondensierter Aufzählung in der spätantiken Dichtung.

50 Frank Brommer, Herakles. Die zwölf kanonischen Taten des Helden in antiker Kunst und Literatur, Darmstadt ${ }^{5} 1986$; ders., Herakles II. Die unkanonischen Taten des Helden, Darmstadt 1984; zu Herakles in christlichen Kontexten siehe Henrike Maria Zilling, Jesus als Held. Odysseus und Herakles als Vorbilder christlicher Heldentypologie, Paderborn 2011, bes. 139-224.

51 Siehe den Kommentar von Giovanni Ravenna (Hrsg.), Le nozze di Polemio e Araneola (Sidonio Apollinare, Carmina XIV - XV). Introduzione, testo, tradizione e commento, Bologna 1990, z. St. (auch zu den Quellen); Patrizia Mascoli, Personaggi femminili in Sidonio Apollinare, Invigilata lucernis 22 (2000), 89-107, hier: $94 \mathrm{f}$.

52 Zur Tradition der Verwendung des Mythos in lateinischen Epithalamien siehe Michael Roberts, The Use of Myth in Latin Epithalamia, TAPA 119 (1989), 321-348, zu Sidonius 338-344. 
Stier, die Joche, Cerberus, die Hydra, der Gastfreund, Nessus, Eryx, die Vögel, der Thraker, Cacus, die Amazone, der Kreter, der Fluss, der Libyer, die Jungfrau, das Himmelsgewölbe, Oeta. Dieses Werk, und, wenn es denn noch etwas gibt, was die Götter kleidet, haben die Hände der Jungfrauen es geschaffen.

Sidonius tritt mit diesem doppelten Versuch offenbar in einen poetischen Wettstreit ein, der sich in der Spätantike (oder genauer: in der Literatur des spätantiken Gallien) augenscheinlich einer gewissen Beliebtheit erfreut. Denn Sidonius' gallischer Landsmann Ausonius hatte diesem Thema ein ganzes Gedicht gewidmet, das in jeweils einem Vers eine Leistung des Heros aufführt (ecl. 17 Green): ${ }^{53}$

\author{
(MONOSTICHA) DE AERVMNIS HERCVLIS \\ Prima Cleonaei tolerata aerumna leonis. \\ Proxima Lernaeam ferro et face contudit hydram. \\ Mox Erymantheum vis tertia perculit aprum. \\ Aeripedis quarto tulit aurea cornua cervi. \\ Stymphalidas pepulit volucres discrimine quinto. \\ Thraeiciam sexto spoliavit Amazona balteo. \\ Septima in Augei stabulis inpensa laboris. \\ Octava expulso numeratur adoria tauro. \\ In Diomedeis victoria nona quadrigis \\ Geryone extincto decimam dat Hiberia palmam. \\ Undecimo mala Hesperidum destricta triumpho. \\ Cerberus extremi suprema est meta laboris.
}

Monosticha über die Mühen des Hercules

Als erste ist die Mühe des cleonäischen Löwen ertragen, als nächste erlegte er mit Feuer und Fackel die lernaeische Hydra. Bald durchbohrte die dritte Gewalt den erymanthischen Eber. Viertens trug er das goldene Geweih der leichtfüßigen Hindin davon. Die Stymphalischen Vögel vertrieb er in der fünften Gefahr. Sechstens beraubte er die thrakische Amazone ihres Gürtels. Der siebte Aufwand der Mühe war in den Ställen des Augias. Der achte Siegesruhm wird durch die Vertreibung des Stieres gezählt. In den Gespannen des Diomedes liegt der neunte Sieg. Durch den Tod des Geryon gibt Spanien die zehnte Siegespalme. Im elften Triumph sind die Äpfel der Hesperiden herunter gepflückt. Cerberus ist das letzte Ziel der äußersten Mühe.

Sidonius wie Ausonius verfolgen auf unterschiedlichen Weisen und mit unterschiedlichen Mitteln letztlich doch vergleichbare Ziele, nämlich die Demonstration ihrer Fähigkeiten zu artistisch anspruchsvoller Darstellung. Beiden Autoren gemeinsam ist, dass sie dabei keine Berührungsangst auch vor Themen der paganen Mythologie und Götterwelt haben. ${ }^{54}$ Für Ausonius ist das in erster Linie ein Bildungsgut, das neben christlichem Bildungsgut als poetisches Material zur Verfügung steht. Das gilt auch prinzipiell für seinen jüngeren Landsmann Sidonius. Und dabei stehen dann

53 The Works of Ausonius, ed. with Introduction and Commentary by R. P. H. Green, Oxford 1991, z. St. 54 Vgl. Ulrich Schmitzer, Amor in der Unterwelt. Zum Gedicht Cupido Cruciatus des Ausonius. in: ders. (Hrsg.), Suus cuique mos. Beiträge zur paganen Kultur des lateinischen Westens im 4. Jahrhundert n. Chr., Göttingen 2006 (Vertumnus 1), 167-184. 
die Ein-Wort und die Ein-Vers-Darstellungen letztlich auf einer Ebene: Sie nützen den tradierten paganen Stoff, um daran ihre formale Meisterschaft zu demonstrieren, unbeschadet der Tatsache, dass der Stoff geistesgeschichtlich eigentlich längst obsolet ist. Während Ausonius Christliches (wie in der Ephemeris) und Paganes ohne wesentlichen Unterschied für solche Demonstrationen verwendet, beschränkt sich Sidonius sogar völlig auf die paganen Mythen. Allenfalls subkutan kommt Christliches ins Spiel: So erscheint Sidonius' Hercules beinahe wie ein Gegenstück zu christlichen Märtyrern (ohne dass er allegorisierend in diese Reihe integriert würde) $)^{55}$ - die es allerdings in seiner Zeit auch schon nicht mehr gab. Damit wird ein wichtiger Teilaspekt der christlichen Gedankenwelt frei, um das Spiel mit dem Mythos zu unterstützen. Das konnte man selbstverständlich auch in Sidonius' Tagen nicht offen proklamieren, aber als literarische Strategie war es eine legitime Option geworden.

Im Rahmen von carm. 9 ist der Hercules-Abschnitt (anders als bei Ausonius und auch anders als im Epithalamium carm.15) Teil eines kontinuierlich durchlaufenden Katalogs. In der Fortsetzung grenzt Sidonius seine Themenwahl weiter ab gegen die Mythen von Arethusa (101-105), Tantalus, Pelops und Thyest (106-116), Paris und den Beginn des Troianischen Krieges, den Ilias-Stoff also bis zur Eroberung Troias (117129), Odysseus und Achill (130 - 167) - all das wäre ja noch euhemeristisch heilbar oder sogar christlich allegorisierbar. ${ }^{56}$ Wirklich in den Kernbereich paganer Mythoreligion geht es dann in den folgenden Versen (carm. 9,168-180): ${ }^{57}$

\author{
Non divos specialibus faventes \\ agris, urbibus insulisque canto, \\ Saturnum Latio Iovemque Cretae \\ Iunonemque Samo Rhodoque Solem \\ Hennae Persephonem, Minervam Hymetto, \\ Vulcanum Liparae, Papho Dionem, \\ Argis Persea, Lampsaco Priapum, \\ Thebis Evhion Ilioque Vestam, \\ Thymbrae Delion, Arcadem Lycaeo, \\ Martem Thracibus ac Scythis Dianam,
}

$55 \mathrm{Zu}$ Herakles/Hercules im christlichen Denken siehe Abraham J. Malherbe, Herakles, RAC 14 (1988), 568-583. Wenn unser Eindruck nicht trügt, dann verfährt Sidonius komplementär zu den Kirchenvätern (sofern sie Hercules nicht als Inkarnation unchristlichen Verhaltens ablehnten, sondern ihn wegen seiner virtus in die eigene Gedankenwelt integrierten): Er macht Hercules nicht zum Teil der christlichen Welt, sondern transferiert die Märtyrer in die gedankliche Sphäre des Hercules. Siehe außerdem Marcel Simon, Hercule et le Christianisme, Paris 1955 (Publications de la Faculté des Lettres de l'Université de Strasbourg).

56 Siehe z. B. Ulrich Schmitzer, Odysseus - ein griechischer Held im kaiserzeitlichen Rom, in: Andreas Luther (Hrsg.), Odyssee-Rezeptionen, Frankfurt 2005, 33-53, hier: 49f. Siehe auch den Beitrag in diesem Band von Fabienne Jourdan, Orpheus and ,Orphism in the Christian Literature (in Greek) of the First Five Centuries.

57 Stefania Santelia, Sidonio Apollinare e gli dèi pagani (a proposito di Carm. 9,168-180), Invigilata lucernis 21 (1999), 341-355 (mit zahlreichen Einzelerklärungen und vorausgehenden Parallelstellen, aber ohne weitergehende Interpretation). 


\begin{abstract}
quos fecere deos dicata templa, tus, sal, far, mola, vel superfluarum consecratio caeremoniarum.
\end{abstract}

Nicht singe ich von Göttern, die besonderen Fluren, Städten, Inseln gewogen waren, wie Saturn Latium, Iuppiter Creta, Iuno Samos und Sol Rhodos, Persephone Henna, Minerva dem Hymettos, Vulcan Lipari, Venus Paphos, Perseus Argos, Priapus Lampsakos, Euhion Theben und Vesta Troia, Thymbra dem delischen Apollo, Arkadien dem Lykaios, Mars den Thrakern und Diana den Skythen, [von Göttern also,] welche die geweihten Tempel zu Göttern machten, nämlich Weihrauch, Salz, Getreide, Kuchen oder die Weihe überflüssiger Riten.

Auch hier muss man genau lesen: Die olympischen und nicht-olympischen Götter werden nicht prinzipiell angezweifelt. Ihre Existenz ist eine poetische Option, ihr Kult aber, durch den sie zur religiösen Realität würden, ist aber unter den Rahmenbedingungen des Christentums nicht mehr akzeptabel - und kaum einer wird in Sidonius' Zeit und Umwelt tatsächlich noch heidnische Opfer im vollen Umfang wie vor der Konstantinischen Wende vollzogen haben. Auch das macht die Scheidung zwischen Mythos und Kult für den Autor leichter.

Und kaum weniger herausfordernd sind die unmittelbar folgenden Hinweise auf die verschiedenen heidnischen Mysterien bis hin (durch eine unmittelbar vorausgehende lacuna im Kontext verunklärt) zum Vestakult (carm. 9,198-200): ${ }^{58}$

ex ipsis rapuit deos favillis,

per templum male fluctuante flamma

gaudens lumine perdito Metellus.

Und aus der Asche selbst riss die Götter - da durch den Tempel übel die Flamme wogte - froh Metellus, obwohl er sein Auge verlor.

Sidonius zeigt keine Berührungsangst, er qualifiziert die Götter und die zugehörigen Sagen nicht durch negative Attribute ab (siehe oben) ${ }^{59}$ - das hat er nicht nötig, sondern er kann sie als Stoffe sui iuris bestehen lassen, auch wenn er sie nicht bedichten möchte.

Die folgenden Passagen des carmen 9 sind für unsere Zwecke weniger wichtig, hierbei geht es dann nicht mehr um antike und pagane Stoffe, sondern um antike Dichter - ein umfangreicher Dichterkatalog, der viel auch über die Kanonisierung der

58 Die Geschehnisse um die Rettung des Palladium aus dem brennenden Vestatempel durch Caecilius Metellus, der trotz dieser heldenhaften Tat erblindete, da er dabei das für Männer eigentlich unzugängliche Heiligtum betreten hatte, sind mitsamt den antiken Quellen kurz zusammengefasst bei Barbara Kowalewski, Frauengestalten im Geschichtswerk des T. Livius, München/Leipzig 2002, 339. 59 Vgl. im Gegensatz dazu z. B. Ov. met. 5,319f. falsoque in honore Gigantas / ponit (eine Muse über den abzulehnenden Gesang der Pieriden). 
klassischen griechischen und lateinischen Literatur ${ }^{60}$ in der Spätantike lehrt und der nahtlos in zeitgenössische Literaturszene übergeht (carm. 9,302-310):61

\author{
Sed ne tu mihi comparare temptes, \\ quos multo minor ipse plus adoro, \\ Paulinum Ampeliumque Symmachumque, \\ Messalam ingenii satis profundi, \\ et nulli modo Martium secundum, \\ dicendi arte nova parem vetustis \\ Petrum et cum loquitur nimis stupendum, \\ vel quem municipalibus poetis \\ praeponit bene vilicum senatus.
}

\begin{abstract}
Aber sollst nicht versuchen, die mit mir zu vergleichen, die ich - selbst viel jünger - viel mehr verehre, den Paulinus, Ampelius und Symmachus, Messala von genügend tiefschürfendem Geist und den Martius, der hinter keinem zurückstehen muss, Petrus, durch die neue Kunst der Rede gleich den Alten und, wenn er spricht, über die Maßen staunenswert, oder den Verwalter/Vilicus, den der Senat mit Recht den Dichtern aus den Provinzstädten vorzieht.
\end{abstract}

Die Einschätzung der poetischen Verhältnisse vollzieht sich in den durchaus geläufigen Bahnen antiken literaturgeschichtlichen Denkens. Die Autoren der Vergangenheit sind der Maßstab für die Bewertung der gegenwärtigen, ohne dass damit automatisch eine Abwertung verbunden wäre. ${ }^{62}$ Sidonius macht demgemäß auch keinen Unterschied zwischen traditionell-paganen und modern-christlichen Autoren. Sie erscheinen vielmehr in einer langen kontinuierlichen Reihe.

Sidonius lenkt nun am Ende seines langen Katalogs in wenig vorhersehbarer Weise das Gedicht in andere Bahnen. Dennoch bleibt die Frage noch unbeantwortet, was Sidonius denn nun anstelle der zurückgewiesenen Stoffe bedichten will. Wird er ein poetisches, gar christliches Gegenprogramm entwickeln? Wird er damit auch den angeredeten Felix auf eine entsprechende Höhe heben? Doch es kommt anders (carm. 9,318-328): ${ }^{63}$

60 Carm. 9,269-270 enthält einen der frühesten Hinweise auf Ovids Exil non qui tempore Caesaris secundi / aeterno incoluit Tomos reatu; vgl. auch carm. 23,158-161 et te carmina per libidinosa / notum, Naso tener, Tomosque missum, / quondam Caesareae nimis puellae / ficto nomine subditum Corinnae. $61 \mathrm{Zu}$ den Namen siehe die Erläuterungen von Anderson (s. Anm. 1) z. St. Es handelt sich durchgängig um zeitgenössische Dichter, wobei über Petrus nichts bekannt ist und bei (V)vilicus unklar bleiben muss, ob es sich um einen Eigennamen oder ein Amt handelt (siehe Anderson z. St.). Loyen (s. Anm. 1) bezieht vilicus als Umschreibung auf Flavius Merobaudes.

62 Die Formulierung erinnert an Ov. trist. 4,10,55f. utque ego maiores, sic me coluere minors / notaque non tarde facta Thalia mea est. Die mittlere Position in der Dichterhierarchie entspricht der mittleren Stellung in der altersmäßigen Abfolge.

63 Siehe auch Lobato (s. Anm. 39), 110 -114. Anderson (s. Anm. 1), lv, Anm. 1 diskutiert die buchgeschichtlichen Implikationen von rarae ... brevique chartae, doch ist sehr die Frage, ob man auf dieser Realienebene dem Text wirklich beikommt oder ob nicht viel eher der literarkritische Aspekt, der Anschluss an die libellus-Thematik vom Anfang des Gedichts einschlägig ist. 


\begin{abstract}
Nos valde sterilis modos Camenae rarae credimus hos brevique chartae, quae scombros merito piperque portet. Nam quisnam deus hoc dabit reiectae, ut vel suscipiens bonos odores, nardum, ac pinguia Nicerotianis quae flagrant alabastra tincta sucis, Indo cinnamon ex rogo petitum, quo Phoenix iuvenescit occidendo, costum, malobathrum, rosas, amomum, myrrham, tus opobalsamumque servet?
\end{abstract}

Wir aber vertrauen diese Weisen unserer sehr unfruchtbaren Muse selten einer Papyrusrolle an, und dann nur einer kleinen, die besser Makrelen und Pfeffer enthalten sollte. Denn welcher Gott wird der Zurückgewiesenen (Rolle) geben, dass sie gar gute Düfte aufnimmt und Narde sowie die fetten Alabastergefäße, die getränkt mit den Essenzen des Niceros brennen, Zimt aus dem indischen Scheiterhaufen gewonnen, wo der Phoenix sich verjüngt, indem er stirbt, Kostwurz, Salböl, Rosen, Balsam, Myrrhe, Weihrauch, Balsam bringt?

Sidonius' Muse ist nach dieser eigenen Charakteristik sterilis, ${ }^{64}$ also wenig Ertrag bringend oder ganz unfruchtbar. Sie reicht nur für ein kurzes Schriftstück aus, dessen Träger als Einwickelpapier für Fische, Gewürze oder Kräuter bessere Verwendung fände, aber nicht für verfeinerte Genüsse (im Bild der duftenden Essenzen geschildert) taugt. Das ist eine schonungslose Selbstdiagnose: Sidonius hat nicht die Fähigkeit zu schöner Dichtung. Darüber hinaus führt sie zur generellen Feststellung, dass die traditionellen, von paganen Inhalten getragene Dichtung tot ist (einer der vielen immer wieder ausgerufenen und doch niemals eingetretenen Tode der Literatur) - so wie auch die paganen Orakel ihren Dienst einstellten (die bekannte Antwort der delphischen Sibylle an Julian; Artemii Passio 35,31-33 = Philostorgios 7,1c): Eıا $\pi \alpha \tau \varepsilon \tau \tilde{\omega}$

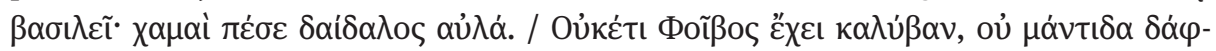

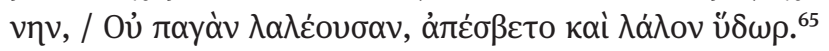

Doch die Form, in der diese anscheinend schonungslose Selbstdiagnose daher kommt, ist voller Ambivalenz und führt in ein interpretatorisches Dilemma: Sidonius hat ja in seiner Priamelreihe über gut dreihundert Verse sehr wohl gezeigt, dass er all die Mythen kennt und gewiss ein geeigneter Autor für ihre Umsetzung wäre, indem er sie paradoxerweise gerade nicht behandelt.

Gerade diese praeteritio zeigt in einer klassischen rhetorischen Volte, dass diese Mythen eben doch mögliche Stoffe der Literatur sind, dass es keine dichtungsexternen, weltanschaulichen Gründe gibt, sie nicht zu behandeln. Insofern bleibt es allein

64 Die Junktur scheint singulär: Egidio Forcellini, Totius latinitatis lexicon ( ${ }^{4} 1864-1926$, Vol. 4a, 483) bietet s.v. sterilis an vergleichbaren Wendungen lediglich Hinweise auf Plin. epist. 5,2 steriles epistulae; 5,17 sterile saeculum; Iuv. 7,203 sterilis cathedra; vgl. außerdem Sen. ben. 2,27,1 Lentulus ... ingenii fuit sterilis (nach OLD).

65 „Sagt dem Kaiser: Zu Boden fiel das kunstreiche Gebäude. Phoibos hat kein Obdach mehr, keinen weissagenden Lorbeer, keine sprechende Quelle, versiegt ist das mit Sprache begabte Wasser.“ 
eine Frage der jeweiligen poetischen Fähigkeiten. Indem Sidonius diese für sich verneint, setzt er die wohlbekannte recusatio-Technik ${ }^{66}$ fort, die unter dem Vorwand des mangelnden Talents große Themen ablehnt - conantem debilitabit onus (Ov. trist. 2,334) - und sie anderen, vorgeblich besser geeigneten zuweist. Das ist schon in der klassischen Dichtung ein kalkuliertes Verfahren, das in Wahrheit die ästhetische Überlegenheit der eigenen Dichtung unter Beweis stellen soll, doch mit der spezifischen Akzentuierung, dass zunächst überhaupt kein Gegenprogramm vorgelegt wird.

Bevor der Text - immerhin ein Einleitungsgedicht zu einem Gedichtbuch - ganz und gar in der Aporie endet, dreht sich noch einmal die Argumentationsrichtung. Denn obwohl andere, vor allem der Bruder des Felix, als Dichter zu Ehren des Felix eigentlich viel besser geeignet wären als Sidonius, will er doch das poetische Wagnis auf sich nehmen, wenn auch auf einem leichten, von Moral- und Kunstrichtern - die Catones stehen für beides ${ }^{67}$ - billig zu kritisierendem Terrain (carm. 9,338-346):
sed nec turgida contumeliosi
lectoris nimium verebor ora,
si tamquam gravior severiorque
nostrae Terpsichores iocum refutans,
rugato Cato tertius labello
narem rhinoceroticam ${ }^{68}$ minetur.
Non te terreat hic nimis peritus;
verum si cupias probare, tanta
nullus scit, mihi crede, quanta nescit.

Aber ich fürchte nicht die aufgeblasenen Mäuler der verächtlichen Leser, wenn jemand gleichsam
Ernsthafterer und Strengerer unserer Terpsichores Scherz verschmäht und als dritter Cato mit
kraus gezogener Lippe eine Rhinozerosnase droht. Auch dich soll dieser allzu Kundige nicht er-
schrecken. Wenn du die Wahrheit erfahren willst: So viel weiß keiner, glaube mir, wie er nicht weiß.

Mit dieser sokratischen Pointe ${ }^{69}$ endet das Gedicht, das so manchen Leser - auch modernen - durchaus ratlos hinterlässt. Also noch einmal gefragt: Bezeichnet Sidonius damit den Tod der Poesie ${ }^{70}$ Oder ist das eine Variante des aus der klassischen lateinischen Dichtung wohlbekannten Topos, wonach Kleindichtung vordergründig mit der Großdichtung nicht mithalten kann, der Autor aber aufgrund seines Unvermögens nichtsdestoweniger die weniger prestigeträchtige Kleindichtung betreibt und

66 Sieh dazu Wimmel (s. Anm. 43) passim.

67 Vgl. Loyen (s. Anm. 1), z. St. Siehe auch den (möglichen) Hinweis auf P. Valerius Cato als Kunstrichter im Gallus-Papyrus non ... Kato, iudice te vereor; dazu Mario Capasso, Il ritorno di Cornelio Gallo. Il papiro di Qasr Ibrîm venticinque anni dopo, Napoli 2003, 65-73.

68 Im grotesken Bild ist Hor. sat. 1,6,5 [non] naso suspendis adunco (über Maecenas) fortgeschrieben. 69 Zur Bedeutung der klassischen Philosophie (und der Philosophen) für Sidonius generell siehe auch Bernhard Hebert, Philosophenbildnisse bei Sidonius Apollinaris. Eine Ekphrasis zwischen Kunstbeschreibung und Philosophiekritik, Klio 70 (1988), 519-538.

70 So Lobato (s. Anm. 39). 
sich in Wahrheit überlegen zeigt ${ }^{71}$ - noch dazu in einer perfekten poetischen Architektur. $^{72}$

Ein Antwort ergibt sich nicht aus dem Einzelgedicht, sondern erst aus dem Blick auf die gesamte Sammlung der carmina minora, auf die insgesamt fünfzehn Gedichte:

9: Widmungsgedicht an Felix - 346 Verse

10: Praefatio zum ersten Epithalamium - 22 Verse

11: Epithalamium für Ruricius und Hiberia - 133 Verse

12: An den Senator Catullinus - 22 Verse

13: An Kaiser Maiorian - 40 Verse

14: An Polemius: Prosabrief mit angehängter Praefatio zum Epithalamium - 30 Verse

15: Epithalium für Polemius und Araneola - 201 Verse

16: Dankgedicht an den Bischof Faustus - 127 Verse

17: An den Senator Ommatius - 20 Verse

18: Über die Bäder seiner Villa - 12 Verse

19: Über sein Schwimmbecken - 4 Verse

20: An seinen Bruder Ecdicius - 4 Verse

21: Über einen des Nachts gefangenen Fisch - 4 Verse

22: Sidonius an seinen Freund Leontius (Prosa), der Burgus des Pontius Leontius - 235 Verse

23: An Cosentius - 512 Verse

24: Geleitgedicht an das Buch - 101 Verse

Aufgrund ihres Umfangs fallen die sehr kurzen Gedichte - insgesamt vier - für eine nähere Betrachtung aus. Von den verbleibenden elf sind neun, also die überwältigende Mehrzahl voll mit Inhalten aus der traditionellen paganen Götter- und Mythenwelt. So wird in carm. 15, dem bereits anzitierten einen der beiden Epithalamien der Tempel der athenischen Minerva zum Hof der Weisheit der sieben klassischen Philosophen - von Pythagoras bis Thales $^{73}$ - und Webewerkstatt für textile Kunstwerke mit zahllosen Mythendarstellungen - all das gerechtfertigt durch das Urbild einer glücklichen Hochzeit, der Hochzeit von Thetis und Peleus (nicht der von Kanaa).

So wird der burgus des Pontius Leontinus in einer vor allem auf Statius zurückweisenden Tradition unter Anrufung der Musen ${ }^{74}$ als mythischer Herrschersitz verklärt und auf eine Begegnung von Dionysos und Apollo zurückgeführt (wobei sich Sidonius aus dem gesamten Arsenal von Attributen, Begleitern und Taten bedient, die ihm die Tradition zur Verfügung stellt). Daraus entsteht eine Ekphrasis, die den Vergleich mit Ovid und eben Statius nicht zu scheuen braucht. So kommen in carm. 11, dem ersten

71 Siehe z. B. Silvia Condorelli, Il poeta doctus nel V secolo D.C. Aspetti della poetica di Sidonio Apollinare, Napoli 2008.

72 Lobato (s. Anm. 39), 124.

73 Siehe zu Letzterem nunmehr Andreas Schwab, Thales von Milet in der frühen christlichen Literatur. Darstellungen seiner Figur und seiner Ideen in den griechischen und lateinischen Textzeugnissen christlicher Autoren der Kaiserzeit und Spätantike, Berlin/Boston 2011 (Studia Praesocratica 3), 312326.

74 Siehe zur Bedeutung der Musen für Sidonius generell Jean-Marie André, Le culte des Muses dans l'esthétique de Sidoine Apollinaire, Aevum 83 (2009), 209-220. 
Hochzeitsgedicht, die Schwäne der Venus aus ihrem übernatürlichen Tempel, um das Hochzeitspaar zu ehren.

Und selbst wenn einmal christliche Inhalte im Vordergrund stehen, wie in carm.16 mit guten Grund, ist es doch an den Bischof Faustus gerichtet, dann geschieht das in eigenartiger Akzentuierung (carm. 16,1-10):

\author{
Phoebum et ter ternas decima cum Pallade Musas \\ Orpheaque et laticem simulatum fontis equini \\ Ogygiamque chelyn, quae saxa sequacia flectens \\ cantibus auritos erexit carmine muros, \\ sperne, fidis; magis ille veni nunc spiritus, oro, \\ pontificem dicture tuum, qui pectora priscae \\ intrasti Mariae, rapiens cum tympana siccus \\ Israel appensi per concava gurgitis iret \\ aggeribus vallatus aquae mediasque per undas \\ pulverulenta tuum clamaret turba triumphum;
}

Den Phoebus und die dreimal drei Musen zusammen mit Pallas, der zehnten, und Orpheus und das vorgetäuschte Wasser der Pferdequelle und die ogygische Leier, die die ihr folgenden Felsen im Gesang erweichte und durch das Lied die ihr lauschenden Mauern errichtete, die verschmähe, meine Saite; vielmehr komm nun jener Geist, so bitte ich, der deinen Bischof künden wird, der du das Herz der älteren Maria ${ }^{75}$ betreten hast, als Israel, die Tamburins fortreißend, trockenen Fußes durch die Krümmung der Fluten ging, von den Dämmen des Wassers schützend umgeben und als mitten durch die Wogen des Wassers die trockene Schar deinen Sieg laut verkündete.

Das ist beinahe in nuce das Verfahren des gesamten Gedichtbuches (allerdings mit dem Unterschied, dass hier der recusatio die positive Zielbestimmung folgt - eine Konzession möglicherweise an das geistliche Amt des Adressaten): Die heidnischen Mythen und Götter sind auf diese Weise präsent, gerade weil sie als absent charakterisiert sind. Sie hinterlassen jenseits aller persönlicher Religiosität eine poetische Leerstelle, die nur mit Mühe durch die Stoffe und das Personal der Bibel gefüllt ${ }^{76}$ werden kann. Diese schmerzliche Lücke, so sollte durch die bisherige Interpretation plausibel geworden sein, ist für Sidonius in seinem literarischen Werk aber nicht tolerabel. Und so füllt er sie entweder durch die direkte Erwähnung oder noch kunstvoller, indem er sie so beredt nicht erwähnt, dass sie eben doch zum Gegenstand der Dichtung werden.

Auch wenn die Gedichte der carmina minora wohl entstanden und publiziert sind, bevor Sidonius ins Bischofsamt berufen wurde, ${ }^{77}$ ist es doch bemerkenswert, in wel-

75 Exodus 15,20f. (Luther-Übersetzung): „Und Mirjam, die Prophetin, Aarons Schwester, nahm eine Pauke in ihre Hand, und alle Weiber folgten ihr nach hinaus mit Pauken im Reigen. Und Mirjam sang ihnen vor: Laßt uns dem HERRN singen, denn er hat eine herrliche Tat getan; Roß und Mann hat er ins Meer gestürzt.“

76 Zum biblisch-theologischen Hintergrund des gesamten Gedichts und damit zur Theologie des Sidonius insgesamt siehe Harries (s. Anm. 8), $108 \mathrm{f}$.

77 Siehe Schetter (s. Anm. 34). 
chem Umfang die Mythen ${ }^{78}$ gegen die ein Tertullian, Arnobius oder Lactanz so leidenschaftlich gekämpft hatten, ${ }^{79}$ nun wieder ihren Platz beanspruchen können. ${ }^{80}$ Die Nachwehen der scharfen apologetischen Auseinandersetzungen, die bis tief ins 4. Jahrhundert zu spüren gewesen waren, hatten nicht nur ihr Brisanz, sondern auch ihre Funktion verloren. Die Christen, die noch von Julian Apostata als intellektuell nicht in der Lage, an dieser Vermittlung teilzuhaben, abgewertet worden waren, sehen sich nun allein im Stande, auch die pagane Tradition zu bewahren. Die heidnischen Götter und deren Sagenwelt werden wie schon für Ausonius so jetzt auch für Sidonius Gegenstand der Kultur, nicht der Religion und Moral. Sie sind Teil der imaginären Bibliothek (und auch der realen Bibliotheken, aus denen sie eben nicht eliminiert werden), ${ }^{81}$ des umfassenden Wissensspeichers, ${ }^{82}$ dessen sich Sidonius bedient wie er ihn auch selbst bedient. Der Mythos wird, von Spezialfällen wie bei der Begegnung mit Bischof Faustus abgesehen, eben nicht in Kategorien des Glaubens und der religiösen Überzeugung gemessen, sondern ist Teil des kulturellen Gemeinguts, das in der christlichen Umwelt eine neue Heimat gefunden hat. ${ }^{83}$

Nicht nur die Mächtigen konnten sich im Glanz der Tradition sonnen, wenn sie in den panegyrischen Texten, wie im carmen 7, wie einst Alexander der Große und andere bedeutende Männer in mythologischem Ambiente gepriesen wurden. Die Bildung als Argument für die Eignung zum Kaiser müssen sogar die barbarischen Westgoten und deren König Theoderich II. anerkennen, zumal Theoderich wohl sogar einmal Schüler

$78 \mathrm{Zu}$ ähnlichen Beobachtungen über die Rolle der Religion und Mythologie in den Briefen des Sidonius siehe David Amherdt, Sidoine Apollinaire. Le quatrième livre de la correspondance. Introduction et commentaire, Bern et al. 2001 (Sapheneia 6), $37 \mathrm{f}$.

79 Zur ebenfalls dezidiert ablehnenden Haltung des Paulinus von Nola siehe Robert Kirstein, Paulinus Nolanus. Carmen 17, Basel 2000 (Chrêsis 8).

80 Zur ambivalenten Haltung der Christen gegenüber der traditionellen Bildung insgesamt siehe Alexander Demandt, Die Spätantike. Römische Geschichte von Diocletian bis Justinian 284-565 n. Chr., 2. überarbeitete Auflage, München 2007 (HdAW 3,6), 490 - 492.

81 Siehe auch Natalia Rusnac, From villa to Cloister. The Religious Transformation of the Book in Late Antique Gaul, Viator 44 (2013), 1-24.

82 Zur Idee der Bibliothek und des Lesens siehe anhand von Sidon. epist. 4,11,6 (triplex bibliotheca quo magistro Romana, Attica, Christiana fulsit: die Bibliothek des Claudius Mamertus; dazu Franz Bömer, Der lateinische Neuplatonismus und Neupythagoreismus und Claudianus Mamertus in Sprache und Philosophie, Leipzig 1936) Ulrich Eigler, Lectiones Vetustatis. Römische Literatur und Geschichte in der lateinischen Literatur der Spätantike, München 2003 (Zetemata 115), bes. 103-112. Siehe außerdem Ulrike Egelhaaf-Gaiser, Bleibende Klänge. Das hymnische Briefsiegel des Bischofs Sidonius (epist. 9,16), Millennium 7 (2010), 257-292 (v. a. mit Blick auf die Bedeutung des Horaz für die epistolographische Selbstdarstellung des Sidonius); Sigrid Mratschek, Identitätsstiftung aus der Vergangenheit. Zum Diskurs über die trajanische Bildungskultur im Kreis des Sidonius Apollinaris, in: Therese Fuhrer (Hrsg.), Die christlich-philosophischen Diskurse der Spätantike: Texte, Personen, Institutionen, Stuttgart 2008, 363-380 (zur Bedeutung von Plinius minor und Tacitus).

83 Siehe auch das Lob der traditionellen Bildung in christlichem Umfeld in Sidon. epist. 4,1.Vgl. bündig Demandt (s. Anm. 80), 384 f. über Sidonius’ Kritik an den Goten: „Das, was ihnen zur Humanität fehle, sei nicht die Bibel, sondern die Philosophie und Dichtung.“ 
des Avitus war und von diesem just die klassische Bildung gelernt hat. Das kehrt als Verdienst und Herrschertugend jetzt wieder zu Avitus zurück (carm. 7, 494-497): ${ }^{84}$

\author{
solumque moratur \\ quod cupias, nescisse Getas. mihi Romula dudum \\ per te iura placent, parvumque ediscere iussit \\ ad tua verba pater docili quo prisca Maronis \\ carmine molliret Scythicos mihi pagina mores.
}

\begin{abstract}
Allein hindert mich noch, dass die Goten das nicht kennen, was du willst. Mir gefallen seit langem die Gesetze des Romulus durch dich, mein Vater befahl auf dein Wort hin, dass ich schon als kleines Kind genau lernte, womit mir Gelehrigem die alte Schrift durch die Dichtung des Vergilius Maro die skythischen Sitten weniger hart machte.
\end{abstract}

Das billigen auch die Götter in ihrer von Jupiter einberufenen Ratsversammlung, die als Rahmen den Anfang wie den Schluss des Panegyricus auf Avitus bildet. Vielmehr aber reicht die Wirksamkeit der paganen Mythen auch bis in die sich als personale Poesie gebende Kleindichtung und damit in die private Sphäre (bzw. deren literarische Konstruktion). Damit wird die Tradition der durch Kallimachos und seine Nachfolger in Rom begründeten gelehrten und anspielungsreichen Dichtung auch über die konstantinische Wende und deren Folgen fortgesetzt, nicht ganz bruchlos zwar, denn es kommen ja nun auch christliche Inhalte hinzu, aber im römischen Gallien eben auch ohne Autodafé.

Misst man Sidonius nicht mit dem sachfremden Maßstab des scheinbar Originellen und Authentischen, sondern an seinem Anspruch, das als vorbildlich und wichtig erkannte Wissen früherer Zeiten zu bewahren und für eine fundierte Bildung fruchtbar zu machen, dann ist auch Sidonius' Muse eben nicht sterilis. Vielmehr bringt sie Ertrag in einer Zeit, in der - zumindest für Sidonius in seiner gallischen Umwelt des 5. Jahrhunderts - die klassische Bildung mitsamt dem Mythos auch ideologiebefreit gelesen werden konnte und damit einen neuen, auf die künftigen Renaissancen vorausweisenden Wert bekam. ${ }^{85}$

84 Zum Goten- und Theoderichbild des Sidonius siehe Kaufmann (s. Anm. 18), 106-139.

85 Kaufmann (s. Anm. 18), 221-224 u. ö. weist mit Recht darauf hin, dass der Kreis der Gebildeten in dieser Zeit sehr klein war, doch ändert das nichts an der prinzipiellen Ausrichtung von Sidonius’ Werk auf eben jene Adressaten. 


\title{
„Scheinbare Extravaganz". \\ Pagane und christliche Platoniker über die Wunderlichkeit des Mythos
}

\begin{abstract}
It seems that the Duchess of Somerset has been going into some Board School somewhere where the children were taught fairy-tales, and then going into some Board of Guardians somewhere else and saying that fairy-tales were full of ,nonsense, “ and that it would be much better to teach them about Julius Caesar „or other great men.“ Here we have a complete incapacity to distinguish between the normal and eternal and the abnormal or accidental.
\end{abstract}

(G. K. Chesterton, The Illustrated London News, Dec $2^{\text {nd }}, 1905$ )

\section{Einleitung}

In den ersten „christlichen Jahrhunderten“ des Römischen Reiches ist die platonische Philosophie sicherlich einer der geistigen Orte, an denen sich die quantitative Präsenz von und der qualitative Umgang mit antiken Mythen am intensivsten belegen lassen. Dabei gilt es allerdings, „Platonismus“ als Synekdoche zu verstehen und zwischen dem Platonismus als philosophischer Einzelströmung und dem Platonismus als allgemeiner Denkform zu unterscheiden: Als allgemeine Denkform hatte der Platonismus in vielen, vielleicht sogar in nahezu allen Bereichen den Status eines gegenüber den Einzelauffassungen von der Welt relativ unabhängigen diskursindifferenten Ausdrucksmediums gewonnen, und so lässt sich feststellen:

Mit einer Aussage „... war Platoniker“ ist von etwa 220 n. Chr. an sehr wenig gewonnen. Der Platonismus gewann - fast schlagartig - eine erhebliche Breitenwirkung. Platonische Fachsprache wurde zum Vehikel nahezu jeder philosophischen Diskussion. Aber auch die absichtlich dunklen Offenbarungen der hermetischen Schriften „platonisieren“. Es dürfte schwer sein, ProsaAutoren [...] des 3., 4. und 5. Jahrhunderts zu benennen, die nicht irgendwie eine Einwirkung des Platonismus erkennen lassen. ${ }^{1}$

Zu den so - das heißt: sensu lato - verstandenen „Platonikern“ gehörten auch christliche Denker, die gegen Einzelaussagen der platonischen Philosophenschule im engeren Wortverständnis argumentierten und Einspruch erhoben. Folgendes soll nun Ziel meiner Erörterung sein: Zu zeigen, dass der Umgang mit den Mythen zu den Bereichen gehört, in denen dieses platonisch gedachte Argumentieren gegen schulmäßig Platonisches besonders deutlich wird und vor allem, wie der pagane Platonismus auf die damit entstehende Herausforderung reagiert. Und so wird die Tatsache, dass von den christlichen Platonikern mit den Bibelerzählungen mutatis mutandis nach dem Muster der paganen

1 Heinrich Dörrie: Die platonische Philosophie des Kelsos in ihrer Auseinandersetzung mit der christlichen Theologie. Göttingen 1967, S. 50. 
platonischen Mythendeutung umgegangen wird, den Hintergrund für das Verständnis der Polemik bilden müssen, die sich zwischen christlichen und paganen Platonikern über die Einzelheiten des Umgangs mit dem paganen Mythos entspinnt. Bestenfalls wird sich nach Sichtung einiger aussagekräftiger Beispielbelege dazu ein systematisches Fazit ziehen lassen. Begonnen sei mit einem Blick auf den für uns als historische Gestalt ziemlich rätselhaften Neuplatoniker Sal(l)ustios und seine konzise Programmatik des neuplatonischen Mythenverständnisses. ${ }^{2}$

\section{Die átoпía des Mythos als Abwegigkeit: Sallust}

Zwischen den Jahren 361 und 363 entsteht, wohl auf Anregung Kaiser Julians II. Apostata - und als theoretisches Instrument seines neuplatonisch durchtränkten Revitalisierungsprogramms der paganen Religiosität, eine kleine Schrift mit dem Titel Über

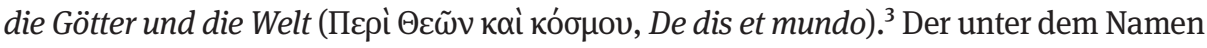
Sal(l)ustios bekannte Autor dieses „platonischen Katechismus“, ${ }_{4}$ erklärt in einem bemerkenswerten Abschnitt seiner handbuchartigen Lehrschrift, dass an der Wahrheit der alten Mythen trotz ihrer „scheinbaren Abwegigkeit“ oder „scheinbaren Extravaganz“ festgehalten werden sollte. Das entscheidende Textstück darf als Aufgriff traditioneller Themen der Auseinandersetzung mit den Vorwürfen christlicher Denker gegen die paganen Mythen gelten, aber auch als theoretische Selbstvergewisserung der platonischen Denktradition in dieser Angelegenheit. Sallust führt als Erklärung für seine Haltung in dieser Frage zunächst ein Effizienzargument ad verecundiam an (De dis et mundo III 1), wie es ähnlich des Öfteren in der antiken Literatur auftaucht, insbesondere wenn es um die Frage des Vertrauens in Orakel geht: Dass die Mythen zweifellos göttlichen Ursprungs sind, zeige sich daran, wie die größten der Dichter und die besten der Philosophen

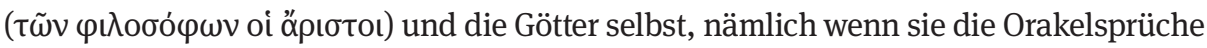

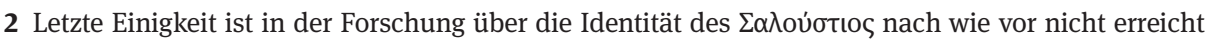
worden. Die beiden gehandelten Kandidaten sind: Saturninius Secundus Salustius, Berater des Kaisers und von Julian II. zum Prätorianerpräfekten des Ostens ernannt (PLRE I 814-817), und Flavius Sallustius, Prätorianerpräfekt von Gallien und 363 Konsul mit Julian (PLRE I 797 f.; vgl. 796). Von Saturninius Secundus Salustius ist philosophische Betätigung überliefert, die Indizien scheinen also bis auf Weiteres insbesondere für ihn zu sprechen.

3 Textgrundlage für den Traktat ist die Ausgabe von Gabriel Rochefort (Hg.): Saloustios, Des dieux et du monde. Paris ${ }^{2} 1983$; zum Vergleich der Interpretations- und Übersetzungsvarianten oft interessant: Arthur Darby Nock (Hg.): Sallustius, Concerning the Gods and the Universe. Cambridge 1926, sowie: Enrique Ángel Ramos Jurado (Hg.): Salustio: Sobre los dioses y el universo. Madrid 1989, S. 266-316. 4 Als ein solcher ist das Werk wohl tatsächlich zu verstehen. Zur Katechismusform platonischer Handbücher (nicht nur) im vierten Jahrhundert vgl. Christian Schäfer: Julian Apostata und die philosophische Reaktion gegen das Christentum: Die „Pseudomorphosen“ des platonischen Denkens im „magischen Zeitalter“. In: ders. (Hg.): Kaiser Julian ,Apostata“ und die philosophische Reaktion gegen das Christentum. Berlin 2008, S. 41-64. Zur „Restauration“ der alten Religion unter Julian vgl. auch Theresa Nesselrath: Kaiser Julian und die Repaganisierung des Reiches. Konzept und Vorbilder. Münster 2013. 
formulierten, von der mythischen Ausdrucksform Gebrauch gemacht hätten. Warum dies auch in Anbetracht der Abwegigkeit der bunten Mythenwelt so als richtig und zustimmungswürdig zu erachten ist, bezeichnet Sallust anschließend als ein Beantwortungsproblem, das der Philosophie obliegt. Die Antwort der Philosophie aber laute folgendermaßen: Nach dem simile simili-Prinzip gleiche doch alles seinem Ursprung.

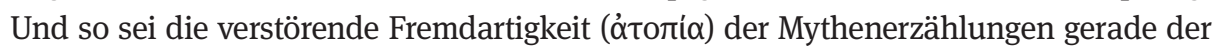
beste Hinweis darauf, dass die Mythen göttlich sind ( $\theta \varepsilon \tilde{o}$ o oi $\mu$ ṽ $\theta$ o $)$. Gleichen die Mythengeschichten doch gerade darin den Göttern, dass sie so seltsam bekannt und gleichzeitig unbekannt wirken, so vertraut menschlich und doch so verstörend nichtmenschlich, so offensichtlich überall und doch so geheimnisvoll, so präsent und gleichzeitig so wirklichkeitsenthoben, so einfach überzeugend und gleichzeitig so rea-

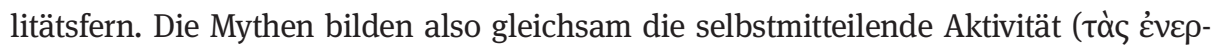
ycíac) der Götter ab, wie sie insbesondere bekanntermaßen in ihrer sich im Offensichtlichen verbergenden Ausdrucksweise in den Orakeln regelrecht „zur Sprache kommt“ (und insbesondere in diesem Punkt erfolgt der Aufgriff der langen Tradition der Orakelapologetik bei Sallust).

An diese Stelle (De dis et mundo III 3) schließt sich unmittelbar der berühmte Ausspruch des Autors an, eigentlich könne in diesem Sinne ja auch die ganze Welt

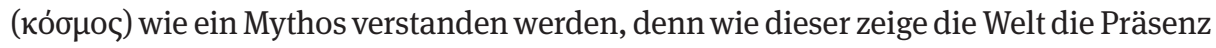
des Göttlichen sowohl in der offenkundig sinnlich zugänglichen Verfassung des wahrnehmbar körperlichen Universums als auch in der darin verhüllt uns sinnlich

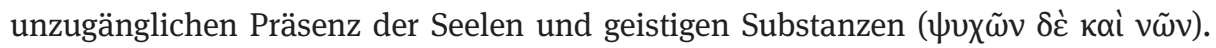
Weltbau, Mythos und Orakel sind nur verschiedene Weisen der Selbstmitteilung des Göttlichen: Alle drei sind semantisch (im etymologischen Sinn von $\sigma \tilde{\eta} \mu \alpha$ als greifbar äußeres Zeichen, sichtbare Bezeichnung) verschiedene, doch inhaltsgleiche Ausdrucksweisen der göttlichen (Selbst)Äußerung. Die Art dieser Äußerung aber ist adressatenspezifisch menschengemäß - in Geschichten und sichtbaren Dingen. Das Problem ist: Das bloß Menschliche kongruiert nicht mit dem Göttlichen, und das zeigt auf, wie die Weise des Gesagten danach verlangt, dass dem Inhalt des Gemeinten nachgespürt werde.

Dies einmal festgesetzt, stellt sich Sallust dem wohl traditionellsten Vorwurf gegen die Mythen (De dis et mundo III 4) und wirft die Frage auf, warum die mythischen Erzählungen in so auffälliger Häufung moralisch Anstößiges, ja teilweise sogar Abartiges von den Götter erzählen: Ehebruch, gegenseitiges Bestehlen und Gewalt gegen die Eltern etwa - ein stets wiederkehrender Kritikpunkt seit Xenophanes von Kolophon, ${ }^{5}$ aufgenommen und radikalisiert in der Dichterkritik Platons in der Politeia ${ }^{6}$ und von der christlichen Polemik gegen die pagane Religion. Gilt also auch für diese An-

5 Vgl. bei Xenophanes vor allem die Fragmente 21 B $10-12$.

6 So in den beiden großen Dichterkritiken im zweiten (379a-398b) und im zehnten Buch der Politeia (595a-608b). Eine gute Bestandsaufnahme bietet Stephen Halliwell: The Republic's Two Critiques of Poetry. In: O. Höffe (Hg.): Platon, Politeia. Berlin 1997, S. 313-332. 
stößigkeiten die Dialektik von Verhüllen und Enthüllen, wie das für den Kosmos als ganzen oder die Orakelsprüche so anzunehmen ist? In den Worten von Sallust:

Ist denn auch all dies der Bewunderung würdig, weil es die Seele sogleich darauf bringt, dank der scheinbaren Extravaganz das Gesprochene wie einen Schleier und die Wahrheit als unaussprechlich anzunehmen? ${ }^{7}$

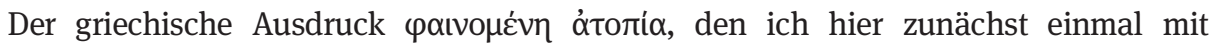
„scheinbare Extravaganz“ übersetzt habe, kann auf mehrerlei Weise verstanden werden. Sallust scheint damit, d.h. mit der Charakterisierung dieser „Extravaganz“ als paıvo$\mu \varepsilon ́ v \eta$, erstens sagen zu wollen, man müsse das Zugeständnis machen, dass diese ótoтí $\alpha$ einem geradezu ins Gesicht springt und tatsächlich verstört. Zweitens aber besagt der

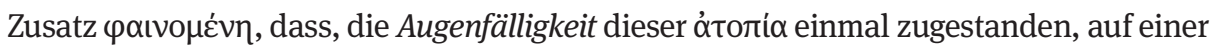
zweiten Auffassungsebene eher die Augenscheinlichkeit als das hermeneutische Erklärmoment der richtigen Mythenauffassung zu gelten habe.

Anders als das christliche Realsymbol, das die im Miterleben der Augenzeugen belegte Konkretisierung des Logos im einmaligen Einzelfall der Geschichte bedeutet, ist das Mythische in seinen Geschichten nicht historisch und im Einzelfall miterlebbar. ${ }^{8}$ Sallust folgt hier der platonischen Deutungslinie, wie sie etwa von Plutarch vorgeben wurde. ${ }^{9}$ Doch im Anwendungsschluss ist Sallust deutlicher und fordernder als Plutarch: Das im Mythos Gesagte ist Vermittlung und will erschlossen statt bezeugt werden. So kommt Sallust zu der wohl berühmtesten Aussage seines Traktats und gleichzeitig zu einer der vielleicht treffendsten Aussagen, die ein antiker Autor jemals über den Mythos und die Dinge, die er erzählt, formuliert hat:

Diese Dinge sind nie passiert, doch sie geschehen fortwährend. Was überzeitliches Denken als ein „zugleich“ von allem wahrnimmt, zerlegt der Diskurs menschlichen Denkens in ein zeitliches Nacheinander. ${ }^{10}$

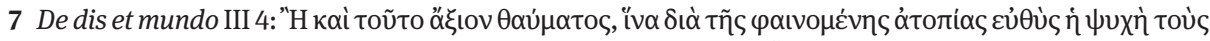

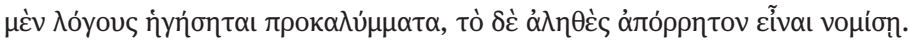

8 Anders als das Vertretungssymbol ist das Realsymbol ein hinweisendes Sinnbild, in dem die bezeichnete Wirklichkeit selbst schon in realer Weise präsent ist -,,it intrinsically constitutes what it signifies“ (Stephen M. Fields: Being as Symbol. Washington, D.C. 2000, S. 24). Dagegen haben beide Arten des Symbolischen den Anspruch, eine nicht als gegenwärtig fassbare Realität als gegenwärtig erscheinen zu lassen.

9 Vgl. Plut. mor. 25C. Zur Deutung ist u. a. hilfreich: Maren Niehoff: Philo and Plutarch on Homer. In: dies. (Hg.): Homer and the Bible in the Eyes of Ancient Interpreters. Leiden/Boston 2012, S. 127-153, v. a. S. 139.

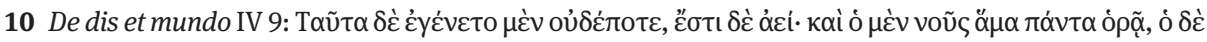

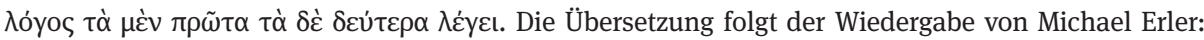
Praesens divinum. In: Markus Janka/Christian Schäfer (Hg.): Platon als Mythologe. Darmstadt 22014, S. 61-78, hier S. 67. 
Wären die Dinge, die in den alten Mythen erzählt werden, auch in dieser Weise historisch geschehen, wären sie nach Sallusts Dafürhalten tatsächlich skandalös. Doch sind sie so eben nicht geschehen, sie sind vielmehr die narrative Verschlüsselung ewiger welterklärender Abläufe in einer dem Menschen gemäßen Sprachgestalt. Von der Güte der Götter ist gerade im Umfeld Kaiser Julians oft die Rede, da es ja unter anderem darum gehen muss, auch in dieser Hinsicht ein ebenbürtiges oder besseres Gegenprogramm zum Christentum zu propagieren. Diese Güte der Götter äußert sich in der neuplatonischen Programmatik der paganen Autoren nun aber vor allem darin, sich secundum modum recipientis mitzuteilen, und das hat gleichzeitig eine pädagogische Funktion für den menschlichen Adressaten - eine wichtige Erklärfigur in der neuplatonischen Theologie. ${ }^{11}$

Auf dieser Grundlage unterscheidet Sallust vier Arten, oder eher Auffassungsweisen des Mythos, und er macht sie deutlich am Einzelbeispiel des Mythos von Kronos, der seine Kinder verschlingt:

Die Auffassung als theologische Mythen ( $\theta \varepsilon$ co入оуıкоi), die tatsächlich anagogischen Charakter haben und etwas Bedeutsames über das Göttliche aussagen, wenn auch vielleicht nur insofern, als es im Menschen wirkt und die Seele verstehen lässt, was das Göttliche in ihr oder an ihr ist: So zeigt die Geschichte vom Vater, der sich sein eigen Fleisch und Blut einverleibt, bildhaft die Reflexion des Geistes, der im Ausgang von sich selbst die Weltwirklichkeit durchgeht, um in sich selbst zurückzukehren; - die „physische“ ( sichtbaren Weltbau zeigt, wie Kronos, aufgefasst als Chronos, die Eigenart der Zeit lehrt, das von ihr Hervorgebrachte auch wieder zu verschlingen;

- die psychischen Auffassungsarten ( $\psi$ vхккоi), die im narrativen Bild vom nachwuchsverschluckenden Vater erklären, wie Gedanken als von der menschlichen Geisttätigkeit hervorgebrachte trotzdem in dieser Geisttätigkeit verbleiben;

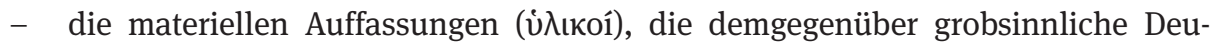

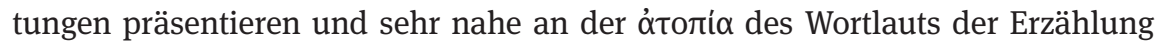
bleiben: Sallust schmäht an dieser Stelle die Ägypter dafür, dass sie mit ihrer Darstellung der Götter mit Tierleibern oder Tierhäuptern dieser Auffassungsweise nahestehen.

Keine dieser Auffassungsweisen, auch nicht die materiell identifizierende, nimmt die mythische Erzählung allerdings primär als einmalige Geschichte, die sich so zeitlich lokalisierbar tatsächlich, historisch ereignet hat.

Während mit dem historischen Faktum alles erfüllt zu sein scheint und die „Fülle der Zeit“ dann ein für allemal für sich steht, verlangen die verschlüsselten unzeitlich gültigen mythischen Geschichten nach einer erklärenden Entschlüsselung - darin Märchen vergleichbar, die man Kindern erzählt, nicht, um sie zu lehren, dass es die

11 So bei Plot. enn. VI 9[9]3,37-54. Vgl. dazu ergänzend die Ausführungen z. B. bei Pierre Hadot: Wege zur Weisheit. Frankfurt 1999 (frz. 1995), S. 195. 
„atopischen“ Schreckgestalten wie Drachen, Hexen und andere Geschäftsführer des Bösen wirklich gibt, sondern um sie zu lehren, dass das Böse in all seinen Auftretensgestalten überwunden werden kann, wie es in einem berühmten Ausspruch Chestertons heißt. ${ }^{12}$ Auch diese bunten und teilweise befremdlichen Märchen sollen ja den Auftakt dazu geben, zu einer reifen Bestimmung von Gut und Böse zu führen und im Loslassen der Geschichten zur Überzeugung zu gelangen, es lohne sich, für das Gute einzustehen. Damit bewegt sich Sallust gänzlich innerhalb des Rahmens, den die platonische Tradition vorgibt. ${ }^{13}$

Sallust kontrastiert in diesem Zusammenhang (De dis et mundo III 3) offenbar bewusst ein aus dem Christentum bekanntes Zugangsprinzip, das sich vielleicht am bündigsten mit einem Hinweis auf ein Bibelzitat anzeigen lässt: „Vater, ich danke dir, dass du das den Klugen und Weisen verborgen hast, den Kleinen aber offenbart hast“ (Mt 11,25). Für Sallust kommt es mit der platonischen Allgemeinauffassung offenbar im Gegenteil darauf an, dasjenige, was den im Geiste Kleinen immer hinter einem Getöse von Extravaganzen verschlüsselt bleiben wird, durch Geistesübung zu entschlüsseln. Der Wortlaut der Mythenerzählungen hat es dann sozusagen mit dem Christentum gemeinsam, „Platonismus fürs Volk“ zu sein, nicht aber der Sinn der Mythen: Der erschließt sich der philosophischen Askesis, dem Abstreichen des Bildlichen und dem Lösen von den Phänomenen, wie es der Schulplatonismus lehren will und wie es den Weisen vorbehalten bleibt. (Das wiederum zeigt, wie weit der Platonismus des vierten Jahrhunderts vom antiken religiösen Denken entfernt steht, wo das Bild häufig genug schlicht das Gemeinte ist. ${ }^{14}$ Es ist interessant zu sehen, wie Sallust im Bestreben, die christliche Denkfigur vom Realsymbol zu vermeiden, damit in recht „unantike“ Deutungsmuster verfällt. Spätere Platoniker werden das - teilweise zumindest und unter vielen Mühen - zu korrigieren haben. ${ }^{15}$ ) Das alles soll nach Sallusts Ansicht das Bildliche freilich nicht gänzlich annullieren. Aber es zeigt, wie das Göttliche im Konkreten der plastischen Wirklichkeit von Welt und Mythos „vermummt“ ist. Ähnlich, wie Thomas Mann es beschreibt:

12 „Fairy-tales do not give the child the idea of the evil or the ugly; that is in the child already, because it is in the world already. Fairy-tales do not give a child his first idea of bogy. What fairy-tales give the child is his first clear idea of the possible defeat of bogy. The baby has known the dragon intimately ever since he had an imagination. What the fairy-tale provides for him is a St. George to kill the dragon." (G. K. Chesterton: Tremendous Trifles. New York 2007, S. 49).

13 Vgl. z. B. die wohl aus der Wende vom zweiten zum dritten Jahrhundert stammende Schrift des Pseudo-Plutarch De Homero (II) 92. Dort wird gesagt, der Mythos habe zwar den Charakter eines Rätsels (alvvy $\mu \alpha$ ), aber darin sei angesichts der pädagogischen Absicht dahinter nichts Sonderbares

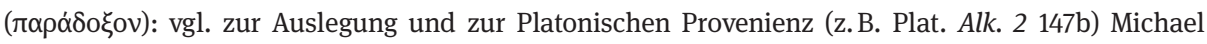
Hillgruber: Die Pseudoplutarchische Schrift De Homero, Teil 2. Stuttgart/Leipzig 1999, S. 211.

14 Vgl. dazu u.a. Clifford Ando: The Matter of the Gods. Religion and the Roman Empire. Berkeley/Los Angeles/London 2008, dort insbesondere das Belegbeispiel auf S. 22-27.

15 Vgl. dazu z.B. Harold Tarrant: Literal and Deeper Meanings in Platonic Myths. In: Catherine Collobert/Pierre Destrée/Francisco J. Gonzalez: Plato and Myth. Studies on the Use and Status of Platonic Myths. Leiden/Boston 2012, S. 47-66. 
Gleichzeitigkeit ist die Natur und Seinsart aller Dinge, ineinander vermummt erscheinen die Wirklichkeiten, und nicht weniger ist ein Bettler ein Bettler, weil möglicherweise ein Gott sich in ihn verstellt. Ist nicht ein Strom ein Gott, von Stiergestalt oder auch von der eines bekränzten Mannweibs mit doppelartiger Brust, hat er das Land nicht geschaffen, und nährt er es nicht? Das hindert nicht ein sachliches Verhalten zu seinem Wasser, nüchtern gleich diesem: man trinkt's, man befährt es, man wäscht sein Leinen darin, und nur das Wohlgefühl, das man empfindet beim Trinken und Baden, mag einer Mahnung an höhere Gesichtspunkte gleichkommen. Zwischen Irdischem und Himmlischem ist die Grenze fließend, und nur ruhen zu lassen brauchst du dein Auge auf einer Erscheinung, damit es sich breche ins Doppelgesichtige. ${ }^{16}$

Positiv konfrontieren lässt sich dieser Gedanke bei Sallust mit einer Stelle aus der wohl an die Wende des zweiten zum dritten Jahrhundert zu verweisenden pseudo-plutarchischen Schrift De Homero ([II] 92), die für diese Tradition der Mythenauffassung so etwas wie einen Schlüsselcharakter zu haben scheint. Ähnlich wie bei Sallust herrscht hier

der Gedanke vor, daß die in der Dichtung verborgene Wahrheit mit Hilfe des Mythos vor falschen Interpretationen durch die Masse geschützt werden kann; nur die Lernbegierigen dringen zu ihr vor und werden durch die mythische Verkleidung zusätzlich zum Nachdenken angespornt, während die Unverständigen gar nicht erst in Versuchung geraten, die Geheimnisse zu entweihen, sondern sich an der äußeren Hülle erfreuen. ${ }^{17}$

Doch lässt sich die scheinbare, oberflächliche, offenkundige oder vermeintliche ó тоті́ $\alpha$ des Mythischen eben noch in anderen Schattierungen auffassen und erklären als bei Sallust. Im Folgenden soll daher der Versuch unternommen sein, die átoтí des Mythischen nach möglichen Bedeutungsvarianten zu entschlüsseln, die sich allesamt bei platonischen Autoren finden lassen, um dadurch diese verschiedenen Varianten mit verschiedenen platonischen Denkern in Verbindung zu bringen, bei denen sich diese áтоті́ $\alpha$ sozusagen dingfest machen lässt. Das Hauptaugenmerk wird dabei auf stichprobenartig ausgesuchten Autoren des vierten Jahrhunderts liegen und auf dem bei Sallust formulierten Gedanken der vorsätzlich befremdenden Abwegigkeit der Mythenbilder, denn das dürfte nach redlichem Ermessen die einende Hauptthese der paganen philosophischen Auffassungen im vierten Jahrhundert darstellen. Den Anfang machen soll allerdings ein Blick auf Platon. In Platons Auffassung vom Mythenerzählen finden sich nämlich die Versatzstücke der Erklärung bei Sallust allesamt präformiert die pädagogische Entfremdung genauso wie die gezielte Provokation des Denkens, die Bildwerttheorie genauso wie der anagogische Sinn der Mythen.

16 Thomas Mann: Joseph und seine Brüder, Bd. 2. Frankfurt a.M. 1986, S. 902.

17 Hillgruber (s. Anm. 13), S. 212, übrigens explizit mit Verweis auf De dis et mundo III 4. Vgl. zusätzlich zum „Hintersinn“ der Mythen in den spätantiken platonischen Deutungen Reinhold Merkelbach: Isis regina - Zeus Serapis. Stuttgart/Leipzig 1995, S. 335-339. 


\section{Die átoría des Mythos als Kuriosität: Platon}

Für Platons Philosophie ist die Dialogform charakteristisch und sie ist auch für die inhaltliche Deutung der platonischen Werke von kaum zu überschätzendem Belang. ${ }^{18}$ Dass in den Dialogen auch monologische Passagen von Mythenerzählungen auftauchen, ist somit nicht so ohne Weiteres zu erwarten. Auffällig ist dabei allenthalben, dass jeder Platonische Mythos traditionelle mythische Versatzstücke oder Strukturen integriert. Und das mit Absicht: Mit einem Mythos will Platon offenbar immer etwas Bekanntes anklingen lassen, da das Mythische dazu dient, über geläufige Motive Neues oder Außerordentliches, das der Dialog erbracht hatte, narrativ nahe zu bringen. Dieses Verfahren ist dem Platonischen Mythos mit der Einführung neuer Bedeutungen für überkommene „normalsprachliche“ Wörter durch Platon in den Dialogen gemeinsam. ${ }^{19}$

Warum das bei Platons Mythenerzählungen so ist, lässt sich wohl vor allem mit folgendem Hinweis erklären: Eines der identifizierenden Kennzeichen ${ }^{20}$ der Mythen bei Platon ist, dass sie bevorzugt am Beginn oder am Ende einer dialektischen Dialogpassage stehen und somit ihre psychologische oder pädagogische Stoßrichtung offenbaren. Der Mythos gibt Anlass zu einer argumentativ begründenden Erörterung oder schließt eine solche ab, etwa, um ihre Ergebnisse emotional zu festigen. Der Mythos ist somit zum guten Teil auch wie eine captatio benevolentiae über das Hilfsmittel des kulturell Vertrauten zu verstehen, als das Einbringen einer „heimeligen“ Motivik aus bekannten Mythenthemen.

Aus den solcherart dialogdienlichen Charakteristika der Platonischen Mythen lassen sich nun verschiedene durchaus positive Wirkungen in der Absicht des Mythenerzählens ersehen, die Jean Pépin als „objektive“ und „subjektive Wohltaten“ (bienfaits) oder „Dienste“ der Platonischen Mythen folgendermaßen zusammengefasst hat: ${ }^{21}$

Auf der „objektiven Seite“ steigert oder erschließt der Platonische Mythos in der bildlichen Wiederholung des in der Argumentation Gewonnenen den Bedeutungsreichtum einer Aussage durch vielfache Auslegungsmöglichkeiten; er erleichtert die Analyse und Darstellung eines komplexen Problems durch den Appell an Intuition, visuelles Vorstellen und Ähnliches; und er respektiert und kennzeichnet Tabufelder

18 Für die folgenden Überlegungen vgl. auch Christian Schäfer: Art. „Mythos/Mythenkritik“. In: Chr. Horn/J. Müller/J. Söder (Hg.): Platon-Handbuch. Stuttgart 2009, S. 209-213.

19 Vgl. zu diesem Vorgehen beispielhaft Karl Kerényi: Griechische Grundbegriffe. Zürich 1964, S. $12-$

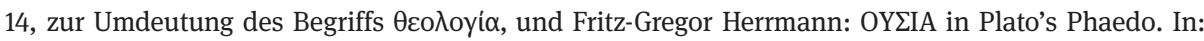
ders. (Hg.): New Essays on Plato. Language and Thought in Fourth-Century Greek Philosophy. Swansea 2006, S. 43-73, vor allem S. 44-59, zur Neudeutung von oủoía.

20 Vgl. hierzu die Merkmalssammlung des platonischen Mythos bei Glenn W. Most: Platons Exoterische Mythen. In: M. Janka/Chr. Schäfer (Hg.): Platon als Mythologe. Neue Interpretationen zu den Mythen in Platons Dialogen. Darmstadt 22014, S. 9-21, 13-15.

21 Vgl. Jean Pépin: Mythe et allégorie. Paris 1972, S. 479-482. 
und Grauzonen von Themenbereichen, indem er in Bildern davon redet. Das also ist der Effekt der kulturellen Oikeiosis des Gedankens, seiner funktionalen „Heimeligkeit".22

Von der „subjektiv wohltuenden“ Seite her betrachtet ist es mit dieser zunächst gezielt eingesetzten Heimeligkeit allerdings schnell vorbei. Der Mythos nämlich entfaltet beim Hörer eine kinetische Energie, er stimuliert zum Weiterdenken, und das oft vor allem durch seine prima facie absurd anmutenden oder kuriosen Darstellungselemente, seine ótoríaı also - so sagt es Platon deutlich im Phaidros (229e): Die mythische Rede von Chimären und Pegasen und anderen Kuriositäten, átoríaı (,Verlegenheiten“ übersetzt Ernst Heitsch ${ }^{23}$ ), dieser Art verweise den Menschen doch letztlich auf sich selbst zurück. Denn bevor man sich die Frage stellen dürfe, ob diese mythischen ótođía alle wahr seien, müsse man sich ja genau genommen erst einmal darauf besinnen, ob der Mensch in seiner Bauart und seinen Möglichkeiten denn nicht ein viel kurioseres Wesen sei als all diese Mythengestalten oder sogar der phantastisch unwahrscheinliche Typhon in den mythischen Urgeschichten. Diese Phaidros-Stelle ist im Übrigen auch deswegen für den Zusammenhang mit Sallust so interessant, weil sie die ótoтía der Mythen durch das explizite Zitat des delphischen Aufrufs „Erkenne dich selbst“ mit dem Orakelwesen in Verbindung bringt.

Der Platonische Mythos nimmt somit den philosophischen Theorieübungen des Dialogs, die er kontrastiert, bildhaft zusammenfasst oder widerspiegelt, die Langeweile und Trockenheit, womit er gleichzeitig den Dialog auflockert und durch den gezielten Einsatz der kuriosen Erzählmomente mit Spannung lädt; und er ist dank dieser kuriosen Denkanstöße gleichsam ein hermeneutischer Belastungstest, wie eine Nagelprobe zur Aussonderung oder Unterscheidung derer, die sich auf Denken und Argumentation des Autors - oder zumindest: des Sprechers im Dialog - einlassen wollen oder nicht. ${ }^{24}$

Beide bei Sallust vermerkten Seiten des Mythischen sind also bei Platon deutlich da und erklären sich aus der pädagogischen Funktion, die Platon im Mythos sieht und die er deswegen in seinen Dialogen auch forçieren möchte: Das narrativ Zugängliche als Zugangserleichterung und Appell an die Vorstellungskraft und gleichzeitig das motivisch Verstörende als pädagogischer Anreiz, als Denkanstoß für diejenigen, die weiterdenken können und wollen. Wichtig ist vor allem der zweite Aspekt, da er im Weiteren eine Erklärung für die taktische Verwendung der óto $\boldsymbol{i}^{\alpha} \alpha$ eröffnet: Denn diese ist wie gesagt zu

22 Ähnlich lautet das Fazit zum Er-Mythos der Politeia bei Stephen Halliwell: The Life-and-Death Journey of the Soul: Interpreting the Myth of Er. In: G. R. F. Ferrari (Hg.): The Cambridge Companion to Plato's Republic. Cambridge 2007, S. 445-473: „tests the limits of understanding“, „yields a surplus of possible meanings that cannot be adequately encompassed by any simple interpretation“, ,stands in a kind of challenging counterpoint [...] with the rest of the Republic" (S. 445).

23 Platon, Phaidros. Übersetzung und Kommentar von Ernst Heitsch (Platon, Werke Bd. III,4), Göttingen 1993, ad locum.

24 Ähnliches zeigt die Sammlung Platonischer Selbstaussagen zu den verschiedenen Mythen bei Geneviève Droz: Les mythes platoniciens. Paris 1992, S. 15. 
verstehen als ein pädagogischer oder hermeneutischer Belastungstest. Wenn Kurt Flaschs augenzwinkernde Behauptung stimmt, der Platonismus habe nie für sich in Anspruch genommen, eine „Philosophie des gesunden Menschenverstands“ zu sein,, ${ }^{25}$ dann ist die $\alpha$ толі́ $\alpha$ des Mythischen bei Platon gerade sehr platonisch: Sie bewirkt eine Herausnahme des Hörers oder Lesers aus dem Üblichen und dem common sense des alltäglich Begegnenden, sie stört ihn förmlich auf und wird somit zum Anfang des Nachdenkens. ${ }^{26}$

Platon selbst gesteht die ó Teilen bewusst in einen traditionellen Rahmen gesetzten - Mythen an verschiedenen

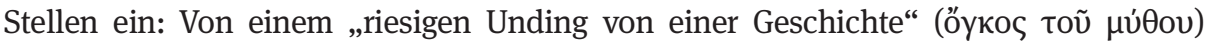
spricht er etwa im Politikos (277d) und entschuldigt sich für die konventionsbrechende Sperrigkeit der Erzählung; ${ }^{27}$ seine Dialogfigur Phaidros lässt Platon (Phaidr. 275b) anmerken, Sokrates habe die erstaunliche Gabe, ganz wunderliche „ägyptische“ und noch fremdartigere Mythen jederzeit wie bestellt aus dem Ärmel schütteln zu können; und im Gorgias (523a) muss Sokrates den Kallikles als Einleitung zum Vortrag seines Jenseitsmythos vorwarnen: „Was ich dir jetzt erzähle, wird dir wie ein abwegiges Mär-

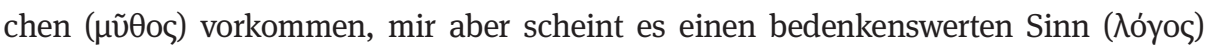
auszudrücken.“

25 So Kurt Flasch im Vorwort zu ders. (Hg.): Parusia. Studien zur Philosophie Platons und zur Problemgeschichte des Platonismus. Festgabe für Johannes Hirschberger. Frankfurt a.M. 1965.

26 Man sollte nicht übersehen, dass damit ein bedeutender Aspekt des traditionellen Mythenerzählens noch eingefangen wird, nämlich derjenige der Herausnahme aus der Gegebenheit des Normalen in zeitlicher Hinsicht: Zwar ist der platonische Mythos (soweit man weiß) nicht mehr Mythos in seiner Funktionalität als rituelle Vergegenwärtigung und er wird deswegen wohl auch keine Umsetzung in gottesdienstliche „Handlungszitate“ gekannt haben. Doch immerhin lässt sich auch vom platonischen Mythos behaupten: Als Mythos ist er in seiner eigenen Art und Weise anti-,,säkular“, da er den Hörer gezielt aus den Problemlagen des Saeculums - der Weltzeit - herausholt und, wenn doch nicht festlich, so doch geistig erhebend in Distanz zum solchermaßen aufgefasst Säkularen tritt. Platons Mythos erfüllt damit als Teil der platonischen Weltsicht die Diagnose, die Mircea Eliade dem Phänomen „Mythos“ in einer seiner heraushebenswerten kulturellen Transformationen ausstellt: Mythologie drängt in einigen Kulturen dazu, so Eliade, statt die ewige rituelle Wiederkehr in kosmischen Perioden - wie rituell vergegenwärtigend wirkenden Jahrestagen der erzählten Ereignisse - vorzugeben und mit Inhalt zu füllen, das Ewige als das dem Rhythmus der Wiederkehr Enthobene oder diesen Rhythmus Überdachende anzupeilen und sich damit der „Weltzeit“ zu entziehen, sie zu übersteigen oder in irgendeinem Sinne obsolet zu machen (vgl. Mircea Eliade: Ewige Bilder und Sinnbilder. Frankfurt a.M. 1998, S.65 - 68). In dem Maße, wie auf Platons Mythen Hans-Georg Gadamers Verdikt tatsächlich zutreffen sollte, dass sie nicht die „unenträtselte Gewißheit“ des religiösen Weltbezugs, sondern „das ins Kosmische ausgezogene Lineament der sich im Logos deutenden Seele“ zum Thema haben, wird Eliades Diagnose also womöglich zutreffen, und in dem Maße, wie der spätere Platonismus die Mythen als beides affirmiert sehen wollte, zum entsprechenden Teil ebenfalls (vgl. Hans-Georg Gadamer: Plato und die Dichter. In: ders.: Gesammelte Werke 5. Tübingen 1985, S.187-211; das Zitat findet sich auf S. 208). Zu einem Beispiel der rituellem Auffassung der Mythen im Platonismus vgl. auch unten Anm. 44.

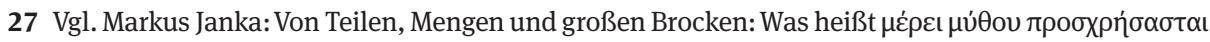
in Platons Politikos? In: RhM 145 (2002), S. 186-197. 
Die Platonische Theorie der Provokationsleistung des Mythenerzählens mit kuriosen Verstörelementen löste nun eine lange Tradition der Auseinandersetzung mit Sinn und Wert des Mythischen in der Philosophie aus. Sallust gehört in diese Tradition. Aber auch andere, von denen jetzt noch in stichprobenartiger Auswahl die Rede sein soll.

\section{3. '́xоті́ $\alpha$ als Befremdlichkeit und Unanständigkeit: Plutarch, Kelsos und Origenes}

Der (sit venia verbo) „Topos der átoтía“ spielt auch eine maßgebliche Rolle in der Diskussion um die allegorische Mythendeutung. Ganz im Sinne der von Platon vorgezeichneten heilsam verstörenden Funktion des Mythos und der von Sallust ins Auge gefassten psychagogischen Funktion dieser Verstörung spricht etwa Maximos von Tyros $(4,6 a)$ am Ende des zweiten Jahrhunderts von den anagogischen Wirkungen der Mythen als „,anleitende Handreichungen“ ( $\chi \varepsilon\llcorner\rho \alpha y \omega y i \alpha$ ist der hier verwendete Fachterminus der platonischen Terminologie) ${ }^{28}$, welche die Seele in ihrer Auslegungsarbeit an Text und

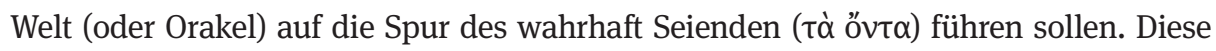
platonische Allgemeinauffassung hält sich erstaunlich invariant über die Jahrhunderte durch und lässt sich an der Wende vom vierten zum fünften Jahrhundert bei Augustinus belegen, wenn er ganz platonisch sagt, die dunklen Worte des Bibeltextes bildeten eine stets neue Herausforderung an den Verstand, transponierend den richtigen Sinn hervorzuholen. Auch hier steht das Motiv der „Hintersinns“, der erst hervorgeholt werden will, und der heilsamen Wirkung dieser Hintersinnsprovokation für den Verstand, der dadurch zur Tätigkeit angeregt wird, im Zentrum der Aufmerksamkeit. ${ }^{29}$

Plutarch berichtet nun, dass die Alten als den mit Mühe hervorzuführenden „Hintersinn“ (úróvoı $\alpha$ ) genau das benannten, was später mit dem terminus technicus $\alpha \lambda \lambda$ пуорí $\alpha$ bezeichnet wurde. ${ }^{30}$ Dieser unterschwellige Hintersinn (oder eher tragende „Untersinn“) der บ்ió-voı $\alpha$ ist in der mythischen Erzählung selbst nicht offen präsent und

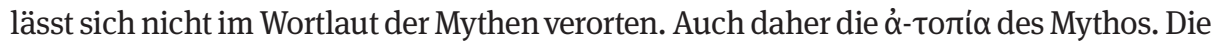
Befremdlichkeit des Wortlauts kann im Sinne eines Alteritätsmoments dann als effizienter Ursprung der Allegorese als hermeneutischem Prinzip gelten, die á zeichnet aber bemerkenswerterweise auch gleichzeitig die Grenze der Allegorisierbarkeit, und das ist nun besonders interessant:

28 Diese $\chi \varepsilon\llcorner\rho \alpha y \omega y i ́ \alpha$ ist typisch platonische Ausdrucksweise. Sie wird genauso von christlichen Denkern verwendet: Vgl. Wiebke-Marie Stock: Theurgisches Denken. Zur Kirchlichen Hierarchie des Dionysius Areopagita. Berlin 2008, S. 171-196. Für den Text des Maximos von Tyros folge ich der Übersetzung: Maximos von Tyros, Philosophische Vorträge. Übersetzt von Otto und Eva Schönberger. Würzburg 2001. 29 Vgl. Aug. doctr. chr. II 6,7: quod totum provisum esse divinitus non dubito ad edomandam labore superbiam et intellectum a fastidio revocandum, cui facile investigata plerumque vilescunt. Zu dieser Stelle, dem Zitat des Maximos und dem in der Spätantike bekannten Motiv, Autoren drückten sich bewusst und gezielt unklar aus, vgl. auch Hillgruber (s. Anm. 13), S. 213.

30 Plut. mor. 19E (De audiendis poetis 4). Dazu einmal mehr Hillgruber (s. Anm. 13), S. 213. 
Diese Grenze sahen die Platoniker nämlich auch dort, wo zum Beispiel die konkurrierende stoische Schule in der Allegorisierung alter Mythen weitgehend bedenkenlos vorging. Während die Stoiker ihre Mühe darauf verwendeten, die Mythen auf das „physikalische“ Erklären des Zusammenkommens der weltkonstitutiven Elemente zu zentrieren, ${ }^{31}$ blieben die Platoniker bei der Platonischen Grundüberzeugung, der Mythos müsse ein moralisches und vor allem psychagogisches Potential haben und selbst dort, wo man den Stoikern Recht zu geben habe, dass hier in bunten Abfolgeerzählungen von der Bauart der Welt die Rede ist, müsse diese Bauart in der narrativen Darbietung einen kosmo-logischen, also in der Welterkenntnis sinnstiftenden und somit moralisch anleitenden Wert ${ }^{32}$ aufweisen - ganz so wie bei Platons kosmologischen Mythen, die allesamt ein „psychozentrisches Weltbild“33 malten. Tatsächlich sind uns Fälle überliefert, in denen sich die Platoniker gegen die Stoiker dort absetzen, wo die ó толí $\alpha$ der Mythen als allzu plastisch den moralischen Sinn des Mythenerzählens überhaupt gefährdet, zu verdecken droht oder gänzlich ad absurdum führt. ${ }^{34}$ Es gibt für die paganen

31 Vgl. dazu das Schlusskapitel des stoischen Mythenhandbuchs des Lucius Annaeus Cornutus (nat. 35, 13): „In dieser Weise, mein junger Schüler, solltest du nun schon auch das übrige, was über die Götter in mythischer Form überliefert zu sein scheint, nach dem hier dargebotenen Vorbild auf die aufgezeigten Grundelemente beziehen können; sei dabei überzeugt, dass die Früheren nicht die ersten besten waren, sondern dass sie fähig waren, die Natur des Kosmos zu verstehen, allerdings dazu neigten, sich über sie in Symbolen (symbola) und Rätseln (ainigmata) philosophisch zu äußern“ (Lucius Annaeus Cornutus, Einführung in die griechische Götterlehre, hgg., eingeleitet und übersetzt von Peter Busch und Jürgen K. Zangenberg. Darmstadt 2010). Ohne allzu stark zu vereinfachen lässt sich tatsächlich behaupten, dass die stoische Allegorese sich darum drehte, ,die traditionellen Götter in Eigenschaften, Teile und Vorgänge der physischen Welt komplett aufzulösen, jene durch diese restlos zu ersetzen“ (Fabio Berdozzo: Götter, Mythen, Philosophen. Lukian und die paganen Göttervorstellungen seiner Zeit. Berlin 2011, S. 181). Gleichermaßen interessant wie verwirrend ist vor diesem Hintergrund, dass Eusebius von Caesarea, die Schrift des Porphyrius Adversus Christianos zitierend, überliefert, der Lieblingsschüler Plotins habe dem Origenes unterstellt, er sei bei den Stoikern Chairemon und Cornutus für die allegorische Methode in die Schule gegangen, die er dann auf die Bibelexegese anwendete (Eus. h.e. 6,19,8, GCS 9,2, S. 560). Die Leitlinie für die platonische Kritik an der stoischen Methode der Allegorisierung gab Plutarch vor, insbesondere in seinen Ausführungen mor. 19E-20B (De audiendis poetis 4). Vgl. dazu u. a. Niehoff (s. Anm. 9), S. 136-137.

32 Zur Unterscheidung von Kosmographie und Kosmologie in der Philosophie der Antike, wobei jene sinnneutral als „Plan oder Beschreibung der Welt [...] in ihrer Struktur, ihren etwaigen Abstufungen, regionalen Unterschieden, usw.“ anzusehen ist, diese aber als eine Weltdarstellung, die unter Einrechnung des Menschen eine sinngebende Bedeutung des Kosmos eröffnet, vgl. Rémi Brague: Die Weisheit der Welt - Kosmos und Welterfahrung im westlichen Denken. München 2005 (frz. 1999), S. 12 und S. 14.

33 Vgl. David Sedley: Teleology and Myth in the Phaedo. In: Proceedings of the Boston Area Colloquium in Ancient Philosophy 5 (1989), S. 359-383, insbesondere S. 373.

34 Dabei kam diese Art der Allegorisierung ursprünglich als eine der dort als möglich gehandelten Auslegungsvarianten des Mythos offenbar aus der Schule Platons selbst und wurde von den Stoikern dann übernommen. Aus der Testimonienlage ergibt sich, dass insbesondere Xenokrates, der zweite Nachfolger Platons in der Akademie, hier eine richtungsweisende Rolle gespielt hat. Vgl. dazu John Dillon: The Heirs of Plato. A Study of the Old Academy (347-274 BC). Oxford 2003, S. 154. 
wie für die christlichen Platoniker eine auch für jede Allegorisierung unüberbrückbare Anstößigkeit des Mythos.

Es ist in diesem Zusammenhang von nicht zu unterschätzender Bedeutung, wenn Origenes gegen Kelsos in folgendem Fall „platonisch“ Stellung bezieht (Cels. IV 48): Im Heiligtum der Hera in Argos - nach anderen Quellen in Samos - gab es (offenbar) eine Darstellung der Göttin, wie sie den Göttervater Zeus oral befriedigte. Wie auch immer der ursprüngliche Sinn der Darstellung gewesen und welche Geschichte auch immer hier verarbeitet gewesen sein mag: Die Stoiker hatten den Aussagen der Origenes-KelsosDebatte nach anscheinend weder Bedenken noch Mühe, dieses Bildnis als kosmogo-

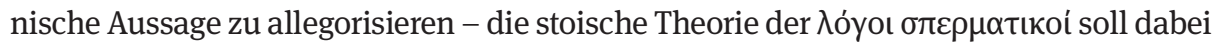
eine gewisse Rolle gespielt haben. ${ }^{35}$ Nun scheint Kelsos dieser Auslegung irgendwie Sympathien entgegengebracht $\mathrm{zu}$ haben oder doch zumindest bei Origenes in Verdacht zu stehen, diese stoische Auslegung zu verteidigen oder Verständnis für sie aufzubringen. Origenes für seinen Teil wendet sich nun erstens gegen die Darstellung selbst, da sie das Wesen des Göttlichen profaniere, und zweitens gegen den Versuch, diese Profanation auch noch durch die allegorische Zuweisung eines höheren - und sei es auch nur „physikalisch“ allegorisierenden - Sinns zu adeln und akzeptabel machen zu wollen. Die erste Stoßrichtung ist klar gegen die alten griechischen Religiositätsausdrücke gerichtet und will das Christentum als frei von solcherlei (!) Unanständigkeiten in der Gottesdarstellung erweisen; die zweite Stoßrichtung ist eigentlich keine christliche, sondern eine genuin platonische: ${ }^{36}$ Was die alte Religion an inakzeptablen Anstößigkeiten aufweise, dürfe auch nicht in der Menschengemeinschaft (bei Platon: der Polis)

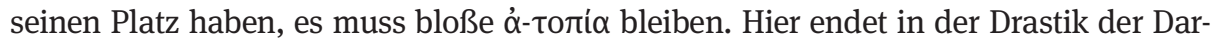
stellung die effektive Möglichkeit, dem Mythos einen psychagogischen Sinn und ein moralisches Entfaltungspotential zuzuweisen und ihn für ein für beide Seiten würdiges Gott-Mensch-Verhältnis in Anspruch zu nehmen. Die Polemik des Origenes gegen Kelsos erweist sich somit als genialer Kunstgriff, wobei es dem Platoniker Origenes zustatten

35 Vgl. Marianne Wifstrand Schiebe: Chrysippos und das obszöne Bild von Zeus und Hera. Eine forschungskritische Sichtung der Evidenz. In: Mnemosyne 65 (2012), S. 469-479; Robert Lamberton: Homer the Theologian. Neoplatonist Allegorical Reading and the Growth of the Epic Tradition. Berkeley 1986, S. 210; Maarten Jozef Vermaseren: Studies in Hellenistic Religions. Leiden 1979, S. 218.

36 Korrekter ausgedrückt ist weder die erste ausschließlich oder auch nur eindeutig „,christlich“ noch die zweite ausschließlich oder eindeutig „platonisch“: Wie noch des Näheren zu sehen sein wird, ist es gerade ein Anliegen auch und insbesondere der Platoniker, bestimmte Praktiken und Darstellungsformen des Religiösen philosophisch zu kritisieren und gewissermaßen ,aufzuheben“; andererseits ist es ein Zug, den das Christentum mit dem Platonismus und der gewichtigen Mehrheit der antiken Philosophenschulen gemein hat, dass auch religiöse Formen und Vorstellungen, die nicht zum eigenen Sinnsystem gehören, als ernstzunehmende Quelle von Wahrheiten und Weisheit verstanden werden im Sinne des Christentums also etwa als eine praeparatio evangelii. Damit teilen Platonismus und Christentum wie in so vielen anderen Dingen einen Grundzug, der für das Verhältnis von Denksystemen oder -schulen ein Charakteristikum der Zeit seit etwa dem ersten Jahrhundert vor Christus bezüglich der Einschätzung religiöser Praktiken und „Weisheitslehren“ darstellt: Vgl. dazu die einschlägige Studie von Peter van Nuffelen: Rethinking the Gods. Philosophical Readings of Religion in the Post-Hellenistic Period. Cambridge 2011. 
kam, dass der Platoniker Kelsos offenbar den Fehler begangen hatte, sich irgendwie auf die Seite der stoischen Allegorese der fraglichen Darstellung zu stellen oder ihr Sympathien entgegenzubringen: ${ }^{37}$ Der Christ Origenes konnte sich anhand der umstrittenen Deutung eines paganen Mythos mit seiner Position als der bessere Platoniker erweisen als Kelsos, jedenfalls aber konnte er sich für pagane Platoniker als annehmbarer erweisen als ein paganer Stoiker.

An solchen drastischen Beispielen und anhand der hermeneutischen Verzweiflungstat, sich in der Verteidigung der mythischen Götterdarstellung schließlich vielleicht sogar solchen stoischen Allegorisierungen an die Brust zu werfen, lässt sich auch verdeutlichen, wie hart im Platonismus das Ringen darum war, den Wortsinn und die plastische Darstellungsweise des Mythos ernstzunehmen und sich nicht einfach darüber hinwegzusetzen. Zumindest was die Mythen Platons betraf, war es platonische communis opinio, dass beides, Wortsinn und Materialsinn, bis zu gewissen Punkten stets widerspruchsfrei Hand in Hand gehen könne. Auch hier findet der christliche Platonismus ganz ähnliche Wege wie der pagane. So gehört der Platoniker Augustinus zu den Bibelexegeten, die den mehrfachen Wortsinn des Bibeltextes dadurch verteidigen, dass sie jede der Sinnstufen, angefangen von der wortwörtlichen Auffassung, als mit den anderen vereinbar ansehen, auch wenn die elaborierteren Sinnstufen stets den Verständnisschlüssel zum Literalsinn bilden können.

So gilt für die im Platonismus mit Hingabe und immer besserer Ausarbeitung betriebene Orientierung am Hintersinn und der Erschließungsarbeit, die das Wesentliche der Aussage nicht im Text, sondern „hinter“ dem Text sieht, Ähnliches wie für die philosophische Weltdeutung. Diese war in der Antike früh an den Punkt gelangt, der den Aufruf nötig werden ließ, die Erscheinungen über der Hintergründigkeitsarbeit in der Wirklichkeitserklärung nicht gänzlich zu vergessen, „die Erscheinungen zu retten“, wie

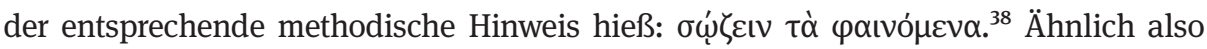
musste die Beschäftigung mit dem Mythos immer wieder zu dem Methodenhinweis zurückkommen, den Wortsinn nicht aufzugeben, sondern ihn in der Erklärungsarbeit zu „retten“.

37 Einem Beitrag aus dem Auditorium der Frankfurter Tagung folgend sei diese Bestandsaufnahme der Position des Origenes noch durch folgenden Hinweis ergänzt: Origenes hat an anderer Stelle auch mit den óтоті́丿ı der Bibelgeschichten gerungen und sie von Fall zu Fall wegen ihrer Abwegigkeit als nicht mehr akzeptabel befunden; vgl. dazu u.a. die mittlerweile zum Klassiker avancierte Arbeit von Joseph W. Trigg: Origen. London 1934, S. 34 u.ö.

38 In dieser Form überliefert bei Simpl. in Cael. 292 b 24. 


\section{4. '́топі́ $\alpha$ als Unsinn oder Konventionsbruch: Kaiser Julian und Heraklit}

Kaiser Julian nimmt Mitte des vierten Jahrhunderts den Faden dort auf, wo ihn die christlich-pagane Debatte bereitliegen hatte: ${ }^{39}$ Mythen erzählen heißt soviel wie „einen instabilen Kompromiss zwischen Wahrheit und Lüge“40 $\mathrm{zu}$ finden, sagt er in einer bemerkenswerten mythentheoretischen Passage seiner Schrift Gegen den Kyniker Herakleios. Dabei ist der Wortlaut der Mythen Lüge, der psychagogische oder moralisch Einsicht stiftende Sinn dagegen wahr. Julians Definition vom mythischen Wortlaut als „Schattenspiel“41 einer strahlenden Wahrheit, deren intensives Licht die meisten Menschen ihrer fehlenden Geisteskraft oder Initiation wegen nicht direkt anzusehen vermögen, geht einerseits via die Schattenspielmetapher des Höhlengleichnisses auf die Vorlage der als Mythos erzählten pia fraus ${ }^{42}$ in Platons Politeia ( $414 \mathrm{bc}$ ) zurück, mit deren

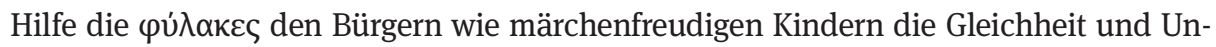
gleichheit des politischen Systems aitiologisch erklären sollen. Tatsächlich ist die pia fraus gewissermaßen eine narrative Auflösung und verschärfende Vereinfachung des Platonischen Aufbaukonzepts für die politische Gemeinschaft - Platonismus fürs Volk

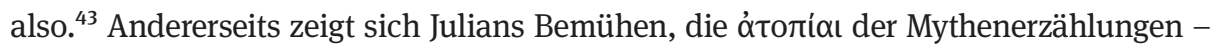
und damit die Anstößigkeiten, wie sie Origenes als Argument ins Feld führte - von vornherein ins Leere laufen zu lassen: ${ }^{44}$ Die $\alpha$ to $\pi_{i} \alpha ı$ sind natürlich Lügen ( $\left.\psi \varepsilon v \delta \tilde{\eta}\right)$, und wo die Mythen die Wahrheit sprächen, seien sie frei von jeder $\alpha$ толí $\alpha$. Mythen haben somit den Charakter eines Rätsels ( $\alpha$ ı̌vı $\mu \alpha):{ }^{45}$ Solange man am Wortlaut bleibt, ergibt sich nur Unsinn, sobald man den Wortlaut untergeht und gewissermaßen hinter sich bringt, eröffnet sich ein ganz anderes Verständnis, es eröffnet sich eine Welt. In dieser Struktur, das heißt in der Rätselhaftigkeit der Rätsel und in der Tatsache, dass Rätsel überhaupt gestellt werden, liegt aber durchaus eine unbestreitbare Sinnhaftigkeit. Ähnlich wie bei einem Witz eröffnet sich nämlich im Moment des Begreifens schlagartig

39 Im Folgenden nach der Schrift Jul. or. 7 (Gegen den Kyniker Herakleios).

40 Maria Carmen De Vita: Giuliano imperatore filosofo neoplatonico. Mailand 2011, S. 108 (mit Hinweis auf die Quelle bei Aelius Theon prog. 3).

41 De Vita (s. Anm. 40), S. 108 (mit Anm. 143) und Jul. or. 7, 206c-207c.

42 Julian selbst spricht von einem Lügengebilde, das sich nach der Notwendigkeit der Seelenanleitung des Lesers richtet (De Vita [s. Anm. 40], S. 107 und Anm. 138: Jul. or. 7, 205c).

43 Vgl. dazu Malcolm Schofield:The Noble Lie. In: G. R. F. Ferrari: The Cambridge Companion to Plato’s Republic. Cambridge 2007, S. 138-164.

44 Aber bei Julian gilt immerhin: Die Mythen sind an Rituelles rückgebunden, sie haben ,einweisenden" Charakter (sie sind $\tau \varepsilon \lambda \varepsilon \sigma \tau$ “ der Mythopoiie tut man Gottes Werk (mit).Vgl. zur Theurgie auch im christlichen Kontext beispielsweise Stock (s. Anm. 28), S. 152-176, und Charles Stang: Apophasis and Pseudonymity in Dionysius the Areopagite: „No Longer I“. Oxford 2012, S. 105-116.

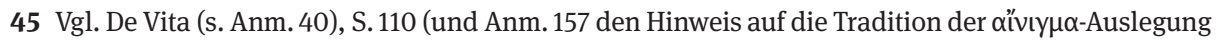
bei Plutarch und Origenes). 
eine ganze stimmige Welt. Auch dieser Gedanke ist in der Tradition gut verbürgt. ${ }^{46}$ Und es ist ein Gedanke, der nach Julian sozusagen die Nagelprobe für die „Echtheit“ des Mythos vorgibt: Eine Erzählung, die keinen welterschließenden hinterweltlichen Sinn aufzuweisen hat, wo der Groschen nicht in einer sinnerschließenden Einsicht fällt, ist kein Mythos, sondern bleibt bloße Lüge, ein Schattenspiel ohne Verweis auf die Lichtquelle, ähnlich wie ein Rätsel oder ein Witz ohne Pointe. In seiner Entgegnung auf einen Kunstmythos des Kynikers Herakleios erhebt Julian genau diesen Vorwurf: Herakleios habe eine bunt ausstaffierte seltsame Geschichte produziert, die keinen philosophischen Erklärwert besitze - und die deswegen schlicht als obszön zu gelten habe. Julian argumentiert hier in der Sache also ähnlich wie Origenes.

In diesem Sinne zitiert Julian dann auch das berühmte Diktum des alten Heraklit von

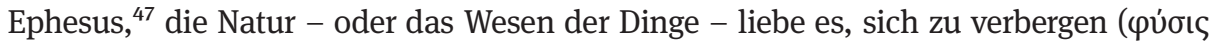

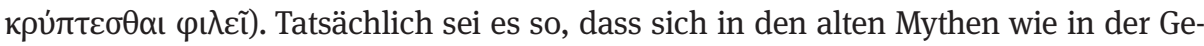
samtwirklichkeit das Wesen der Dinge gleichzeitig zeige und verberge, es sei „hidden in plain view“. Der bei Sallust in De dis et mundo vorfindbare Gedanke, dass sich die Wahrheit in den Mythen als so vertraut menschlich und doch so verstörend nichtmenschlich, so offensichtlich überall und doch so geheimnisvoll, so präsent und gleichzeitig so realitätsenthoben, so schlicht überzeugend und gleichzeitig so wirklichkeitsfremd darbietet, wird mit dem ebenfalls aus Sallust bekannten Gedanken verbunden, die gesamte Welt sei als ein einziger, positiv änigmatischer Mythos anzusehen.

Dazu passt dann im Übrigen auch das Wort, das bei Julian an die systematische

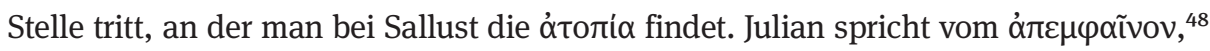
das heißt das „Unangemessene“, „Unpassende“, das „Misfit“, naiv etymologisierend ganz im Sinne des eben zu Julian Geäußerten: das, was in der Erscheinung oder Auftretensweise seinem Inhalt entgegensteht oder nicht mit ihm zu kongruieren scheint.

\section{5. ótomí $\alpha$ als Ortlosigkeit: Porphyrios und noch einmal Julian}

Sallust hatte es damit auf den Punkt gebracht, dass er den Mythos mit der Welt als ganzer verglich, statt ihn mit einer Sage aus vergangener Zeit gleichzusetzen: Diese Dinge, die hier erzählt werden, die átoríaı eingeschlossen, sind nie und nirgends geschehen, doch

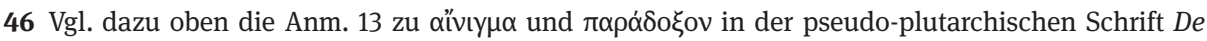
Homero (II) 92.

47 Die Neuplatoniker zitieren Heraklit mit großer Häufigkeit und zahlreiche Heraklitzitate sind uns überhaupt nur durch Schriften der Platoniker bekannt. Im Falle von Julians Mythentheorie in or. 7 kommt aber noch hinzu, dass er seinem Argumentationsgegner, dem Kyniker Herakleios, den besseren Philosophen, den alten Herakleitos aus Ephesos entgegenhält. Dies geschieht nicht nur durch direkte Zitate, sondern auch durch die Häufung typisch „herakliteischer“ Motive wie eben dem Motiv des Rätsels in der Welterschließung (vgl. dazu etwa Heraklit fr. B56, B34 und B93).

48 Vgl. De Vita (s. Anm. 40), S. 111-114; Jul. or. 7, 219a; 217cd; 8, 170ab. 


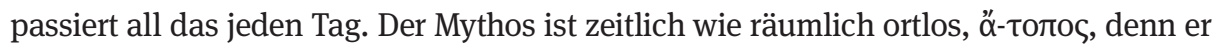
erzählt den Lauf der Welt, nicht den Verlauf einer Geschichte.

Hier gerät man vielleicht an den Kern der eigentlichen Kontroverse von christlichen und paganen Platonikern über den Wert von Mythen. Es geht nicht um einzelne

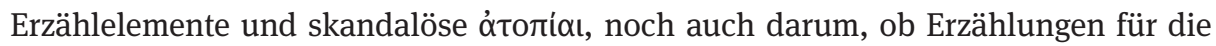
Wahrheit überhaupt etwas taugen. Es geht, so scheint es, um das Bezugsobjekt des Erzählten als raumzeitlicher Gegenstand. Repräsentativ für die christliche Auffassung dürfte die Aussage des Zweiten Petrusbriefs $(2$ Petr 1,16) stehen: Nicht auf ausgeklügelt

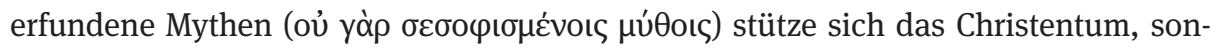
dern auf das Augenzeugnis eines geschichtlich greifbaren göttlichen Machterweises, also auf einmalige historische Tatsachenerfahrungen. Gegen diesen Gedanken der geschichtlichen Parusie in der christlichen Auffassung protestiert Kaiser Julian in seinem Helios-Hymnos, und es ist einem dabei, als würde er hier ganz gezielt gegen den Johanneischen Logos-Hymnos angehen: Die Sonne ist das, was man zu allen Zeiten also ungeschichtlich und keinesfalls einmalig - gesehen und zum normativen Ausrichtungspunkt des Lebens und der Zeiten gemacht hat, ${ }^{49}$ Christus dagegen habe von den noch Lebenden keiner jemals gesehen - ein schwerwiegendes Problem für das

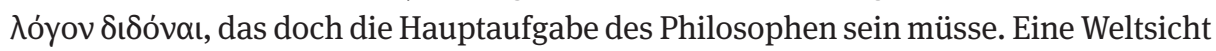
von mythischer Zeitlosigkeit und eine Philosophie des semper, ubique, ab omnibus wird hier der historischen Versicherung „wir haben Seine Herrlichkeit gesehen“ (Joh 1,14) und der Theologie des in illo tempore wirksam entgegengesetzt. Die átoтí findet sich in dieser Betrachtungsweise geradezu positiv gewendet zu einer Ubiquität, die zur Welterklärung besser taugt als ein zeitlich isolierbares Einzelereignis. Der erzählte Mythos ist für Julian die narrativ aufgelöste Grammatik des Kosmos. Gerade als Erzählung eines räumlich wie zeitlich ortlosen Zustands der Welt wird nach Julians These der Mythos also kosmo-logisch in dem von Platon geforderten Sinne. Wie der Mythos in diesem kosmologischen Sinne gesehen als Form göttlicher Selbstmitteilung dem Weltbau gleichgestellt werden kann oder vielmehr der Kosmos (wie bei Sallust gesehen) als ein einziger Mythos verstanden werden darf, belegt nicht zuletzt das zunächst einmal naiv romantisch anmutende Datum, dass die Griechen in den Gestirnkonstellationen ewig wiederkehrende Bebilderungen ihrer Mythen erkannten.

Der einzige vollständig erhaltene Text einer allegorisierenden Auslegung eines (Stücks aus einem) Mythos durch einen führenden Platoniker ist m.W. die um 304/305

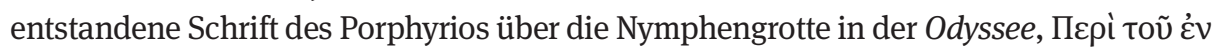

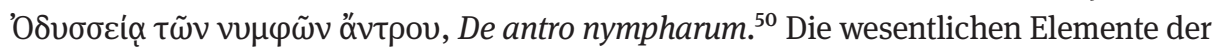

49 Der Gedanke verweist zurück auf Plat. pol. 508a-e.

50 Maßgebliche Edition ist bis auf Weiteres immer noch die von L. G. Westerink: Porphyry, The Cave of the Nymphs in the Odyssey. Buffalo 1969; neuer: Robert Lamberton: Porphyry, On the Cave of the Nymphs. Barrytown, N.Y. 1983. Zur Singularität und Bedeutung des Textes als einziger im Ganzen erhaltener neuplatonischer Traktat der Mythenallegorisierung vgl. z. B. Katell Berthelot: Philo and the Allegorical Interpretetaion of Homer in the Platonic Tradition (With an Emphasis on Porphyry's De 
kanonisch-platonischen Mythenauslegung lassen sich anhand dieser kleinen Auslegungsschrift allesamt dingfest machen und überprüfen. Den Anfang macht genau die Feststellung des Autors, die von Homer beschriebene Höhle oder Grotte gebe es geographisch in Ithaka gar nicht, und diese óto $i \dot{\alpha} \alpha$ als reale Ortlosigkeit setze sich darin fort, dass die Beschreibung der Höhle eigentlich zur Erzählung nichts beizutragen scheint und einem deshalb seltsam fehl am Platz vorkommen müsse (Porph. antr. 2). ${ }^{51}$ Das stoße den aufmerksamen Leser darauf hin, dass sich hier in Wahrheit eine Beschreibung der

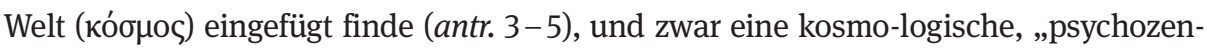
trische“ Beschreibung, die dazu angetan ist, zu zeigen, wie sich die zyklische Bewegung der Seelen vom Göttlichen und von den Göttern zu den Seelen im Wirklichkeitsaufbau und als Wirklichkeitsaufbau begreifen lässt (v.a. antr. 7 und 9: „ein Symbol aller unsichtbaren Mächte“, und von da an passim). ${ }^{52}$ Doch das muss dafür an dieser Stelle genügen.

\section{6. '́xoría als Unnatürlichkeit: Augustinus und Athanasius (und C. S. Lewis)}

Ein kurzer und durchaus eklektischer Blick auf die Einschätzung christlicher Platoniker soll diese Ausführungen abschließen. Wie bereits gesagt: Der Hauptstreitpunkt der allegorisierenden Interpretation welterklärender Erzählungen scheint vor allem in der Bedeutung der Frage zu liegen, ob das Erzählte als historisch verortbar angenommen werden darf. In diesem Sinne nahmen die christlichen Denker die Bibelgeschichten als historisch und symbolisch an, eben als realsymbolisch im Sinne der Symboldefinition Walter Benjamins: als Anschauung des Universalen im greifbaren Einzelvorkommnis. ${ }^{53}$ Der platonischen Mythenauslegung erschien dieser Partikularaspekt dagegen als zu vernachlässigen und schließlich als zu überwinden, als pädagogisches $\psi \varepsilon \varepsilon \tilde{\delta} \delta$, , denn in diesem historisch-partikularen Sinne eines Einzelvorkommnisses war das Erzählte nie

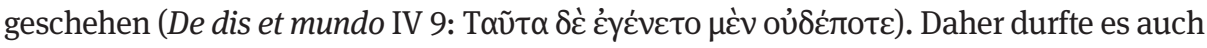

antro nympharum). In: Maren Niehoff (Hg.): Homer and the Bible in the Eyes of Ancient Interpreters. Leiden/Boston 2012, S. $155-174$, v. a. S. 165.

51 Dieses Interesse am geographischen Realwert des bei Homer Erzählten und dem Wert des Literalsinns des Mythos ist bei all dem unbestreitbar. In diesem Sinne ist es auch richtig, dass „the allegorical meaning attributed to the description of the cave does not discredit the literal meaning nor does it empty its significance. On the contrary, it seems that Porphyry, and the Neo-Platonists in general, attached importance to the literal meaning and to the historical or geographical exactness of the texts they interpreted“ (Berthelot [s. Anm. 50], S. 168).

52 Es fehlt zur Untermauerung dieser psychozentrischen Weltdeutung selbstverständlich auch nicht der Hinweis darauf, dass Platon im Höhlengleichnis das Schicksal der Seele im Kosmos ebenfalls sehr adäquat mit dem Bild einer Höhle beschrieben habe (Porph. antr. 8).

53 Vgl. Walter Benjamin: Der Ursprung des deutschen Trauerspiels. Frankfurt 1978, S. 140 -141, sowie die Einführung von Pablo Maurette zu seiner Übersetzung: Porfirio, El antro de las ninfas en la Odisea/ Puntos de partida hacia los inteligibles. Buenos Aires 2007, S. 17-27. 
ruhig als anstößig wirken, solange es nur zum Denken anzustoßen vermochte. Generell gilt ja, dass was im Leben als störend wirkt, in der Philosophie als aufstörend wirkt, nämlich für das Nachdenken.

Der Unterschied in der Auffassung lässt sich vielleicht ganz gut anhand der christlichen Deutung der biblischen Wundergeschichten im Kontrast zu den paganen mythischen Geschichten dokumentieren: Von Wundern, so meinen die christlichen Platoniker, sollte man sich wünschen können, dass sie einem wirklich passierten. Von dem, was von Skylla, Orion, Arethusa und Daphne und anderen wundersamen Vorgängen in den paganen Mythen erzählt wird, kann man sich nicht wünschen, dass es einem wirklich - historisch - passiere. Hier kann man tatsächlich nur darauf hoffen, dass solches sich nie ereignet hat. Und so sagt Augustinus, dass ein Wunder unsere Natur weder vergewaltigt noch ihr überhaupt in irgendeiner Weise entgegensteht, sondern sie in eigener Weise komplettiere: „Ein Wunder (portentum) geschieht nicht wider die Natur, sondern wider die bekannte Weise der Naturabläufe“ (Aug. civ. XXI 8,35; dort auch die Erklärung: portentum heiße das Wunder, weil es etwas anzeigt oder auf etwas vorverweist, praeostendo).

Warum das mit der christlichen Theologie zusammenpasst, in der der universale Logos der Welt historische Wirklichkeit wird, erklärt Athanasius in seinen Predigten über die Auferstehung, wenn er sagt, Christus habe Menschengestalt angenommen und als Mensch gelebt, damit die, welche ihn als Schöpfer des gesamten Kosmos anerkennen, aus seinen Werken hier auf Erden erkennen können, dass in diesem Menschenleib das Wort Gottes wohnte. ${ }^{54} \mathrm{C}$. S. Lewis hat in seinem (in einigen Facetten freilich vielleicht durchaus verwirrenden) Essay Miracles diese Bemerkung des Athanasius so ausgedeutet: ${ }^{55}$ Christus, wahrer Mensch und wahrer Gott, wirkte als historischer Mensch dasselbe wie als Gott, der alle Naturgesetze eingerichtet hat. So tat Jesus in historischer Einmaligkeit dasselbe wie der Schöpfer im immerwährenden Hervorbringen und Bewahren der Schöpfung, nur als Mensch, und das wird - anders als im Schöpfungsablauf als ganzem - als Wunder begriffen, also als Ereignis, das als historisch isolierbarer Ablauf in Staunen versetzt, oder als ein Ereignis, das eine im Normalzusammenhang des Geschehens frappierende, zunächst unerklärbar erscheinende Anomalie beschreibt, obwohl, oder gerade weil es ein historischer Beleg dieses Normalzusammenhangs ist. Jesus tut also vor den Augen seiner historischen Mitmenschen das, was sie in gewöhnlicher Weise aus den Schöpfungsregeln und Schöpfungsabläufen kennen, aber eben in außerordentlicher, einmalig greifbarer Weise. Damit bricht er nicht mit der Natur, er übertrumpft sie auch nicht, er setzt sie nicht außer Kraft, sondern er vollendet sie spektakulär im Einzelnen. Als Beispiel nimmt Lewis die Wundererzählung von der Weinverwandlung: Dass sich Wasser in Wein verwandelt, ist nichts Spektakuläres, jeder weiß, dass das andauernd und überall auf der Welt geschieht: Damit er Trauben trägt

54 Athan. incarn. (PG XXV, 96-198), I 18, vgl. den gleichen Gedanken in VI 43 und VII 49.

55 Der Essay Miracles war ursprünglich (1947) als eigenständige Broschüre erschienen, bildete danach aber das Kapitel 2 von C. S. Lewis: God on the Dock. Essays in Theology and Ethics. Grand Rapids 1970, S. 25-36. 
und damit diese Trauben gepresst werden können, muss man den Weinstock wässern. Das Zugeführte Wasser wird durch natürliche Abläufe und durch das Zutun des Menschen (Keltern, Lagern etc.) zu Wein. Wein ist „die Frucht des Weinstocks und der menschlichen Arbeit“, wie eine liturgische Zeile es sagt. Jesus vollführt genau diesen Regelablauf des Verwandelns von Wasser, das bereitsteht, unter menschlichem Zutun (nämlich seinem eigenen Wirken) in Wein. Nur eben instantan. Und dass der Wein besonders gut ist, zeigt, dass hier auf Vollendung von etwas Natürlichem abgezielt wird. Insofern ist das Wunder ein Zeichen für das Wirken Gottes.

So ist das Wunder in christlicher Sicht keineswegs ein Bruch mit den natürlichen, bekannten Abläufen, sondern eine bedeutsame Raffung und momentane Vollendung der Abläufe, die der Schöpfer seiner Schöpfung zugedacht hat. Eine christliche Wundererzählung entspricht weder der Intention noch dem Genre nach einem antiken Mythos, sondern sie berichtet von etwas, das jeder als natürlich gerne akzeptiert, und was in der gedrängten Intensivform, in der es sich als Wunder ereignet, historisch als zeichenhafte Vollendung der Natur spektakulär offenbar wird. Das Wundersame liegt mithin darin, dass etwas Natürliches und als solches Bekanntes sich in besonderer Weise ereignet und dieses Besondere oder diese Weise als das Wirken von etwas verstanden wird, das souverän über der Natur steht, dieser Natur aber deswegen noch lange nicht entgegensteht. Wunder sind daher nichts Widernatürliches, auch nichts Unnatürliches, ihre Außerordentlichkeit liegt nicht darin, dass sie aus der Ordnung der Welt ausscheren, sie sind vielmehr ein punktuelles Aufzeigen der Vollendungsgestalt des Natürlichen. Die Belege dafür aus den Schriften der alten christlichen Theologen ließen sich häufen, als pars pro toto stehe aber lediglich folgende Aussage des Augustinus:

Gott wirkt auch die Blitze und Donner gewöhnlicher Art. Weil aber auf dem Berg Sinai dergleichen in ungewöhnlicher Weise sich ereignete [ ... und] aus bestimmten Merkmalen sich ergab, dass durch dieselben gewisse Zeichen gegeben würden, so waren es Wunder. (Aug. trin. III 5,38)

Konsequenzen daraus waren erstens: Die Erklärung von Wundern, portenda oder miracula, als gerafften und über sich hinausweisenden Vollendungsabläufen lässt auch wahre Wunder von dem trennen, was die mittelalterliche Tradition als monstrositas vom miraculum unterschied. Eine solche historische monstrositas tut genau das, was die mythischen ótotíaı zu tun drohen, wenn sie als „wirklich wahr“ angenommen würden: Sie würden den Rahmen des für den Menschen (in platonischer Sicht) Akzeptablen sprengen. Denn:

It cannot be too strongly insisted that a world which is to be a moral order must be a physical order characterized by law or regularity. [...] The theist is only concerned to invoke the fact that lawabidingness [...] is an essential condition of the world being a theatre of moral life. Without such regularity in physical phenomena there could be no probability to guide us: no prediction, no prudence, no accumulation of ordered experience, no pursuit of premeditated ends, no formation 
of habit, no possibility of character or culture. Our intellectual faculties could not have developed. $^{56}$

Die Deutung des Augustinus zeigt, dass sich ein Wunder eben tatsächlich unter anderem dadurch auszeichnet, dass der Mensch es sich für sein eigenes Leben herbeiwünschen können muss, dass es eine positive Bedeutsamkeit im Sinne eines Vollendungsvorgriffs hat, die ein Menschenleben gleichwohl nicht vollkommen und natursprengend verändert. Es ist ein Zeichen innerhalb eines naturentsprechenden Regelverhaltens und mehr noch: auch ein Hinweiszeichen für dieses Verhalten. Das unterscheidet das Wunder etwa von den oben beispielhalber genannten Metamorphosen-Mythen zu Skylla oder Daphne wie bei Ovid, so wunderbar sie auch anmuten mögen. Ein Wunder muss, so könnte man vielleicht sagen, in der First-person-perspective (positiv) annehmbar sein.

Zweitens: Wunder können, so hat sich daraus schon ergeben, als Zeichen verstanden werden, als on $\mu$ ĩov oder signum (wie im Hendiadyoin „Zeichen und Wunder“). Zeichenhaft ist aus christlicher theologischer Perspektive das Handeln durch Wunder in Übereinstimmung mit Gottes Plan für die Welt, die sich hier besonders intensiv und bedeutsam historisch kundtut. Hier tut jemand - der Wundertäter als Өcoupyós - Gottes Dinge, die Vollendungsgestalt des Schöpfungsplans blitzt hier in einem einzelnen Geschehnis oder in einem individuellen Menschen auf und macht das Wirken Gottes an und in der Welt, insbesondere sein Heilswirken, somit transparenter. Von ó толí keine Spur.

\section{Fazit}

Der Kampf um Mythos und Mythendeutung im Platonismus des christianisierten Kaiserreichs lässt sich somit in seinen Hauptpunkten auf einige wenige Fragen zusam-

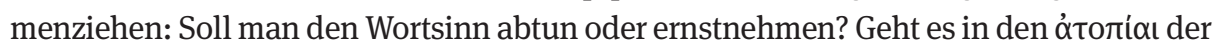
Mythen um ein als raumzeitlich ortlos allegorisierbares Symbol oder um ein Realsymbol? Bis zu welcher Grenze ist der Mythos (psychagogischer) Anstoß und ab wann ist er (,atopische“) Anstößigkeit? Bringt oder bedingt der Mythos ein Abstoßen (nach „oben“), weil er abstoßend ist? Und wenn ja: Bis zu welcher Grenze darf man diese Dialektik in theoretischer Redlichkeit annehmen, bis zu welcher Grenze ist sie für moralische Redlichkeit annehmbar? Die Frage ist damit letztlich nicht: Ist der Mythos wahr? Denn so kann sie nicht beantwortet werden. Die Frage ist: Geht die Wahrheit im Mythos auf?

56 So F. R. Tennant: Philosophical Theology, Bd. 2: The World, the Soul, and God. Cambridge 1937, S. $199 \mathrm{f}$. Ausführlicher zum gleichen Gedanken Friedrich Hermanni: Metaphysik. Versuche über letzte Fragen. Tübingen 2011, S. 138. 



\section{Christliche Bischöfe und klassische Mythologie in der Spätantike*}

Fragt man danach, wie und inwiefern Bischöfe als herausragende und autoritative Vertreter des spätantiken Christentums sich mit der klassischen Mythologie ${ }^{1}$ auseinandergesetzt haben, so ist zunächst zu konstatieren, dass eine derartige Auseinandersetzung nicht im Mittelpunkt ihres pastoralen Interesses stand. Das Quellenmaterial zu diesem Thema erweist sich daher als eher begrenzt.

Grob gesagt kann man die dokumentierten Reaktionen christlicher Bischöfe der Spätantike hauptsächlich zwei zu unterscheidenden Debatten zuordnen: Zum einen geht es um die heidnische Religion und deren Konzeptionalisierung im Schema der sogenannten theologia tripartita. Zum anderen geht es um die Stellung der paganen Literatur, besonders der paganen Dichter, im spätantiken christlichen Bildungskanon.

In beiden Debatten, so die hier vertretene These, zeigt sich, dass die Göttergeschichten der klassischen Mythologie für christliche Bischöfe kein theologisches Problem und auch kein Thema intensiver und polemischer Auseinandersetzung darstellten. Dennoch sind bestimmte Wertungen und Positionierungen einzelner christlicher Bischöfe zu beobachten, deren Hintergrund und Motivation im Folgenden ebenfalls beleuchtet werden sollen.

Was die erste Debatte hinsichtlich der Konzeptionalisierung der heidnischen Religion im Schema der sogenannten theologia tripartita ${ }^{2}$ angeht, so sind die Voten zweier Bischöfe, des Eusebios von Cäsarea und Augustins von Hippo, einschlägig.

Zunächst also Eusebios von Cäsarea: In seiner apologetischen Schrift Praeparatio Evangelica setzt er sich mit heidnischer Religion anhand des Schemas der theologia tripartita auseinander. So schreibt Eusebios in p.e. 4,1,2:

\footnotetext{
* An dieser Stelle sei allen Teilnehmern und Organisatoren der Konferenz gedankt. Die hier vorliegende überarbeitete Fassung meines Konferenzbeitrags hat sehr von der anschließenden Diskussion profitiert, besonders sei Clifford Ando, Hartmut Leppin und Jörg Rüpke gedankt.

1 Unter ,klassischer Mythologie، seien hier vor allem die von griechischen Dichtern wie Homer und Hesiod sowie lateinischen Dichtern wie Vergil überlieferten Göttergeschichten verstanden.

2 Die Literatur zum Konzept der theologia tripartita ist umfangreich; immer noch nützlich ist der Überblick von G. Lieberg, Die theologia tripartita in Forschung und Bezeugung, in: ANRW I,4, 1973, 63 115. Neuere Literatur findet sich z. B. in der Bibliographie zu J. Rüpke, Varro's tria genera theologiae: Religious Thinking in the Late Republic, in: Ordia Prima 4, 2005, 107-129. - Die Junktur theologia tripartita ist nicht antik, vgl. die Diskussion ebd., $108 \mathrm{f}$.
} 
[Die Griechen] unterteilen die gesamte Theologie [ $\theta \varepsilon \circ \lambda$ oy'́a] in drei Arten: Die mythische (sie wird von den Dichtern vorgetragen), die physische (sie ist von den Philosophen ersonnen worden) sowie die Theologie, die unter dem Schutz der Gesetze in jeder Stadt und in jeder Landschaft bewahrt wird [...]. ${ }^{3}$

Eusebios hatte sich im zweiten und dritten Buch der Praeparatio Evangelica bereits mit den ersten beiden Arten von theologia beschäftigt: So hatte er einem Abriss der Theologie der Ägypter (p.e. 2,1) einen Abriss der Theologie der Griechen folgen lassen (p.e. 2,2,1-51). Beide Abschnitte bestanden im Wesentlichen aus langen Zitaten aus Diodorus Siculus. Anschließend (p.e. 2,2,52-62) zitiert er dann auch die Passage aus Diodor, in der dieser die poetische Theologie der Griechen unter Rekurs auf die Schrift Hiera Anagraphê des Euhemeros zu erklären versucht. Eusebios lässt also bewusst bei der Darstellung der heidnischen (ägyptischen und griechischen) Theologie heidnische Stimmen zu Worte kommen. Dies betrifft nicht nur die Stoffdarbietung, sondern gerade auch die Konzeptualisierung und Interpretation heidnischer Mythologie, für die z.B. auch die historisch-rationalistische Deutung des Euhemeros herangezogen wird.

In p.e. $2,4^{4}$ legt Eusebios dar, aus welchen Gründen die Christen die Mythologie der Griechen ablehnen: Die Gnade des allmächtigen Gottes, die Lehre Christi und eigene Überlegung hätten sie gelehrt, dass es blasphemisch sei, den Namen Gottes toten Menschen beizulegen (hier rekurriert Eusebios also auf die euhemeristische Theorie). Auch macht Eusebios geltend, dass man Ausschweifungen, Grausamkeit, Kinder- und Vatermord kaum als göttliche Taten verehren kann. Die klassische Mythologie bestehe aus unmoralischen Fabeln, so lautet das bekannte und schon etwas abgedroschene ${ }^{5}$ Argument, die des wahren Gottes unwürdig sind.

Für unsere Thematik ist nun wichtig, dass Eusebios in diesem Abschnitt (p.e. 2,4,45) selber erklärt, dass er als Christ den (gebildeten) Heiden die gute Nachricht von der Nichtigkeit der falschen, d.h. der mythologischen, Götter gar nicht mehr verkünden müsse: Die wahrhaft frommen ${ }^{6}$ unter ihnen seien schon durch eigenes Überlegen zu dem gleichen Schluss gekommen und hätten die mythologischen Fabeln verworfen. Einige hätten dabei die gesamte Religion ihrer Vorfahren zurückgewiesen, anderen wiederum hätten - um dem Vorwurf des Atheismus zu entgehen - ,physische Theorien' hinter den poetischen Mythen entdeckt. Eusebios konstatiert also, dass selbst die

3 Ed. É. des Places, Eusèbe de Césarée. La préparation évangélique, Livres IV - V,1-17 (SC 262), Paris

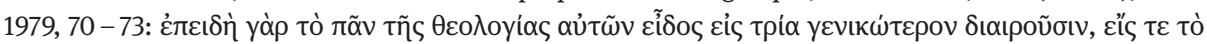

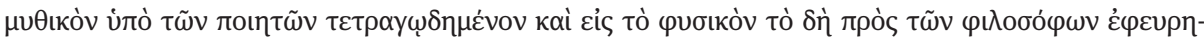

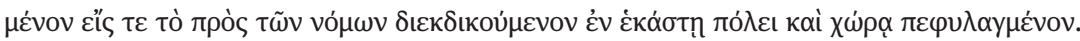

4 Ed. É. des Places, Eusèbe de Césarée. La préparation évangélique, Livres II-III (SC 228), Paris 1976, $98-103$.

5 Für Parallelen vgl. z. B. J. Geffcken, Zwei griechische Apologeten, Leipzig/Berlin 1907, 202-205 u. $225-229$.

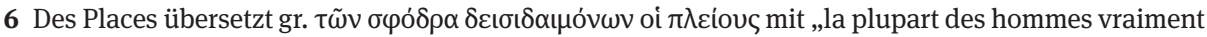
pieux“. 
gebildeten Heiden die klassische Mythologie religiös nicht (mehr) ernst nehmen. ${ }^{7}$

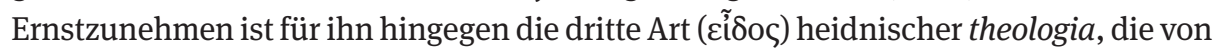
ihnen die städtische ( $\pi$ олıтıкòv) genannt und als öffentliche Theologie von den Gesetzen des heidnischen Staates geschützt wird (p.e. 4,1,2).

Diese dritte Art der Theologie aber - so erklärt er dann in p.e.4,1,2-3 - ist nicht nur alt und von den Vorfahren ererbt, sondern sie erweist auch durch sich selbst die Macht

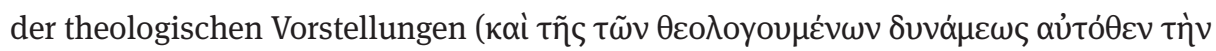

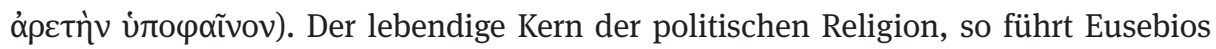
weiter aus, sind die Orakel; sie sind es - und hier scheint Eusebios eine heidnische Quelle (= Porphyrios?) zu zitieren, welche die Heiden davon überzeugen, dass sie auf dem richtigen Wege sind, wenn sie die traditionellen Gottheiten verehren, und dass die

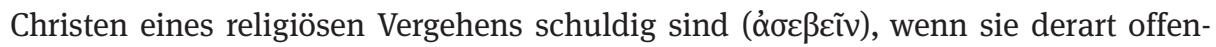
sichtliche und wohltätige Mächte für nichts erachten und gegen die Gesetze verstoßen; die hergebrachte Religion der Vorfahren sei auf jeden Fall zu bewahren und nicht durch innovatorische Umtriebigkeit zu erschüttern. Das Heidentum, so lautet das hier zitierte heidnische antichristliche Argument, stützt sich auf eine alte religiöse Tradition, die aktuell durch die Erfahrung der Macht der Orakel auch immer wieder wirksam beglaubigt wird. ${ }^{8}$ Deshalb ist es dann auch berechtigt, dass diejenigen, die die traditionelle heidnische Religion aufgeben (= die Christen), mit der Todesstrafe bedroht werden. ${ }^{9}$

7 In der christlichen Perspektive Eusebs wird das als teleologische Entwicklung dargestellt, die Heiden sind aufgewacht und zur religiös aufgeklärten Vernunft gekommen. Die Frage, inwieweit die Göttergeschichten Bestandteil der heidnischen Religion waren, wird damit christlich beantwortet; Euseb hat (wie auch Augustin) die apologetische Tendenz, die Unterscheidung zwischen der öffentlichen Religion und der theologia fabulosa möglichst weit zu eliminieren. Vgl. J. Scheid, Les dieux, l'état et l'individu. Réflexions sur la religion civique à Rome, Paris 2013, 105, der betont, dass die Mythen nie integraler Bestandteil der öffentlichen heidnischen Religion waren. Bezugnahmen auf die Mythen konnten den Kult ergänzen und ausschmücken (Scheid: ,un ornement destiné à charmer les dieux et les hommes“).

8 Eusebius, p.e. 4,1,3 (SC 262, 72-75). Vgl. p.e. 3,17,2-3 (SC 228, 260-261).

9 Eusebios scheint seine heidnische Quelle mehr oder weniger wörtlich zu zitieren bzw. zu paraph-

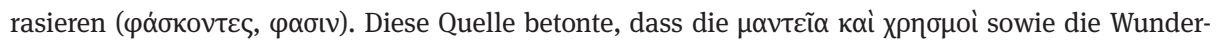
heilungen und die (durch die Orakel geäußerten) Denunziationen der Christen die Heiden von der

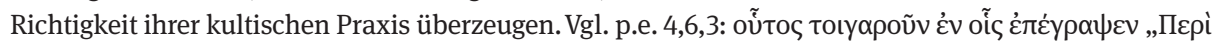

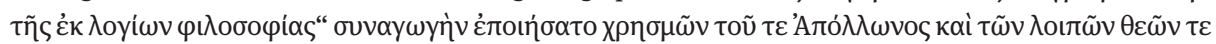

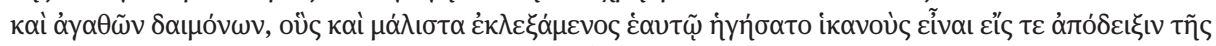

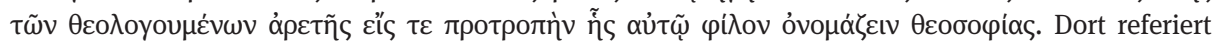
Eusebios einen doppelten Skopus der Porphyriosschrift „Über die aus Orakeln geschöpfte Philoso-

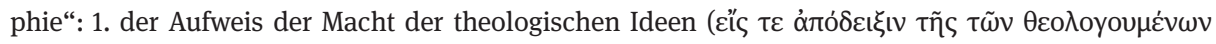

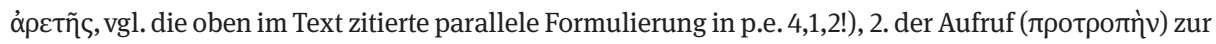
Theosophie. S. auch H. Lewy, Chaldaean Oracles and Theurgy, 3. Auflage (von M. Tardieu besorgt), Paris 2011, 509-512, der die Orakelschrift des Porphyrius als Quelle hinter p.e. 4,5,1-2 sieht. - Zur Orakelschrift vgl. aus der rezenten Literatur C. Riedweg, Porphyrius über Christus und die Christen: De Philosophia ex oraculis haurienda und Adversus Christianos im Vergleich, in: A. Wlosok (Hrsg.), L'Apologétique chrétienne gréco-latine à l'époque prénicénienne (Fondation Hardt Entretiens 51), Vandoeuvres-Génève 2004, 151-203, sowie die jüngst vorgeschlagene Rekonstruktion ihres Aufbaus, 
Eusebios Ausführungen zur theologia tripartita machen deutlich, dass aus seiner Sicht die klassische Mythologie von gebildeten Heiden und Christen ähnlich beurteilt wird. Der religiöse Unterschied zeigt sich erst in der Einschätzung der öffentlichen Religion und deren kontinuierlicher Legitimation durch die Orakel: Orakel und Wunderheilungen an heidnischen Heiligtümern beglaubigen die Wirksamkeit der paganen Götter.

Werfen wir nun einen Blick auf Augustin: Im 6. und 7. Buch seiner Schrift De civitate Dei (Gottesstadt) beschäftigt auch er sich mit der theologia tripartita, und zwar nach der Version des Varro. Bemerkenswert ist, dass für Varro/Augustin die theologia fabulosa der Dichter nicht nur durch den Grammatik- und Rhetorikunterricht verbreitet, sondern vor allem auf der Bühne vorgetragen wird. Augustin zitiert Varro (civ. 6,5):

\begin{abstract}
Als die mythische Art bezeichnet man die, welche hauptsächliche bei den Dichtern, als die physikalische die, welche bei den Philosophen, und als die staatliche die, welche öffentlich im Schwang ist. Bei der zuerst genannten [...] findet sich viel Erdichtetes, das gegen die Würde und die Natur von Unsterblichen verstößt. Bei diesen Göttern der Dichter kommt es nämlich vor, dass eine Gottheit aus dem Haupte, eine andere aus dem Schenkel und wieder eine aus Blutstropfen geboren worden sei; dass Götter gestohlen, Unzucht getrieben, dem Menschen als Sklaven gedient hätten; kurz es wird da alles auf Götter übertragen, was einem Menschen, und zwar selbst dem verächtlichsten Menschen, begegnen kann. ${ }^{10}$
\end{abstract}

Varro kritisiert also die mythische Theologie mit dem Argument, dass ihre Darstellung der Götter nicht gottgeziemend ist. Die Kritik Varros aufnehmend argumentiert Augustin, dass die varronische Unterscheidung zwischen mythischer Theologie und staatlicher Theologie künstlich und auch heuchlerisch sei: Beide Arten von Theologie hängen eng zusammen, in beiden Arten von Theologie handelt es sich um die gleichen Götter. Augustin schreibt (civ. 6,6):

Du sagst nämlich, die Götter der Fabel eigneten sich für das Theater, die natürlichen für die Welt, die staatlichen für die Stadt, da doch die Welt ein göttliches Werk ist, Stadt und Theater dagegen Werke der Menschen sind und keine anderen Götter in den Theatern verlacht werden als die,

A. Wintjes, Die Orakel als Mittel der Offenbarung bei Porphyrios, in: H. Seng/M. Tardieu (Hrsg.), Die Chaldaeischen Orakel. Kontext - Interpretation - Rezeption, Heidelberg 2010, 43-62.

10 Mythicon appellant, quo maxime utuntur poetae; physicon, quo philosophi, ciuile, quo populi. Primum ... quod dixi, in eo sunt multa contra dignitatem et naturam inmortalium ficta. In hoc enim est, ut deus alius ex capite, alius ex femore sit, alius ex guttis sanguinis natus; in hoc, ut dii furati sint, ut adulterarint, ut seruierint homini; denique in hoc omnia diis adtribuuntur, quae non modo in hominem, sed etiam quae in contemptissimum hominem cadere possunt. Ed. B. Dombart/A. Kalb, Sancti Aurelii Augustini De civitate Dei, Liber I - IX (CCSL 47), Turnhout 1955, 170 f. Die Übersetzung hier und im Folgenden nach derjenigen von A. Schröder in der Bibliothek der Kirchenväter (BKV), z.T. mit leichten Modifikationen. 
welche man in den Tempeln anbetet und ihr denselben Göttern Spiele aufführt, denen Ihr Opfer schlachtet. ${ }^{11}$

\section{Und Augustin fährt fort:}

Wieviel aufrichtiger und schärfer wäre eine Einteilung, wonach Du unterschiedest zwischen den natürlichen und den von den Menschen eingeführten Göttern und sagtest, hinsichtlich der eingeführten Götter enthielten die Schriften der Dichter anderes als die der Priester, aber die beiderseitigen Schriften seien untereinander so nahe verwandt durch die Bande der Unwahrheit, dass beide den Dämonen erwünscht sind, denen die Lehre der Wahrheit verhasst ist. ${ }^{12}$

Und weiter sagt Augustin:

Wer in diesen Dingen unerfahren genug ist, könnte etwa meinen, nur in den Schöpfungen der Dichter und bei der Aufführung von Bühnenspielen würden von solchen Göttern Dinge gefeiert, die der göttlichen Majestät unwürdig sind und sie abscheulichen Possen aussetzen; der Götterdienst dagegen, den nicht Schauspieler, sondern die Priester abhalten, sei von aller Unziemlichkeit gereinigt und frei. Wäre dem so, so wäre nie jemand auf den Gedanken gekommen, dass man zu Ehren der Götter schändliche Theaterstücke aufführen solle, nie hätten die Götter selbst fordern dürfen, sie ihnen darzubieten. Doch eben deshalb tut man solches in den Theatern im Dienste der Götter ohne Bedenken, weil man Ähnliches auch in den Tempeln tut. ${ }^{13}$

In der polemischen Interpretation Augustins wird - wie Leonardo Lugaresi beobachtet hat - das Theater zum Ort, an dem sich die mythische Theologie und die staatliche Theologie treffen. Dass der staatliche Kult aber durch die Schauspiele gleichsam verdorben ist, ist auch ein Werk der Dämonen. ${ }^{14}$

In seinem Brief an den Kurialen Nectarius von Calama, der gegenüber Augustin die Feiern zu Ehren der Flora in seiner Heimatstadt verteidigt hatte, kommt Augustin auch auf die Immoralität der Götter der klassischen Mythologie zu sprechen (Augustin, ep. 91,4-5). ${ }^{15}$ Er kennt das Argument, dass die Göttermythen nicht wörtlich zu verstehen seien, und er weiß, dass im Rahmen des heidnischen Kultes Interpretationen

11 Dicis quippe fabulosos accommodatos esse ad theatrum, naturales ad mundum, ciuiles ad urbem, cum mundus opus sit diuinum, urbes uero et theatra opera sint hominum, nec alii dii rideantur in theatris, quam qui adorantur in templis, nec aliis ludos exhibeatis, quam quibus uictimas immolatis.

12 Quanto liberius subtiliusque ista diuideres, dicens alios esse deos naturales, alios ab hominibus institutos, sed de institutis aliud habere litteras poetarum, aliud sacerdotum, utrasque tamen ita esse inter se amicas consortio falsitatis, ut gratae sint utraeque daemonibus, quibus doctrina inimica est ueritatis! 13 Videri fortasse cuipiam nimis harum rerum ignaro potest ea sola de diis talibus maiestati indigna diuinae et ridicula detestabilia celebrari, quae poeticis cantantur carminibus et ludis scaenicis actitantur; sacra uero illa, quae non histriones, sed sacerdotes agunt, ab omni esse dedecore purgata et aliena. Hoc si ita esset, numquam theatricas turpitudines in eorum honorem quisquam celebrandas esse censeret, numquam eas ipsi dii praeciperent sibimet exhiberi. Sed ideo nihil pudet ad obsequium deorum talia gerere in theatris, quia similia geruntur in templis (CCSL 47, 173f).

14 L. Lugaresi, Il teatro di Dio. Il problema degli spettacoli nel cristianesimo antico (II-IV secolo), Brescia 2008, 643 u. 646f mit Verweis auf Augustin, civ. 8,20.

15 Ed. A. Goldbacher, CSEL 34, Wien 1895, 429-431. 
vorgetragen werden, welche die Unmoralität der Göttererzählungen entschärfen. Dennoch ist Augustin nicht überzeugt: Die Ehebrüche Juppiters werden durch viele Medien verbreitet - sie werden gemalt, in Skulpturen aus Erz oder Stein dargestellt, sie werden aufgeführt und besungen, sie werden in tänzerischen Darbietungen dargestellt. Es ist diese, modern gesprochen, massive Medienpräsenz der unmoralischen antiken heidnischen Mythologie, die - so das Argument Augustins - die Sitten gefährdet, zumal da der heidnische Kult (z.B. der des Juppiter Capitolinus) sich nicht ausdrücklich von deren Immoralitäten (z. B. dem Ehebruch) distanziert. Auch in dem Brief an Nectarius akzeptiert Augustin also die Unterscheidung zwischen heidnischem Kult und heidnischer Literatur nicht. Doch scheint er die theatralische Darstellung mythologischer Szenen (besonders im Pantomimus) ${ }^{16}$ für erheblich bedenklicher zu halten als die Schullektüre der heidnischen Klassiker.

Augustins Kritik an der theologia fabulosa erweist sich somit als Teil eines traditionellen theaterkritischen Diskurses. Leonardo Lugaresi und Ruth Webb haben dargelegt, dass und wie das Theater von christlichen Bischöfen der Spätantike als Konkurrenz zum Gottesdienst empfunden werden konnte. ${ }^{17}$ Für Augustin wie für Johannes Chrysostomos ging es bei dieser Konkurrenz nicht nur um die Aufmerksamkeit des beiderseits umworbenen Publikums, sondern auch um den Wettbewerb um finanzielle Ressourcen: Das Geld christlicher Mäzene soll den Armen oder dem Kirchenbau zugutekommen und nicht auf die Schauspiele verschwendet werden. ${ }^{18}$ Bezeichnenderweise versuchte Johannes Chrysostomos auch, in polemischer Absicht die Juden, deren attraktive Synagogengottesdienste auch Christen anzogen, mit dem Theater und dessen ,unmoralischen` Tänzen zu assoziieren. ${ }^{19}$

In diesem Zusammenhang sei auch das Epigramma Paulini erwähnt, ein poetischer, in Hexameter gefasster Dialog, der in einer Pariser Handschrift, dem Parisinus Latinus 7558 (f. 87v-90r) überliefert ist. Der Text wurde offenbar ca. 410 n.Chr. in Gallien verfasst. ${ }^{20}$ Dialogpartner sind ein Pilger und ein Abt. ${ }^{21}$ Der christliche Autor des

16 S. K. Sallmann, Christen vor dem Theater, in: J. Blänsdorf (Hrsg.), Theater und Gesellschaft im Imperium Romanum, Tübingen 1990, 243-259, bes. 248f. Sallmann betont zu Recht, dass ,viele Christen nicht vom Theaterbesuch abzubringen waren“ (249). S. weiterhin G. Binder, Pompa Diaboli Das Heidenspektakel und die Christenmoral, in: G. Binder/B. Effe (Hrsg.), Das antike Theater. Aspekte seiner Geschichte, Rezeption und Aktualität, Trier 1998, 115-147, bes. 128-131. Rezente wichtige Veröffentlichungen zum Thema sind die schon erwähnte monumentale Monographie von Lugaresi (s. Anm. 14) sowie das letzte Kapitel der Monographie von Ruth Webb, Demons and Dancers. Performance in Late Antiquity, Cambridge, Mass. 2008.

17 Vgl. aber auch die Predigt Ps.-Augustin, sermo 281,1 (PL 39, 2276) und dazu P. Gemeinhardt, Das lateinische Christentum und die spätantike Bildung, Tübingen 2007, 325f, wo die heidnische Götterfabeln als per se Konkurrenz zur Predigt bezeichnet werden.

18 Augustin, ep. 138,14; für die Belege bei Johannes Chrysostomos s. Webb (s. Anm. 16), 201f; Lugaresi (s. Anm. 14), 695-812.

19 Webb (s. Anm. 16), $201 \mathrm{f}$.

20 Für Edition und Übersetzung des Textes (er ist auch greifbar in der Edition von C. Schenkl, CSEL 16, Wien 1888, 503 - 508) sowie eine Diskussion der Datierung und Autorschaft betreffenden Fragen s. jetzt 
Werkleins notiert kritisch, dass die bei den gerade überstandenen Germaneneinfällen zerstörten Theater in den Städten wieder hergerichtet werden. ${ }^{22}$ Eine lange Passage beklagt sich über die (christlichen) Ehefrauen: In diesem Zusammenhang wird deren skandalöse Beschäftigung mit der Lektüre der Klassiker, z.B. Vergils oder Ovids, hervorgehoben: Eine Schauspielerin z.B. deklamierte als Dido verkleidet die entsprechenden Verse der Aeneis. Nach dem polemischen Urteil des christlichen Autors hatten diese christlichen Frauen aus der Katastrophe der Germaneninvasion nichts gelernt. ${ }^{23}$ Es ist doch eher unwahrscheinlich, dass diese literarisch gebildeten christlichen Frauen die Kritik des seine asketische Neigung nicht verleugnenden Autors akzeptiert hätten und die eigene Haltung als widersprüchlich oder problematisch empfunden hätten.

\section{II}

Die zweite Debatte, innerhalb deren sich einige christliche Bischöfe genötigt sahen, zur klassischen Dichtung und ihren Mythen Stellung zu beziehen, verhandelt die klassische paideia und deren Curriculum. Dichter wie Homer und Hesiod gehörten zum Kerncurriculum des Grammatik- und Rhetorikunterrichtes. Spätestens seit dem einschlägigen Werk von Henri-Irénée Marrou $^{24}$ wissen wir, dass das spätantike Christentum das antike Bildungssystem nicht ersetzen wollte und nicht ersetzt hat. Die christlichen Kinder der Eltern, die es sich leisten konnten (also eine Minderheit), besuchten den gleichen Grammatik- und Rhetorikunterricht wie die heidnischen Kinder aus den entsprechenden Schichten. Der Hintergrund der folgenden Ausführungen ist also die massive, durch die Verbreitung des Christentums zunächst nicht oder kaum beeinträchtigte Präsenz der antiken elitären Bildungstradition, in deren Rahmen die klassische Mythologie ihren Platz hatte. Was immer christliche Bischöfe auch gegen die heidnischen Göttergeschichten einzuwenden hatten, christliche Kinder lernten Latein und Griechisch weiterhin mit Hilfe von Homer und Vergil.

\footnotetext{
A. Fo, Il cosiddetto Epigramma Paulini attribuito a Paolino di Béziers: testo criticamente riveduto, traduzione e studio introduttivo, in: Romanobarbarica 16, 1999, 97-167. Als Autor hat man den Bischof Paulinus von Béziers identifizieren wollen (vgl. Hydatius, Chronicon § 73, ed. A. Tranoy, Hydace. Chronique [SC 218], Paris 1974, 124), s. ebd. 106 f; S. Ratti, Polémiques entre Païens et Chrétiens, Paris 2012, 73f. Vgl. auch K. Smolak, Zwischen Bukolik und Satire: Das sogenannte Sancti Paulini Epigramma, in: International Journal of the Classical Tradition 6,1, 1999, 3-20. Smolak kündigt eine das Epigramma betreffende Arbeit seiner Schülerin A. Schuller an, die aber m.W. bislang nicht erschienen ist.

21 So die Rekonstruktion von Fo (s. Anm. 20), 126-135, dessen Textverständnis (besonders der Z. 5) sich von dem von Schenkl u.a. unterscheidet.

22 Fo (s. Anm. 20), 154, Z. 14.

23 Fo (s. Anm. 20), 160, Z. $75-81$.

24 H.-I. Marrou, Histoire de l'education dans l'antiquité, Paris 1950. Diese Gesamtdarstellung ist bis heute nicht ersetzt.
} 
In der zweiten Hälfte des 4. Jahrhunderts finden wir im griechischen Osten die pointierten Stellungnahmen zweier gebildeter Bischöfe: zum einen des Basileios von Cäsarea, zum anderen des Amphilochios von Ikonion.

Basileios ist Verfasser der Schrift: „An die Jugendlichen, wie sie aus der heidni-

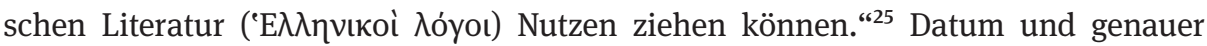
biographischer Ort dieser Schrift bleiben unklar; immerhin, der Eingangssatz scheint klar zu machen, dass es sich um eine Mahnschrift handelt, einen logos protreptikos, gerichtet an zwei Jugendliche, deren Eltern Basileios entweder verwandtschaftlich oder freundschaftlich nahe stehen. Die Schrift des Basileios ist ein Paradebeispiel traditioneller rhetorischer paideia, gespickt mit Anspielungen auf die griechische Literatur, vom Epos über die Historiker bis zur Philosophie. Das Argument der Schrift ist einfach: Die christlichen Jugendlichen werden aufgefordert, den Kanon der griechischen Literatur kritisch zu lesen:

Ihr sollt nicht diesen Männern [d.h. den paganen Autoren] gleichsam Steuer und Segel Eures Verstandes übergeben und ihnen dahin folgen, wohin sie Euch führen, sondern ihr müsst vielmehr erkennen, was an Nützlichem aus ihnen zu gewinnen ist und was man übergehen muss. ${ }^{26}$

Das von Basileios empfohlene Kriterium der Auswahl für die Lektüre von Dichtern, Historikern, Rhetoren und Philosophen ist der moralische Nutzen: Insofern z. B. die Dichter von den Taten und Reden guter Männer berichten, sind sie nützlich, insofern sie sich aber mit schlechten Menschen beschäftigen, sind sie zu meiden (c. 4,3f). Von den Rhetoren sollen die Jugendlichen nicht das Lügen lernen (z. B. vor Gericht) - ist doch den Christen ohnehin geboten (1 Kor 6,7) nicht zu prozessieren - sondern sie sind mit Nutzen zu lesen, wenn sie die Tugend loben und das Laster tadeln.

Besonders die Dichtung Homers ist für Basileios - und hier stimmt er mit antiken heidnischen Stimmen wie Horaz und Dion Chrysostomos ${ }^{27}$ überein und beruft sich auf einen anonymen (vermutlich nichtchristlichen) fähigen Homerexegeten ${ }^{28}$ - ein einziges Lob auf die Tugend (c. 5,26f). Basileios zitiert anschließende eine von eben diesem Homerexegeten übernommene Auslegung von Odyssee 6,135 ff, d. h. eben der Passage, in der erzählt wird, wie Odysseus als Schiffbrüchiger vor Nausikaa ans Land steigt. Basileios schreibt:

25 Ed. F. Boulenger, Saint Basile. Aux jeunes gens sur la manière de tirer profit des lettres helléniques (Collection des Universités de France), Paris 1952. Übersetzung teilweise nach A. Stegmann, Des Heiligen Kirchenlehrers Basilius des Großen Bischofs von Cäsarea ausgewählte Homilien und Predigten (BKV), München 1925, 445-468 (die Kapiteleinteilung differiert zwischen den beiden Ausgaben).

26 Toũ

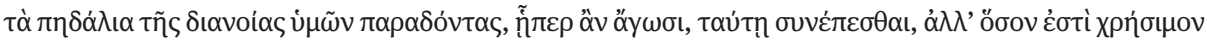

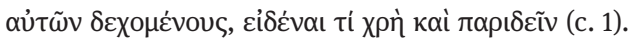

27 Stegmann (s. Anm. 25), 453 Anm. 1 verweist auf Horaz, ep. I,2; Dion Chrysostomus, or. 43.

28 Boulenger (s. Anm. 25), 65 vermutet, dass Basileios hier auf Libanios, dessen Schüler er war, verweist. 
Damit, so sagte nämlich der, der das Denken des Dichters erklärte, wollte Homer nur laut verkünden: „Ihr Menschen müsst euch um die Tugend kümmern, die selbst mit dem Schiffbrüchigen schwimmt und den nackt ans Land Gelangten als ehrwürdiger erweist als die glückseligen Phäaken.“29

Wichtig ist, dass für Basileios die heidnischen Klassiker einschließlich der Dichter nicht deshalb kritisch zu betrachten sind, weil deren polytheistische Religiosität die christliche Jugend verführen könnte. Die eigentlich theologische Dimension wird bei ihrer Lektüre also gar nicht berührt, denn - so stellt Basileios gleich anfangs dar - den

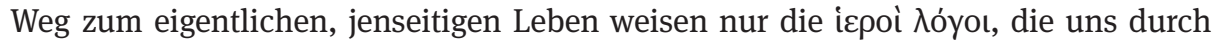
geheimnisvolle Lehren unterrichten. Diese heiligen Schriften aber - d.h. die Bibel können von den Jugendlichen noch gar nicht verstanden werden (2,27-32)(!). ${ }^{30}$ Die heidnischen Klassiker aber können als eine Art Vorbereitung und Propädeutikum zu ihrer Lektüre dienen. ${ }^{31}$

Überhaupt betrachtet Basileios sein Verhältnis $\mathrm{zu}$ den heidnischen Klassikern äußerst entspannt. Er schreibt (c. 3,1-4):

Besteht nun zwischen den beiderseitigen Lehren eine Verwandtschaft, so wird ihre Kenntnis uns von Nutzen sein. Wenn nicht, dann macht eine vergleichsweise Parallelisierung uns auf den Unterschied aufmerksam und dient nicht wenig zur Befestigung des Besseren. ${ }^{32}$

Ähnlich wie Basileios äußert sich auch sein Freund Amphilochios von Ikonion: Dieser, ein Vetter des Gregor von Nazianz, war ein Schüler des Libanios und hatte einige Jahre als Anwalt in Konstantinopel praktiziert, bevor er durch Vermittlung des Basileios Bischof von Ikonion wurde. ${ }^{33}$ In seinem Gedicht „Jamben an Seleukus“34 erteilt er ganz wie Basileios - einem Jugendlichen Ratschläge für die höhere Bildung. Eberhard Oberg hat vermutet, dass Amphilochios Tutor für Jugendliche war, die ihren Heimatort verließen, um in der Stadt die höhere Schule zu besuchen..$^{35}$ Als Bildungsziele bezeichnet Amphilochios die Gottesfurcht/das Verlangen nach Gott sowie die Ausbil-

29 ’Ev Toútoเs yò

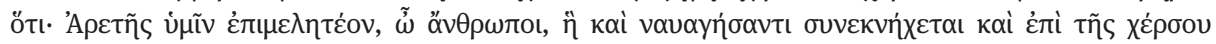

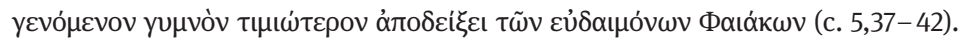

30 Basileios dürfte also gerade nicht der Meinung gewesen sein, die heidnischen Klassiker ließen sich für den Schulgebrauch durch - gegebenenfalls in klassische Versmaße gebrachte - biblische Bücher ersetzen (s.u.).

31 Basileios vergleicht die heidnische Klassikerlektüre hier u.a. mit sportlich-tänzerischen Übungen zur militärischen Vorbereitung.

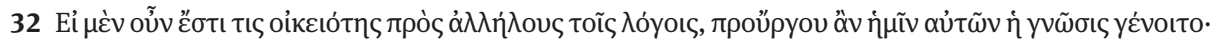

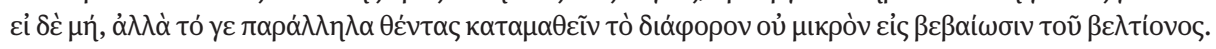
$33 \mathrm{Zu}$ Amphilochios s. G. Röwekamp, Amphilochius von Ikonium, in: LACL, $29 \mathrm{f}$.

34 Die Standardedition des Gedichtes ist E. Oberg, Amphilochii Iconiensis Iambi ad Seleucum, Berlin 1969. Übersetzung hier und im Folgenden nach E. Oberg, Das Lehrgedicht des Amphilochios von Ikonion, in: JbAC 16, 1973, 67-96.

35 Oberg, Lehrgedicht (s. Anm. 34), 71. 
dung eines guten Charakters. Der Jugendliche soll nicht nach Geld und Reichtum streben, da diese Güter unbeständig seien. Ein guter Charakter hingegen ist ein beständiger Schatz. Zur Ausbildung eines solchen Charakters aber helfen die paganen Klassiker:

Lies Dichtungen, / geschichtliche Werke, übe dich an der geläufigen Zungenfertigkeit der Redner / wie an den feinen Problemen der Philosophen. ${ }^{36}$

Doch soll - hier stimmt Amphilochios mit Basileios überein - deren Lektüre nicht unkritisch erfolgen: Vielmehr soll der junge christliche Leser das moralisch Nützliche (= das Lob auf die Tugenden) von der heidnischen Mythologie unterscheiden:

Der klugen Biene Arbeit ahme nach, / die sich auf alle Blüten niederläßt, / jedoch bei jeder nur das Nützliche mit großer Klugheit erntet, / wobei sie die Natur selbst zur Lehrmeisterin hat. / Mit Überlegung pflücke reichlich von dem, / was zuträglich ist. Wenn aber etwas Schaden bringt, / erkenne das Böse und fliege rasch davon. ${ }^{37}$

Und weiter heißt es:

\begin{abstract}
Also: Alle Lobgesänge auf die Tugend, die / sie geschrieben haben, worin sie die Tugend preisen und hinwiederum / Schlechtigkeit tadeln, die lerne eifrig / und achte auf den Sinn wie auf die Schönheit der Darstellung. / Lobreden auf die Götter aber, dies flache Geschwätz, / unheilige

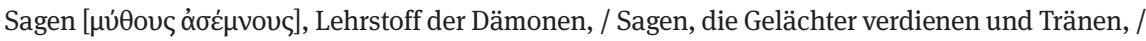
sie sind wie Schlingen und Fallstricke, von ihnen wende dich ab. / Beide lies [Oberg: „lerne beides kennen"], die Götter und die Schriften, / die lächerlichen Götter und die liebenswerten Schriften

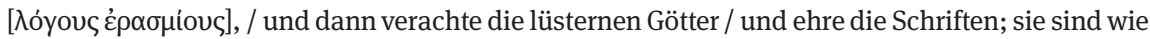
ein Gewächs; / doch meide die Dornen und pflücke die Rose! $!^{38}$
\end{abstract}

Der Gedanke ist der gleiche wie bei Basileios, nur deutlicher und ausführlicher formuliert: Die griechischen Mythen können schädlich sein, weil sie lächerlich und unmoralisch sind. Damit treten sie neben die Schauspiele, Tierkämpfe und Pferderennen: Deren Gefährdungspotential aber schätzt Amphilochios - urteilt man nur nach dem Umfang der diesen Themen gewidmeten Ausführungen (Z. 77-180) - als erheblich höher ein als dasjenige der mythologischen Dichtung. Wiederum wird - wie

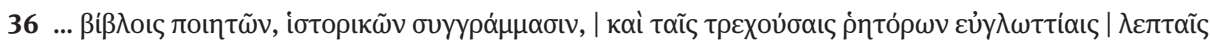

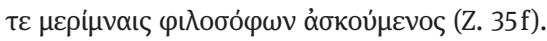

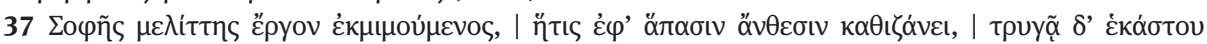

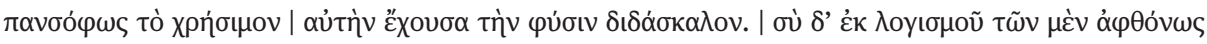

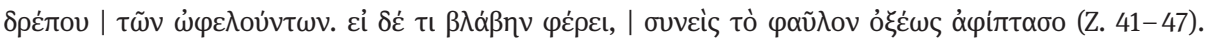

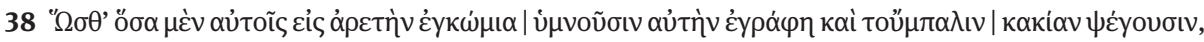

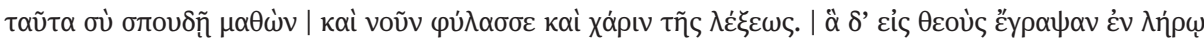

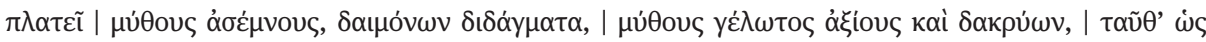

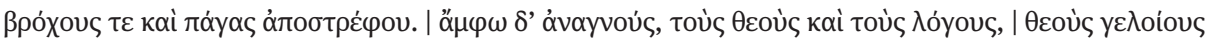

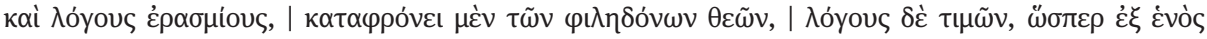

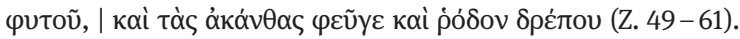


bei Basileios eine eigentlich religiöse oder theologische Dimension nicht berührt Amphilochios befürchtet nicht, dass die Mythen zum Polytheismus verführen könnten. Auch heidnische Gebildete begründeten ihre religiösen Überzeugungen nicht mit einer wörtlichen Interpretation von Homer oder Hesiod: In diesem Sinne ist die Rede von Homer als der ,Bibel der Heiden ${ }^{63}$ sicher irreführend; allenfalls ein allegorisch interpretierter Homer war akzeptabel. Wie heidnische Gebildete auch, versucht Amphilochios zwischen dem problematischen Inhalt und der literarischen Qualität der heidnischen Dichter zu unterscheiden.

Die Ratschläge des Basileios von Cäsarea und des Amphilochios von Ikonion für eine auswählende Lektüre des literarischen Kanons sind also weder neu noch spezifisch christlich: Sie finden sich in Bezug auf die Dichter ähnlich z.B. auch bei Plutarch. ${ }^{40}$

Die heidnischen Klassiker haben dabei für Amphilochios - wie auch für Basileios - propädeutischen Charakter:

Sobald du aber deinen Geist hinreichend an verschiedenen / Schriften wie in einer Kampfbahn geübt und vorbereitet hast, / verlege deine Mühe auf die von Gott geoffenbarten Schriften selbst, / die beiden Testamente, und sammle einen großen Schatz / aus dem alten wie auch aus dem immer neuen Testament / [...] / Ihnen widme willig deinen ganzen Eifer. / Du wirst aus ihnen lernen, einen rechtschaffenen Charakter auszuprägen / und den wahren und alleinigen Gott zu verehren. ${ }^{41}$

Und Amphilochios bemerkt nach einigen theologischen Ausführungen zur Gotteslehre:

Für das Studium der Schriften, die bei Griechen gelesen werden, / sei wie ein Richter, der seine Stimme nach dem Gesetz abgibt: / Ordne an, es solle, wie es sich gehört, / dem Freimut der wahren Dogmen dienen / und der weisheitsvollen Betrachtung der Heiligen Schriften. / Denn gerechterweise muß die Weisheit des Geistes, / die von oben her ist und aus Gott kommt, / Herrin über die untere Bildung sein / wie über eine Magd, die sich nicht grundlos aufspielt, / sondern gewohnt ist, ordentlich zu dienen. / Denn der göttlichen diene die niedere Weisheit. ${ }^{42}$

Eberhard Oberg hat zu Recht gemeint, dass diese Zeilen nicht im Sinne eines strikten Curriculums zu verstehen seien („Unterstufe: Heidnische Literatur [...]; Oberstufe:

39 Vgl. dazu G. Stroumsa, Scripture and Paideia in Late Antiquity, in: M. R. Niehoff (Hrsg.), Homer and the Bible in the Eyes of Ancient Interpreters, Leiden 2012, 29-42.

40 Plutarch, Quomodo adolescens poetas audire debeat (Moralia Nr. 2, 14D-37B).

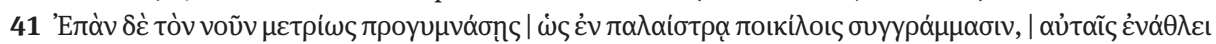

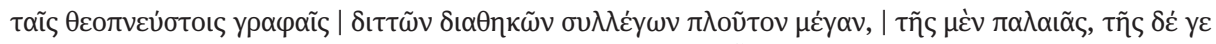

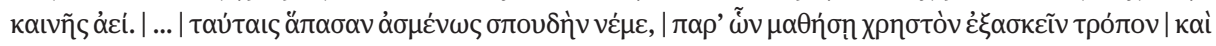

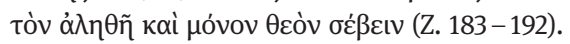

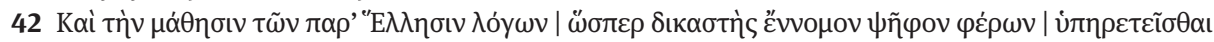

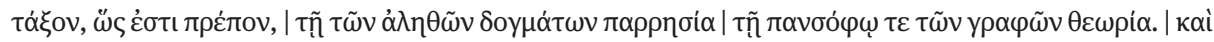

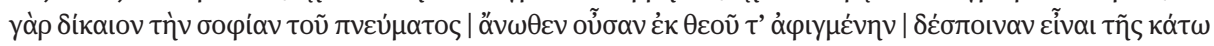

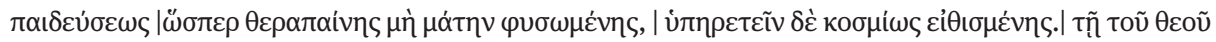
yà 
Heilige Schrift“). ${ }^{43}$ Es handele sich, so Oberg, vielmehr um eine „Rangordnung“. Man könnte hier also von einer Art curricularer Hierarchisierung sprechen. Sie dient zum einen dazu, die christlichen Schriften als grundsätzlich mit dem paganen Bildungscurriculum vereinbar zu erweisen, zum anderen innerhalb des Spektrums der paganen paideia die spezifisch christliche Differenz zu markieren.

Obwohl Absicht und Tendenz der Ausführungen von Amphilochios und Basileios eigentlich recht klar sind, haben sie manchen modernen Interpreten ratlos gelassen. So schreibt Philip Rousseau in seiner einschlägigen Biographie des Bischofs von Cäsarea: ${ }^{44}$

The final impression is of a work in some fundamental way inconclusive. It is disorganized, in that its logic is often shifting, and more often set in abeyance. It is deceitful, in that the texts referred to are mere objects of plunder, superficially useful, and interpreted out of context. It is narrowly addressed, to those susceptible of its sleights of hand; hardly suitable as a general treatise for broader sectors of the Christian community.

Und Rousseau fährt fort:

So we have to conclude that Basil consistently rejected, probably from the earliest period following his departure from Athens, the claims of the traditional curriculum. [...] For him the whole educational edifice had already been dismantled, like a neglected temple, and was to be recycled within the fabric of a Christian building.

Für Rousseau ist die Basileiosschrift also unklar und sogar täuschend, ihm zufolge glaubt Basileios an die literarische Bildung, die er zugleich preist und vorzeigt, nicht mehr: Die Klassikerzitate sind nur Spolien einer Bildungsruine. Eberhard Oberg merkt seinerseits zur Schrift des Basileios von Cäsarea an, indem er sie mit dem Gedicht des Amphilochios vergleicht: „Aber auch er kann trotz größerer Ausführlichkeit das eigentliche Problem nicht lösen. “45

Die Voten von Rousseau und Oberg gehen insofern in die Irre, als sie voraussetzen, was erst zu beweisen wäre, nämlich dass hochgebildete spätantike Christen wie Basileios oder Amphilochios in einem fundamentalen und unauflöslichen Gegensatz zur antiken Bildungstradition standen. Pointiert gesagt: Das „eigentliche Problem“, von dem Oberg redet, existierte nicht in der von ihm angenommenen Weise. Basileios von Cäsarea und Amphilochios von Ikonion sind weder Repräsentanten eines christlichverlegenen oder gar christlich-verlogenen Umgangs mit der überlieferten Bildungstradition, noch bezeugen sie deren Niedergang.

Vielmehr werden die Äußerungen der beiden christlichen Bischöfe nur im Kontext der erneuten Blüte dieser paideia und deren selbstbewusster christlicher Rezeption recht verständlich. Des Amphilochios „Jamben an Seleukus“ sind - ebenso wie die

43 Oberg, Lehrgedicht (s. Anm. 34), 86f (Apparat!).

44 P. Rousseau, Basil of Caesarea, Berkeley/Los Angeles 1994 (Paperback 1998), 56.

45 Oberg, Lehrgedicht (s. Anm. 34), 80 (Apparat). 
quantitativ umfangreiche Dichtung seines Vetters Gregor von Nazianz, folgt man den Thesen Alan Camerons, ${ }^{46}$ als Zeugen einer Erneuerung der poetischen Produktion und Rezeption im vierten Jahrhundert zu lesen. Diese Erneuerung von Elementen der traditionellen paideia findet sich sowohl bei heidnischen als auch christlichen Autoren.

Die Partizipation an einer übergreifenden Bildungstradition kann zwei Funktionen erfüllen: Zum einen schließt die antike paideia die kleine Schicht der Gebildeten zusammen, sie verhilft ihnen zu einem gemeinsamen Idiom, zu einem gemeinsamen Code. Auf der anderen Seite erlaubt es eine gemeinsame Bildungstradition auch, sich $\mathrm{zu}$ unterscheiden, eigene Identitäten auszubilden und Differenzen zu artikulieren. ${ }^{47}$ Integration und Differenzierung erweisen sich in dieser Perspektive als die sozialen Hauptfunktionen von Bildung. Auch Christen, die wie z. B. Hieronymus ihren persönlichen Konflikt zwischen Christentum und antiker Bildung inszenieren, ${ }^{48}$ tun dies doch in einer Form und in einer Sprache, welche die antike Bildungstradition voraussetzt und - in erneuerter Weise - affirmiert.

Basileios und Amphilochios signalisierten mit ihren Schriften zum einen, dass sie als spätantike Hochgebildete sowohl die sprachlichen Codes als auch die durch die antike paideia vermittelten Werte - die sich im philosophischen Tugendideal resümierten - teilten. Zum anderen versuchten sie, im Rahmen und mit Hilfe dieser paideia die christliche Differenz zu formulieren. Indem sie die heidnischen Klassiker als Vorbereitung zur Lektüre der heiligen Schrift empfehlen, spielten sie ganz bewusst auf gängige curriculare Ideen an: Die rhetorisch-literarische Bildung als Vorbereitung für die Philosophie, sowie - innerhalb des philosophischen Curriculums - die Ethik (die Lektüre der heidnischen Klassiker soll zur Tugend erziehen!) als Vorbereitung für Physik und Metaphysik.

Die Integration von Christentum und Heidentum durch curriculare Hierarchisierung kann auf diese Weise die christliche Differenz (und d.h. in den Augen der Bischöfe Basileios und Amphilochios natürlich auch: die christliche Überlegenheit) formulieren, indem sie den Rahmen und den Code der gemeinsamen paideia nicht sprengt, sondern erweitert und somit bestätigt.

Dass die von Amphilochios und Basileios vorgeschlagene Lösung in den Kreisen christlicher Gebildeter zumindest teilweise konsensfähig war, könnte eine Bemerkung ihres paganen Lehrers Libanios anzeigen. Die Oratio 16 des Libanios ist an die Adresse der christlichen Antiochener gerichtet: Der heidnische Rhetor ruft die gegen den Kaiser rebellische Stadt zur Umkehr auf und empfiehlt in diesem Zusammenhang auch, die

46 A. Cameron, The Empress and the Poet, in: Yale Classical Studies 27, 1982, 217-289. S. auch R. Cribiore, The School of Libanius in Late Antique Antioch, Princeton/Oxford 2007, 161.

47 K. Vössing, Schule und Bildung im Nordafrika der römischen Kaiserzeit (Collection Latomus 238), Brüssel 1997, 595-613. S. auch P. Gemeinhardt, Das lateinische Christentum und die antike Bildung, Tübingen 2007, 165 - 306; C. Lepelley, The Use of Secularised Latin Pagan Culture by Christians, in: D. M. Gwynn/S. Bangert (Hrsg.), Religious Diversity in Late Antiquity, Boston/Leiden 2010, 447-492.

48 Hieronymus, ep. 22,30 (ed. J. Labourt, Saint Jérôme. Lettres, t. 1, Paris 1982, 145). 
Stadt Zeus und den anderen heidnischen Göttern zu übergeben, „über die Euch lange vor dem Kaiser [Julian] von Kindesbeinen an Homer und Hesiod unterrichteten.“49 Und Libanios fährt fort:

Ihr glaubt, dass man Euch bewundern muss, weil Ihr gebildet seid, und ihr nennt die epische Dichtung Bildung. Aber für die wichtigsten Bildungsinhalte greift Ihr auf andere Lehrer zurück: Wenn diese Bildungsinhalte Euch verschlossen wären, müsstet Ihr klagen; doch Ihr flieht sie, obwohl sie Euch offen stehen. Wenn immer die Rede von Plato und Pythagoras ist, so schützt Ihr die Mutter, die Ehefrau, die Wirtschafterin, den Koch und die Tatsache vor, dass Ihr schon lange davon überzeugt seid. Ihr schämt Euch nicht, Euch darüber zu schämen und Ihr begebt Euch ins Schlepptau derjenigen, denen Ihr gebieten solltet. Auch haltet Ihr es für notwendig, weiterhin schlecht zu denken, weil ihr einstmals schlecht gedacht habt, was ungefähr so ist, als ob jemand, der sich in seiner Jugend prostituiert hat, diese schlechte Angewohnheit auch für den Rest seines Lebens beibehält.. ${ }^{50}$

Da Libanios weiß, dass er diese Christen nicht überzeugen kann, hält er - so sagt er selbst anschließend- seinen Aufruf zur Konversion bewusst kurz. Für die gebildeten Christen, die hier angesprochen sind, ist die Götterwelt der mythischen Dichter Homer und Hesiod Bildungsgut ohne besonderen religiösen Gehalt. Doch, so Libanios, lehnen diese Christen die höhere, philosophische Bildung ab. ${ }^{51}$ Anscheinend - so Libanios - machten sie geltend, dass die philosophische Gotteslehre von minder gebildeten Christen nicht verstanden werden kann. ${ }^{52}$ Auch argumentierten sie, dass sie den Glauben ihrer Kindheit nicht aufgeben wollten. Libanios scheint auf diese Weise insinuieren $\mathrm{zu}$ wollen, dass diese Christen gar keine Bildung erfahren haben: Weder wollen sie sich von der breiten Masse und deren primitiven religiösen Vorstellungen unterscheiden, noch wollen sie mit der Religion ihrer Kindheit brechen. Die Bildung dieser Christen ist in den Augen des Libanios gar keine Bildung, denn sie differenziert nicht.

Im Hinblick auf die heidnischen Göttergeschichten aber zeigt die Libaniospassage, dass der Vorschlag einer curricularen Akzeptanz heidnischer Literatur und

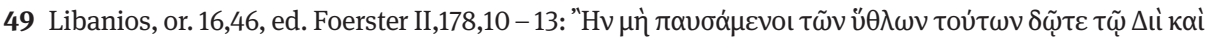

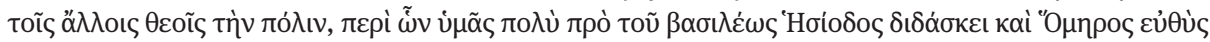
$\dot{\varepsilon} \kappa \pi \alpha i \delta \omega v$.

50 Libanios, or. 16,47, ed. Foerster II,178,13-179,4: 'Ү

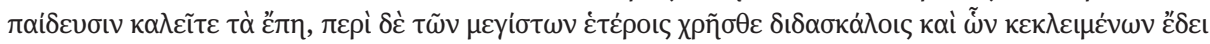

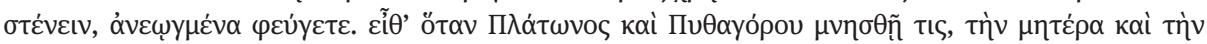

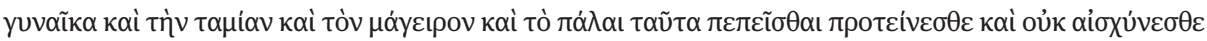

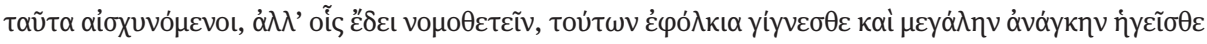

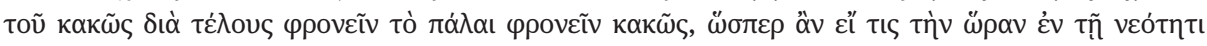

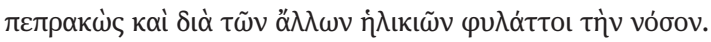

51 So rekonstruiere ich den hier vorgetragenen Gedankengang. Man könnte auch erwägen, ob Libanios hier die philosophische Mythenallegorese im Blick hat. Aber es fehlt der explizite Bezug.

52 Man könnte Libanios hier so verstehen, dass die gebildeten Christen in Antiochien geltend machten, dass das Christentum der simplices den wichtigsten Teil der philosophischen Theologie, nämlich den Monotheismus, immer schon enthält. 
Dichtung, wie wir sie bei Basileios von Cäsarea und Amphilochios von Ikonion finden, vor einem bestimmten Hintergrund zu sehen ist: Er theoretisiert und formuliert explizit ein Arrangement, das gebildete christliche Kreise möglicherweise ohnehin praktizierten. Dass sie sich mit diesem Arrangement scharf von ihren gebildeten heidnischen Zeitgenossen abgegrenzt hätten, ist aber nicht zu vermuten: Auch diese dürften Homer nicht als „Bibel“ verstanden haben - und auch unter ihnen dürfte die Zahl derjenigen, welche die Philosophie Platos oder Pythagoras ernsthaft studiert hätten, eher begrenzt gewesen sein.

Es ergibt sich der Eindruck, dass das Thema der klassischen Mythologie für bestimmte gebildete Heiden und Christen eher zur comfort zone gehörte: In deren Beurteilung stimmte man weitgehend überein, zumal der Schwerpunkt möglicher Konflikte zwischen Heiden und Christen ohnehin nicht hier lag, sondern eher bei öffentlichen heidnischen (und christlichen) Feiern und Prozessionen und - in beschränkterem und komplexerem Maße - bei einer heidnischen philosophischen Theologie.

Die heidnische Mythologie wurde in den Augen einiger christlicher Bischöfe dann problematisch, wenn sie den Schulraum verließ: Augustin konstatiert kritisch, dass sich zum einen die Theologie der Dichter von der staatlichen Theologie nicht säuberlich trennen lasse. Zum anderen ist - wie schon bemerkt wurde - die dichterische Theologie für ihn vor allem im Theater präsent und entfaltet dort ihre verderbliche Wirkung auf ein größeres Publikum.

Mir scheint, dass auch Augustin mit der theaterkritischen Akzentuierung seiner Kritik an den paganen Göttergeschichten auf einen Heiden und Christen übergreifenden Bildungskonsens rekurrieren kann. Ruth Webb hat in der schon erwähnten Studie zu Recht darauf hingewiesen, dass Kritik am Theater und seinen auf die Emotionen zielenden Spektakeln keineswegs eine Innovation der Kirchenväter darstellt. Vielmehr stehen diese in einer Tradition moralisierender Kritik am Theater und seiner Zelebration der Fiktionalität:

The Church Fathers were also members of a social and intellectual elite that had always been suspicious of the theater and the rowdy celebrations of the people. At the same time, the Church as an institution took over and adapted existing attitudes towards performers and performance enshrined in Roman law. [...] What all these critics have in common is the rejection of fiction, the refusal to grant an autonomous status to theatrical representation, and the denial of the boundaries between theater and life."“53

D.h. aber, dass auch die Kritik an den klassischen Göttergeschichten, die als Kritik an deren Repräsentation auf der Theaterbühne formuliert ist, die erwähnte gebildete comfort zone nicht wirklich verlässt. Wiederum aktivieren christliche Intellektuelle

53 Webb (s. Anm. 16), 199f. Webb notiert, dass das Theater in Rom als ,fremd“ und die Schauspielerinnen als ,pornai‘ bezeichnet wurden (mit Verweis auf C. Edwards, The Politics of Immorality in Ancient Rome, Cambridge 1993, 99-103). 
einen Teil des vorhandenen Spektrums intellektueller Werte und Wertungen, um die christliche Differenz zum Heidentum zu artikulieren.

\section{III}

Die Haltung einiger gebildeter christlicher Bischöfe zur klassischen Mythologie lässt sich noch einmal konturieren und nuancieren, wenn man die christlichen Reaktionen auf angebliche gesetzgeberische Maßnahmen des Kaisers Julian gegen christliche Grammatik- und Rhetoriklehrer betrachtet. Bekanntlich ist bei diesem Vorgang das Gesetz Julians (Codex Theodosianus 13,3,5 vom 17.6.362) von einem Brief (ep. 61c BidezCumont $=$ ep. 36 Wright $)^{54}$ zu unterscheiden, in dem Julian das Problem christlicher Grammatik- und Rhetoriklehrer aus seiner Sicht behandelt. Das Gesetz redet überhaupt nicht von christlichen Lehrern, sondern regelt nur die Anstellungsmodalitäten städtischer Rhetorik- und Grammatiklehrer und schreibt (unpraktischerweise) vor, dass alle derartige Ernennungen vom Kaiser selbst genehmigt werden müssen. ${ }^{55}$

In welchem Verhältnis der Brief Julians zu diesem Gesetz steht (und ob es überhaupt einen direkten Bezug gibt, ob also der Brief das Gesetz plausibilisieren sollte) ist unklar: Das Hauptargument des Briefes ist, dass Grammatik- und Rhetoriklehrer, die überzeugte Christen sind, die heidnischen Klassiker (wie z. B. Homer und Hesiod) nicht lehren sollten, da sie deren religiöse Überzeugung nicht teilen und deren Ansichten über die Götter für blasphemisch und irrtümlich halten. Nun, da die Religionsfreiheit

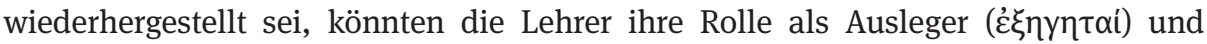
,Propheten` der Götter wieder einnehmen. Diejenigen aber, die das aufgrund ihrer Überzeugungen nicht könnten, sollen sich „in die Kirchen der Galiläer begeben und Matthäus und Lukas auslegen“. ${ }^{56}$

Christen, welche die heidnischen Klassiker lehren, ohne selbst Heiden zu sein, offenbaren hingegen nur ihre schamlose Geldgier. Der Brief Julians schließt mit der ausdrücklichen Feststellung, dass kein Jugendlicher, der die Schulen besuchen will, ausgeschlossen werden soll. ${ }^{57}$

Es ist ebenfalls unklar, an wen genau dieser Brief adressiert ist: Richard Goulet hält heidnische Lehrer, die vom religiösen Wert der Klassiker überzeugt werden sollten, für das Primärpublikum. ${ }^{58}$ Klaus Rosen sieht christliche Lehrer als die hauptsächlichen

54 L'Empereur Julien. Oeuvres complètes, t. 1,2: Lettres et fragments, Texte revu et traduit par J. Bidez, Paris 1960, 73-75; The Works of the Emperor Julian, with an Engl. Translation by W. C. Wright, Vol. III, Cambridge, Mass. 1961, 116-123.

55 K. Rosen, Julian. Kaiser, Gott und Christenhasser, Stuttgart, 270f. Rosen hält den im Codex Theodosianus überlieferten Gesetzestext für eine „Kurzfassung des Gesetzes“.

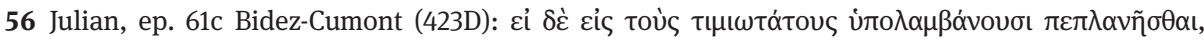

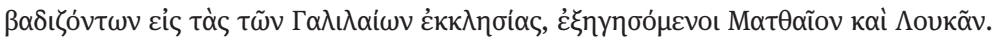

57 Julian, ep. 61c Bidez-Cumont (424 A).

58 „Ce que Julien souhaite, c'est qu'il y ait dans ce groupe des maîtres formalistes qui se sont desolidarisés des croyances traditionelles, des paiens timorés que les temps nouveaux inciteront à confesser 
Adressaten. Die gebildete christliche Elite, so Rosen, musste nun mit Bestürzung realisieren, „wie Julian die Brücke einriss, die sie, oft zunächst zögernd und mit schlechtem Gewissen, für sich und ihre Kinder zwischen Glauben und heidnischer Literatur geschlagen hatten“. ${ }^{59}$ Auch Rosen scheint also bei gebildeten Christen eine zwiespältige Haltung zur paganen paideia vorauszusetzen. Henri-Irénée Marrou konstatiert - mit aktualisierendem Akzent vor dem Hintergrund der französischen Debatten um die école laique - dass Julian die erste „konfessionelle Schule“ schaffen wollte, beauftragt mit religiöser Propaganda. Marrou bemerkt: „Il est remarquable de voir dans quelle atmosphere de parfaite neutralité s'était epanoui le haut enseignement dans cette deuxième moitié du IV siècle."60

Schauen wir auf die christlichen Reaktionen auf Julians Maßnahme, so fällt auf, dass sie sich auf die Christen beschränkte, die an der höheren Bildung besonders interessiert waren. Prominente Rhetoren wie Prohäresius in Athen ${ }^{61}$ und Marius Victorinus in Rom gaben aus Protest ihren Unterricht auf ${ }^{62}$ - obwohl sie vom Gesetz Julians persönlich nicht betroffen gewesen sein dürften.

Die Kirchenhistoriker des 5. Jahrhunderts, Sokrates und Sozomenos, übernahmen die unzutreffende christliche Behauptung, Julian habe christlichen Kindern den Besuch der griechischen Schulen untersagt. ${ }^{63}$ Beide behaupteten, dass dieser Verlust des Zugangs zur griechischen paideia durch Apollinaris von Laodikeia den Älteren und Apollinaris von Laodikeia den Jüngeren kompensiert wurde: ${ }^{64}$

leur foi.“ (R. Goulet, Prohérésius le païen et quelques remarques sur la chronologie d’Eunape de Sardes, in: ders., Études sur les Vies des Philosophes de l'Antiquité tardive, Paris 2001, 323-347, 330).

59 Rosen (s. Anm. 53), 273.

60 H. I. Marrou, Histoire de l'éducation dans l'antiquité, Paris 1950, 428.

61 In dem in Anm. 58 zitierten Artikel bezweifelt R. Goulet das Christentum des Prohäresius mit Gründen.

62 Augustin, conf. 8,5,10; Hieronymus, chron. a. 363 (ed. R. Helm, GCS Eusebius VII, 242,24-243,1). Die Formulierung, die Augustin in Bezug auf Marius Victorinus wählt (quam legem ille amplexus) lässt erkennen, dass der römische Rhetor das Julianische Gesetz gerne zum Anlass nahm, sich zurückzuziehen - Zwang wurde dabei nicht ausgeübt. Vielleicht nutzte der nunmehrige Christ Marius Victorinus einen ohnehin geplanten Rückzug aus Altersgründen für publikumswirksamen Protest gegen die auch bei Heiden umstrittene Maßnahme, vgl. Ammianus Marcellinus 22,10,7; 25,4,20. - Augustin, civ. 18,52 behauptet gar, Julian habe den Christen verboten, die heidnische Literatur zu lehren und zu lernen. 63 Sokrates, h.e. 3,16, ed. Socrate de Constantinople, Histoire ecclésiastique, Livres II - III, Texte grec de l' édition de G. C. Hansen, trad./notes par P. Périchon/P. Maraval (SC 493), Paris 2005, 308 - 317; Sozomenus, h.e. 5,18, ed. Sozomène, Histoire ecclésiastique. Livres V-VI, Texte grec de l'édition de J. Bidez/G. C. Hansen, introd./trad./annotation par G. Sabbah/A.-J. Festugière/B. Grillet (SC 495), Paris 2005, 184-191. Die Quelle dieser Behauptung bei den beiden Kirchenhistorikern ist vermutlich Rufin, h. e. 10,33 .

64 S. dazu H.-G. Nesselrath, Die Christen und die heidnische Bildung: Das Beispiel des Sokrates Scholastikos (Hist. Eccl. 3,16), in: J. Dummer/M. Vielberg (Hrsg.), Leitbilder der Spätantike - Eliten und Leitbilder, Stuttgart 1999, 79-100. Eine diskussionswürdige quellenkritische Analyse des Sokrateskapitels bietet P. Speck, Sokrates Scholastikos und die beiden Apolinarioi, in: Philologus 141, 1979, 361 369. 
Laut der Kirchengeschichte des Sokrates (ca. 440 n.Chr. verfasst ${ }^{65}$ ) schrieb der Grammatiklehrer Apollinaris der Ältere die fünf Bücher Mose und die geschichtlichen Bücher des Alten Testaments in klassische Versmaße um. Sein Sohn Apollinaris der Jüngere habe die Arbeit des Vaters auf das Neue Testament ausgedehnt und die Evangelien wie auch die apostolischen Briefe in Dialoge nach Art Platos verwandelt (h.e. 3,16). Die Vorsehung aber erwies sich laut Sokrates als stärker als der Anschlag des Kaisers und die Bemühungen der beiden Apollinarioi: Der Kaiser starb, das Gesetz wurde zurückgenommen und die Anstrengungen von Vater und Sohn Apollinaris wurden als überflüssig betrachtet.

Interessanterweise zitiert Sokrates an dieser Stelle einen möglichen frommen Einwand (h.e. 3,16,8): Wie kann man behaupten, dass die Vorsehung dies so gefügt habe? Könne man auch zugeben, dass der Tod Julians ein Werk der Vorsehung war, so gilt dies doch nicht für das Überflüssigmachen der poetischen Versuche von Vater und Sohn Apollinaris! Ihr Projekt sei wertvoll gewesen: Die heidnische paideia, die den Polytheismus lehrt, schade dem Christentum!

Der von Sokrates zitierte fromme Einwand scheint es für möglich zu halten, dass die Christen die paganen Schulklassiker durch eine passend umgedichtete, stilistisch verbesserte Bibel ersetzen. ${ }^{66}$ Sokrates widerlegt diesen Einwand länglich (h.e. 3,16,927): Seine Argumentation läuft darauf hinaus, dass die pagane Bildung neutralisiert werden kann: Christus und seine Jünger halten die griechische Kultur weder für schädlich noch für von Gott inspiriert. ${ }^{67}$ Die griechischen Philosophen sind nützlich, weil sie eine Schulung in Logik bieten, die man braucht, um die gottlosen Epikureer zu widerlegen! Dies können weder die Bibel noch die Schriften der Apollinarioi bieten. So können die Christen die intellektuellen Waffen der heidnischen Gegner gegen diese selbst wenden. Julian hat die Christen von der heidnischen Bildung ausgeschlossen, weil er wusste, dass die Mythen leicht widerlegbar waren.

Sozomenos erzählt die gleiche Episode in den Details etwas abweichend von Sokrates; ${ }^{68}$ deutlich ist hier - wie auch sonst in seiner Kirchengeschichte - sein Bemühen, den Vorgänger zu verbessern. Wichtig ist für unseren Zusammenhang, dass er die mangelnde Rezeption der Apollinariswerke anders erklärt als Sokrates: Sozomenos zufolge hätten diese Erfolg gehabt, wenn nicht das gebildete Publikum die heidnischen

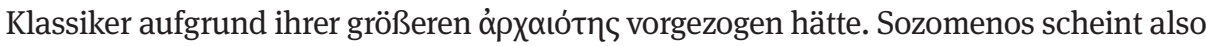

65 Socrate de Constantinople. Histoire ecclésiastique, Livre I, Texte grec de l' édition de G. C. Hansen, trad./notes par P. Périchon/P. Maraval (SC 477), Paris 2004, $9 \mathrm{f}$.

66 M. Wallraff, Der Kirchenhistoriker Sokrates, Göttingen 1997, 90-91, Anm. 302f findet hier „die Existenz eines bildungsfeindlichen Flügels innerhalb des Christentums“ bezeugt, der wenig Spuren in den literarischen Quellen hinterlassen habe. Allerdings sieht auch Wallraff die frommen christlichen Kritiker nicht als radikal bildungsfeindlich, auch ihnen sei an literarischer, den Stil formender Bildung gelegen gewesen - freilich hätten sie den religiös-polytheistischen Inhalt vermeiden wollen.

67 Sokrates verweist auf 1 Thess 5,21 und Kol 2,8 sowie auf ein bekanntes Agraphon Jesu („Werdet erprobte Wechsler ...“), vgl. M. Pesce (Hrsg.), Le parole dimenticate di Gesù, Roma 2007, 473 u. $687 \mathrm{f}$. 68 Sozomenus, h.e. 5,18. Man hat versucht, die Diskrepanzen zu Sokrates zu erklären - letztlich ohne überzeugende Ergebnisse, s. Nesselrath (s. Anm. 64), $84 \mathrm{f}$. 
- so die m.E. zutreffende Beobachtung Martin Wallraffs - die Haltung der frommen christlichen Bildungsfreunde einzunehmen, denen Sokrates geantwortet hatte. ${ }^{69}$

Die Einschätzung des Sozomenos ist gewiss realistisch: Die Papyri belegen, dass nur die Klassiker in der Schule gelesen wurden. Werke jüngeren Datums, seien sie heidnisch oder christlich, wurden nicht in den Lehrplan aufgenommen. ${ }^{70}$

Sozomenos nimmt Apollinaris von Laodikeia auch gegen den impliziten Vorwurf des Sokrates in Schutz, er habe naiverweise geglaubt, man könne die Heiden durch den einfachen Verweis auf die Schrift widerlegen. Sozomenos schreibt:

Apollinaris schrieb ein sehr bemerkenswertes Werk gegen den Kaiser und die heidnischen Philosophen, dessen Titel „Die Wahrheit“ lautete. Dort bewies er klar, ohne die Autorität der Bibel zu bemühen, dass diese weit entfernt davon wahren, zur richtigen Ansicht über Gott gelangt zu sein. ${ }^{71}$

Ungefähr 100 Jahre nach Julians Gesetz diskutierten also Sokrates und Sozomenus also anhand der literarischen Bemühungen der beiden Apollinarioi die Frage, ob eine alternative, nur auf die Bibel gegründete paideia möglich sei.

Alan Cameron hat einen möglichen zeitgenössischen Kontext zu den Bemerkungen der beiden Kirchenhistoriker vorgeschlagen: Cameron meint, Sokrates habe diese Kritik nur formulieren können, so lange die Kaiserin Eudokia († 460) noch nicht ihre Bibelpoesie, d.h. ihren homerischen Cento zum Neuen Testament sowie ihre Metaphrase des Oktateuchs, geschrieben habe. Die implizite Korrektur des Sozomenos wertet Cameron hingegen als eine Reaktion auf die literarische Produktion der Kaiserin. ${ }^{72}$ Die Hypothese Camerons ist allerdings alles andere als zwingend: Sozomenos erwähnt Eudokia mit keinem Wort. $^{73}$

Es ist auch eher unwahrscheinlich, dass die Werke der beiden Apollinarioi irgendetwas mit Julians Gesetz zu tun haben. Sie deuten daher auch nicht auf eine grundsätzliche Ablehnung der heidnischen Klassiker und deren Mythologie. Viel eher sind sie ein weiteres Zeugnis für den bereits erwähnten Aufschwung der poetischen Produktion in der zweiten Hälfte des 4. Jahrhunderts. Ein Christ, der die Bibel sprachlich Homer und Plato anverwandelt, bekämpft nicht die klassische Bildung oder

69 Wallraff (s. Anm. 66), 91 Anm. 303.

70 Cribiore (s. Anm. 46), 137-173. S. auch P. Parsons, City of the Sharp-Nosed Fish. Greek Papyri beneath the Egyptian Sand Reveal a Long-Lost World, London 2007, der bemerkt: „Schoolboys and adults alike dieted heavily on the Classics, that is the Greek literature of the classical and early Hellenistic period. The authors most represented in the papyri are authors of the third century BC or earlier. It is as if, from our point of view, their taste had stopped with Dryden.“

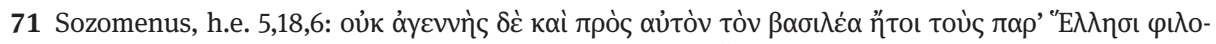

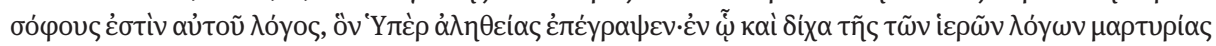

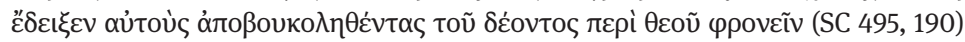

72 Cameron (s. Anm. 46), 283. S. die kritische Diskussion bei G. Agosti, L'epica biblica nella tarda antichità greca. Autori e lettori nel IV e V secolo, in: F. Stella (Hrsg.), La scrittura infinita. Bibbia e poesia in età medievale e umanistica, Firenze 2001, 67-104, 87.

73 Agosti (s. Anm. 72). 
verzichtet demonstrativ auf sie, sondern erweist ihr seine Reverenz. Christen wie Sokrates und Sozomenos (und nicht nur diese) waren überzeugt, dass Julian sie von der heidnischen paideia ausschließen wollte.

In einer frühen Reaktion, der Oratio gegen Julian - sie wurde 364 oder 365 verfasst $^{74}$ - sieht Gregor von Nazianz die Maßnahme Julians als Teil einer umfassenden Politik, das Christentum aus der Öffentlichkeit zu verbannen. Julian - so Gregor wollte dem Christentum die Bildung (入óyoı) entziehen. Und er lässt Julian sagen:

Uns gehört Wissenschaft und Bildung, denn wir verehren die Götter. Für Euch passt Dummheit und Rohheit; euer oberster Grundsatz und eure Weisheit ist: Glaube! $!^{75}$

Gregor destruiert Julians Begriff des $\dot{\varepsilon} \lambda \lambda \eta v i \zeta \zeta \varepsilon v$, der literarische Kultur und Kult zugleich umfasst: Weder, so argumentiert Gregor, kann mit $\dot{\varepsilon} \lambda \lambda \eta v i \zeta \varepsilon$ เv eine einheitliche Kultpraxis gemeint sein (dazu ist die Kultpraxis auch unter den Griechen zu verschieden) noch ist es plausibel, dass Teilhabe an der literarischen paideia zur Kultteilnahme verpflichtet:

Selbst wenn es zutreffen würde, dass die Sprachhellenisten und die Kulthellenisten ein- und dieselben wären, würde doch noch nicht der Kult Anspruch auf die Wissenschaft haben, so dass wir mit Recht ausgeschlossen würden. ${ }^{76}$

Mit anderen Worten: Gregor versucht der durch Julian vorgenommenen ,Konfessionalisierung، der literarischen Bildung die Grundlage zu entziehen.

Gregor malt in einem längeren Abschnitt (or.4,111-122) die Konsequenzen aus, die sich ergeben würden, wenn der von ihm unterstellte Plan Julians realisiert würde, in den Schulen „das Vorlesen der hellenistischen Lehren und das Auslegen derselben einzuführen, um durch dieses moralisch zu erziehen und in den Geheimnissen zu unterrichten“. Er schreibt:

Möge ihr Theater bereit stehen! Ich weiß nicht, wie sie sonst ihren Tempel genannt haben wollen. Die Rufer sollen schreien: „Das Volk trete zusammen!“ Vorne sollen diejenigen Platz nehmen, die durch ihr graues Haar, ihre Anciennität oder ihre Stellung im öffentlichen Leben Vorrang haben oder sich durch Geburt und Würde auszeichnen oder durch irdische Weisheit, die mehr Vergnügen bietet als wahre Frömmigkeit. ${ }^{77}$

74 Gregor von Nazianz, or. 4, ed. J. Bernardi, Grégoire de Nazianze, Discours 4- 5 contre Julien (SC 309), Paris 1983, 86 - 293. Die Reden Gregors sind jetzt bequem zu greifen in C. Moreschini (Hrsg.), Gregorio di Nazianzeno. Tutte le orazioni, Milano 2000; die Datierung hier 1192.

75 Gregor von Nazianz, or. 4,102 (Übersetzung hier und im Folgenden mit leichten Modifikationen nach

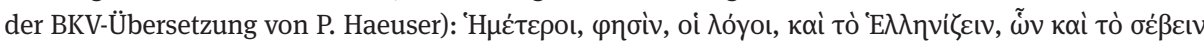

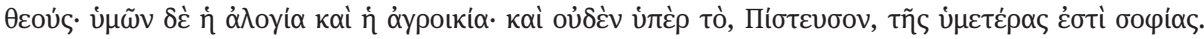

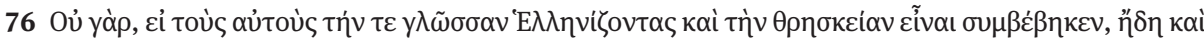

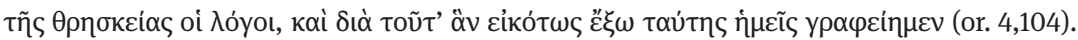

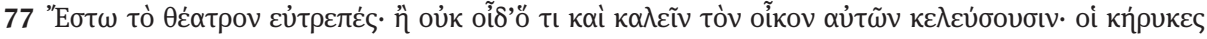

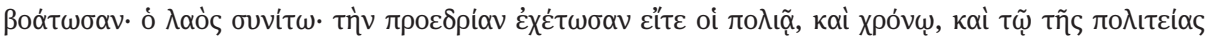




\section{Und weiter führt Gregor aus:}

Was aber wird von nun ab geschehen? Du wirst Männer herbeibringen, welche die - natürlich wie ihr selbst sagen werdet - göttlichen Worte auslegen müssen; Du wirst theologische und Moralbücher nachschlagen. Sag mir, was für Bücher werden es sein, und wer wird sie verfasst haben? Es wird sich hübsch machen, wenn von Hesiods Göttergeschichten mit ihren Kämpfen und Wirren, von den schrecklichen Namen und Taten der Titanen und Giganten vorgesungen wird. Man wird erzählen von Kotus, Briareus, Gyges, von Enceladus, von euren Drachenfüßlern, von Blitze schleudernden Göttern, von Inseln, welche diesen entgegengeworfen wurden als Geschosse und zugleich als Gräber für die Entgegenstürmenden. [...] Solche sauberen Geschichten aus Hesiod werden den Zuhörern vorgetragen werden. [...] Hierauf möge man allegorische, wundersame Auslegungen ersinnen, wobei aber die Rede von ihrem Thema abkommen und in Schlünde und Abgründe fallen wird, da dem Denken der feste Grund fehlt. ${ }^{78}$

Homer ist nicht besser. Gregor schreibt:

Welche Stellung wird man dem großen Homer anweisen, der bald als Komödiendichter, bald als Tragödiendichter über die Götter geschrieben hatte? In seinen bewunderten Dichtungen findest Du nämlich beides: Unglück und Lächerlichkeiten. ${ }^{79}$

\section{Und nachdem Gregor einige dieser „Lächerlichkeiten“ aus der Ilias zitiert hat, bemerkt}

er:

Wer von Euch ist so ideal veranlagt, so groß und besitzt tatsächlich so viel von des Zeus Einsicht, dass er alle diese so weise und schlau ersonnenen, ganz außergewöhnlichen Erzählungen, die noch vermehrt werden können, mit theoretischen, überirdischen, für uns nicht fassbare Erwägungen auf das Ziemliche zurückzuführen vermöchte? ${ }^{80}$

Die heidnische Mythenallegorese ist für Gregor nur eine billige Ausflucht: Entweder sind die Mythen wahr, dann bräuchte man sich ihrer nicht zu schämen; man müsste sie

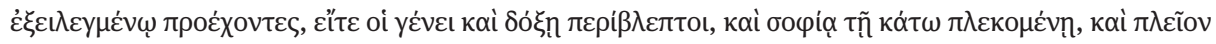

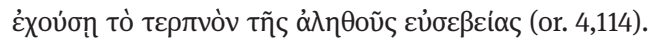

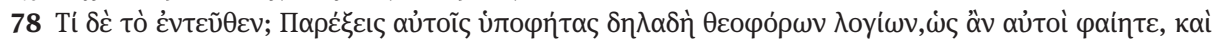

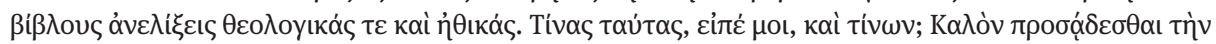

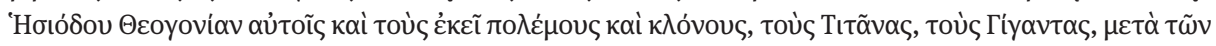

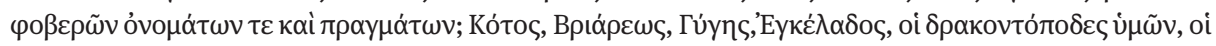

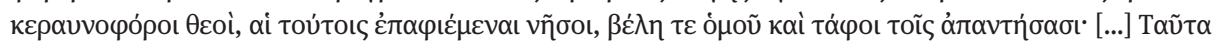

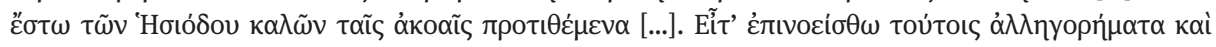

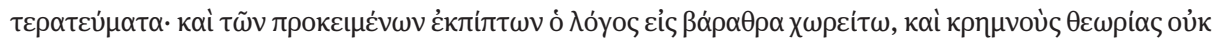

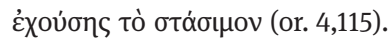

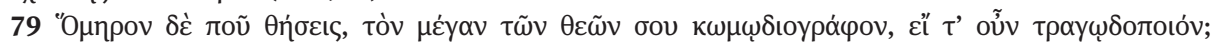

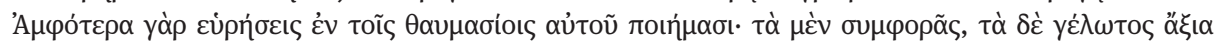
(or. 4,116).

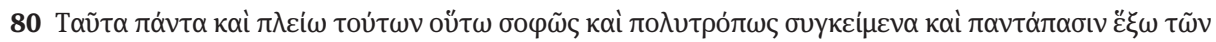

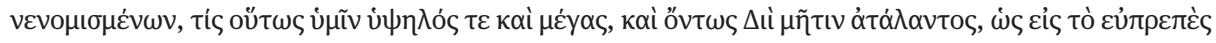

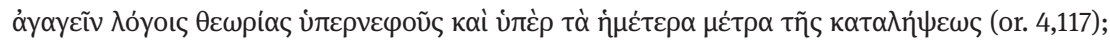


dann verteidigen und beweisen, dass sie nicht schändlich sind. Oder sie sind unwahr, dann solle man doch erst die theologische Wahrheit lehren. Die Heiden schämen sich der Mythen und kompensieren das, indem sie von der tieferen Bedeutung des Mythos sprechen. Doch haben nur wenige zu den Mythen Zugang, denn die Bildung (paideusis) ist eben nicht allgemein zugänglich. Deswegen wird viel Geld ausgegeben, um die Mythen in bildlichen Darstellungen, Skulpturen und Weihegeschenken in den Tempeln und an Altären zu propagieren. Die christlichen Allegorien sind im Übrigen mit den heidnischen nicht zu vergleichen, denn bei ihnen ist die Verhüllung anständig und verletzt nicht den guten Geschmack und auch der verborgene Gedanke ist klar und wunderbar. Und Gregor führt im Einzelnen aus (or. 4,121), wie die heidnischen Mythen weder Friedfertigkeit, noch Ehrfurcht gegenüber den Eltern, noch Verachtung des Geldes, noch Mäßigung und Enthaltsamkeit lehren können.

In seiner Polemik gegen Julian bestreitet Gregor das, was Basileios von Cäsarea und Amphilochios von Ikonion konzediert hatten: Aus den heidnischen Mythen lässt sich laut Gregor keinerlei positive, den Erwerb von Tugenden fördernde Botschaft gewinnen. Doch sollte man Gregor nicht gegen seine beiden Freunde ausspielen: Seine Stellungnahme ist das zugespitzte Votum eines hochgebildeten Christen gegen das Projekt Julians, die klassische Mythologie mit einer religiösen Bedeutung aufzuladen, die diese zu dieser Zeit für viele Zeitgenossen - Christen und Heiden - nicht oder nicht mehr hatte.

\section{IV}

Ein Résumé sei formuliert: Einige spätantike christliche Bischöfe polemisierten gegen klassische Mythologie, vor allem dann, wenn diese entweder eine besondere mediale Präsenz außerhalb der Schule aufwies (im noch existierenden heidnischen Kult, in bildlichen Darstellungen, auf der Bühne) oder wenn philosophisch gebildete Heiden behaupteten, die heidnischen Mythen verhüllten einen tieferen theologischen Sinn. Als Lehrstoff im Grammatik- und Rhetorikunterricht erregte heidnische Mythologie kaum oder gar nicht den Zorn dieser gebildeten Bischöfe - jedenfalls insofern dieser sich öffentlich artikulierte. Das liegt zum einen an der Selbstverständlichkeit der Bildung und ihres eher schmalen Curriculums für die Gebildeten. Zum anderen aber hatte die Masse der Gemeindeglieder keinen oder doch nur beschränkten Zugang zu dieser Bildung - das Thema war damit für die homiletische Verwertung wenig geeignet: Die Zahl derjenigen, die Homer oder Vergil partienweise zitieren konnten und die diesbezügliche literarische Anspielungen formulieren oder verstehen konnten, dürfte doch recht beschränkt gewesen sein: Augustin, Basileios von Cäsarea, Amphilochios von Ikonion und Gregor von Nazianz waren auch unter ihren Bischofskollegen Ausnahmegestalten. Gelegentliche Mahnungen in Kirchenordnungen seit 
dem 3. Jahrhundert (Syrische Didaskalie, Apostolische Konstitutionen), die heidnischen Bücher zu meiden, ändern nichts an diesem Gesamtbefund..$^{81}$

Christlicherseits setzte man in dieser Debatte eine konsequente ,Säkularisierung“ der heidnischen Mythen als Bildungsstoff voraus, denn diese waren nur insofern (einigermaßen) erträglich, als die Götter, von denen sie erzählen, als poetische Fiktion markiert und somit kein möglicher Gegenstand von Glauben und Verehrung waren. Diese Prämisse war in der Spätantike nicht von vorneherein unplausibel: Die Göttergeschichten der Dichter hatten für heidnische Religiosität ohnehin nicht den Rang und die Funktion, welche die Bibel für das Judentum oder Christentum hatte. ${ }^{82}$ Die christliche Mythenkritik war für Nichtchristen auch insofern zumindest nachvollziehbar, als sie das Lächerliche und die Immoralität der heidnischen Göttererzählungen attackierte und damit auf eine Facette eines schon bestehenden, Heiden und Christen verbindenden antiken mythenkritischen Diskurses rekurrierte. Auch die Einbeziehung des theaterkritischen Diskurses in den mythenkritischen Diskurs bedeutete keine christliche Innovation und war für gebildete Heiden plausibel. Das eigentlich Christliche bestand hier einmal mehr nicht so sehr in der Artikulation einer Revolution der Werte und Wertungen, sondern eher in der einseitigen Akzentuierung und polemischen Zuspitzung bestimmter Facetten eines schon vorhandenen, die religiöse Differenz übergreifenden, Wertungsspektrums. Einige gebildete Christen (Bischöfe) konnten auf diese Weise die antike paideia von innen heraus transformieren (oder vielleicht besser: dekonstruieren).

\footnotetext{
81 Apostolische Konstitutionen 1,5-6,6 (ed. M. Metzger, Les constitutions apostoliques, t. 1 [SC 320], Paris 1985, 116), vgl. Syrische Didaskalie 2 (ed. A. Vööbus, CSCO 401, 17,7-18,3) und dazu den Kommentar von G. Schöllgen, Die Anfänge der Professionalisierung des Klerus und das kirchliche Amt in der Syrischen Didaskalie (JbAC Ergänzungsband 26), Münster 1998, $176 \mathrm{f}$.

82 Das belegt gerade die theologia tripartita, die Augustin in ihrer von Varro vorgetragenen Version als - aus seiner christlichen Sicht natürlich untauglichen - heidnischen Versuch verstehen konnte, zwischen der Theologie der Dichter und der staatlichen Theologie zu unterscheiden.
} 



\section{Die Mimesis des Heros: Pagane Helden in christlicher Deutung}

Tò yà

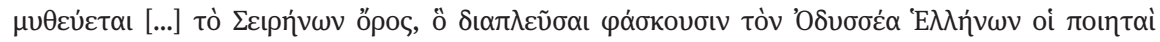

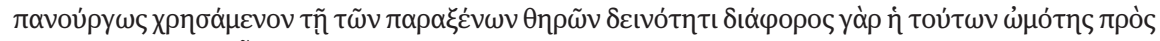

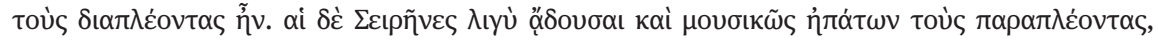

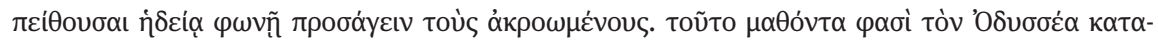

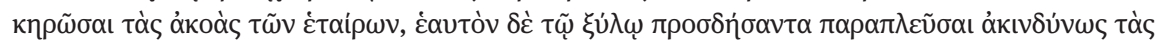

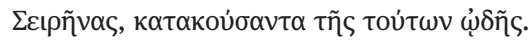

Denn ein solches Meer ist voll wilder Tiere und unpassierbar, wie zum Beispiel das sizilische, von dem die Sage geht, daß der [...] Sirenenberg sich dort finde; Odysseus hat es nach den griechischen Dichtern durchsegelt, indem er die grausamen, bösen Bestien gar schlau behandelte; die Sirenen waren nämlich von ausnehmender Wildheit gegen die Vorüberfahrenden. Sie pflegten aber gar süß und lieblich zu singen, täuschten so die Vorübersegelnden und verlockten sie durch ihre liebliche Stimme, heranzufahren. Da er dies inne geworden, verstopfte Odysseus seinen Gefährten die Ohren mit Wachs; er selbst aber ließ sich an den Mast binden, fuhr so ungefährdet an den Sirenen vorbei und hörte ihren Gesang. ${ }^{1}$

Die Sirenen, die im paganen Mythos sowohl Weisheit als auch die Erfüllung aller Träume versprachen und eine positive wie negative Konnotation innehatten, werden von den Christen in einer diese Ambivalenz zusammenführenden Deutung zu einem verführerischen Lockmittel, das den Gläubigen vom rechten Pfad abbringen will und gerade in der paganen Bildung bestehen mag, besonders, wenn es etwa im „(pseudo)christlichen Gewand der Häresie daherkam“.²

1 Hippol., Ref. omn. haer. 7,13,1f.; H. Rahner, Griechische Mythen in christlicher Deutung, mit 11 Abb. und einem Geleit- und Schlüsselwort v. A. Rosenberg, 4. Aufl., Basel 1984, S. 308f. Ders., Symbole der Kirche. Die Ekklesiologie der Väter, Salzburg 1964. Übersetzung nach: Des heiligen Hippolytus von Rom Widerlegung aller Häresien, aus dem Griech. übers. v. K. Preysing (BKV, 1. Reihe, Bd. 40), München 1922, S. 194.

2 Vgl. Oehl, der besonders die polemische Auseinandersetzung der Kirchenväter mit der Häresie in den Fokus seiner Untersuchung stellt: B. Oehl, Mythos und Häresie, in: R. v. Haehling (Hrsg.), Griechische Mythologie und frühes Christentum, Darmstadt 2005, S. 311-338; hier S. 333-338, Zitat S. 317. Clemens von Alexandrien verwendet das Verhalten des Helden Odysseus, der an den Sirenen vorbeisegelt, überraschenderweise als Negativfolie. Vgl. dazu C. Markschies, Odysseus und Orpheus - christlich gelesen, in: R. v. Haehling (Hrsg.), Griechische Mythologie und frühes Christentum, Darmstadt 2005, S. 227-253, hier S. 235. Die Sirenen stehen bei Clemens, vermutlich in der christlichen Interpretation seiner Umwelt, für die Wissenschaften, die er wiederum verteidigt (Clem. Alex., Strom. VI,89,1): „Es ist, so formuliert er [Clemens] dagegen, gut und recht, vom Weg der Unbildung abzukommen und sich durch die besonderen Sirenen der griechischen Wissenschaft vom Wege locken zu lassen. "Markschies, S. 235. Darin sieht Markschies eine „energische Mythenkorrektur“, wenngleich Clemens seine Forderung an anderer Stelle wieder einschränkt und damit auch seine neue christliche Lesart des Mythos (Clem. Alex., Protr. XII,118,1). Vgl. Markschies, S. $235 \mathrm{ff}$. 
Es ist Hippolyt, der Kirchenvater, der auf das mythische Bild des an den Mastbaum seines eigenen Schiffs gefesselten Odysseus zurückgreift. Was er hier unternimmt, ist Homerexegese. Wie er haben noch zahlreiche andere Kirchenväter seit der Mitte des zweiten Jahrhunderts Homer verwendet. Der pagane Mythos dient ihnen dabei einerseits als populärer Referenzpunkt, um Argumentationen Gewicht zu verleihen und die christliche Botschaft durch Nachahmung und Umdeutung eines bekannten epischen Bildes zu vermitteln, und andererseits als Negativfolie und Gegenbild, von dem sich ihre christliche Botschaft gezielt unterscheidet. In jedem Fall gemeinsam ist ihnen die Gewissheit der allgegenwärtigen Vertrautheit mit dem homerischen Epos. ${ }^{3}$ Markschies kommentiert das nicht nur von Hippolyt, sondern ebenso von Clemens von Alexandrien aufgegriffene Bild des an den Mast gefesselten Odysseus mit folgenden Worten:

\begin{abstract}
Wenn aber dieser Mast zugleich das Kreuz Christi bedeutet und mit dem Kreuz Christi nach Clemens die Befreiung von den Lastern und schlechten Leidenschaften, also eben von der Macht der Gewohnheit, geschenkt wird, dann kann man [sich] den an den Mastbaum gefesselten Odysseus tatsächlich als Urbild der Kreuzesnachfolge jedes Christen vorstellen. Man kann vermutlich gar nicht überschätzen, welche Bedeutung für die Verbreitung des Christentums in der antiken Welt solche Umkonditionierungen der durch den Schulunterricht allgemein verbreiteten homerischen Szenen hatten [...]. ${ }^{4}$
\end{abstract}

So wie für den Intellektuellen Tertullian alles, was in den christlichen Schriften steht, auch geschehen und wahr ist, gilt dies parallel auch für die Homergläubigkeit seit hellenistischer Zeit. Der Bekanntheitsgrad des Epos seitdem ist enorm, nicht nur wegen der vielen Übersetzungen, sondern auch weil dekorative Bilder auf Ölkannen, Wasserkrügen und Weinschalen alltäglich die Szenen aus dem Mythos nacherzählen, die homerischen Epen die Grundlage jeder Bildung waren. ${ }^{5}$ Die Begeisterung für Homer erfasste auch die Kirchenväter, nicht alle, aber doch viele, denn es gibt kaum einen, der ihn nicht zitiert und christlich interpretiert oder zumindest vehement gegen ihn polemisiert hat. Unweigerlich stellt sich daher die Frage, inwieweit die paganen Vorbilder den christlichen Autoren bewusst oder unbewusst bei der Ausgestaltung der neuen Heilslehre dienten.

3 Dazu Oehl (s. Anm. 2), S. 338: „Der verstärkte Gebrauch mythischer Bilder in der antihäretischen Polemik steht nicht im Widerspruch zu der ablehnenden Haltung der Christen gegenüber dem paganen Mythos im allgemeinen und dessen tatsächlicher oder vorgeblicher Übernahme durch häretischgnostische Gruppen im besonderen. Es war legitim, hier Feuer mit Feuer zu bekämpfen. Denn der Mythos ist Instrument der Polemik und Reservoir allgemein verständlicher Metaphern und leistet so einen Dienst für die rhetorische Ausformung des antihäretischen Schrifttums.“

4 Clem. Alex., Protr. XII,118,1-4 (GCS Clemens Alexandrinus I,83,8-30); Markschies (s. Anm. 2), S. 237.

5 C. Schneider, Geistesgeschichte des antiken Christentums, 2 Bde., München 1954. Vgl. hier Bd. 1, S. 319. Markschies (s. Anm. 2), S. 237. K. O. Sandnes, Imitatio Homeri? An Appraisal of Dennis R. MacDonald's „Mimesis Criticism“, in: Journal of Biblical Literature 124 (2005), S. 715-732, hier S. $716 \mathrm{f}$. 
Bereits Erich Auerbach hat das Prinzip der Mimesis in der Literaturgeschichte untersucht und insbesondere in den Schriften des Neuen Testaments und der Kirchenväter das Prinzip der figuralen Deutung nachgewiesen. Wenn sich auch seine Ausführungen zu den frühchristlichen Schriften und seine Vergleiche mit der paganen Literatur auf bestimmte Beispiele konzentrieren, so bieten sich seine Betrachtungen doch als Ausgangspunkt einer Untersuchung an, die der Frage nachgeht, ob und inwieweit bekannte Bilder der paganen Mythen von christlicher Seite nachgeahmt und nutzbar gemacht wurden bzw. ob heidnische Heroen gleichsam als Präfiguration christlicher Helden zu lesen sind.

Ich möchte Auerbachs Thesen kurz darstellen, um dann an weiteren Beispielen zu zeigen, inwieweit in die frühchristliche Literatur die Figuren des Epos als Deutungsmuster eingeflossen sind.

\section{Auerbachs Mimesis-Gedanke in antiken Kontexten}

„Mimesis“ ist ein griechisches Wort, das im aristotelischen Sinne „Nachahmung“ bedeutet. ${ }^{6}$ Mit der erzählenden Nachahmung hat Auerbach sich in Mimesis z. B. in seinem bekannten Fortunata-Kapitel oder auch im Kapitel über Ammianus Marcellinus Verhaftung des Petrus Valvomeres beschäftigt. ${ }^{7}$ Dabei bezieht er die christliche Literatur mit ein und kommt zu einer ganz eigenen, neuen Bewertung dieser Gattungen. Ausgangspunkt meiner Überlegungen ist zunächst ein älterer Aufsatz Auerbachs aus dem Jahr 1938 mit dem Titel Figura, da er sich dort in einem breiten literaturwissenschaftlichen Abriss mit dem Phänomen der Gestaltnachahmung befasst hat. ${ }^{8}$ Der Figura-Aufsatz stellt eine analytische Abhandlung über die Bedeutung des Figura-Begriffs in der heidnischen und christlichen Literatur dar, unter besonderer Berücksichtigung der kontextuellen Hermeneutik der mit dem Wort verbundenen Vorstellungen, die dann später von Auerbach z. B. im VII. Kapitel von Mimesis über Adam und Eva wieder aufgegriffen werden. ${ }^{9}$

Im platonisch-aristotelischen Sprachgebrauch stoßen wir auf zahlreiche Worte für

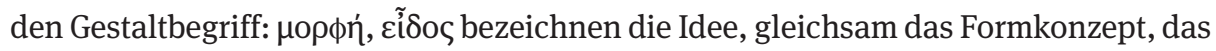
die Materie „informiert“; $\sigma x \tilde{\eta} \mu \alpha$ ist die sinnlich wahrnehmbare Gestalt dieser Form, so Auerbach. ${ }^{10}$ Diese Begriffsweisen fließen in das ein, was die Römer dann unter figura

6 In der Poetik ist genauer Mimesis als die „nachahmende Darstellung einer Handlung“ definiert. Ich habe die zweite verbesserte und erweiterte Auflage von Mimesis aus dem Francke Verlag, Bern 1959, benutzt. Die erste Auflage stammt aus dem Jahr 1946. E. Auerbach, Mimesis. Dargestellte Wirklichkeit in der abendländischen Literatur, 2. Aufl., Bern 1959.

7 Auerbach (s. Anm. 6), Kap. II, S. $28 \mathrm{ff}$., Kap. III, S. $58 \mathrm{ff}$.

8 E. Auerbach, Figura, in: Archivum Romanicum 22 (1938), S. 436-489.

9 Auerbach (s. Anm. 6), Kap. VII, S. $139 \mathrm{ff}$.

10 Auerbach (s. Anm. 8), S. 438. 
verstehen: plastisches Gebilde wie bei Terenz (Eun. 317) - darin schwingt das Verhältnis von Urbild und Abbild mit, des Gestaltwandels und Traum- oder Trugbildes. ${ }^{11}$

Mit der Rezeption paganer Bildungsinhalte bleibt die christliche Apologetik von solchen Überlegungen nicht unbeeinflusst. Es entwickelt sich ein Diskurs darüber, wofür der Name Christus-Jesus steht. Bekanntermaßen ist der Christusname die griechische Version des hebräisch-aramäischen Messias bzw. Meschiah und meint der Gesalbte. Daran sind zahlreiche Vorstellungen geknüpft. So ist der Gesalbte etwa ein König und Erlöser in der Drangsal, einer durch Verfolgung und Fremdherrschaft gekennzeichneten Endzeit. Gerade dieses Beispiel setzt Bezüge zur alttestamentlichen Realprophetie. So sei die Namensgebung Josua-Jesus (Gott ist Hilfe/Heil Rettung) „eine Realprophetie oder vorausdeutende Gestalt des Zukünftigen“ ${ }^{12}$ Dabei wird implizit eine weitere Analogie deutlich. So wie erst Josua und nicht Moses das Gottesvolk in das gelobte Land führte, sei erst das „zweite Volk“ der Christen heilsfähig und steuere auf die ewige Seligkeit zu, weil es auf Jesu Gnade und nicht auf das Gesetz setze. Ein weiteres Beispiel ist das apodiktisch mitgeteilte Abrahamsopfer: „Nimm Isaak, deinen einzigen Sohn, den du lieb hast, und gehe hin in das Land Morija und opfere ihn daselbst zum Brandopfer auf einem Berge, den ich dir sagen werde. “13 Die Opferung Isaaks kann zum einen als Präfiguration des Sohnesopfers, das sich in der Passion erfüllt, verstanden werden. Zum anderen ist es im Sinne Auerbachs von exemplarischer Bedeutung für den gravierenden Stilunterschied zwischen zwei epischen antiken Texten: dem homerischen Epos und der biblischen Erzählung. ${ }^{14}$

Trotz aller Stilgegensätze erscheinen mimetisch bestimmte erzählerische Bilder wie etwa die Narbe als Merkmal einer Verwundung und individuelles Erkennungszeichen unabhängig von der stilistischen Eigentümlichkeit bei Homer einerseits und in der biblischen Erzählung andererseits. Der totgeglaubte Odysseus wird in der homerischen Narbenerzählung aus der Perspektive der alten Amme wieder lebendig, als diese die Narbe betastet. ${ }^{15}$ Das Motiv der Narbe als Erinnerung an die heroische Tat ist Bestandteil des einfachen Glaubens im Heroenkult, wie er auch in den sophistischen Dialog Eingang gefunden hat, so beim Heroicus Philostrats, den in diesem Zusam-

11 Belegstellen bei Auerbach (s. Anm. 8), S. 440 - 49: Lucrez, Cicero, Catull, Vergil, Statius, Virtuv, Plinius Ä. bis Quintilian. Vor allem Quintilian bietet interessante Anknüpfungspunkte in seiner Darstellung des rhetorischen Figurenbegriffs, der schließlich Tropen mit einschließt (Inst. 8 u. 9); siehe Metonymie und Metapher etc., S. $447 \mathrm{ff}$.

12 Auerbach (s. Anm. 8), S. 451.

13 Gen 22,2.

14 Die Adjektive und Abschweifungen der homerischen Gedichte verhindern, so Auerbach, die einseitige Konzentration des Lesers und Hörers auf die aktuelle Krisensituation; „sie verhindern, selbst im schrecklichsten Ereignis, das Aufkommen einer drückenden Spannung. Hier aber beim Abrahamsopfer, ist die drückende Spannung da.“ Auerbach (s. Anm. 6), S. 13, siehe auch S. 9-14.

15 Hom., Od. 19,350 - 505. 
menhang Betz analysiert. ${ }^{16}$ Der tote Heros erscheint leibhaftig in einem gereinigten Körper, der die Narben der heroischen Taten noch zeigt, die Wunden dagegen sind transformiert. Die Narbe des Heros als narratives Grundmotiv, das die Funktion eines identifizierenden Leidensmerkmals hat, kennen wir gleichfalls von den Wundmalen Christi. Furcht und Zweifel an der leiblichen Gegenwart des Heros oder eben Christus werden durch das Erkennen und vor allem das Betasten überwunden. ${ }^{17}$

Interessanterweise greift die frühchristliche Literatur die Motivparallelen heroischer Epiphanien nur sehr indirekt auf, sie konzentriert sich zumeist auf die Deutung der Passion und der Auferstehung im Kontext des Alten Testaments, wobei sich Auerbachs literaturhistorische Betrachtungsweise auf eine „Reihe von Figuren, das heißt Vorverkündigungen und Vorandeutungen des Erscheinens Jesu und der damit zusammenhängenden Ereignisse“ im Alten Testament fokussiert. ${ }^{18}$ Dabei wird deutlich, dass Auerbach die figurale Deutung zumeist, wenn auch nicht ausschließlich, auf die literarischen Verbindungen zwischen Altem und Neuem Testament bezieht. ${ }^{19}$

\section{Figuration bei Tertullian}

In den Schriften Tertullians erkennt Auerbach ein hervorragendes Beispiel der figuralen Deutung. So schreibt der Apologet in Adversus Marcionem, Josua, dessen Name erst bei Hieronymus von dem Jesu unterschieden werden sollte, verkörpere erstmalig eine Figur, die auf Jesus verweise. Hanc prius dicimus figuram futurorum fuisse („Erstmals offenbart sich uns die Gestalt, die auf Zukünftiges verweist“). ${ }^{20}$

Dabei ist die Gestalt des leidenden Gerechten besonders hervorzuheben, denn es geht um die Figuration des Leidens, die Gestaltwerdung des Leidenden durch den Josua-Jesus-Konnex. Das Mysterium des Heils war nach diesem Konzept zur Zeit des Josua noch verborgen, doch in seinem Namen bereits angekündigt. Also ist die prophetische Figur als Hinweis auf Christus gemeint, wobei die Genannten als reale Figuren gelebt haben. Das ist nicht ganz unwichtig, denn Tertullian will keineswegs alttestamentliche Heroen marginalisieren, sondern vielmehr diese als „Vorausdeuter“ vereinnahmen. So wird parallel Adam als Figura Christi und Eva als Figura Ecclesia in der Schrift De anima ${ }^{21}$ entwickelt - wobei im Zusammenhang mit dem Schlaf Adams

16 H.-D. Betz, Heroenverehrung und Christusglaube. Religionsgeschichtliche Betrachtungen zu Philostrats Heroicus, in: ders., Gesammelte Aufsätze IV. Antike und Christentum, Tübingen 1998, S. 128 151, hier S. $130-140$.

17 So etwa durch Jesu Erscheinen vor den Jüngern in Jerusalem (Lk 24,36 - 43; Joh 20,19 - 23) oder als er dem ungläubigen Thomas erscheint, der die Wundmale berühren darf (Joh 20,24-29). In der Version von Lukas teilt Jesus mit den Jüngern außerdem das Mahl (Lk 24, 36-43).

18 Auerbach (s. Anm. 6), S. 51.

19 Auerbach (s. Anm. 6), S. 51f. Siehe auch S. 75.

20 Tert., Adv. Marc. 3,16, mit Bezug zu Num 13,16. Übersetzung H. M. Zilling.

21 Tert., Anim. 43. Vgl. Monog. 5, siehe Auerbach (s. Anm. 8), S. 451. 
die kritische Auseinandersetzung mit philosophischen Positionen steht, waren diese doch nach Tertullian der irrigen Ansicht, Schlaf sei etwas „Außernatürliches“:

Si enim Adam de Christo figuram dabat, somnus Adae mors erat Christi dormituri in mortem, ut de iniuria perinde lateris eius vera mater viventium figuraretur ecclesia.

Denn wenn Adam als Vorbild Christi diente, so bedeutet der Schlaf Adams den Tod Christi, der im Tode entschlafen sollte. Durch den Verlust in seiner Seite [sc. durch die Entnahme der Rippe für die Schaffung Evas] sollte die wahre Mutter der Lebendigen, die Kirche, vorgebildet werden... ${ }^{22}$

„nämlich durch Blut und Wasser, Abendmahl und Taufe“, so Auerbach. ${ }^{23}$ Dazu weiter Auerbach: „Die Art der Interpretation zielte darauf ab, die im AT auftretenden Personen und Ereignisse als Figuren oder Realprophetien der Heilsgeschichte des Neuen zu deuten." ${ }^{24}$

In Adversus Marcionem $(4,40)$ benutzt Tertullian den Ausdruck figuram implere (Vorausdeutung, die Gestalt erfüllen) und parallel dazu auch in der Schrift De fuga in persecutione $^{25}$ im Sinne von confirmare (Bestätigung, Erfüllung, aber auch Ankündigung). Damit meint er die Erfüllung der Schrift in Christus. Christus ist die historische Erfüllung und Bestätigung der auf ihn hindeutenden Realprophetien. ${ }^{26}$

In Tertullian, wie übrigens auch in Hieronymus und Augustin, sieht Auerbach einen hervorragenden Verteidiger des „figuralen Realismus, das heißt die grundsätzliche Aufrechterhaltung des geschichtlichen Wirklichkeitscharakters der Figuren [...]“. ${ }^{27}$ Wie seine griechischen Vorgänger ${ }^{28}$ vertritt Tertullian die These, dass Moses und die Propheten älter seien als die Schriftsteller der Griechen. Das Christentum stellt er als Erbe des Judentums dar, in Christus habe sich die Prophezeiung des Alten Testaments auf einen Erlöser erfüllt. ${ }^{29}$ Damit ist, was Auerbach mit aller Deutlichkeit

22 Tert., Anim. 43. Zitiert nach: Tertullians sämtliche Schriften, Bd. 2: Die dogmatischen und polemischen Schriften, aus dem Latein. übers. v. K. A. H. Kellner, Köln 1882, S. 355.

23 Auerbach (s. Anm. 8), S. 451, Anm. 20; vgl. Auerbach (s. Anm. 6), S. 51f. Auerbach macht an dieser Stelle eine philologische Anmerkung zu figuraretur, was hier zugleich „gebildet“ und „figuriert“ bedeutet.

24 Auerbach (s. Anm. 8), S. 451.

25 Tert., Fug. 11.

26 Tert., Adv. Marc. 4,40,3: Corpus suum illum fecit „Hoc est corpus meum“ dicendo, id est „figura corporis mei“. Figura autem non fuisset, nisi veritatis esset corpus. - „Er machte es [sc. das Brot] zu seinem Körper, indem er sagte, ,das ist mein Körper, es ist die Figur meines Körpers‘. Denn eine Figur kann nicht sein, ohne die Wahrhaftigkeit eines Körpers.“ Übersetzung H. M. Zilling. - Ceterum vacua res, quod est phantasma, figuram capere non posset. Aut si propterea panem corpus sibi finxit, quia corporis carebat veritate, ergo panem debuit tradere pro nobis. Faciebat ad vanitatem Marcionis, ut panis crucifigeretur. [...] non intelligens veterem fuisse istam figuram corporis Christi, dicentis per Hieremiam: Adversus me cogitaverunt cogitatum dicentes: Venite, coiciamus lignum in panem eius, scilicet crucem in corpus eius.

27 Auerbach (s. Anm. 6), S. 187.

28 Tert., Apol. 19,1; Eus., Pr. ev. IX,7,1; Just., Apol. I,44,8; 54,5; Tat., Orat. 31; 35-41; Theoph. Ant., Autol. 3,16-29.

29 Tert., Apol. 21. 
benennt, „durch die Methode der umdeutenden Interpretation das Alte Testament als Volksgeschichte und Gesetz der Juden entwertet [...]““, ${ }^{30}$ zudem werden „dessen Episoden als Figuren oder Realprophezeiungen der Ereignisse im Neuen gedeutet“ “ ${ }^{31}$

So wie schon an dem Beispiel Josua-Jesus dargestellt, verweist Auerbach auf die in besonderer Weise bei Tertullian entwickelten Figura-Vorstellungen und die Verwirklichung historischer Tiefenbewegungen in der christlichen Geschichtsbetrachtung, welche einer heilsgeschichtlichen Orientierung gehorchen. Auerbachs weitere Analyse setzt in dem berühmten Fortunata-Kapitel an. ${ }^{32}$ Die Textreferate und literaturwissenschaftlichen Analysen gerinnen in der Beschreibung dessen, was Auerbach als „Veränderung der alltäglichen Tiefe“ bezeichnet hat. ${ }^{33}$

\section{Von Petrons Gastmahl zum Markusevangelium}

Auerbachs Analyse basiert auf seiner sozialgeschichtlichen Deutung der neureichen Gesellschaft an der Tafel des Trimalchio, gezeichnet durch die erzählende Figur des Encolpius, im direkten Vergleich mit der Schilderung der Verleumdungsgeschichte des Petrus im Markusevangelium. ${ }^{34}$

Das Thema von Encolpius' Tischgenossen ist der Reichtum und die Unbeständigkeit des Lebens, dessen ganze Grundlage ein neu erworbener, also traditionsloser Wohlstand ist. Trimalchio und Fortunata sind extreme Exponenten einer „Freigelassenenklasse“ im Rom des ersten nachchristlichen Jahrhunderts. Sie haben, wie der Name von Trimalchios Frau, Fortunata, es verkündet, als Händler und Spekulanten „Glück gehabt“. Auerbach führt aus, dass das Glück, genauso wie das Unglück, in der griechischen und älteren römischen Literatur als ein von außen hereinbrechendes Schicksal verstanden wurde, wobei Petrons Glücksjägergesellschaft doch eine gänzlich neue Perspektive einnimmt. Anders als die exorbitanten Einzelschicksale antiker Tragödiengestalten teilen die antiken Aufsteiger des Petronius ein Gruppenschicksal, das eine höchst praktisch-irdische und durchaus innergeschichtliche Anschauung der „Schicksalswendung“ zeige. ${ }^{35}$

Anders bei Homer: Diesem dient die Schilderung der Herkunft stets der Darlegung einer weit zurückreichenden aristokratischen Traditionslinie, welche die unveränderlichen Werte einer Adelsgesellschaft heroisch verklärt und in unsterblicher Lied-

30 Auerbach (s. Anm. 6), S. 51.

31 Auerbach (s. Anm. 6), S. 75.

32 Auerbach (s. Anm. 6): Dort (Kap. II) setzt er drei annähernd zeitgenössische Textpassagen aus dem ersten und dem beginnenden zweiten nachchristlichen Jahrhundert miteinander in Beziehung. Zunächst betrachtet er Petrons romanhafte Episode aus dem Gastmahl des Trimalchio (Petron. $37 \mathrm{f}$.), dann eine Rede in den Annalen des Tacitus (Ann. I,17ff.) und schließlich die Verleugnung des Petrus aus dem Markusevangelium (Mk 14,66).

33 Auerbach (s. Anm. 6), S. 37-42.

34 Petron. $37 \mathrm{f}$.

35 Auerbach (s. Anm. 6), S. 33. 
form wiedergegeben hat, bemerkt Auerbach. ${ }^{36}$ Petron dagegen zeigt uns scharf wie auf einem Foto antiken Realismus. Dabei bleibt er völlig auf der Oberfläche, denn obgleich er dramatische Schicksalsschläge beleuchtet, berühren diese kaum.

Petronius legt auf die zeitgeschichtliche Seite seines Werkes keinen Wert. Hätte er es getan, hätte er die einzelnen Verhältnisse und Ereignisse mit bestimmten politischen-ökonomischen Lagen der ersten Kaiserzeit verknüpft, so wäre vor dem Auge des Lesers ein geschichtlicher Hintergrund entstanden, den die Erinnerung ergänzt hätte [...]. ${ }^{37}$

Ich verkürze, dass Auerbach mit dem Begriff der „Veränderung der alltäglichen Tiefe“ eigentlich einen historisch-analytischen Eingriff an der Literatur vornimmt, indem er einen fundamentalen Gegensatz zwischen der pagan-antiken und der frühchristlichen Literatur beschreibt: hier die historische Statik der Tiefenschichten, auf deren unveränderlichem, sozialgeschichtlichen Fundament die antike Literatur ruhe, dort das umwälzende Konzept der christlichen Heilsgeschichte, die, in einfacher Sprache verfasst, eine vertikale historische Linie hin zum Erlöser festlege.

Der Kirchenvater Eusebius schreibt passend dazu in seiner Kirchengeschichte:

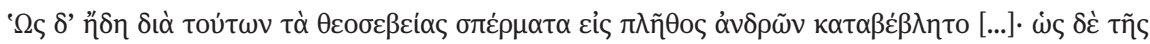

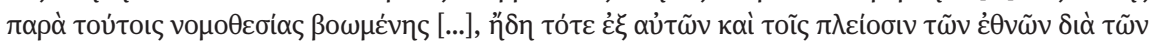

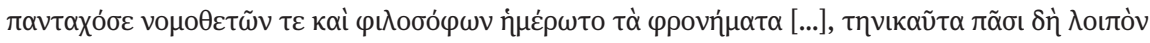

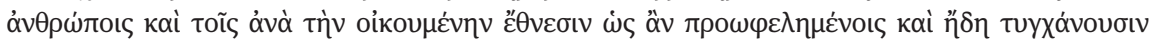

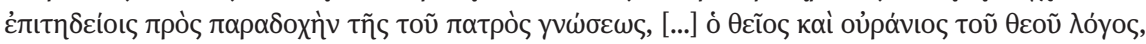

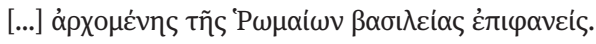

Erst als nun durch diese Gottesfreunde die Samen der Gottesfurcht in die Masse getragen wurden [...], erst als durch das Bekanntwerden der jüdischen Gesetze [...] infolge der Bemühungen von Gesetzgebern und Philosophen, die überall auftraten, zahlreiche Völker gesitteter wurden [...], erst jetzt, zu Beginn des römischen Kaiserreiches [weltgeschichtlicher Bezug], erschien allen übrigen Menschen und den Heiden des ganzen Erdkreises, da sie vorbereitet und bereits fähig waren, die Erkenntnisse des Vaters anzunehmen, [...] der erhabene und himmlische Logos Gottes in Menschengestalt..$^{38}$

Diese Konzeption war - trotz des Versuches von christlicher Seite, eine dynamische, ungebrochene Entwicklung aufzuzeigen und zu erklären - für Heiden wohl kaum akzeptabel.

Auerbach ist darin Recht zu geben, dass etwa die Misericordia mit deklassierten Menschen und ein Verständnis der Oberschicht mit den humiliores zumindest nicht grundsätzlich existiert haben, weil die Distinktionsbarrieren nahezu unüberwindlich waren. Vor diesem Hintergrund lesen wir mit den Evangelien eine ganz andere, neue

36 Auerbach (s. Anm. 6), S. $30 \mathrm{f}$.

37 Auerbach (s. Anm. 6), S. 35.

38 Eus., Hist. eccl. I,2,22f. Übersetzung nach: Des Eusebius Pamphili Bischofs von Cäsarea Kirchengeschichte, aus dem Griech. übers. v. P. Häuser (BKV, 2. Reihe, Bd. 1), München 1932, S. $23 \mathrm{f}$. 
Literatur. Und so ist etwa die Verleumdungsgeschichte des Petrus im Markusevangelium tatsächlich eine andere Art von Geschichte:

Petrus, auf dessen eigenen Bericht [so Auerbach] die Erzählung zurückgehen dürfte, war ein Fischer aus Galiläa, einfachster Herkunft und einfachster Bildung [...]. Aus der beliebigen Alltäglichkeit seines Lebens wird Petrus zu der ungeheuersten Rolle aufgerufen [...]. ${ }^{39}$

Faktisch handelt es sich um eine folgenreiche Polizeiaktion unter alltäglichen Personen aus dem Volk, mit einem zum auferstandenen Gottessohn gewordenen Antihelden, der aus der Schwäche und dem elenden Kreuzestod heraus seine Stärke bezieht, eine vorher ungekannte Konzeption.

\section{Die „Torheit des Kreuzes“ als Heldengeschichte?}

Der christliche Glaube an das Kreuz war für die Heiden nicht nur skandalös, sondern vor allem eine Absurdität, eine Torheit, denn sowohl Griechen, Römer als auch Juden

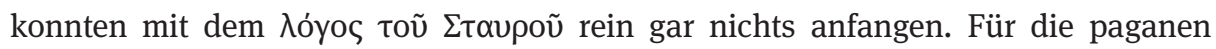
Zeitgenossen der Frühchristen war deren Festhalten an einem solchen Glauben nichts anderes als Torheit, ${ }^{40}$ galt doch die Kreuzesstrafe als schlimmste Strafe, als Strafe für Sklaven und peregrini, und das Kreuz selbst, crux, als Schimpfwort und Fluch, weshalb „ein gekreuzigter Messias, Gottessohn oder Gott für sie alle ein Widerspruch in sich selbst, Anstoß und Torheit bedeuten musste“..$^{41}$ In diesem Kontext steht der Kommentar des Origenes gegen die Anfechtung des christlichen Glaubens an den Gekreuzigten, der den schändlichsten Tod, mors turpissima crucis, erlitten hat. ${ }^{42} \mathrm{Im}$ Passionsbericht der Evangelien hat sich der Schock über den gewaltsamen öffentlichen Tod Jesu erhalten. Das Markusevangelium endet sogar in seiner ursprünglichen kürzeren Fassung mit dieser Erschütterung, dort heißt es, dass die Frauen, nachdem

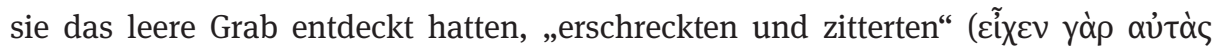

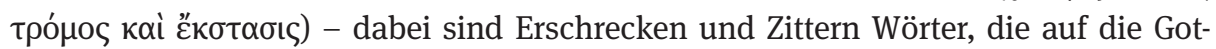
tesgegenwart verweisen..$^{43}$ Statt des misshandelten Körpers befand sich nämlich ein hell gekleideter, strahlender Jüngling im Grabraum.

Der markinische Schluss macht deutlich, dass gleichzeitig mit dem „Wort vom Kreuz“ eine Heldengeschichte beginnt. Der Gekreuzigte besiegt den Tod durch die Auferstehung und wird zum Retter der Menschheit. Mit dieser Botschaft beginnt die

39 Auerbach (s. Anm. 6), S. 44 f., zu Mk 14,66.

40 Z.B. Just., Apol. I,13,4. Hierzu und zum Folgenden H. M. Zilling, Jesus als Held. Odysseus und Herakles als Vorbilder christlicher Heldentypologie, Paderborn 2011, S. 39-40; 46.

41 M. Hengel, Mors turpissima crucis. Die Kreuzigung in der antiken Welt und die „Torheit“ des „Wortes vom Kreuz“, in: J. Friedrich u.a. (Hrsg.), Rechtfertigung. Festschrift für Ernst Käsemann zum 70. Geburtstag, Tübingen/Göttingen 1976, S. 125-184, hier S. 131.

42 Siehe den Verweis auf Orig., Comm. in Mt 27,22 ff. bei Hengel (s. Anm. 41), S. 125, Anm. 1

43 Mk 16,18; 16,1-8. 
Erfolgsgeschichte des Christentums. Anders gewendet, die Umwidmung der mors turpissima crucis in ein Tropaion, ein Siegeszeichen, schafft erst das Bild des heroischen und mächtigen Gottessohnes. ${ }^{44}$ Dabei gelingt den Christen nicht nur eine außergewöhnliche Umdeutung der Gestalt des Gekreuzigten, sondern auch der Umstände seines Todes: Das leere Grab und die Erscheinungen des Auferstandenen, die Himmelfahrt und der Sitz zur Rechten Gottes erinnern einerseits an pagane und alttestamentliche Bezüge und unterscheiden sich andererseits grundlegend in ihrer heilgeschichtlichen Bedeutung und Interpretation von diesen und erschaffen so etwas Neuartiges.

\section{Das leere Grab und der Auferstandene}

Das leere Grab ist Voraussetzung für das Wunder der Auferstehung und den Osterglauben, ist es doch gleichsam Beweis und notwendige Bedingung für den Glauben an die leibliche Auferstehung Jesu. Da das leere Grab zwar in den Evangelien, aber noch nicht in den früher entstandenen Schriften, insbesondere den paulinischen Briefen genannt wird, liegt die Vermutung nahe, dass die Bedeutung des leeren Grabes überhaupt erst durch den Glauben an die Auferstehung wichtig wird. ${ }^{45}$ Der Auferstehungsglauben birgt indes jede Menge Schwierigkeiten für seine Verkündiger und Anhänger. Gleichzeitig festigt er den Zusammenhalt der frühen Gemeinden enorm. ${ }^{46}$

Die Auferstehung am dritten Tag gewinnt im Licht der jüdischen Tradition ein anderes Gewicht und eine neue Konnotation, wenn man bedenkt, dass nach dem jüdischen Glauben die Seele den Körper erst am dritten Tag endgültig verlasse und somit das Antlitz des Toten danach nicht mehr erkennbar sei. Wenn nach der Schilderung des Evangeliums nach Markus die Frauen also den Leichnam Jesu am dritten Tag besuchen, dann auch, um sicher zu gehen, dass sie ihn noch finden, um ihn in später in ein anderes Grab umlegen zu können, da er als Gekreuzigter nicht an einem ehrenvollen Platz begraben werden durfte. ${ }^{47}$

Es gibt nur wenige Beispielberichte von leeren Gräbern aus der antiken Literatur. Fündig werden wir zunächst im Alten Testament. So ist der entrückte Henoch schlicht nicht mehr da und hat dementsprechend kein Grab (Gen 5,24) und die Suche nach Elias bleibt auch nach drei Tagen noch erfolglos (2 Kön 2,17). In diesen Zusammenhang

44 Just., Apol. I,55,3.

45 M. Wolter, Die Auferstehung der Toten und die Auferstehung Jesu, in: E. Gräb-Schmidt, R. Preul (Hrsg.), Auferstehung (Marburger Theologische Studien 116), Leipzig 2012, S. 13-54; hier S. 41f. Auferstehung und die Visionen vom Auferstandenen: S. 45 ff. Zur Bedeutung des Auferstehungsglaubens: S. 52 .

46 Vgl. dazu J. Thiessen, Die Auferstehung Jesu in der Kontroverse. Hermeneutisch-exegetische und theologische Überlegungen, Zürich/Berlin 2009, S. 55 ff., mit einem umfassenden Forschungsüberblick zu den Auslegungen des leeren Grabes. C. A. Evans, Jesus and his World. The Archeological Evidence, London 2012, S. 113-140, zu den archäologischen Funden und jüdischen Traditionen zur Zeit Jesu. 47 Evans (s. Anm. 46), S. 116f.; 139. 
gehöre, so Wolter, ebenfalls, dass nach Dtn 34,5f. das Grab des Moses nicht bekannt sei. ${ }^{48}$ Ein Leichnam und das dazugehörige Grab fehlen ebenso in der paganen Herakles-Mythologie: Nach Diodorus Siculus IV,38,5 wurden die Knochen des Heros nach seinem Tod vergeblich gesucht und ,als sie nicht einen einzigen Knochen fanden, nahmen sie an, dass Herakles [...] von den Menschen zu den Göttern versetzt worden sei““. ${ }^{49}$ Herakles, der sich selbst den Flammen übergibt und in den Himmel aufsteigt (s. u.), und Moses, dessen Grabstätte unbekannt ist, sind die beiden bekanntesten Figuren aus der Umwelt der frühen Christen, deren Gräber leer oder unauffindbar waren, wobei beide - wenn auch in unterschiedlicher Weise - eine figurale oder gestaltende Vorbildfunktion für die Geschichte Jesu nahelegen könnten.

Von Moses kann Josephus bezogen auf seine Abwesenheit auf dem Berg Sinai (Ex 32,1) berichten:

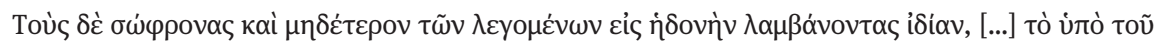

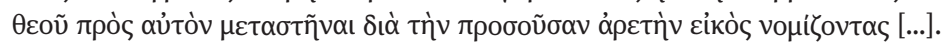

Die Klugen aber, denen keine von beiden Ansichten gefiel, hielten es [...] für wahrscheinlicher, dass er von Gott zu ihm selbst versetzt worden sei wegen der offensichtlichen Tugend [...]..$^{50}$

Und aufgrund des fehlenden Grabes erklärt Josephus:

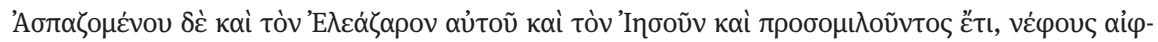

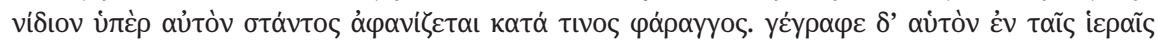

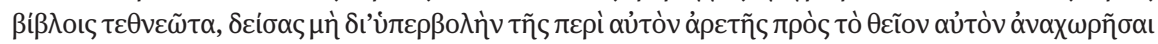

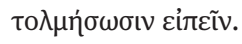

Darauf umarmte er [sc. Moses] Eleazar und Josua, und während er noch sprach, blieb plötzlich eine Wolke über ihm stehen, und er entschwand wie in einer Schlucht. In den heiligen Büchern aber hat er geschrieben, er sei gestorben, weil er fürchtete, man könnte wagen zu sagen, er habe sich wegen der Außerordentlichkeit seiner Tugend zur Gottheit entfernt. ${ }^{51}$

Die exzeptionelle Bedeutung des Moses ist in den verschiedenen kulturellen Kontexten immer auf seine Nähe zu Gott, seine Gesetzgebung, seine Bedeutung für das Gottesvolk, die in ihm zum Ausdruck kommende Folgenhaftigkeit des göttlichen Willens, des Zorns gegen das ungehorsame Volk, aber auch in seiner Entrückung zu sehen.52

Diese Fälle haben gemeinsam, dass man nach dem Leichnam fahndet und ihn nicht findet, daraus auf die Entrückung und implizit auf ein leeres Grab schließt. Mit der Sicht auf Herakles, seine göttliche Herkunft, seinen Todeskampf, die Himmelfahrt

48 Diese Beispiele und noch weitere Quellenzitate bei Wolter (s. Anm. 45), S. 22-29; S. 27 zu Moses.

49 Wolter (s. Anm. 45), S. 23.

50 Ios., Ant. III,97. Zitiert nach Wolter (s. Anm. 45), S. 27.

51 Ios., Ant. IV,326. Zitiert nach Wolter (s. Anm. 45), S. 27.

52 Vgl. dazu etwa J. Assmann, Religion und kulturelles Gedächtnis. Zehn Studien, 2. Aufl., München 2004, S. 29 ff., zur Konfiguration von Erinnerung in der Abschiedsrede des Moses (Dtn 4,9; 6,10 - 12) und S. 162, zum Zorn des Moses beim Anblick seines Volkes, das um das goldene Kalb tanzt, als er mit den Gesetzestafeln zu ihnen zurückkehrt. Zur Entrückung des Moses siehe Wolter (s. Anm. 45), S. 27. 
und Apotheose erreichen wir einen paganen Kontext, respektive eine pagane Figura, wenngleich Auerbach nur alttestamentliche Gestalten, auf die die Christen Bezug nehmen können, als Figurationen beschreibt. Die Ausweitung des Begriffs ist dennoch möglich und denkbar und soll im folgenden Abschnitt bezogen auf Herakles und Polykarp als These vertreten werden.

Bezogen auf die Besonderheit der christlichen Deutung verhindert möglicherweise einerseits das leere Grab einen Heroenkult um die Gestalt Jesu nach paganem Vorbild, da ja ohne eine Grabstätte der übliche Grabkult nicht möglich ist, und andererseits verweist es auf die Auferstehung und Himmelfahrt Jesu, mithin auf seine göttliche Natur und seine zentrale Rolle in der Heilsgeschichte, die über die Bedeutung des paganen Heros für den Menschen weit und fundamental hinaus geht. ${ }^{53}$ So ist wiederum die christliche Auferstehungshoffnung schon im Alten Testaments vielfach angelegt (Jes 25,8; Ps 22,28-32; Dan 12,2! u. a.), wird aber letztendlich erst durch die leibliche Auferstehung Jesu begründet. ${ }^{54}$ Dabei stellte schon Kelsos nach dem Zeugnis des Origenes die Frage, warum die Christen die Auferstehung Jesu nicht so deuten wie etwa die Erscheinungen des Pythagoras, des Orpheus, des Protesilaos, Theseus oder Herakles. ${ }^{55}$ Betz vertritt dazu die These, die Christen, die in einer Umwelt lebten, in der sich die Heroenverehrung großer Beliebtheit erfreute, hätten eine Heroisierung Christi bewusst abgelehnt, wenn auch die Passionserzählung und die Apostelgeschichte noch Anzeichen einer beginnenden Heroisierung des Gekreuzigten enthielten. ${ }^{56}$

Auch Herakles hinterlässt wie Moses kein Grab (zumindest nicht in der Fassung nach dem Hercules Oetaeus) und gilt trotzdem als Heros und bemerkenswerterweise wie Jesus nach seiner Himmelfahrt als Gott. Darin ist er jedoch als Heros und Gott ein Einzelfall in der paganen Mythologie. Eine Heroisierung ist also, wie die Verehrung des Herakles zeigt, durch das leere Grab noch nicht wirklich ausgeschlossen. Dies sei ergänzend zu Betz angemerkt, der besonders in diesem Umstand und in der zeitlichen Begrenzung der nachösterlichen Erscheinungen einen bewussten Entschluss gegen die schon begonnene Heroisierung Jesu sieht. Das leere Grab verweist sicherlich auf die Entrückung und Auferstehung des Verstorbenen und eröffnet damit den Schritt, die Apotheose zu erklären: Immerhin vollzieht sich so, dass aus dem gemarterten MessiasMenschensohn am Kreuz der Gottessohn hervortritt.

In einer weiteren Auslegung des Figura-Begriffes von Auerbach könnte man sagen, dass es den frühen Christen naheliegend erscheinen musste, und zwar aufgrund einer Vielzahl von Vorbildern aus den paganen und jüdischen Mythen, Jesus als Heros zu begreifen. So auch Betz: Der ungerechte gewaltsame Tod, der durch die göttliche Herkunft und Auferstehung in ein Heilsereignis transformiert wird sowie die Him-

53 Vgl. dazu auch Betz (s. Anm. 16), S. 151.

54 Thiessen (s. Anm. 46), S. 150 f. Thiessen hält es für unwahrscheinlich, dass die neutestamentliche Hoffnung der leiblichen Auferstehung auf hellenistische Einflüsse zurückzuführen ist, vielmehr sieht er sie in der Tradition des Alten Testaments begründet.

55 Betz (s. Anm. 16), S. 128. Vgl. Orig., Cels. II,55.

56 Betz (s. Anm. 16), S. 129; $148 \mathrm{ff}$. 
melfahrt sollten dabei mitbedacht werden (Lk 24,26; 24,51). ${ }^{57}$ Hinzu kommen die Kindheitserzählungen und Wundergeschichten, die nicht nur Vorbilder im paganen Mythos, sondern ebenso in den Schriften des Alten Testaments haben. ${ }^{58}$ Das Muster, nach dem sich Epiphanien ereignen, macht die Bezüge deutlich, so z.B. im Lukasevangelium bei den Berichten über die Emmausjünger oder die Erscheinungen des Auferstandenen vor den Elfen: Die plötzliche Erscheinung des Auferstandenen ruft zunächst Furcht hervor (Lk 24,36; vgl. insgesamt hierzu und zum Folgenden Philostrats Heroikos 21,6-8; 22,10-22), gefolgt vom Moment des Wiedererkennens und der schwindenden Zweifel, wobei ungläubiges Berühren und Betasten eine Rolle spielt (Lk 24,39), schließlich findet die Freude über die Wiederkehr des Auferstandenen in der Mahlgemeinschaft ihren Ausdruck, gefolgt von seinem Verschwinden (Lk 24,30 f.). Dieses Muster ist sowohl von fundamentaler Bedeutung für die Gemeindebildung als auch die Mission, denn die verunsicherten und abgefallenen Jünger werden auf diese Weise zurückgewonnen und berichten über die Epiphanie des Heros-Christus. Gleichzeitig spielt es eine konstitutive Rolle für die Kultgründung, welche wiederum maßgeblich mit der Mahlgemeinschaft verknüpft ist. ${ }^{59}$

Entscheidend ist, hierin folge ich Betz, dass die Evangelisten sich jedoch letztendlich gegen eine Heroisierung Jesu nach paganem Vorbild entschieden haben - und damit den einzigartigen Anspruch des Gekreuzigten begründeten. Dabei war das leere Grab wie in Mk 16,6 von zentraler Bedeutung, machte dieses doch „einen Heroenkult am entscheidenden Punkt unmöglich““. ${ }^{60}$ Die Phase der Epiphanien schließlich begrenzten die Evangelisten auf die Zeitspanne vor der Himmelfahrt.

Stattdessen wurde die Auferstehung Jesu durch eine Erhöhungschristologie interpretiert, nach der er seinen Platz als Kosmokrator zur Rechten Gottes einnahm. Eine solche Christologie hatte zur Folge, dass seine universale Gegenwart mit dem Heiligen Geist und dem Wort der Verkündigung verbunden wurde. ${ }^{61}$

57 Hierzu und zum Folgenden siehe Betz (s. Anm. 16), S. 149.

58 So hat etwa der Jesusknabe im Kindheitsevangelium des Thomas durchaus Ähnlichkeiten mit dem jungen Herakles. Siehe Evangelium Thomae de infantia Salvatoris/Kindheitserzählung des Thomas 3,3; 4,1 f.; vgl. 7,2; 9,3 (Evangelia infantiae apocrypha/Apocryphe Kindheitsevangelien, übers. und eingel. von G. Schneider, Freiburg u.a. 1995 [Fontes Christiani 18], S. 147-171). Zu Herakles siehe etwa Theokr. 24; Pind., N. 1,35-70; Diod. 3,67; Apollod. 2,4,9. Vgl. dazu Zilling (s. Anm. 40), S. 153 ff. Siehe außerdem S. 161-173: zum Vergleich der Geburtsgeschichten, S. 173-176: zur Gottessohnschaft. Die Wundergeschichten greifen oft alttestamentliche Motive auf wie etwa die Speisung der 5000 (Mk 6,3544 par Mt 14,13-21; Lk 9,10 - 17; Joh 6,1-13), die an die wunderbare Brotvermehrung des Elisa erinnert, der hundert Männer mit zwanzig Gerstenbroten sättigt (2 Kön 4,42-44), oder die Totenerweckung der Tochter des Synagogenvorstehers Jairus (Mk 5,21; 5,35-43), des Jünglings zu Naïn (Lk 7,11-17) sowie die Auferweckung des Lazarus (Joh 11,1-45), diese greifen die Auferweckung des Sohnes einer Witwe durch Elias auf (1 Kön 17,17-24).

59 Vgl. dazu Betz (s. Anm. 16), S. 138, Anm. 39.

60 Betz (s. Anm. 16), S. 151.

61 Betz (s. Anm. 16), S. 151. 
In der Auseinandersetzung der Theologen über den Auferstehungskontext zeigt sich die Notwendigkeit die, wie Paulus es ausdrückt, Torheit des Wortes vom Kreuz zu

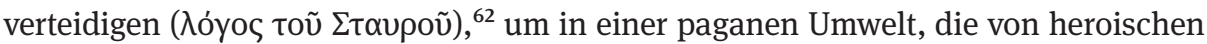
Mythen belebt wird, zu bestehen. So lassen die Passionserzählungen Ansätze einer Heroisierung Jesu erkennen, die paganen Vorbildern folgt, wie auch die Geschichte des von einer Jungfrau geborenen Gottessohnes, der schließlich nach großem Leiden in den Himmel auffährt, dem Mythos des Herakles ähnelt. ${ }^{63}$ Doch werden viele Ansätze einer Heroisierung des Gekreuzigten schließlich nicht genutzt, obwohl oder gerade weil sie in der Umwelt des frühen Christentums so präsent waren. Denn letztendlich unterscheidet sich die christliche Botschaft grundlegend vom Heroenkult in der Heilsund Erlösungstheologie. Die frühchristlichen Schriftsteller wählen (und darin ist Auerbachs Beobachtung zu bestätigen) neue Formen, um die Inhalte ihres Glaubens darzustellen. Sie wählen z. B. bei der Führung des Altersbeweises die Hinweise der Propheten des alten Bundes als Deutungszusammenhang, die auf Jesus hinweisen, und eben nicht die Götter und Helden ihrer paganen Umwelt. ${ }^{64}$

Das Besondere an Auerbachs Betrachtung ist, dass er die Sicht auf die Vielzahl der Kontexte lenkt, in die die Gestalt Jesu nach christlich-hermeneutischer Tradition eingebettet wird, wenn er auch den Figura-Begriff hauptsächlich auf die innerchristlichen Interpretationszusammenhänge beschränkt.

Selbst in dieser möglicherweise bewussten Abgrenzung von den alten Göttern, Heroen und Mythen lässt sich trotzdem bemerken, dass die Beschränkung der Christen auf die Deutung des Neuen Testaments als Erfüllung des Alten nicht verhindern konnte, dass 1) alle kulturellen Kontexte des Alten Testaments mit einflossen, somit auch alle paganen Einflüsse auf die Entstehung des Judentums und 2) auch die frühen Christen, die Evangelisten, Apostel, Missionare und Kirchenväter immer ein Teil ihrer Umwelt, ihres kulturellen Kontextes, eben auch der paganen Mythen und Götterwelt waren. ${ }^{65}$ Doch sie haben sicherlich versucht - das zeigen die Auseinandersetzungen mit der paganen Umwelt - sich von ihrem kulturellen Kontext abzuheben, sie erschaffen eine neue Erinnerungsgemeinschaft, eine neue Deutung ihrer Geschichte als Volk Gottes und damit einen neuen ,Mythos' mit eigenen Heroisierungsmechanismen.

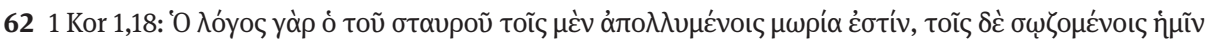

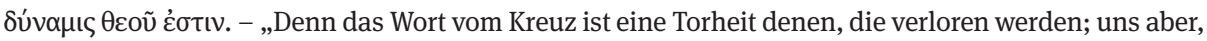
die wir selig werden, ist’s eine Gotteskraft.“ Vgl. Zilling (s. Anm. 40), S. 39 ff.

63 Betz (s. Anm. 16), S. 149. Zilling (s. Anm. 40), S. 153-188.

64 Vgl. die Gottesknechtslieder bei Jesaja: Während im Alten Testament der Gottesknecht im engeren Sinn für von Gott in besonderer Weise erwählte Menschen stand (Jes 42,1-9; 49,1-9; 50,4-9; 52,1353,12), wird im Neuen Testament Jesus typologisch als Gottesknecht gedeutet (Mt 12,18; Lk 17,22-37). 65 Siehe dazu Assmann (s. Anm. 52), S. 18f.: „Und dazu [zum Erinnern] bedienen sich beide, das Kollektiv und der Einzelne, des Archivs der kulturellen Traditionen, des Arsenals der symbolischen Formen, des ,Imaginaires‘ der Mythen und Bilder, der ,Großen Erzählungen', der Sagen und Legenden, Szenen und Konstellationen, die nur immer im Überlieferungsschatz eines Volkes lebendig und reaktivierbar sind.“ 
Am Ende wird das Kreuz - Symbol des schändlichsten aller Tode - zum Siegeszeichen und der Gekreuzigte zum Triumphator.

Dass Jesus als Mensch gelitten hat und gestorben ist, ist seitdem eine nach menschlichem Ermessen unfassbare Geschichte (vgl. den Ausspruch credo quia absurdum, der sinngemäß bei Tertullian auftaucht) ${ }^{66}$ und eine neue Heilslehre, die in der Auslegung durch die Evangelisten und die Kirchenväter im Rahmen der alttestamentlichen Heilsgeschichte verortet und figurativ gedeutet wird. Gleichzeitig dient die deutliche Herabsetzung und Geringschätzung etwa des paganen Gottessohnes Herakles durch die Kirchenväter dem Zweck, mögliche Parallelen zu verwischen und als unstatthafte These zu verwerfen, um so die Einzigartigkeit des christlichen Heilsgeschehens zu festigen. ${ }^{67}$ Tatsächlich lässt sich aber gerade abseits der bewussten Auseinandersetzung mit den paganen Vorbildern zeigen, wie weit die antiken Heroen und ihre Geschichten im Denken der christlichen Autoren verwurzelt waren.

\section{Der Tod des Märtyrers - Herakles und Polykarp}

Erstaunlich sind die Parallelen des heroischen Aufstiegs in der klassischen Heldengeschichte, auf die ich im Folgenden an zwei Beispielen, die auch als Erlöserfiguren gesehen werden können, eingehen werde: zum einen der heroische Menschenretter Herakles, zum anderen der „listenreiche“ Odysseus, der viel zu erdulden hat, am Ende seiner Irrfahrten aber die Heimat Ithaka findet.

Auf Herakles Tatenzyklus werde ich nicht näher eingehen, sondern seinen heroischen Todeskampf betrachten, welcher in der lange Zeit Seneca zugeschriebenen Tragödie Hercules Oetaeus beschrieben ist. ${ }^{68}$ Dort endet der Heros auf einem gigan-

66 Tert., Carn. 5,4 (CCSL 2,881,26-29): Crucifixus est dei filius; non pudet, quia pudendum est. Et mortuus est dei filius; credibile est, quia ineptum est. Et sepultus resurrexit; certum est, quia impossibile. „Gottes Sohn ist gekreuzigt; ich schäme mich nicht, weil es beschämend ist. Gottes Sohn ist gestorben: dies ist glaubwürdig, weil es unschicklich (ineptum) ist. Er wurde begraben und ist auferstanden: dies ist gewiss, weil es unmöglich ist.“ Übersetzung nach M. Fiedrowicz (Hrsg.), Handbuch der Patristik. Quellentexte zur Theologie der Kirchenväter, Freiburg 2010, S. 613, Nr. 778 mit Anm. 207: dort die Angabe der Parallelstellen und Literaturhinweise; besonders R. D. Sider, Credo quia absurdum?, Classical World 73 (1980), S. 417-419; siehe auch H. M. Zilling, Tertullian. Untertan Gottes und des Kaisers, Paderborn 2004, S. $176 \mathrm{ff}$.

67 So etwa Just., Dial. 67,2f.; 69,2ff. oder Tert., Nat. 2,14: Hercules’ Apotheose sei in Wahrheit eine Selbstrichtung und der Selbstmord eines Mörders gewesen; vgl. auch Min. Fel. 22,7; Firm., Err. 7,6. Vgl. dazu Zilling (s. Anm. 40), S. 189 ff. mit weiteren Belegen.

68 In der Forschung lange umstritten, geht man inzwischen davon aus, dass dieses Stück zu Unrecht Seneca zugeschrieben wurde. Trotzdem wird es zumeist mit den Stücken Senecas gemeinsam untersucht. Gewiss scheint, dass das Stück spätestens Anfang des 2. Jahrhunderts n.Chr. entstanden ist, was es in jedem Fall in die zeitliche Nähe der Entstehung der Evangelien rückt und seine Bekanntheit zur Zeit des Martyriums Polykarps zumindest möglich macht.Vgl. zunächst H. Canciks Beitrag „Seneca und die römische Tragödie“ in dem von Manfred Fuhrmann herausgegebenen Handbuch Römische Literatur, Frankfurt a. M. 1974, S. 251-260, der die Frage der Echtheit des Hercules Oetaeus als Aporie 
tischen Scheiterhaufen, um nach der Selbstverbrennung als Flammenbesieger und in den Himmel gefahrener vergöttlichter Heros einen neuen Anfang zu nehmen. ${ }^{69} \mathrm{Um}$ letzte Zweifel an seiner Apotheose zu zerstreuen, erscheint der Totgeglaubte vor seiner klagenden Mutter, somit bietet gerade diese Szene eine Parallele zur Auferstehung Christi. ${ }^{70}$ Herakles' stoische Haltung, so Nesselrath, transformiere das schuldbeladene Ende des Heros, mehr noch: „Die Tragödie wird von der Apotheose aufgehoben.“71

Eine erhabene Haltung im Tod findet sich außerdem nicht nur bei Sokrates, sondern bekanntermaßen, Nesselrath verweist darauf, ebenso in der stoischen Philosophie und als Topos in der christlichen Märtyrerliteratur - siehe z. B. die Schilderung des Martyriums des Polykarp. ${ }^{72}$ Hier wie dort betet der Heros-Martys auf dem Scheiterhaufen gleichsam in den geöffneten Himmel: „Ich komme, Vater.“ Mit diesem Ruf beginnen die Herakles-Verbrennung und das bei beiden stattfindende Flammenwunder. Auch der Zeuge und Autor des Martyriumsberichts Polykarps schreibt, dass dieser in den Himmel geblickt und gesprochen habe: „Herr, allmächtiger Vater/

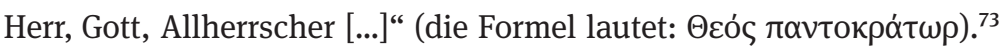

bezeichnet. Er hält daran fest, Senecas Beitrag für die Entwicklung der kaiserzeitlichen Tragödien hoch zu bewerten sowie im Hercules Oetaeus ein außerordentlich bedeutsames Zeugnis für das Verständnis der Heraklesreligion zu sehen. Das Werk ordnet er in die zweite Hälfte des ersten nachchristlichen Jahrhunderts ein. Weiterhin vergleiche zu den Senecatragödien O. Zwierlein, Kritischer Kommentar zu den Tragödien Senecas, Mainz/Stuttgart 1986, zum Hercules Oetaeus S. 313; 339. Siehe auch H.-G. Nesselrath, Herakles als tragischer Held in und seit der Antike, in: H. Flashar (Hrsg.), Tragödie. Idee und Transformation (Colloquium Rauricum 5), Stuttgart/Leipzig 1997, S. 307-331, S. 315.

69 Sen., Herc. 0. $1464-1472 ; 1594 ; 1615$ ff.; 1967 ff. Im Folgenden zitiert nach: Herkules auf dem Öta, in: Seneca. Sämtliche Tragödien. Lat. u. dt., Bd. 2, übers. u. erl.v.T.Thomann, Zürich/Stuttgart 1969, S. 257391.

70 So auch Nesselrath (s. Anm. 68), S. 317.

71 Nesselrath (s. Anm. 68), S. 318.

72 Nesselrath (s. Anm. 68), S. 317 ff. Das berühmteste Beispiel ist neben dem Tod des Sokrates gewiss der Tod des stoischen Philosophen Seneca, der sich in seinen Schriften oft mit dem rechten Sterben auseinandergesetzt hat. Siehe dazu etwa Sen., Epist. 26,10: Una est catena, quae nos alligatos tenet, amor vitae, qui ut non est abiciendus, ita minuendus est, ut si quando res exiget, nihil nos detineat nec inpediat, quo minus parati simus, quod quandoque faciendum est, statim facere. - „Es gibt nur eine Kette, die uns gefesselt hält, nämlich die Liebe zum Leben. Wir dürfen sie nicht von uns weisen, aber wir müssen ihren Druck mindern, damit uns unter dem Druck der Umstände nichts zurückhalte und hindere bereit zu sein, unverzüglich das zu tun, was einmal doch geschehen muss.“ 54,7: Hoc tibi de me recipe: non trepidabo ad extrema, iam praeparatus sum, nihil cogito de die toto. - „Lass Dir von mir sagen: ich werde vor dem letzten Augenblick nicht zittern, ich bin schon bereit, ich rechne nie mit einem ganzen Tag, den ich etwa noch zu leben hätte.“ Übersetzung nach: Lucius Annaeus Seneca. Philosophische Schriften, Bd. 3: Briefe an Lucilius, übers., m. Einl. u. Anm. vers.v. O. Apelt, Wiesbaden 2004, S.100;188. Mart. Polyc. 12,1. Der Text nach: A. Lindemann, H. Paulsen (Hrsg.), Die Apostolischen Väter, Tübingen 1992, S. 244-285.

73 Sen., Herc. O. 1726; Mart. Polyc. 14,1; vgl. Offb 1,8; 4,8; 16,7; 21,22; s. P. Guyot, R. Klein (Hrsg.), Das frühe Christentum bis zum Ende der Verfolgung, Darmstadt 1997, S. 333, Anm. 51. 
Herakles gehorcht in der Annahme des Todes seiner göttlichen „Bestimmung“ - so wird der Martertod auch im Martyrium Polycarpi genannt. ${ }^{74}$ Herakles hadert nicht mit seiner Bestimmung, sondern folgt ihr, sobald er sie erkannt hat. Epiktet formuliert daraus die Lehre: Wie Herakles als Zeussohn seinen göttlichen Auftrag annimmt, so sollen die Menschen die Lebensbedingungen annehmen, unter denen sie leben. Die imitatio des Dulders wird am Beispiel des Herakles zum ethischen Gebot erhoben, der einst wilde Heros zum weisen, durch seine Frömmigkeit standhaften Vorbild umgedeutet. $^{75}$

Man könnte dies auch so formulieren: Das mimetische Konzept ist dem ImitatioMotiv der Märtyrer verwandt. Dazu heißt es im Martyriumsbericht des Polykarp, der von dem zentralen Gedanken der Nachfolge Christi beherrscht wird:

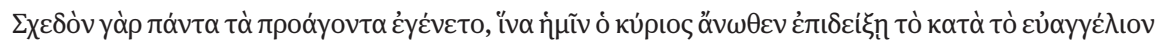

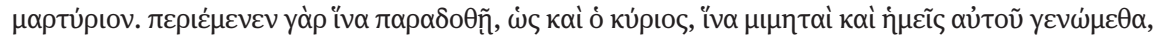

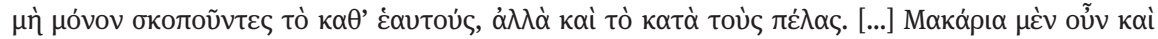

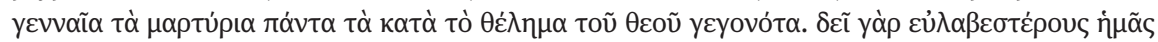

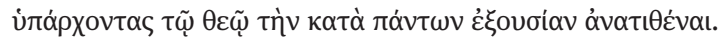

Denn beinahe alles, was vorging, geschah, damit uns der Herr noch einmal das Schauspiel des Martyriums, wie es im Evangelium erzählt ist, vor Augen führe. Denn er wartete, bis er ausgeliefert wurde, wie auch der Herr, damit auch wir seine Nachahmer werden, ,indem wir nicht nur unser eigenes Wohl, sondern auch das des Nächsten im Auge haben“. [...] Segensreich und ehrenvoll waren alle Martyrien, wenn sie nach Gottes Willen geschahen; denn wenn wir gottesfürchtig sind, müssen wir Gott die Macht über alles zuschreiben. ${ }^{76}$

\section{So spricht Hercules:}

Iam virtus mihi / in astra et ipsos fecit ad superos iter. [...] Paterna caelo, pars data est flammis tua. [...] Virtus in astra tendit, in mortem timor.

Schon hat mein Heldentum mir den Weg zu den Gestirnen und den Überirdischen selbst bereitet. [...] Des Vaters Teil wurde dem Himmel, dein Teil [sc. der irdisch-mütterliche] den Flammen anheimgegeben [...]. Den Sternen strebt Heldentum, Furcht dem Tode $\mathrm{zu}^{77}$

74 Mart. Polyc. 6.

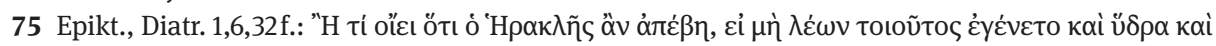

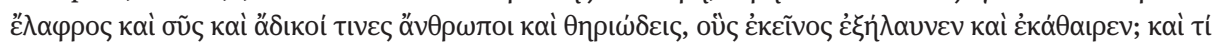

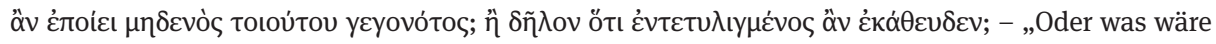
wohl aus Herakles geworden, wenn ihm nicht ein solcher Löwe begegnet wären und eine Hydra, ein Hirsch und ein Eber und manche verbrecherischen und wüsten Kerle, die er verjagte und ausrottete? Und was hätte er getan, wenn keins dieser Ungetüme existiert hätte? Dann hätte er sich doch sicher eingemummelt und geschlafen. “ Übersetzung nach: Epiktet, Teles und Musonius. Wege zu glückseligem Leben, übertr. u. eingel. v. W. Capelle, Zürich 1948, S. 174.

76 Mart. Polyc. 1,1-2,1.

77 Sen., Herc. O. 1942f.; 1968-1971. 
Alkmene, seine Mutter, wird zur Zeugin seiner Himmelfahrt:

[...] in astra fertur. Fallor an voltus putat / vidisse natum? misera mens incredula est. / Es numen et te mundus aeternum tenet, / credo triumphis.

Auf zu den Gestirnen fährt er. Täusche ich mich oder wähnt nur mein Auge, es habe den Sohn geschaut? Ein gramvoller Sinn ist ungläubig. Doch eine Gottheit bist du und auf ewig des Himmels Besitz: Ich glaube an deine Triumphe. ${ }^{78}$

Somit besingt sie den neuen Gott. ${ }^{79}$ Nachdem die Mutter das Zeugnis der Auferstehung und der Apotheose gegeben hat, folgt der Chor mit einem Lobpreis des Helden und seiner Anrufung als Schutzpatron (!):

Sed tu, domitor magne ferarum / orbis que simul pacator, ades; / nunc quoque nostras respice terras [...]. Fortius ipso genitore tuo / fulmina mitte.

Du großer Bezwinger von Ungeheuern und des Erdkreises Friedensbringer in einem, steh uns bei, auch jetzt sieh herab auf unsere Erde [...]. Machtvoller als dein Erzeuger selbst schleudere die Blitze. ${ }^{80}$

Man hat den Eindruck, Herakles werde hier regelrecht als Heiliger angerufen. Zusammengefasst ergibt sich, um auf Auerbach zurückzukommen, durchaus die Anschauung, dass einige Heroen als Präfigurationen christlicher Helden gedient haben könnten. Neben Herakles und Odysseus ist auch an Prometheus, besonders aber an Orpheus zu denken.

Prometheus hingegen wurde weniger intensiv von den Kirchenvätern aufgegriffen. Die Apologetik hebt darauf ab, dass Christus der wahre Prometheus sei (Tertullian, Apol. 18). Das Motiv des stellvertretenden Leiden zum Wohle der Menschen bietet einen weiteren Bezugspunkt, der Prometheus, um es mit Karl Marx zu sagen, „zum vornehmsten Heiligen und Märtyrer macht“. ${ }^{81}$ Prometheus, der Menschenfreund, leidet fest an den Felsen geschmiedet ohne Unterlass und ohne Aussicht auf Erlösung - in Lukians Prometheus spricht Merkur von einer Kreuzigung und Annagelung an den Felsen. Orpheus dagegen überwindet den Tod und verfügt über göttliche Wunderkräfte wie der Theios Aner ( $\theta \varepsilon \tilde{o}$ os ávń $\rho)$, der göttliche Mensch Jesus. So stellt etwa Eusebius im 3. Buch der Theophanie Jesus als wirkmächtigen Wundertäter und Heiland dar, durch den der Logos als musikalisches Instrument wirkt. Er heilt gleichsam die „rohen tierischen Leidenschaften der Seelen mit den Heilmitteln göttlicher Lehre und zeigt den kranken Seelen, [...] wie ein vorzüglicher Arzt durch ein ihnen verwandtes und ähnliches Hilfsmittel Gott im Menschen“, und er erweckt sogar Tote wieder zum Leben

78 Sen., Herc. O. 1978-1981. Siehe die Darstellung der Himmelfahrt des Herakles auf der Igeler Säule, Abb. 16 in Zilling (s. Anm. 40).

79 Sen., Herc. O. 1982.

80 Sen., Herc. O. $1989-1996$.

81 Dissertation über die „Differenz der demokritischen und epikureischen Naturphilosophie“, 1841, MEW Erg.-Bd. 1, S. 263. 
wie Lazarus. ${ }^{82}$ Auch Clemens von Alexandrien setzt in der Eröffnung seines Protreptikos dem Orpheus-Mythos den wahren Orpheus Christus entgegen - Christus ist hier gleichsam der bessere Orpheus:

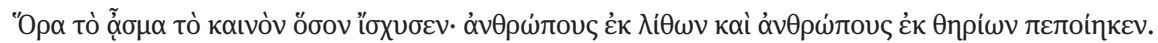

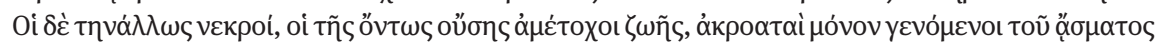

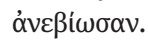

Sieh, was das neue Lied vollbrachte: Menschen hat es aus Steinen, Menschen aus Tieren gemacht. Und die sonst wie tot waren und keinen Anteil am wahren Leben hatten, sie wurden wieder lebendig, sobald sie nur Hörer des Gesanges geworden waren. ${ }^{83}$

Orpheus zähmt zwar die Tiere und sogar unheimliche Pflanzen, Christus dagegen „zähmt“ die Menschen. ${ }^{84}$ Clemens fragt seine Hörer: „Wie kommt es denn, dass ihr so leeren Mythen Glauben geschenkt habt?“85 Diese Frage demonstriert, dass in der Glaubensvermittlung immer wieder an den fundamentalen Mythen angesetzt wurde und gleichzeitig die Abgrenzung zwischen Christentum und Heidentum eine wichtige Rolle gespielt hat. Bei Justin wird die apologetische Abgrenzungstendenz besonders deutlich, er stellt nämlich den Tod des Orpheus durch Zerfleischung als „dämonisches Plagiat der Kreuzigung Christi“ dar. ${ }^{86}$

Mythos und Martyrium bilden, so meine These, eine literarische Kontinuität. Sie können deshalb so wirkmächtig sein, weil sie die Geschichten des Lebens und Sterbens nutzen. Der Martyriumsbericht der Christen kann dafür die bereits existierenden Muster und Topoi mit dem ganz eigenen Anliegen des neuen Glaubens füllen.

82 Eus., Theoph. III,39 (GCS Eusebius III/2,143,17-21). Zitiert nach der Übersetzung der syrischen Überlieferung nach W. Storch (Hrsg.), Mythos Orpheus, 3. Aufl., Leipzig 2001, S. 87 f. Dazu Markschies (s. Anm. 2), S. $240 \mathrm{f}$.

83 Clem. Alex., Protr. I,4,4 (GCS Clemens Alexandrinus I,5,30-33), zitiert nach: Des Clemens von Alexandreia Mahnrede an die Heiden / Der Erzieher Buch 1, aus dem Griech. übers. v. O. Stählin (BKV, 2. Reihe, Bd. 7), München 1934, S. 75. Storch (s. Anm. 82), S. 85. Markschies (s. Anm. 2), S. 242f. In seinem Panegyricus auf das dreißigjährige Regierungsjubiläum Kaiser Konstantins stellt Eusebius nach dem Vorbild des Clemens von Alexandrien ebenfalls die von den Heiden bewunderte Wirkung des Orpheus der mächtigeren Wirkung Jesu gegenüber. Eus., Laud. 14 (GCS Eusebius I,242,17-233,4).

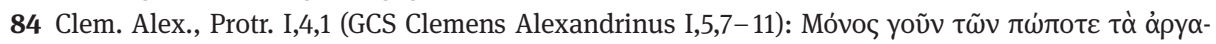

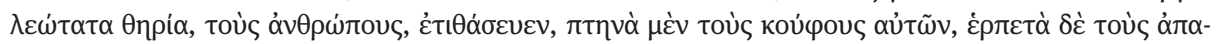

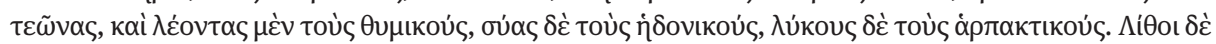

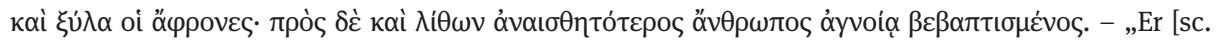
Christus] allein unter allen, die je lebten, zähmte die wildesten Tiere, die Menschen, sowohl Vögel, das sind die Leichtfertigen, als auch kriechende Tiere, das sind die Betrüger, und Löwen, das sind die Jähzornigen, und Schweine, das sind die Wollüstigen, und Wölfe, das sind die Raubgierigen. Stein und Holz aber sind die Unvernünftigen; ja noch gefühlloser als Stein ist ein Mensch, der in Torheit versunken ist.“

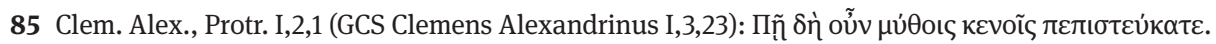
86 Zitat Markschies (s. Anm. 2), S. 246, mit Bezug auf Just., Dial. 69,2 und Apol. I,54,6. 
Wundert es da, dass die dramaturgischen Erzählmuster seines [sc. des Herakles] Mythos und seines Martyriums sich verselbstständigt und auch auf die christliche Passions- und Märtyrerliteratur abgefärbt haben? ${ }^{87}$

In diese Richtung deutet auch, dass die Kirchenväter andererseits gegen eine solche Heroen-Transformation argumentierten und dazu offenbar allen Anlass hatten. ${ }^{88}$ Dass Jesus als Märtyrer die Imitatio des Leidens auch selbstständig begründet, dafür gibt die reiche christliche Märtyrerliteratur ein deutliches Zeugnis ab. ${ }^{89}$ Dennoch, das zeigt der Ausblick auf die narrativen Parallelen in den Martyrien des paganen Heros Hercules und des Christen Polykarp, hat die Märtyrerliteratur sich bei den klassischen Vorbildern bedient und dort ihre literarischen Anleihen genommen.

Der Topos des Heros als Märtyrer und seiner Apotheose findet sich in den paganen Heraklesbildern am stärksten in Senecas Hercules-Tragödien dargestellt. Die Annahme einer direkten Beeinflussung der Evangelisten durch Autoren wie Seneca ist nicht nachweisbar, kategorisch auszuschließen ist sie indessen nicht. Paulus formuliert als erster christlicher Autor das Glaubensbekenntnis vom Auferstandenen. Wenig später entsteht in Rom der Hercules Oetaeus. ${ }^{90}$ Zwierlein weist zu Recht darauf hin, dass der schmerzverachtende Feuertod des Herakles auch im Rom des 2. Jahrhunderts nicht nur bekannt war, sondern als vorbildhaft bewundert wurde. Dies zeigt etwa

[...] das Beispiel des vormals aus Rom ausgewiesenen Kynikers Peregrinus Proteus, der sich im Jahre 165 vor vielen Zuschauern auf einem Scheiterhaufen selbst verbrannte, um gemäß der Lebenshaltung des Hercules die Erhabenheit des Philosophen über Schmerz und Tod zu demonstrieren. Dieses Exemplum erregte damals großes Aufsehen (vgl. Philostr. vit. soph. 2,1,33) und wurde auch von Athenagoras in seiner Schutzrede für die Christen an die Kaiser Marc Aurel und Luc. Verus (legat. pro Christ. c. 26), ferner z.B. von Tertullian (ad martyr c. 4) und später von Ammianus Marcellinus $(29,1,39)$ einer rühmenden Notiz für wert befunden. ${ }^{91}$

\section{Auch Cancik betont die chronologische und örtliche Koinzidenz:}

In den Jahren, als - vielleicht in Rom - die Grundform der Evangelien geschaffen wurde, als Paulus - aus dem durch einen besonderen Herakleskult bekannten Tarsos stammend - in Rom die neue jüdisch-hellenistische Lehre vom Gottessohn und Erlöser verkündete, entstand das Drama vom Herkules auf dem Oeta [.....$^{92}$

87 Hierzu, zum Vorhergehenden und Folgenden siehe Zilling (s. Anm. 40), S. 178 ff. Auch Nesselrath zieht, wie bereits erwähnt, in seiner Analyse des Hercules Oetaeus den naheliegenden Vergleich zwischen der Apotheose des Herakles und der Auferstehung Christi. Vgl. Nesselrath (s. Anm. 68), S. 317. 88 Belege und Verweise bei Zilling (s. Anm. 40), S. 36-39; S. 114-123. Nach der These von Betz zeigt sich dieser Konflikt schon in den Evangelien und der Apostelgeschichte, in denen die beginnende Heroisierung Jesu schließlich unterbunden wird. Vgl. Betz (s. Anm. 16), S. 129.

89 Zilling (s. Anm. 40), S. 204-211.

90 Zwierlein (s. Anm. 68), S. 339 ff. Zwierlein vermutet, dass der Anonymus ein Zeitgenosse Juvenals gewesen sei.

91 Zwierlein (s. Anm. 68), S. $341 \mathrm{f}$.

92 Cancik (s. Anm. 68), S. 258. 
Cancik vertritt aufgrund der von ihm angenommenen zeitlichen Übereinstimmung die Ansicht, dass ein gemeinsamer, allgemein aufgekommener Topos vorausgesetzt werden kann. Des Weiteren verweist er auf das Motiv der Erniedrigung des Erlösers Hercules im Hercules furens. Er sieht darin ein Paradoxon, das den Erlöser schlägt, der zuvor die Erlösung und Befreiung als gewalttätiger Retter vertreten hat. Seine Taten, die Bluttat an der eigenen Familie eingeschlossen, brachten immense Gewalttätigkeiten mit sich. ${ }^{93}$ Die zweite Herculestragödie knüpft hier an und lässt konsequent den heroischen Gewalttäter selbst leiden; diese Tragödie „stürzt den Heros in tiefstes, ganz unheroisches körperliches Leiden“, so Cancik. ${ }^{94}$ Im eigenen erduldeten Leid ist der Heros Gottesknecht und erntet als Lohn die Vergöttlichung und damit die Unsterblichkeit. ${ }^{95}$

Das Konzept der Nachahmung zeigt sich indessen möglicherweise ebenfalls in dem anzunehmenden Selbstverständnis Jesu als leidender Gerechter (Ps 22) und mehr noch als leidender Messias, Gottes- und Menschensohn in der Tradition des leidenden Gottesknechtes (Mk 8,31). Diese Rolle findet sich im sogenannten Deutero-Jesaja (speziell im vierten Gottesknechtslied in Jes 52,13-53,12) in der christlichen Lesart so ausformuliert. Die nachösterliche Christianisierung des jüdischen Vorbildes ist unabhängig vom schwierigen Problem des jesuanischen Selbstverständnisses - naheliegend (vgl. Lk 24,26 und Jes 53,4f.). Zumindest wird sowohl in der judaistischen als auch in der theologischen Forschung davon ausgegangen, dass Jesus als frommer Jude, der in der Tradition seines Volkes unterwiesen war, insbesondere die Prophetie des Jesaja kannte und eventuell auf sich selbst bezogen hat. ${ }^{96}$ Gleichzeitig ist es plausibel, dass die ersten christlichen Gemeinden die Leid- und Todeserfahrung des Messias mit dem Konzept des leidenden Gottesknechtes zusammenbrachten und so besser deuten konnten.

Die Passionsberichte der Evangelisten fallen verglichen mit der Tragödie des Hercules oder der Märtyrerliteratur knapp aus und berichten von einem für den an-

93 Zilling (s. Anm. 40), S. 160.

94 Cancik (s. Anm. 68), S. 257.

95 Zilling (s. Anm. 40), S. 160. Herakles ist sich seiner Apotheose zwar nicht sicher, aber sie ist auf dem Scheiterhaufen auch für ihn zum Greifen nahe und vorhergesagt. Siehe Sen., Herc. O. 1435ff.; vgl. Ov., Met. 9,235ff.; Pind., N. 1,60-70: Teiresias verkündet Herakles’ Apotheose. Vgl. Lk 17,22-37, vom Kommen des Menschensohnes.

96 Einen sehr guten Überblick bietet das Tagungsheft zur debatte der Biblischen Tage vom 25. bis 27. März 2013 der Katholischen Akademie Bayern: Heft 5/2013 mit einschlägigen Beiträgen zu der Thematik u.a. von L. Schwienhorst-Schönberger, Die vier Gottesknechtslieder und die Gestalt des Knechtes JHWHs, S. 21-23; U. Mittmann, Zur neutestamentlichen Rezeption der Gottesknechtslieder am Beispiel des Lukasevangeliums, S. 24-26, die u. a. eine überzeugende synoptische Darstellung von Lk 23,32- 49 und parallel die Bezüge zur Gottesknechtsüberlieferung bei Jesaja herstellt; kritisch dagegen S. Talabardon, „Der Knecht des Ewigen“ - Jescha’ja 52,13-53,12 in jüdischer Interpretation, S. 32-34; Talabardon verweist darauf, dass das Eponym in erster Linie mit Moses in Verbindung gebracht wird (S. 32). Ferner, dass es durch den christlichen Zugriff auf den Titel einen Streit um die Deutungshoheit gibt, der sich auch in der Apologetik findet (S. 34). 
tiken Menschen unfassbaren Ereignis: dass nämlich ein Gottessohn wie ein Schwerverbrecher am Kreuz hängt und so hilflos ist und so gewöhnlich stirbt wie jeder andere Gekreuzigte. Für die paganen Zeitgenossen der Frühchristen war die religiös-kultische Verehrung eines Gekreuzigten nichts anderes als eine Torheit, eine $\mu \omega \rho$ í $\alpha$, in der Wiedergabe bei Justin eine $\mu \alpha v i \alpha$ (Apol. I,13,4), also eine Verrücktheit. ${ }^{97}$

Die Kreuzigung diskreditiert Jesus am stärksten und ist in der antiken Polemik ein Haupteinwand gegen das Christentum. ${ }^{98}$ Wenn Justin nun argumentiert, dass nicht der Kreuzestod, sondern Jesu Taten entscheidend seien, dann liegt der Vergleich mit dem Heros auf der Hand. Justin will den Fokus von der Unmöglichkeit des sterbenden GottMenschen am Kreuz abwenden und auf die Taten lenken. Ein Gott leidet und stirbt nicht, sterblich sind dagegen die „barbarischen Halbgötter und Heroen der Urzeit“. Das Leiden gehört zu ihren Taten..$^{99}$ Entscheidend ist: Helden sind durch ihr Leiden am Ende siegreich. Das Leiden der Heroen ist eben kein Leiden im Todeskampf, sondern es leidet der Held immer im Kontext des Lebens und der ihm gestellten Aufgaben. Christus am Kreuz dagegen ist die elendigste menschliche Kreatur und erst durch die Entwicklung der Auferstehungstheologie bekommt sein Leiden nachträglich einen Sinn für seine Anhänger.

Für die Kirchenväter ist dies das beständigste Vermittlungsproblem. Aufgrund des Einflusses des Heroenkultes, des antiken Totenkultes und den bestehenden

verbreiteten Vorstellungen von der höheren Daseinsform der abgeschiedenen Seelen auf christliche Kreise [...], bei dem immer lebendiger sich bekundenden Bedürfnis, die vermeintliche Lücke zwischen Gott und Welt durch die Statuierung von Mittelwesen auszufüllen, konnte es nicht wohl ausbleiben, dass wenn auch unter anderen Namen und mit vielfach modifizierten Attributen, die christlichen Vollkommenen mit der Zeit in eine Stellung einrückten, ähnlich derjenigen, welche in der gleichzeitigen heidnischen Weltanschauung die Heroen einnahmen, ${ }^{100}$

konstatiert bereits Ernst Lucius 1904 in seiner Untersuchung zu den Anfängen des christlichen Heiligenkultes. So wundert es nicht, dass die frühchristlichen Autoren bei ihren Versuchen, über das Skandalon des Kreuzes zu sprechen und zu predigen, die bekannten Bilder des Mythos transformierten und verwendeten und gleichzeitig um die Verwerfung und Abgrenzung bemüht waren. ${ }^{101}$

97 Aug., Civ.19,23: Toter Gott, gekreuzigter Mensch - mors turpissima crucis (Orig., Comm. in Mt 27,22ff.; Hengel [s. Anm. 41], S. 125, Anm. 1).

98 Just., Apol. I,22,3f.; 13,4; Hengel (s. Anm. 41), S. 129.

99 Hengel (s. Anm. 41), S. 128, siehe Hengels Anm. im Nachtrag auf S. 181. C. M. Bowra, Heldendichtung. Eine vergleichende Phänomenologie der heroischen Poesie aller Völker und Zeiten, Stuttgart 1964, S. 98.

100 E. Lucius, Die Anfänge des Heiligenkultes in der christlichen Kirche, Tübingen 1904, S. 42.

101 Vgl. dazu etwa Lact., Inst. 7 f., der sich dezidiert gegen Hercules wendet und bei seiner Betrachtung der griechischen Götter auf die Darstellung Homers verweist; Just., Apol. I,18, der Odysseus’ Abstieg in die Unterwelt bei Homer als Vergleich und Unterscheidung für den christlichen Glauben an die Unsterblichkeit der Seele heranzieht. In Apol. I,21 argumentiert Justin mit mythologischen Parallelen zur Himmelfahrt Jesu, die z.B. im Vergleich mit den Zeussöhnen und Herakles nichts Befremdliches sei. 


\section{Das Kreuz als Mastbaum - Odysseus und Christus}

Eingängig ist das Bild von der Kirche als rettendes Schiff, wobei „der gewaltige Mastbaum mit der quergestellten Antenne oder Rahe [...] wie von selbst an das Kreuz [erinnert] “. ${ }^{102}$ Automatisch erblickten antike Christen in den Mastbäumen der Schiffe das Kreuz Christi, der durch diese unwillkürliche Assoziation zum unsterblichen Seefahrer wurde. So erklärt Gregor von Nyssa:

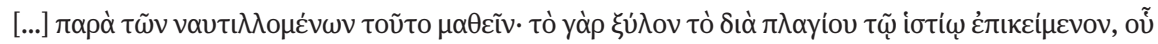

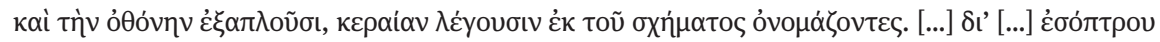

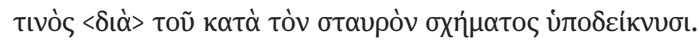

... wie dies auch von den Seeleuten zu lernen ist; denn das Holz, das waagrecht über dem Segel liegt, woran sie auch das Tuch entfalten, heißen sie Querholz [keraia], indem sie es nach seiner Gestalt benennen. Deswegen [...], weil es jenes ist, [...] das seine ihm eigene Kraft, [...] gleichsam wie durch ein Sinnbild und einen Spiegel durch die Gestalt des Kreuzes anzeigt. ${ }^{103}$

Hippolyt führt es folgendermaßen aus:

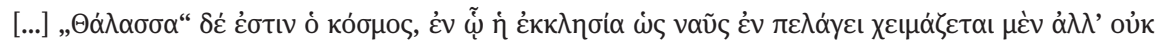

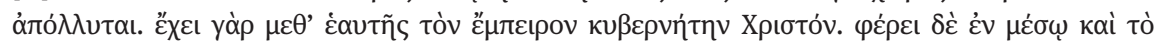

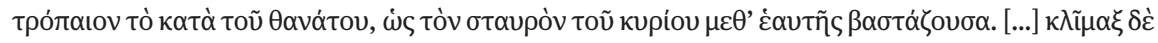

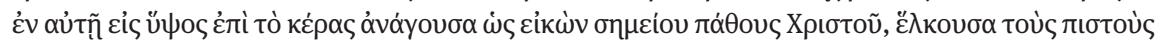

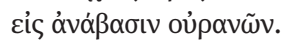

... das Meer ist die Welt, in welcher die Kirche wie ein Schiff auf dem Meere umhergeworfen, aber nicht vernichtet wird, denn sie hat bei sich den erfahrenen Steuermann Christus. In ihrer Mitte führt sie das Banner gegen den Tod, da sie das Kreuz des Herrn mit sich trägt. [...] Die Leiter, welche oben auf den Mastbaum führt, ist die Nachahmung des erlösenden Leidens Christi, welches die Gläubigen zieht, um in den Himmel einzugehen. ${ }^{104}$

Hier erscheint die Kirche als Schiff, welches durch das dämonische Meer der Welt segelt und den Steuermann Christus bei sich hat. ${ }^{105}$ Hippolyt vergleicht in der Refutatio omnium haeresium (= Elenchos = Widerlegung oder Philosophumena) die

Tert., Idol. 20, ereifert sich über Christen, die nach ihrer Bekehrung weiter beim Namen des Hercules schwören. Aug., Civ. 22,10, fordert, die Heiden sollten zugeben, ihre Götter seien wie Hercules nichts weiter als verstorbene Menschen.

102 Hierzu und zum Folgenden siehe Rahner (s. Anm. 1), S. 281-328, Zitat S. 316.

103 Greg. Nyss., In Christi resurrectionem oratio (Gregorii Nysseni opera IX,302,19-303,8). Übersetzung nach: Gregor von Nyssa. Die drei Tage zwischen Tod und Auferstehung unseres Herrn Jesus Christus, eingel., übers. u. komm. v. H. R. Drobner, Leiden 1982, S. 35.

104 Hippol., De Antichristo 59 (GCS Hippolytus I,2,39f.). Übersetzung nach: Hippolytus', des Presbyters und Martyrers, Buch über Christus und den Antichrist, übers. und mit Einl. vers. v. V. Gröne (BKV, 1. Reihe, Bd. 28), Kempten 1872, S. 54f. Vgl. Ambrosius, der das Bild aufgreift in Expl. Psalm. 43,17 (CSEL 64,355,8-16).

105 Rahner (s. Anm. 1), S. 294-300. 
Ansichten gnostischer Häresien mit dem Bild vom aufgepeitschten Meer und expliziert seine Botschaft mit dem Mythos vom Sirenenbesieger Odysseus. Hippolyt zieht nämlich für die Christen den Schluss, sie sollten wie Odysseus ein strategisches Abwehrverhalten gegen die dämonischen Verführungen der Häresien an den Tag legen:

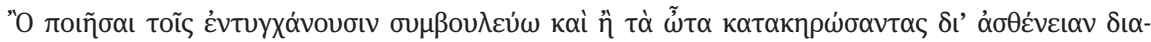

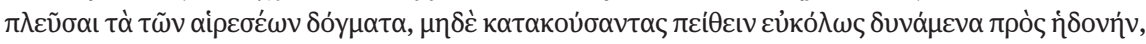

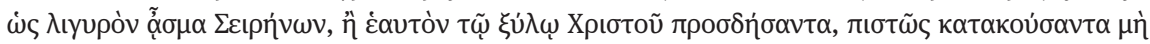

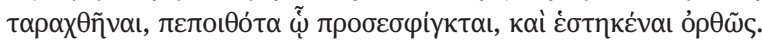

Mein Rat für die, welche sich mit derlei [nämlich den Häresien] beschäftigen, geht dahin, entweder wegen ihrer Schwachheit mit zugeklebten Ohren die Ansichten der Häresien zu durchsegeln und auch nicht auf das zu hören, was, wie der liebliche Gesang der Sirenen, leicht zur Wollust anreizen kann, oder aber sich an das Holz Christi zu binden und in Treuen zu lauschen und sich nicht verwirren zu lassen, sondern aufrecht stehen zu bleiben, im Vertrauen auf das, an das man gebunden ist. ${ }^{106}$

Da der „Normalchrist“ sich wegen seiner Schwachheit in riskantes Fahrwasser begibt, wenn er sich mit häretischen Lehren befasst, sollte dieser sich wie des Odysseus Gefährten Wachs in die Ohren gießen und so den Häresien mit Taubheit begegnen. Dagegen bräuchten die glaubensstarken Christen keine Angst vor den Sirenen zu haben, weil die Fesseln des Glaubens sie aufrecht am „Holz Christi“ halten würden. ${ }^{107}$ Die konkrete Gefahr, die von den Häresien drohe, sei die, dass sie nämlich zur Wollust, also zu sündhafter Unzucht verleiteten. Dazu muss man wissen, dass von den Vätern die grundsätzliche Gefahr der Häresie als Trennung von den „Anordnungen des Bi-

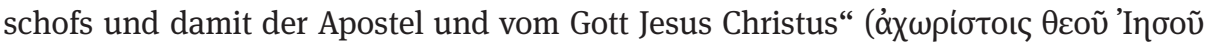

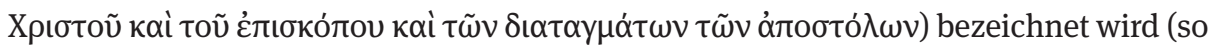
drückt es Ignatius in seinem Brief an die Trallianer aus [7,1-2]). Ignatius nennt mithin die Voraussetzungen dafür, kein Häretiker zu werden. Das bedeutet im Umkehrschluss, wer die Häresien hört, setzt seine christliche Existenz und damit sein individuelles Heil aufs Spiel. Mit anderen Worten, es geht nicht nur um eine Auseinandersetzung um Leben und Tod, sondern um das ewige Leben - eine Verheißung, die wir eben auch von den Sireneninseln kennen.

Odysseus bewährt sich am Mastbaum nicht durch ein Wunder, sondern durch einen Trick, der zwar auf göttliche Weisung, aber doch in der Ausführung einer menschlichen List gleichkommt. Erniedrigung und Fesselung des Odysseus sind freiwillig oder besser gesagt, sie entspringen der Ratio des klugen Odysseus, den Bogen nicht zu überspannen. Ihm ist klar, dass er, wenn er sich noch weiter vorwagt, sein Leben verlieren wird. In Odysseus verbindet sich intellektuelle Einsichtsfähigkeit mit

106 Hippol., Ref. omn. haer. 7,13,3.

107 Ebenso Clem. Alex., Protr. XII,118,1-4 (GCS Clemens Alexandrinus I,83,8-30). Vgl. dazu Markschies (s. Anm. 2), S. $236 \mathrm{f}$. 
dem glücklichen Umstand, in besonderer Weise ein Günstling weiblicher Gottheiten zu sein, die ihm lebensrettende Anweisungen vermitteln, ohne die er das Sirenenabenteuer sicherlich nicht bestanden hätte.

Wie steht es aber mit Christus am Kreuz? Von außen betrachtet ist er ein Anticharismatiker und ein Versager. Die Bewährung scheitert, er bewirkt an sich selber kein Wunder. Das ist nur auf den ersten Blick ein Paradoxon, oder vielmehr eine Verkennung, denn es geht ja gerade darum, in der Sprache der Evangelien, den Kelch des Leidens auszutrinken. Christus steigt also nicht vom Kreuz herab, sondern am Kreuz schwindet seine charismatische Autorität, die er sich vor allem als Wundertäter aufgebaut hat. Er schreit sogar verzweifelt: „Mein Gott, mein Gott, warum hast du mich verlassen?“, wodurch er sein Scheitern sogar offen ausspricht. Im Kern liegt die „revolutionäre Macht“ des Gekreuzigten darin, dass mit Christus ein Mensch stirbt und dann aber aufersteht. Wenn das so ist, dann besteht zumindest für die Menschen nach christlicher Auffassung die prinzipielle Hoffnung, es ihm gleichzutun. Erst die nachträgliche christliche Interpretation, dass gerade der stellvertretende Sühnetod des Heilands für die Menschheit notwendig war, macht den heroischen Sinn dieses Sterbens aus. Das Kreuz wird so zum zentralen Siegessymbol umgedeutet.

Jedoch bedarf dieser Zusammenhang einer erfolgreichen Vermittlung. Hier greifen die Kirchenväter, wie wir an einem frühen Vertreter gesehen haben, auf die Möglichkeiten einer christlichen Homerinterpretation zurück. Diese leistet jedoch noch mehr als die Kommunikation des Kreuzes als Siegeszeichen. Die vorhin besprochene Hippolytstelle zeigt ganz deutlich, wie zudem die Rechtgläubigkeit gegen Häresien argumentativ bewältigt wurde. Dazu (etwas pathetisch) Carl Schneider: „Der Mast, an den Odysseus sich binden lässt, ist das Kreuz, das vor den Sirenen der Sünde und der Welt errettet." ${ }^{108}$ Erstaunlich bleibt indessen der Umstand, dass in dieser Auseinandersetzung Christus mit Odysseus verbunden und auf die topische Kontinuität des an den Mastbaum gefesselten Odysseus als Strategie zur Häretikerabwehr abgehoben wird.

Da das Bild des Odysseus z. B. durch die weit verbreitete Keramik so vertraut und deutlich ist, wird es in dem beschriebenen antihäretischen Kontext verwendet und untermauert etwa die Katechese, auch der Herr habe in der Wüste und vor allem in Getsemani einer teuflischen Versuchung widerstanden. Darum wird Christus bei Hippolyt als Odysseus oder Kapitän dargestellt. Auf diese Weise wird nun allerdings auch Odysseus heilig. Das Bild des Odysseus am Mastbaum erlebt durch die christliche Verwendung Kontinuität und erfährt dabei eine nachdrückliche Christianisierung und Transformation. D.h. in der christlichen Deutung erfolgt die Vereinnahmung des paganen Bildes, dann nämlich, wenn Christus als Kapitän oder eben als Odysseus der Kirche erscheint. Ein Problem bleibt jedoch bestehen: Odysseus leidet nicht stellvertretend für die Gefährten, sondern er leidet in eigener Sache oder an seiner Hybris. Christus dagegen stirbt den Sühnetod und rettet die Menschheit, insofern ist die

108 Schneider (s. Anm. 5), Bd. 1, S. 320. 
Bildkorrespondenz oder die Analogie verzerrt. Die Heilsbedeutung des Todes Jesu ist in der Tat originell. Die jüdische Tradition des leidenden Gottesknechtes kennt die Vorstellung, dass dieser „um unserer Sünde willen durchbohrt und zerschlagen wird“ (Jes 53,5). Neu ist indessen die Heilsbedeutung des elenden Martertodes am Kreuz.

Doch weil man sich des Skandalons bewusst war, suchten die Kirchenväter einerseits nach Vermittlungsmöglichkeiten und griffen dabei auf die altbekannten Mythen und Figuren zurück, andererseits waren sie gezwungen, die Christologie von solchen paganen Heroen- und Göttervorstellungen zu unterscheiden. In der Dogmatik der Kirchenväter wurde die Anstößigkeit des Kreuzes in eine heilstheologische Notwendigkeit umgedeutet: Nur durch das Kreuz sollte die Sündenvergebung gewährleistet und die Auferstehung „im Hafen des Heils“ möglich sein. Damit bot sich für die Kirchenväter an, auf das bekannte Bild von Odysseus am Mastbaum zurückzugreifen. Es geht diesen dabei nicht um den berühmten Helden des paganen Mythos, sondern darum, Heilswege durch das Mittel der Allegorie deutlich zu machen.

Die Analyse der Verhältnisse im Rom zur Zeit des Hippolyt weist außerdem auf das Ringen der Gemeinden hin, der gnostischen Infiltrierung etwas entgegenzusetzen und im Machtkampf gegen den Bischof Kallist zu bestehen. Damit wird das Bild des mythologischen Helden zudem ein Instrument innerchristlicher Auseinandersetzungen. ${ }^{109}$

\section{Schluss}

Um einen Bogen zurück zu Auerbach zu schlagen - dieser ist der Ansicht, ${ }^{110}$ dass der Ort des Geschehens, das Milieu und überhaupt die Jesus-Figur selbst mit dem erhabenen Stil der klassisch-antiken Literatur völlig unvereinbar gewesen seien. Die figurale Deutung erkennt Auerbach insbesondere als spezielles Merkmal der christlichen Tradition. Meines Erachtens zeigen jedoch neben den alttestamentlichen die mythologischen Beispiele, dass die christliche Interpretation der Geschichte Jesu und die Figuration der Erlösergestalt Vorstellungen, Verweise und Erzählmuster aufgreifen, die von den Kontexten der paganen Umwelt ebenso wenig zu trennen sind wie von ihren jüdischen Vorbildern. So hat schon Joseph Campbell in seiner umfassenden Betrachtung der immer wiederkehrenden Topoi des Helden gezeigt, dass letztendlich keine mythische oder religiöse Erzählung von den archetypischen Abläufen des Monomythos zu trennen ist, weder Jesus noch Buddha, weder die griechischen noch die

109 Vgl. dazu auch Oehl (s. Anm. 2), S. 338: „Man knüpfte an die bereits vorchristliche Praxis an, den Mythos in die Polemik einzubeziehen, entwickelte übernommene Bilder aber eigenständig weiter und passte sie an die Bedürfnisse der eigenen Polemik an.“

110 Auerbach stützt sich hierin auf Norden, vgl. Auerbach (s. Anm. 6), S. 45-49. 
römischen Götter und Heroen. ${ }^{111}$ Selbst das leere Grab, so ungewöhnlich es auch erscheint, ist nicht ohne Parallele. ${ }^{112}$

Ich wage zum Schluss meiner Ausführungen die These, dass die Märtyrerliteratur sich stärker als die Evangelien von der klassischen Literatur beeinflussen lässt verwiesen sei in diesem Zusammenhang nur kursorisch auf Assmanns erinnerungsgeschichtlichen Ansatz. ${ }^{113}$ Neben dem Umstand, dass intellektuelle Christen als ehemalige Heiden durchaus umfassend gebildet waren, ${ }^{114}$ hat das gemeinsame kulturelle Gedächtnis sicherlich eine Rolle gespielt.

Auerbach ist indes zuzustimmen, wenn er ausführt, dass die Evangelien und die Apostelgeschichte erstmals „die Entstehung einer geistigen Bewegung in der Tiefe des alltäglichen Volkes, mitten aus dem zeitgenössischen alltäglichen Geschehen heraus“ dargestellt haben und dass dieses „für die Verfasser der neutestamentlichen Schriften revolutionäres Weltgeschehen“ gewesen sei. ${ }^{115}$ Diese haben neue historische Ordnungsbegriffe gefunden (Auerbach listet hierzu Begriffe wie Zeit des „Gesetzes“, der „Sünde“, der „Gnade“, der „Gerechtigkeit“, der „Liebe“, der „Kraft“ und des „Geistes“ auf). ${ }^{116}$ Zudem dürfe man nicht vergessen, dass die bar jeder Wissenschaftlichkeit und Objektivität erzählte Heilsgeschichte „[...] aus der Geschichte heraus, in die Endzeit [...] führt, also nach oben, [...] und dass überhaupt die bei den antiken Betrachtern ruhenden Tiefenschichten in Bewegung gerieten“. ${ }^{117}$

Mit der beginnenden Heidenmission verwandelten sich endgültig eine Reihe von alttestamentlichen Figuren zu Vorverkündern Jesu, erhalten sinnliche Erscheinungen eine religiöse Bedeutung, verweist wie gesagt Adams Schlaf auf Christi Todesschlaf, zeigt Adams Seitenwunde und die daraus entnommene Rippe, das Weib Eva, die Mutter-Kirche sowie Blut und Wasser der Seitenwunde Christi die Sakramentssymbole.

In seinem Mimesis-Kapitel zu Adam und Eva (Kap. VII) führt Auerbach dazu ein volkstümliches französisches Weihnachtsspiel aus dem 12. Jahrhundert an: Jedes Geschehen sei dort in seiner alltäglichen Wirklichkeit zugleich von welthistorischer Relevanz. Bemerkenswert sei es, dass zunächst Gott selbst Figura genannt würde, was sich zunächst auf den Darsteller, den Geistlichen, der Gott zu figurieren hatte, bezöge

111 J. Campbell, Der Heros in tausend Gestalten, Frankfurt a. M. 1999, vgl. etwa S. 42 ff.; S. 247 ff. 112 Wie ungewöhnlich das leere Grab ist, zeigt sich nicht zuletzt am anhaltenden Ringen um die Auslegung in der Forschung. Vgl. dazu etwa Thiessen (s. Anm. 46), S. 55-78, mit Hinweisen auf die wichtigsten Positionen und Argumentationen. Theologisch bedeutet die Auferstehung im christlichjüdischen Verständnis die Annahme eines Opfers und damit die Vollendung des Sühnetodes Jesu aus christlicher Perspektive.

113 J. Assmann, Das kulturelle Gedächtnis. Schrift, Erinnerung und politische Identität in frühen Hochkulturen, 5. Aufl., München 2005, S. 48-56; ders., Die mosaische Unterscheidung oder der Preis des Monotheismus, München/Wien 2003, S. $89 \mathrm{ff}$.

114 So etwa K. Pietzner, Ungebildete Konkurrenten? Die Auseinandersetzung zwischen Christen und Heiden in vorkonstantinischer Zeit (Studien und Texte zu Antike und Christentum), Tübingen 2011.

115 Auerbach (s. Anm. 6), S. 46.

116 Auerbach (s. Anm. 6), S. 48.

117 Auerbach (s. Anm. 6), S. 48. 
und den man sich scheute „Gott“ zu nennen, so wie die anderen Darsteller, etwa von Adam und Eva, mit den Namen ihrer Rollen angesprochen wurden. Man könne es aber auch so erklären, meint Auerbach weiter, dass in der Gottesgestalt „schon der erlösende Heiland figural gegenwärtig“ sei. ${ }^{118}$

Darauf beziehe ich mich, wenn ich meine, dass im antiken Heros - ob nun in der Literatur oder in der bildenden Kunst oder auf Alltagsgegenständen - eine Figur angelegt oder ein Typus figuriert ist, welcher von nachhaltigem Einfluss auf die Autoren des Neuen Testaments, der Märtyrerliteratur aber auch auf Künstler, Kunst- und Kulturgeschichte geblieben ist.

118 Auerbach (s. Anm. 6), S. 151. 


\section{Herakles - Herakleios - Christus. Georgios Pisides und der kosmorhýstes}

In den Jahren um 630 - nach dem byzantinischen Sieg über die Sāsāniden, aber noch vor dem Beginn der Auseinandersetzungen mit den muslimischen Arabern - verfasste Theophylakt Simokates sein Geschichtswerk über die Herrschaft des Kaisers Maurikios (582-602). ${ }^{1}$ Der eigentlichen Darstellung vorangestellt ist ein rhetorisch überhöhter, pathetischer Dialog zwischen den Personifikationen der Philosophie und der Geschichte, in dem beide ihre Wiederauferstehung feiern, nachdem sie unter dem „Ty-

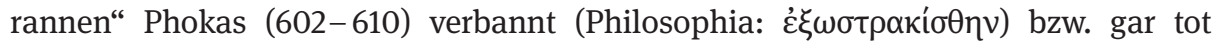

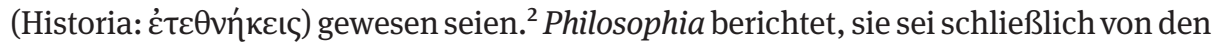
„Herakliden“ gerettet worden, und spielt damit recht eindeutig auf den Sturz und die Ermordung des Phokas durch Herakleios (610 -641) und seine Anhänger an. ${ }^{3}$ Doch auch Historia weiß ihren Wohltäter zu benennen: „den großen Erzpriester und Vor-

\footnotetext{
$1 \mathrm{Zu}$ Theophylakt und seinem Geschichtswerk ist grundlegend die Monographie von Mi. Whitby, The Emperor Maurice and His Historian: Theophylact Simocatta on Persian and Balkan Warfare, Oxford 1988; s. auch D. Brodka, Die Geschichtsphilosophie in der spätantiken Historiographie. Studien zu Prokopios von Kaisareia, Agathias von Myrina und Theophylaktos Simokattes, Frankfurt a.M./Berlin u. a. 2004; wichtig sind überdies O. Veh, Untersuchungen zu dem byzantinischen Historiker Theophylaktos Simokattes. Wissenschaftliche Beilage zum Jahresbericht 1956/57 des Human. Gymnasiums Fürth i. Bay., Fürth 1957; Mi. Whitby, Greek Historical Writing after Procopius: Variety and Vitality, in: Av. Cameron/L. I. Conrad (Hgg.), The Byzantine and Early Islamic Near East I: Problems in the Literary Source Material, Princeton (N.J.) 1992, 25-80, bes. 45-54; Mi. Whitby/Ma. Whitby, The History of Theophylact Simocatta. An English Translation with Introduction and Notes, Oxford 1986, ND 1988; P. Schreiner, Theophylakt Simokates. Geschichte. Übersetzt und erläutert, Stuttgart 1985; J. D. C. Frendo, History and Panegyric in the Age of Heraclius: The Literary Background to the Composition of the Histories of Theophylact Simocatta, DOP 42 (1988), 143-156; S. Efthymiadis, A Historian and His Tragic Hero: A Literary Reading of Theophylact Simokatta's Ecumenical History, in: R. Macrides (Hg.), History as Literature in Byzantium, Farnham/Burlington 2010, 169-185. Einige einleitende Bemerkungen auch bei M. Meier, Prokop, Agathias, die Pest und das ,Ende‘ der antiken Historiographie. Naturkatastrophen und Geschichtsschreibung in der ausgehenden Spätantike, HZ 278 (2004), 281310, hier 304-310. - Zur Datierung des Geschichtswerks s. etwa Schreiner, a.a.O., 2f.; 13; Whitby, Emperor, 39f.; Whitby/Whitby, a.a.O., XVI. Die düstere Grundstimmung des Werks und vermeintliche Anspielungen auf die arabischen Angriffe seit Mitte der 630er Jahre haben neuerdings Efthymiadis, a. a.O., 171; 180, zu Spekulationen über eine mögliche Entstehungszeit in der 2. Hälfte der 630er Jahre veranlasst. Die von ihm herangezogenen Anspielungen sind indes alles andere als klar, und für die ,Grundstimmung' des Werkes (die zunächst einmal nur aus der Perspektive moderner Einschätzungen als düster erscheint) lassen sich auch andere Erklärungen beibringen, z. B. die mögliche Intention, das Schicksal des Maurikios möglichst tragisch und ergreifend als an den aktuellen Kaiser gerichtete Mahnung zu zeichnen.
}

2 Theophyl. Sim. Dial. 4-5.

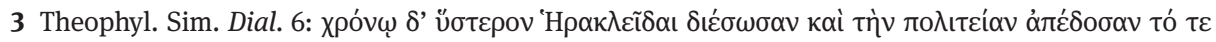

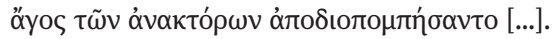


steher der gesamten Oikoumene“. ${ }^{4}$ Man hat damit verschiedentlich Sergios, den Patriarchen von Konstantinopel (610-638), identifizieren wollen. ${ }^{5}$ Das aber ist wenig wahrscheinlich, denn im Folgenden vergleicht die Figur der Historia ihre Wiedererweckung explizit mit der Rückführung der Alkestis aus dem Totenreich durch Herakles $^{6}$ und verwendet damit ein Bild, das sich (ebenfalls unter Hinweis auf die Oikoumene) auch beim zeitgenössischen Dichter Georgios Pisides findet - und zwar mit ausdrücklichem Bezug auf Herakleios. ${ }^{7}$ Dass hinter dem „großen Erzpriester und Vorsteher der gesamten Oikoumene“ denn auch tatsächlich der Kaiser, und nicht der Patriarch, zu sehen ist, wird bereits aus dem Umstand ersichtlich, dass die im Dialog unmittelbar vorausgehende Erwähnung der Herakliden (s.o.) die Parallele HeraklesHerakleios für den weiteren Gesprächsverlauf geradezu festschreibt. ${ }^{8}$

Mit dieser an prominenter Stelle vorgetragenen Analogie zwischen dem aktuellen Kaiser und dem mythischen Helden steht Theophylakt nicht allein. Namentlich sein Zeitgenosse Georgios Pisides hat wiederholt das Herakles-Exempel in Verbindung mit Herakleios evoziert, in unterschiedlichen Kontexten, zumeist explizit, mitunter aber auch vermittelt durch subtile Anspielungen - ja, selbst eine Passage beim sog. Fredegar könnte auf eventuelle Herakles-Herakleios-Bezüge hindeuten. ${ }^{9}$ Man kann es sich leicht machen und ganz simple Gründe für dieses Phänomen anbringen: Zunächst natürlich den Namen des Kaisers, der die Herakles-Assoziation geradezu vorgegeben haben muss; dann die generelle Vorliebe des Georgios für mythologische Beispiele und Analogien, ${ }^{10}$ weiterhin die traditionelle Prominenz des Herakles-Themas in der (spät) antiken Panegyrik ${ }^{11}$ und herrscherlichen Ikonographie, ${ }^{12}$ ferner die Herakles-Asso-

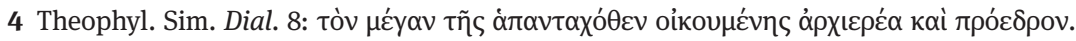

5 So etwa Schreiner (s. Anm. 1), 240 f., Anm. 12; Whitby, Emperor (s. Anm. 1), 40; 44; Whitby/Whitby (s. Anm. 1), 4, Anm. 9.

6 Theophyl. Sim. Dial. 9.

7 Georg. Pisid. Her. 1,71-73.

8 Für diese Identifikation des „großen Erzpriesters“ mit Kaiser Herakleios plädiert neben H. Hunger, Die hochsprachliche profane Literatur der Byzantiner, Bd. 1-2, München 1978, I 315, mit großem Nachdruck auch Frendo (s. Anm. 1), 144f., Anm. 11, der zudem darauf hinweist, dass in der Spätantike

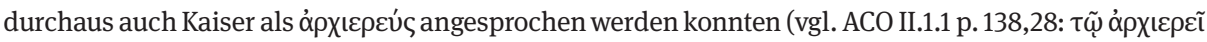

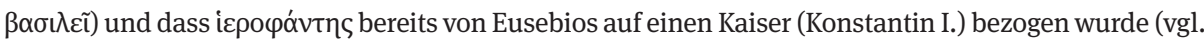
Euseb. Triak. 3; VC 4,22). Trotz der klaren Argumente Frendos versucht allerdings Whitby, Greek Historical Writing (s. Anm. 1), 47, mit Anm. 97, die Sergios-Identifikation weiterhin aufrecht zu erhalten. 9 Fredeg. 65; dazu S. Esders, Herakleios, Dagobert und die „beschnittenen Völker“. Die Umwälzungen des Mittelmeerraums im 7. Jahrhundert in der Chronik des sog. Fredegar, in: A. Goltz/H. Leppin/ H. Schlange-Schöningen (Hgg.), Jenseits der Grenzen. Beiträge zur spätantiken und frühmittelalterlichen Geschichtsschreibung, Berlin/New York 2009, 239-311, hier 290.

10 Dazu s. etwa Ma. Whitby, A New Image for a New Age: George of Pisidia on the Emperor Heraclius, in: E. Dabrowa (Hg.), The Roman and Byzantine Army in the East, Krakau 1994, 197- 225.

11 Vgl. dazu Th. Nissen, Historisches Epos und Panegyrikos in der Spätantike, Hermes 75 (1940), 298 325, hier 302-307. Menander Rhetor (D. A. Russell/N. G. Wilson, Menander Rhetor. Edited with Translation and Commentary, Oxford 1981, p. 80) hat den Herakles-Vergleich sogar als probates Mittel, 
ziationen früherer Herrscher (insbesondere Commodus sowie die Angehörigen der Tetrarchie) ${ }^{13}$ und schließlich eine mögliche ,Herakles-Mode' in gebildeten Kreisen der Zeit - letzteres jedenfalls könnte ein zu Beginn des 20. Jahrhunderts entdecktes anonymes Gedicht über die Taten des Herakles nahelegen, das vor allem aus metrischen Gründen in das 7. Jahrhundert datiert wird, ${ }^{14}$ oder auch ein Papyrusfund mit einem Schultext, der (wahrscheinlich) die an den Schüler gerichtete Aufforderung enthält, Herakles mit dem Kaiser zu vergleichen. ${ }^{15}$ All dies mag eine Rolle gespielt haben.

Im Folgenden möchte ich jedoch versuchen aufzuzeigen, dass dem HeraklesThema im speziellen Fall des Herakleios wohl noch eine weitere, tiefgründigere Funktion zukommt: Offenkundig war dieser Kaiser nämlich darum bemüht, in der Repräsentation mit Christus assoziiert zu werden (ich formuliere diesen Sachverhalt bewusst ein wenig sperrig, weil die Evidenz schmal ist und nicht immer zwischen Ursache und Wirkung, zwischen gezielten Maßnahmen und situativen Reaktionen, differenziert werden kann). Eine plumpe, explizit artikulierte Parallelisierung oder gar Gleichsetzung des Kaisers mit Christus hätte den Zeitgenossen des 7. Jahrhunderts indes wohl allzu viel abverlangt - wenngleich die Augusti seit Konstantin wiederholt auf diesem Feld experimentiert haben. ${ }^{16}$ Die Bezüge ließen sich nur behutsam, vornehmlich in spezifischen Brechungen und häufig indirekt vermitteln und durften nicht erkennbar vom Kaiser selbst forciert werden. An diesem Punkt gewinnt die Panegyrik an Bedeutung, da sie Herrscherbilder transportiert, diese aber zugleich auch stets mit besonderen Erwartungen, die an den Kaiser herangetragen werden, auszubalancieren

ein Herrscherlob zu beginnen, empfohlen. Georgios Pisides ist ihm in seinem Panegyricus In Bonum Patricium darin gefolgt.

12 Vgl. A. Grabar, L'empereur dans l'art byzantin, Strasburg 1936, ND London 1971, 93f.; $141 \mathrm{f}$.

13 Commodus: O. Hekster, Commodus. An Emperor at the Crossroads, Amsterdam 2002; E. MeyerZwiffelhoffer, Ein Visionär auf dem Thron? Kaiser Commodus, Hercules Romanus, Klio 88 (2006), 189215. Tetrarchie: F. Kolb, Diocletian und die erste Tetrarchie. Improvisation oder Experiment in der Organisation monarchischer Herrschaft?, Berlin/New York 1987. Generell zur Funktion des Herakles als Bezugsfigur für antike Herrscher: U. Huttner, Die politische Rolle der Heraklesgestalt im griechischen Herrschertum, Stuttgart 1997.

14 B. Knös, Ein spätgriechisches Gedicht über die Arbeiten des Herakles, BZ 17 (1908), 397-429 (Edition); M. L. West, Greek Metre, Oxford 1988, 184, Anm. 72; Whitby (s. Anm. 10), 206.

15 H. Harrauer/P. J. Sijpesteijn, Neue Texte aus dem antiken Unterricht, Wien 1985, 125-136, Nr. 134, Taf. 60; B. Palme, Aufsatzthemen aus dem Schulunterricht (P. Rain. Unterricht 134), in: M. Puhle/ G. Köster (Hgg.), Otto der Große und das Römische Reich. Kaisertum von der Antike zum Mittelalter. Ausstellungskatalog. Landesausstellung Sachsen-Anhalt aus Anlass des 1100. Geburtstages Ottos des Großen, Regensburg/Magdeburg 2012, 338.

16 Vgl. etwa zu Konstantin S. Rebenich, Vom dreizehnten Gott zum dreizehnten Apostel? Der tote Kaiser in der Spätantike, ZAC 4 (2000), 300 - 324, ND in: H. Schlange-Schöningen (Hg.), Konstantin und das Christentum, Darmstadt 2007, 216-244; zu Justinian s. M. Meier, Das andere Zeitalter Justinians. Kontingenzerfahrung und Kontingenzbewältigung im 6. Jahrhundert n.Chr., Göttingen ${ }^{2} 2004$, 547 ff.; allgemein etwa M. Büchsel, Die Entstehung des Christusporträts. Bildarchäologie statt Bildhypnose, Mainz 22004; M. Meier, Göttlicher Kaiser und christlicher Herrscher? Die christlichen Kaiser der Spätantike und ihre Stellung zu Gott, Das Altertum 48 (2003), 129-160. 
hat und somit eine zentrale, jedoch hochkomplexe Quellengattung konstituiert, die kommunikative Prozesse zwischen Herrschern und Beherrschten spiegelt. Georgios Pisides, dessen panegyrische Dichtungen ohnehin zu den wichtigsten Dokumenten aus der Zeit des Herakleios zählen, drängt sich vor diesem Hintergrund als Untersuchungsobjekt geradezu auf. An seinem Beispiel möchte ich aufzeigen, wie das auf den ersten Blick ausgesprochen traditionelle und im Kontext anderer mythischer Bezugsgrößen nicht eben originell erscheinende Herakles-Exempel mitunter in spezifischer Weise aufgeladen werden und dadurch zum indirekten Vermittler einer KaiserChristus-Parallele avancieren konnte. $\mathrm{Zu}$ diesem Zweck werde ich in fünf Schritten vorgehen: (1.) Nach einigen einleitenden Bemerkungen zu Georgios Pisides und seinem Werk werde ich (2.) zentrale Passagen, in denen der Dichter das Herakles-Thema anstimmt, vorstellen. Auf der Grundlage dieses Materials ist danach (3.) grundsätzlich über die Herakleios-Christus-Parallelen und (4.) die Möglichkeiten, die das HeraklesExempel dabei bot, zu reflektieren, bevor schließlich (5.) kurz die Frage zu diskutieren sein wird, warum gerade Herakleios in besonderer Intensität die Christus-Assoziation betreiben ließ.

\section{1.}

Das moderne Urteil über Georgios Pisides ist gespalten. ${ }^{17}$ Galt er der älteren Forschung mitunter noch als Epigone, an dem sich der vermeintliche Niedergang der spätantiken Dichtung festmachen ließ, ${ }^{18}$ so wird neuerdings seine besondere Mittlerstellung

17 Die Forschung zu Georgios Pisides hat vor allem den Arbeiten Mary Whitbys entscheidende Impulse zu verdanken, vgl. Whitby (s. Anm. 10); dies., The Devil in Disguise: The End of George of Pisidia's Hexaemeron Reconsidered, JHS 105 (1995), 115-129; dies., Defender of the Cross: George of Pisidia on the Emperor Heraclius and His Deputies, in: dies. (Hg.), The Propaganda of Power. The Role of Panegyric in Late Antiquity, Leiden/Boston/Köln 1998, 247-273; dies., George of Pisidia's Presentation of the Emperor Heraclius and His Campaigns. Variety and Development, in: G. J. Reinink/B. H. Stolte (Hgg.), The Reign of Heraclius (610 - 641). Crisis and Confrontation, Leuven/Paris/Dudley (Ma.) 2002, 157-173; dies., George of Pisidia and the Persuasive Word:Words, Words, Words ..., in: E. Jeffreys (Hg.), Rhetoric in Byzantium, Aldershot/Burlington 2003, 173-186; s. ferner Nissen (s. Anm. 11), 301-325; J. D. C. Frendo, The Poetic Achievement of George of Pisidia, in: A. Moffatt (Hg.), Maistor. Classical, Byzantine and Renaissance Studies for Robert Browning, Canberra 1984, 159-187; C. Ludwig, Kaiser Herakleios, Georgios Pisides und die Perserkriege, in: Varia III (= Poikila Byzantina 11), Bonn 1991, 73-128; D. M. Olster, Roman Defeat, Christian Response, and the Literary Construction of the Jew, Philadelphia 1994, bes. 51-71 (vgl. bes. ebd., 64f., Anm. 1, mit Angaben zur älteren Literatur); ders., The Date of George of Pisidia's Hexaemeron, DOP 45 (1991), 159-172, hier 159, Anm. 1 (Literatur); F. R. Gahbauer, Georg der Pisidier, in: S. Döpp/W. Geerlings (Hgg.), Lexikon der antiken christlichen Literatur, Freiburg/Basel/ Wien ${ }^{3} 2002$, 285; zuletzt J. Howard-Johnston, Witnesses to a World Crisis. Historians and Histories of the Middle East in the Seventh Century, Oxford 2010, 16 -35; aktuelle Edition mit Einführung, Kommentar und italienischen Übersetzungen: L. Tartaglia (Ed.), Carmi di Giorgio di Pisidia, Turin 1998.

18 Vgl. etwa die unterkühlte Beurteilung des Georgios bei H.-G. Beck, Kirche und theologische Literatur im byzantinischen Reich, München 1959, 448f. - Hunger (s. Anm. 8), II 112f., erkennt zwar die „literaturhistorische [...] Bedeutung des Pisides“ an, hebt ansonsten aber insbesondere die „propa- 
zwischen antiker und mittelalterlicher Literatur betont ${ }^{19}$ und auf seine außerordentlichen poetischen Qualitäten hingewiesen. ${ }^{20}$ Seine Werke gelten mittlerweile nicht nur als zentrale Dokumente für die Herrschaftszeit des Herakleios, sondern auch als Zeugnisse höchster literarischer Kunstfertigkeit. ${ }^{21}$ Zuletzt konnte James HowardJohnston Georgios Pisides gar als einen ,poet of rare talent, with relatively few peers in classical antiquity“ bezeichnen. ${ }^{22}$

Georgios verfasste Werke panegyrisch-historischen und theologischen Inhalts, und in diese Kategorien wurden seine Dichtungen bis vor wenigen Jahren auch stets geschieden - wobei man davon ausging, dass zunächst (bis etwa 630) seine panegyrischen Schöpfungen, danach die theologischen entstanden seien. ${ }^{23}$ Mittlerweile betont die Forschung hingegen recht einmütig, dass sich Theologie und Panegyrik (und damit die Reflexion aktueller politischer Inhalte) bei Georgios kaum trennen lassen. ${ }^{24}$ Und in der Tat greift beides - wie bei einem oströmischen Dichter des frühen 7. Jahrhunderts ja auch gar nicht anders zu erwarten - bei ihm stets ineinander. Ob man Georgios tendenziell eher als Panegyriker (so etwa Theodor Nissen) oder als Theologen sehen möchte (so etwa Mary Whitby oder Irene Huber), ist daher letztlich eine akademische Frage aus moderner Perspektive. ${ }^{25}$

gandistische Tendenz seiner Epik“ als Charakteristikum hervor. Der „reiche mythologische Apparat“ diene vor allem „der Verherrlichung des gottgleichen Kaisers“. Weitestgehend positive Einschätzungen allerdings schon bei K. Krumbacher, Geschichte der byzantinischen Litteratur von Justinian bis zum Ende des Oströmischen Reiches (527-1453). Zweite Auflage bearbeitet unter Mitwirkung von A. Erhard/ H. Gelzer, München 1897, 709-712, vgl. bes. 709 (,der beste Profandichter der byzantinischen Zeit“); O. Bardenhewer, Geschichte der altkirchlichen Literatur, Bd. 5: Die letzte Periode der altkirchlichen Literatur mit Einschluß des ältesten armenischen Schrifttums, Darmstadt ${ }^{2} 2007$ (ursprünglich Freiburg 1932), $168-173$.

19 Etwa von Hunger (s. Anm. 8), II 167 („Mann des Übergangs“); Frendo (s. Anm. 17), 162; ders., Classical and Christian Influences in the Heracliad of George of Pisidia, The Classical Bulletin 62.4 (1986), 53-62, bes. 53; 61; P. Schreiner, G. Pisides, in: LexMa 4, München/Zürich 1989, 1287 f., hier 1288; Olster, Roman Defeat (s. Anm. 17), 51-71; Whitby, Presentation (s. Anm. 17), 173; dies., Persuasive Word (s. Anm. 17), 174; J. O. Rosenqvist, Die byzantinische Literatur. Vom 6. Jahrhundert bis zum Fall Konstantinopels 1453, Berlin/New York 2007, 23.

20 Vgl. bes. Howard-Johnston (s. Anm. 17), 26-31.

21 Beide Aspekte hebt Howard-Johnston (s. Anm. 17), 16-35, hervor.

22 Howard-Johnston (s. Anm. 17), 27; ähnlich ebd., 16.

23 Dieses Verständnis liegt z.B. noch der (unvollendet gebliebenen) Georgios-Edition Pertusis zugrunde, der sein Augenmerk zunächst auf die ,panegyrischen' Gedichte richtete (und zur Herausgabe der ,theologischen` nicht mehr kam), vgl. G. Pertusi, Giorgio di Pisidia. Poemi, I: Panegirici epici. Edizione critica, traduzione e commento, Ettal 1959, mit der Rez. von I. Dujčev, BZ 57 (1964), 412- 416. 24 S. etwa Frendo (s. Anm. 17), 179 ff.; Olster, Date (s. Anm. 17), 159; Whitby (s. Anm. 10), 201; dies., Devil (s. Anm. 17), 115; I. Huber, Ansichten eines Zivilisierten über die unzivilisierte Welt: Das Sāsāniden-Bild des Georgios Pisides und sein historischer Wert für den spätantiken Iran, Klio 90 (2008), 162-192, hier 165.

25 Nissen (s. Anm. 11); Whitby (s. Anm. 10), 218 („George is first a man of God, and only second an imperial panegyrist“); dies., Devil (s. Anm. 17), 116; Huber (s. Anm. 24), 166f. Ob und in welcher Weise 
Georgios, der wahrscheinlich dem pisidischen Antiocheia entstammte, ${ }^{26}$ befand sich - möglicherweise mit Unterbrechungen ${ }^{27}$ - im Umfeld des Herakleios (er nahm wahrscheinlich an dessen Perserfeldzug 622 teil), ${ }^{28}$ pflegte aber auch ein enges Nahverhältnis zum Patriarchen Sergios, in dessen Auftrag er häufig dichtete und in dessen Klerikerstab er tätig war: Als Diakon diente er an der Hagia Sophia in Konstantinopel, wo er verschiedene Ämter bekleidete (skeuophylax, referendarius, chartophylax). In die Hauptstadt war er spätestens um 610/11 gelangt; damals jedenfalls entstand sein frühestes bekanntes Gedicht, ein kurzer Lobgesang auf Herakleios und seinen Putsch gegen Phokas (In Heraclium ex Africa redeuntem), ${ }^{29}$ mit dem der Dichter sich offenbar um Patronage von höchster Stelle bemühte. ${ }^{30}$ Die enge Verbindung theologischer und politischer Inhalte in Georgios' Werken manifestiert sich dann bereits anschaulich in seinem neuerdings auf das Jahr 613 datierten ${ }^{31}$ Ostergedicht In Christi Resurrectionem, das Herakleios' Sohn auf Kämpfe gegen Awaren und Perser vorbereitet, aber auch in den aktuellen Diskussionen um die politische Funktion des umfangreichen, insgesamt beinahe 2000 Verse umfassenden Hexaemeron. ${ }^{32}$ Ein Gedicht Contra Severum (629?) ${ }^{33}$ sollte die kaiserliche Religionspolitik unterstützen, während das Bellum Avaricum im Auftrag des Sergios die Rettung des belagerten Konstantinopel durch die Gottesmutter im Jahr 626 überhöht. In denselben Kontext gehört der Panegyricus In Bonum Patricium, ein verzweifelter Hilferuf an den Kaiser, die von Awaren und Persern eingeschlossene Hauptstadt, in der Georgios sich damals selbst befand, nicht im Stich zu lassen (626). Herakleios' Erfolge wiederum werden (wohl 623) in der Expeditio Persica (über den Feldzug 622) und insbesondere der Heraclias (entstanden nach dem 10. Mai 628) gepriesen - letzteres ein unvollendeter (ursprünglich wohl drei Gesänge umfassender) Abriss der größten Leistungen des Herakleios, den Georgios nach dem Triumph über die Perser verfasste - derselbe Ereigniszusammenhang bildet auch den Hintergrund der Dichtung In Restitutionem

man die angebliche Selbstcharakterisierung, die Georg. Pisid. Sev.695-699 gibt, ernst nehmen darf, ist noch völlig ungeklärt.

26 Whitby (s. Anm. 10), 201, mit Anm. 18.

27 Howard-Johnston (s. Anm. 17), 31-34, vermutet neuerdings, dass Georgios nach der Abfassung der Expeditio Persica (623) temporär (bis 629) die Gunst des Kaisers verloren habe (aufgrund einer unglücklichen Formulierung, die man als Anspielung auf Herakleios' Inzestehe mit dessen Nichte Martina habe interpretieren können).

28 Diese Vermutung basiert auf Georg. Pisid. Exped. Pers. 2,122-126; 3,131-136.

29 Zur Datierung: Frendo (s. Anm. 17), 167-171, mit ausführlicher Widerlegung des mittlerweile allgemein abgelehnten Datierungsvorschlags von Pertusi (s. Anm. 23), 18f. (619/20); Whitby (s. Anm. 10), 200; dies., Presentation (s. Anm. 17), 159; zuletzt Howard-Johnston (s. Anm. 17), 17.

30 Howard-Johnston (s. Anm. 17), 17.

31 So Howard-Johnston (s. Anm. 17), $18 \mathrm{f}$.

32 Dazu s. bes. Olster, Date (s. Anm. 17), der die politischen Implikationen zum Argument für einen neuen, späteren Datierungsvorschlag (638) macht, sowie die Replik von Whitby, Devil (s. Anm. 17). Das Hexaemeron dürfte über einen langen Zeitraum hin entstanden sein; seine Vollendung wird um 630 angesetzt.

33 So die Datierung durch Howard-Johnston (s. Anm. 17), 23. 
S. Crucis über die Rückführung der von den Persern 614 aus Jerusalem verschleppten Kreuzreliquien im Jahr 630. Reflexionen über das irdische Leben stellen schließlich die späten Dichtungen De vanitate vitae und De vita humana dar. Als letztes Erzeugnis gilt eine Prosavita des persischen christlichen Märtyrers Anastasios († 628) aus dem Jahr 632; ${ }^{34}$ kurz danach dürfte Georgios Pisides verstorben sein, jedenfalls deutet nichts darauf hin, dass er den Beginn der arabischen Expansion noch erlebt hätte. ${ }^{35}$ Seine insgesamt 115 überlieferten Epigramme entstanden wahrscheinlich als Parerga über die Jahre hin. Weitere Dichtungen lassen sich erschließen, sind aber nicht mehr erhalten $^{36}$ - so etwa eine Darstellung der frühen Regierungsjahre des Herakleios, ein Werk über die römischen Gegenoffensiven im Perserkrieg 624-626 und 627/28 oder auch die immerhin noch in einigen substanziellen Fragmenten greifbare dritte Akroasis der Heraclias. ${ }^{37}$

Als historische Quellen sind Georgios’ Dichtungen zwar von unschätzbarem Wert (insofern sie vielfach singuläre Informationen bieten), jedoch ausgesprochen schwer $\mathrm{zu}$ handhaben. ${ }^{38}$ Denn auch in den vermeintlich historisch-epischen Darstellungen wie der Expeditio Persica oder dem Bellum Avaricum gibt der Dichter keine zusammenhängenden Beschreibungen, sondern verfährt vielmehr impressionistisch, greift Einzelepisoden heraus, an denen bestimmte Leistungen und Eigenschaften der Protagonisten (zumeist des Kaisers) vorgeführt werden, und erschwert damit die Rekonstruktion von Ereigniszusammenhängen. Seine Dichtungen sind daher eher als Zeugnisse für die Repräsentation und Darstellung des Kaisers von Bedeutung, für die kaiserliche imago und für Erwartungen, mit denen der Herrscher konfrontiert wurde, aber auch für Hoffnungen und ,Stimmungen', die - etwa nach dem Sieg über die Sāsāniden 628 - offenbar gezielt gefördert wurden. Dabei bedient sich Georgios, den wir uns hochgebildet und mit der antiken Literatur wohlvertraut vorstellen müssen, eines relativ begrenzten Pools an literarischen Techniken und Motiven, die in der Forschung der letzten beiden Jahrzehnte aufgearbeitet worden sind. ${ }^{39} \mathrm{Zu}$ ihnen zählt die Synkrisis, d.h. die vergleichende Gegenüberstellung eines Protagonisten mit anderen Gestalten. ${ }^{40}$ Georgios wählt dabei eher selten Personen, die man im modernen

34 Edition und französische Übersetzung: B. Flusin, Saint Anastase le Perse et l'histoire de la Palestine au début du VII ${ }^{\mathrm{e}}$ siècle, Tome I: Les textes, Paris 1992, 202-259.

35 Vgl. Howard-Johnston (s. Anm. 17), $26 \mathrm{f}$.

36 Vgl. Pertusi (s. Anm. 23), 17-31; Howard-Johnston (s. Anm. 17), 25.

37 Die Frage, ob sich über die bei Theophanes und in der Suda identifizierbaren Georgios-Fragmente eine dritte Akroasis der Heraclias erschließen lässt, ist umstritten; einen Überblick über die Diskussionslage bietet Whitby, Presentation (s. Anm. 17), 168-172.

$38 \mathrm{Zu}$ den Möglichkeiten und Grenzen einer historischen Auswertung des Georgios Pisides s. HowardJohnston (s. Anm. 17), $30 \mathrm{f}$.

39 Vgl. dazu bes. Whitby, Presentation (s. Anm. 17), 157 f.; Howard-Johnston (s. Anm. 17), 21.

40 Nissen (s. Anm. 11), 301 ff.; Whitby (s. Anm. 10), 205. Eine kurze Definition der Synkrisis mit Blick auf die spätantike Literatur bietet C. Rapp, Comparison, Paradigm and the Case of Moses in Panegyric and Hagiography, in: Ma. Whitby (Hg.), The Propaganda of Power. The Role of Panegyric in Late Antiquity, Leiden/Boston/Köln 1998, 277-298, hier 279. 
Sinne als historisch bezeichnen würde: Homer, Demosthenes, Plutarch, Scipio, Alexander, Timotheos von Athen, Xerxes oder auch Konstantin I. ${ }^{41}$ Er schöpft vielmehr hauptsächlich aus einem üppigen Reservoir biblischer und mythischer Helden, wobei er kategorial kaum zwischen ihnen differenziert und keine Probleme damit hat, Personen aus dem Alten Testament Gestalten aus dem klassischen Mythos an die Seite zu stellen. ${ }^{42}$ Unter letzteren spielt die Figur des Herakles, wie bereits angedeutet, eine zentrale Rolle. ${ }^{43}$

\section{2.}

Mary Whitby glaubte die zentralen Funktionen der Herakles-Bezüge bei Georgios Pisides erfasst zu haben, als sie 1994 konstatierte: „It presents Heraclius as saviour and redeemer, justifying the violent overthrow of Phocas as the elimination of a bestial and corrupt force, and the wars against Persia as a crusade against an evil power with an alien religion. The Heracles image is ideal for the purpose because it stresses the violent, brutish and sub-human qualities of the opposition, and because Heracles is the great civilizing hero of classical mythology. “44

Begibt man sich daran, die einschlägigen Textbelege zu sichten, lässt sich diese Bewertung zunächst einmal bestätigen: So geht etwa aus einer insgesamt recht kryptischen Passage der Expeditio Persica zumindest so viel hervor, dass Herakles (= Herakleios) die Hydra besiegte (= Sieg über Chosroes), ohne sie jedoch bereits vernichtet zu haben - der Kontext (Herakleios’ Perserfeldzug 622) erscheint religiös aufgeladen, denn Georgios spricht von einem „vielköpfigen Irrtum“ der Hydra ( $\dot{\eta}$

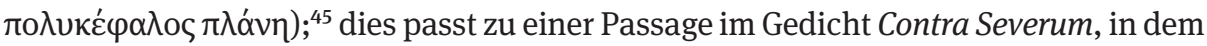
der Pisidier die zahlreichen Nacken (= Gruppierungen) der acephali (d.h. der Miaphysiten) beklagt, sie mit den Köpfen der Hydra vergleicht und seine Hoffnungen in

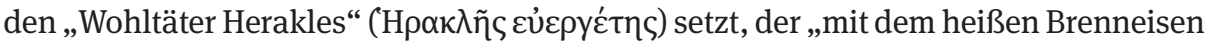

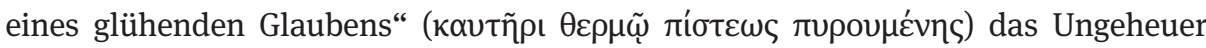

41 Vgl. Whitby (s. Anm. 10), 205, mit den Belegen.

42 Im Einzelnen s. dazu Whitby (s. Anm. 10), 206 ff., mit Diskussion der wichtigsten Exempla.

43 In diesem Sinne bereits Whitby (s. Anm. 10), 206: „The image recurs in almost all of George’s political poems, but it is used with remarkable versatility and variation.“

44 Whitby (s. Anm. 10), 208.

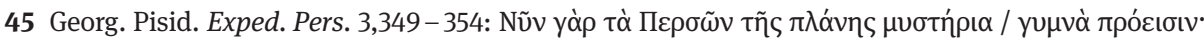

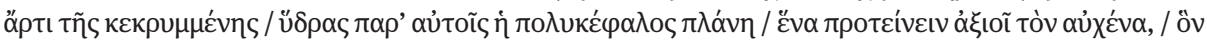

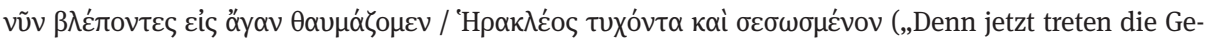
heimnisse des Irrtums [Irrglaubens?] der Perser enthüllt hervor; seit kurzer Zeit erachtet es der vielköpfige Irrtum der Hydra, die verborgen war, bei ihnen für recht, einen einzigen Nacken hervorzustrecken; und da wir diesen nun sehen, wundern wir uns außerordentlich, dass er mit Herakles zusammentreffen und sich dabei retten konnte“). Dazu s. den Kommentar von Pertusi (s. Anm. 23), $160 \mathrm{f}$. In den anschließenden Versen (355-359) äußert der Dichter die Hoffnung, dass es Herakleios in

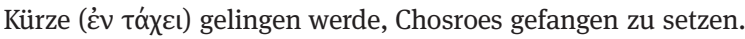


vernichte. ${ }^{46}$ Einmal mehr wird der Kampf gegen die Hydra dann im Bellum Avaricum apostrophiert, wobei das Ringen gegen ihre stets nachwachsenden Häupter hier wohl für die Beseitigung der durch das Missregiment des Phokas entstandenen Schäden und

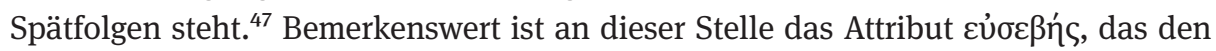
mythischen Helden mit einer zentralen Kaisertugend ausstattet, so dass in der For-

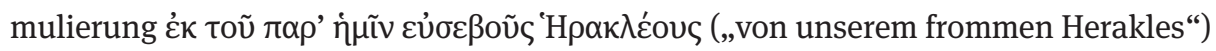
die Distanz zwischen Mythos und aktuellem Geschehen gänzlich aufgehoben erscheint: Herakles und Herakleios verschmelzen gleichsam zu einer überzeitlichen Entität. Dieselbe literarische Technik der Verkürzung wendet der Dichter an, wenn er in

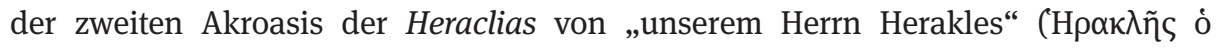

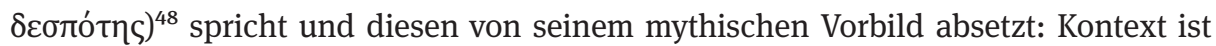

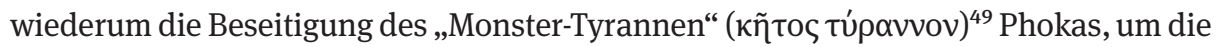
herum Georgios ein komplexes Netz aus Anspielungen webt, das Elemente des Perseus- und des Herakles-Mythos miteinander verbindet, ${ }^{50}$ um schließlich gegenüber den mythischen Exempla die universale Dimension der Aktionen des Kaisers zu betonen. ${ }^{51}$

Auf den ersten Blick bewegt sich Georgios mit Passagen wie den beschriebenen ganz im Rahmen traditioneller Mythenrezeption in der spätantiken Panegyrik. ${ }^{52}$ Whitbys Schlussfolgerung, dass Herakles vor allem als „saviour and redeemer“ präsentiert werde und dabei von seinem Kapital als großer Zivilisationsbringer lebe, ist insofern grundsätzlich zuzustimmen. Allerdings hat Whitby ebenfalls darauf hingewiesen, dass Georgios in der Art, wie er mit mythischen Exempla umgeht, eine erstaunlich große, jeweils kontextabhängige Variationsbreite erkennen lässt. ${ }^{53}$ Man denke dabei nur an die verschiedenen Konnotationen, mit denen er die Hydra zu verbinden vermag. Die Variatio kann dabei immerhin so weit gehen, dass etwa in dem Ostergedicht In Christi Resurrectionem gar der Sohn des Kaisers, Herakleios Konstantinos, auf Herakles' Kampf gegen die Hydra verwiesen wird (und zwar z.T. mit Versen, die nahezu identisch später in der Heraclias auf den Kaiser als Herakles bezogen werden). ${ }^{54}$ Generalisierungen werden damit schwierig; was sich für eine bestimmte Textpassage festhalten lässt, muss keineswegs auch für andere Stellen im Werk des Pisidiers gelten. Die von ihm entworfenen mythischen und biblischen Referenzen erweisen sich gewissermaßen als instabil, ja als fluide. Insofern lohnt es sich,

46 Georg. Pisid. Sev. 65-71.

47 Georg. Pisid. Bell. Avar. 49-57, mit Pertusi (s. Anm. 23), 211; Tartaglia (s. Anm. 17), 160, Anm. 9.

48 Georg. Pisid. Her. 2,21.

49 Georg. Pisid. Her. 2,22.

50 Georg. Pisid. Her. 2,12-23. Dazu s. H. Hunger, On the Imitation (MIMH $\mathrm{I} \Sigma$ ) of Antiquity in Byzantine Literature, DOP 23/24 (1969/70), 15-38, hier 24; Whitby (s. Anm. 10), 209.

51 Georg. Pisid. Her. 2,19-23.

52 So hatte insbesondere Nissen (s. Anm. 11), $301 \mathrm{ff}$., die Werke des Pisidiers beurteilt.

53 Whitby (s. Anm. 10), 208; dies., Devil (s. Anm. 17), 122.

54 Georg. Pisid. In Chr. Res. 106-111; Her. 1,78-79. Whitby, Devil (s. Anm. 17), 123; Howard-Johnston (s. Anm. 17), 19. 
genauer hinzusehen. Ich möchte im Folgenden einige Versgruppen zur Diskussion stellen, die über das Herakles-Exempel zwar ebenfalls Herakleios als Retter und Erlöser erscheinen lassen, dies jedoch in einer recht unkonventionellen Weise vermitteln - und die zugleich Implikationen beinhalten, die bisher noch nicht hinreichend beachtet worden sind.

Der mythische Held ist bereits in Georgios' frühestem Gedicht In Heraclium ex Africa redeuntem (610/11) präsent - ohne freilich namentlich genannt $\mathrm{zu}$ werden. Georgios Pisides stimmt ein Hohelied auf die geistig-spirituellen Fähigkeiten des Kaisers an und konfrontiert ihn dabei mit jenen, „denen nicht ein allweiser Verstand eingeprägt ist und die kein göttliches Wesen ziert“, nämlich den bewaffneten Reitern und treffsicheren Jägern. ${ }^{55}$ Die Herakles-Assoziation wird durch die Formulierung

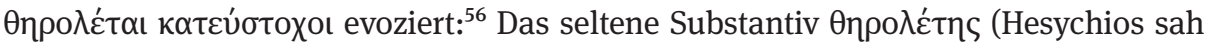

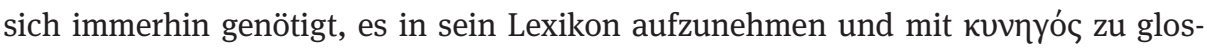
sieren) dient etwa auch in einem Epigramm der Anthologia Graeca zur Umschreibung

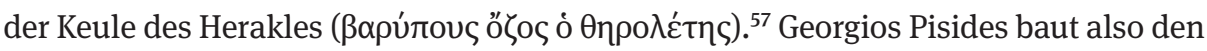
ungestümen „Monsterschlachter“ Herakles zum Gegenpol des besonnenen Kaisers auf (der ja auch gerade ein ,Monster‘, nämlich Phokas, geschlachtet hat, vgl.v. 39-62) und lässt ihn im Vergleich zu diesem zunächst einmal defizitär erscheinen; dies fällt jedoch nicht negativ auf den mythischen Helden zurück, denn niemand - nicht einmal ein Herakles - vermag eben die göttlichen Qualitäten eines Herakleios zu erreichen, wie der Dichter gleich eingangs konstatiert: „Ein Wort vermag dich nicht zu beschreiben, da ja das Wort Gottes selbst festgelegt hat, dass du über diese fließenden Worte gesetzt wurdest." 58

Das Motiv des Jagens wird auch im Folgenden weiterverfolgt - und damit die Herakles-Assoziation aufrecht erhalten: Der Kaiser setzt jeglicher Zornaufwallung wie wilden Tieren nach, jedoch aus einer Haltung der Milde heraus; ${ }^{59}$ er möchte die

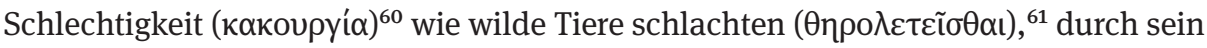

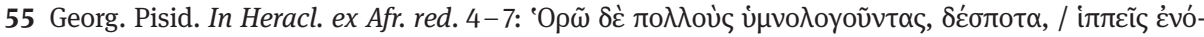

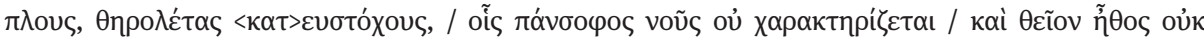

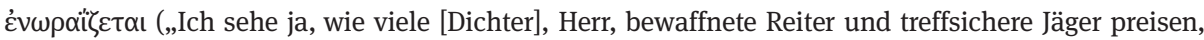

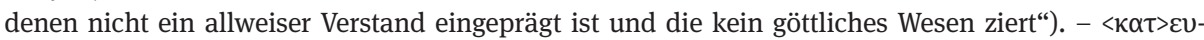
бтóxouৎ ist Konjektur Pertusis, vgl. dort den App. z. St.

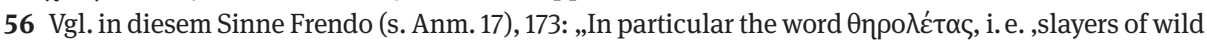
beasts or monsters' [...] suggests such heroes as Perseus and especially Heracles“; vgl. auch Whitby (s. Anm. 10), 211; dies., Presentation (s. Anm. 17), 160.

57 Anth. Graec. 16,104,4.

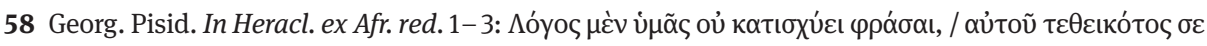

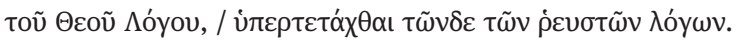

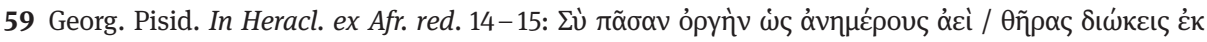

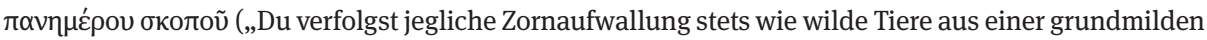
Haltung heraus").

60 Gemeint sein könnte Häresie im allgemeinen Sinne, vgl. Frendo (s. Anm. 17), 173 f.

61 Georg. Pisid. In Heracl. ex Afr. red. 16. 
Wesen werden Bestien gezähmt - konkret: die Perser und Barbaren (= Awaren) ${ }^{62}$ Die Grundaussage ist klar: Herakleios ist der bessere Herakles, und wie dieser spannt er seinen Bogen, aber aus dem Impetus der Philanthropia - also einer zentralen Kaisertugend - heraus. ${ }^{63}$

Ein längerer Abschnitt des Gedichts behandelt die Beseitigung des „Tyrannen“ Phokas durch Herakleios (v. 39-62). Insbesondere in diesen Versen wird die implizite Herakles-Herakleios-Analogie bemüht: Nicht nur, dass Phokas (mit apokalyptischem Subtext) als „herrschendes Tier“ bezeichnet und somit als Zielobjekt der Monsterjagd des Herakles-Herakleios gekennzeichnet wird; ${ }^{64}$ der Dichter rühmt den Kaiser überdies für seine bewusst getroffene Entscheidung, die Mühsal auf sich zu nehmen und den „Tyrannen“ zu beseitigen: „Du hättest die Gelegenheit gehabt, den Mühen ( $\pi$ óv $\omega v$ ) fernzubleiben, da du ja nicht schuld an unserem Unheil bist. “65 Das entsprechende Signalwort lautet róvor; es erscheint im Gedicht zweimal an prominenter Stelle (Versende) ${ }^{66}$ und verweist einmal mehr auf Herakles, dessen róvor in der Antike bekanntlich sprichwörtlich waren. ${ }^{67}$ Die Tatsache aber, dass die Entscheidung, den mühevollen Weg anzutreten, in derart deutlicher Weise als ein bewusster Akt hervorgehoben wird, deutet darüber hinaus auf die berühmte Erzählung von Herakles am Scheideweg als Referenzpunkt hin: ${ }^{68}$ Wie der mythische Held sah sich auch Herakleios vor die Wahl gestellt zwischen einem angenehmen, leichten Leben einerseits und einem Dasein voller Mühen - dieses aber achtbar und tugendhaft - andererseits. Und wie das mythische Vorbild wählte der Kaiser letzteres. ${ }^{69}$

Bereits in seinem ersten für uns greifbaren Gedicht arbeitet Georgios also mit dem Herakles-Exempel. Der mythische Held erscheint als implizite Vergleichsfolie für den Kaiser und dient dabei zu dessen Erhöhung. Herakles wird in seinen bekannten Rollen als Jäger wilder Monster sowie als vorbildlicher Held, der sich bewusst für ein tugendhaftes Leben voller Mühsal entscheidet, evoziert. In der erstgenannten Rolle besteht seine Funktion darin, die Vollkommenheit des Kaisers zu illustrieren: Dieser übertrifft sogar den archetypischen Heros schlechthin, weil er neben dessen ohnehin

62 Georg. Pisid. In Heracl. ex Afr. red.19-21. Die Verse enthalten eine subtile Anspielung auf Orpheus, der aber - wie Herakles - ebenfalls nicht namentlich genannt wird, vgl. Frendo (s. Anm. 17 ), 174.

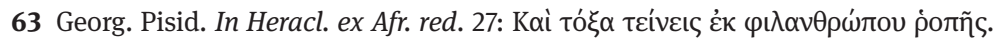

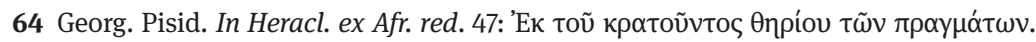

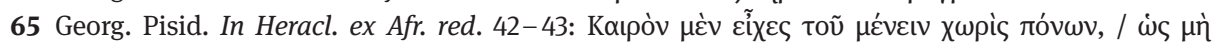

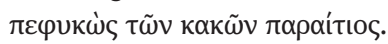

66 Georg. Pisid. In Heracl. ex Afr. red. 42; 48.

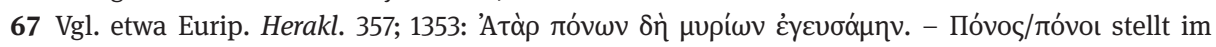
Schrifttum des Georgios eine bevorzugte Vokabel dar, für die sich - gerade im Bezug auf Herakleios zahlreiche Belege finden lassen. M.E. lässt sich daraus aber nicht folgern, dass der Terminus als Signalbegriff (u.a. mit Verweis auf Herakles) letztlich aussagelos sei; vielmehr könnte der Dichter auch die Intention verfolgt haben, das Herakles-Thema untergründig über weite Strecken hin präsent $\mathrm{zu}$ halten.

68 Prodikos D-K 84 B 2 = Xen. Mem. 2,1,21-34.

69 Georg. Pisid. In Heracl. ex Afr. red. 44-55. 
herausragenden Eigenschaften auch noch kluge Berechnung, Milde und Menschenfreundlichkeit mit einbringt. Der Rekurs auf die Geschichte von Herakles am Scheideweg hingegen konfrontiert uns einmal mehr mit überlegtem Handeln und verweist die Rezipienten darauf, dass Herakleios mit der Beseitigung des Phokas gezielt den Pfad der Tugend eingeschlagen hat. Was von Zeitgenossen auch als Verbrechen interpretiert werden konnte - nämlich ein Kaisermord -, gerät somit zur Urtat eines tugendhaften Helden als Folge seiner bewussten Entscheidung für das Gute.

Konsistent sind diese indirekten Rekurse auf die Herakles-Figur allerdings nicht, da der Held in unterschiedlicher Weise funktionalisiert wird: einmal als Kontrastfolie, ein anderes Mal als konkreter Anknüpfungspunkt mit Vorbildcharakter. Ohnehin ist anzunehmen, dass Georgios Pisides in dieser frühen Phase der Herrschaft des Herakleios - die um 610/11 auch noch keineswegs gesichert oder gar fest etabliert war ${ }^{70}$ zunächst einmal lediglich von der Namensassoziation Herakles-Herakleios ausgehen und dem Kaiser, dessen Patronage er ja ersstrebte, gewissermaßen Vorschläge bzw. Angebote machen konnte. Von einem bereits minutiös ausgearbeiteten ,Repräsentationsprogramm', das der Dichter in irgendeiner Weise aufgegriffen und reflektiert hätte, wird man für diesen frühen Zeitpunkt jedenfalls noch nicht ausgehen können.

Dies dürfte im Jahr 626, als der Pisidier aus dem belagerten Konstantinopel heraus einen eindringlichen Appell an den Kaiser verfasste, möglichst rasch vom Perserfeldzug in seine bedrohte Hauptstadt zurückzukehren, anders ausgesehen haben. Das zweigliedrige Gedicht In Bonum Patricium preist im ersten Teil (v. 1-48) die enge Verbindung zwischen Herakleios und seinem in Konstantinopel zurückgebliebenen Bevollmächtigten Bonos; ${ }^{71}$ der deutlich längere zweite Abschnitt (v. 49-170) enthält in immer neuen Variationen den pathetischen Rückkehr-Aufruf an Herakleios. Gleich im ersten Vers des Panegyricus wird das Herakles-Thema angesprochen, indem ein Vergleich zwischen der mythischen Vorzeit und dem aktuellen Augenblick gezogen

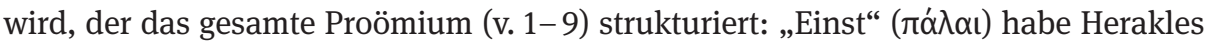
auf Befehl des Eurystheus eher geringe Aufgaben verrichten müssen; denn welchen Nutzen hätten die Tötung eines Ebers oder die Erdrosselung eines Löwen der Ge-

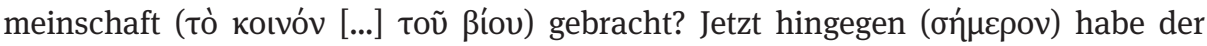

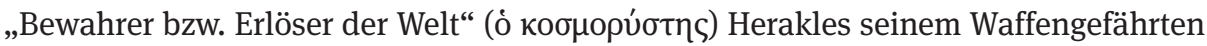
( $\tau \tilde{\omega}$ ouvó $\pi \lambda \omega)$ - dem im ersten Gedichtteil direkt angesprochenen Bonos - eine Welt in

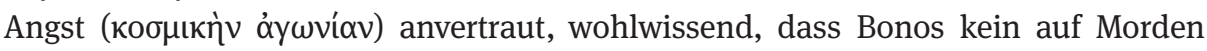

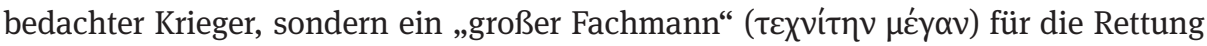

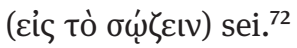

70 Vgl. W. E. Kaegi, New Evidence on the Early Reign of Heraclius, BZ 66 (1973), 308-330; ders., Heraclius. Emperor of Byzantium, Cambridge 2003, $58 \mathrm{ff}$;; D. M. Olster, The Politics of Usurpation in the Seventh Century: Rhetoric and Revolution in Byzantium, Amsterdam 1993, 18-21.

71 PLRE IIIA 242-244 (Bonus 5).

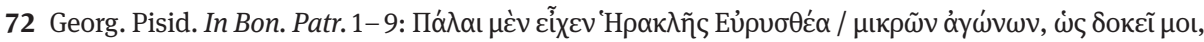

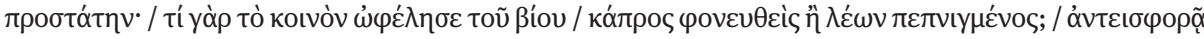

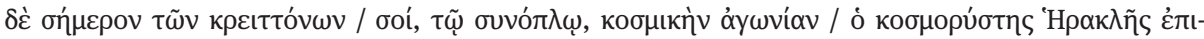


Zwei Punkte sind an diesem Proömium auffällig: Zum einen wird nun explizit die Gleichsetzung Herakles-Herakleios vollzogen; letzterer wird sogar ausdrücklich Herakles genannt (v. 7). Zum anderen erscheinen die róvoı (der Terminus wird im weiteren Verlauf des Gedichtes noch mehrfach fallen $)^{73}$ des mythischen Helden geradezu lächerlich im Vergleich mit jenen des Kaisers und seines Beauftragten - und dies nicht nur wegen der kosmischen Dimensionen, in denen Herakleios zu agieren hat (vgl. die

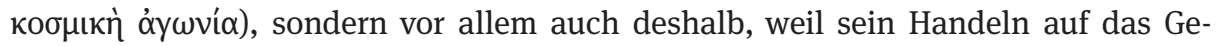
meinwesen bezogen ist und dabei nicht auf den Krieg als solchen, sondern auf die

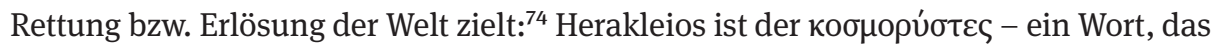
wohl von Georgios Pisides geprägt wurde (jedenfalls konnte ich keinen älteren literarischen Beleg ausmachen $)^{75}$ und dessen Semantik das im Neuen Testament ver-

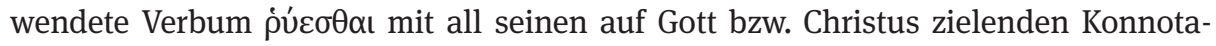
tionen evoziert. ${ }^{76}$ Angesichts dieser subtilen Überhöhung des Kaisers (durch die gezielte Herabsetzung des mythischen Herakles, der in der Antike selbstverständlich als Inbegriff des Zivilisationsbringers galt) ${ }^{77}$ lässt der Umstand aufhorchen, dass die auf das Proömium folgenden, die innige Verbindung zwischen Herakleios und Bonos preisenden Verse (v. 10 -48) Elemente zeitgenössischer theologischer Diskurse auf-

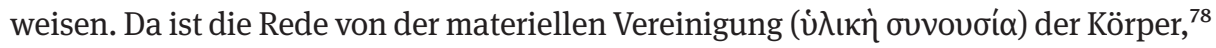
vom Fleisch, ${ }^{79}$ von der Henosis ${ }^{80}$ und vom Pneuma. ${ }^{81}$ Sachlich zielt der Dichter auf die Aussage, dass sich aufgrund des engen Nahverhältnisses zwischen dem Kaiser und seinem Vertrauten ( $\varepsilon \omega \omega !)^{82}$ letztlich eine einzige Seele in beiden Körpern befinde

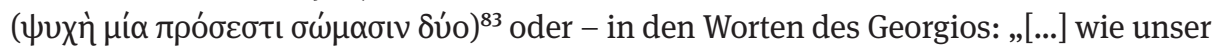

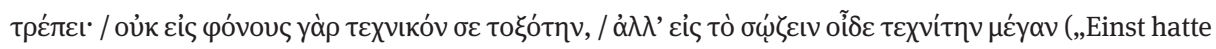
Herakles in Eurystheus einen Auftraggeber für geringe Aufgaben, wie mir scheint; denn was nutzte der menschlichen Gemeinschaft ein getöteter Eber oder ein erwürgter Löwe? Heute jedoch vertraut im Austausch für Größeres der Weltenerlöser Herakles Dir, seinem Waffengefährten, eine in Angst befindliche Welt an; denn er weiß, dass Du kein bogenbewehrter Krieger bist, der sich aufs Morden versteht, sondern ein großer Fachmann für die Rettung“).

73 Vgl. Georg. Pisid. In Bon. Patr. 14; 19; 57; 90; 91; 100; 101; 114; 115.

74 Vgl. Whitby (s. Anm. 10), $206 \mathrm{f}$.

75 Vgl. auch Olster, Roman Defeat (s. Anm. 17), 61; Tartaglia (s. Anm. 17), 199, Anm. 19.

76 Vgl. bes. 1 Thess 1,10; daneben etwa auch Mt 6,13; 27,43; Lk 1,74; Röm 7,24; 11,26; 15,31; 2 Kor 1,10; Kol 1,13; 2 Thess 3,2; 2 Tim 3,11; 4,17-18; 2 Petr 2,7; 2,9. Zur Beleglage s. W. Bauer, Griechisch-deutsches Wörterbuch zu den Schriften des Neuen Testaments und der frühchristlichen Literatur. 6., völlig neu bearbeitete Auflage hg. von K. Aland/B. Aland, Berlin/New York 1988, $1476 \mathrm{f}$.

77 Vgl. J. Trilling, Myth and Metaphor at the Byzantine Court. A Literary Approach to the David Plates, Byz 78 (1978), 249-263, hier 260.

78 Georg. Pisid. In Bon. Patr. 21; vgl. 26; 37.

79 Georg. Pisid. In Bon. Patr. 22.

80 Georg. Pisid. In Bon. Patr. 23.

81 Georg. Pisid. In Bon. Patr. 24.

82 Georg. Pisid. In Bon. Patr. 36.

83 Georg. Pisid. In Bon. Patr. 27. 
Herr [sc. der Kaiser] in dir [sc. Bonos] ist, auch wenn er weit entfernt zu sein scheint“ (

Mit dieser Feststellung gerät der gesamte zweite Teil des Gedichts letztlich zur Makulatur; denn der Appell, der Kaiser möge doch zurückkehren, ist überhaupt nicht erforderlich, da dieser ja in der Gestalt des Bonos bereits anwesend ist. Doch trotz seiner Präsenz, die zuvor mittels eines christologischen Vokabulars dargelegt wurde, ist er nicht sichtbar. Der Herr steht seinen Untertanen bei, aber man wünschte ihn sich unmittelbar fassbar. Geht es da noch um Herakleios? Geht es um Christus? Im Fol-

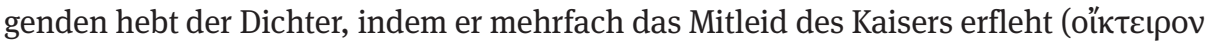
$\dot{\eta} \mu \tilde{\alpha} \varsigma),{ }^{85}$ auf die vergangenen Sünden der Konstantinopolitaner $a b^{86}$ und verweist darauf, dass Herakleios stets für alle die Mühen auf sich nehme: ${ }^{87}$ „Denn immer hast du dich für uns den Mühen unterworfen, da du für alle unsere Schwächen ertragen hast.“88 Ziel seines Wirkens ist nicht weniger als die „Rettung/Erlösung der Welt“

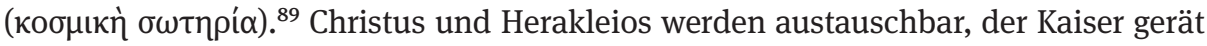
zum „Retter bzw. Erlöser der Welt“ - zum kosmorhýstes.

Diese Vorstellung - ganz unabhängig von der Frage, in welchem Maße sie vom Kaiser selbst forciert oder an ihn herangetragen wurde oder sich im kommunikativen Wechselspiel entwickelte - konnte im 7. Jahrhundert noch nicht vollkommen unverblümt artikuliert werden. Zwar sind die Andeutungen und Allusionen durchaus eindeutig, aber den letzten Schritt ist der Dichter dennoch nicht gegangen. ${ }^{90}$ Der kaiserliche, christusgleiche Weltenerlöser konnte nur in leichter Brechung als solcher erscheinen (auch wenn der Pisidier seine erhoffte Rückkehr offen als $\pi \alpha \rho o v \sigma i ́ \alpha$ bezeichnen konnte). ${ }^{91}$ Aus diesem Grunde dürfte Georgios zu Beginn des Panegyricus das

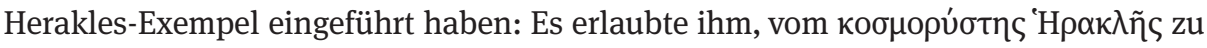
sprechen und den Namen des tatsächlich Gemeinten dabei vornehm zu verklausulieren, obwohl jeder Zuhörer wissen musste, um wen es ging. Der Bezug auf den Helden aus grauer Vorzeit garantierte das letzte noch verbliebene Moment an Distanz - jedenfalls vordergründig; auf einer subtileren Ebene hingegen hob er sie wieder auf und fundierte sogar die Herakleios-Christus-Analogie. Darauf ist noch zurückzukommen.

In der allgemeinen Jubelstimmung nach dem Eintreffen der Nachricht vom Tod des Perserkönigs Chosroes II. entstand in Konstantinopel seit 628 die Heraclias. Der Dichter verleiht zu Beginn des Epos dem Hochgefühl der Byzantiner beredten Aus-

84 Georg. Pisid. In Bon. Patr. 47-48.

85 Georg. Pisid. In Bon. Patr. 56; 60. Vgl. Röm 9,15.

86 Georg. Pisid. In Bon. Patr. 60 - 75.

87 Georg. Pisid. In Bon. Patr. 84-110.

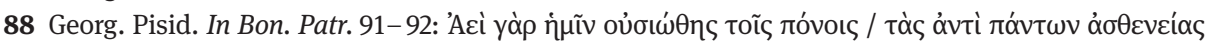
$\beta \alpha \sigma \tau \alpha ́ \alpha \alpha \varsigma$.

89 Georg. Pisid. In Bon. Patr. 123.

90 Vgl. in diesem Sinne auch Whitby (s. Anm. 10), 214, zu den Kaiser-Christus-Parallelen bei Georgios: „George stops short of explicit analogy between Heraclius and Christ, but only just.“

91 Georg. Pisid. In Bon. Patr. 121; vgl. Exped. Pers. 3,314. 
druck, indem er den Tod des „Feuerverehrers“ ( sich selbst für einen Gott gehalten habe, ${ }^{93}$ in Hybris verfallen sei (Georgios greift hier auf die Exempla Belsazars und des Xerxes zurück) ${ }^{94}$ und mit unbeschreiblicher Grausamkeit gewütet habe. ${ }^{95}$ Jetzt aber könnten der gesamte Kosmos, alle Elemente, aufatmen: „Doch Himmel, Erde, Feuer, Wasser, Luft und Wolken, ja der ganze Kosmos der überirdischen und unterirdischen Dinge applaudiert mit uns angesichts der Ratschlüsse Gottes, da einer gefallen ist und alle gerettet wurden."96

Mit dieser Einleitung verleiht der Dichter dem Folgenden einen kosmisch-religiösen Rahmen, ${ }^{97}$ innerhalb dessen auch der Vergleich zwischen Herakles und dem Kaiser zu deuten ist, der sich unmittelbar an den Triumphgesang ob des Todes des

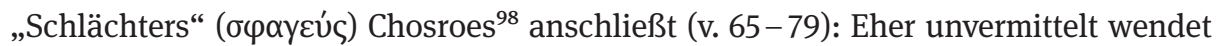
sich der Dichter nun direkt an Homer und attackiert ihn, weil er Herakles ohne Bedacht

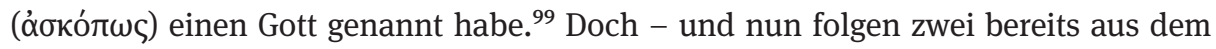
Panegyricus auf Bonos bekannte Verse - welchen Nutzen hätten die Tötung eines

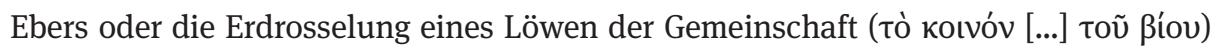
gebracht? ${ }^{100}$ Implizit folgt aus dieser Frage, dass nur ein Herakles, der auch dieser speziellen Anforderung - d.h. Nutzen für die Gemeinschaft zu erbringen - gerecht wird, mit gutem Grund als Gott erscheinen mag. Und tatsächlich fordert Georgios nun,

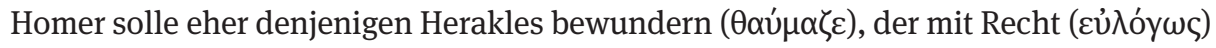
kosmorhýstes heiße. ${ }^{101}$ Einmal mehr wird hier der Kaiser mit der terminologischen Neuprägung, die ihn in die Nähe zu Christus rückt, beschrieben, wobei die Kombi-

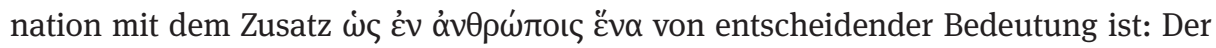

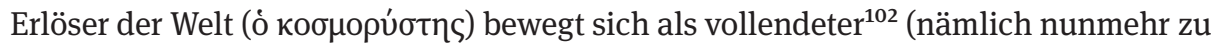
Recht als Gott zu bezeichnender) Herakles unter den Menschen. Die Christus-Analogie ist hier offenkundig, und einmal mehr wird sie durch den Herakles-Bezug leicht verklausuliert, zugleich aber auch indirekt bestätigt. Denn Herakles lebte ebenfalls als

92 Georg. Pisid. Her. 1,14; vgl. 1,181. Huber (s. Anm. 24), 127.

93 Georg. Pisid. Her. 1,22-23, mit Pertusi (s. Anm. 23), 263; Huber (s. Anm. 24), 179.

94 Georg. Pisid. Her. 1,31-35 (Belsazar; vgl. Tartaglia [s. Anm. 17], 197, Anm. 11); 1,27- 30 (Xerxes; vgl. Exped. Pers. 2,303-305).

95 Georg. Pisid. Her. 1,36-48; Huber (s. Anm. 24), $178 \mathrm{f}$.

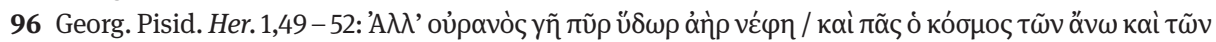

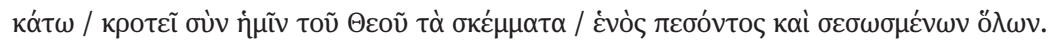

97 Vgl. Hunger (s. Anm. 50), 24, der von einem „Kreuzzug“ („crusade“) spricht.

98 Georg. Pisid. Her. 1,64.

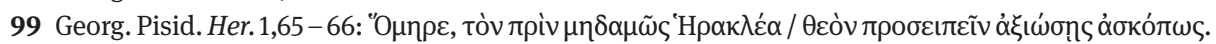
Der Vorwurf beruht wohl auf einem Missverständnis von Odysseus’ Begegnung mit Herakles in der Nekyia der Odyssee (Od. 11,601-603).

100 Georg. Pisid. Her. 1,67-68 = In Bon. Patr. 3-4.

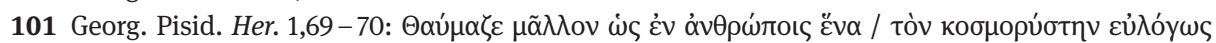

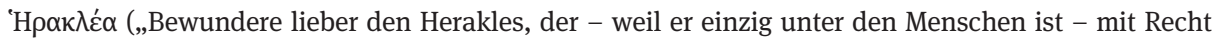
Erlöser der Welt [genannt wird]“).

102 Vgl. pointiert Trilling (s. Anm. 77), 260: „Heraclius is not only compared to Herakles, he is Herakles. In fact he is even more Herakles than Herakles himself.“ 
Sohn Gottes und einer Sterblichen unter den Menschen. In den folgenden Versen werden einige seiner mythischen Großtaten auf Herakleios hin gedeutet (ein in der Panegyrik geläufiges Verfahren). ${ }^{103}$ Georgios nennt exemplarisch Herakles’ Abstieg in den Hades (= Herakleios' Vordringen ins Perserreich), ${ }^{104}$ die Bezwingung des Kerberos (= Chosroes), ${ }^{105}$ die Wiedererweckung der Alkestis (= Wiederherstellung der christlichen Oikoumene), ${ }^{106}$ die Tötung des Drachen (der die Äpfel der Hesperiden bewachte = Chosroes), ${ }^{107}$ die Vernichtung der Hydra (= Chosroes), ${ }^{108}$ die Reinigung des Augiasstalles (= Wiederherstellung einer ehrbaren Lebensführung? ${ }^{109}$ und die Erdrosselung des Nemeischen Löwen (= Chosroes). ${ }^{110}$ „Und nun“, so der Dichter weiter, ,ist Herakles in seinem Werk fortgeschritten, da er sich die Goldenen Äpfel nahm - alle Städte [sc. die zuvor von den Persern besetzt gewesen waren]““.111

Bemerkenswert sind indes die nun folgenden Verse: „Es verzog sich die Quelle des finsteren Abends, Licht verbreitete sich und die Finsternis verschwand“ - wir befinden uns plötzlich mitten im Schöpfungsbericht (vgl. Gen 1,4-5) - und weiter: „Und ein

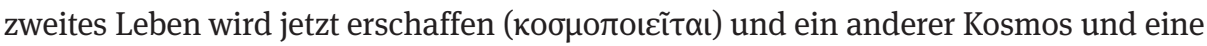
erneuerte Schöpfung (кті́бıৎ).“112 Die von Georgios geknüpfte Assoziationskette ist

103 Georg. Pisid. Her. 1,71-79, mit Nissen (s. Anm. 11), 302f. Die Kriterien für die von Georgios getroffene Auswahl erschließen sich nicht unmittelbar, und bei einigen Beispielen lässt sich die Frage, in welcher Weise sie auf Herakleios hin zu deuten sind, nicht mit letzter Sicherheit beantworten. Whitby (s. Anm. 10), 207, Anm. 55, warnt daher zu Recht davor, „to press the historical allusions of specific labours“ - auch deshalb, weil Georgios sie z.T. in anderen Kontexten auch anders verwendet. Ich richte mich im Folgenden nach den Deutungen, die Tartaglia (s. Anm. 17), 199, Anm. 20 - 21, vorschlägt.

104 Georg. Pisid. Her. 1,71; vgl. Apollod. Bibl. 2,122-126.

105 Georg. Pisid. Her. 1,72; vgl. Apollod. Bibl. 2,125-126.

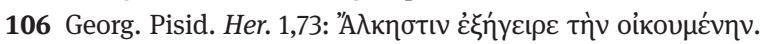

107 Georg. Pisid. Her. 1,74; vgl. Apollod. Bibl. 2,113; 121. Ob der Dichter tatsächlich alle von Herakles besiegten Ungeheuer einzig auf Chosroes gedeutet wissen wollte, erscheint mir zumindest unsicher (auch wenn der Kontext der ersten Akroasis der Heraclias dies nahelegt). M.E. wäre mitunter durchaus auch an den gestürzten „Tyrannen“ Phokas zu denken. So bezeichnet der Dichter etwa nicht nur

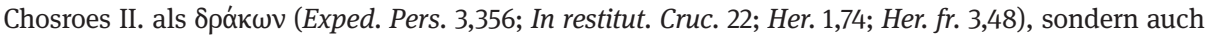
seinen Vorgänger (Bell. Avar. 50). Huber (s. Anm. 24), 179f., versteht indes sämtliche bei Georg. Pisid. Her. 1,71-79 genannten Monster als Anspielungen auf Chosroes.

108 Georg. Pisid. Her. 1,75; vgl. Apollod. Bibl. 2,77-80.

109 Georg. Pisid. Her. 1,76; vgl. Apollod. Bibl. 2,88-91.

110 Georg. Pisid. Her. 1,77; vgl. Apollod. Bibl. 2,74-75. Georgios bezeichnet Chosroes hier als ,Zerstörer

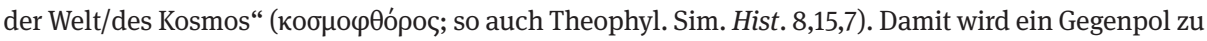

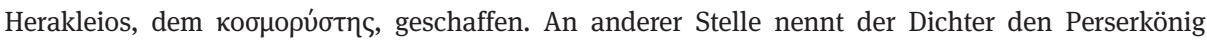

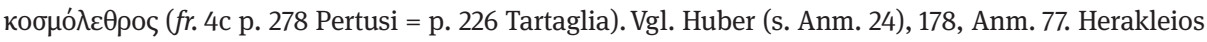

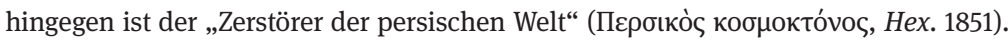

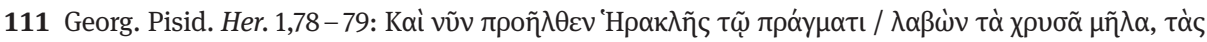

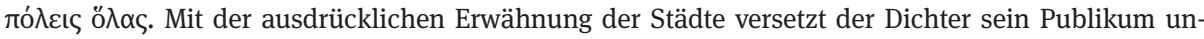
vermittelt wieder in die aktuelle Situation und macht dabei deutlich, dass er die zuvor genannten Taten des Herakles tatsächlich auf zeitgenössische Vorgänge bezogen wissen wollte.

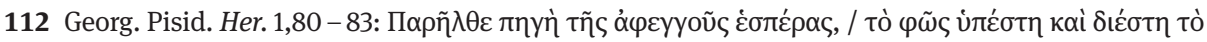

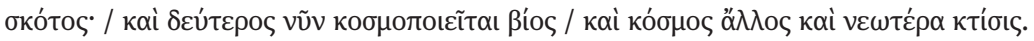


damit bei der Sintflut angelangt. Folgerichtig erscheint Herakleios in den folgenden

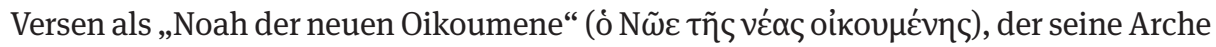
in seinem Herzen gefunden habe, ${ }^{113}$ wohingegen Chosroes mit der Sintflut identifiziert wird. ${ }^{114}$ Mit deutlichen Bezügen auf den biblischen Sintflutbericht betont der Pisidier einmal mehr die Verdorbenheit und Sündhaftigkeit der Menschen - bis Herakleios-

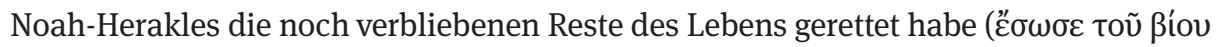
$\tau \dot{\alpha} \lambda \varepsilon^{\prime}(\psi \alpha v \alpha) .{ }^{115}$

Georgios Pisides arbeitet - dies sollte deutlich geworden sein - vielfach mit recht freien Assoziationsketten, die nicht immer modernen Ansprüchen an präzise Textstrukturierung genügen. Es geht dem Dichter indes auch weniger darum, unbedingt über längere Partien hin die Kohärenz seiner Vergleiche und Analogien aufrecht zu erhalten, sondern sein Vorgehen ist eher als impressionistisch anzusehen: Er entwirft Bilder, die wiederum spezifische Assoziationen evozieren, mit denen dann weiter gearbeitet wird. So dürfte der abrupte Übergang von Herakles zu Noah und der Sintflut ${ }^{116}$ wahrscheinlich nur beim modernen Rezipienten Verwunderung auslösen, der gewohnt ist, zwischen biblischen und mythischen Figuren zu differenzieren; ${ }^{117}$ in Byzanz machte die Kombination mythischer und biblischer Beispiele dagegen sogar Schule. ${ }^{118}$ Innerhalb des Gesamtzusammenhangs der ersten Akroasis der Heraclias steht jedoch zunächst einmal der Triumph über die Niederringung des Sāsānidenreiches im Vordergrund, der ganz auf den Kaiser zentriert und entsprechend ausgestaltet wird. Vor einem in höchstem Maße religiös aufgeladenen Hintergrund wird Herakleios dabei in zweifacher Weise präsentiert: Als Retter bzw. Erlöser der Welt (durch Auslöschung des gefährlichsten auswärtigen Gegners) erscheint er in der Rolle eines neuen, sich unter den Menschen bewegenden Gottes, des vollendeten Herakles. Als Neugestalter der Oikoumene hingegen, als Initiator einer erneuerten Schöpfung, die aufgrund menschlicher Sündhaftigkeit erforderlich wurde, zeigt er sich als „Noah der neuen Oikoumene“. Das dabei entstehende Amalgam aus mythischen und christlichen Bezügen zielt jedoch insgesamt vor allem auf eines: Die HerakleiosChristus-Analogie. Denn nicht nur der kosmorhýstes Herakles barg entsprechende Implikationen; auch Noah wurde typologisch auf Christus hin gedeutet. ${ }^{119}$ Sowohl der Herakles-Rekurs als auch das Noah-Exempel bewirken damit denselben Effekt.

Die Herakles-Bezüge im Panegyricus auf Bonos und im ersten Gesang der Heraclias spielen also mit der Herakleios-Christus-Parallele, indem sie einerseits auf diese hindeuten, sie andererseits aber auch leicht verschleiern. Dass es sich dabei

113 Georg. Pisid. Her. 1,84-85.

114 Georg. Pisid. Her. 1,88.

115 Georg. Pisid. Her. 1,89-92; vgl. Gen 6,12; 6,17; 7,1-24; 8,11.

116 Das Herakles-Motiv klingt allerdings später (Georg. Pisid. Her. 1,94) noch einmal an, wenn der Dichter erneut die róvos erwähnt.

117 Trilling (s. Anm. 77), 260; Whitby (s. Anm. 10), 212.

118 Hunger (s. Anm. 50), $23 \mathrm{f}$.

119 Vgl. etwa Origen. Hom. in Gen. 2,3; Joh. Chrysost. De Lazaro Conc. VI PG 48,1037. 
keineswegs um singuläre Ausnahmefälle im Werk des Pisidiers handelt, wird deutlich, wenn man die bereits angesprochene Passage aus der Expeditio Persica genauer betrachtet und vor allem ihren Kontext mit berücksichtigt: Dem Hinweis auf den Sieg des Herakles-Herakleios gegen die irrgläubige Hydra Chosroes geht eine Passage voraus, in welcher der Kaiser sich aufgrund der awarischen Bedrohung gezwungen sieht, von der Perserfront nach Konstantinopel zurückzukehren, und dementsprechend umsichtige Maßnahmen trifft. ${ }^{120}$ Das Herakles-Motiv wird dabei bereits subtil angedeutet, indem Georgios wiederholt auf die freiwillige Übernahme schwerer róvoı durch Herakleios hinweist ${ }^{121}$ und die Feinde der Byzantiner als wilde Tiere bezeichnet, die es zu jagen gelte. ${ }^{122}$ Gleichzeitig aber mischt sich noch eine weitere Assoziation in die Darstellung: Christus. So wird des Kaisers bevorstehende Rückkehr in „die Polis“ als $\pi \alpha \rho o v \sigma i ́ \alpha$ bezeichnet ${ }^{123}$ und - was noch weitaus deutlicher ist - der Herrscher schlüpft nun in die Rolle des guten Hirten, und zwar nicht irgendeines guten Hirten, sondern des Erzhirten

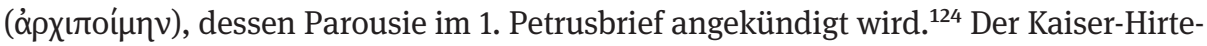
Vergleich zieht sich über mehrere Verse hin (v. 3,322-335) und wird dabei geschickt mit den bereits genannten Herakles-Assoziationen verwoben. ${ }^{125}$ Herakleios ist Herakles dies wird in v. 3,354 offen ausgesprochen. Aber er ist auch Christus: Wenige Zeilen,

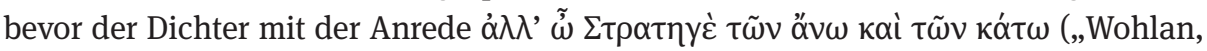
Gebieter über Himmel und Erde!“") sein großes Schlussgebet für den Kaiser und seine Nachkommen beginnt, ${ }^{126}$ wendet er sich noch einmal direkt an Herakleios. Die Anrede

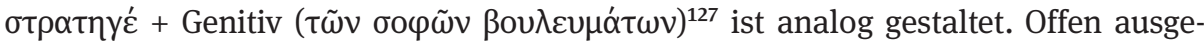
sprochen wird die Parallele zwar nicht (ja, sie wird später sogar wieder leicht relativiert); ${ }^{128}$ aber jeder zeitgenössische Zuhörer wird sie vernommen haben: Georgios präsentiert am Ende der Expeditio Persica einen Herakles-Herakleios-Christus.

120 Georg. Pisid. Exped. Pers. 3,305-340.

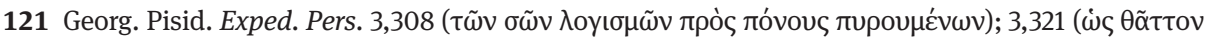

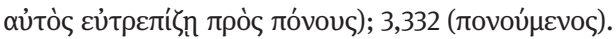

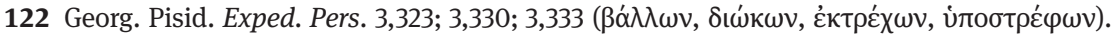

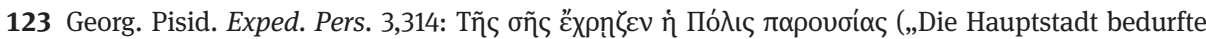
deiner Parousie“).

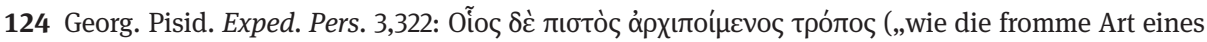

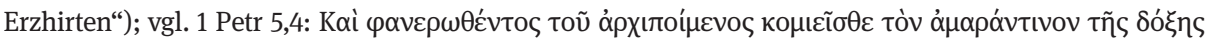

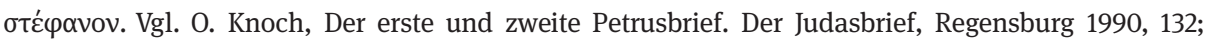
R. Feldmeier, Theologischer Handkommentar zum Neuen Testament, Bd. XV.1, Leipzig 2005, $157 \mathrm{f}$. 125 Hirten und Herde: Georg. Pisid. Exped. Pers. 3,324; 3,327; 3,328; 3,335.

126 Georg. Pisid. Exped. Pers. 3,385-461.

127 Georg. Pisid. Exped. Pers. 3,374.

128 Die Parallelisierung wird später behutsam zurückgenommen, wenn der Dichter den Kaiser als

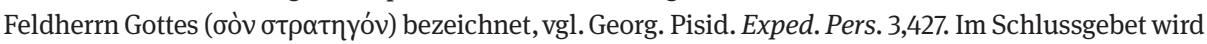
Herakleios zudem in die Rolle eines Neuen Moses gerückt (diese Parallele wurde seit Konstantin verschiedentlich gezogen, vgl. Euseb. VC 1,12; 1,20,2; 1,38,2; 2,12,1; dazu Rapp [s. Anm. 40], 292-295; B. Isele, Moses oder Pharao? Die ersten christlichen Kaiser und das Argument der Bibel, in: A. Pečar/K. Trampedach [Hgg.], Die Bibel als politisches Argument. Voraussetzungen und Folgen biblizistischer Herrschaftslegitimation in der Vormoderne, München 2007, 103-118; Georgios parallelisiert auch 
Wie gesehen, ist für die über das Herakles-Exempel vermittelte Christus-Assoziation der wohl von Georgios in die Literatur eingeführte Terminus des kosmorhýstes, des „Retters bzw. Erlösers der Welt“, von einiger Relevanz. Im Schrifttum des Pisidiers begegnet diese Neuprägung insgesamt viermal: Im Panegyricus auf Bonos und in der Heraclias - über beide Passagen habe ich bereits gehandelt - sowie im Gedicht Contra Severum und im Hexaemeron. ${ }^{129}$

Der Beleg im Hexaemeron findet sich kurz vor dem Ende des monumentalen Gedichts in einem Gebet an Gott, das Georgios pathetisch mit den Worten „Oh, Ar-

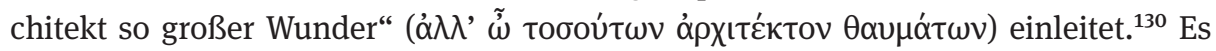
folgen eine Parallelisierung der Tore Konstantinopels mit den Pforten des Himmels ${ }^{131}$

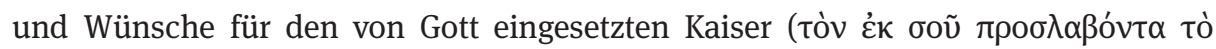

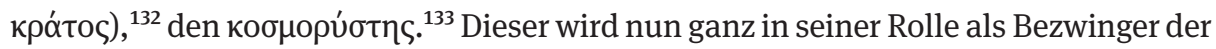
Perser präsentiert; ${ }^{134}$ er möge alle Orte unter der Sonne beherrschen, denn es sei

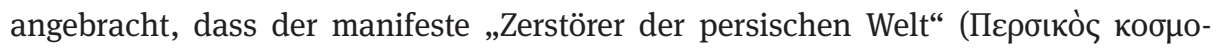

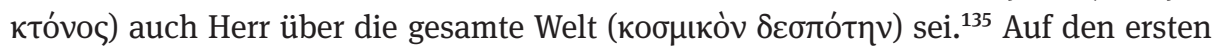

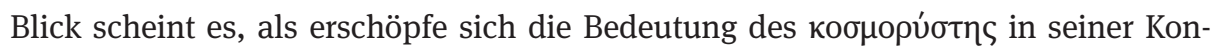
kretisierung als „Zerstörer der persischen Welt“ - ganz so, wie in der Heraclias der

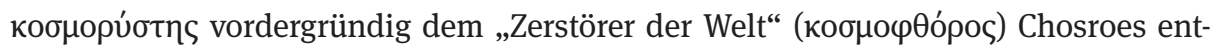
gegengestellt wird. ${ }^{136}$

Allerdings hatte der Autor den unmittelbar vorausgehenden Abschnitt ebenfalls mit den identischen Worten „Oh, Architekt so großer Wunder“ eingeleitet und darauf einen überschwänglichen Christus-Hymnus angestimmt. ${ }^{137}$ Für den Leser des Gedichts war also, als er im Anschluss daran ein zweites Mal dieselbe Anredeformel zur Kenntnis nehmen musste, der Christus-Bezug noch unmittelbar präsent - auch wenn es nunmehr um den Kaiser ging; doch konnte jetzt mit dem geschickt platzierten

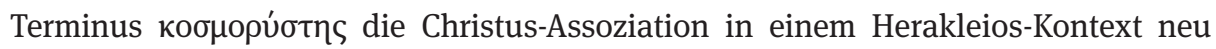
aktiviert werden. Auch im Hexaemeron dient das Wort also dazu, implizit das Herakleios-Christus-Muster zu evozieren.

Die einzigartige Vollkommenheit des Herakleios, aufgrund derer ihn Georgios wie gezeigt - mehrfach von seinem Vorbild Herakles abgehoben hatte, dominiert

\footnotetext{
Sergios mit Moses, vgl. Bell. Avar. 495-501; Hex. 1828), wobei Georgios sein enges Nahverhältnis zu Gott und Christus hervorhebt (Exped. Pers. 3,415-425). Zum Vergleich des spätantiken Kaisers mit Moses s. Rapp (s. Anm. 40), bes. 295f. (zu Herakleios).

129 Georg. Pisid. In Bon. Patr. 7; Her. 1,70; Sev. 452; Hex. 1800 (ed. Tartaglia).

130 Georg. Pisid. Hex. 1792ff. (ed. Tartaglia). Zu dieser Passage vgl. Olster, Date (s. Anm. 17), 168f.; Whitby, Devil (s. Anm. 17), 118-120.

131 Georg. Pisid. Hex. 1793-1798 (ed. Tartaglia).

132 Georg. Pisid. Hex. 1799 (ed. Tartaglia).

133 Georg. Pisid. Hex. 1800 (ed. Tartaglia).

134 Vgl. bes. Georg. Pisid. Hex. 1800-1801 (ed. Tartaglia).

135 Georg. Pisid. Hex. 1800-1806 (ed. Tartaglia).

136 Georg. Pisid. Her. 1,77. S.o. Anm. 110.

137 Georg. Pisid. Hex. 1720 - 1791 (ed. Tartaglia).
} 


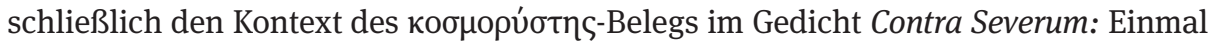
mehr wird der Kaiser als erfolgreicher Bezwinger der Perser präsentiert: „der kosmorhýstes, der Schlächter des Chosroes, unser Bollwerk, der Richter über Persien“

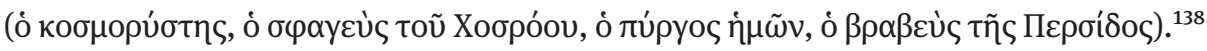
Aber es bleibt eben nicht bei diesen militärischen Qualitäten: Herakleios „besänftigt erstens mit Waffen und zweitens mit Worten alle wilden Tiere in ihrem Gemüt“ (тò

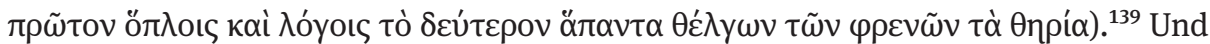
daher werde er, so Georgios weiter, auch die Severianer noch überzeugen. ${ }^{140}$

Die herausragenden Qualitäten des Kaisers manifestieren sich also in allen Bereichen: dem Krieg, dem vernunftgemäßen Handeln, der Religion. Es ist gerade diese Vollkommenheit, die den kosmorhýstes Herakleios vor allen anderen Wesen - auch vor einem mythischen Zivilisationsbringer wie Herakles - in besonderer Weise auszeichnet, und es ist diese Eigenschaft, die ihn in unmittelbare Nähe zu Christus rückt.

\section{3.}

Bezüge zwischen Herakleios und Christus, sei es in Form von Analogien, Parallelen oder auch nur leisen Andeutungen, lassen sich in der Dokumentation zu diesem Kaiser allenthalben nachweisen, so dass ich mich im Folgenden kurz fassen kann. Das Phänomen selbst ist in der Forschung mittlerweile bekannt, ${ }^{141}$ wenngleich noch nicht systematisch aufgearbeitet worden. Insbesondere das Schrifttum des Georgios Pisides dürfte bei einer genaueren Analyse ohne Zweifel noch weiteres einschlägiges Belegmaterial erbringen. Doch schon jetzt ist auch bei diesem noch wenig erforschten Autor manches offenkundig, ${ }^{142}$ so etwa die erwähnte Darstellung des Herakleios als ó $\rho{ }^{-}$ $\pi o i ́ \mu \eta v$ Christus ${ }^{143}$ oder auch die Beschreibung des kaiserlichen adventus in Jerusalem anlässlich der Rückführung der Kreuzreliquien, die eindeutig Christi Einzug in die heilige Stadt evoziert. ${ }^{144}$ In der Expeditio Persica weckt die sprachliche Ausgestaltung der Schilderung einer blutenden Fußverletzung des Kaisers Assoziationen an die Passion Christi, ${ }^{145}$ ebenso wie in der Heraclias die triumphale Rückkehr des Augustus

138 Georg. Pisid. Sev. 452-453.

139 Georg. Pisid. Sev. 454-455.

140 Georg. Pisid. Sev. $456-457$.

141 J. W. Drijvers, Heraclius and the Restitutio Crucis. Notes on Symbolism and Ideology, in: G. J. Reinink/B. H. Stolte (Hgg.), The Reign of Heraclius (610 - 641). Crisis and Confrontation, Leuven/Paris/ Dudley (Ma.) 2002, 175-190, bes. $184 \mathrm{ff}$.

142 Vgl. Whitby (s. Anm. 10), 214.

143 Vgl. Whitby (s. Anm. 10), $213 \mathrm{f}$.

144 Vgl. Georg. Pisid. In restitut. Cruc. 5-8; dazu Mt 21,8 - 9; Joh 12,13; Frendo (s. Anm. 17), 180, Anm. 78; Olster, Date (s. Anm. 17), 161; Whitby (s. Anm. 10), 215; dies., Presentation (s. Anm. 17), 161 („Heraclius' arrival in Jerusalem is analogous to that of Christ on Palm Sunday“).

145 Georg. Pisid. Exped. Pers. 2,239-247, mit Trilling (s. Anm. 77), 259f.; Whitby (s. Anm. 10), 205, Anm. 41; 215; dies., Presentation (s. Anm. 17), 163, mit Anm. 36. 
nach Konstantinopel mit impliziten Christus-Bezügen operiert. ${ }^{146}$ Ganz unverhohlen wird schließlich in einer Theophanes-Passage, die auf die verlorene dritte Akroasis der Heraclias zurückgeht, Herakleios mit Gott parallelisiert: „Nachdem der Kaiser aber in sechs Jahren Persien niedergerungen hatte, schloss er im siebten Jahr Frieden und kehrte unter großem Jubel nach Konstantinopel zurück, wobei er damit eine mystische Schau erfüllte. Denn nachdem Gott in sechs Tagen die gesamte Schöpfung vollbracht hatte, nannte er den siebten ,Ruhetag'. So auch der Kaiser: Nachdem er in sechs Jahren viele Mühen auf sich genommen hatte, wandte er sich im siebten Jahr in Frieden und Freude der Hauptstadt zu und ruhte.“147

Der Pisidier bewegte sich mit derartigen Evokationen allerdings keineswegs erratisch in einer ansonsten ganz anders geprägten Umgebung, sondern griff - im Gegenteil - offenbar verbreitete Tendenzen auf. ${ }^{148}$ In diesem Diskussionszusammenhang spielt auch die Übernahme des Basileus-Titels durch Herakleios nach dem Sieg über die Perser eine Rolle: Der Kaiser und sein Sohn Herakleios Konstantinos erscheinen in

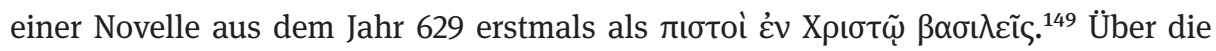
Gründe für diese Reform ist in der Forschung viel spekuliert worden. ${ }^{150}$ Zuletzt hat Otto Kresten dafür plädiert, die Motive des Kaisers als ein komplexes Amalgam aus DavidBezügen, Assoziationen im Zusammenhang der Rückführung des Kreuzes nach Jerusalem und messianisch-eschatologischen Elementen zu deuten: Demzufolge habe Herakleios den Restitutionsakt mit der Überführung der Bundeslade durch König David parallelisiert, um dem Alten Bund zwischen Gott und dem auserwählten Volk einen Neuen Bund (mit den Römern) an die Seite zu stellen; aus diesem Grund habe er den davidischen Königstitel basileús angenommen. ${ }^{151}$ Sollte sich diese Deutung als zutreffend erweisen, dann wären die inhärenten Christus-Parallelen offenkundig. ${ }^{152}$

146 Georg. Pisid. Her. 1,192-218, mit Whitby (s. Anm. 10), 215f.; dies., Devil (s. Anm. 17), $119 ; 121$.

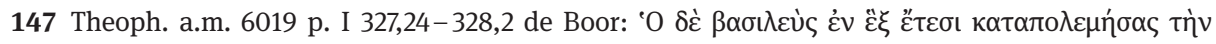

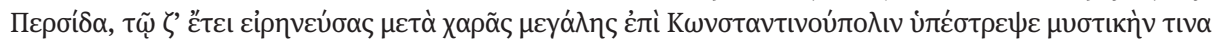

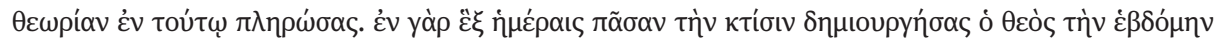

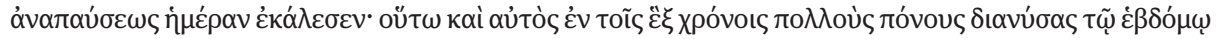

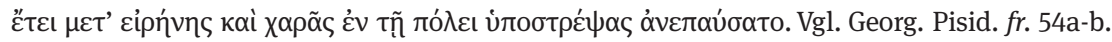

148 So auch Whitby (s. Anm. 10), $216 \mathrm{ff}$.

149 J. Konidaris, Die Novellen des Kaisers Herakleios, in: D. Simon (Hg.), Fontes Minores V, Frankfurt a. M. 1982, 33-106, hier 84; zur Datierung der Novelle ebd., $58 \mathrm{f}$.

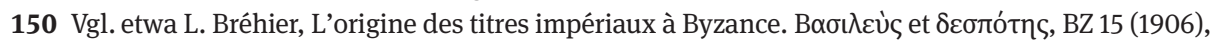
161-178, bes. 172-178; I. Shahîd, The Iranian Factor in Byzantium during the Reign of Heraclius, DOP 26 (1972), 293-320; E. K. Chrysos, The Title BA II $\Lambda$ EY $\Sigma$ in Early Byzantine International Relations, DOP 32 (1978), 29-75.

151 O. Kresten, Oktateuch-Probleme: Bemerkungen zu einer Neuerscheinung, BZ 84/85 (1991/92), 501511, hier 504, Anm. 13; ders., Herakleios und der Titel $\beta \alpha \sigma \iota \lambda \varepsilon u ́ c$, in: Varia VII (= Poikila Byzantina 18), Bonn 2000, 178-179; vgl. auch Shahîd (s. Anm. 150), 307 f.; S. Spain Alexander, Heraclius, Byzantine Imperial Ideology, and the David Plates, Spec 52 (1977), 217-237, bes. 232-234; M. Mundell Mango, Imperial Art in the Seventh Century, in: P. Magdalino (Hg.), New Constantines. The Rhythm of Imperial Renewal in Byzantium, 4th-13th Centuries, Aldershot 1994, 109-136, hier 128; Rapp (s. Anm. 40), 295; W. Brandes, Heraclius between Restoration and Reform. Some Remarks on Recent Research, in: G. J. 
Herakleios wurde indes ohnehin vor allem über die David-Typologie (vgl. 2 Sam 7,12-13) auf Christus bezogen. ${ }^{153}$ Die Gleichsetzung des Kaisers mit David ist u. a. in der Homilie auf die Belagerung Konstantinopels 626, die der Zeitzeuge Theodoros Synkellos verfasste, in hohem Maße präsent. ${ }^{154}$ Als herausragende Evidenz für die besondere Relevanz der David-Thematik gelten in der Forschung allerdings die vieldiskutierten Silberteller mit David-Motiven („David plates“), die „were manufactured on the order of Heraclius to promulgate the new ideology of his reign“. ${ }^{155}$ Möchte man Georgios Pisides glauben (der sich ansonsten auffallend zurückhaltend gegenüber der David-Typologie zeigt), ${ }^{156}$ so hat Herakleios das David-Exempel sogar selbst vor seinen Soldaten vorgebracht. ${ }^{157}$ Ganz unwahrscheinlich erscheint dies nicht angesichts der Tatsache, dass der Kaiser seinen 630 geborenen Sohn auf den Namen David taufen ließ und auch damit ein deutliches Signal setzte. ${ }^{158}$ Die David-Rekurse des Herakleios waren immerhin derart zahlreich und prominent, dass sie selbst im fernen Franken-

Reinink/B. H. Stolte (Hgg.), The Reign of Heraclius (610 - 641). Crisis and Confrontation, Leuven/Paris/ Dudley (Ma.) 2002, 17-40, bes. 19. Das Kreuz als neue Bundeslade: Georg. Pisid. In restitut. Cruc. 71-77, mit Tartaglia (s. Anm. 17), 244f., Anm. 16; s. auch Ludwig (s. Anm. 17), 97 ff. - Der Titel basileús ist allerdings - entgegen der immer wieder anzutreffenden Behauptung - nicht ganz neu unter Herakleios, sondern vereinzelt auch schon früher belegt, so etwa für Konstantin I. (OGIS 721 = SEG 37, 1650 [326 n. Chr.]), für Constantius II. (TAM III.1, 13 [= R. Heberdey (Ed.), Tituli Pisidiae linguis Graeca et Latina conscripti. Tituli Termessi et Agri Termessensis, Wien 1941]) und für Arkadios (ISmyrna II.1 [IK 24.1], 845) [Hinweise von Christoph Begass].

152 Vgl. Y. Stoyanov, Defenders and Enemies of the True Cross. The Sasanian Conquest of Jerusalem in 614 and Byzantine Ideology of Anti-Persian Warfare, Wien 2011, $66 \mathrm{f}$.

$153 \mathrm{Zu}$ den Rekursen des Herakleios auf David vgl. etwa Spain Alexander (s. Anm. 151), 229-234; Ludwig (s. Anm. 17), 93 ff.; dies., David - Christus - Basileus. Erwartungen an eine Herrschergestalt, in: W. Dietrich/H. Herkommer (Hgg.), König David - biblische Schlüsselfigur und europäische Leitgestalt, Stuttgart u.a. 2003, 367-382, bes. 370; 373-378; Mundell Mango (s. Anm. 151), 122-131; Drijvers (s. Anm. 141), 184f.; Kaegi, Emperor (s. Anm. 70), 114; 139. Der von R. Stichel, Scenes from the Life of King David in Dura Europos and in Byzantine Art, Jewish Art 23/24 (1997/98), 100 - 116, bes. 100 -103, und U.

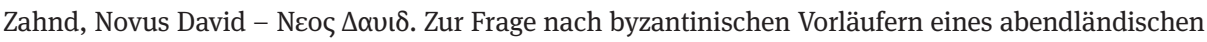
Topos, FMSt 42 (2008), 71-87, bes. 80 - 83, unternommene Versuch, die Relevanz des David-Exempels unter Herakleios infrage zu stellen, wirkt angesichts der überwältigen Evidenz wenig überzeugend. 154 Vgl. etwa Theod. Synk. 2-5 p. 298,19-299,39; 38 p. 313,32-37; 52 p. 320,20-21 (= F. Makk, Traduction et commentaire de l'homélie écrite probablement par Théodore le Syncelle sur le siège de Constantinople en 626. Appendice: Analecta Avarica de L. Sternbach, Szeged 1975); Ludwig (s. Anm. 17), 95-97.

155 Drijvers (s. Anm. 141), 185. Zu den ,David plates‘ s. etwa Spain Alexander (s. Anm. 151); Trilling (s. Anm. 77); Mundell Mango (s. Anm. 151), 122-131; Whitby (s. Anm. 10), 218f.; Ludwig (s. Anm. 153), 370; 373-378. Kritik an dem bis vor kurzem als selbstverständlich vorausgesetzten Zusammenhang dieser Objekte mit der kaiserlichen Selbstdarstellung äußern R. E. Leader, The David Plates Revisited: Transforming the Secular in Early Byzantium, Art Bulletin 82 (2000), 407-427; V. Tsamakda, König David als Typos des byzantinischen Kaisers, in: F. Daim/J. Drauschke (Hgg.), Byzanz - Das Römerreich im Mittelalter, Teil 1: Welt der Ideen, Welt der Dinge, Mainz 2010, 23-54, bes. 30 - 33.

156 Vgl. Whitby (s. Anm. 10), 218f., mit Anm. 107; Howard-Johnston (s. Anm. 17), 32, mit Anm. 47-48. 157 Georg. Pisid. Exped. Pers. 2,113-115.

158 PLRE IIIA 390 (David 8). 
reich beim sog. Fredegar reflektiert wurden. ${ }^{159}$ Für Herakleios bot sich David als Referenzpunkt aus mehreren Gründen an: Beide Herrscher gelangten auf eher ,unkonventionelle ' Weise auf den Thron; beide bekämpften Tyrannen und Ungläubige; beide pflegten ungehörige Beziehungen zu Frauen (David zu der verheirateten Bathseba, Herakleios zu seiner Nichte Martina); beide unterwarfen sich und ihre Herrschaft bedingungslos dem göttlichen Willen. Beide schließlich - dieser Aspekt dürfte nach 630 von besonderer Bedeutung gewesen sein - transferierten heilige Objekte an ihren Ort: David die Bundeslade, Herakleios die Kreuzreliquien. ${ }^{160}$

\section{4.}

Insbesondere über die vielfältigen David-Bezüge lassen sich somit die Christus-Assoziationen des Herakleios erfassen - und auf diese Weise konnten sie in der Repräsentation auch nachdrücklich vermittelt werden, ohne allzu großen Anstoß zu erregen. In einer ähnlichen Weise wird man die Verwendung des Herakles-Exempels $\mathrm{zu}$ beurteilen haben, denn für Zeitgenossen war auch in diesem Fall die ChristusParallele augenfällig. Ich kann mich auch in diesem Punkt kurz fassen, denn die auf Christus verweisende Herakles-Typologie ist jüngst von Henrike Maria Zilling luzide herausgearbeitet worden: ${ }^{161}$ „Beide sind Göttersöhne und werden von sterblichen Müttern geboren; beide vollbringen in den Augen der Nachwelt verehrungswürdige, außergewöhnliche Taten und Wunder, beide sterben einen grausamen Tod und beide fahren in den Himmel auf, in das Reich ihrer göttlichen Väter. “162 Die Abstammung des mythischen Helden vom höchsten Gott und einer sterblichen Frau fügte sich nahtlos in die spätantike Zweinaturenlehre. ${ }^{163}$ Insbesondere aber musste sein „Leiden als Mensch vor der Rückkehr zum göttlichen Vater“ (auf dem Berg Oita) für christliche Zeitgenossen entsprechende Assoziationen hervorrufen. ${ }^{164}$ Angesichts dieser manifesten Parallelen nimmt es nicht wunder, dass christliche Autoren Herakles, der bei Dion Chrysostomos immerhin als soter und Herrscher über das gesamte Menschengeschlecht erscheinen konnte ${ }^{165}$ und in der Bevölkerung überdies ungemein populär war, als Konkurrenz wahrnahmen. Scharfe Polemiken resultierten daraus, in denen vor allem seine burlesken Seiten, sein ungehemmtes Saufen, Fressen und seine sexuelle Zügellosigkeit (d.h. gerade jene Eigenschaften, die ihn so beliebt gemacht

159 Vgl. Fredeg. 4,64: Aeraclius imperatur arma sumens, telam priliae et phalange a suis postergum preparatum relinquens, singolare certamen, ut novos Davit, procedit ad bellum. S. H. Wander, The Cyprus Plates and the Chronicle of Fredegar, DOP 29 (1975), $345 \mathrm{f}$.

160 Drijvers (s. Anm. 141), 185; vgl. auch Ludwig (s. Anm. 17), 95.

161 Zum Folgenden s. H. M. Zilling, Jesus als Held. Odysseus und Herakles als Vorbilder christlicher Heldentypologie, Paderborn u.a. 2011, $119 \mathrm{ff}$.

162 Zilling (s. Anm. 161), 153.

163 Zilling (s. Anm. 161), $151 \mathrm{f}$.

164 Zilling (s. Anm. 161), 161.

165 Dion Chrys. 1,84. 
hatten), hervorgehoben und attackiert wurden. ${ }^{166}$ Freilich bin ich nicht davon überzeugt, dass Herakles „diesen Kampf schließlich verloren“ habe, wie Zilling unter Berufung auf eine Äußerung aus dem frühen 5. Jahrhundert, wonach Herakles in Rom nicht mehr als Gott verehrt werde, konstatiert. ${ }^{167}$ Etwa um dieselbe Zeit entstand immerhin der 6. Hymnos des Synesios, in dem Christus mit dem (namentlich nicht genannten) Herakles direkt parallelisiert wird: Wie Herakles reinigte Christus Land, Meer, Luft, die Tiefe der Erde und stieg in den Hades hinab. ${ }^{168}$ Überdies hat Zilling selbst herausgearbeitet, wie Prodikos' Erzählung von Herakles am Scheideweg in sublimierter Form in die christliche Zwei-Wege-Lehre eingehen konnte und den Heros damit weiterhin als Folie präsent hielt. ${ }^{169}$ Herakles wurde also in der Tat zwar nicht mehr als Gott verehrt, aber er barg dennoch ein Potential, das in den vielfältigen Analogien zu Geburt, Leben und Leiden Christi beruhte - und das jederzeit aktiviert werden konnte, um auf Christus zu verweisen. Als mythischer Held gehörte Herakles im 7. Jahrhundert zum angestaubten Bildungsschatz einer jahrhundertealten Tradition; man konnte dieses gelehrte Wissen abrufen und demonstrieren - wie das eingangs erwähnte anonyme Herakles-Gedicht zeigt. ${ }^{170}$ Aber ein christlicher Kaiser, der sich wie einst Commodus oder die Tetrarchen direkt auf Herakles als mythisches Vorbild und Gottheit berufen und diesen gar imitiert hätte, hätte sich im Kontext des Imperium Christianum doch wohl eher lächerlich gemacht. Wenn man das Exempel dennoch abrief, dann konnte die Sinngebung nur noch innerhalb der veränderten Rahmenbedingungen, d.h. vor einem christlichen Hintergrund erfolgen - und damit wurden unweigerlich die altbekannten Herakles-Christus-Parallelen aktiviert.

\section{5.}

Die abschließende Frage, warum Herakleios in einer bis dahin singulären Intensität mit Christus assoziiert wurde - weitaus nachdrücklicher als etwa Konstantin oder Justinian $^{171}$-, bedarf einer eigenständigen Untersuchung und kann an dieser Stelle

166 G. K. Galinsky, The Herakles Theme. The Adaptations of the Hero in Literature from Homer to the Twentieth Century, Oxford 1972, 4; 189; Zilling (s. Anm.161), 121;189ff.; 222f. Aus dieser Haltung konnten durchaus gewalttätige Auseinandersetzungen resultieren, wie aus Augustin. epist. 50 Goldbacher hervorgeht: Nach der Zerstörung von Heraklesbildnissen im afrikanischen Sufeta durch christliche Eiferer kam es zu Ausschreitungen, bei denen die Christen 60 Tote zu beklagen hatten, vgl. Zilling (s. Anm. 161), 197.

167 Zilling (s. Anm. 161), 151, unter Hinweis auf Augustin. serm. 24,6 (= C. Lambot [Ed.], Sancti Aurelii Augustini Sermones de Vetere Testamento [CCSL 41], Turnhout 1961, p. 332).

168 Synes. Hymn. 6,33-39, mit dem Kommentar von J. Gruber/H. Strohm, Synesios von Kyrene. Hymnen. Eingeleitet, übersetzt und kommentiert, Heidelberg 1991, 217; vgl. dazu auch Hunger (s. Anm. 50), 22f., der darauf hinweist, dass die Herakles-Christus-Parallele auch ikonographisch greifbar ist.

169 Vgl. Zilling (s. Anm. 161), $208 \mathrm{ff}$.

170 Vgl. Hunger (s. Anm. 8), II 110: „reiner Lern- und Merkstoff für die Schule im weitesten Sinne“. 171 Vgl. Rebenich (s. Anm. 16); Meier, Zeitalter (s. Anm. 16), 547 ff. 
daher nur noch perspektivisch angerissen werden. Von zentraler Bedeutung scheint mir in diesem Zusammenhang die in spätjustinianischer Zeit einsetzende sog. ,Liturgisierung‘ zu sein, d.h. die Durchdringung sämtlicher für uns fassbarer Lebensbereiche der oströmisch-byzantinischen Gesellschaft mit christlich-religiösen Inhalten und entsprechender Symbolik. ${ }^{172}$ In dem Maße, in dem die Gesellschaft des Imperium Romanum, ja dieses selbst, eine wachsende sakrale Aufladung erfuhr, musste auch der Kaiser, der als Beauftragter Gottes ja eine sichtbare Distanz zu seinen Untertanen zu wahren hatte, einen neuerlichen Sakralisierungsprozess durchlaufen. ${ }^{173}$ Hatte schon Justinian die Parallelen zwischen Kaiser und Christus bemüht, so war für die nachfolgenden Kaiser angesichts der sich wandelnden Rahmenbedingungen kaum noch ein Zurückgehen hinter die bereits bestehenden Marken möglich - eher das Gegenteil war der Fall.

Im speziellen Fall des Herakleios dürften noch weitere Faktoren hinzugekommen sein: Die blutige Beseitigung des Phokas in einem langwierigen Bürgerkrieg hatte ebenso wie dessen eigene Usurpation die etablierte Ordnung massiv infrage gestellt: ${ }^{174}$ Seit Konstantin das Imperium Christianum geschaffen hatte, hatte es keinen erfolgreichen Thronräuber im Osten mehr gegeben, wie der Kirchenhistoriker Euagrios noch gegen Ende des 6. Jahrhunderts mit besonderem Nachdruck festgehalten hatte. ${ }^{175}$ Nicht nur Phokas war also ein Zerstörer der seit nunmehr rund 300 Jahren geltenden Ordnung gewesen, sondern auch Herakleios. Umso mehr musste dieser sich darum bemühen, diesen Makel abzustreifen. Ich habe an anderer Stelle nachzuweisen versucht, dass der Kaiser sich wohl aus diesem Grunde immer wieder als Restitutor der alten Ordnung präsentierte, ja dass seine eigene Repräsentation offenbar Teil eines übergreifenden Ordnungsdiskurses war, der aufgrund der Kaisermorde 602 und 610 mit einiger Intensität geführt wurde. ${ }^{176}$ Die Ordnung war aber auch aus anderen Gründen bedroht: Im ersten Jahrzehnt der Herrschaft des Herakleios verlor das Oströmische Reich so viele Territorien wie nie zuvor; die römische Weltherrschaft schien an ihr Ende gelangt. ${ }^{177}$ Auch auf diese Herausforderungen musste der Kaiser reagieren, und dies konnte nicht nur auf militärischem Weg geschehen. Mit den persischen Erfolgen dürften sich - wir können dies punktuell fassen - eschatologische Naherwartungen verbreitet haben (so wie kurz darauf auch im Kontext der arabischen Ex-

172 Zur ,Liturgisierung، s. v.a. Av. Cameron, Images of Authority: Elites and Icons in Late Sixth-Century Byzantium, P\&P 84 (1979), 3-35, ND in: dies., Continuity and Change in Sixth-Century Byzantium, London 1981, XVIII.Vgl. auch M. Meier, Sind wir nicht alle heilig? Zum Konzept des „Heiligen“ (sacrum) in spätjustinianischer Zeit, Millennium 1 (2004), 133-164, mit weiterer Literatur (133, Anm. 1); Meier (s. Anm. 1).

173 Dazu im Einzelnen demnächst M. Meier, Liturgification and Hyper-Sacralization: The Declining Importance of Imperial Piety in Constantinople between the $6^{\text {th }}$ and $7^{\text {th }}$ Centuries A.D. (im Druck). 174 Dazu ausführlich M. Meier, Kaiser Phokas (602-610 n.Chr.) als Erinnerungsproblem, BZ 107 (2014), 139-174.

175 Euagr. $H E$ 3,41.

176 Meier (s. Anm. 174).

177 Überblick bei Kaegi, Emperor (s. Anm. 70), 58 ff. 
pansion), die unweigerlich auch den Kaiser in den Fokus rückten. ${ }^{178}$ Nicht zuletzt mit der Inszenierung der Rückführung der Kreuzreliquien nach Jerusalem im Jahr 630 dürfte dieser auch auf Anmutungen dieser Art reagiert haben. Innerhalb eines solchen Amalgams aus generellen Verdichtungen religiöser Ausdrucksformen im gesamten Imperium Romanum, aus persönlich-situativen Erfordernissen, aus den gewaltigen außen- (und innen-)politischen Herausforderungen und aus eschatologischen Naherwartungen dürfte die traditionelle Kaiser-Christus-Parallele in besonderem Maße an Relevanz gewonnen haben; wie bereits angedeutet, dürfte diese, komplexe Kommunikationsprozesse voraussetzende Entwicklung sicherlich kaum von Herakleios allein ausgegangen sein. Aber er wird versucht haben, ihre Richtung und Wirkungsweise wo irgend möglich zu beeinflussen. Georgios Pisides als Dichter in seinem Umfeld könnte ihm dabei behilflich gewesen sein, indem er gezielt das Herakles-Exempel aktualisierte und dem Kaiser damit eine Möglichkeit anwies, die Christus-Parallelen einerseits in unmissverständlicher Weise zu evozieren, sie dabei gleichzeitig aber auch so zu verschleiern, dass die letzten Grenzen des Sagbaren nicht überschritten wurden.

178 Einführend vgl. dazu W. Brandes, Die apokalyptische Literatur, in: F. Winkelmann (Hg.), Quellen zur Geschichte des frühen Byzanz (4.-9. Jahrhundert). Bestand und Probleme, Berlin 1990, 305-322. 


\section{Fabienne Jourdan}

\section{Orpheus and 'Orphism' in the Christian Literature (in Greek) of the First Five Centuries $^{1}$}

The study of the use of Orpheus and Orphism in the Christian literature of the first centuries A. D. is hampered by a series of prejudices that are most of the time due to some modern and Christian projections on the ancient figure of Orpheus and on the religious movement Orpheus is supposed to have introduced. Contrary to the opinion of some scholars of the nineteenth and of the beginning of the twentieth centuries, the Christian writers of the first five centuries A. D. do not perceive Orpheus and Orphism as real rivals of Christ and Christianity. They do not see in the religious movement ascribed to Orpheus a kind of religion unified firstly around a "holy Scripture", as their own religion is around the Bible; or unified around a central myth, that of Dionysos or Zagreus, which would have contained in itself the principles of a theology characterized by an original sin, a suffering and then risen god and a message of redemption for humanity; neither do they see in this movement a religion unified around a prophet inaugurating a new religion set against the religion usually practised in the city of the time. In other words, for them, Orphism is not a kind of preChristianity.

Moreover, contrary to their followers, these Christian writers do not compare Orpheus' and Christ's descents into the underworld. Indeed, it was only in the Middle Ages that the focus on the journey into Hades to bring back Eurydice is used as an allegorical picture of Christ's journey into hell and his victory over death. ${ }^{2}$

They do not even draw any link between Orpheus and David, at least in their writings, (I will not mention the iconography here) ${ }^{3}$ as being both marvellous singers and musicians - Clement of Alexandria is the first and only one (before the Middle Ages) to suggest such a link, but in a negative manner. ${ }^{4}$ As to the link between Or-

\footnotetext{
1 I have chosen to leave this paper in its oral form. It consists in a summary of my previous research on Orpheus in the Church Fathers of the first five centuries (see Fabienne Jourdan, Orphée et les chrétiens, T. I-II, Paris, 2010-2011 and "Orpheus [Orphik]", RAC 26, 2014, 576-613). The full references to the Church Fathers and to secondary literature are fully listed there. Here I will just indicate a few references to the texts. I am grateful to Prof. Hartmut Leppin for his invitation to the symposium and to Philippe Charles for checking the English.

2 See John Block Friedman, Orphée au Moyen Âge, French transl. by Jean-Michel Roessli, Paris-Fribourg, 1999 [Orpheus in the Middle Ages, Cambridge, Mass., 1970], 109-78.

3 See Fabienne Jourdan, "The Orphic Singer in Clement of Alexandria and in the Roman Catacombs: Comparison Between the Literary and the Iconographic Early Christian Representation of Orpheus", to be published in Studia patristica, Jourdan, Orphée et les chrétiens (cf. fn. 1), I, 366-73 and JeanMichel Roessli, "Assimilation chrétienne d'éléments païens: Construction apologétique ou réalité culturelle?", to be published in Laval théologique et philosophique.
}

4 Clem. Alex. protr. I 5, $2-4$. 
pheus and Christ it is finally made only by the same Clement in his Protrepticus in order to exhort the Greeks to convert through a depiction of Christ as a new Orpheus. However, this portrait is an exception in late Antiquity. Something similar can be found only in Eusebius, who follows Clement in his Eulogy of Constantine, ${ }^{5}$ and in the Roman iconography. ${ }^{6}$ This portrait is based on the picture of Orpheus as singer that is rarely used by the Christian writers of that time.

So, what do these writers see in Orpheus when they mention him in their texts?

They retain four features of the figure. First, they focus on its religious nature, namely Orpheus' status as founder of Greek religious institutions and more precisely the Mysteries. More generally they see in Orpheus the founder of paganism itself. It is indeed striking for us modern scholars that they do not make of Orpheus the doctor of a small sectarian group, but the creator of the Greek religion itself. However, this picture is based on the pagan representation of the character and on considering the Mysteries as the most tangible pagan way to have contact with the gods. The second feature the Christian writers retain is the pagan presentation of Orpheus as a Barbarian because of his supposed Thracian origin. The Christians enhance this feature because, after the Jews, they were also considered as Barbarians (in both meanings of the word, that is as foreigners but also as uncultivated people). They could therefore use this origin of Orpheus to their own advantage. The same applies to the third main feature of Orpheus retained, namely his supposed journey to Egypt - the traditional journey to the land of Wisdom that the Greeks supposed every ancient philosopher and theologian had made. Finally, they resort to the Jewish legend born in Alexandria in the second century B. C. according to which Orpheus had become a convert to monotheism and written a poem revealing the Biblical message to his pupil Museus and therefore to the Greeks. ${ }^{7}$

My aim here is to show how the Christians make use of these features of Orpheus to nourish their polemics against the Pagans, but also against other Christians they consider heretics. For this purpose, I will be beginning by sketching the polemical context in which they mention Orpheus and his work. Then I will be describing how the features I have just named and others were used sometimes critically, sometimes positively according to the Christians' intentions.

The whole contribution will perhaps contain some repetitions, but they are part and parcel of the purpose: in order to give an overall view on the topic, I will be trying to expound two ways of considering it according to the perspective chosen, either according to the Christian general intentions or according to the way Orpheus and his work themselves are treated.

5 Eus. l.C. XIV $4 \mathrm{f}$.

6 See Jourdan, Orphée et les chrétiens (cf. fn. 1), I, 381-99 with updated bibliography.

7 Concerning this legend and this poem, see Fabienne Jourdan, Le poème judéo-hellénistique attribué à Orphée, Paris, 2010, with updated bibliography. 


\section{Polemical context and Christian strategies in the use of the figure of Orpheus}

\section{A. Polemical context in which Orpheus is mentioned}

The Christian writers of the first centuries evoke Orpheus to serve their offensive or exhortative purposes and they always mention him in the context of a debate with paganism, sometimes also with heterodoxy - the latter considered an imitation of paganism. In this context, they pursue two goals:

1. Some of them aim at criticising and condemning paganism (and also heterodoxy which is accused of imitating it), through the figure of its supposed founder;

2. Others (but sometimes also the same) want to show the presence in paganism, always through the intermediary of its founder, of an allusion to the Biblical message or of a prefiguration of the Christian one, sometimes even of the discourse considered as orthodox itself.

In all cases, Orpheus is mentioned in highly polemical contexts.

Because of these intentions, Orpheus appears in works directed at the Pagans, at the Christians recently converted and familiar with Hellenism and sometimes in passages aimed at the heterodoxes themselves.

More precisely, Orpheus is mentioned in the following types of works:

1. In texts with highly critical purposes, like the apologies, ${ }^{8}$ the more or less direct answers to the Pagans, ${ }^{9}$ the fictitious debates such as the one in the PseudoClementine novel, ${ }^{10}$ the aggressive discourses addressed to the Greeks such as Tatian's, and finally in works criticising the heterodoxes ${ }^{11}$ - in the latter case the mention of Orpheus is used in order either to denounce the heterodox doctrine or to serve the so-called orthodox Christian view itself.

2. Orpheus also appears in works in which attacks are mixed with a call to conversion $^{12}$ or in which the attacks are mixed with the desire to convince and to teach the (Christian) readers, ${ }^{13}$ and finally to attract them. ${ }^{14}$ In this case and

8 In Theophilus of Antioch, Ad Autolycum; Athenagoras, Legatio sive supplicatio pro Christianis; Theodoret of Cyr, Graecarum affectionum curatio.

9 In Origen, Contra Celsum; Gregory of Nazianzus and Cyril of Alexandria in their respective Contra Iulianum.

10 Homiliae Clementinae and Supplementum ad recognitiones Clementinas.

11 In Ps.-Hippolytus, Refutatio omnium haeresium; Clement of Alexandria, Stromateis; Epiphanius, Adversus haereses; Cyril of Alexandria, Contra Iulianum and Didymus the Blind, De Trinitate.

12 In Pseudo-Justin, Cohortatio ad Graecos - I will not mention here the book De monarchia because it could be the work of a Jew, see Christoph Riedweg, Jüdisch-hellenistische Imitation eines orphischen Hieros Logos. Beobachtungen zu OF 245 und 247 (sog. Testament des Orpheus), Tübingen, 1993, 6 and id., "Iustinus Martyr II", RAC 19, 2001, 848-73, 851.

13 As in Clement of Alexandria's Stromateis or Eusebius' Praeparatio evangelica. 
in Gregory of Nazianzus' poems only, the figure of Orpheus as singer is enhanced. In his poems Gregory is indeed less concerned with a religious debate than with an attempt to establish the cultural superiority of Christianity.

\section{B. Three strategies served by the mention of Orpheus}

In these different works, the mention of Orpheus serves three kinds of strategies.

\section{The denunciation}

First, the Christian writers aim at defending their peers against a series of religious and moral accusations and they use these very accusations against their adversaries. In this context, the attack against Orpheus and his works is a very efficient weapon. Orpheus' verses are quoted literally to prove the atrocity and impiety of the pagan traditions. ${ }^{15}$ Moreover the pagan interpretations of these verses serve as targets first to denounce the sophistry the Greek allegorists use to defend their traditions ${ }^{16}$ and on the other hand to justify the Christian use of allegory in the reading of the Bible. $^{17}$

In this offensive context, Orpheus himself is also taken to task. He is sometimes accused of being a demon who turns the Greeks away from the Truth; ${ }^{18}$ sometimes his coming after Moses is emphasized in order to prove, again through the supposed founder of the Greek religion, that the Greek religious traditions came after the Christian ones and are consequently inferior. ${ }^{19}$

In the other polemical context mentioned, Orpheus' verses are finally denounced for being used by to the so-called heretics as models. ${ }^{20}$

All these kinds of criticisms can be found in Clement for instance

\section{The highlighting of Orpheus' merits in order to denigrate the Greek traditions}

In contrast to these criticisms, the second strategy using the mention of Orpheus consists in pointing out certain of his merits, with the view, however, to discredit Greek traditions. Two examples can be given here. First, his Barbarian origin is underlined

14 In the Protrepticus of Clement of Alexandria.

15 In Athenag. leg. XVIII 3 and 6; XX 4f; Tat. orat. VIII 4; Clem. Alex. protr. II 17, 2; 21, 1; Eus. p.e. II 3, 23 and 34 (= Clem. Alex. protr. II 17 and 21); Theod. affect. III 54, for instance.

16 Athenag. leg. XXII; Orig. Cels. I 18; Eus. p.e. III 9; Hom. Clem. VI 17-19; Clem. recogn. suppl. X 29f and $35 \mathrm{f}$.

17 Orig. Cels. IV 17.

18 Clem. Alex. protr. I 3, 1; cf. II 13, 3; 13, 5; Hom. Clem. VI 17, 1; $18,1$.

19 Tat. orat. XXVII 2; XLI 1f; Clem. Alex. strom. I 14, 59, 1; 14, 60, 1; Eus. p.e. IX 27; Aug. civ. XVIII 37.

20 Ps.-Hippol. haer. V 20, 4f; Epiph. haer. XXXI 4, 8-10. 
by Tatian to show to the Greeks that their supposed cultural superiority is fake because the inventor of their culture was not Greek himself (and it cannot be forgotten in this context that Tatian was Assyrian and not Greek). ${ }^{21}$ The second example concerns Tatian as much as his alleged pupil Clement. Both emphasize the anteriority of Orpheus as poet, who, according to them, came even before Homer and Heraclitus, in order to assert that the whole Greek culture, namely poetry, religion and philosophy, plagiarizes Orpheus' production. ${ }^{22}$ This accusation is brandished to denounce the Greeks as villainous, ${ }^{23}$ but also serves another purpose than mere criticism: Clement makes use of it to claim that the whole Greek culture was influenced by the Biblical message because it is copied from Orpheus who knew this message.

\section{Orpheus as a model}

This attitude leads to the third way the Christian writers make use of Orpheus, namely presenting him as a model. This presentation is inseparable from the use of the Jewish legend according to which Orpheus had converted to monotheism and written a sacred poem to teach it to Musaeus. The Christian writers take up and continue this legend in order to prove to the pagans that their religious founder had already 'sung' in agreement with the Biblical message and to exhort them consequently to convert as he himself did. ${ }^{24}$ This strategy turns out to be an efficient tool. That is why the Christian writers do not always hesitate to write new verses themselves that they attribute to Orpheus, and this not only to prove that the poet sings in agreement with the Christian message itself this time, but with the presumed orthodox one, as we can read in Didymus about the Holy Spirit. ${ }^{25}$

These three general attitudes, namely the pure denunciation of Orpheus, his praise in order to denounce the rest of the Greek traditions and finally his being presented as a model, are not exclusive. They can be found in the same writer and even in the same work, as is the case in Clement and Eusebius for instance.

Now, this use of Orpheus can also be presented in another way that outlines how each feature ascribed to the figure was effectively used in the Christian polemics of the first five centuries A. D.

21 Tat. orat. I 2; XXVII 2; XLI $1 \mathrm{f}$.

22 Tat. orat. XLI 1f; Clem. Alex. strom. V 14, 116, 1f; VI 2, 5, 3f; 2, 17, 1f; 2, 26, 1f; 2, 27, 1 f; cf. Ps.-Just. coh. Gr. XVII 1; XXXVI 4.

23 In Clem. Alex. strom. VI (cf. fn. 22).

24 Such an exhortation can be found in Clem. Alex. protr. and strom. and in Ps.-Just. coh. Gr. for instance. On this text, see Jourdan (cf. fn. 7), with complete bibliography and references.

25 Didym. trin. II 27 (PG 39, 753, 15-756, 4). 


\section{The treatment of Orpheus and his work by the Christian writers}

A synthesis of the Christian treatment first of Orpheus and then of his work will show how each feature serves the condemnation of paganism or on the contrary how it is taken up by the Christians in favour of Christianity itself.

\section{A. Orpheus}

The Orpheus mentioned by the Christians is essentially the theologian and mystagogue, sometimes the singer and citharist, and in a few cases the hero of some other episodes of his pagan legend.

\section{The theologian and mystagogue}

Many aspects of the figure of the theologian are used by the Christian polemists.

\section{a. The founder of the Greek mysteries and religion}

First, because of his status as founder of the Greek mysteries and by extension of the Greek religion itself, Orpheus is the target of criticism as well as the object of praise.

On the one hand, this status explains his denunciation as an impious person who introduced a sacrilegious representation of the gods; ${ }^{26}$ as a deceiver responsible for the moral ruin of humanity, ${ }^{27}$ and consequently as a servant of the Devil. ${ }^{28}$ In the context of the polemics against heterodoxy, Orpheus is even considered as the instigator of its mistakes because it is said to have supplied it with the seeds of its misleading myths. ${ }^{29}$ By extension, this status as theologian, associated with the image of the citharist, leads to condemning Orpheus as a sophist, a charlatan, and finally as a magician or sorcerer ${ }^{30}$ - all kinds of condemnations which were also turned against the Christians at that time.

On the other hand, when the Christian writers want to prove the possibility of an agreement between their traditions and the pagan ones, they mention this status of theologian to assume that the famous founder of the Greek religion was showing this

26 Athenag. leg. XVIII 3-6; XX; XXXII 1; Clem. Alex. protr. I 3, 1; II 13, 3-17, 2; 21, 1; VII 74, 3; Hom. Clem. VI 17, 1; 17, 3; Clem. recogn. suppl. X 35, 1-3; Orig. Cels. I 17; VII 54; Epiph. haer. XXXIII 8, 7-11. 27 Clem. Alex. protr. I 3, 1; II 13, 3; 13, 5; Orig. Cels. I 18; Hom. Clem. VI 17, 2; Clem. recogn. suppl. X 35, 2f; Ps.-Just. coh. Gr. XXXVI 3f; Epiph. haer. XXXIII 8, 7-11.

28 Clem. Alex. protr. I 3, 1; Hom. Clem. VI 17, 1; 18, 1.

29 Ps.-Hippol. haer. V 20, 4f; Epiph. haer. XXXI 4, 8-10.

30 Clem. Alex. protr. I 1, 1; 3, 1 for instance. 
agreement in his own work. In this case, they underline that Orpheus was the first theologian of the Greeks. ${ }^{31}$

In Clement moreover, the figure of the mystagogue is endowed with a specific role. Since the Protrepticus presents the mysteries as centred around the figure of Dionysos, in this book Orpheus becomes the servant and priest of a kind of unique god. ${ }^{32}$ Of course, Clement first criticises this presentation, but it prepares the portrait of Christ as a new and better Orpheus, the hierophant and great priest of the one and only God. ${ }^{33}$

\section{b. The fiction of the conversion}

For the Christians, the theologian is also the person who, according to the Jewish-hellenistic legend, converted to monotheism after being instructed by the Egyptian pupils of the Hebrews ${ }^{34}$ or by Moses himself. ${ }^{35}$ This legend is welcomed as proof of the validity of Christianity: If the founder of the pagan religion himself converted, how could his pupils, the Greeks, hesitate to convert in their turn? ${ }^{36}$

However, this legend also served the criticism of Orpheus. This criticism can be soft, as in Clement who notes that this conversion is not complete ${ }^{37}$ or in the Ad Grae$\cos$ in which it is pointed out that it does not result from a personal choice, but from a decision of the Providence who made use of Orpheus as a tool for its own project. ${ }^{38}$ However the criticism can also be more aggressive: the legend serves the denunciation of Orpheus as the author of a vain and impious work - the introduction of polytheism - he is said to have abandoned himself later, ${ }^{39}$ or as a semi-prophet unable to transmit clearly the truth he had a glimpse of. ${ }^{40}$ Theodoret goes so far as to reverse the legend and denounces Orpheus as an apostate who first knew the truth, but made a bad use of it in order to deceive the Greeks and lead them to idolatry. ${ }^{41}$

\section{c. The chronological status}

A feature often linked with the figure of the theologian is its chronological status. The Christian writers insist on the fact that Orpheus was said to have preceded Homer in

31 Clem. Alex. strom. V 14, 116, 1; VI 2, 5, 3 and 2, 26, 1f; Eus. p.e. X 4, 10; Ps.-Just. coh. Gr. XXXV I 4; Kyr. Alex. c. Iulian. I 35 (cf. Ps.-Just. monarch. II 4); Didym. trin. II 27; Lact. inst. I 5, 4.

32 See Jourdan, Orphée et les Chrétiens (cf. fn. 1), I, 178-225.

33 Clem. Alex. protr. XII 120, 2-5.

34 Ps.-Just. coh. Gr. XIV 2.

35 Artapan in Eus. p.e. IX 27.

36 Ps.-Just. coh. Gr. XXXVI 4.

37 Clem. Alex. protr. VII 74, 4.

38 Ps.-Just. coh. Gr. XV 2.

39 Theoph. Ant. Autol. III 2, 2.

40 Aug. civ. XVIII 14; c. Faust. XIII 2 and 5.

41 Theod. affect. II $32 \mathrm{f}$. 
time. This statement serves two kinds of argumentation: the denunciation of paganism as a whole through its presumed founder; ${ }^{42}$ or, on the contrary, the exhortation to monotheism using the same founder of paganism, but presented as a convert. ${ }^{43}$ However, this primacy in time is also sometimes questioned in order to discredit the pagans' pretensions to superiority because they pretend to have come first. ${ }^{44}$ Moreover, the Christian writers also insist on the fact that Orpheus came after Moses in order to show that all kinds of culture and religion ultimately derive from the Prophet.

\section{d. The status of Barbarian}

Fourthly Orpheus the theologian is considered as a Barbarian. This feature, as was already pointed out, serves the criticism of the Greek culture as borrowed from foreign countries, ${ }^{45}$ but it is also used to the advantage of Orpheus himself, who is thus placed at the origin of the Greek culture ${ }^{46}$ and connected to other Barbarians, namely the Jews and Christians themselves. ${ }^{47}$

\section{f. The journey to Egypt}

Finally, the last feature linked to the status of Orpheus as theologian is the fiction of his journey to Egypt. It serves argumentations similar to the previous ones. On the one hand, it is used to discredit the primacy of the Greek culture because it was supposedly borrowed from Egypt. ${ }^{48}$ In this context, Egypt is either seen as the country of idolatry par excellence $e^{49}$ or, on the contrary, as the depository of the Hebrew religion. ${ }^{50}$ In both cases, the fiction contributes to denouncing Orpheus as a plagiarist. ${ }^{51}$

42 Athenag. leg. XVII 1; XVIII 3; Tat. orat. XLI 1f; Clem. Alex. protr. I 3, 1; strom. I 21, 131, 1; Epiph. haer. XXXIII 8, 9; Aug. civ. XVIII 14 and 37.

43 Ps.-Just. coh. Gr. XXXVI 4 (cf. monarch. II 4); Kyr. Alex. c. Iulian. I 35; Clem. Alex. strom. V 14, 116, 1; VI 2, 5,3 and 2, 26, 1 f; Eus. p.e. X 4, 10; cf. Didym. trin. II 27 and Lact. inst. I 5, 4 (though he never used the fiction himself).

44 Tat. orat. XLI 2 attributes Orpheus' work to Onomacritus and Clement of Alexandria follows him (strom. I 131, 1-5), adding that some Pythagoreers wrote a part of it (strom. I 15, 66, 2); see also Eusebius against Porphyry: Eus. p.e. III 9, 14; X 4, 4.

45 Tat. orat. I 2; XXVII 2; XLI 1f; Theoph. Ant. Autol. II 30; Clem. Alex. strom. I 15, 66, 1; Theod. affect. I 21; 114; II 30; 95; Epiph. haer. IV 2, $6 \mathrm{f}$.

46 Tat. orat. I 2; XXVII 2; XLI 1f.

47 This underlies Tatian's and Clement of Alexandria's reasoning.

48 Eus. p.e. III 9, 12; Theod. affect. I 21f; 96, 4f; Epiph. haer. IV 2, $6 \mathrm{f}$.

49 Eus. p.e. X 8, 1-16.

50 Theod. affect. II 32.

51 Clem. Alex. strom. V 14, 125, 1-126, 1. 
On the other hand, this journey is used as a proof of the encounter of Orpheus, directly or not, with Moses. ${ }^{52}$

\section{The singer and citharist}

The second main feature of Orpheus mentioned by the Christian writers is the figure of the musician, and more precisely of the singer and citharist. This figure is firstly the target of different accusations we have already seen. (Orpheus the singer is also accused of being a sophist, a charlatan and an instigator of sacrilegious myths. ${ }^{53}$ ) It is not sure that Ephrem discredits the miracles of Orpheus' songs in the underworld in comparison with the miracles of Christ victorious over Death. ${ }^{54}$

However, the figure of the singer is the one which has been the most used to link Orpheus and Christ, as Clement and the Roman iconography show. The evocation of the powers of the Orphic song enables Clement to enhance in contrast the efficiency of the Word. ${ }^{55}$

\section{Other legends}

There are still four episodes in the legend of Orpheus, but they are rarely evoked by the Christians, and when they are, it is always in an unfavourable manner.

First, the presence of Orpheus in the expedition of the Argonauts is just mentioned in chronological argumentations in order to insist either on Orpheus anteriority compared with other theologians ${ }^{56}$ or on the contrary to underline his coming after Moses. ${ }^{57}$

The descent into the underworld and the fact that Orpheus is murdered are only mentioned by Origen. But in doing so, Origen just replies to Celsus who pretended to make use of both these episodes to compare Orpheus and Christ at the disadvantage of the latter. ${ }^{58}$

Finally, the lack of virility or the pederasty attributed to the figure is just alluded to by Clement who uses these features as images to expose the idolatrous in Orpheus. ${ }^{59}$

52 Ps.-Just. coh. Gr. IX 3f; XIV 2; Eus. p.e. IX 27; X 8, 1-16; Theod. affect. II 30 and 32; cf. Clem. Alex. strom. I 15, 66, 2 about Pythagoras to whom Clement links Orpheus' doctrine (strom. I 21, 131, 3-5). 53 See fn. 30.

54 Carm. Nisib. XXXVI 5, 11.

55 This is the project achieved in Clem. Alex. protr., see Jourdan, Orphée et les Chrétiens (cf. fn. 1), I.

56 Lact. inst. I 5, 4.

57 Tat. orat. XLI 1; Clem. Alex. strom. I 21, 131, 1; Theod. affect. II 47 and 49; III 29.

58 Orig. Cels. II 55 f; VII 53.

59 Clem. Alex. protr. I 3, 1. 


\section{B. The literary and religious production attributed to Orpheus}

The Christian writers, however, don't make use only of the figure of Orpheus itself, but also of Orpheus' work, precisely of the theologian and mysteriological work ascribed to him and sometimes of the moral prescriptions he is said to have made. In all cases, the evocation of this work serves the criticism as well as the praise or the Christian appropriation of his lore.

\section{The Orphic theology}

\section{a. Orpheus' theology and theogony}

First of all, Orpheus' verses are often quoted or paraphrased in order to prove the impiety of the Greek theology because they offer many examples of atrocities (for instance the series of incests evoked in the Orphic theology ${ }^{60}$ or the presence of the figure of the snake emphasized by Athenagoras, Clement and Tatian ${ }^{61}$ ). Moreover, this poetry is a very good opportunity to criticise the materialism and immanentism inherent in the Greek religion. ${ }^{62}$ As a consequence Orpheus' theological work is mostly evoked in a manner that is unfavourable to the Greeks, but it cannot be forgotten that the Hymns, on the contrary, are quoted by Clement to show that they contain conceptions of the Divine similar to the ones described in the Bible. ${ }^{63}$ However, in this case, Clement resorts mostly to texts that have already been transformed by his Jewish and perhaps Christian predecessors.

\section{b. Pagan interpretations of this theology}

This Orphic theology had already been commented on by the pagans and the Christians don't omit to evoke these commentaries. ${ }^{64}$ They do so to justify the right to read the Bible allegorically, as Origen does. ${ }^{65}$ But they also support the view that paganism is synonymous with materialism because the Christian authors point out that these interpretations often lead to assimilating the gods with the four elements. ${ }^{66}$ Clement is an exception when he uses previous Stoic and Pythagorean interpretations of Orphic verses which he adapts to his own Christian eschatological views. ${ }^{67}$

60 Athenag. leg. XX 1-4; Tat. orat. VIII and X; Clem. Alex. protr. II 16, 1.

61 Athenag. leg. XX 1-4; Tat. orat. VIII; Clem. Alex. protr. II 12, 2; 16, 3.

62 Athenag. leg. XIX 1; XX 4f; Eus. p.e. III 9; Hom. Clem. VI 17; Greg. Naz. or. IV 115.

63 Clem. Alex. strom. V 14, 122, 2; 14, 128, 3.

64 Athenag. leg. XXII; Hom. Clem. VI 17-19; Clem. recogn. suppl. X 29f and 35f; Orig. Cels. I 18; Eus. p.e. III 9.

65 Orig. Cels. IV 17; cf. I 18.

66 Athenag. leg. XXII; Hom. Clem. VI 12 and 24; Eus. p.e. III 9; Theod. affect. III 44 and 54; Arnob. nat. V 32-45; Firm. err. I 1-7.

67 Clem. Alex. strom. V 8, 45, 5f; 8, 46, 4; 8, 49, $3 \mathrm{f}$. 


\section{c. Motives of the Orphic theology used by the Christian writers}

But the most interesting in this use of the Orphic theology is the choice of a series of motives that serves a Christian appropriation of the Orphic lore.

\section{c. 1. Motives of this lore}

First, the monism that impregnates this poetry is certainly the main reason for this appropriation and it had certainly already contributed to the choice of Orpheus by the Jews as author of the so-called Testament. ${ }^{68}$ Even when real pagan verses are quoted, the monism displayed by them is emphasized in order to show the agreement with the biblical message, such as in Clement. ${ }^{69}$

A series of other, less recurrent motives, is also used and transformed by the Christians.

The most noticeable are the following:

- The motive of the breath present in these verses: in the Pseudo-Clementine novel, it is pointed out in order to show a parallel with the breath of the Genesis $^{70}$ and Didymus the Blind resorts also to this motive present in a rewritten verse in order to read it as a prefigurative hint at the Holy Spirit and therefore at his doctrine of the Trinity. ${ }^{71}$

- A second motive is that of the god, Phanès or Protogonos, who, when appearing, makes all things appear with him: Lactantius, for instance, sees in him an image of the Creator ${ }^{72}$ and in the Theosophy of Tübingen this figure is associated with the Only Son, that is the Monogenes, seen as the agent of Creation. ${ }^{73}$

- The motive of the bisexual god (Zeus or Phanès, according to the version of the myth mentioned), is also used as image of the Creator in Clement ${ }^{74}$ (Lactance, however, denounces this motive as unsuitable to describe the birth of the Son ${ }^{75}$ ).

- The story of the swallowing of Phanès by Zeus and the regurgitation of all the gods by the same Zeus is mentioned by Clement who gives to it an eschatological meaning. ${ }^{76}$

- More generally, the fact that all the meaning of this poetry is supposed to be concealed and that Orpheus would have made a sharp distinction between the initiates and the non-initiates is evoked not only by Clement, but also by Theodoret

68 See Riedweg, Jüdisch-hellenistische Imitation (cf. fn. 12).

69 Clem. Alex. strom. V 14, 122, 2; 14, 128, 3.

70 Clem. recogn. suppl. X 32, 1.

71 Didym. trin. II 27.

72 Lact. inst. I 5, 4; cf. epit. 3.

73 II 9 Beatrice $=61$ Erbse.

74 Clem. Alex. strom. V 14, 125, 1-126, 4.

75 Lact. inst. IV 8, 4 and 6.

76 Clem. Alex. strom. V 14, 122, 2 f. 
who mentions it in order to justify the necessity of faith as a preliminary to gaining access to the knowledge about God. ${ }^{77}$

\section{c. 2. Pythagorean and Stoic (rather than Orphic or specifically Orphic) motives}

Although two other motives are more familiar, I would however tend to consider them Pythagorean and Stoic rather than Orphic (or specifically Orphic), namely the image of the body as grave of the soul - Augustin uses it as a good prefiguration of the Christian notion of the Original $\operatorname{Sin} ;{ }^{78}$ and the conception of the transmigration of the souls: Clement considers it as an image of the Last Judgement. ${ }^{79}$ As for the doctrine of the reincarnation, it is condemned by all Christian writers who mention it. ${ }^{80}$

\section{c. 3 Motives adduced by the Christian writers}

In addition, with their interpretation and rewriting of Orphic verses, the Christian writers themselves introduce new motives in this poetry. We have seen the introduction of the image of the Creator and of the Holy Spirit, but Clement even quotes a forged verse mentioning a relationship between Father and Son, showing that the core of the Christian faith is also present in a prefigurative way in this poetry. ${ }^{81}$

\section{c. 4. Presumed or "modern" Orphic motive: the Death of Dionysos}

Finally, there is a motif that must be evoked because it is actually more pointed out by modern scholars than by the Christian writers themselves in order to compare Orphism and Christianity, namely the story of Dionysos, his murder and resurrection, - a story, which does not actually specifically belong to the Orphic lore. Justin is the only one who sees a pagan plagiarism of biblical stories in it and he doesn't link it to Orpheus. ${ }^{82}$ Neither Clement, nor Arnobius or Firmicus who mention this story makes any comparison between it and Christ's lot $^{83}$ and it is not sure whether any of them tries to conceal the possibility of such a comparison. The parallel between the eating of Dionysos and the Eucharist or the comparison between the murder of the god and his consequences on humanity and the Original Sin is actually first of all the result of modern projections. ${ }^{84}$ The aim of such projections is to recon-

77 Theod. affect. I 114; II 86.

78 Aug. c. Iul. IV 15, 78; 16, 83.

79 Clem. Alex. strom. V 8, 45, $5 \mathrm{f}$.

80 Clem. Alex. strom. III 3, 13, 3; Greg. Naz. carm. I 1, 8, 22- 52 (PG 37, 448-450); Aug. c. Jul. IV 16, 83.

81 Clem. Alex. strom. V 14, 116, 2.

82 Just. dial. 69; apol. I 54.

83 Clem. Alex. protr. II 17, 2-18, 2; Arnob. nat. V 19; Firm. err. VI.

84 On this topic, see for instance Radcliffe Edmonds, “Tearing Apart the Zagreus Myth: A Few Disparaging Remarks on Orphism and Original Sin”, Classical Antiquity 18, 1999, 35-73; Fabienne Jour- 
struct orphism as a coherent system prefigurating - or at least having affinities with - Christianity or even sometimes with Protestantism. Even when Firmicus considers Dionysos as a sacrificial victim, his words are to be taken as an interpretatio christiana of the Greek episode he comments on. ${ }^{85}$

\section{The foundation of the mysteries}

The second work attributed to Orpheus, after his theology, is the foundation of the mysteries. The mention of these cults serves first of all the criticism of the impiety of the Greek traditions. ${ }^{86}$ However, the notion of mystery itself is welcomed in the Christian literature. Clement makes a rich use of it in order to exhort the pagans to convert and Theodoret takes up the same notion in order to justify his call to faith. ${ }^{87}$

What is more interesting here is that the Christian writers totally ignore the eschatological aspect of the Greek mysteries and the idea that they were conceived as a means of getting into contact with the gods. This concealment is certainly due to their own intention to underline these aspects in their own practices. ${ }^{88} \mathrm{At}$ least, they don't make the parallels drawn by some scholars of the nineteenth and of the beginning of the twentieth centuries who wanted to compare the mysteries and the Christian practices by pointing out the supposedly similar topics of death and resurrection, divine lineage, revelation, salvation, communion, and so on. All these topics have different meanings according to the framework in which they appear. ${ }^{89}$

dan, "Manger Dionysos. L'interprétation du mythe du démembrement par Plutarque a-t-elle été lue par les néo-Platoniciens?”, Pallas 67, 2005, 153-174 and Jourdan, Orphée et les chrétiens (cf. fn. 1), I, 195-8 and 217-20 with updated bibliography.

85 Firm. err. VI 5.

86 Tat. orat. VIII 6; X 1; Clem. Alex. protr. II 12-22; Eus. p.e. II 3, 23-34; Greg. Naz. or. IV 115; V 31; XXXIX 5; Theod. affect. I 114; Epiph. haer. IV 2, 6f; Aug. civ. XVIII 14.

87 Theod. affect. I 114; II 86.

88 See Clem. Alex. protr. XII $119 \mathrm{f}$.

89 See, contra Alfred Firmin Loisy, Les mystères païens et le mystère chrétien, Paris, [1914] 1930², who tried to draw many such parallels, André Boulanger, Orphée. Rapports de l'Orphisme et du Christianisme, Paris, 1925, 84-116; André Jean Festugière, L'Idéal religieux des Grecs et l'Évangile, Paris, 1932, 133-62; Martin P. Nilsson, Geschichte der Griechischen Religion II (Handbuch der Altertumswissenschaft 5.2), München, [1941] 1974³ , 685-93; Hugo Rahner, Mythes grecs et mystère chrétien, French transl. by Henri Voirin, Paris, 1954 [Griechische Mythen in christlicher Deutung, Zürich, 1945], 18-60; Arthur D. Nock, "Hellenistic mysteries and christian sacraments", Mnemosyne $4^{\text {th }}$ ser. 5, 1952, 178-213; the summary of the state of the research on this topic in Miguel Herrero de Jáuregui, Orphism and Christianity in Late Antiquity, Berlin, 2010; and my positions in Jourdan, Orphée et les chrétiens (cf. fn. 1), I, 160 f. 


\section{The ascetic way of life}

Orpheus is not only the author of a religious work, but is also supposed to have prescribed a specific way of life and diet. The most famous element of this diet is the ban on eating meat. This aspect of Orpheus' work is generally ignored by the Christians. I have found just one allusion to it by Hieronymus who praises Orpheus for having introduced vegetarianism - this allusion occurs in the context of the refutation of Jovinianus who denounces this practice. ${ }^{90}$

\section{A religion of the Book?}

Finally, a description of Orphism as a religion based on written lore could have been an expected thing, followed by a comparison with Christianity as the religion of the Book. This was indeed one of the most famous clichés prevailing until a few decades ago. However, this comparison is only suggested by Origen, and this in order to reply to Celsus who uses Orphic lore to support his views. ${ }^{91}$ On the contrary, Origen asserts that all Orphic writings have disappeared at his time of life in contrast with the Bible. He does not suppose that Orphic texts could have been a kind of Greek canon. This comparison has only a polemical value and must not be used to reconstruct a socalled Orphism.

\section{Conclusion: Motives used for the Christian appropriation of Orpheus and for the depiction of Christ as a new and better Orpheus}

As a conclusion the motives can be pointed out that contributed to the Christian appropriation of Orpheus and more precisely to the specific use of Orpheus by Clement to depict Christ as a new and better Orpheus. To me, there are four such motives: the existence of the Jewish-hellenistic discourse in which Orpheus praises monotheism; the status of Barbarian, which likens Orpheus to the Christians; the status of the very first theologian, which permits to assert that the seeds of Christianity are present at the beginning of the Greek religion itself; and finally, the image of the singer endowed with marvellous powers, leading to the link with the efficiency of the Word through the biblical image of the new Song. Clement adds the figure of David in his emphasis on the power of the Song, and even if he denies any comparison between the pagan citharist and the Psalmist, he paves the way for a development that will be made in the Middle Ages.

90 Hier. adv. Iovin. II 14 (PL 23, 304c).

91 Orig. Cels. I 18 (cf. Theod. affect. II 111). 


\section{Clifford Ando \\ Mythistory': The Pre-Roman Past \\ in Latin Late Antiquity}

It [the Origo gentis Romanae] is a work of mythography, not history. [And Roman mythography, as distinct from a handbook of Greek mythology that happens to be written in Latin...]

Alan Cameron ${ }^{2}$

\section{1.}

I quote as an epigraph an aside by Alan Cameron concerning the Origo gentis Romanae, the brief study of Roman pre-history transmitted with the corpus of Aurelius Victor. But the true object of my paper today is not that Origo, but rather the Origo gentis Romanorum, the very similar but also very different work included in the codex-calendar of 354. That Origo, I maintain, is a work of history, not mythography; and a work of Roman history at that. Although I will base those assertions primarily on a reading of the document's form, I would like to suggest that the similar focus of the two works at the level of content reflects a new context for the production of historical knowledge of Italy before Rome - of knowledge of Roman pre-history - in the emergent and evanescent contest between pagan and Christian priorities in the fourth century Latin west.

\section{2.}

The section of the Codex-Calendar with which I am here concerned commences under the title, "Likewise, the origin of the race of the Romans, from the time when they first began to rule in Italy": ${ }^{3}$

Picus the son of Saturn ruled in the Laurentine field, as far as the place where Rome now is, for 38 years. In that time there were neither cities nor villages, but they dwelled scattered here and there.

1 I adopt the term "mythistory" as it was revived for contemporary theory by William McNeill ("Mythistory, or Truth, Myth, History and Historians," AHR 91 [1986], 1-10), especially as elaborated in Joseph Mali, Mythistory. The Making of Modern Historiography (Chicago 2003). See also Donald R. Kelley, "Historia Integra: François Baudouin and his Conception of History," Journal of the History of Ideas 25 (1964), 35-57.

2 Alan Cameron, Greek Mythography in the Roman World (New York 2004), 328 and 328 n. 5.

3 "Chronographus anni CCCLIIII," in Theodor Mommsen, ed., Chronica Minora saec. IV. V. VI. VII. Volumen I. MGH AA 9 (Berlin 1892), 13-148, 143. 
Faunus the son of Picus ruled in the same place for 43 years. When in that time Hercules was returning from Spain, he built and dedicated the altar which is at Rome in the Forum Boarium, because he had killed Cacus the son of Vulcan there in a cave.

Latinus ruled in the same places ... He named his citizens "Latins" from his own name. Troy was captured during his reign, whence Aeneas the son of Venus and Anchises came and joined himself with Latinus and together they fought a war against the Rutulians. In that war Latinus was killed and his rule passed to Aeneas.

Aeneas founded the city of Lavinium and ruled there for thirty years.

Ascanius the son of Aeneas ruled for 36 years. He founded Alba Longa.

THE ALBAN KINGS

Postumius Silvius the grandson of Aeneas reigned 37 years. Those descended from him ruled afterwards at Alba and were called the Silvii.

Aeneas Silvius reigned 31 years.

Latinus 51.

Alba 28.

etc.

ITEM ORIGO GENTIS ROMANORVM, EX QUO PRIMVM IN ITALIA REGNARE COEPERVNT

Picus Saturni filius regnavit agro Laurentino usque ad eum locum ubi nunc Roma est, ann. XXXVIII. eo tempore ibi nec oppida nec vici erant, sed passim habitaverunt.

Faunus Pici filius eisdem locis regnavit annis XLIIII. eo tempore Hercules cum ab Hispania reverteretur, aram quae est Romae ad forum boarium posuit et dedicavit eo quod Cacum filium Vulcani ibi in spelunca sua occiderat.

Latinus isdem locis regnavit ... hic ex suo nomine cives suos Latinos appellavit. hoc regnante Troia capta est, unde Aeneas Veneris et Anchisae filius venit et se cum Latino iunxit unaque bellum gesserunt adversus Rutulos. eo proelio Latinus occisus est et regnum eius penes Aeneam remansit. Aeneas oppidum condidit Lavinium ibique regnavit annis tribus.

Ascanius Aeneae filius regnavit annis XXXVI. Albam longam condidit.

REGES ALBANI

Postumus Silvius Aeneae nepos regnavit ann. XXXVII. ab hoc prognati postea Albae regnaverunt ac Silvi sunt cognominati.

Aeneas Silvius regnavit annos XXXI.

Latinus $L I$.

Alba XXVIII.

$\ldots$

The text reflects three impulses that distinguish it from other texts that rehearse much the same or functionally similar information. First, the text commences before the start of Rome. Second, the information is presented systematically and serially, which is to say, available information is selected and ordered such that the totality is both comprehensive and without internal contradiction: there are no gaps; there is no doubt; there is little room for information or speculation outside the narrow demands of a chronological accounting of succession to rulership. Third, the somewhat undisciplined narrative listing that takes us from Picus - and by implication Saturn to Aeneas and Ascanius rapidly resolves to a true list. This occurs, I believe, in large measure because political power now exists in a context in which its narration can be reduced to the succession of individuals to stable office, which is to say, because the context is now the city ("Aeneas founded the city of Lavinium"; "He founded 
Alba Longa"). The discrete character of office holders is henceforth unimportant. Indeed, it would distract from what the list qua form is intended to convey, namely, stability at the level of civic institutions.

The Origo gentis Romanorum thus represents an effort to rewrite the history of Italy before the city of Rome as directly continuous with its history ab urbe condita, and the text advances that claim to continuity through the use of a characteristically Roman form for the organization of historical knowledge, namely, the list. (In so speaking, I should acknowledge a debt to two splendid articles by Jörg Rüpke on the list as Roman historical form. ${ }^{4}$ ) In this way, what had been a domain of merely mythological speculation is claimed instead as a domain of historical knowledge, with all the political implications that this act entails.

As we shall see, most other texts that provide such information deliver it piecemeal, subordinating it to different explanatory agendas and therefore conveying it in texts of quite distinct formal qualities. Let me now survey some of these, and in so doing attempt to isolate some of the distinctive features of Roman historical and social thought operative in these texts. With those in mind, I will return in closing to the two Origines.

\section{3.}

In texts of the classical period, mythological information of the sort selected and arranged in the Origo gentis Romanorum of the Codex-Calendar of 354 is generally conveyed in pursuit of one or another of three ends: postulating the existence of some pre-historical relationship among discrepant peoples, whether in terms of kinship or mere homology of culture or parallel historical development; offering an aetiology for a custom or rite; or explaining or commenting upon some prestige text.

So, for example, four chapters of Plutarch's Roman Questions contain information directly relevant to the history of Italy before the arrival of Aeneas. ${ }^{5}$ Bracketing the question of whether one should regard this text as pre-eminently Greek or Roman, one might reassemble the relevant information in chronological order as follows:

- Italy was first inhabited by barbarians who lived without settlements or agriculture; Janus came to Italy from over the sea and taught them agriculture and an orderly way of life (§ $22=$ mor. 269 A).

\footnotetext{
4 Jörg Rüpke, “Fasti: Quellen oder Produkte römischer Geschichtsschreibung?,” Klio 77 (1995), 184202; idem, “Geschichtsschreibung in Listenform: Beamtenlisten unter römischen Kalendern,” Philologus 141 (1997), 65-85. See also idem, “L’histoire des fasti romains: aspects médiatiques et politiques,” Revue historique de droit français et étranger 81 (2003), 125-40.

5 For elucidation of this difficult text I am indebted to John Scheid, ed., Plutarch. Römische Fragen: Ein virtueller Spaziergang im Herzen des alten Rom (Darmstadt 2012).
} 
- Or perhaps Kronos came first, also from over the sea $(\S 41=$ mor. $274 \mathrm{E})$, and while he was king the inhabitants of Italy had neither greed nor injustice - or perhaps he taught them farming ( $\$ 42=$ mor. $275 \mathrm{~A})$ ?

- Or there was a sequence Janus-Kronos or Kronos-Janus, followed by Evander and Aeneas, all coming from over the sea $(\S 41=$ mor. 274E).

In other words, one rapidly discovers that the material cannot in fact be resolved to any one schema, or at least, it is not presented with such an end in mind. The purposes for which the information is conveyed do not require this, nor, apparently, does the form of knowledge subtended by the Quaestiones or its literary form. That is to say, isolating cultural phenomena one from another, to each of which a discrete explanation is provided, did not require a response in the form of a systematized and internally consistent narrative, nor, apparently, did Plutarch expect readers to demand rationality at that level of the text as a whole. The form of inquiry, and the material under study, existed within an epistemic framework in which incoherence and contradiction were tolerated.

To skip ahead to the Roman Latin reception of this material at the end of the fourth century, which is to say, one or more generations after the writing of the two Origines, one might contrast with Plutarch's Quaestiones the treatment provided in the commentary on the Aeneid by Servius and the Saturnalia of Macrobius. I will naturally not have time to consider in detail all relevant material in Servius, a fact all the more lamentable when one considers the light Alan Cameron has shed on the literary culture of Rome in the era when it was written. ${ }^{6}$ But let me draw your attention to one feature of his text, and then illustrate that point. One might have expected the commentary to exhibit considerable similarity to the Quaestiones: points of information are adduced in explanation of isolated lemmata; and as a result, the "knowledge" conveyed by the commentary as a whole certainly had the potential to be non-systematic and under-rationalized. The commentary, moreover, would have "users" rather than "readers," which fact might have had implications for the coherence of its content.

But in point of fact, Servius takes considerable pains to present the history of Italy before Aeneas as both knowable and known, which is to say, as an object of historical knowledge; and in consequence requires of it (and Vergil's allusions to it) real coherence. Thus in commenting on Aeneid 1.1, Vergil's language must be so explained as to produce a systematic chronology of the arrivals in Italy of Antenor and Aeneas.

6 See esp. Alan Cameron, "Literary Allusions in the Historia Augusta," Hermes 92 (1964), 363-77, and idem, "The Fate of Pliny's Letters in the Late Empire," CQ 16 (1965), 289-98. For all its learning, the related chapter in Cameron's The Last Pagans of Rome (Oxford 2011), 567-626, seems to me diminished by its relentless and misguided concentration on what Cameron takes to be religious history. See also Philippe Brugisser, Romulus Servianus. La légende de Romulus dans les Commentaires à Virgile de Servius: mythographie et idéologie à l'époque de la dynastie théodosienne (Bonn 1987). 
QUI PRIMUS. Many ask, why he said that Aeneas was the first to come to Italy, when a little later he says that Antenor founded a city before the arrival of Aeneas, and indeed, it is agreed that he did so. But in observing the order of events, Vergil spoke learnedly. For at the time when Aeneas arrived in Italy, the boundary of Italy extended only to the Rubicon, which fact Lucan recalls... Whence it is clear that Antenor did not reach Italy but Cisalpine Gaul, where Venetia is. Afterwards in truth, the boundaries of Italy being moved to the Alps, novelty created the error. Nevertheless, many wish the question to be resolved by the following means, so that Vergil seem to have added the words "to Lavinian shores" on this ground, lest he signify Antenor. But the above explanation is the better one (Servius ad Aen. 1.1). ${ }^{7}$

Here the explanation is historical: the term Italy did not embrace land north of the Apennines when Aeneas arrived. (The Origo gentis Romanae offers a different explanation, namely, that primus can refer to priority in importance rather than time, an interpretation of the term also known to Servius [Origo gentis Romanae 1.1-9].)

Likewise, in commenting on Aeneid 1.2, the names of cities are given specific reference and origin and order in time, so as to produce a unitary history. The necessity to avoid contradiction is explicitly stated as an aim of the commentary in his remarks on Aeneid 1.6:

Genus unde Latinum. If the Latins already existed and Latium is mentioned, this is contradictory to his statement that the Latins trace their origin from Aeneas. A first and pleasing grounds for acquittal is as follows, that one does not use unde to refer to a person but to a place, for unde is an adverb that concerns place, not derivation from a person. Nevertheless, Cato in his Origines writes this, whose authority Sallust follows in Bellum Catilinae, namely, that the first to occupy Italy were called 'Aborigines'. After the arrival of Aeneas, having been joined to the Phrygians, these were called 'Latins' under a single name. Therefore the Latins descend not only from the Trojans but also from the Aborigines. But this is the true explanation. We know that the conquered take the name of the victor. Therefore, with Aeneas as victor, the nomen Latinum could perish. But wanting to render the Latins favorable to himself, he not only kept the name of Latin for them but even imposed it on the Trojans... Whence [Vergil] himself introduces Juno in the twelfth book asking that the Latin name may not perish. Likewise in the curse of Dido we read ... (Servius ad Aen. 1.6). ${ }^{8}$

7 QUI PRIMUS quaerunt multi, cur Aeneam primum ad Italiam venisse dixerit, cum paulo post dicat Antenorem ante adventum Aeneae fundasse civitatem. constat quidem, sed habita temporum ratione peritissime Vergilius dixit. namque illo tempore, quo Aeneas ad Italiam venit, finis erat Italiae usque ad Rubiconem fluvium: cuius rei meminit Lucanus ... unde apparet Antenorem non ad Italiam venisse, sed ad Galliam cisalpinam, in qua Venetia est. postea vero promotis usque ad Alpes Italiae finibus, novitas creavit errorem. plerique tamen quaestionem hanc volunt ex sequentibus solvi, ut videatur ob hoc addidisse Vergilius 'ad Lavinia litora', ne significaret Antenorem. melior tamen est superior expositio. 8 GENUS UNDE LATINUM si iam fuerunt Latini et iam Latium dicebatur, contrarium est quod dicit ab Aenea Latinos originem ducere. prima est iucunda absolutio, ut 'unde' non referas ad personam, sed ad locum; namque 'unde' adverbium est de loco, non de ductu a persona. tamen Cato in originibus hoc dicit, cuius auctoritatem Sallustius sequitur in bello Catilinae, primo Italiam tenuisse quosdam qui appellabantur Aborigines. hos postea adventu Aeneae Phrygibus iunctos Latinos uno nomine nuncupatos. ergo descendunt Latini non tantum a Troianis, sed etiam ab Aboriginibus. est autem vera expositio haec. novimus quod victi victorum nomen accipiunt. potuit ergo victore Aenea perire nomen Latinum. 
Servius thus has recourse to linguistic sleight of hand: unde refers to place and not to persons as agents. A potential misreading avoided, Servius can say, est autem vera expositio haec, this then is the true story, after which he affirms the truth of his reading by reference to its internal consistency with other details in the epic.

Of course, at times the data do not lend themselves to certain resolution. In commenting on Aeneid 7.47, Servius must examine a conflict between sources of varied genres, and likewise at Aeneid 7.48, he must acknowledge the existence of a conflict among possible sources. But in both cases, Servius would seem to demand that there have been a single truth: hence in the former passage, discrepancy is explained away by reference to poetic usage, while in the latter, by virtue of his use of accipimus, Vergil is read as accepting one account among many possible accounts, such that Vergil himself affirms that certainty is not possible. The same explanation is given in even fuller form in the commentary on Aeneid 7.678:

Many people have written partial studies about the cities of the world, the most full treatments being that of Ptolemy in Greek and Pliny in Latin. Concerning the cities of Italy, Hyginus has written most fully, and Cato in the Origines. If you pay close attention to them, disagreement is found regarding the agents of the foundation of cities, to such an extent that not even the origin of the city of Rome can be rigorously known... If, therefore, certain understanding is not clear regarding so great a city, it is not surprising if there is doubt in the case of others. Therefore we ought not to condemn on grounds of inadequacy historians or commentators saying varied things, for antiquity itself creates the error (Servius ad Aen. 7.678). ${ }^{9}$

But Servius goes on to seek, insofar as possible, to produce a systematic history, of both Lavinium (again) and of Praeneste.

With these priorities, when Servius turns in book 8 to the pre-history of Italy, he again attempts a systematic ordering of many of precisely those discrepant data that Plutarch had declined to systematize: Janus was first; Janus received Saturn; Saturn brought laws and agriculture; and so forth (Servius ad Aen. 8.319, 322, and 328).

The same impulse is visible in an even more totalizing way in the Saturnalia. Thus in chapter 1.7 of that work, namely, the chapter devoted to the origins of the Saturnalia, Praetextatus as speaker provides a systematic ordering of the very information provided by Plutarch, with the same datum serving, in circular fashion, as both pretext for the aetiology and as evidence for its correctness (what follows below is merely an excerpt):

sed volens sibi favorem Latii conciliare nomen Latinum non solum illis non sustulit, sed etiam Troianis inposuit. ... unde et ipse inducit in duodecimo libro rogantem Iunonem, ne pereat nomen Latinum. item in execratione Didonis legimus ...

9 De civitatibus totius orbis multi quidem ex parte scripserunt, ad plenum tamen Ptolomaeus graece, latine Plinius. de Italicis etiam urbibus Hyginus plenissime scripsit, et Cato in originibus. apud omnes tamen si diligenter advertas, de auctoribus conditarum urbium dissensio invenitur, adeo ut ne urbis quidem Romae origo possit diligenter agnosci. ... si igitur tantae civitatis certa ratio non apparet, non mirum si in aliarum opinione dubitatur. unde nec historicos nec commentatores varia dicentes imperitiae condemnare debemus: nam antiquitas ipsa creavit errorem. 
(19) The region now called Italy was ruled by Janus, who - as Hyginus reports, following Protarchus of Tralles - held this land together with Cameses, another native, in a power-sharing arrangement whereby the region was called Camesene, the settlement Janiculum. (20) This arrangement was later reduced to the sole rule of Janus, who is held to have had two faces, so that he could see what was in front of him and what was behind - something surely to be explained with reference to the shrewdness and cleverness appropriate to a king, who ought to know the past and foresee the future: compare Antevorta and Postvorta, whom the Romans worship as very fitting companions of divination. (21) When Saturn arrived by ship, he was received hospitably by Janus and taught him agriculture; and when Janus improved his way of life, which had been wild and uncouth before the fruits of the earth were discovered, he rewarded Saturn by making him a partner in his rule. (22) When Janus became the first to coin money, he maintained his respect for Saturn in this, too: because Saturn had arrived by ship, he had the likeness of his own head stamped on one side of the coin, a ship on the other, to preserve the memory of Saturn for posterity. We know that the bronze was stamped that way from the gambling game in which boys throw denarii high in the air and shout "head" or "ships," bearing witness to antiquity thereby. (23) We know that Janus and Saturn ruled together in harmony and collaborated in founding neighboring settlements from Maro, who reports,

This [settlement's] name was Janiculum, that one's Saturnia (Aen. 8.358),

and it's also obvious from the fact that later generations dedicated two neighboring months to them, so that December has the festival of Saturn while January has the other's name. (24) When Saturn suddenly disappeared in the middle of their reign, Janus devised a way to increase his honors. First he named his entire kingdom "Saturnia," then he established an altar, as though for a god, and sacred rites that he called the "Saturnalia": by so many centuries do these rites antedate the city of Rome (Macrobius Saturnalia 1.7.19-24; trans. R. A. Kaster). ${ }^{10}$

What is more, Macrobius adopts from Plutarch and Peripatetic cultural history many of the same anthropological interests: how and when were rites established; what was life like before farming; and so forth. But unlike Plutarch, Macrobius feels an

10 (19) Regionem istam, quae nunc vocatur Italia, regno Ianus optinuit, qui - ut Hyginus Protarchum Trallianum secutus tradit - cum Camese aeque indigena terram hanc ita participata potentia possidebant, ut regio Camesene, oppidum Ianiculum vocitaretur. (20) Post ad Ianum solum regnum redactum est, qui creditur geminam faciem praetulisse, ut quae ante quaeque post tergum essent intueretur: quod procul dubio ad prudentiam regis sollertiamque referendum est, qui et praeterita nosset et futura prospiceret, sicut Antevorta et Postvorta, divinitatis scilicet aptissimae comites, apud Romanos coluntur. (21) Hic igitur Ianus, cum Saturnum classe pervectum excepisset hospitio, et ab eo edoctus peritiam ruris, ferum illum et rudem ante fruges cognitas victum in melius redegisset, regni eum societate muneravit. (22) Cum primus quoque aera signaret, servavit et in hoc Saturni reverentiam ut quoniam ille navi fuerat advectus, ex una quidem parte sui capitis effigies, ex altera vero navis exprimeretur, quo Saturni memoriam in posteros propagaret. Aes ita fuisse signatum hodieque intellegitur in aleae lusu, cum pueri denarios in sublime iactantes capita aut navia lusu teste vetustatis exclamant. (23) Hos una concordesque regnasse vicinaque oppida communi opera condidisse - praeter Maronem, qui refert, Ianiculum huic, illi fuerat Saturnia nomen - etiam [ob] illud in promptu est, quod posteri quoque duos eis continuos menses dicarunt, ut December sacrum Saturni, Ianuarius alterius vocabulum possideret. (24) Cum inter haec subito Saturnus non comparuisset, excogitavit Ianus honorum eius augmenta ac primum terram omnem dicioni suae parentem Saturniam nominavit, aram deinde cum sacris tamquam deo condidit, quae Saturnalia nominavit: Tot saeculis Saturnalia praecedunt Romanae urbis aetatem. Observari igitur eum iussit maiestate religionis quasi vitae melioris auctorem: simulacrum eius indicio est, cui falcem, insigne messis, adiecit. 
urgent need to produce a unified account: hence the claim, later in book 1, that it is in fact possible to produce a single statement of what the mythici and physici say concerning Janus:

(1) I've recalled now that Janus ruled with Saturn and what the mythographers and physical scientists have to say about the latter: now I'll present what both groups claim about Janus. (2) The mythographers report that under Janus' rule everyone's homes were well fortified by an aura of holiness and religious scruple: for that reason it was decreed that he be worshipped as a god, and because of his benefactions the entrances and exits of buildings were consecrated to him. (3) Xenon, too, in the first book of his Italica, relates that Janus was the first to build temples to the gods in Italy and to establish sacred rites, and for that reason he earned the right always to be named first when rituals are performed (Macrobius Saturnalia 1.9.1-3; trans. R. A. Kaster). ${ }^{11}$

This demand for certain and systematic knowledge is, I would argue, a paradoxical consequence of Macrobius's desire to situate the origins of the Saturnalia "centuries before the foundation of Rome," as he often avers. ${ }^{12}$ In other words, the drive to prehistory does not issue in an allowance for uncertainty or incoherence, but the opposite. Indeed, one might say that Macrobius, like the author of the Origo gentis Romanorum, seeks to render myth as history.

\section{4.}

The emergence of these trends toward systematization and rationalization in the ordering of knowledge, and towards pre-history as a focus of that knowledge, needs to be understood in light of earlier priorities and commitments in respect to the function of myth and the nature of historical inquiry in classical Rome. Let me say a few brief words about these issues in turn.

First, even in systematizing works like the chronicle of Cornelius Nepos, an author of obvious importance to the neoteric and Alexandrian poets of the second half of the first century, the overwhelming ideological drive does not appear to have been to produce a coherent history of pre-Roman Italy, that being a product for which there was then no need. Nepos seems rather to have been motivated by the traditional ambitions of Hellenistic mythography and chronography, namely, establishing pre-historical kinships among peoples and demonstrating synchronisms in their sub-

11 (1) Et quia Ianum cum Saturno regnasse memoravimus, de Saturno autem quid mythici, quid physici aestiment iam relatum est: de Iano quoque quid ab utrisque iactetur in medium proferemus. (2) Mythici referunt regnante Iano omnium domos religione ac sanctitate fuisse munitas idcircoque ei divinos honores esse decretos et ob merita introitus et exitus aedium eidem consecratos. (3) Xenon quoque primo Italicon tradit Ianum in Italia primum dis templa fecisse et ritus instituisse sacrorum, ideo eum in sacrificiis praefationem meruisse perpetuam.

12 See e.g. Macrobius Saturnalia 1.7.24, quoted above, as well as 1.7.36: Et Praetextatus: 'bene et opportune similis emendatio sacrificiorum relata est; sed ex his causis, quae de origine huius festi relatae sunt, apparet Saturnalia vetustiora esse urbe Roma ...' 
sequent history. ${ }^{13}$ Thus Italian pre-history is not an object of interest in its own right, but only insofar as Italy and Greece can be shown to have existed in simultaneity: Homer and Hesiod lived while the Silvii were ruling at Alba, and 160 years before the founding of Rome (Chronica fr. 1 FRHist = fr. 2 Peter = Gellius 17.21.3); Archilochus flourished when Tullius Hostilius ruled at Rome (Chronica fr. 4 FRHist = fr. 4 Peter = Gellius 17.21.8); and so on. Like others, Nepos is interested in the extra-Italian origins of various Italian peoples, including the Veneti (Exempla fr. 7 FRHist $=$ fr. 14 Peter = Pliny Nat. 6.5). His efforts might be most notable for extending this framework for the political use of myth to his own people, as it were (Exempla fr. 10 FRHist = fr. 9 Peter = Pliny Nat. 3.125):

Melpum, too, perished; it was outstanding for its wealth. Cornelius Nepos says that it was destroyed by the Insubres, Boii and Senones on the same day that Camillus took Veii. ${ }^{14}$

Nepos here seeks to embrace the history of Transpadana within the network of cities whose histories counted, and which therefore counted as cities, within the larger Mediterranean world. ${ }^{15}$

\section{5.}

The subject of the city brings me to a more complex topic, namely, the relationship between a theory of politics, or perhaps a political anthropology, and the nature and politics of historical knowledge. This is a topic about which I have written at length elsewhere - and within the narrow domain of religion it has been the focus of recent work by myself, as well as Hubert Cancik and Jörg Rüpke. ${ }^{16}$ I will therefore write briefly and only insofar as necessary to the topic of this essay, and I will choose examples pertinent to the themes treated by the other passages that I cite.

Roman authors of the classical period consistently maintained that human communities have a history only once they have constituted themselves as a polity. By

\footnotetext{
13 Synchronisms in ancient culture are a major theme of Denis Feeney, Caesar's Calendar. Ancient Time and the Beginnings of History (Berkeley 2007), esp. 7-67.

14 [Interiit] ... item Melpum opulentia praecipuum, quod ab Insubribus et Bois et Senonibus deletum esse eo die, quo Camillus Veios ceperit, Nepos Cornelius tradidit.

15 For a fuller study of Nepos as Transpadane historian see Clifford Ando, "The Changing Face of Cisalpine Identity," in Alison Cooley, ed., A Companion to Roman Italy (Oxford, forthcoming).

16 Hubert Cancik, "Historisierung von Religion: Religionsgeschichtsschreibung in der Antike (Varro - Tacitus - Walahfrid Strabo)," in Glenn Most, ed., Historicization = Historisierung (Göttingen 2001), 1-13; Clifford Ando, “The Ontology of Religious Institutions," History of Religions 50 (2010), 54-79; idem, "The Roman City in the Roman Period," in Stéphane Benoist, ed., Rome, a City and its Empire in Perspective: The Impact of the Roman World Through Fergus Millar's Research. Rome, une cité impériale en jeu: l'impact du monde romain selon Fergus Millar (Leiden 2012), 109-124; idem, Religion et gouvernement dans l'empire romain (Turnhout 2014), chapter 4; Jörg Rüpke, "Do Gods Have a History? Historicisation of Religion in the Roman Republic," History of Religions 53 (2014) 246-268.
} 
contrast, one might say of Aristotle that for him, the oikos has an ontology that both transcends and predates the political, and one could make a similar claim for the cultural histories produced by both Dicaearchus and Theophrastus. For Romans, by contrast, history commences $a b$ urbe condita.

Consider, for example, the histories of law and religion. As we have seen, in the mythological tradition in the classical period, and also in texts produced by intellectuals of the fourth and early fifth century, laws were first established in Italy by Kronos or Saturn, even as religion as a disposition might have existed already under Janus. But when jurists of the classical period wrote histories of law, they urged that law could only have a history when there existed politically-articulated populations to create laws with which to govern themselves. Consider first the handbook of Pomponius:

Accordingly, it seems that we must account for the origin and development of law itself. (1) The fact is that at the outset of our civitas, the populus decided to conduct its affairs without fixed statute law or determinate legal rights; everything was governed by the kings by their own hand. (2) When the civitas subsequently grew to a reasonable size, then Romulus himself, according to the tradition, divided the citizen body into thirty parts and called them curiae on the grounds that he improved his curatorship of the commonwealth (reipublicae curam) through the advice of these parts. And accordingly, he himself enacted for the people a number of statutes passed by advice of the curiae; his successors legislated likewise (Pomponius Encheiridion fr. 178 Lenel = Dig. 1.2.2.pr.-2; trans. de Ste. Croix). ${ }^{17}$

And then the commentary on the Twelve Tables by Gaius:

Since I am aiming to give an interpretation of the ancient laws, I have concluded that I must trace the law of the Roman people from the very beginning of their city, not because I like to make excessively wordy commentaries, but because I can see that in every subject a perfect job is one whose parts hang together properly: and certainly the most important part of anything is its beginning (Gaius ad legem duodecim tabularum bk. 1 fr. 418 Lenel = Dig. 1.2.1; trans. de Ste. Croix). ${ }^{18}$

Although the opening sentence of Pomponius might seem to suggest that the "origin of law itself" is chronologically prior to, or perhaps transcends, the foundation of the Roman community, the origin of law not only postdates the mere aggregation of persons under royal rule, but occurs in consequence of the political articulation of the

17 Necessarium itaque nobis videtur ipsius iuris originem atque processum demonstrare. (1) Et quidem initio civitatis nostrae populus sine lege certa, sine iure certo primum agere instituit omniaque manu a regibus gubernabantur. (2) Postea aucta ad aliquem modum civitate ipsum Romulum traditur populum in triginta partes divisisse, quas partes curias appellavit propterea quod tunc rei publicae curam per sententias partium earum expediebat. et ita leges quasdam et ipse curiatas ad populum tulit: tulerunt et sequentes reges.

18 Facturus legum vetustarum interpretationem necessario prius ab urbis initiis repetendum existimavi, non quia velim verbosos commentarios facere, sed quod in omnibus rebus animadverto id perfectum esse, quod ex omnibus suis partibus constaret: et certe cuiusque rei potissima pars principium est. 
people as a community of citizens capable of deliberation and self-rule. We see an identical claim in respect to the historical ontology of law in Gaius, where he insists a history of law must begin $a b$ urbis initiis, "from the foundation of the city".

Likewise as regards the history of religion as described by Varro (see esp. Antiquitates rerum divinarum frr. 2 A, 5 \& 12 Cardauns). As is well known, Varro distinguished sharply between three ways of talking about religion: a scientific mode, concerned with the nature of the gods themselves; a poetic mode, concerned with myth as rehearsed by various literatures; and civic religion, that is, religion as a set of practices and institutions among a particular population. Within this last framework, religion can only have a history once there exists a political community to endow institutional forms with legitimacy and permanence:

Wherefore he wrote first about human things and later about divine ones ..., because political communities come into being first and later the things instituted by them. ... Just as the painter is prior to the painting, or the builder to the building, so political communities are prior to those things that are instituted by political communities (Varro Antiquitates rerum divinarum fr. 5 [4] Cardauns). ${ }^{19}$

Or again, in fragment 12, Varro allows that he conducts his inquiry in vetere populo, and hence he must restrict his scope to the historiam nominum et cognominum that has been received $a b$ antiquis. ${ }^{20}$

Now, the Romans knew that populations and cities had histories that predated the narrowly political acts that sometimes brought civic institutions to life. In particular, they knew well that colonial foundations often occurred de novo rather than ex nihilo. This produced an important tension in Roman historical awareness. On the one hand, the prior existence of some polity in spaces now occupied by a Roman colony was necessarily obscured by the institutions of public memory common to Greek and Roman civic life, by which the past before the new beginning becomes knowledge we must remember to forget. At the same time, the Romans much more than the Greeks tended to preserve awareness of the pre-colonial past as a fundamental feature of metropolitan knowledge. Hence notices of colonial foundations in Roman authors often quite specifically recall a site's pre-Roman past at the moment of its erasure. ${ }^{21}$

19 Propterea se prius de rebus humanis, de divinis autem postea scripsisse ... quod prius extiterint civitates, deinde ab eis haec instituta sint. ... Sicut prior est ... pictor quam tabula picta, prior faber quam aedificium, ita priores sunt civitates quam ea, quae a civitatibus instituta sunt.

20 Varro Antiquitates rerum divinarum fr. 12 (55) Cardauns: Non se illa iudicio suo sequi, quae civitatem Romanam instituisse ... si eam civitatem novam constitueret, ex naturae potius formula deos nominaque eorum se fuisse dedicaturum. ... Sed iam quoniam in vetere populo esset, acceptam ab antiquis nominum et cognominum historiam tenere, ut tradita est, debere se ... et ad eum finem illa scribere et perscrutari, ut potius eos magis colere quam despicere vulgus velit.

21 See, e.g., Livy 9.28.7 (Suessa et Pontiae eodem anno coloniae deductae sunt. Suessa Auruncorum fuerat; Volsci Pontias, insulam sitam in conspectu litoris sui, incoluerant) or 10.1.1-2 (... Soram atque Albam coloniae deductae. Albam in Aequos sex milia colonorum scripta. Sora agri Vosci fuerat, sed pos- 
Translated into a narrowly Roman context, what this historical self-consciousness produced in late antiquity was an amusing sense of disquiet. Rome had to have a history before Rome; nothing was truly new under the sun, least of all the sites of cities. Vergil's poem explained that pre-history and indeed its central conundrum. As with the foundation of colonies on territory seized from defeated populations, so in general, the naming of a community and its city, and the choice of its language, are all the victor's to dispose. One was therefore compelled to ask, why do the Romans not speak Trojan? The answer: Aeneas did win the war with the Rutulians, of course, but he surrendered the rights of the victor in pursuit of reconciliation, thus fulfilling the promise of Jupiter to Juno in the twelfth book.

\section{6.}

Before I proceed to offer some conclusions, I should acknowledge that the patterns that I here describe do not obtain everywhere. The genres of chronography and universal history both staked totalizing claims to knowledge that entailed further, related claims to systematicity and demanded coherence of their data. In consequence, Latin exemplars of these genres of the classical period do of course occasionally provide surveys of Italian pre-history, which is to say, histories of Italy before Rome. Hence the first fragment of Nepos's Chronica refers to Saturn:

All Greek and Roman writers of antiquity admit that Saturn, the chief of this race, was a man. Nepos and Cassius know this in their histories, and Thallus and Diodorus say it, too (Chronica fr. 2c FRHist $=$ fr. 1 Peter $=$ Minucius Felix Octavius 21.4).$^{22}$

Nonetheless, if we understand the deictic "this" in the phrase "this race" to derive from Nepos's own diction, then even this claim is a relational one: Saturn is the princeps of this race, as others are the principes of other races.

One should also cite the universal history of Pompeius Trogus. In the epitome of that work by Justin, we reach the early history of Italy in book 43. It seems clear from chapter 43.1.3 and following that Trogus did produce a unified account of Italy from the reign of Saturn, nor is it surprising that this was possible. Nevertheless, it seems worthwhile observing, too, that in the epitome of Justin, the opportunity to invent a continuous history is very importantly declined:

Some time afterwards, he [Aeneas] went to war with Mezentius, king of the Etrurians, and being killed in it, Ascanius his son succeeded him, who, removing from Lavinium, built Alba Longa,

sederant Samnites; eo quattuor milia hominum missa) or Festus s.v. Saticula 458 L (Sati<cula oppid >um in Samnio captum est: quo <postea colon>iam deduxerunt triumviri M. Valerius Corvus, Iunius Scaeva, P. Fulvius Longus ex senatus consulto Kal. Ianuaris P. Papirio Cursore, C. Iunio II. Cos.).

22 Saturnum enim principem huius generis et examinis omnes scriptores vetustatis Graeci Romanique hominem prodiderunt. scit hoc Nepos et Cassius in historia et Thallus ac Diodorus hoc loquuntur. 
which for three hundred years was the capital of his kingdom. (2.1) At length, after many kings had reigned in this city, Numitor and Amulius became joint sovereigns (Justin Epitoma historiarum Philippicarum Pompei Trogi 43.1.13-43.2.1; trans. after John Shelby Watson). ${ }^{23}$

But Trogus is exceptional. On the contrary, it was, I think, precisely because of their commitment to commencing the narration of history with the foundation of Rome because of their commitment to understanding history as occurring within political societies, which is to say, within juridically articulated civitates - that Romans did not write universal history.

\section{7.}

Let me conclude by returning to late antiquity. The Origo gentis Romanae represents a curious hybrid of the genres we have considered thus far. ${ }^{24}$ On the one hand, its opening chapters clearly participate in the project of a Servius or Macrobius, in so far as it seeks to vindicate the truth of details in Vergil's Aeneid. Hence, as I have already remarked, the Origo defends the use of primus in respect to Aeneas by glossing it with princeps (1.4). And on the other, the Origo is subordinated to an overall project that tells the pre-history of Rome as continuous with the later history of the city down to the present day:

The origin of the Roman people from its founders Janus and Saturn through the kings succeeding one another until the tenth consulate of Constantius ... ${ }^{25}$

These phrases contain a variety of interesting elisions and equations. Most importantly, the history of the people before it was a populus is rendered continuous with the history of the people as a polity: the gens becomes the precursor to the civitas. That move, which is to say, the effacing of the foundation as a turning point in history, indeed, as the beginning of history, is itself made possible by another elision, this time of the Republic. Observe that the Preface asserts the continuity of Roman history from Janus to Constantius by reference to a continuity of kings: per succedentes sibimet reges.

23 Bellum deinde adversus Mezentium, Etruscorum regem, gessit, in quo cum ipse occidisset, in locum eius Ascanius filius successit, qui Lavinio relicto Longam Albam condidit, quae CCC annis caput regni fuit. (2.1) Post multos deinde huius urbis reges ad postremum Numitor et Amulius regno potiti sunt. 24 Studies of the text abound, but they display a rather relentless focus on Quellenforschung and mythological content rather than offering readings of the text in its context of production. See most recently Hans Jürgen Hillen, Von Aeneas zu Romulus (Düsseldorf 2003); Markus Sehlmeyer, Origo Gentis Romanae (Darmstadt 2004); and Christopher J. Smith, "The Origo gentis Romanae: Facts and Fictions," Bulletin of the Institute of Classical Studies of the University of London 48 (2005), 97-136.

25 ORIGO GENTIS ROMANAE a Iano et Saturno conditoribus, per succedentes sibimet reges, usque ad consulatum decimum Constantii ... 
The relationship of this second, overtly political project to the first, which is to say, the project of exegesis, is not straightforward. In the political project, Vergil can of course be adduced as providing verification of details of many kinds, notably concerning Saturn (3.1-5). But it is crucial to observe that neither Vergil in the west nor Homer in the east - despite their status as prestige texts par excellence in their respective cultures - can any longer suffice as a proof text for culture writ large. They were no longer the only prestige texts in the social worlds in which they were read, and in those new worlds, it was no longer sufficient to have only pointillist knowledge of the pre-Roman past, discontinuous data attached to lemmata from a poem that itself narrated only a few months. To be sure, Servius and no doubt others presented the Aeneid as containing the whole of the gesta populi Romani. But this only drew attention to its partial nature. Neither its discontinuities, nor its form, sufficed to provide the quality of knowledge that the historical self-awareness of a legitimate Graeco-Roman polity required. It was this lack that called forth in high and late antiquity histories of the Roman gens, and likewise histories of Roman institutions that were, paradoxically, so many centuries older than the city of Rome. ${ }^{26}$

Let me now state clearly what I have heretofore implied. The new emphasis in late antiquity on the writing of pre-history, which is to say, this new desire to rewrite myth as history, is a response to the emergence of Judaeo-Christian narrative. What is more, I believe its emergence in the fourth century had a political dimension, even in the narrow sense. As earlier Rome had required mythological connections to the Greek world, and so these were generated by everyone from Cato to Nepos, so now Rome required a past to rival the one that commenced in the Torah. Indeed, one might say that it was precisely the ideological priority given by Biblical narrative to a non-poliadic people that compelled this re-orientation in anthropological awareness within Roman historical self-understanding. The politics of this moment faded, of course, even if the knowledge it produced lived on. I observe in closing that Paul the Langobard's continuation of Eutropius is not merely a continuation into the present, but also the past: in his version, the history of Rome commences with Janus. ${ }^{27}$

26 Here this essay converges with an earlier study, Clifford Ando, "The Palladium and the Pentateuch: Towards a Sacred Topography of the Later Roman Empire,” Phoenix 55 (2001), 369-410, at 383-397 = idem, The Matter of the Gods (Berkeley 2008), 168-186. Also, it is precisely this need to understand mythistorical inquiry in the broadest possible context that handicaps Markus Sehlmeyer's learned study, Geschichtsbilder für Pagane und Christen. Res Romanae in den spätantiken Breviarien (Berlin 2009).

27 Paul, Historia Romana bk. 1 commences: Primus in Italia, ut quibusdam placet, regnavit Ianus. deinde Saturnus, Iovem filium e Graecia fugiens, in civitate, quae ex eius nomine Saturnia dicta est, cuius ruinae hactenus cernuntur in finibus Tusciae haud procul ab urbe. ... 


\section{Geteilte und umstrittene Geschichten: Der Chronograph von 354 und die Katakombe an der Via Latina}

\section{Einleitung ${ }^{1}$}

Der als Chronograph von 354 bezeichnete luxuriöse Buchkalender ist als eine zentrale Quelle für die Geschichte der Religion, des Heidentums ${ }^{2}$ als auch des Christentums genutzt worden. ${ }^{3}$ Seine Kalender, in Form sowohl römischer fasti als auch christlicher ferialia ${ }^{4}$ bieten vereinzelte Belege für den christlich liturgischen Kalender des vierten Jahrhunderts beziehungsweise den ersten Beweis für diese Kalender überhaupt. Da die christliche Identität des Urhebers und des originären Rezipienten zu keinem Zeitpunkt angezweifelt worden ist, hat sich die Analyse auf den internen Grad der Christianisierung konzentriert. Die Verknüpfung von heidnischem und christlichem Material ist als ein Indikator des Christianisierungsprozesses der römischen Aristokratie während des vierten Jahrhunderts angesehen worden. ${ }^{5}$

1 Ich bin dankbar für die kritischen Anmerkungen in verschiedenen Stadien der Textentstehung im Rahmen der Kolleg-Forschergruppe „Religiöse Individualisierung in historischer Perspektive“ und der Diskussion während der Mythologie-Tagung in Frankfurt, insbesondere Clifford Ando, Marlis Arnhold, Kim Bowes, Kate Cooper, Richard Gordon, Hartmut Leppin, Winrich Löhr und Eric Rebillard. Frau Ngoc-An Phan Tran, Erfurt, danke ich für die intensive sprachliche Textbearbeitung und Übersetzungen.

2 Z.B. Michele Renée Salzman, On Roman Time:The Codex-Calendar of 354 and the Rhythms of Urban Life in Late Antiquity (The Transformation of the Classical Heritage 17), Berkeley 1990.

3 Z.B. Hansjörg auf der Maur, „Feste und Gedenktage der Heiligen“, in: Philipp Harnoncourt und Hansjörg auf der Maur (Hrsg.), Feiern im Rhythmus der Zeit II/1 (Gottesdienst der Kirche: Handbuch der Liturgiewissenschaft 6,1), Regensburg 1994, 65-357; Karl-Heinrich Bieritz, „Gottesdienst und Gesellschaft“, in: Martin Klöckener, Angelus A. Häußling und Reinhard Meßner (Hrsg.), Gottesdienst der Kirche: Handbuch der Liturgiewissenschaft 2: Theologie des Gottesdienstes Band 2: Gottesdienst im Leben der Christen, Regensburg 2008, 83-158.

4 Für das Genre siehe Jörg Rüpke, The Roman Calendar from Numa to Constantine: Time, History and the Fasti, Malden, Mass. 2011; Jörg Rüpke, Kalender und Öffentlichkeit: Die Geschichte der Repräsentation und religiösen Qualifikation von Zeit in Rom (Religionsgeschichtliche Versuche und Vorarbeiten 40), Berlin 1995, 527-533.

5 Salzman (s. Anm. 2); Michele Renée Salzman, „How the West Was Won: The Christianization of the Roman Aristocracy in the West in the Years after Constantine“, in: Carl Deroux (Hrsg.), Studies in Latin Literature and Roman History 6 (Collection Latomus 217), Bruxelles 1992, 451-479; Michele Renée Salzman, „The Christianization of Sacred Time and Sacred Space“, in: William V. Harris (Hrsg.), The Transformations of Urbs Roma in Late Antiquity (JRA Suppl. 33), Portsmouth, Rhode Island 1999, 123 134; Michele Renée Salzman, The Making of a Christian Aristocracy: Social and Religious Change in the Western Roman Empire, Cambridge, Mass. 2002; Michele Renée Salzman, RAC 19 (2001), 1177-1191, s.v. 
Die Frage nach „antiker Mythologie in christlichen Kontexten der Spätantike“ bietet die Gelegenheit, die binäre Opposition, welche vielen Analysen des Dokuments zugrunde liegt, infrage zu stellen und eine neue Perspektive auf den Stellenwert der Religion innerhalb der spätantiken Gesellschaft sowie die komplexe Beschaffenheit von Religion zu eröffnen. Mythologie verstehe ich dabei nicht auf einen Kanon antiker Erzählungen von Göttern und Menschen eingeengt, sondern gehe gerade für Rom von der Beobachtung aus, dass die Grenzen zwischen mythologischen und historischen Erzählungen in der Form wie im Gegenstand fließend sind; in der Funktion kommt es im Blick auf räumliche, soziale und politische Identitäten sogar zu weiten Überschneidungen. Um so wichtiger ist daher die Frage nach den Kontexten solcher Erzählungen, und zwar nicht nur bezogen auf weitere Texte und die durch sie rekonstruierbare Kommunikation, sondern auch im Blick auf physische Räume und Bilder. Das lässt sich im vorliegenden Fall nur begrenzt erreichen, aber doch als Frage formulieren. Das Ziel dieses Beitrags ist es daher, den sozialen und kulturellen Ort und Kontext eines zwar nicht erhalten gebliebenen, aber - dank des Interesses und der Sorgfalt späterer Nutzer und Nachahmer - in seinen Inhalten und Wortlauten als auch in seiner visuellen Ausprägung rekonstruierbaren Kodex klarer aufzuzeigen. ${ }^{6}$ Das bietet die Grundlage für eine sorgfältige Analyse des Buchs, nicht nur als eine Zusammenstellung und ein Objekt der Quellenforschung, sondern auch als ein ganz vereinheitlichtes Werk. Die wohl zeitgleich ausgemalte Katakombe der Via Latina wird ganz zum Schluss meiner Erörterung aufgegriffen, um den isolierenden Blick auf den Text in der Frage nach Räumen und Bildern zu überwinden.

„Kalender II: Chronograph von 354“; Johannes Divjak, „Der sogenannte Kalender des Filocalus“, in: Adolf Primmer, Kurt Smolak und Dorothea Weber (Hrsg.), Textsorten und Textkritik: Tagungsbeiträge (Österreichische Akademie der Wissenschaften, Philosophisch-Historische Klasse: Sitzungsberichte Bd. 693), Wien 2002, 19-38; Gerhard Binder (Hrsg.), Der Kalender des Filocalus oder der Chronograph vom Jahre 354, Meisenheim/Glan 1970; Karl Kempter, Der Kampf des römischen Staates gegen die fremden Kulte, (Diss.) Tübingen 1941; Theodor Mommsen, „Über den Chronographen vom J. 354“, in: Abhandlungen der philologisch-historischen Classe der Königlich-Sächsischen Gesellschaft der Wissenschaften 1, Leipzig 1850, 547-693; Wolfgang Wischmeyer, „Die christlichen Texte im sogenannten Filocalus-Kalender“, in: Adolf Primmer, Kurt Smolak und Dorothea Weber (Hrsg.), Textsorten und Textkritik: Tagungsbeiträge (Österreichische Akademie der Wissenschaften, Philosophisch-Historische Klasse: Sitzungsberichte Bd. 693), Wien 2002, 45-67. Siehe auch Raban von Haehling, Die Religionszugehörigkeit der hohen Amtsträger des Römischen Reiches seit Constantins I. Alleinherrschaft bis zum Ende der Theodosianischen Dynastie (324-450 bzw. 455 n. Chr.) (Antiquitas 3,23), Bonn 1978.

6 Siehe Salzman (s. Anm. 2), 249-268. Der Kalender wurde in karolingischer Zeit kopiert und seine Herrschergeburtstage scheinen die Feier karolingischer Jahrestage der Herrschergeburtstage oder Thronbesteigung inspiriert zu haben (Wolfgang Eric Wagner, „Walahfrid Strabo und der Chronograph von 354, oder: Wie Karl der Kahle darauf kam, Anniversarien für seinen Geburtstag zu stiften“, in: Wolfgang Huschner und Frank Rexroth [Hrsg.], Gestiftete Zukunft im mittelalterlichen Europa: Festschrift für Michael Borgolte zum 60. Geburtstag, Berlin 2008, 193-214). - Zum Mythosbegriff vgl. Jörg Rüpke (Hrsg.), Von Menschen und Göttern erzählen: Formkonstanzen und Funktionswandel vormoderner Epik (Potsdamer altertumswissenschaftliche Beiträge 4), Stuttgart 2002; Ulrike und Jörg Rüpke, Antike Götter und Mythen, München 2010. 
Meine Analyse ist eine Textanalyse. Sie eröffnet einen Weg zu der Weltanschauung, der Geisteshaltung der Produzenten und der mutmaßlichen Erwartung der zugedachten Leser. Daher gründet sich meine Lesart des Textes auf zwei Begriffe, die auf verschiedene Theoretiker zurückzuführen sind. Zum einen der Begriff Aneignung, „appropriation“, wie er von Michael de Certeau geprägt wurde. Dieser Begriff hilft mir, die kreative und selektive Nutzung von Traditionen durch den oder die Urheber zu fassen, und führt somit eine Vorstellung des individuellen Akteurs in der Geschichte ein. Trotz der institutionellen Ursprünge und Hintergründe vieler Texte des Chronographen sind ihre Nutzung und Modifikationen strategisch, gar subversiv. ${ }^{7}$ Zum anderen bin ich angeregt durch Pierre Bourdieus Begriff des „Feldes“ und seiner Analyse von Differenzierungsprozessen bei Dispositionen und Interessen und die daraus resultierenden Handlungen, mit denen sich die Einzelnen positionieren, was wiederum Dispositionen beziehungsweise als komplexes und dauerhaftes Handlungs- und Entscheidungsmuster den Habitus ausbildet. ${ }^{8}$ Während der Aneignungsbegriff auf das Individuum zielt, legt der Habitus den Wert auf die gesellschaftliche Einbettung und Prägung genau dieses Individuums.

\section{Der soziale Ort des Chronographen von 354}

Die erste Seite des Kodex, das Dedikationsblatt, weist zwei Namen, jedoch keinen Autor auf. Der Widmungsträger ist ein Valentinus. Auf Grundlage unseres Wissens über die senatorische Gesellschaftsschicht, zu der ein solch luxuriöses Buch sicher zuzuordnen ist, muss er als Mitglied der Familie der Symmachi identifiziert werden: entweder als der Konsular von Numidia von 330 oder als der Konsular von Campania von 364 bis 375, Bruder des berühmten Oratoren und Priesters Q. Aurelius Symmachus ${ }^{9}$ - oder der Neffe des letzteren. ${ }^{10}$ Die Widmung floreat in deo und der Mahnruf lege passen wohl besser auf einen Jugendlichen. Dieser Eindruck wird unterstützt durch die bullae, getragen von den männlichen putti auf derselben Seite der Handschrift. ${ }^{11}$ Die Tatsache, dass der Osterzyklus bis 411, also noch mehr als fünfzig Jahre, angegeben ist, deutet in dieselbe Richtung; dies würde zu einer normalen Erwartung einer guten Lebensspanne passen. Wenn wir an den Bruder des Symmachus - der selbst die

7 Allgemein Michel de Certeau, L'invention du quotidien: 1. Arts de faire (Collection Folia Essais 146), Paris 1990; für den Begriff ,,appropriation“ siehe Marian Füssel, ,,Die Kunst der Schwachen: Zum Begriff der ,Aneignung“ in der Geschichtswissenschaft“, Sozial.Geschichte 21,3 (2006), 7-28.

8 Pierre Bourdieu, Praktische Vernunft: Zur Theorie des Handelns, Frankfurt a. M. 1998, 20 f.; 50 f. (= Pierre Bourdieu, Raisons pratiques: Sur la théorie de l'action, Paris 1994).

9 Jörg Rüpke und Anne Glock, Fasti sacerdotum: Die Mitglieder der Priesterschaften und das sakrale Funktionspersonalrömischer, griechischer, orientalischer und jüdisch-christlicher Kulte in der Stadt Rom von 300 v.Chr. bis 499 n.Chr. (Potsdamer Altertumswissenschaftliche Beiträge 12/1-3), Bd. 2, Stuttgart 2005, Nr. 876.

10 Salzman (s. Anm. 2), 201.

11 Cod. Vaticanus Romanus 1 ms., Barb. lat 2154, fol. 1. 
Absicht hatte, das voluminöse Werk von Livius' römischer Geschichte aufzubereiten als Empfänger denken, wäre als wahrscheinlichster Auftraggeber, wenn nicht gar als Autor des Textes ihr Vater L. Aurelius Avianus Symmachus anzunehmen, Redner und vielleicht Dichter ${ }^{12}$ und zur Zeit seines Todes im Jahre 376 Mitglied in zwei prestigeträchtigen Priesterkollegien. ${ }^{13}$

Der tatsächliche Urheber des Kodex bezeichnet sich selbst eindeutig durch die Formulierung Furius Dionysius Filocalus titulavit. Sie ist eingesetzt in die zwei Seitengriffe der tabula ansata, welche die Widmung einrahmt. Derselbe Filocalus bezeichnet sich andernorts auch als Urheber einer fragmentarischen Inschrift, die eine Liste von Widmungen bietet (scripsit Furius Dion[nysius Filocalus]), und als der Verehrer und Freund des Damasus auf dessen Epitaph für den Märtyrer Eusebius. ${ }^{14}$ Er muss der Erfinder der extravaganten filocalanischen Buchstaben gewesen sein, die die von Bischof Damasus nach 366 in Auftrag gegebenen Epitaphe der Märtyrer und Bischöfe dominieren. ${ }^{15}$

Wortwahl und Gestaltung sind nicht irrelevant. Titulavit ist ein seltenes Wort, zunächst deutet es auf die Umsetzung einer Inschrift hin. ${ }^{16}$ So wie die sinnbildliche Gestaltung als tabula ansata ist es unüblich auf der Titelseite einer Handschrift. Falls es eine Distanzierung von den Inhalten signalisiert - Ich bin nicht der Autor, sondern nur ein Schreiber - , folglich die Mehrdeutigkeiten eines scripsit beseitigt, hätte ein Autor angegeben sein sollen. Es ist daher wahrscheinlicher, dass Wortwahl und Darstellung eine bestimmte Vorstellung über die Inhalte beim Leser prägen sollten; eine Vorstellung, die nicht mit der Vorstellung eines individuellen Autors zusammenhängt. In Anbetracht der Verwendung von tituli wäre das ein Hinweis auf offizielle Dokumente, auf öffentlich verdiente oder anerkannte Titel, auf Fakten eher als Fiktion - eine Diskussion, die der Historiographie seit jeher in all ihren Gattungen inhärent und immer noch bedeutsam ist. ${ }^{17}$ Dieser Eindruck wird im Fortgang des Werkes dadurch aufrecht erhalten, dass die einzelnen Texte des Kodex häufig einen für ihre jeweilige Gattung ungewöhnlichen Grad an fachspezifischer Erscheinung annehmen, wie im Folgenden gezeigt werden soll.

Für eine soziologische Analyse sollte das Konzept der Autorenschaft durch das der Aneignung kulturellen Kapitals ersetzt werden. Die Transkription Tausender Rollen

12 Symm. epist. 1.2.

13 Rüpke (s. Anm. 9), Nr. 808.

14 Chronographus anni CCCLIIII, in: Theodor Mommsen (Hrsg.), Chronica Minora saec. IV. V. VI. VII., Bd. 1 (MGH AA 9), Berlin 1892, 13-148.

15 Hieron. vir. ill. 103.

16 Solcherart in CIL VIII 4487.

17 Siehe z.B. Franklin R. Ankersmit, Historical Representation (Cultural Memory in the Present), Stanford, Calif. 2001; Jörg Rüpke, „History“, in: Michael Stausberg und Steven Engler (Hrsg.), The Routledge Handbook of Research Methods in the Study of Religion, London 2011, 285-309. 
literarischer Texte aus privaten und öffentlichen Bibliotheken ${ }^{18}$ in Kodizes ist ein zentrales Merkmal jener Zeit und ausschlaggebend für die Transmission aller klassischer Texte. Q. Symmachus (den ich als Bruder des Widmungsträgers zu betrachten oben vorgeschlagen habe) ist, wie schon angedeutet, ein einschlägiger Akteur. Diese Aktivitäten stellen sicherlich die Abfassung einiger neuer Texte in den Schatten, die am „anderen“ Geschlecht veranschaulicht werden kann: Zum Beispiel an der römischen Aristokratin Betitia Faltonia Proba, eine Zeitgenossin, die ein (verloren gegangenes) Gedicht über die Usurpation des Magnentius in den der Produktion des Chronographen unmittelbar vorangegangenen Jahren (351-353) schrieb und einen erhalten gebliebenen Cento, eine Pastiche von Vergilianischen (Halb-)Versen, die Christus priesen, verfasste. ${ }^{19}$ Solche Aktivitäten sind nicht einfach Nebensachen. Ein zeitgenössischer Beobachter, der reisende Philosoph Junior, charakterisiert in seiner Expositio totius mundi et gentium (c. 55) die senatorische Gesellschaftsschicht als an politischen Aufgaben nicht interessiert. Vielmehr würde sie ihr ländliches Eigentum genießen und die Götter verehren. Hier ist Religion in erster Linie nicht eine Arena politischer Konflikte, sondern ein Feld des otium cum dignitate, das die senatorische Lebensweise prägt. ${ }^{20}$ Vor diesem Hintergrund transformieren floreas in deo und die Wortwahl (wie das Emblem) in der oberen Hälfte des Dedikationsblattes eine Lebensweise in einen Wunsch (und eine Mahnung) an einen jungen Mann. Sie deuten nicht, wie der dekontextualisierte Text meist interpretiert wurde, auf eine konfessionelle Verbindung, also das Christentum, hin. ${ }^{21}$

\section{Die Texte}

Der Chronograph von 354 ist ein reichbebilderter Kodex, der in mehreren Handschriften tradiert wurde. ${ }^{22}$ Er enthält chronologische und historiographische Informationen. Die Kompositionsgeschichte der einzelnen Bestandteile lässt sich zum Teil in Stufen bis zum Beginn des vierten Jahrhunderts zurückverfolgen. Für das Gesamtwerk - abgesehen von einzelnen späteren Einschüben - kann das Jahr 354 nicht nur als ein ter-

\footnotetext{
18 Für das Arrangement in spätantiken Bibliotheken siehe z.B. Allen Brent, Hippolytus and the Roman Church in the Third Century: Communities in Tension before the Emergence of a Monarch Bishop (VChr Suppl. 31), Leiden 1995; Henriette Harich-Schwarzbauer, DNP 10 (2001), 356, s. v. „Proba“. 19 Harich-Schwarzbauer (s. Anm. 18); John Matthews, „The Poetess Proba and Forth-Century Rome: Questions of Interpretation“, in: M. Christol, S. Demougin, Y. Duval, C. Lepelley und C. Pietri (Hrsg.), Institutions, Société et vie politique dans l'empire romain au IVe siècle ap. J.-C, Roma 1992, 277-304. Sie starb vor 380.

20 Für letzteres Alexander Demandt, Die Spätantike: Römische Geschichte von Diocletian bis Justinian 284-565 n.Chr. (HdAW 3,6), München $2007^{2}$, 341, dem ich die Bezugnahme auf Junior zu verdanken habe.

21 Siehe z. B. Salzman (s. Anm. 2), 26.

22 Eine vergleichende Beschreibung und Analyse in Salzman (s. Anm. 2) und Henri Stern, Le calendrier de 354: Étude sur son texte et ses illustrations (Bibliothèque archéologique et historique 55), Paris 1953. Kalendertext: Inscr. It. XIII 2.238-261.
} 
minus ante quem non, sondern auch als Dedikationsdatum gesichert gelten. ${ }^{23}$ Furius Dionysius Filocalus dürfte mit der Ausfertigung des Kalenders kurz vor 354 begonnen haben.

Wie schon erörtert wurde, beginnt der Chronograph mit dem Dedikationsblatt (I). ${ }^{24}$ Ihm folgen Darstellungen von vier Stadtgottheiten (II), eine Dedikation an die regierenden Kaiser im Namen des Eigentümers Valentinus und eine kalendarisch geordnete Liste von Kaisergeburtstagen (III). Sie nennt - unter der Überschrift natales Caesarum - die Kaisernamen ${ }^{25}$ im Genitiv und das Datum, zum Beispiel: Divi Traiani XIIII kal. Oct. Gegliedert ist die zweispaltige Liste durch die je mittig gesetzten Monatsnamen in der Form mens(e) martio. Interessanterweise sind auch Monate ohne (aufgelistete) Kaisergeburtstage, nämlich Juni und Juli, in dieser Form genannt.

Es folgen Darstellungen der Planetengötter, geordnet in der Reihenfolge der Wochentage mit Saturn an der Spitze (IV). Astrologische Informationen werden in Listen mit dem Charakter und der relevanten Gottheit der vierundzwanzig Tages- und Nachtstunden des jeweiligen Wochentages und einer kurzen allgemeinen Beschreibung geliefert. Saturn bietet ein gutes Beispiel:

Saturni dies horaque eius cum erit nocturna sive diurna, omnia obscura laboriosaque fiunt: qui nascentur periculosi erunt; qui recesserit non invenietur; qui decubuerit periclitabitur; furtum factum non invenietur. ${ }^{26}$

Wenn der Wochentag und die Nacht- oder Tagesstunde des Saturn herrscht, geschehen alle Dinge dunkel und mühsam: Wer jetzt geboren wird, ist von schwacher Gesundheit. Wer verschwindet, wird nicht wiedergefunden. Wer krank wird, wird es auf Leben und Tod. Ein Diebstahl in dieser Zeit wird nicht aufgeklärt.

Für die folgenden Gottheiten wurde die Sequenz beibehalten mit negativen oder positiven Variationen: utile est anstelle von laboriosa, Neugeborene könnten vitales sein, verlorene und gestohlene Gegenstände könnten gefunden werden oder nicht, kranke Menschen könnten sich schnell erholen (cito convalescet).

Ähnliche Informationen zu den zwölf Zodiakalzeichen folgen (V); sie geben an, welche Aktivitäten zu bevorzugen sind, wenn der Mond im jeweiligen Zeichen steht. Nochmals: Die Liste, eingeteilt in drei Gruppen von Zeichen, ist einigermaßen Standard. Für Widder, Krebs, Waage und Steinbock lautet der Text wie folgt:

23 Salzman (s. Anm. 2), 279-282; Stern (s. Anm. 22), 45 nimmt an, dass es eine Festgabe ist, die zum neuen Jahr dem Valentinus überreicht wurde, der auf der Titelseite benannt ist. Die Datierung folgt den Vorschlägen von Mommsen (s. Anm. 14) und Nicolas-Claude Fabri de Peiresc (1620).

24 Ich folge der traditionellen Nummerierung der Abschnitte.

25 Sachlich betrachtet ist der Plural Augusti im Jahre 354 inkorrekt (für den Versuch einer Erklärung siehe Salzman [s. Anm. 2], 281-282; es könnte sich auf Magnentius' Eigenschaften als Augustus rückbeziehen).

26 Mommsen (s. Anm. 14), 42. 
In his signis tropicis luna cum erit, nummos mutuos dare vel accipere, testamentum facere, telam ordiri, lanas lavare, pecora castrare, conductum facere, migrare utile. ${ }^{27}$

Wenn der Mond in diesen Tierkreiszeichen steht, ist es sinnvoll Beträge zu zahlen oder anzunehmen, ein Testament zu machen, eine Waffe zu richten, Wolle zu waschen, Vieh zu kastrieren, einen Leihvertrag zu schließen, einen Ortswechsel zu vollziehen.

Erziehung - pueros puellas in disciplinas mittere - ist Bestandteil der genannten Tätigkeiten, Religion hingegen nicht. Die entsprechenden Illustrationen sind in der Überlieferung über die Jahrhunderte verlorengegangen.

Erst nach diesen Sektionen erscheint der eigentliche Kalender (VI). Er besteht aus zwölf Doppelseiten; der ganzseitigen Darstellung des Monats mittels einer in einer jahreszeitlich typischen Handlung begriffenen Person steht jeweils der Kalendertext gegenüber. Dabei werden komplexe und anspielungsreiche Abbildungen, die rituelle oder landwirtschaftliche Aktivitäten zeigen, verwendet. ${ }^{28}$ Eine wirkliche Integration beider Teile lässt sich wie in vergleichbaren Kombinationen nicht erkennen. Bezüge, die die Darstellung eindeutig als summierende oder akzentuierende Illustration des Kalendertextes auswiesen, fehlen. Mitsamt ihren auf die Monate bezogenen Verslein Distichen, später noch um Tetrastichen erweitert - sind die Monatsporträts durchaus selbstständig.

Es fehlen jegliche christliche Festdaten. Die im Gesamtwerk enthaltene Liste von depositio-Daten römischer Bischöfe und Märtyrer ist nicht in den Kalender integriert. Im Hinblick auf die Dokumentation konstantinischer Feste ist der Kalender durchaus auf dem neuesten Stand. Er spiegelt demnach Gattungskonventionen, nicht eine kultische Realität wider. Betrachtet man die kalendarischen Details, fügen sich die fasti Furii Filocali ganz in die Tradition der bekannten Kalender ein.

Nach einem Portrait zweier Konsuln - wahrscheinlich von 354 - (VII) folgt eine Liste von Konsuln ${ }^{29}$ ab 509 v.Chr. bis in die Gegenwart (VIII). Diese ist gut erforscht, beschränkt sich jedoch auf zwei Namen pro Jahr, erweitert um die Angabe von Schaltjahren (das Bestehen der julianisch-augusteischen Regeln der vierjährigen Interkalation seit der Kaiserzeit voraussetzend) und die Angabe des Tages der Planetenwoche und des Mondalters für den ersten Januar eines jeden Jahres. Weit entfernt von der chronikartigen Form der Konsularlisten wie die fasti Ostienses aus der frühen Kaiserzeit (und ihre Angabe von Suffektkonsuln, Zensoren und dergleichen) zeigen nur vier Jahre zusätzliche historische Informationen, im Folgenden vollständig angeführt:

27 Mommsen (s. Anm. 14), 47.

28 Im Gegensatz zu Stern (s. Anm. 22) betont Salzman (s. Anm. 2) die Innovation in der bildlichen Darstellung. Gegen ihre Identifikation von Säkularisierungsprozessen siehe z. B. Pierre P. Koemoth, „Autour du prêtre isiaque figuré dans le calendrier romain de 354“, Latomus 68 (2008), 1000 - 1009 für die Novemberillustration.

29 Zur Terminologie Mommsen (s. Anm. 14), 56. 
[1 n.Chr.] Unter diesem Consul wurde Jesus Christus geboren am Freitag, dem 25. Dezember, Mondalter 15.

[29 n.Chr.[] Unter diesen Consuln litt unser Herr Jesus Christus, am Freitag, Mondalter 14.

[33 n.Chr.] Unter diesen Consuln kamen Petrus und Paulus nach Rom, um das Episkopat zu übernehmen.

[55 n. Chr.] Unter diesen Consuln litten Petrus und Paulus, am 29. Juni.

[AD 1] Hoc cons. dominus Iesus Christus natus est VIII kal. Ian. d. Ven. luna XV.

[AD 29] His consulibus dominus Iesus Christus passus est die Ven. luna XIIII.

[AD 33] His cons. Petrus et Paulus ad urbem venerunt agere episcopatum.

[AD 55] His cons. passi sunt Petrus et Paulus III kal. Iul. ${ }^{30}$

Die Ostertermine seit 312 und prognostiziert für ein ganzes Jahrhundert (bis $411 \mathrm{n}$.Chr.) (IX) sowie eine Liste der praefecti urbis (X) folgen. Letztere beginnt mit der „Zeit von Gallienus“; ab 288 n.Chr. sind die Antrittsdaten präzise angegeben, gelegentlich sogar kurzzeitige Vertretungen infolge von Abwesenheit. ${ }^{31}$ Eine kalendarisch geordnete Liste von Begräbnistagen der (natürlich) römischen Bischöfe (XI) umfasst die Ereignisse von 255 bis 310/11, darüber hinaus erweitert durch die jährliche Abfolge an Depositionen von 336 und 352. ${ }^{32}$ Für letztere ist eine außergewöhnlich präzise Ortsangabe vorhanden: Iuli, in via Aurelia miliario III, in Callisti.

Eine ähnliche Liste wird für die depositiones oder dies natales von Märtyrern angegeben (XII). Die Liste wird angeführt von einem Datum in der zweiten Dezemberhälfte, das ist auf Lateinisch der ante diem ... kalendas Ianuarias, schon den ersten Monat des Jahres benennend. Das gleiche gilt auch für die Depositionen der Bischöfe, Dionisius (269 n. Chr.) für VI kal. Ianuarias verzeichnend. In der Märtyrertafel führt die Geburt Christi, allerdings nicht in der Formulierung natalis domini, die Liste an. Dies ist das früheste Zeugnis dieses Termins, wenn man eine spätere Interpolation ausschließt. ${ }^{33}$

Eine erweiterte Betrachtung dieses neuartigen Werkes ist angebracht. Seit Konstantin auch Christus öffentlich verehren ließ, hatte das Christentum an allgemeiner Sichtbarkeit erheblich gewonnen. Das Konstantinische Bauprogramm betraf sowohl die mit der kirchlichen Hierarchie verbundenen Kultplätze wie den Märtyrerkult. ${ }^{34}$ Die großen christlichen Basiliken, eine Adaptation profaner Formensprache für Kult-

30 Mommsen (s. Anm. 14), $56 \mathrm{f}$.

31 Z.B. für 318 n.Chr., siehe Mommsen (s. Anm. 14), 67.

32 Mommsen (s. Anm. 14), 70.

33 Z.B. Michel-Yves Perrin, „Die neue Form der Missionierung: Die Eroberung von Raum und Zeit“, in: Charles Piétri und Luce Piétri (Hrsg.), Die Geschichte des Christentums 2: Das Entstehen der einen Christenheit (250 - 430), Freiburg 1996, 667-704, 692. Die Authentizität wird in Frage gestellt von Hans Förster, Die Feier der Geburt Christi in der Alten Kirche: Beiträge zur Erforschung der Anfänge des Epiphanie- und des Weihnachtsfests (Studien und Texte zu Antike und Christentum 4), Tübingen 2000, 95-103; siehe auch Wischmeyer (s. Anm. 5), 49; doch siehe jetzt Józef Naumowicz, „Le calendrier de 354 et la fête de Noël“, Palamedes 2 (2007), 173-188.

34 Der Prozess war nicht auf Rom beschränkt: Perrin (s. Anm. 33), 681. 
bauten, ${ }^{35}$ entstanden so in den Außenbezirken. Die Institutionalisierung dieses Kultes in architektonischer Form und in den aus dem individuellen Totenkult geläufigen Feiern des Jahrestages ${ }^{36}$ führt durch ihren kalendarischen Niederschlag zurück zum Chronographen. Hier erscheint erstmals die eben an Position XII genannte Liste von dies depositionis von Märtyrerinnen und Märtyrern:

\begin{tabular}{|c|c|}
\hline $\begin{array}{l}\text { VIII kal. Ian. } \\
\text { mense Ianuario }\end{array}$ & natus Christus in Betleem Iudeae \\
\hline XIII kal. Feb. & $\begin{array}{l}\text { Fabiani in Callisti } \\
\text { et Sebastiani in Catacumbas }\end{array}$ \\
\hline $\begin{array}{l}\text { XII kal. Feb. } \\
\text { mense Februario }\end{array}$ & Agnetis in Nomentana \\
\hline $\begin{array}{l}\text { VIII kal. Martias } \\
\text { mense Martio }\end{array}$ & natale Petri de cathedra \\
\hline $\begin{array}{l}\text { non. Martias } \\
\text { mense Maio }\end{array}$ & Perpetuae et Felicitatis, Africae \\
\hline XIII kal. Iun. & $\begin{array}{l}\text { Partheni et Caloceri in Callisti, Diocletiano VIIII et } \\
\text { Maximiniano VIII }\end{array}$ \\
\hline \multicolumn{2}{|l|}{ mense Iunio } \\
\hline III kal. Iun. & $\begin{array}{l}\text { Petri in Catacumbas } \\
\text { et Pauli Ostense, Tusco et Basso cons. }\end{array}$ \\
\hline \multicolumn{2}{|l|}{ mense Iulio } \\
\hline VI idus & $\begin{array}{l}\text { Felicis et Filippi in Priscillae } \\
\text { et in Iordanorum, Martialis Vitalis Alexandri } \\
\text { et in Maximi Silani. hunc Silnaum Novati furati sunt. } \\
\text { et in pretextatae, Ianuari }\end{array}$ \\
\hline III kal. Aug. & $\begin{array}{l}\text { Abdos et Semnes in Pontiani, quod est ad ursum } \\
\text { piliatum }\end{array}$ \\
\hline \multicolumn{2}{|l|}{ mense Augusto } \\
\hline VIII idus Aug. & $\begin{array}{l}\text { Xysti in Callisti } \\
\text { et in Praetextati Agapiti et Felicissimi }\end{array}$ \\
\hline VI idus Aug. & $\begin{array}{l}\text { Secundi Carpofori Victorini et Severiani Albano } \\
\text { et Ostense VII ballistaria Cyriaci Largi Crescentiani } \\
\text { Memmiae Iulianetis et Ixmaracdi }\end{array}$ \\
\hline IIII idus Aug. & Laurenti in Tiburtina \\
\hline
\end{tabular}

35 Michael L. White, Building God's House in the Roman World: Architectural Adaption among Pagans, Jews, and Christians (ASOR Library of Biblical and Near Eastern Archaeology), London 1990, 127139 zu Vorläufern und Verdrängtem; zum Konstantinischen Programm Mary Beard, John North und Simon Price, Religions of Rome 1: A History, Cambridge 1998, 368f.; John R. Curran, Pagan City and Christian Capital: Rome in the Fourth Century (Oxford Classical Monographs), Oxford 2000.

36 Z.B. Paul-Albert Février, „A propos du repas funéraire: Culte et sociabilité“, CahArch 26 (1977), 29 45; Jean Guyon, „Les représentations du cimetière ,Aux deux lauriers““, in: François Hinard (Hrsg.), La mort, les morts et l'au-delà dans le monde romain. Actes du colloque de Caen 20 - 22 novembre 1985, Caen 1987, 293-310; Peter Karpinski, Annua dies dormitionis: Untersuchungen zum christlichen Jahrgedächtnis der Toten auf dem Hintergrund antiken Brauchtums (Europäische Hochschulschriften 23: Theologie 300), Frankfurt a. M. 1987. 
idus Aug. $\quad$ Ypoliti in Tiburtina

et Pontiani in Callisti

XI kal. Septemb. Timotei, Ostense

$V$ kal. Sept. Hermetis in Basillae Salaria vetere

mense Septembre

non. Sept. Aconti, in Porto et Nonni et Herculani et Taurini

Vidus Sept. Gorgoni, in Lavicana

III idus Sept. $\quad$ Proti et Iacinti, in Basillae

XVIII kal. Octob. Cypriani Africae. Romae celebratur in Callisti

$X$ kal. Octob. Basillae, Salaria vetere, Diocletiano IX et Maximiano VIII

consul

pri. idus Octob. Callisti in via Aurelia, miliario III

mense Novembre

$V$ idus Nov. Clementis in Semproniani Claui Nicostrati in comitatum

III kal. Dec. $\quad$ Saturnini in Trasonis

mense Decembre

idus Decem. $\quad$ Ariston in pontum ${ }^{37}$

Ebenso die Bestattung der Märtyrer

25. Dezember: Geboren wurde Christus in Bethlehem in Judäa.

Monat Januar

20. Januar: Fabian in der des Calixtus und Sebastian in der „Katakomben“.

21. Januar: Agnes in der an der Nomentana.

Monat Februar

22. Februar: Geburtstag der Kathedra des Petrus.

Monat März

7. März: Perpetua und Felicitas in Afrika.

Monat Mai

20. Mai: Parthenus und Calocerus in der des Calixtus, als Diokletian zum 9. Mal und Maximian zum

8. Mal Konsul waren [304 n. Chr.].

Monat Juni

29. Juni: Petrus in der „Katakomben“, Paulus in der Ostensischen, als Tuscus und Bassus Konsul waren [258 n.Chr.].

Monat Juli

10. Juli: Felix und Filippus in der der Priscilla und in der der Jordanier: Martialis, Vitalis, Alexander, und in der des Maximus: Silanus. Diesen Silanus haben die Novatianer gestohlen. Und in der der Pretextata: Januarius.

30. Juli: Abdon und Semnen in der des Pontianus, weil er bedeckt zum Bären (verurteilt wurde). Monat August

6. August: Xystus in der des Calixtus und in der des Praetextatus: Agapitus und Felicissimus.

8. August: Secundus, Carpoforus,Victorinus und Severianus im Albanum; und in der Ostensischen die Sieben in der Schleuderfabrik, Cyriacus, Largus, Crescentianus, Memmia, Iulianes und Ixmaracdus.

10. August: Laurentius in der Tiburtinischen.

13. August: Hippolytus in der Tiburtinischen und Pontianus in der des Calixtus.

22. August: Timotheus in der Ostiensischen.

28. August: Hermes in der der Basilla an der alten Salaria.

37 Mommsen (s. Anm. 14), $71 \mathrm{f}$. 


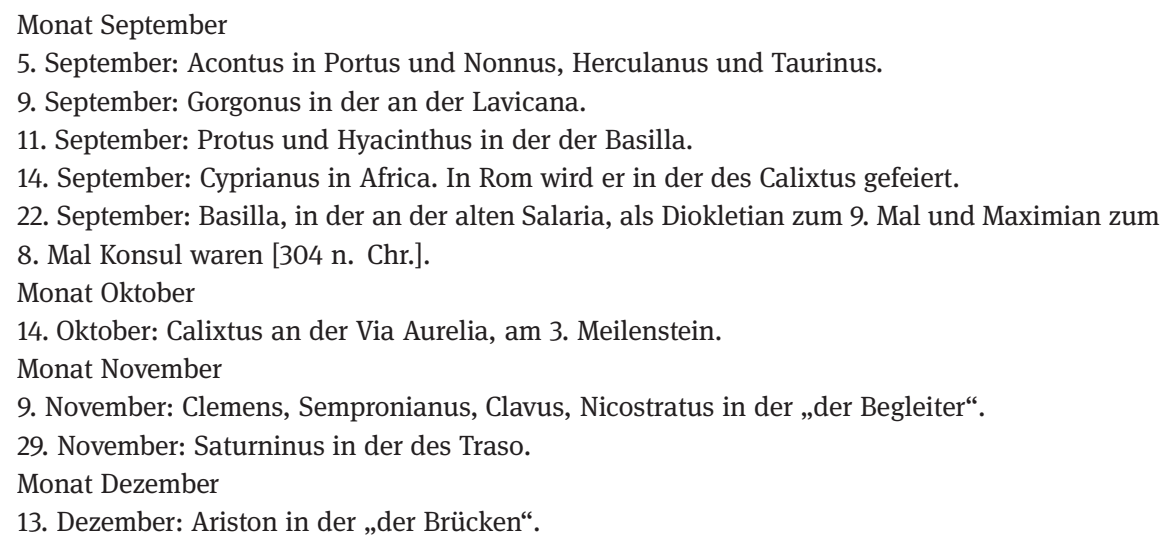

Auffällig ist die julianische Datierung der Gedächtnistage: Prinzipiell wäre eine Rahmenkonzeption mit dem Osterzyklus im Zentrum um einiges plausibler gewesen; das hätte eine Datierung ergeben, die sich relativ zum Osterdatum stabil verhielte. Die stadtrömischen Christen wählen hier den stadtrömischen Kalender. Koordiniert mit ihm werden zumeist die Tage der Bestattung, die dies depositionis, die aber auch als spirituelle Geburtstage, dies natales, bezeichnet werden können. ${ }^{38}$ In spätantiker Zeit wurde oft versucht, den kultisch ausgezeichneten und nicht einfach mit dem Todesdatum identischen dies depositionis an den eigentlichen dies natalis heranzurücken. ${ }^{39}$ Daneben traten dann auch Daten, die sich auf sekundäre kultische Ereignisse, den Bau einer Kirche über dem Grab, bezogen. ${ }^{40}$

Die depositio martyrorum, die Liste der Heiligengedenktage des Chronographen, entwirft eine rituelle Praxis für eine religiöse Gruppe, die etwa zwei Daten je Monat vermerkte und den möglichen Bereich von Osterterminen freiließ. Die Verehrungstage waren auf die zeitlichen Möglichkeiten der Verehrer abzustimmen. Wann diese zu Terminverschiebungen griffen und wann einfach die günstige Datierung bestimmten Märtyrern entgegenkam, lässt sich nicht mehr feststellen. Gemessen am Kalender der Jahrhundertmitte verteilten sich diese Daten ähnlich, wie man es auch von anderen römischen Festen vermuten würde: Sie lagen um und auf den monatlichen Strukturtagen (Kalenden, Nonen, Iden), gelegentlich am Ende von Spielen, auf deren

38 Siehe Hippolyte Delehaye, Les origines du culte des martyrs (SubHag 20), Bruxelles 1953², 35 f. Dies natalis und die griechischen Äquivalente werden oft als ein unspezifischer Begriff für „Jahrestag“ benutzt; ebenso Walter Dürig, Geburtstag und Namenstag: Eine liturgiegeschichtliche Studie, München 1954, 26 - 29. Der erste christliche Beweis in Tert. coron. 3,2; monog. 10,4; resurr. 13,2 (siehe auf der Maur [s. Anm. 3], 92-94).

39 Siehe Yvette Duval, Loca sanctorum Africae: Le culte des martyrs en Afrique du IVe au VIIe siècle, Bd. 2 (Collection de l'Ecole Française de Rome 58), Roma 1982, 571.

40 Siehe Johann Peter Kirsch, Der stadtrömische christliche Festkalender im Altertum: Textkritische Untersuchungen zu den römischen „Depositiones“ und dem Martyrologium Hieronymianum (Liturgiegeschichtliche Quellen 7/8), Münster 1924, 239. 241; Gregory Dix, The Shape of the Liturgy, London 1949, $377 \mathrm{ff}$. 
letztem Tag oder dem Folgetag. Solche Konkurrenz war gefährlich: Mehrfach wurde beklagt, dass attraktive Rennen die Kirchen leer ließen. ${ }^{41}$ Die Anomalie eines zweiten Petrusfestes am 22. Februar (neben dem Gedenktag am 29. Juni) fiel mit den traditionellen Caristia, dem Familienfest zum Abschluss der Totenfeiertage im Februar zusammen.

Wer an den Feiern, die für die aufgeführten Tage angenommen werden müssen, teilnahm, lässt sich nicht bestimmen. Die Liste betraf die Stadt Rom, kaum nur einen Ausschnitt, eine einzelne Gemeinde innerhalb dieser Großstadt. Verehrt wurden aber nicht nur römische Märtyrer. Römische Christen gedachten auch dreier prominenter Märtyrer aus Karthago, der Perpetua und Felicitas sowie des Bischofs Cyprian. Hier konnten sie keine Grabstätten aufsuchen, benötigten also andere Gedächtnisorte. Betrieben worden war dies sicher von Zuwanderern aus Karthago selbst. Der Briefwechsel Cyprians aus den späten vierziger und den fünfziger Jahren des dritten Jahrhunderts (einer der wenigen aus dieser frühen Epoche organisierter Christentümer erhaltenen Briefkorpora) spricht ständig von Personen, die in der einen oder anderen Richtung ihren Wohnort gewechselt haben. Auch für andere Märtyrer müssen wir uns solche „Lobbygruppen“ vorstellen, die einen einzelnen Kult so populär machten, dass er Eingang in die Liste fand. Eine Verpflichtung für alle römischen Christen erwuchs daraus nicht.

Eine chronologisch aufgebaute Liste römischer Bischöfe (XIII) schließt sich an, beginnend mit der Abfolge der Macht vom gekreuzigten Christus zu Peter als Kopfzeile:

Imperante Tiberio Caesare passus est dominus noster Iesus Christus duobus Geminis cons. VIII kal. Apr. et post ascensum eius beatissimus Petrus episcopatum suscepit. ex quo tempore per successionem dispositum, quis episcopus quot annis prefuit vel quo imperante. ${ }^{42}$

Unter der Herrschaft des Kaisers Tiberius litt unser Herr Jesus Christus, am 25. März unter dem Konsulat der beiden Gemini, und nach seiner Himmelfahrt übernahm der glückseligste Petrus den Episkopat. Seit jener Zeit ist als Nachfolgeliste dargestellt, welcher Episkopus wie viel Jahre an der Spitze stand oder auch unter wessen (Kaiser-) Herrschaft.

Die Wortwahl der Einträge ist wieder recht standardisiert:

Petrus ann. XXV mens. uno d. VIIII. fuit temporibus Tiberii Caesaris et Gai et Tiberi Claudi et Neronis, a consul. Minuci et Longini usque Nerine et Vero. Passus autem cum Paulo die III kal. Iulias consul. ss imperante Nerone.

Petrus war für 25 Jahre, einen Monat und neun Tage im Amt und wirkte zu den Zeiten von Tiberius Caesar, Gaius, Tiberius und Nero von den Consuln Minucius und Longinus (30) bis Nero und Verus (55). Er litt aber mit Paulus am 29. Juni unter den gleichen Consuln zur Regierungszeit Neros. ${ }^{43}$

41 Perrin (s. Anm. 33), 694. Zu den freien Osterterminen Charles Piétri, „Les origines du culte des martyrs (d'après un ouvrage recent)“, Rivista di Archeologia Cristiana 3 (1984), 293-319, $301 \mathrm{f}$.

42 Mommsen (s. Anm. 14), 73.

43 Mommsen (s. Anm. 14), 73. 
Nur in sehr wenigen Fällen werden zusätzliche Informationen gegeben:

Für Pius: Sub huius episcopatu frater eius Ermes librum scripsit, in quo mandatum continetur, quae ei precepit angelus, cum venit ad illum in habitu pastoris.

Während seins Episkopats schrieb sein Bruder Hermes ein Buch, in dem ein Auftrag enthalten war, was ihm ein Engel vorgeschrieben hat, als er zu ihm im Gewand eines Hirten kam.

Für Pontianus (235) ist das Exil des Bischofs und Hippolytos' angegeben (ähnliches für Lucius). Fabius: hic regiones divisit diaconibus et multas fabricas per cimiteria fieri iussit. ... Novatus ex Africa et separavit de ecclesia Novatianum et quosdam confessores.

Dieser teilte die Regionen Diakonen zu und ließ viele Bauwerke auf den Friedhöfen errichten ... Novatus aus Africa trennte von der Kirche Novatian und einige Bekenner.

Cornelius: Novatus ... ordinavit Novatianum in urbe Roma et Nicostratum in Africa.

Marcellinus: quo tempore fuit persecutio.

Novatus weihte Novatian in der Stadt Rom und Nicostratus in Africa.

Iulius (337-352): hic multas fabricas fecit (Liste von fünf Basiliken).

Dieser errichtete viele Bauwerke. ${ }^{44}$

Vermutlich waren die notitia regionum urbis und der liber generationis (XIV und XV) ebensowenig Bestandteile des originären Kodex wie die origo gentis Romanorum, ex quo primum in Italia regnare coeperunt, eine Liste (XVI) laurentischer, albanischer und römischer Könige, „Diktatoren“ und schließlich der imperia Caesarum. ${ }^{45}$ Das martyrologium Hieronymianum wurde zu Beginn des fünften Jahrhunderts als weiterer Ausbau der Liste des Filocalus geschrieben - zu einem Zeitpunkt, der für die weitere Entwicklung kalendarisch geordneter liturgischer Textkorpora im Westen entscheidende Bedeutung besitzt. ${ }^{46}$

\section{Das Ensemble}

Der Kodex ist mehr als ein Konglomerat. Die Sammlung ist sicher inspiriert durch die additive Gattung der fasti, die von Anfang an Kalender mit Konsularlisten kombiniert hatte und zusätzlich seit der Kaiserzeit Monatsdarstellungen aufweist, die seit Severischer Zeit auch in anderen Gattungen populär wurden. Wenn die Rekonstruktion des

44 Mommsen (s. Anm. 14), 74-76.

45 Richard W. Burgess, „The Chronograph of 354: Its Manuscripts, Contents and History“, Journal of Late Antiquity 5 (2012), 345-396.

$46 \mathrm{Zu}$ diesem Text und allgemein zur Ausbildung des stadtrömischen christlichen Festkalenders Kirsch (s. Anm. 40); Hans Lietzmann, Petrus und Paulus in Rom: Liturgische und archäologische Studien (Arbeiten zur Kirchengeschichte 1), Berlin 1927², 29-82. Zu den Quellen siehe Noële M. Denis-Boulet, Das Kirchenjahr, übers. von Rudolf Vey (Der Christ in der Welt 9: Die Liturgiegeschichte der Kirche 6), Aschaffenburg 1960 [1959], 59 - 62; siehe Hans Achelis, Die Martyrologien, ihre Geschichte und ihr Wert (Abhandlungen der philologisch-historischen Klasse der Königlichen Gesellschaft der Wissenschaften zu Göttingen, NF 3,3), Berlin 1900. Zur Weiterentwicklung siehe Klaus Gamber, Missa Romensis: Beiträge zur frühen römischen Liturgie und zu den Anfängen des Missale Romanum (Studia Patristica et Liturgica fasc. 3), Regensburg 1970, 91; siehe auch 99-106. 
Chronographen wie vorhergehend beschrieben unterstellt wird, so würde das daraus resultierende Buch als Ganzes durch die zwölf Doppelseiten der fasti und die möglicherweise geringfügig längere Konsularliste bestimmt - alle übrigen Teile beschränken sich ja auf jeweils ganz wenige Seiten. Die Möglichkeiten dieses Kodex wurden sicher sorgfältig beachtet, wie durch die Transkription von volumina in vielen zeitgenössischen Fällen demonstriert wird. Ganz im kalendarischen und chronologischen Interesse der fasti forderte der Kodex weitere Ergänzungen und andere Listentypen, ist soweit also traditionell. Dennoch wäre das Resultat unvorhersehbar gewesen, wenn das Interesse an seiner Herstellung auf jegliches para-historiographische Material beschränkt gewesen wäre. Insbesondere die Wahl der Illustrationen bot viele Möglichkeiten. ${ }^{47}$

Bedeutsam ist somit das Rahmenwerk. Gemäß der Abfolge schon der ersten Seite ist eine religiöse, eine universelle und imperiale sowie eine astrologische Ebene auszumachen.

Es ist am einfachsten, mit letztgenanntem zu beginnen. Interesse an Astrologie ist ein Interesse an Orientierung, das die Notwendigkeit, Entscheidungen unter unsicheren Bedingungen zu treffen, auf eine systematische Modifikation der Zeit projiziert. ${ }^{48}$ Dieses Interesse zeigt sich nicht nur im ersten großen Abschnitt, den ungefähr zehn ersten Seiten des Kodex, sondern durchzieht auch weitere Listen. Es gibt aus der Antike keine andere Liste von Konsuln, die Informationen zu den planetarischen und lunaren Eigenschaften zu Beginn ihrer Amtsjahre enthält. Dieses Interesse erstreckt sich auch auf die Geburt und den Tod Christi. Sein Grundmechanismus, ein Zyklus von 84 Jahren, ist das Instrument, um eine Liste künftiger Ostertermine zu errechnen. Ungeachtet der Zugänglichkeit zu Informationen über die Geschichte des römischen Kalenders und seiner Reformen (wie sie in Macrobius' Saturnalia auf Grundlage deutlich älterer Quellen geschildert wird), kann dieses System lückenlos bis in die frühe Republik zurückverfolgt werden.

Dies ist genau die Attraktivität der Astrologie: Soziale Ereignisse werden naturalisiert, werden mit einer natürlichen, einer kosmologischen Ordnung verknüpft, die über die Menschheitsgeschichte hinausgeht. Trotz der Kritik einiger Intellektueller muss die Astrologie als die am besten ausgearbeitete kosmologische Auffassung angesehen werden, wenn man sie mit allen anderen Ansichten vergleicht, die von der Mehrheit der Bevölkerung des römischen Imperiums geteilt wurden. ${ }^{49}$

Ohne Alternativen ist auch die imperiale Orientierung. Salvis Augustis felix Valentinus, wie von einer geflügelten Fortuna auf ein rundes Schild (IIIa) geschrieben wird, veranschaulicht die Bedeutung des Kaisers für den Widmungsträger, indem er

47 Ich bin Richard Gordon für diese Beobachtung dankbar.

48 Rüpke, Kalender (s. Anm. 4), 563-592.

49 Kocku von Stuckrad, Das Ringen um die Astrologie: Jüdische und christliche Beiträge zum antiken Zeitverständnis (Religionsgeschichtliche Versuche und Vorarbeiten 49), Berlin 2000; Kocku von Stuckrad, ,Jewish and Christian Astrology in Late Antiquity: A New Approach“, Numen 47 (2000), 140. 
letzteren direkt mit dem höchsten Rang der Gesellschaft in Verbindung setzt. Natürlich trifft dies nicht auf jeden Kalender zu, sondern nur auf ein Luxusexemplar wie den Chronographen..$^{50}$ Fortunas Stift zeigt auf felix, die am besten zutreffende Charakterisierung der angestrebten Lebensqualität (und ein beliebter kaiserlicher Beiname). Wenn der Kodex mit der Origo gentis vollendet worden wäre, hätte die Liste der Imperatoren einen „imperialen“ Ring geschlossen. Es ist also ein durch und durch imperiales feriale (IIIb), das ein erstes Beispiel einer datierten Liste durch die erfassten christlichen Bestattungsdaten, den depositiones, bietet.

Die Personifikationen, um genauer zu sein, die Fortunae von Rom, Alexandria, Konstantinopel und Trier erzeugen einen (irdischen) universalen Rahmen für den Widmungsträger - dessen Schild von einer typologisch identischen, weiblichen Figur, also Fortuna, beschrieben wird. Das verstärkt den, oder besser: das weist auf den noch größeren astrologischen Rahmen voraus. Doch anders als letzteres, ist der geographische Universalismus lediglich umrahmend, indem es den internen Fokus auf nur eine der Städte legt, auf Rom. Das scheint ganz natürlich für einen römischen Senator zu sein, aber es ist eine klare Stellungnahme gegen andere Orte. Der Kodex wurde erstellt, kurz bevor Konstantinopel mehr institutionelles Gewicht und Prestige bekam: durch bedeutende Reliquien, die im Jahr 357 in die Stadt transportiert wurden, und durch das Amt eines praefectus urbis, das in Analogie zu Rom eingeführt wurde, ${ }^{51}$ und vielleicht auch durch eine Kurie, die für den „Senat aus zweiter Reihe“ der östlichen Hauptstadt von Julian errichtet wurde..$^{52}$ Vor diesem Hintergrund ist die Einbeziehung, möglicherweise selbst recherchierte Kompilation einer Liste städtischer Präfekte (X) höchst signifikant und eine klare Bekundung, eine Strategie der Differenzierung und Positionierung.

Gleiches gilt für die Liste der Bischöfe (XIII): Sie suggeriert eine einzigartige Sukzessionslinie von Christus zum römischen Amtsträger. Dadurch wird die städtische Institution naturalisiert oder universalisiert. Auch das ist in einer Welt voller Bischöfe, von der schon Jahrzehnte früher Eusebios von Caesarea in seiner „Kirchengeschichte“ einen Eindruck geben konnte, nicht selbstverständlich. Auch im Folgenden ist das Werk selektiv. Die ersten drei Einträge der fasti sind senatus legitimus (1. Januar), dies aegyptiacus (2. Januar) und ludi - votorum nuncupatio (3. Januar). Dies sind Beispiele systematisch-kalendertechnischer Informationen. Doch auch hier trügt der erste Anschein. Weder ist der erste Eintrag in einem Kalender des vierten Jahrhunderts zu erwarten noch ist der zweite Eintrag ein Ausdruck ohne Alternativen für „schwarze Tage“; dies atri wäre einfacher gewesen. In ihrer Sequenz proklamieren die drei Einträge Rom als das Zentrum der ganzen Welt - selbst wenn ich das so in einer etwas dramatisierenden Weise formulieren mag. Die Einträge in Bezug auf Africa in der Liste

50 Siehe Franz Alto Bauer, „Prestigegüter und Kaisernähe in der Spätantike“, in: Berit Hildebrandt und Caroline Veit (Hrsg.), Der Wert der Dinge: Güter im Prestigediskurs (Münchner Studien zur Alten Welt 6), München 2009, 373-398.

51 Demandt (s. Anm. 20), 112.

52 Demandt (s. Anm. 20), 447, Anm. 62. 
der Bischöfe wie auch in den Märtyrerlisten können einen ähnlichen Effekt erzeugen. Doch um es noch einmal zu betonen: Sie sind historisch vertretbar. Doch sie reproduzieren Konstellationen aus dem dritten Jahrhundert und akzentuieren resultierende Konflikte.

Positionierung beinhaltet daher auch den Bereich der Religion. Das gilt insbesondere für die Betonung auf die Konflikte mit Novatianern, die wie die Donatisten einen eigenen römischen Bischof - und mit Sicherheit auch Sukzessionslisten mit anderen Namen als diejenigen von Filocalus besaßen. Zeitgenössische christliche Fragen waren kompliziert, wie nicht nur wir aus der Rückschau sehen: Der exilierte Bischof Liberius, der sich selbst Magnentius angeschlossen hatte, würde bald zurückkehren und sich einem Rivalen, Felix, gegenübersehen, der 335 gewählt worden war. Dies waren keine vereinzelten Ereignisse, vielmehr waren sie charakteristisch für die Rivalitäten und den Pluralismus der römischen Christenheit, wie die folgenden Jahre und Damasus noch demonstrieren sollten. ${ }^{53}$ Eine vereinheitlichte Genealogie war ein so deutliches Statement wie die Entrümpelung konsularischer fasti. Traditionen und Legitimität bestimmter Kulte und Kultplätze für Märtyrer wurden in Frage gestellt, wie Charles Piétri für die merkwürdige Konsulardatierung gezeigt hat, die zur Grablegung von Peter und Paul hinzugefügt wurde und die wahrscheinlich nur in Bezug auf die Einrichtung dieses speziellen Kults galt. ${ }^{54}$ Während die fasti auf vergleichsweise wenig Orte verweisen - im Sinne ihres quasi-universellen Charakters bedürfen die Kulte in den Depositionslisten einer Lokalisierung. Der Ostertermin war eine aktuelle (und fortwährende) kontroverse Streitfrage. ${ }^{55}$ Die Termine nach der römischen Berechnungsmethode - es gab ja andere! - für das nächste halbe Jahrhundert anzugeben bedeutete Partei zu ergreifen - selbstverständlich für die siegreiche Partei.

\section{Der Ort der Religion}

Der Religion wurde schon ab der ersten Seite ein bedeutender Teil des Kodex eingeräumt. Sie verbindet verschiedene Bereiche miteinander, beispielsweise im Falle der wenigen historiographischen Anmerkungen in der Konsularliste. Wenn Christus hier

53 Amm. 27,3,12f.; Jean Guyon, „Die Kirche Roms vom Anfang des 4. Jahrhunderts bis zu Sixtus III. (312-432)“, in: Charles Piétri und Luce Piétri (Hrsg.), Die Geschichte des Christentums 2: Das Entstehen der einen Christenheit (250 - 430), Freiburg 1996, 877-917, $886 \mathrm{f}$.

54 Charles Piétri, Roma christiana: Recherches sur l'Église de Rome, son organisation, sa politique, son idéologie, de Miltiade à Sixte III (311-440) (Bibliothèque des écoles françaises d'Athènes et de Rome 224), Roma 1976, 376-380.

55 Kurz in Charles Piétri und Christoph Markschies, „Theologische Diskussionen zur Zeit Konstantins: Arius, der ,arianische Streit‘ und das Konzil von Nizäa, die nachnizänischen Auseinandersetzungen bis 337“, in: Charles Piétri und Luce Piétri (Hrsg.), Die Geschichte des Christentums 2: Das Entstehen der einen Christenheit (250 - 430), Freiburg 1996, 271-344, 316; für Details Joachim Mayr, „Der Computus ecclesiasticus“, Zeitschrift für Katholische Theologie 77 (1955), 301-330 und Alden A. Mosshammer, The Easter Computus and the Origins of the Christian Era, Oxford 2008. 
eine Bedeutung zukommt, dann ebenso den planetarischen Gottheiten in der gleichen Liste. Die Historisierung der christlichen Traditionen bietet Chancen für eine Verschmelzung von Genres, die im Chronographen freilich insgesamt restriktiv gehandhabt wurde. In einer Epoche einer intensiven Diskussion über den Kanon des „Neuen Testaments“ ist dem Verfasser des Chronographen der Verweis auf einen städtischen Autoren eines kanonisch umstrittenen Textes, und zwar den als Hermas bekannten Autoren des im zweiten Jahrhundert verfassten Pastor Hermae, ${ }^{56}$ von ausreichender Bedeutung, um zwischen den wenigen narrativen Anmerkungen in den Bischofslisten erfasst zu werden. Eine ähnliche Vorzugsbehandlung genießen sonst nur noch Hinweise auf Bauaktivitäten. Wiederum positioniert ein Römer sich selbst und seine Leser (innen).

Als ein Ergebnis der Untersuchung sehe ich es als erwiesen an, dass der Kodex eine private Zusammenstellung ist und seine Einzelteile individuelle Fassungen älterer Traditionen sind. Religion, insbesondere historisierte Religion ${ }^{57}$ bietet einen Rahmen für die Orientierung des Sohnes eines römischen Senatoren, der für andere Unterschiede als diejenigen zwischen Pauschalbegriffen wie „Heidentum“ und „Christentum“ interessiert werden sollte. Das würde zu einem senatorischen Selbstbild passen, selbst über gewöhnlichen Unterschieden zu stehen. ${ }^{58}$ Christliche Kulte und Traditionen konnten in eine Grundstruktur eingebunden werden, die charakterisiert ist durch Astrologie, Vorstellungen von Göttern und jahrhundertealte römische Institutionen. Starke Abgrenzung - beispielsweise zu Novatianern - und das Übergehen scheinbarer Widersprüche - Christen- und Heidentum - waren nur Teil einer individuellen Appropriation von Religion.

Eine solche Charakterisierung - und damit bemühe ich mich abschließend um eine Generalisierung des ansonsten isolierten Beweisstückes des Chronographen trifft auch auf andere weniger sichtbare Ensembles zu. Summarisch sei dafür auf die Katakombe der Via Latina verwiesen, die ungefähr zu der Zeit des Kodexkalenders mit Wandmalereien versehen wurde. Erneut: Erzählungen oder genauer gesagt mythische Erzählungen werden nebeneinander angegeben. Herkules und Alkestis sowie Christus und Mose, der das Rote Meer teilt, konnten in der gleichen Raumgruppe gefunden werden, obwohl sie sich auf verschiedene Räume verteilen. Es existiert schlichtweg kein Indikator dafür - wenn nicht eine petitio principii -, dass diese Räume für heidnische beziehungsweise christliche Mitglieder einer Familie oder auf individuelle Anordnung hin geschaffen wurden. Zum Ende seines Lebens konnte ein Mitglied der höheren Ränge der römischen Gesellschaft einen Umfang an kulturellen, sogar reli-

56 Zum spezifisch römischen Charakter des Textes siehe Jörg Rüpke, „Apokalyptische Salzberge: Zum sozialen Ort und zur literarischen Strategie des ,Hirten des Hermas““, Archiv für Religionsgeschichte 1 (1999), $148-160$.

57 Für das Konzept „historisierter Religion“ siehe Rüpke (s. Anm. 17). Für den historiographischen Kontext s. Markus Sehlmeyer, Geschichtsbilder für Pagane und Christen: Res Romanae in den spätantiken Breviarien (Beiträge zur Altertumskunde 272), Berlin 2009, 165.

58 Ich bin Kate Cooper dankbar für diese Kontextualisierung. 
giösen Gütern in Anspruch nehmen und genießen, dessen Kombinierbarkeit andernorts von religiös Radikaleren in Frage gestellt wurde.

Für einen Angehörigen der Oberschicht handelte es sich allerdings, wenn er nicht gerade im Rampenlicht einer magistratischen Funktion stand, um eine Religion, die im Privaten studiert und bedacht, im privaten Raum genossen und nicht in der Öffentlichkeit praktiziert werden musste oder auch nur sollte. Schließlich lag die Katakombe unter der Erde. Und der Chronograph war ein Buch, eine Sammlung von Listen und Bildern. Er bot viel Raum, um zwischen den Zeilen und Seiten zu lesen. 
Sarah Bassett

\section{"Curious Art": Myth, Sculpture, and Christian Response in the World of Late Antiquity}

Myth, the stories of gods and heroes, stories understood to hover somewhere in the grey area between the white blaze of truth and the black hole of falsehood, was omnipresent in the visual world of the later Roman Empire. ${ }^{1}$ In places public and private; in media as diverse as sculpture and textiles; and in scales ranging from the minute to the monumental, gods and heroes disported themselves with varying degrees of decorum as here a tale of sylvan revelry wove through the border of silken hem, and there a gathering of stately Olympians graced the porticoes of a public space. In its ubiquity myth was unremarkable; except, that is, for the earliest Christian apologists who used it as the centerpiece in their arguments against polytheistic belief and practice. For second- and third-century commentators such as Tatian (c. 120 - c. 180), Athenagoras (c. 133-c. 190), and Tertullian (c. 160 - c. 225), myth, whether encountered through the sounds and cadences of poetry or the shapes and colors of images, took center stage as it encapsulated the error that was Roman belief and practice. Thus, according to Tertullian, who himself looked to the authority of Varro (116-27 B.C.) in structuring his analysis, myth was problematic in that it rooted the understanding of the gods in the quicksands of philosophic argumentation and poetic composition with the former, philosophy, offering only the uncertainty of conjecture, the latter, poetry, mere fable. ${ }^{2}$ Myth was, in other words, an affront to truth. In a like vein Tatian observed that tales of divine metamorphoses, such as that of the aquiline Zeus in pursuit of the comely Ganymede, simply beggared imagination. ${ }^{3}$ As well, the very definition of divinity they offered was suspect, as it showed the immortals caught in the web of human emotions and the impermanence of human experience. ${ }^{4}$

1 Herodotus $(2.23 .1 ; 2.45 .1)$ and Thucydides (1.22.4) define myth as a narrative that is not verifiable. As such it stands in contrast to history. In the fourth century Sallustius, De dis et mundo (On the gods and the world), 3 states unequivocally that myth treats of the divine. On the problems of modern definitions and terminology with respect to the classical world see F. Graf, "Myth" in DNP 9. 444-63. See 452-63 in this same article for an overview of Greek and Roman definitions as they developed between the sixth century B.C. and late antiquity. Graf defines myth as "a traditional narrative of collective significance". This essay layers this basic definition with the ancient understanding of myth as story that is fictitious and implausible. As such it is associated with poetry and seen as distinct from history. See Graf: 445.

2 See generally Tertullian, Ad nationes, 2.1-10. Section 2.1 takes up the tripartite classification of the discussion of the gods set out in Varro's treatise on the divine: their physical nature, which he states is the property of philosophical speculation; their associated myths, the provenance of poetry; and their veneration by different populations. Tertullian argues that the approach is weak as philosophy deals only with speculation and poetry with foolish ideas.

3 Tatian, Oratio ad Graecos, 10 and 26.

4 Tatian, Oratio ad Graecos, 8; Athenagoras, Legatio pro Christianis, 29. 
Worse yet, these stories were unsavory in that they celebrated bad behavior. Those ruffians the gods, rapists, pederasts, and adulterers every one, were a quarrelsome and deceitful lot. Heroes fared no better in their estimation. Consider, for example, Aeneas; a man who abandoned his city and with it his wife before going on to seduce and then jilt Dido. "Must we," quipped an indignant Tertullian, "regard it as a subject of ridicule or indignation that such characters are believed to be gods who are not fit to be men?"5

While these criticisms of myth were applicable to both word and image, images emerged as a discrete target of apologetic vitriol, and among images, one medium, sculpture, bore the brunt of the abuse, for it was sculpture that provoked and nurtured idolatry. The arguments against it were two. To begin with, sculpture demonstrated the falsehood of the gods, the lie of their very existence, and the futility of their worship. Citing the examples the Ephesian Artemis and the Knidian Aphrodite, Athenagoras pointed out that these statues and others of their ilk were mortal inventions, images that were not only conceived of but created by human beings at fixed points in time. Why, he inquires, if the gods truly do exist and are immortal, were their images not present from the beginning? Their images are naught but "earth and stone and matter and curious art." 6 To honor a statue is, therefore, to worship matter, dead material without life or soul, something altogether different from the divine, uncreated and transcendent.

In addition, sculpture provides clear evidence of demons at work in the world. We have the devil to thank not only for bringing us images and with them their artificers, ${ }^{7}$ but also for luring men to their worship. ${ }^{8}$ It is the material essence of sculpture that creates this menace, for, as Athenagoras describes,

When a tender and susceptible soul which has no knowledge or experience of sounder doctrines and is unaccustomed to contemplate truth, and to consider thoughtfully the Father and Maker of all things, gets impressed with false opinions respecting itself, then the demons who hover about matter, greedy of sacrificial odors and the blood of victims, and ever ready to lead men into error avail themselves of these delusive movements of the souls of the multitude, and taking possession of their thoughts, cause to flow into the mind empty visions as if they were coming from the idols and the statues. ${ }^{9}$

5 "Ridendum an irascendum sit, tales deos credi, quales homines esse non debeant?" Tertullian, $A d$ nationes 2.7.7. Trans. P. Holmes in A. Menzies (ed.) Ante-Nicene Fathers (Grand Rapids 1885): 3. 284; Tatian, Oratio ad Graecos, 34 expresses a similar sentiment using more general examples.

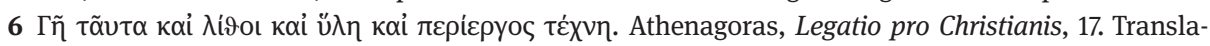
tion: B. P. Pratten in P. Schaff (ed.) Ante-Nicene Fathers (Grand Rapids 1885): 2. 301.

7 Tertullian, De Idololatria, 3.2.

8 Athenagoras, Legatio pro Christianis, 27.

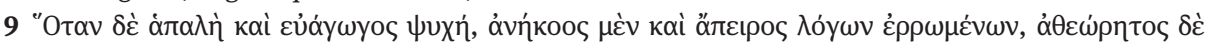

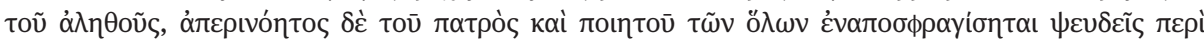

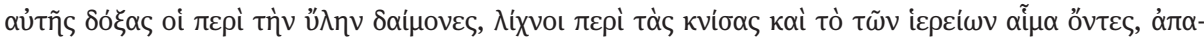

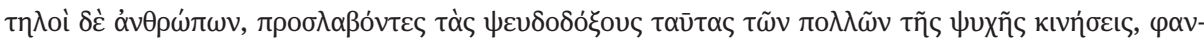

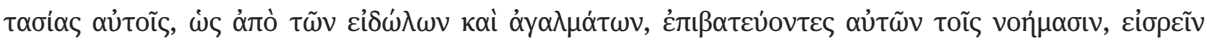

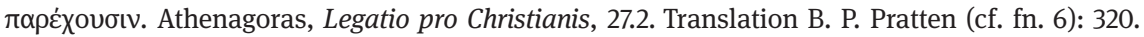


In short, myth and its avatar sculpture were bad business; yet both persisted. Neither the legalization of Christianity at the beginning of the fourth century, nor its ultimate establishment as the religion of state by century's end appears to have diminished their appeal. In cities across the empire statues of gods and heroes maintained their public presence in all manner of civic settings. ${ }^{10}$ Likewise, in the private world of domus and villa, mythological sculpture remained a welcome guest at the dinner table of late antiquity. ${ }^{11}$ Nor was this simply a matter of survival, as new displays, public and private, emerged, some built around sculptured works of antique manufacture, others around works of contemporary production. ${ }^{12}$ Indeed it was only in the sixth century that sculpture well and truly fell from grace, as production slowed and the creation and preservation of installations became less of a concern.

Given the antagonism of the apologists, their certainty that the combined forces of myth and sculpture represented an affront to truth, how was it the case that mythological sculpture remained viable as Christianity became ever more normative a regulating feature of life in the later Roman world? This essay aims to address this apparent contradiction by examining evidence for and response to the use of mythological sculpture in the later Roman world. In so doing it hopes to demonstrate the ways in which the community of Christian faithful, itself ever-expanding and changing over the course of the fourth and fifth centuries as it absorbed new members at all levels of society and moved from outsider to insider status, came to accommodate this great cultural legacy, eschewing the radical stance of the Apologists in exchange for one of acceptance and appreciation that in turn gave way to decline.

Some of the best evidence for understanding the Christian interaction with classical mythological sculpture lies in the material associated with what was arguably the most impressive of all late Roman undertakings, the fourth- and fifth-century development of the city of Constantinople as a new capital for the Roman Empire. Here, in settings public and private, the display of ideal sculpture defied the expectations

10 On urban displays of sculpture see J. Auinger, "The Sculptural Decoration of Ephesian Bath Buildings in Late Antiquity,” in O. Dally and C. Ratté (eds.) Archaeology and the Cities of Asia Minor in Late Antiquity (Ann Arbor 2011): 67-80; M. Aurenhammer and A. Sokolicek, "The Remains of the Centuries. Sculptures and Statue Bases in Late Antique Ephesus: The Evidence of the Upper Agora," in O. Dally and C. Ratté (eds.) Archaeology and the Cities of Asia Minor in Late Antiquity (Ann Arbor 2011): 43-66; F. A. Bauer and C. Witschel (eds.) Statuen in der Spätantike (Wiesbaden 2007); F. A. Bauer, Stadt, Platz und Denkmal in der Spätantike (Mainz 1996); J. J. Pollitt, "The Impact of Greek Art on Rome,” TAPA 108 (1978): 155-74; G. M. A. Hanfmann, From Croesus to Constantine. The Cities of Western Asia Minor and Their Arts in Greek and Roman Times (Ann Arbor 1975), especially 57-74; G. Becatti, “Opere d'arte greca nella Roma di Tiberio," Archeologia Classica 25 (1973): 18-54; D. Strong, "Roman Museums," in D. Strong (ed.) Archaeology in Theory and Practice (New York 1973): $247-64$.

11 On domestic displays of sculpture in late antiquity see L. Stirling, The Learned Collector: Mythological Statuettes and Classical Taste in Late Antique Gaul (Ann Arbor 2005); M. Bergmann, Chiragan, Aphrodisias, Konstantinopel. Zur mythologischen Skulptur der Spätantike (Wiesbaden 1999); D. Brinkerhoff, A Collection of Sculpture in Classical and Early Christian Antioch (New York 1970).

12 Cf. bibliography in fns. 10 and 11. 
of early apologetic commentary. ${ }^{13}$ Representations of gods and heroes crowded the city's fora, streets, and public gathering places. The history of this sculptured population, itself the gift of emperors and high ranking public servants in the period between the foundation of the city in 324 and the death of Theodosius II in 450, indicates both the extent to which displays of statuary remained an essential ingredient in the urban context and the ways in which ideas about and attitudes towards sculpture came to be recalibrated over the course of the fourth and fifth centuries.

Any examination of Constantinopolitan sculptured display must begin with a consideration of the setting. The city, the brain-child of its eponymous founder, Constantine (305-337), stood on the site of the old Greco-Roman town of Byzantium (Fig. 1), a city that had been founded in the seventh century B.C., razed by Septimius Severus (193-211) in the late second century A.D., and then partially rebuilt before being abandoned.

In choosing this site, Constantine launched one of the greatest projects of urban renewal the ancient world had ever known. In the six years between the foundation ceremonies of 324 and the dedication celebrations of 330, new city limits were drawn, old buildings were refurbished, and a monumental armature of colonnaded streets supporting palaces and public gathering places was grafted on to Byzantium's extant plan. The armature's major thoroughfare, the avenue known as the Mese, ran west from the city center, and it was along this scaffolding that the most important Constantinopolitan architectural spaces grew up. In the city center three major complexes coalesced around the Mese's starting point: the forum known as the Augusteion, the Baths of Zeuxippos, and the Hippodrome. Further west, a new space, the Forum of Constantine, circular in shape, straddled the avenue just outside the old city wall. These four complexes stood at the core of the city's Constantinian development. Later in the fourth century at the impetus of Theodosius I (379-395) and members of his dynasty westward expansion continued first with the extension of the Mese and then with the addition of two further fora; the first by Theodosius I, the second by his son and successor Arcadius (395-408). Completion of a new city wall in the early years of the fifth-century reign of Theodosius II (408-450) represented the last major addition to the city's westward push. ${ }^{14}$

13 On the Constantinopolitan collection in particular see most recently S. Bassett, The Urban Image of Late Antique Constantinople (Cambridge 2004) which includes a catalogue of the city's public sculpture and its primary source documentation. Earlier considerations of Constantinopolitan sculpture include C. Mango, “Antique Statuary and the Byzantine Beholder," DOP 17 (1963): 53-75; R. M. Dawkins, “Ancient Statues in Medieval Constantinople,” Folklore 35 (1924): 209-48; G.-C. Heyne, "Priscae artis opera quae Constantinopoli extitisse memorantur," Commentationes Societatis Regiae Scientiarum Gottingensis 11 (1790-91): 209-48.

14 On the development of Constantinople as an imperial capital see Bassett (cf. fn. 13): 17-36; A. Berger, "Streets and Public Spaces in Constantinople," DOP 54 (2000): 161-72; Bauer (cf. fn. 10): 143-268; C. Mango, Le développement urbain de Constantinople (IV ${ }^{\mathrm{e}}-\mathrm{VII}^{\mathrm{e}}$ siècles) (Paris 2004); A. Berger, "Die Altstadt von Byzanz in der vorjustinianischen Zeit," Varia II, Poikila Byzantina 6 (Bonn 1987): 7-30; R. Krautheimer, Three Christian Capitals: Topography and Politics (Berkeley 


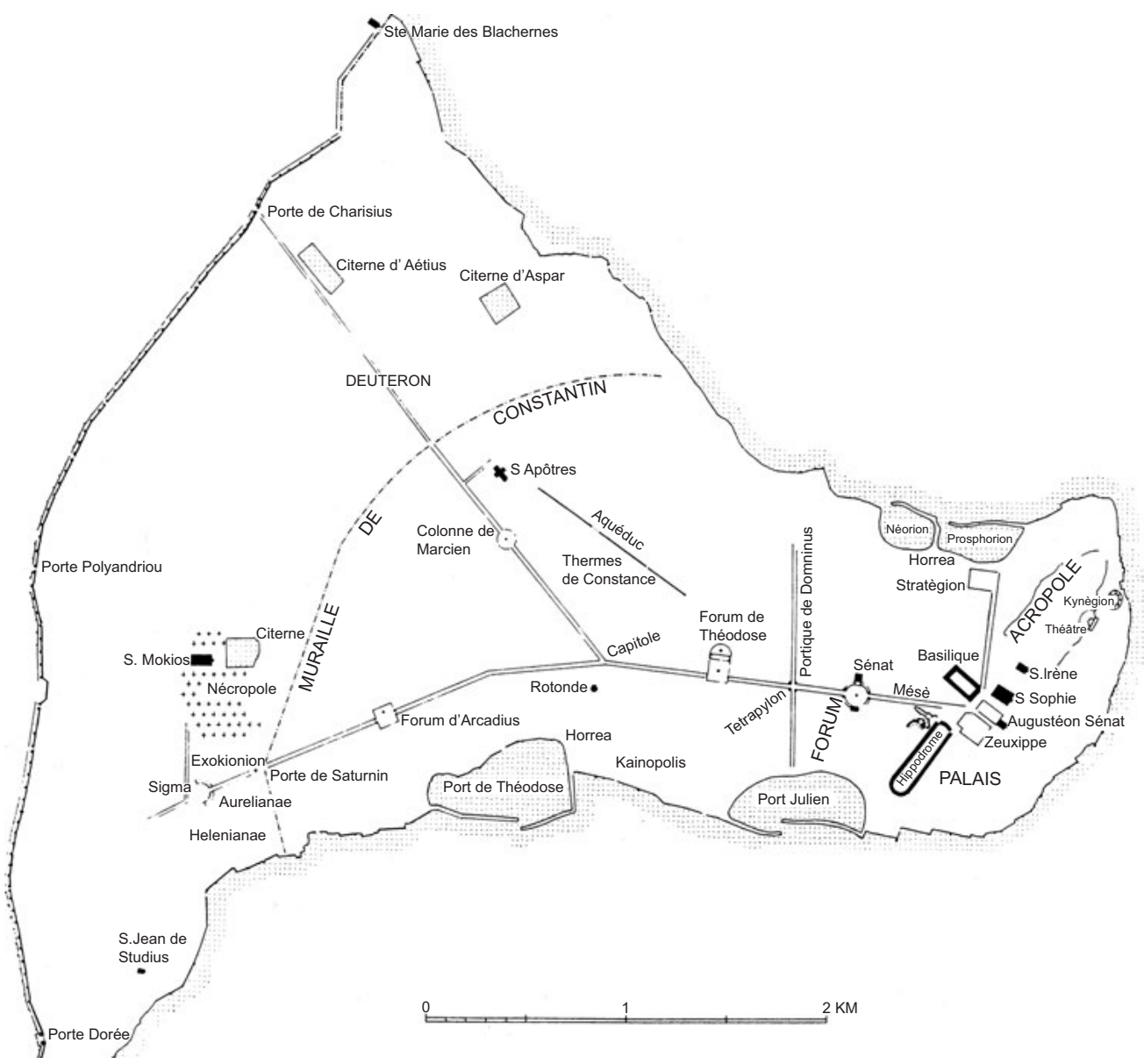

Fig. 1: Plan of Constantinople (after C. Mango, Le développement urbain de Constantinople [IV $-\mathrm{VII}^{\mathrm{e}}$ siècles] [Paris 2004]: Plan II).

Sculptured display was integral to this development from the start. In a manner consistent with traditions in other late Roman cities, these installations included both honorific monuments, the portrait representations of great men and women past and present, and "ideal" or mythic images, the statues of gods and heroes. This sculptured population included works of contemporary manufacture as well as monuments of ancient pedigree brought from the cities and sanctuaries of the an-

1983): 41-68; G. Dagron, Naissance d'une capital: Constantinople et ses institutions de 330 (Paris 1974); H.-G. Beck, “Großstadt-Probleme: Konstantinopel vom 4.-6. Jahrhundert," in H.-G. Beck (ed.) Studien zur Frühgeschichte Konstantinopels (Munich 1973): 1-26; C. DuCange, Historia byzantina duplici commentario illustrata (Paris 1680); P. Gilles (P. Gyllius), De topographia Constantinopoleos et de illius antiquitatibus libri quattuor (Lyon 1561). 
cient world, places such as Rome, Delphi, and Ephesus. ${ }^{15}$ With the exception of a few battered fragments none of this material survives ${ }^{16}$ and it is therefore the evidence of literary sources that allows reconstruction of the public displays implemented under Constantine. $^{17}$

What these sources reveal is a mix of honorific and ideal sculpture in discrete urban settings, with ideal monuments being given pride of place. All told there appear to have been somewhere between 150 and 200 statues in the Constantinian city. Of these around 20 represented Constantine and members of his dynasty, 35 or 40 honored prominent figures from the past, and somewhere between 100 and 110 ranked as mythological sculpture. In terms of manufacture it is likely that the portraits commemorating members of the Constantinian dynasty were for the most part works of contemporary production, while the portraits of historical figures and the mythological sculpture were largely, although perhaps not exclusively,

15 Eusebius, $V C, 3.54$ provides the only contemporary commentary, referring specifically to the sanctuaries of Apollo at Delphi and at Chryse together with the Museion on Mt. Helikon. See Av. Cameron and S. G. Hall (eds. and trans.) Eusebius. Life of Constantine (Oxford 1999): 143. Jerome’s Chronicon provides a global assessment of the emperor's collecting activity in his entry for 324: "Ditatur Constantinopolis paene omnium urbium nuditate quae ante Byzantium dicta." The comment gives a sense of the scope of the enterprise. Shortly thereafter Zosimos, Historia Nova, 2.32 also refers to the global importation of sculpture. See L. Mendelssohn (ed.) Zosimi Historia Nova (Leipzig 1887): 89 -91. Later, and less reliably, Patria Konstantinopoleos 2.73, a $10^{\text {th }}$-century text, lists 25 cities in addition to Rome from which material was alleged to have been taken. See T. Preger (ed.) Scriptores Originum Constantinopolitanarum (Leipzig 1901-07): 189.

16 Material evidence for the late antique city is limited, especially with respect to the imported sculptured materials. Disasters natural and manmade brought about the piecemeal destruction of this collection over the course of the city's long history. Of the antiquities imported to the city in fourth century only a handful survive in the modern city of Istanbul. These include the Obelisk of Theodosius I and the Serpent Column of the Platean Tripod. See Bassett (cf. fn. 13): 219-222 and 224-227 for documentation. Monuments preserved outside Istanbul include a goose recovered from the Hippodrome and the Horses of San Marco in Venice. For the goose see Bassett (cf. fn. 13): 132. For the San Marco horses see Bassett (cf. fn. 13): 222-23. Excavation and recovery of material has been sporadic. Investigations in the 1920s recovered important material pertinent to the Baths of Zeuxippos. See S. Casson, Preliminary report upon the excavations carried out in and near the Hippodrome of Constantinople in 1927 (London 1928); S. Casson, Second report upon the excavations carried out in and near the Hippodrome of Constantinople in 1928 (London 1929); and S. Casson "Les fouilles de l'hippodrome de Constantinople," Gazette des Beaux Arts 30/1 (1930): 215-41. For an overview of more recent archaeological work see C. Barsanti, "Note archaeologiche su Bisanzio Romana,” Milion 2 (1990): 11-50.

17 Roman and Byzantine texts include Christodorus of Thebes, Ekphrasis on the sculpture in the Baths of Zeuxippos ( $5^{\text {th }}$ century) in W. R. Paton (ed. and trans.) The Greek Anthology 1. Loeb Classical Library (London and New York 1916): 58-91; Zosimos (5 ${ }^{\text {th }}$ century) (cf. fn. 15); Chronicon Paschale (7 $7^{\text {th }}$ century) in L. Dindorff (ed.) Chronicon paschale (Bonn 1832); Parastaseis syntomai chronikai ( $8^{\text {th }}$ century) in Av. Cameron and J. Herrin (eds. and trans.) Constantinople in the Eighth Century, the Parastaseis Syntomoi Chronikai (Leiden 1984); Niketas Choniates, De Signis Constantinopoleos $\left(13^{\text {th }}\right.$ century) in J. L. van Dieten (ed.) Niketas Choniates Historia (Berlin 1975): 647-55. 
monuments of ancient - that is pre-fourth-century manufacture - that had been imported from the cities and sanctuaries of the Roman world. ${ }^{18}$

With respect to the mythological, or ideal, sculpture, the most important venues were those of the Baths of Zeuxippos with no less than 48 mythological figures, the Hippodrome with 12, and the Forum of Constantine with ten. ${ }^{19}$ Within each of these settings subject matter appears to have been carefully thought out as each gathering displayed thematic consistency. Thus in the most densely populated of the venues, the Baths of Zeuxippos, two major groups of mythological sculpture emerge: one of gods and demigods associated with water, health, and healing, and another of gods and heroes associated with the epic narratives derived from the Trojan and Theban cycles. The gods and demigods numbered eleven with three statues each of Apollo and Aphrodite, a single figure of Hermaphroditos, and two multi-figured groups, one of Herakles with the nymph Auge and a second showing Poseidon with Amymone. Epic images were linked largely with the Trojan cycle. Among the figures included were those of Achilles, Chryses, and Sarpedon, as well as a series of famous couples attendant at the city's fall: Aeneas and Creusa, Helenos and Andromache,

18 For an overview of sculptured installations in Constantinople see Bauer (cf. fn. 10): 158-66, 17382, 197-202, 209-11, 213-17, 222-24, 227-28, 230-33, 235, 238, 242, 249-54. On the relationship between old and new in sculptured display see: S. Bassett, "Sculpture and the Rhetorical Imagination in Late Antique Constantinople," in O. Dally and C. Ratté (eds.) Archaeology and the Cities of Asia Minor in Late Antiquity (Ann Arbor 2011): 27-41. On ideal sculpture in Constantinople see the catalogue of monuments in Bassett (cf. fn. 13): 143-249. For documentation of the city's late antique honorific portraits see R. Stichel, Die römische Kaiserstatue am Ausgang der Antike (Rome 1982): 76 (no. 7), 83-85 (nos. 47, 52-57), 90 (no. 72), 94-115 (nos. 89-91, 95-101, 105-116, 118-19, 122124, $126-129,131-138,140-44,146)$. For remains of Constantinopolitan honorific sculpture now in Istanbul see N. Firaltı, La sculpture byzantine figurée au Musée archéologique d'Istanbul (Paris 1990): 5-14 (inventory numbers: 1094, 5795, 5028, 73.27, 5077, 5158 A \& B, 4417, 769, 4051, 5673, 5278, 6287, 73.26, 4719). For surviving pieces outside of Turkey see: F. P. Johnson, "The Colossus of Barletta,” AJA 25 (1929): 20 -25; R. Delbrueck, Spätantike Kaiserporträts (Berlin 1933): 217-26; J. Kollwitz, Oströmische Plastik der Theodosianischen Zeit (Berlin 1941): 109-10; S. Sande, "Zur Porträtplastik des sechsten nachchristlichen Jahrhunderts," Acta ad archeologiam et artium historiam pertinentia 6 (1975): 65-106 at 75-76; J. Breckenridge in K. Weitzmann (ed.) Age of Spirituality. Late Antique and Early Christian Art. Third through Seventh Century (New York 1979): 28 - 30; M. Prusac, From Face to Face: Re-Carving of Roman Portraits and the Late-Antique Portrait Arts (Leiden and Boston 2011): 74.

19 On the Zeuxippos see: Bassett (cf. fn. 13): 51-58, 160 - 85 for documentation and commentary; S. Bassett, “'Historiae custos': Sculpture and Tradition in the Baths of Zeuxippos,” AJA 100 (1996): 491-506; R. Stupperich, "Das Statuenprogramm in der Zeuxippos-Thermen. Überlegungen zur Beschreibung der Christodoros von Koptos,” IstMitt 32 (1982): 210 - 35. On the Hippodrome see Bassett (cf. fn. 13): 58-67, 212-32 for documentation and commentary, and S. Bassett, "Antiquities in the Hippodrome of Constantinople,” DOP 45 (1991): 87-96. On the Forum of Constantine see Bassett (cf. fn. 13): 68-71, 188-208 for documentation and commentary. 
Odysseus and Hekube, Kassandra and Ajax, Pyrrhos and Polyxene, and, finally, Oenone and Paris and the reunited Helen and Menelaos. ${ }^{20}$

Nearby, in the Hippodrome, images appropriate to sporting events, victory, and civic identity were the visual currency. Here Herakles struggled through his labors in a series of statues distributed along the circus's central barrier, and there were two monuments of uniquely Roman reference, a Wolf with Romulus and Remus and a Capitoline Goose. ${ }^{21}$

In the Forum of Constantine, where sculpture crowded the rising columnar façade of a nymphaeum, the mythological roster included Paris, Hera, Aphrodite, Athena, Thetis and a group of hippocamps. The particular combination of figures suggests the larger narrative of the wedding of Peleus and Thetis, and within that larger episode the Judgment of Paris. Finally, there was the Palladion, an ancient image of the armed Athena associated first with Troy, then with Rome, before being brought to Constantinople. ${ }^{22}$

What was the purpose of such displays? The only contemporary response comes from Eusebius of Caesarea (263-339) commenting on Constantine's removal of valuables from temples:

\begin{abstract}
In yet other cases the sacred bronze figures, of which the error of the ancients had for a long time been proud, he displayed to all the public in all the squares of the Emperor's city, so that in one place the Pythian was displayed as a contemptible spectacle to the viewers, in another the Sminthian, in the Hippodrome itself the tripods from Delphi, and the Muses of Helicon at the palace. The city named after the Emperor was filled throughout with objects of skilled artwork in bronze dedicated in various provinces. To these under the name of gods those sick with error had for long ages vainly offered innumerable hecatombs and whole burnt sacrifices, but now they at last learnt sense, as the Emperor used these very ones for the laughter and amusement of the spectators. ${ }^{23}$
\end{abstract}

20 For documentation and commentary on the sculpture in the Baths of Zeuxippos see Bassett (cf. fn. 13): $160-85$. For the particular sculpture mentioned here see Bassett (cf. fn. 13): 160 (Achilles, Aeneas and Creusa), 161 (Kassandra), 165 (Andromache), 166 - 68 (Chryse), 170 (Helenos, Helen and Menelaos), 177 (Ajax), 178 (Oenone and Paris), 179 (Odysseus and Hekube), 183 (Pyrhhos and Polyxene), 184 (Sarpedon). Inscribed bases for the support of the Odysseus and Hekube group survive. See Bassett (cf. fn. 13): $180-81$, plates 17 and 18.

21 For documentation and commentary see Bassett (cf. fn. 13): 212-32 for the Hippodrome collection as a whole. For specific works mentioned here see Bassett (cf. fn. 13): 216 (Goose); 218 -19 (individual labors of Herakles); 231 (Wolf with Romulus and Remus).

22 For documentation and commentary see Bassett (cf. fn. 13): 188 (Aphrodite), 188-92 (Athena), 204-205 (Hippocamps and Judgment of Paris), 205-06 (Palladion), 207-08 (Thetis).

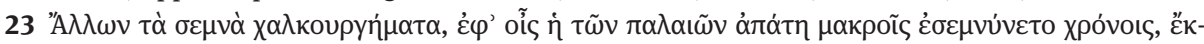

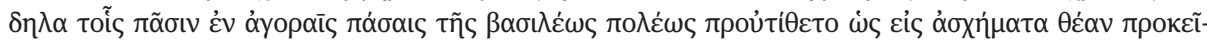

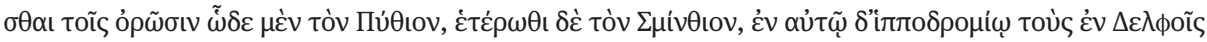

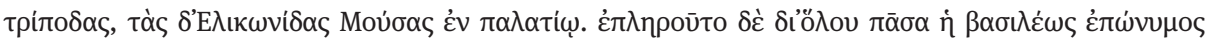

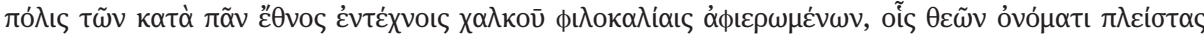

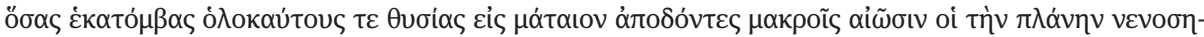


The echo of the apologists resounds through the bishop's observations: for Eusebius, the display of false gods constituted an act of public humiliation.

While it would be imprudent to reject Eusebius's assessment outright, the evidence of the collection itself suggests that there is more at work in this gathering of ideal sculpture than the denigration of pagan images. To begin with, in taking stock of these groupings, it is clear that there is a consistent approach to the display project. Individual collections appear to have conformed to traditional ideas about how sculpture could and should be deployed. Thus, statuary was selected, displayed, and organized around themes appropriate to place. In the Baths of Zeuxippos, the choice of sculpture was consistent with displays seen in the large bathing establishments of Rome and the provincial centers of North Africa and Asia Minor where the presence of gods associated with health and healing and the inclusion of great epic narrative was the norm. ${ }^{24}$ Similar observations may be made about the Hippodrome, which followed the lead of the Circus Maximus at Rome or any one of a number of provincial racetracks in its display of sculpture along the central barrier. That this sculpture included figures such as that of the struggling Herakles was apt: these were the kinds of images that referred both to the struggles of the charioteers who negotiated the course and to the victories that followed. Such images also tended to link themselves to civic identity. Thus, at Tyre, a statue of Herakles, the city's patron god, made a prominent appearance in the circus. ${ }^{25}$ Finally, in the Forum both the presence of a nymphaeum and its adornment with sculpture based on an aquatic narrative is consistent with the locations of and displays in other public fountains at nodal points of civic interaction. ${ }^{26}$

Also important is the fact that these mythic images were not isolated. Instead, they stood throughout the city side by side with works of ancient and contemporary portrait manufacture and other types of public monuments, such as obelisks and honorific columns. ${ }^{27}$ What did this integration of mythic imagery into the city's visual matrix accomplish?

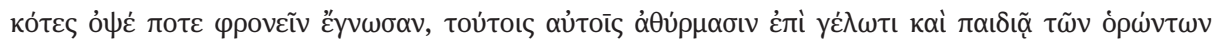

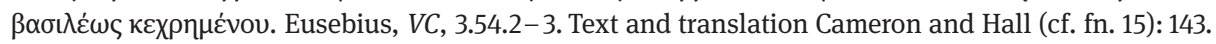
24 Bassett (cf. fn. 13): 53-56. On the sculptured installations of Roman baths see generally H. Manderscheid, Die Skulpturenausstattung der kaiserzeitlichen Thermenanlagen (Berlin 1981).

25 See generally G. Dagron, L'Hippodrome de Constantinople. Jeux, peuple et politique (Paris 2011): 94-107; and Bassett (cf. fn. 13): 58-67. For the specific case of the Herakles at Tyre see J. Humphrey, Roman Circuses (London 1986): 475.

26 On the nymphaeum in the Forum of Constantine see Bassett (cf. fn. 13): 66. For the example of Miletus see Hanfmann (cf. fn. 10): 66-67; G. Kleiner, Ruinen von Milet (Berlin 1968): 114-15; E. Lange, "Die Entwicklungen der antiken Brunnenplastik," JDAI 35 (1920): 100-102; J. Hülsen, Milet V: Das Nymphaeum (Berlin and Leipzig 1919), especially 55-72.

27 For a more thorough discussion of and a suggested approach to understanding the relationship between ancient sculpture and modern, or purpose-made, sculpture in the late antique city see Bassett (cf. fn. 18). 
The iconographic map of the sculptured gatherings, individual and collective, suggests a partial answer. At the Zeuxippos by far the largest number of statues in the display was linked to the Trojan epic, and in a building such as the bath, the kind of space in which civic identity was very much on parade, these mythic images, which were designed in large measure to function on the level of pure entertainment, also worked to describe urban identity. Fifth-century discussion of the foundation of Constantinople by Sozomen (d. 450) makes no secret of the fact that Constantine's first choice of building venue was Ilion, or Troy, rather than Byzantium. ${ }^{28}$ At the root of this interest was the link between Troy and the Roman people. As every schoolboy knew from his labors over the Aeneid, it was the destruction of Troy, the dispersal of its people and gods that brought about the foundation of Rome. Thus, with its emphasis on the moment of the city's fall, the very moment of dispersal, the Trojan myth offered a pre-history of the city, the people, and the empire of Rome that described Constantinople as the heir to this tradition, and as such a New Troy. ${ }^{29}$

Next door, in the Hippodrome, more tales of mythic origin were show-cased with the display of images such as the Wolf with Romulus and Remus. In this instance, the link was, of course, to Rome and its own foundation legend. The image referred not simply to the old capital's foundation myth, but also directly to events that took place in the Constantinopolitan circus, for it was in the Hippodrome that Rome's ancient foundation festival, the Lupercalia, was celebrated. In this ritual reenactment myth sprang to life and Constantinople appropriated the old capital's story for its own, becoming a New Rome. ${ }^{30}$

The theme of a Constantinopolitan connection to the traditions of Troy and Rome came together in the sculptured displays of the Forum of Constantine. The Judgment of Paris group that was part of the larger gathering of figures associated with the wedding of Peleus and Thetis was, of course, the event that set the Trojan epic in motion. And finally there was the Palladion, one of antiquity's great apotropaia. Believed to have fallen to Troy from heaven, it was said to have been kept in the citadel at Ilion as a guarantor of the city's safety. Odysseus and Diomedes carried the statue away, and in their act of rapine created the conditions for the city's fall. According to Roman tradition, Aeneas then rescued the Palladion and brought it to Lavinium, whence it was taken to Rome to act as the city's own defender. There, in the inner sanctum of the Temple of Vesta, it stood as an emblem of the perma-

28 Sozomenos, Historia ecclesiastica, 2.3.2-3.

29 For an extended discussion of the idea of Constantinople as New Troy see Bassett (cf. fn. 13): 7578.

30 On the wolf with the twins see Bassett (cf. fn. 13): 231. For the Lupercalia see Dagron (cf. fn. 25): 67, 72, 82-83, 93, 125-26; Bassett (cf. fn. 13): 64. For an extended discussion of the relationship between Old Rome and New Rome see Bassett (cf. fn. 13): 58-67 and Bassett, “Antiquities” (cf. fn. 19). 
nence of Rome before being brought to Constantinople where its presence testified to the enduring bond between Troy, Rome, and the new capital on the Bosporus. ${ }^{31}$

Troy, Rome, Constantinople: what the sculptured displays in the baths, the circus, and the forum created for the capital was a foundation myth that rooted the city's traditions deep in the soil of the heroic past. That myth and sculpture combined forces to accomplish this task is no accident. In public settings across the Roman world sculptured displays described and documented just such stories. The Constantinopolitan collections were of a piece with this tradition. Further their choice of subject matter reflected the conviction that links to the most ancient antiquity implied in the claim of heroic or divine foundation lent honor and prestige.

Consider for example, the words of the later third-century author, Menander Rhetor, on the writing of urban encomia: "If a city is very ancient you will say that oldest means honorable, and that the city is eternal like the gods." 32 At work in the Constantinopolitan appeal to myth was the desire to grasp that eternity.

That sculpture served as the vehicle for visual delivery is also important. As the great medium of public expression in the cities and sanctuaries of the Roman world, sculpture was the descriptive vehicle that gave life to and documented the history of a place. Accomplishments were commemorated, allegiances expressed, and piety demonstrated with the dedication and maintenance of a vast range of public monuments of which mythic representation was but one aspect. This tradition of public display shaped the image of a city by providing it with visual documentation that not only gave life to claims to importance and prestige, but also, and crucially, enhanced the urban setting and with it civic prestige with the addition of beautiful objects. For it was as much through material essence as iconography that sculpture communicated: sculpture, handsome with the dazzle of rich marble or gleaming bronze, was an index of urban worth in that it gave tangible expression to the value accorded a community by its patrons and benefactors. A city adorned was understood, therefore, as a city steeped in virtue. ${ }^{33}$

A final aspect of Constantinopolitan display was the reused status of the sculpture. With many of the monuments drawn from the cities and sanctuaries of the

31 On the Palladion see Bassett (cf. fn. 13): 205-206. Prokopios, De Bello Gothico, 5.15.10 - 15. H. B. Dewing (ed. and trans.) History of the Wars: The Gothic War, Loeb Classical Library (London and Cambridge, MA 1953-57): 152, and Malalas, Chronographia, 13.8. I. Thurn (ed.) Ioannis Malalae Chronographia (Berlin and New York 2000) offer the earliest and most reliable evidence for the presence of the Palladion (or what was believed to have been the Palladion) in Constantinople.

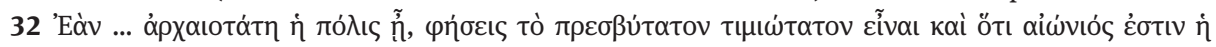

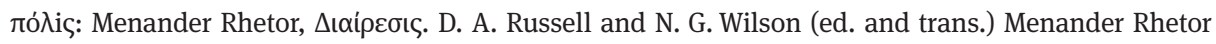
(Oxford 1981): 50-51.

33 That the importation of sculpture to Constantinople were understood as urban adornment is suggested by Socrates (HE 1.16.3) and Sozomenos (HE 2.5.3), both of whom refer to the craftsmanship, beauty, and decorative qualities of the Constantinian sculptured installations. I thank H. Leppin for these references. On ideas about and ideals of civic beauty see H. Saradi, "The kallos of the Byzantine City: The Development of a Rhetorical Topos and Historical Reality,” Gesta 34 (1995): 37-56. 
Roman world, the city found itself a repository of some of the empire's most wellknown sculptured monuments, monuments whose removal to Constantinople from their original settings was an important aspect of their meaning. On a very basic level the installation of sculpture from the far-flung territories of the empire brought the urban wealth of the Roman world to the capital, enhancing the sense of civic virtue. But this wholesale importation of materials also carried with it another connotation. By commandeering such famous monuments as the Wolf with Romulus and Remus, images unique to a particular place, Constantine and his planners claimed not only the wealth of a given city as manifest in the material and craftsmanship associated with sculpture, but also its very soul. To possess a statue like the Capitoline Wolf, an image identified uniquely with Rome, was to lay claim to the identity and power of Rome itself. Indeed, such ownership decreed supremacy. Whether from Rome, Delphi or any one of a number of other cities and sanctuaries, the wholesale in-gathering of the empire's most famous monuments, monuments readily identified with particular places and events, was a way in which to commandeer the history of the empire for the capital and in so doing establish Constantinopolitan hegemony over the cities of the later Roman world. ${ }^{34}$

Pace, Eusebius! Ideal sculpture thrived in Constantinople, not as a subject of ridicule but as a building block of urban identity. With the sculptured installations of the city Constantine and his planners not only visualized a history of mythic origins that gave the place a sense of unrivalled prestige, but also lent the capital an air of beauty expressive of the sense of civic virtue. As this activity indicates, the Constantinian response to classical ideal sculpture was something altogether different from that of the Apologists. Instead of condemning and spurning sculptured tradition, Constantine embraced it as the means to create a compelling image of power.

The Constantinian installations created a backdrop against which the city's ongoing history could unfold, a history that by century's end found expression in public sculpture of a different sort: honorific portraiture. With the accession of Theodosius I in 379 and the subsequent success of his dynasty, the sculptured displays of Constantinople began to focus less on ideal sculpture and more on honorific installations. In fact the number of imperial statues appears to have doubled during the period of Theodosian rule. Thus, sources report approximately 20 statues of Constantine and other members of his family, ${ }^{35}$ a handful of statues representing members of

34 On the issue of appropriation, plunder, and cultural hegemony in the Roman world see most recently I. Östenberg, Staging the World: Spoils, Captives, and Representations in the Roman Triumphal Procession (Oxford 2009). For the specific case of Constantinople see Bassett (cf. fn. 13): 47-49. 35 The numbers are approximate and an exact count is impossible given the overlapping nature of the sources. For images of members of the Constantinian dynasty see Malalas (cf. fn. 31), 13.8; Chron. Pasch. (cf. fn. 17), 528 - 29; John Lydus, Liber de mensibus, ed. R. Wuensch (Stuttgart 1967), 4.138; G. Cedrenus, Compendium historiarum in I. Bekker (ed.) Georgius Cedrenus et Joannis Scylitzae (Bonn 1838-39): 1.564; and the various references in the Parastaseis syntomoi chronikai (cf. fn. 17), 7, 11, 16, 34, 36, 44a, 49, 57, 58, 68. See also C. Mango, The Brazen House (Copenhagen 1954): 46, 48; 
the dynasty of Valentinian I (364-75), ${ }^{36}$ and around 40 statues of Theodosius the Great (379-95) or members of his house. ${ }^{37}$ In part this shift in interest can be explained by the fact that the installations of mythological sculpture engineered under the Constantinian mandate were complete and successful in accomplishing their work. It also reflects the new ruling dynasty's desire to imprint the city with its own dynastic stamp. With the display of portraits of members of the Theodosian house throughout the capital, the city's contemporary rulers integrated themselves into a trajectory of history that began with Troy and continued in Rome, before locating in Constantinople. ${ }^{38}$

Although this focus on dynastic representation altered the nature of public sculptured display, the collection and display of mythological sculpture continued albeit in numbers greatly reduced. In the public arena there is only one notable addition, a statue of Skylla added to the central barrier of the Hippodrome during the reign of Arcadius. ${ }^{39}$ It was instead in unofficial contexts that the most interesting and telling displays of mythological sculpture came into being, probably in the second and third decades of the fifth century. One of these collections, a gathering put together by the court official Lausos in a public portico adjacent to his Constantinopolitan palace, suggests the emergence of a new approach to the question of mythological sculpture, an approach that at first glance appears closer to the condemnatory points of view expressed by Eusebius and his apologetic predecessors, but that emerges upon further consideration as profoundly appreciative of myth and its sculptured tradition.

Who was this Lausos and what was the substance of his collection? Known in an official capacity as grand chamberlain at the court of Theodosius II, Lausos was also the patron of The Lausaic History, a collection of stories by Palladius (c. 364-c. 430) about holy men and women of the Egyptian desert. ${ }^{40}$ This track record makes it clear that Lausos was an interested and influential Christian. It is therefore somewhat surprising to learn that he was also a major collector of the very type of art condemned by Eusebius and the apologists, mythological sculpture. Although his collection was

\footnotetext{
R. Janin, Constantinople byzantine (Paris 1964): 59-62, 73, 62-64; and Bauer (cf. fn. 10): 148, 162, 166, 173, 227.

36 The Parastaseis (cf. fn. 17), 11 notes a statue of Valentinian in the Augusteion without specifying which of the three emperors bearing the name is intended. Similarly, Parastaseis, 12 places a statue of Valentinian at the Modion, or granary. Cameron and Herrin (cf. fn. 17): 199 together with Stichel (cf. fn. 18): 76 (no. 7) suggest identification with Valentianian I, the emperor who established the Modion, against Janin (cf. fn. 35): 66, 69 who favors identification with Valentianian III. Parastaseis, 19 documents equestrian statues of Valentinian I or II at an unidentified location. See also Stichel (cf. fn. 18): 83 (no. 47).

37 See Stichel (cf. fn. 18): 84 (no. 52), 84-87 (nos. 54-57), 90 (no. 72), 94-96 (nos. 89-91), 97-99 (nos. 95-101), 100-101 (nos. 106-12).

38 Bassett (cf. fn. 18).

39 Bassett (cf. fn. 13): 227-30.

40 On Lausos: PLRE 2. 660 -61, s.n. “Lausos.”
} 
destroyed by fire in the latter years of the fifth century, literary sources, the histories of Cedrenus (fl. $11^{\text {th }}$ century) and Zonaras (fl. $12^{\text {th }}$ century), ${ }^{41}$ describe at least thirteen statues on display at the chamberlain's palace: an Athena from the sanctuary at Lindos on Rhodes, a joint project by the sixth-century B.C. sculptors Skyllis and Dipoinos; a Hera from Samos by another early sculptor, Bupalos of Chios; the colossal chryselephantine Zeus by Phidias from the fifth-century temple in the sanctuary at Olympia; Praxiteles's fourth-century Aphrodite of Knidos; two statues by Praxiteles's contemporary Lysippos, an Eros from Myndos and the personification of Kairos, possibly from the sculptor's workshop; and, finally, a series of statues of wild animals and half-human creatures that included tigresses, vultures, giraffes, unicorns, pans, and centaurs, pieces that were likely to have been of Hellenistic or Roman manufacture. ${ }^{42}$

By any index this gathering was extraordinary. Most likely to have been put together during the period of the 420s or the 430s during one of the two periods in which Lausos occupied the post of chamberlain, the collection included seven of the ancient world's most famous temple statues, images often referred to as cult images, ${ }^{43}$ each one the work of an artist of renown; animals real and fantastic of unnamed authorship; and a single personification, a statue of Kairos by Lysippos.

41 Two sources describe the Lausos gathering: two passages in Georgius Cedrenus's Compendium historiarum (cf. fn. 35): 1.564 and 1.616, and a single passage in Zonaras's Epitome historiarum, ed. T. Büttner-Wobst (Bonn 1897): 3.131. On Cedrenus and Zonaras see H. Hunger, Die hochsprachliche profane Literatur der Byzantiner (Munich 1928): 393-94 (Cedrenus) and 416-18 (Zonaras). Because of its chronological remove from the collection, C. Blinkenberg characterized Cedrenus's account of the collection as “ein Gewebe von Fabeln”. See Blinkenberg, Knidia: Beiträge zur Kenntnis der praxitelischen Aphrodite (Copenhagen 1933): 32-34. Others have also challenged the reliability of the texts on the basis of their late date. See T. Stevenson, "What happened to the Zeus of Olympia?," Ancient History Bulletin 21/1-2 (2007): 65-88, especially 65 fn. 2 for references. Stevenson reviews the evidence and eventually agrees with the reliability of the sources. In fact both Cedrenus and Zonaras can be shown to have derived their material from earlier sources, specifically the work of the fifthcentury historian Malchus, thus undermining challenges to their authenticity. For a full analysis of texts and sources see Mango's discussion in C. Mango, E. D. Francis, and M. Vickers “The Palace of Lausus at Constantinople and its Collection of Ancient Statues," Journal of the History of Collections 4 (1992): 89-98 at 89-92. For a catalogue of the individual statues see Bassett (cf. fn. 13): 23238.

42 For the documentation concerning the palace and collection of Lausos see Bassett (cf. fn. 13): 98120 and S. Bassett, “'Excellent Offerings': The Lausos Collection in Constantinople,” Art Bulletin 82 (2000): 6-25. Also important are the contributions of J. Bardill, "The Palace of Lausos and Nearby Monuments in Constantinople: A Topographical Study,” AJA 101 (1997): 67-95; Mango, Francis, Vickers (cf. fn. 41); R. Guilland, Études de topographie de Constantinople byzantine (Berlin 1969): 32; R. Guilland, "Études sur la topographie de Constantinople byzantine: le Palais de Lausos," Helleniki 7 (1962): 95-104; C. M. Bowra, "Palladas and the Converted Olympians,” BZ 53 (1960): 1-7; A. Nagl, “Lausos” in RE, suppl. 7. 365-66; P. Gilles (cf. fn. 14): 129-32.

43 On the problem of nomenclature for sacred temple images see A. Donohue, Xoana and the Origins of Greek Sculpture (Atlanta 1988) and A. Donohue, "Greek Images of the Gods: Considerations of Terminology and Methodology,” Hephaistos 15 (1997): 31- 45 who argues that the concept of the cult 
In its makeup and presentation the Lausos ensemble represented a wholly different approach to myth and sculpture than the massed, interconnected gatherings of ideal statuary that resonated off of one another around the city under Constantine. To begin with, the nature of the sculpture was different. Evidence for statuary associated with the Constantinian collections suggests very strongly that the sculpture, whether used or reused, original or copy, was of a type designed specifically for civic display contexts. By contrast at least half of the sculpture gathered by Lausos came from sacred places, specifically, sanctuaries. Further, typological analysis indicates a preference for standard works of late-classical or Hellenistic manufacture for sculpture in the city's Constantinian displays. Unusually, in the Lausos collection the statues appear to have been unique creations of comparatively early sixth- fifth- or fourth-century B.C. manufacture. Finally, the Constantinian selections narrated a foundation myth that shaped urban identity. There is no hint of such magisterial epic in the Lausos group.

What then to make of such a gathering? If the meticulous documentation of attribution and provenance recorded in the sources is any index, it was the temple statuary that captured contemporary imagination. The focus on individual provenance documents an awareness not only of the origins of the individual images in the great Hellenic sanctuaries, but also cognizance of their geographical distribution. Further, there is a sense of the chronological flowering of individual religious centers. Samos and Lindos were prominent in the seventh and sixth centuries B.C., while Olympia saw its floruit in the fifth and fourth centuries, and Knidos in the fourth. Inclusion of these details suggests an understanding of these images in terms of the religious history and sacred geography of the Hellenic world. ${ }^{44}$

In a like manner, attribution to artist defined the sculpture in terms of artistic chronology by connecting each statue with a discrete historical moment: the Athena and the Hera were made in the sixth century B.C., the Zeus in the fifth, and the Aphrodite and the Eros in the fourth. On display in this chronological unfolding was a history of visual form, a history familiar from such ancient authors as Pliny the Elder (23-79). In fact each of each of the artists represented in the collection holds a place in Pliny's developmental outline of sculptured form. Skyllis, Dipoinos, and Bupalos are recognized as the first sculptors to achieve fame by working in marble, while Phidias is praised for revealing the possibilities of sculpture as a medium, possibilities which were then taken up and elaborated by Praxiteles and perfected by the innovations of Lysippos. Implicit in these observations is the belief in a canon of naturalistic representation and with it a notion of artistic perfectibility. Explicit in the sculpture itself was the range of stylistic experience with the still frontality of Bupa-

image one invented by the early Apologists and is as such inaccurate and misleading. This essay recognizes the importance of her critique, preferring the term 'temple statue'.

44 For an extended consideration of this issue see Bassett (cf. fn. 13): 101-103. 
los's sixth-century Hera standing in marked contrast to the contrapposto poise of Praxiteles's fourth-century Aphrodite or the dazzling torsion of Lysippos's Eros. ${ }^{45}$

Taken together the statues appear to have created a visual epitome both of the history of Hellenic religion and of sculptured form. But how did such epitomes relate to the other major group, that of the animals and mythical creatures? If the detail lavished on the account of the images can be said to have shaped an interpretation of this group within the framework of a human history defined in terms of sacred geography and aesthetic chronology, then the corresponding lack of such description in the catalogue of animals sets these figures outside of that construct. In the absence of provenance or attribution, the animal statues appear to have taken their place within a different order, that of the natural world. The exotic nature of the beasts described and the inclusion of such mythic creatures as pans and centaurs makes clear the nature of this world: this is not the domestic space of the farmyard, but the savage world of the untamed wild. In the Lausos collection these alien, outright barbarous images stood cheek by jowl with some of the most refined and noble creations of the Hellenic past. Comparison must have been inevitable as artifice confronted nature and civilization faced the barbarous.

This visual confrontation suggests the echo of apologetic response to the world of myth and the forms of sculpture. Juxtaposition of great gods with exotic animals and mythical creatures invited comparison between the two groups, a comparison that stressed likeness, ascribing the characteristics of beasts to images of the divine. Like animals these images were without either sense or sensibility. They neither saw, nor heard, nor spoke, nor tasted, nor touched, and they were completely and utterly without soul being only "earth and stone and matter and curious art."46 This was the humiliation of the gods writ large.

It appears, however, to have been only one aspect of the project. The comparison of wild nature with aesthetic artifice was another, one that perhaps worked to suggest new ways of thinking about myth and its images. On the one hand, it is true that the epitome of historical styles summarized in the collection's holdings underscored further the apologist's complaint that images of the gods were but flawed

45 See Plinius, Naturalis Historia, 36.4.9-14 (on Skyllis, Dipoinos and Bupalos); 36.4.15-24 (on Phidias and Praxiteles); 34.19.61-66 (on Lysippos). On Pliny’s idea of art history see J. J. Pollitt, The Ancient View of Greek Art: Criticism, History, and Terminology (New Haven 1974): 73-84. S. Ferri, Plinio il Vecchio, Storia delle arti antiche (Rome 1946); J. Isager, “The Composition of Pliny's Chapters on the History of Art,” Analecta Romana Instituti Danici 6 (1971): 49-62 and J. Isager, Pliny on Art and Society (London 1991). See Bassett (cf. fn. 10):103-105 for an expanded discussion of the idea of artistic perfectibility in late antiquity.

46 Absence of language and a corresponding failure to command the rhetorical structures associated with speech was understood as a hallmark of the primitive and the barbaric. It was, as such, considered a characteristic of foreigners, children, and animals. See Donohue, Xoana (cf. fn. 43): 122-23; R. Sorabji, Animal Minds and Human Morals, the Origins of Western Debate (Ithaca 1993): 7-16, 80 -86. For the range of Roman attitudes towards animals see M. Beagon, Roman Nature (Oxford 1992). 
human creations. On the other hand, with this failing established, that same emphasis on aesthetic chronology proposes an understanding of this sculpture outside of the context of cult. Specifically, it suggests seeing the great works of great artists in place of the great gods of great sanctuaries. In other words, it proposes an understanding of the sculpture in fully aesthetic terms; that is, as art. ${ }^{47}$

That this may be an aspect of the collection's meaning is suggested above all by the presence of the odd statue in the group, Lysippos's personification of kairos. ${ }^{48}$ Defined generally as the "opportune moment", and more specifically in aesthetic terminology as "congruence", the essential element in the creation of beauty, Kairos personified represented neither god nor beast but a mediating figure between the two camps that facilitated contemplation of aesthetic issues by calling attention to the contrast between artifice and nature and the formal history outlined in the sequence of statues. Individually, each statue could be seen to have represented a type of aesthetic congruence. Collectively, the group demonstrated the changing idea of such congruence over time and the mastery on the part of the Greek artists of the imitation of nature. The emphasis on formal issues also had bearing on the animal statues. Untouched by the refining force of congruence, exotic animals and mythical creatures represented nature, the source of artistic invention, in its unperfected state. Kairos thus pulled the raw stuff of animal imagery into league with the perfected artistry of the images by making both statue groups the subject of aesthetic meditation, inviting the contemplation of the relationship at once contradictory and complementary between the natural and the man-made, the imperfect and the perfect object.

If this is the case, then the Lausos collection demonstrated how the gods of Hellenic cult and mythic tradition could be the subject not of religious veneration, but of aesthetic contemplation. In short, it proposed a new way of seeing the sculptured representations of gods and heroes. In this regard it is comparable to other contemporary approaches to the problem of mythological sculpture in general and temple statuary in particular. Contemporary legislation regarding the fate of temples and their images expresses similar sentiments. An edict from the Theodosian Code notes that temple sculptures should be "measured by the value of their art rather than

47 For a fuller consideration of this issue see Bassett (cf. fn. 13): 111-120.

48 Bassett (cf. fn. 13): 108-109. On Lysippos's statue and kairos as an aesthetic phenomenon see A. Stewart, "Lysippan studies I: The Only Creator of Beauty," AJA 82 (1978): 163-71. For further discussion of kairos: A. Corso, Prassitele: fonti epigrafiche e letterarie; vita e opera (Rome 1991): 133; R. Wittkower, "Chance, Time, and Virtue," Journal of the Warburg and Courtauld Institutes 1 (1937-38): 313-21; and two essays by D. Levi, "Il kairos attraverso la letteratura Greca," Rendiconti della Real Accedemia Nazionale dei Lincei: Classe di Scienze Morali Storiche e Filologiche 5th ser. 32 (1923): 260 - 80 and "Il concetto di kairos e la filosofia di Platone," Rendiconti della Real Accademia Nazionale dei Lincei: Classe di Scienze Morali Storiche e Filologiche 5th ser. 33 (1924): 7-117. 
their divinity," ${ }^{49}$ and in a different setting, Prudentius (c. 348 -c. 412) recommended a similar approach to a predominately pagan Roman Senate:

You should give up your childish festivals, your laughable rites, your

shrines unworthy of so great an empire.

Oh noble Romans, wash your marble statues wet with dripping spatters of gore

let these statues, the works of great craftsmen, stand undefiled;

let them become the most beautiful adornments of our native city - may no

depraved purpose taint these works of art, no longer in the service of evil. ${ }^{50}$

"Works of art, no longer in the service of evil": this emphasis on the possibility of aesthetic appreciation reveals both a belief in rehabilitation and with it a desire for preservation which in turn springs from a profound regard for the past and its traditions at odds with apologetic fervor.

Both the poetic exhortations of Prudentius and the terse directives of the law code indicate the extent to which the question of mythological sculpture, that flashpoint for apologetic condemnation, was subject of debate into the later fourth and fifth centuries. But it did so under different conditions. Whereas Tatian, Athenagoras, and Tertullian spoke with the aggrieved voices of outsiders, Prudentius and the authors of the law code did so with the authority of Christian insiders, promoting not destruction, but preservation. In so doing they suggest a new phase of understanding that acknowledged both the discomfort of the Apologists and the value of the traditions of sculptured representation. In short, what these sources suggest is a desire for compromise.

49 "Aedem olim frequentiae dedicatam coetui et iam populo quoque communem, in qua simulacra feruntur posita artis pretio quam divinitate metienda iugiter patere publici consilii auctoritate decernimus neque huic rei obreptivum officere sinimus oraculum. Ut conventu urbis et frequenti coetu videatur, experientia tua omni votorum celebritate servata auctoritate nostri ita patere templum permittat oraculi, ne illic prohibitorum usus sacrificiorum huius occasione aditus permissus esses credatur. Dat. Prid. Kal. Dec. Constantinopoli Antonio et Syagrio conss." Codex Theodosianus 16.10.8 (November $30^{\text {th }}$, 382). Translation C. Pharr, The Theodosian Code and Novels and the Sirmondian Constitiutions (Princeton 1952): 473. For further consideration of the desire to protect pagan patrimony see: J. Alchermes, "Spolia in Roman Cities of the Late Empire: Legislative Rationales and Architectural Reuse,” DOP 48 (1994): 167-78; C. Leppelley, “Le musée des statues divines: la volonté de sauvegarde le patrimoine artistique paeien à l'epoque théodosienne," CahArch 42 (1994): 5-15.

50 "Deponas iam festa velim puerilia, ritus / ridiculos tantoque indigna sacraria regno. / Marmora tabenti respergine tincta lavate, / o procures: liceat statuas consistere puras, / artificum magnorum opera: haec pulcherrima nostrae / ornamenta fiant patriae, nec decolor usus / in vitium versae monumenta coinquinet artis.” Prudentius, Contra Symmachum 1.499-505 in H. J. Thomson (ed.) Prudentius, Volume 1. Loeb Classical Library (London and Cambridge, MA 1953): 388. Translation: Alchermes (cf. fn. 49): 171. 
The Lausos collection appears as a visual manifestation of this stance. Both as act and as argument the Lausos collection challenged the legitimacy of an entire genre of subject, myth, and what was arguably its premier representational medium, sculpture. It was an act to make an apologist proud, for beyond humiliation, this act of collecting, which was at base an act of deracination that removed images from the sacred places that gave them life and meaning, should have presaged the final destruction of pagan cult and with it some of the Roman world's longest lived and most valued cultural traditions. And yet, it did not, at least for the short term. What it proposed instead was a desire to co-exist with and to preserve the past and a means by which to do so: the contemplation of the beautiful.

That such a means of understanding found fertile ground seems to have been the case. To begin with the Lausos collection was not the only gathering of its kind. A contemporary group is known from the Palace of Marina. Marina, daughter of the emperor Arcadius, is reported to have furnished a bath complex in her Constantinopolitan residence with statues of Herakles, river gods, and a relief depicting the battle of the gods and the giants. Although renowned for her piety, a piety expressed in her dedication to virginity and acts of Christian charity, Marina apparently saw no conflict between the claims of Christian devotion and the display of classical sculpture within the confines of her personal apartments. ${ }^{51}$

And of course the great public displays of the city itself give testimony to the fact of their on-going appreciation. Pagan sculpture survived well into the middle ages in Constantinople, the victim not of Christian aggression, but of disasters natural and man-made. From the fourth century on, earthquakes and lightning strikes felled individual statues, while fires took out whole gatherings of sculpture, the Zeuxippos and Lausos collections among them. ${ }^{52}$ The last match was struck in 1204 when the great works of art so central to the city's identity were destroyed or carried away during the sack of Constantinople by the army of the fourth Crusade, a gutting of the urban patrimony that contemporaries took as an occasion for mourning. As Niketas Choniates (c. 1155-c. 1215) makes clear in his great threnody on the city's fall, the destruction of art signaled not only the loss of urban beauty, but also the unraveling of the very fabric of civilization. Niketas's lament reveals the extent to which the aesthetic appreciation of Hellenic tradition had become integral to the Byzantine

51 For documentation see Bassett (cf. fn. 13): 241-242. See also C. Mango, "The Palace of Marina, the Poet Palladas, and the Bath of Leo VI,” in E. Kipraiou (ed.) Euphrosynon: Apheiroma ston Manole Chatzedake (Athens 1991): 1. 321-30; P. Magdalino, "The Bath of Leo the Wise and the Macedonian Renaissance Revisited,” DOP 42 (1988): 97-118; P. Magdalino, “The Bath of Leo the Wise,” in A. Moffat (ed.) Maistor: Classical, Byzantine, and Renaissance Studies for Robert Browning (Canberra 1984): $225-40$.

52 For a chronological list of fires and earthquakes see Janin (cf. fn. 35): 35-36. On fires specifically see A. M. Schneider, "Brände im Konstantinopel," BZ 41 (1941): 382-403. On earthquakes see E. Guidoboni, I terremoti prima del Mille in Italia e nell'area mediterranea (Bologna 1989): 190 -94 and J. Dück, “Die Erdbeben von Konstantinopel,” Die Erdbebenwarte 3 (1903/1904): nr. 6-12. 
mentality. ${ }^{53}$ It was, I suggest, in collections such as the Lausos gathering that this notion first took hold.

From apologetic condemnation to institutionalized acceptance; the shift in attitude that took place between the second century and the fifth represented a sea change in the approach to ideal sculpture. Yet the move from a stance of profound suspicion and animosity to one of cultural accommodation did not represent a steady or controlled tidal swell, as the waves of change broke unevenly over the territories of the Roman world, reflecting the larger process of Christianization itself. ${ }^{54}$ That process, which took hundreds of years to complete, proceeded initially by fits and starts and moved at an uneven pace, engaging the empire's various cultures in different times and places with various rates of success. It was Christianity's encounter with one particular group, the imperial house, which conclusively redirected the conversation. After the Constantinian acceptance of the Christianity, the new religion moved from outsider to insider status and stayed there, save for a brief hiatus during the reign of Julian (360 - 63). With this change in alignment it was only a matter of time before religious and cultural habits began to shift away from the traditions that had shaped Roman behavior for centuries towards a new set of normative cultural practices. That said, the path leading to the establishment of Christianity in the wake of Constantine's profession of faith was neither straightforward nor direct when it came to confronting cultural tradition. Indeed as the fourth-century sculptured installations of Constantinople suggest - installations that were created a full decade after the emperor had proclaimed his allegiance to Christ - there was in no small regard indifference to some of the more pressing concerns of the Christian faithful. Yet, as the comments of Eusebius make clear, the challenge to classical modes of seeing and understanding persisted. It was only, however, by century's end that the burbling undercurrent of suspicion and distrust first voiced by the Apologists swelled to become sufficiently strong a part of mainstream discussion to warrant definitive action, action that was designed not to destroy but to strike a compromise between old and new by finding a neutral ground on which antagonists might meet. The Lausos collection, together with the proclamations of the law code and the appeal of Prudentius, belongs to that moment.

There were no easy answers to the problem of reception, and the urge to find a workable compromise bespeaks the value of myth and its avatar sculpture in late

53 For the text see Niketas Choniates (cf. fn. 17). On Niketas's response to and characterization of the destruction of the Crusader sack see: A. Cutler, "The De Signis of Nicetas Choniates, a Reappraisal," AJA 72 (1968): 113-18.

54 The reception of mythological sculpture in many ways parallels the process of Christianization in the Roman world as laid out in H. Leppin, "Christianisierungen im Römischen Reich. Überlegungen zum Begriff und zur Phasenbildung,” ZAC 16 (2012): 247-78. Leppin proposes a phased model of Christianization in which there appear first various individual Christianities across the territory of the empire. A period of neutralization follows this initial phase. The final phase sees the total dominance of Christianity. 
Roman society. It was, as we have seen, one of the primary means of giving visual life and permanence to the ideas and ideals that percolated in contemporary thought and imagination; ideas and ideals that had been inculcated in every school boy through the study of myth and its agent poetry. The argument about sculpture was therefore an extension of an on-going conversation about the nature and role of intellectual tradition, or paideia, in the face of emerging Christian values, and it is in the context of this larger discussion that the emergence of aesthetic value as a means to facilitate reconciliation can best be understood..$^{55}$

The record of that discussion as it evolved over the course of the fourth and fifth centuries survives at least in part in the works of the Church Fathers. Among the many contributions to the conversation is Basil of Caesarea's (c. 330-379) address to young men on the proper use of Greek literature. ${ }^{56}$ Here at the same time that he acknowledges the perils of Greek poetic tradition - the bawdy stories, the bad exempla against which one should stop one's ears in imitation of Odysseus when faced with the sirens ${ }^{57}$ Basil also is at pains to remind his listeners of the good, pointing out, "all the poetry of Homer is praise of virtue." 58 As his comment suggests, that which is useful is that which reveals and promotes virtue. Basil therefore stresses that the past, its modes of thought and expression, are not without merit, and that it is incumbent upon youth to seek out and be aware of what is useful and apply it to constructive ends. ${ }^{59}$

The address offers no direct advice about art and its reception; nevertheless it is possible to take away two useful directives pertinent to the understanding of things visual from the text. To begin with, properly chosen, it is clear that mythological subject matter, whether in the context of a poem or the visual medium of sculpture, can be edifying. In addition, Basil makes it known that the very process of artistic creation and the marshaling of aesthetic judgment that goes into both the execution and the appreciation of a work of art is itself an exercise in virtue. That this is the case is

55 For the classic study of the paideia see: W. Jaeger, Paideia: Die Formung des griechischen Menschen, 3 vols. (Berlin 1934-47), trans. G. Highet, Paideia: The Ideals of Greek Culture, 3 vols. (New York 1939-44). Ongoing scholarship is rich. Important general studies include P. Brown, Power and Persuasion in Late Antiquity (Madison 1992); R. A. Kaster, Guardians of Language: The Grammarian and Society in Late Antiquity (Berkeley 1988); and H.-I. Marrou, Histoire de l'éducation dans l'antiquité (Paris 1948), trans. G. Lamb, A History of Education in Antiquity (London 1956).

56 For text and translation see Basilius Caesariensis, Прò

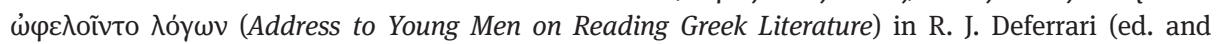
trans.) St. Basil. The Letters, Volume 4. Loeb Classical Library (London and Cambridge, MA 1934): $378-435$.

57 4.2, Deferrari (cf. fn. 56): 388.

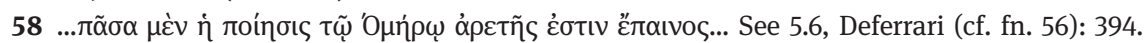

59 The theme of useful and appropriate selection and the equation of usefulness with virtue appears throughout the text, but see especially sections 1.4-5, Deferrari (cf. fn. 56): 380; 4.1-4, Deferrari (cf. fn. 56): 386 - 88; and, finally, 5.12-14, Deferrari (cf. fn. 56): 398 in which Basil recounts the legend of the Choice of Herakles. 
suggested by his remarks on two monumental chryselephantine sculptures, the Zeus by Phidias at Olympia and the Hera by Polykleitos at Argos. In the course of a discussion on the futility of wealth Basil notes that the two artists would have been the laughing stock of their age had they boasted only of the sculptures' materials - gold and ivory - and "overlooked their art." ${ }^{60}$ It was, in other words, art, that is the craftsmanship that allowed the transformation of "earth and stone and matter" into something beautiful and compelling, a visualization of virtue that gave the statues merit.

Basil's exhortation to youth evokes the larger intellectual and emotional environment in which to understand the particular problem of ideal sculpture. It was an environment that recognized the potentially volatile charge of classical culture in Christian contexts and so sought to neutralize it by identifying and emphasizing what it saw as elements of worth and in so doing redirecting function. This context of reconciliation was at far remove from the barbed hostility of the early apologists. Where Tatian, Athenagoras, and Tertullian viewed myth and sculpture in black and white terms as an affront to truth, Basil and his contemporaries, Prudentius and the framers of the law code, saw shades of grey and in them found the potential for virtue. For Basil virtue was expressed in subject matter. For Prudentius and the authors of the code, it was present in the substance and shape of sculpture itself.

The emergence of aesthetic value as a means to understand mythological sculpture was an acknowledgement of the one certain thing that could be salvaged from the images of the gods and heroes, their beauty. It was also a way in which to grapple with the ambivalence surrounding the question of subject matter, for the emphasis on aesthetic value had the effect of neutralizing the religious content of images and in so doing changing their function. Under the new rules sculpture ceased to be a locus of interaction between human and divine, and became an expression of the human potential for virtue because of its ability to embody beauty. As a result the contemplation of beauty, the very visualization of virtue, reflected on the patrons, public and private, who chose sculptured images for display. Whole cities and within them individual patrons expressed their virtue through the possession and display of things beautiful. Beauty as virtue: here was the real congruence, the kairos, between Christian and pagan, past and present, truth and fiction.

In the way of kairos itself, this moment of congruence was short-lived. At the end of the fifth century and the beginning of the sixth fires burning through the center of Constantinople destroyed a substantial amount of the city's population of mythological sculpture, the holdings of the Baths of Zeuxippos and Lausos collections included. ${ }^{61}$ The statuary was never replaced. To a certain extent this was a matter

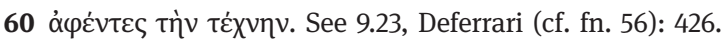

61 Cedrenus (cf. fn. 35) and Zonaras (cf. fn. 41) both report the destruction of the Lausos collection. Cedrenus 1.647 also records the burning of the Baths of Zeuxippos during the Nika riots of 532. Prokopios, De Aedificia, 1.10.3 in H. B. Dewing (ed. and trans.) On Buildings. Loeb Classical Library (London and Cambridge, MA 1940): 83 reports that the baths were repaired by Justinian. A burn layer in 
of practicality: classical mythological sculpture, whether of ancient manufacture or new production, was no longer so readily available. But it was also the case that there was a less of a need for this type of imagery. As the fifth century gave way to the sixth, the issue of Constantinopolitan hegemony began to be seen in new, more fully Christian terms. To this end new types of images based on a new mythology came to the fore, relics associated with the great protagonists of the early Church and their images, or icons. With the importation of the remains of the Apostles Timothy, Luke and Andrew, the proto-martyr Stephen, and those of the forty martyrs of Sebaste, not to mention objects such as the Virgin's cincture or fragments of the True Cross, Constantinople built a new identity on the foundations of the old. ${ }^{62}$ As a complement to its status as New Rome and New Troy, the city was now the New Jerusalem, a place in which urban primacy and the virtue that made such preeminence possible were expressed not through the beauty of mythological sculpture, but in the glory and radiance of Christian remains.

the archaeological record supports the destruction by fire. Reuse of statue bases in the rebuilding strongly suggests that the sculpture was not replaced. See Casson, Second report (cf. fn. 16): 12. 62 The earliest importation of relics to Constantinople was undertaken during the reign of Constantius (337-60) who brought the remains first of Timothy (356) and then of Luke and Andrew (357). Later the Theodosians brought other remains: fragments of the True Cross were deposited in the palace and at the foot of the Column of Constantine, the Virgin's cincture and St. Luke's portrait of Mary with the infant Jesus. Other reported importations, or translations as they are known, included those of the head of John the Baptist (391 and/or 453), Samuel (406), Joseph, son of Jacob (415), Zacharius the father of John the Baptist (415), Stephen, the first martyr (438-39), and those of the 40 martyrs of Sebaste (451). For sources and discussion see C. Mango, "Constantine's Mausoleum and the Translation of Relics,” BZ 83 (1990): 51-62; P. Speck, “The Virgin's Help of Constantinople,” BMGS 27 (2003): 266-71 and the following set of essays by J. Wortley, "Relics and the Great Church," BZ 99 (2006): 631-47; "Relics of the Friends of Jesus at Constantinople," in J. Durand and B. Flusin (eds.) Byzance et les reliques du Christ (Paris 2004): 143-57; "Byzantine Component of the Relic Hoard of Constantinople," GRBS 40 (1999): 353-78; "The Earliest Relic Importations to Constantinople," in Jean-Luc Deuffil (ed.) PECIA: resources en médiévistique (Saint Denis 2005): 207-225; and "The Marian Relics at Constantinople," GRBS 45 (2005): 171-87. 



\section{Dressed in Myth: Mythology, Eschatology, and Performance on Late Antique Egyptian Textiles}

Among the rich corpus of archaeological finds from late antique Egypt, today textiles tend to occupy an obscure and isolated place in scholarship. This obscurity is disappointing for several reasons, not least because of the extraordinary number of textiles that have survived, but also since the initial wave of discoveries of such textiles in the late $19^{\text {th }}$ and early $20^{\text {th }}$ centuries elicited such enormous enthusiasm and popular appreciation. The period witnessed a bumper crop of textile finds from the dry climate of the Egyptian desert. It is estimated that up to 150,000 specimens were found during this period, ${ }^{1}$ although the exact number remains impossible to determine, as fragments that originally belonged to the same piece of textile were, as per standard practice, dispersed to different museums making it very difficult to know which fragments (so-called "orphans") belong together.

The complex collecting histories and the poor archaeological documentation that the textiles come with, as well as a frustrating lack of precision in their chronology, are all important factors that have complicated scholarly attempts to place them within their proper social, religious, and historical context. Yet textiles are of major importance to our understanding of late antique social and religious life, and not least the topic of this volume, the use of mythology in late antiquity. The textiles not only constitute magnificent documents of change and continuity but also give us crucial insights into the persistence of Classical myths within a Christian environment. One of the most striking aspects of the massive corpus of Egyptian textiles is the apparent ease with which pagan and Christian motifs were produced and used simultaneously. The mythological motifs as well as other aspects of their iconography furthermore attest to cross-Mediterranean contact and cultural exchange. Nevertheless, textiles only play a minor role in scholarship outside of the specialized and frequently rather technical reports and catalogues in which they are most often presented and discussed at any length. ${ }^{2}$ An important aim of this paper is therefore to

\footnotetext{
* I would like to thank Hartmut Leppin and his team of organizers for their hospitality and interest in my work during the Frankfurt colloquium. A generous grant from the Danish Council for Independent Research's Sapere Aude career programme allowed me to complete this paper version. Many ideas for this paper were formed, developed, and substantially improved in conversation with Stine Birk. I would also like to thank Lea Stirling for reading an earlier draft, and Nils Arne Pedersen for help with Coptic. The impetus for the paper itself owes much to the pioneering work of Sabine Schrenk, Annemarie Stauffer, Henry Maguire, and Thelma Thomas.

1 As estimated by D. Thompson, Coptic Textiles in the Brooklyn Museum (Brooklyn 1971), 4-5. 2 Textiles are, for example, almost entirely absent from the recent Oxford Handbook of Roman Egypt, edited by C. Riggs (Oxford 2012), although admittedly this volume does not aim to cover
} 
bring this marginalized body of evidence more firmly into the mainstream of late antique historical scholarship.

The paper has two equal parts; the first concerns the general function and use of textiles decorated with figural images (many depicting mythical protagonists), as well as the thorny issues of chronology and the reconstruction of the physical and visual environment in which the textiles were once an integral part. This first part provides important information on the viewing context in which these textiles functioned. I will also be arguing that in order for this field of study to move forward, textiles must not be seen as exclusively decorative, daily-life objects, it is equally important to understand them as objects of performative display, self-representation, and as expressions of eschatological thinking within the funerary context. The second part focuses more explicitly on the use of mythology in late antique Egyptian textiles, such as a famous wall-hanging that is now in the Abegg-Stiftung in Switzerland (Fig. 1). ${ }^{3}$ On this extraordinary example, that is more than $2 \mathrm{~m}$ tall and roughly $1.5 \mathrm{~m}$ wide, Atalante is identified by lettering thus allowing us to identify the other figure as Meleager; it is stylistically dated to the late $4^{\text {th }}$ or early $5^{\text {th }}$ century. But what was the function of such mythological motifs, and how did pagan myths participate in the period's increasingly Christianized viewing culture?

\section{Late Antique Egyptian Textiles: Context, Chronology, and Function}

Before turning to these larger questions, it is first important to treat the issues of context, chronology, and function which are of crucial importance to assigning the textiles to their proper place in the archaeological record. The majority of the Egyptian textiles originally belonged to funerary ensembles, where they survived amazingly intact until their extraction in the late $19^{\text {th }}$ and early $20^{\text {th }}$ centuries during what has rightly been called a phase of "mummymania" across Europe. Occasionally, textiles have been found in houses, domestic or monastic dumps, but these examples are usually less well-preserved and of less interest to the themes under discussion

Late Antiquity. An accessible, recent overview of late antique Egyptian textiles can be found in T. Thomas, "Coptic and Byzantine Textiles Found in Egypt: Corpora, Collections, and Scholarly Perspectives", in: Egypt in the Byzantine World 300-700, edited by R. Bagnall (Cambridge 2007), 137162. Much of the critique raised here also resonates with T. Thomas, "Costume, Fashion and Taste in Late Antique Egypt: 'Decorative Devices' from the Textile Collection in the Kelsey Museum”, Bulletin of the University of Michigan Museums of Art and Archaeology 12 (1997-2000), 88-101.

3 S. Schrenk, Textilien des Mittelmeerraumes aus spätantiker bis frühislamischer Zeit (Riggisberg 2004), 41-45 (cat. no. 5), purchased 1966 on the German art market, claimed to have been found in Antinoopolis. H: $2.13 \mathrm{~m}$. W: $1.56 \mathrm{~m}$. Because of its exceptional quality, it has been suggested that this wall hanging was produced in a Roman workshop and exported to Egypt. 
here. ${ }^{4}$ Proper documentation of the archaeological contexts of textiles is usually entirely lacking, and when known, mostly too insubstantial for any kind of in-depth study. Although many publications have named particular sites as the provenance of individual textiles, particularly Akhmim (Panopolis) in Upper Egypt, which was one of Antiquity's most famous textile production centres, such locations should not be taken for granted, as it was during the modern antiquities trade that Akhmim became synonymous with Egyptian textiles. ${ }^{5}$ On the other hand, it is certainly true that the deserts outside Akhmim are littered with tombs that have been emptied of their contents (Fig. 2).

Other Egyptian towns provided a similarly rich harvest of textile finds. Antinoopolis in Middle Egypt is one such important site that yielded large quantities of textiles for European and American museums during early and largely undocumented excavations, as well as later episodes of looting. ${ }^{6}$ The Abegg-Stiftung's Meleager and Atalante wall-hanging (Fig. 1) is, for example, said to have been found in Antinoopolis, although its precise provenance is unverifiable. Particularly diligent in excavating at Antinoopolis was the notorious Frenchman Albert Gayet; many of the excavated textiles were dispersed to museums and private collections in North America and Europe, particularly in his home country. ${ }^{7}$ Often, individual textiles were cut into smaller pieces that could be sold to the highest bidder, thus frequently ending up in different museums. This was standard practice among excavators at the time, which has

4 A. P. Schieck, Die koptischen Textilien. Gewebe und Gewänder des ersten Jahrtausends aus Ägypten (Köln 2005), 7.

5 On the problem of Akhmim as a provenance, see Schrenk (cf. fn. 3), 15; C. Fluck, "Akhmim as a Source of Textiles", in: Christianity and Monasticism in Upper Egypt. Volume I. Akhmim and Sohag, edited by G. Gabra and H. N. Takla (Cairo 2012), 211-223; and H. Persson, "Collecting Egypt. The Textile Collection of the Victoria and Albert Museum", Journal of the History of Collections 24.1 (2012), 3-13, esp. 3-4. On the necropoleis of Akhmim, see K. P. Kuhlmann, Materialien zur Archäologie und Geschichte des Raumes von Achmim (Mainz am Rhein 1983), 50 - 86. On excavation history, see M. Erikson, Textiles in Egypt 200-1500 A. D. in Swedish Museum Collections (Göteborg 1997), 20-25; Thomas, "Textiles" (cf. fn. 2), 137-145. We have some very interesting first-hand accounts of the discovery of textiles at Akhmim by the Swiss collector-cum-antiquarian Robert Forrer (1866 -1947), whose 1895 travelogue Mein Besuch in El-Achmim (Strassburg) described the excavation of mummies wrapped in textiles, the transportation of these mummies to Cairo as well as the sale of textiles, presumably also from graves, at Luxor. Forrer's interests were immensely diverse, as he published on everything from Celtic numismatics to mammoth hunters. He named his house 'Villa Panopolitana' after the site of Panopolis/Akhmim.

6 New Italian excavations of the northern necropolis at Antinoopolis may help us contextualize these finds in the future, see H. Froschauer, "Antinoupolis. Erster Vorbericht zu den Textilfunden aus der Nekropole Nord (Grabungskampagnen Frühjahr und Herbst 2007)”, Analecta Payrologica 18-20 (2006-2008), 269-274.

7 Exact numbers are discussed in A. Geijer, "A Silk from Antinoë and the Sasanian Textile Art”, Orientalia Suecana 12 (1963), 1-36; and repeated in Erikson (cf. fn. 5), 21. On Gayet, see also N. A. Hoskins, The Coptic Tapestry Albums and the Archaeologist of Antinoé, Albert Gayet (Seattle 2004); and F. Calament, La revelation d'Antinoé par Albert Gayet (Cairo, 2 vols., 2005), and Thomas, “Textiles” (cf. fn. 2), 141-142. 
left modern scholars and conservators with a complex jigsaw puzzle to re-assemble. In some cases, fragments of the same textiles have ended up in collections divided across as many as two continents and seven countries. ${ }^{8}$ In the public presentation of his work, Gayet thrived on the shock value that these partly mummified bodies offered to fin-de-siècle Parisian audiences. ${ }^{9}$

Because of this chequered excavation history, the precise find-spots of individual textiles are rarely known, and even more rarely can the textiles be connected with architecture and other finds that would have been part of a complete, funerary ensemble, which makes it extremely difficult to reconstruct their role within the larger context of funerary archaeology and burial rituals. ${ }^{10}$ However, recent years have seen important work in museum archaeology - that is in tracing the collecting histories and the often doubtful find-spots assigned to textiles in the $19^{\text {th }}$ and early $20^{\text {th }}$ century and then, when possible, to reconstruct the contexts in which they were found, based on notebooks and the correspondence between excavators and the museums who funded their work or acquired finds. ${ }^{11}$ Newer excavations have furthermore introduced more specialized scientific methods to record and preserve wrapped bodies, providing much valuable information in the process. ${ }^{12}$

In those relatively rare cases where we are familiar with the archaeological context, it is clear that the dead were placed in shallow graves at a depth of roughly $1.5 \mathrm{~m}$, sometimes built up with bricks (Fig. 3). ${ }^{13}$ These graves were most frequently simple pits that in some cases were defined at the bottom by a wooden board, but

8 Schrenk (cf. fn. 3), 175, cat. no. 58.

9 D. Montserrat, "Unidentified Human Remains: The Erotics of Biography”, in: Changing Bodies, Changing Meanings. Studies on the Human Body in Antiquity, edited by D. Montserrat (London 1998), 162-197; and N. Cox, "La mort posthume: Maurice Heine and the poetics of decay", Art History 23.3 (2000), 417-449.

10 F. Dunand, "Between Tradition and Innovation: Egyptian Funerary Practices in Late Antiquity”, in: Egypt in the Byzantine World, edited by R. Bagnall (Cambridge 2007), 163-184, discusses late antique Egyptian funerary practices, but does not deal with the significance of textiles in any detail. On Roman-period funerary religion in Egypt, see C. Riggs, The Beautiful Burial in Roman Egypt: Art, Identity, and Funerary Religion (Oxford 2001), and now M. A. Stadler, "Funerary Religion. The Final Phase of an Egyptian Tradition", in: Oxford Handbook of Roman Egypt, edited by C. Riggs (Oxford 2012), 383-397.

11 Important contributions to this field are the individual contributions to S. Schrenk (ed.), Textiles in situ. Their Find Spots in Egypt and Neighbouring Countries in the First Millennium CE (Riggisberg 2006). See also Persson (cf. fn. 5) on the case of the Victoria \& Albert Museum.

12 E. Cortes, "Recovering Contexts: The Roman Mummies Excavated by The Metropolitan Museum of Art at Dahshur, Egypt”, in: Dressing the Dead in Classical Antiquity, edited by M. Carroll and J. P. Wild (Stroud 2012), 75-88. On the reconstruction of contexts for textiles, see also N. Kajitani, “Textiles and Their Context in the Third- to Fourth-Century CE Cemetery of al-Bagawat, Khargah Oasis, Egypt, from the 1907-1931 Excavations by The Metropolitan Museum of Art, New York”, in: Textiles in situ. Their Find Spots in Egypt and Neighbouring Countries in the First Millennium CE, edited by S. Schrenk (Riggisberg, 2006), 95-112.

13 Kuhlmann (cf. fn. 5), 62 (with a reconstruction of one such grave found at Achmim); Erikson (cf. fn. 5), 21. 
only very rarely included a coffin. Such burial grounds were often used over a very long time, and sometimes bodies were piled on top of each other in up to 10 to 15 layers, which, if better documented, would have allowed us to more closely understand the nature of such continuities of both place and practice. The bodies themselves seem to have been wrapped in numerous layers of textiles. Occasionally, adorned textiles also functioned as cushions to support the head and the feet of the deceased. ${ }^{14}$

It is often assumed in scholarship that the practice of wrapping bodies in textile replaced proper mummification and that this change in burial rites was a consequence of the process of Christianization, thus reflecting new, Christian conceptions of the body and its place in the afterlife. ${ }^{15}$ However, this is questionable since some cases of mummification can be dated to well after the $4^{\text {th }}$ century. ${ }^{16}$ It has also been shown that Christian and pagan tombs were often located close to each other and within the same burial grounds, for example, in the case of Bagawat, suggesting that much previous work has over-emphasized the extent to which burial traditions can be classified according to religious differences. ${ }^{17}$ Identifying religious affiliation based exclusively on the textile finds thus remains a fundamental problem, and one needs to be very careful when assigning a grave to either a pagan or a Christian occupant. This issue is, of course, of great importance to how we interpret the use and function of mythological motifs on textiles found in tombs, but is greatly hindered by insufficient archaeological documentation.

Another problematic issue that concerns the study of the textiles is chronology. Dating of the textiles beyond stylistic measures remains extremely difficult and has not made further exploration any easier. Among the 35,000 pieces of textiles known to Pierre du Bourguet when he published his fundamental catalogue of parts of the Louvre collection in 1964, only one could be placed within a relative chronology based on non-stylistic criteria. ${ }^{18}$ To that may be added the so-called Aurelius Collu-

14 Such as in the well-known case of Euphémiâan in Brussels, see now A. P. Schieck, "Late Roman Cushions and the Principles of Their Decoration", in: Clothing the House. Furnishing Textiles of the $1^{\text {st }}$ Millennium AD from Egypt and Neighbouring Countries. Proceedings of the $5^{\text {th }}$ Conference of the Research Group ‘Textiles from the Nile Valley', Antwerp, 6-7 October 2007, edited by A. De Moor and C. Fluck (Tielt 2009), 115-131.

15 V. Gervers, "Medieval Garments in the Mediterranean World”, in: Cloth and Clothing in Medieval Europe. Essays in Memory of Professor E. M. Carus-Wilson, edited by N. B. Harte and K. G. Ponting (London 1983), 279-315, esp. 280; and Erikson (cf. fn. 5), 21, but see remarks in Dunand (cf. fn. 10). More generally on Coptic attitudes towards the body as observed through textual evidence, see G. Fischhaber, Mumifizierung im koptischen Ägypten. Körperlichkeit im 1. Jahrtausend n. Chr. (Wiesbaden 1997).

16 G. Gabra and M. Eaton-Krauss, The Treasures of Coptic Art in the Coptic Museum and Churches of Old Cairo (Cairo 2006), 170.

17 Dunand (cf. fn. 10), 163 and 179.

18 P. de Bourguet, Musée National du Louvre. Catalogue des Étoffes Coptes I (Paris 1964), 17-21; and see A. Lorquin, Les tissues coptes au musée national du Moyen Age - Thermes de Cluny (Paris 1992), 
thus and Tisoia cloth that was found by Gayet at Antinoopolis and which is now in Brussels. It was discovered in a grave alongside a will, giving us the names of the two individuals that are portrayed within the arcades of the upper part of this cloth, as well as a date around 454-456, thus providing us with a terminus post quem for the deposition of the grave and a likely date for the fabrication of its textiles within the third quarter of the $5^{\text {th }}$ century. The grave is also exceptional for being the only burial excavated by Gayet that contained a coffin. Many other textiles are in publications given a broad $4^{\text {th }}$ - to $6^{\text {th }}$-century date, based on stylistic criteria - but, of course, when addressing questions of religious change and continuity, it makes quite a difference whether a motif belongs to the $4^{\text {th }}$ or to the $6^{\text {th }}$ century, as the social context in which they functioned might have changed dramatically. Recent advances in radiocarbon dating have yet to aid progress, at least for our purposes, as they give relatively broad dates covering several centuries. ${ }^{19}$

Putting the issue of chronology aside, we can look at the use and function of the textiles that were found in these late antique graves. Several different types of clothing but also wall hangings and mattress coverings were used to wrap the bodies of the deceased or to cover funerary beds, but the most common type of garment was the tunic that very often had been previously worn, which is clear from the evidence of both wear and tear as well as repairs. ${ }^{20}$ Other items, such as burial shrouds, were deliberately made for the funerary context and do not bear any signs of previous use. Fig. 4 shows three quite standard variations of the tunic; the central one is the most simple with just a few rectangular fields for decoration and oblong bands on the sleeves. To the left and to the right are two elaborate examples that both have a set of clavi running down the middle as well as four orbiculi, covering the knees and the shoulders. Men and women wore the same kinds of garments, ${ }^{21}$ making it very difficult to detect potential gender preferences in choice of iconography and decoration, although in some cases it may be speculated whether particular images

11. For a good overview of the problems of dating, see F. Pritchard, Clothing Culture. Dress in Egypt in the First Millennium AD. Clothing from Egypt in the Whitworth Art Gallery, The University of Manchester (Manchester 2006), 13-25. Another chronological fix point comes from an undisturbed child's grave excavated by Petrie at Hawara in the Fayum. The grave contained textile fragments as well as toys, lamps, footwear, and, most significantly, a coin of a son of Constantine I dated to c. 340, now in the Ashmolean. This coin allows us to date the textiles to around the middle of the $4^{\text {th }}$ century, but they unfortunately do not include figural representations and are thus of relatively little comparative value for the purposes of the present study. On Greek, Roman and Byzantine tombs at Hawara, see now I. Uytterhoven, Hawara in the Graeco-Roman Period. Life and Death in a Fayum Village (Leuven 2009). The tomb in question is her Grave Context no. 34 (ibid., 203). On scientific dating methods, see Egyptiennes. Etoffes coptes du Nil, edited by M.-C. Bruwier (Mariemont 1997), 107-116.

19 For an overview of radiocarbon-dated textiles in the Abegg-Stiftung, see Schrenk (cf. fn. 3), 476478.

20 For the evidence from Bagawat, see Kajitani (cf. fn. 12), 103. Here, adult garments had been preworn, whereas children's tunics had not. On burial shrouds from Bagawat, see ibid., 106-107.

21 Also clear from the better documented excavations of Bagawat: Kajitani (cf. fn. 12), 103. 
were chosen because they were appropriate to the sex, age, or life experiences of the wearer.

From surviving papyri, we get a sense of the issues of patronage and personal choice that were responsible for the layout of textiles. The papyri inform us that customers had a considerable degree of freedom to choose particular motifs and desired forms of decoration, leaving room for individual specifications to be made. ${ }^{22}$ It is usually assumed that consumers were able to choose from a variety of standard motifs in somewhat elusive pattern-books, almost as if browsing through a mail order catalogue. So in that sense, these textiles allowed for individual messages to be communicated and could as such be used as a medium to express social and religious identity. This observation resonates well with other evidence that suggests that decorum was an important aspect of everyday dress in Roman Egypt. ${ }^{23}$ It may furthermore be fruitful to see these textiles as part of a middle-class culture which has its own aesthetic sensibilities, in reference to Emanuel Meyer's recent book on urban life and aesthetics in the Roman world. ${ }^{24}$

The overall design of tunics allowed for various kinds of ostentatious display, not least through elaborate and colourful figural representations on the orbiculi. The design of the tunics also allowed for further forms of displaying wealth, even to the extent that jewellery could be mimicked through a variety of representational devices. Fig. 5 shows a fragment of a tunic, probably dating to the $4^{\text {th }}$ century and now in Boston, which on both sides of the collar is decorated with imitations of precious stones and gold. ${ }^{25}$ A representation of Dionysos finding the sleeping Ariadne (both figures are identified in Greek) decorates the lower orbiculus of the same garment. The other orbiculus shows a single bust of Dionysos. A $6^{\text {th }}$-century example shows very nicely how pagan motifs, the heavily stylized sea monsters or nereids on the clavi and the nude dancing figure, could co-exist with Christian symbols, such as a prominent cross, which clearly imitates an actual, hanging cross (Fig. 6). ${ }^{26}$ Such

22 E. Wipszycka, “Textiles, Coptic: Organization of Production”, in: The Coptic Encyclopedia, vol. 7, edited by A. S. Atiya (New York 1991), 2218-2221, esp. 2220, and see Thomas, "Costume" (cf. fn. 2), 95-96. M. Cannata, "Funerary Artists. The Textual Evidence”, in: Oxford Handbook of Roman Egypt, edited by C. Riggs (Oxford 2012), 597-612, concludes that during the Roman period, Egyptian artists and artisans were generally not specialized in producing for the funerary market. It is very likely that the same is true for later textile production, making it even more difficult to distinguish between 'domestic' and 'funerary' production.

23 Thomas, "Costume" (cf. fn. 2), 94.

24 E. Mayer, The Ancient Middle Classes. Urban Life and Aesthetics in the Roman Empire 100 BCE 250 CE (Cambridge, MA 2012).

25 Boston, Museum of Fine Arts, inv. 46.402, purchased 1946 in Paris; see Age of Spirituality. Late Antique and Early Christian Art, Third to Seventh Century, edited by K. Weitzmann (New York 1979), 146-147 with a further example of the imitation of jewellery; LIMC, Dionysos (in peripheria orientalia), no. 112 .

26 Brooklyn Museum, acc. no. 38.753, see Thompson (cf. fn. 1), 82-83. 
playful representations are testimony to the creative ambitions of the Egyptian textile makers.

Although we need to be aware that the textiles found in the graves cannot simply be seen as accurate reflections of the everyday appearance of late antique Egyptians, ${ }^{27}$ some observations on the performative character of the textiles can be made. Recent research on Roman dress has indeed stressed the performative value of textiles in different contexts. The presence or lack of clavi had for long been used to denote status and rank on the Roman toga, a tradition which is continued on these tunics through the use of very elaborate examples. ${ }^{28}$ Some tunics could also be quite bulky, emphasizing not the actual size of the wearer but his or her physical stature. The performative value of the textiles is furthermore emphasized by their rich use of vivid colours (including occasionally the use of gold thread) and lavish, tactile materials.

It can furthermore be argued that the textiles served as objects of movable performative display that in various ways mirrored the reality of human experiences and rituals. ${ }^{29}$ This is perhaps most striking in the case of the many textiles that represent dancing figures and that have recently been studied by Elisabeth Lässig. ${ }^{30}$ One example, dating to the $6^{\text {th }}$-century and now in Gothenburg, depicts dancing figures within the architectural setting of an arcade (Fig. 7). ${ }^{31}$ Such garments may very well have been worn during such occasions with the representation of maenads and satyrs deliberately juxtaposed with the performance of real-life ritual. They have consequently sometimes been referred to as festival or ritual garments.

Textiles have generally been regarded as objects of daily life, and, of course, in a general sense, that is very much what they are (and those that have been uncovered in domestic contexts, such as Karanis in the Fayum or Kellis in the Dakhla, obviously were). They allow us to come close to the people who wore them in their everyday routines. Yet they also hold significance beyond daily life, not least because of the funerary context in which the majority of them have been found. However, in spite of the fact that most of the textiles come from graves, little attention has been paid to their funerary significance and the potential meanings that they may have

27 Thomas, "Costume" (cf. fn. 2), 93-94.

28 S. Stone, "The Toga: From National to Ceremonial Costume", in: The World of Roman Costume, edited by J. L. Sebesta and L. Bonfante (Madison, WI 2001), 13-45, esp. 15. On use, see also M. Rassart-Debergh, Textiles d'Antinoé (Egypte) en Haute-Alsace. Donation E. Guimet (Colmar 1997), 100 105. For a recent study focusing on the performative value of Byzantine textiles in the liturgical context, see W. T. Woodfin, The Embodied Icon. Liturgical Vestments and Sacramental Power in Byzantium (Oxford 2012).

29 See also S. Davis, Coptic Christology in Practice. Incarnation and Divine Participation in Late Antique and Medieval Egypt (Oxford 2008), 165-170.

30 E. Lässig, “Tanz auf spätantiken Textilien aus Ägypten”, Mitteilungen zur christlichen Archäologie 17 (2011), 51-76.

31 Erikson (cf. fn. 5), 104-106, cat. no. 5. Further contemporary examples, now in the Louvre, similarly depict dancing figures within an arcade, see Bourguet (cf. fn. 18), 96-97, nos. C 32, and C 33, from the Fayum. 
had within that context. On a general level, the funerary significance of textiles is noted in a will, dated to 723: "When I leave my body, it will be above all your duty to take care of the clothing of my body and of my sacred offering." 32 Although mummification on the whole may have been on the decline, the several layers of textile wrappings that were often used demonstrate a continued interest in keeping the body intact as a whole, a sentiment which is reflected in the quote. The multiple layers of textile constituted a container for the body, similar to the function of a sarcophagus; a point that may also help to explain the overall lack of coffins in these Egyptian tombs.

In light of their funerary context, the textiles' dancing scenes may have held a particular meaning by signifying a general sense of joie-de-vivre and aspirations for a pleasant afterlife, perhaps even in the company of Dionysos. The textiles were thus meaningful objects in both life and death, and their meaning was very much dependent on the context in which they were used (and indeed re-used). This means that within the funerary context, the mythological scenes would have functioned as bearers of meaning in themselves. The funerary significance of the textiles becomes especially clear when we compare their iconography with other media, such as Egyptian funerary architecture from the same period, as well as evidence from other parts of the Mediterranean, notably sarcophagi, one of the main funerary arts in the city of Rome, Greece, and Asia Minor during the imperial period. ${ }^{33}$ Images of abundance seemingly had a particular significance within this context, both on Roman sarcophagi and on Egyptian textiles. ${ }^{34}$ The popularity of sea nymphs, either as a framing device or as the centre piece of decoration, for example in the case of two $6^{\text {th }}$-century medallions in the Louvre, is furthermore unlikely to be a coincidence in both of these media, again reflecting aspirations for a pleasant afterlife (Figs. 8a b).$^{35}$ Consideration of specific iconographies may strengthen this argument, especially when applying a cross-media approach. So, for instance, there is a tendency to regard hunt scenes as a theme linked to the imperial cult and virtus, ${ }^{36}$ although much of this finds direct parallel in funerary arts in the city of Rome where it does not seem

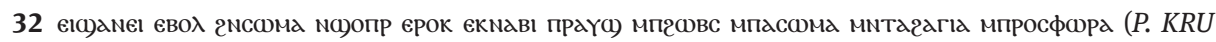
68.64-6, translation quoted from Dunand [cf. fn. 10], 180).

33 P. Zanker and B. C. Ewald, Mit Mythen leben. Die Bilderwelt der römischen Sarkophage (München 2004).

34 For a particularly magnificent example, see Au fil de Nil. Couleurs de l'Égypte chrétienne, edited by J. Santrot et al. (Paris 2001), 119.

35 Bourguet (cf. fn. 18), 98, cat. no. C 36, inv. nos. X 4339 and X 4311. For an $8^{\text {th }}$-century example, see ibid., 192, cat. no. E19. Nereids are also depicted in $5^{\text {th }}$-century architectural sculpture from Egypt, see Ägypten. Schätze aus dem Wüstensand. Kunst und Kultur der Christen am Nil, edited by M. von Falck and F. Lichtwark (Wiesbaden 1996), 83, cat. no. 16.

36 E.g. Y. Bourgon-Amir, Les tapisseries coptes du Musée Historique des Tissus, Lyon (Montpellier 1994), $29-37$. 
to have had that direct meaning, but rather been used as a means of expressing particular aspects of the deceased individuals' identity. ${ }^{37}$

The same point can be made regarding the use of portraits on Egyptian textiles. ${ }^{38}$ A particularly splendid example, now in the Louvre, was found in Antinoopolis, and is dated to the $6^{\text {th }}$ century (Fig. 9).$^{39}$ In the centre, we see a medallion portrait of a woman who wears a diadem set with polychrome stones in her hair, alluding to high status and prestige. Such portraits have a strongly heroizing or even divinizing function which is underlined here by the inclusion of a nimbus in the background. The medallion is placed within a square frame that is filled by four naked nereids, riding on sea monsters and here used as a framing device, as well as a variety of different fish. This fragment is testimony to a deeply traditional iconography that is also found on Roman funerary monuments, and again sarcophagi in particular, where portrait medallions are frequently supported by sea monsters or nereids. These socalled Meerthiasoi have by several scholars, notably Paul Zanker, been interpreted as a particular Glücksvision appropriate for the allusions to the afterlife. ${ }^{40}$ Another splendid example of a portrait on a tabula is now in Lyon and has been dated to the $5^{\text {th }}$ or $6^{\text {th }}$ century. ${ }^{41}$ This is one of a set of three that originally adorned a tunic. A woman is portrayed in the central square with a laurel branch in her hair, an attribute that again serves to conjure up divine or heroic associations to the viewer. Such portraits are not only testimony to the flourishing of the portrait arts at a time when this genre was in steady decline in round sculpture, but also suggest that there was a rich funerary tradition in which textile portraits of the deceased served to commemorate and heroize those buried in them..$^{42}$ Yet unlike mummy portraits that have received a veritable surge of scholarly interest in the last 30 years or so, these funerary portraits have been largely overlooked.

\section{Mythological Themes on Late Antique Egyptian Textiles}

This second part focuses explicitly on the role of the mythological motifs that decorated late antique Egyptian textiles, while keeping in mind the previous remarks on their context and function within the funerary sphere. The motifs are entirely drawn

37 S. Birk, Depicting the Dead. Self-Representation and Commemoration on Roman Sarcophagi with Portraits (Aarhus 2013), 108-109.

38 For an overview of the Egyptian portrait tradition, see now B. Borg, "Portraits", in: Oxford Handbook of Roman Egypt, edited by C. Riggs (Oxford 2012), 613-629.

39 Louvre, inv. AF 5472; Bourguet (cf. fn. 18), cat. no. C 77; Santrot et al. (cf. fn. 34), 124, cat. no. 87. 40 Zanker and Ewald (cf. fn. 33), 117-134.

41 Lyon, Musée des Tissus de Lyon, inv. 29215, purchased in 1910, and see Santrot et al. (cf. fn. 34), 88 , cat. no. 58 .

42 Cf. the vitality of the North African mosaic portrait tradition into Late Antiquity. 
from the repertoire of Classical (rather than Egyptian) myths, a fact that may help us to understand the cultural context in which they were produced and viewed. Large-scale mythological scenes, especially the most spectacular examples, such as the so-called Dionysiac wall-hanging in the Abegg-Stiftung that, following reconstruction, appears to have been $2 \mathrm{~m}$ tall and at least $7 \mathrm{~m}$ wide, have by far attracted the most attention in art historical scholarship. ${ }^{43}$ The original display context of this work of art is entirely lost to us, but the wall-hanging itself certainly attests to the continued interest in the world of Dionysos and his followers into the $4^{\text {th }}$ century. But what form of continuity do these mythological scenes attest to - paganism, paideia, or tradition in terms of aesthetics and literary culture?

There are a wide variety of mythological representations on Egyptian textiles, and in the following I will be necessarily selective and focus on some examples that I find particularly useful for shedding light on the function of mythology within particular contexts. Generally, one can divide the mythological motifs into two broad categories; narrative scenes with interacting figures within the same frame and single-figure scenes where the protagonist does not interact with other figures, although these may belong to a larger iconographic programme or series. First I will discuss the single-figure scenes that in fact constitute the largest group and appear to have offered the opportunity to express aspirations for the afterlife as well as other aspects of religious and social identity.

Iconographic connections between such single-figure representations can be confidently established in a number of cases, providing a sense of the way in which the decoration of the textiles was conceived and executed. ${ }^{44}$ Two examples from Russian collections demonstrate this. A personification of the Nile, identified by lettering and dated to the $3^{\text {rd }}$ or $4^{\text {th }}$ century, is now in Moscow's Pushkin Museum (Fig. 10). ${ }^{45}$ The Nile is here shown with a cornucopia emphasizing the aspect of abundance; this is a popular theme on Egyptian textiles, which is unsurprising given the river's local significance and symbolism. The continuous cycle of the flooding of the Nile furthermore provided a suitable metaphor for life, death, and re-birth to many Egyptians, and it can also be observed in late antique architectural sculpture in other funerary settings. Another medallion, which originally adorned the same tunic and is now on display in St Petersburg, emphasizes this aspect (Fig. 11). ${ }^{46}$ The St Petersburg

43 Schrenk (cf. fn. 3), 26-34, cat. no. 1, acquired 1986 on the German art market.

44 I have explored elsewhere the idea that single-figures on tunics could function as markers of religious identity (T. M. Kristensen, "Textiles, Tattoos and the Representation of Pilgrimage in the Roman and Early Christian Periods”, HEROM - Journal on Hellenistic and Roman Material Culture 1 [2012], 107-134, esp. 123-124).

45 Pushkin Museum, Moscow, see von Falck and Lichtwark (cf. fn. 35), 308-309, cat. no. 349. On the iconographic significance of the Nile in Late Antiquity, refer to T. Thomas, Late Antique Egyptian Funerary Sculpture. Images for This World and for the Next (Ann Arbor, MI 2000), 63-64.

46 Hermitage Museum, St Petersburg, see von Falck and Lichtwark (cf. fn. 35), 307, cat. no. 348. On the iconography of Ge in the Egyptian funerary context, see Thomas (cf. fn. 45), 64-65. 
medallion depicts the earth goddess Ge, here again identified by lettering and framed by a similar floral circular band as the Nile roundel, which suggests that they were made by the same workshop and thus belong together. The themes that connect these two singular representations are fertility and the cycle of life and death, which both would have been particularly apt in the funerary context, constituting a coherent iconography by means of the juxtaposition of different mythological figures and personifications. As such, the pair expressed a coherent eschatological whole.

Seasonal personifications seemingly attest to a similar form of iconographic coherency, and tunics could be adorned with depictions of the seasons such as winter (keimerini) and spring (earini), as exemplified by two examples from Antinoopolis now in the Louvre (Fig. 12). ${ }^{47}$ Further fragments belonging to the same tunic were located in Rouen a few years ago. One of them, a third medallion depicting another personification identified by lettering as Kairos, the right or opportune moment, fits the iconography for the personification of the autumn (Fig. 13). Here, we have again a deeply symbolic iconography that appears to signify the life cycle and its possible renewal.

Scenes with a singular figure could also be linked through various framing devices, particularly architectural imitations such as arcades, as can be seen in the case of the Meleager and Atalante wall-hanging in the Abegg-Stiftung (Fig. 1). Both protagonists are in this case clad in very elaborate garments bearing small medallions, and Atalante carries a diadem, emphasizing luxury and regal status. They stand in an arcade that is crowned by a triangular pediment with a bird seemingly clasping the hind legs of another animal. Hermes also appears above the capital separating the two main characters. While the two protagonists in that particular case do not interact, they are linked by means of composition in a way that is very similar to what can be observed on relief sculpture, and Asiatic and Attic sarcophagi in particular, where the arcade commonly was used to frame individual figures that often take on a certain statuesque quality. ${ }^{48}$ The very elaborate garments and the luxurious style of the diadem in this case may allude to the figures having a secondary function as participants in a kind of mythological role-play that may have had a particular significance intentional in the funerary context and can be compared with how portraits were applied to mythological figures on Roman sarcophagi. ${ }^{49}$ With its architectural frame,

47 Louvre, inv. no. X 4187, see Bourguet (cf. fn. 18), 75, cat. no. B 25, $5^{\text {th }}$ century; M.-H. Rutschowscaya, Coptic Fabrics (Paris 1990), 119; M. Durand "Inscribed Fabrics from Egypt. A Study in Greek and Coptic Textile Epigraphy”, Journal of Coptic Studies 11 (2009), 157-180, esp. 165-166.

48 On the statuesque, see P. Stewart, Statues in Roman Society. Representation and Response (Oxford 2003), 92-111.

49 For the relationship between this depiction and the issue of self-representation, see also S. Schrenk, “(Wall-)Hangings Depicted in Late Antique Works of Art?”, in: Clothing the House. Furnishing Textiles of the $1^{\text {st }}$ Millennium AD from Egypt and Neighbouring Countries. Proceedings of the $5^{\text {th }}$ Conference of the Research Group ‘Textiles from the Nile Valley’ Antwerp 6-7 October 2007, edited 
the entire composition in fact takes on the appearance of a tomb, complete with pediment. Hermes, seen between the two protagonists, may also have the function as Psychopompos in this context. The floral motifs and birds add to the atmosphere of eternal peace and abundance.

Other framing devices could be used to highlight particular aspects of a mythological narrative or to juxtapose different iconographies. A $6^{\text {th }}$-century tabula is testimony to a particularly local blend of a Nilotic scene, showing putti in small boats and a rich variety of plants and fish, used here to frame a central scene with a depiction of the bathing Aphrodite (Fig. 14). ${ }^{50}$ Such Nilotic scenes were common in Egypt and testify to a tradition of appropriating myth and situating it within one's own natural and physical environment. The bathing Aphrodite is similarly also depicted in the architectural sculpture that adorned contemporary funerary monuments and wherever her cosmic associations seemed appropriate for provoking thoughts on life and death. In other cases, we observe a combination of both single figures and scenes with interacting figures, sometimes also framed within arcade-like architecture..$^{51}$ In one example that was excavated by Gayet at Antinoopolis during the 1902-03 season, 13 fragments have been reconstructed to make up a tunic that is richly adorned with mythological figures such as centaurs and lapiths, which are depicted in a struggle on the two medallions (Fig. 15). The two collar-like rectangular tabulae of the same tunic show amazons on horseback as part of an amazonomachy as well as a series of dual-figure scenes, including Narcissus looking at his reflection in the mirror to the far right. This scene features the nymph Echo, thus seemingly referencing Ovid's version from the Metamorphoses, and suggesting an interesting link between art and text to which we will return below. Amongst other scenes, we see Hercules chasing the nymph Auge as the second from the right, and Aphrodite and Ares (or Adonis) in the centre. This rich and complex iconography amounts to a veritable 'picture-book' from which mythological stories could be conjured up. It is also clear that many of these figures could easily have been represented on their own and it is, therefore, possible that they may have been taken out of a pattern-book from which models could be pulled and juxtaposed as appropriate or desired by the patron. There does not seem to be an overarching narrative that structures the composition of the tunic's decoration other than an interest in depicting mythological pairs, and we should certainly not always expect strict iconographic coherency or an intended programme to be present. ${ }^{52}$

More generally, narrative scenes with multiple figures within the same frame had the great advantage that they allowed for more flexibility in representing interaction

by A. De Moor and C. Fluck (Tielt 2009), 146-154, esp. 149. On the application of portraits on mythological figures on Roman sarcophagi, see Birk (cf. fn. 37), 94-107.

50 Santrot et al. (cf. fn. 34), 122, cat. no. 85. For another example of Aphrodite's bath on textiles, refer to ibid., 123. For Aphrodite on architectural sculpture, see Thomas (cf. fn. 45), 48-49.

51 Louvre, inv. E 29294, see Santrot et al. (cf. fn. 34), 112-113, no. 77, here dated to the $3^{\text {rd }}$ century. 52 A point also made in relation to Pompeian wall-painting by Mayer (cf. fn. 24), 166-212. 
between the protagonists, even between mortals and immortals. ${ }^{53}$ In one example from Antinoopolis, dating to the $5^{\text {th }}$ century, we see a representation of Dionysos in a tabula in which he is joined by a reveller sitting in a boat (Fig. 16). The motif can be compared to a series of grave stelai from Terenouthis in the Delta in which the deceased is represented as standing or lying on a boat. ${ }^{54}$ This motif is usually interpreted as a representation of the journey to Styx, and coins found in graves, presumably placed there in order for the deceased to be able to pay Charon, have been cited in support. But again we may envision a more local iconography that could also refer to the power of the Nile in providing life and fertility, an aspect emphasized here by the rich floral ornamentation that is reminiscent of Nilotic scenes. Either way, it demonstrates once again a use of mythology that reflects the wearer's aspirations for the afterlife.

Staying for a moment with the world of Dionysos, this is indeed a very popular theme on late antique Egyptian textiles which benefits from further scrutiny. What was at stake in these images? And what is the relationship between art and text, notably in the Dionysiac motifs that we see on textiles and the popularity of Nonnus' epic poem Dionysiaca? Anthony Snodgrass amongst others has explored at length just how difficult it is to prove a precise correlation between an image and a specific text, and of course, there are other versions of Dionysiac stories that the textile artisans could have used as their inspiration. ${ }^{55}$ Are we then talking about parallel worlds of art and text? ${ }^{26}$ The presence of text itself is rare on textiles, and when present serves simply to identify the main protagonists in a particular narrative, as we have seen in a number of cases above. ${ }^{57}$ Yet, dialogue between art and text may of course also take other forms, as was for example argued in the above case of Narcissus and Echo. Intriguingly, Nonnus was himself from Akhmim, thus representing a possible link between these two forms of expression. We also know from evidence, such as a $6^{\text {th }}$-century papyrus that quotes parts of the Dionysiaca from memory that the poem was read and had become quite popular very soon after its publication. ${ }^{58}$ A plethora of recent literature has emphasized the ways in which the work could be read and appreciated by pagans and Christians alike, and pointed to the many inter-textual references that exist between this work and a paraphrase of the Gospel of John, possibly written by Nonnus. ${ }^{59}$

53 Louvre, inv. X 4792, see Bourguet (cf. fn. 18), 74, cat. no. B 24, from Antinoopolis.

54 F. Hooper, Funerary Stelae from Kom Abou Billou (Ann Arbor, MI 1961), 25.

55 A. Snodgrass, Homer and the Artists. Text and Picture in Early Greek Art (Cambridge 1998).

56 Here echoing J. P. Small, The Parallel Worlds of Classical Art and Text (Cambridge 2008).

57 Durand (cf. fn. 47).

58 R. Shorrock, "Nonnus", in: A Companion to Ancient Epic, edited by J. M. Foley (Malden, MA 2005), 383.

59 R. Shorrock, The Myth of Paganism. Nonnus, Dionysus and the World of Late Antiquity (London 2011); Accorinti in this volume. 
Nevertheless, it may well be the case that such visual representations developed on their own independent trajectory. An example may demonstrate that this is very likely to have been the case. We previously saw a representation of Dionysos finding Ariadne on a tunic (Fig. 5) which framed the two protagonists in a similar way to the use of the motif on sarcophagi or in wall-painting. This theme is elaborately described in the $47^{\text {th }}$ book of the Dionysiaca, in which Ariadne, having been deserted by Theseus, longs to fall asleep and is then finally saved by Dionysos. In the case of a $5^{\text {th }}$-century tunic now in the Metropolitan Museum of Art and said to be from Akhmim, we see a variety of Dionysiac motifs, as well as another depiction of Dionysos and Ariadne on a tabula on the shoulder (Fig. 17). Below them are seated two figures seemingly with their hands tied behind their backs. This is rather odd, but may represent a misunderstanding of the standard iconography in which Dionysos and Ariadne are accompanied by putti and revellers. There seems to be no attempt to tie the story to its literary counterpart, not even through the identification of the figures by means of letters.

Yet, in spite of this reservation, the Dionysiaca may hold significance as an eschatological text within the funerary context and thus provide some further context for understanding the meaning of the Dionysiac motifs that were chosen for the adornment of textiles. The text describes Dionysos' life as a series of struggles which he must overcome in order to be given admission to heaven and represents as such a quest for salvation, which would have appealed to both pagans and Christians. Within the text, there are furthermore embedded stories of death and subsequent resurrection, such as the case of Tylos in the $25^{\text {th }}$ book, a story that frequently has been compared with the Biblical Lazarus which Nonnus also tells in his Paraphrase of the Gospel of John. ${ }^{60}$ This Lydian hero is killed by a serpent but then resurrected to life by his sister Moira who cleverly applied an antidote, known as the

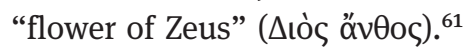

The case of Ariadne is also illuminating in this context. One of the most significant aspects of Ariadne's appearance in the Dionysiaca is that she is killed off not once, but twice; first, in the $25^{\text {th }}$ book, Perseus kills her with a spear (25.98-112), and then again, in the $47^{\text {th }}$ book, Ariadne is petrified when Perseus exposes her to the deadly face of Medusa, much to the anger of Dionysos who loses his bride, but in the end, she is given a home in the heavens (47.664-712). This metaphorical reading of the text as one of trial but also ultimate reward may again have been suitable for pagans and Christians alike and goes some way in explaining why Dionysiac motifs (and not least representations of Ariadne in particular) were so frequently favoured on late antique Egyptian textiles intended for the funerary sphere. ${ }^{62}$ Ariadne's

60 Shorrock (cf. fn. 59), 97-98.

61 Non., Dio. 25.528, 25.539.

62 V. F. Lenzen, The Triumph of Dionysos on Textiles of Late Antique Egypt (Berkeley, CA 1960) explores this theme from the viewpoint of representation, but does not dwell on its eschatological significance. 
long monologue in book 47 where she addresses Sleep and asks "to send me another delectable dream ... so that that I may know the sweet bed of love in a deceptive dream" (47.345-347) may also be read along eschatological lines as a metaphor of death and the afterlife. ${ }^{63}$

This leads us to the much discussed question of the Christianizing fashion in which pagan deities are described in the Dionysiaca, a phenomenon which has been explored by Glen Bowersock amongst others. ${ }^{64}$ Can this phenomenon be identified among the textiles as well? In relation to this question, much has been made of a cruciform flower that is found on the so-called Shawl of Sabina, excavated by Gayet at Antinoopolis in the 1902-1903 season and which is worthy of further exploration in the present context (Figs. 18-19). ${ }^{65}$ This particular piece of textile gives us a good sense of the extraordinary use of colour on the textiles. The shawl, which is now in the Louvre with further fragments in other collections, is decorated with two tabulae that represent Artemis, and Apollo and the nymph Daphne respectively. A central orbiculus has been interpreted as representing Bellerophon, Pegasus, and the Chimaera. It was previously dated to the $6^{\text {th }}$ century, but new radiocarbon results point to an earlier date around $340-440 .{ }^{66}$ Because of the high quality of this particular textile and its original iconography, it has been suggested that it functioned as a wall hanging or even a type of table cloth (and then was re-used in the funerary context) - but that does not necessarily detract from its funerary significance.

The shawl was found in a tomb that belonged to a woman named Sabina, hence its modern name. She was buried with a Gnostic stone, an ivory fish, a glass vase with a cross and the letters alpha and omega, strongly indicating that it belonged to a Christian occupant. ${ }^{67}$ So, it seems that we here have a Christian funerary context in which textiles with representations of pagan mythology featured very prominently.

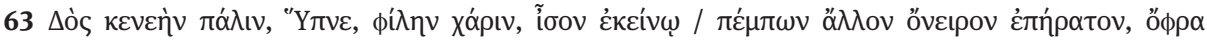

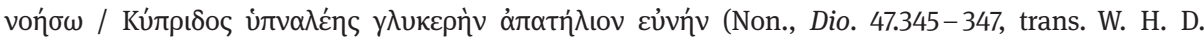
Rouse). For an exploration of sleep as a metaphor of death and a form of epiphany, refer to, most recently, V. Platt, Facing the Gods. Epiphany and Representation in Graeco-Roman Art, Literature and Religion (Cambridge 2011), 335-393. For Ariadne on Roman sarcophagi, see Birk (cf. fn. 37), index, 'Ariadne'.

64 G. Bowersock, "Dionysus as an Epic Hero", in: Studies in the Dionysiaca of Nonnus, edited by N. Hopkinson (Cambridge 1994), 156-166; and see Shorrock (cf. fn. 59).

65 Musée du Louvre, inv. E 29302, excavated by Gayet at Antinoopolis in 1902-1903 and went on display immediately after in the Musée Guimet in Paris from which it was later transferred to the Louvre. H: $1.10 \mathrm{~m}$. W: $1.40 \mathrm{~m}$. Further fragments belonging to the same textile are also in Lyon (Musée des Beaux-Arts and Musée Historique des Tissus). The key publication is now M.-H. Rutschowscaya, La châle de Sabine (Paris 2012). See also idem., "La châle de Sabine", in: Études coptex VI. Huitième journée d'études. Colmar 29-31 mai 1997 (Paris 1997), 21-28; Santrot et al. (cf. fn. 34), 108-111, no. 76. The iconography of Apollo and Daphne is also discussed in A. Stauffer, Spätantike und koptische Wirkereien. Untersuchungen zur ikonographischen Tradition in spätantiken und frühmittelalterlichen Textilwerkstätten (Bern 1992), 145-148.

66 Rutschowscaya 2012 (cf. fn. 65), 115-117.

67 E. Guimet, Les portraits d'Antinoé (Paris 1912), 17. 
In one of the tabulae, Daphne holds a cruciform flower in her hand. The flower is centrally placed within the frame of the figural panel, suggesting that it may be an important part of the iconography. It has been interpreted as a sign of the Christianization of the scene and caused quite a sensation upon its discovery ${ }^{68}$ However, there are many reasons to be careful with such interpretations, as in other contexts, artists had no problems representing full-blown mythological narratives without any need to Christianize them through the addition of crosses or any other form of Christian iconography. The cross (if that is what it really is) is furthermore an isolated Christianizing element in the present example. We may therefore instead ask whether a particular aspect of the story of Apollo and Daphne was emphasized by the addition of the flower which clearly stands out through the use of the rich red colour.

First, we need to address the overall composition of the piece. The textile applies a strongly heroizing iconography which would befit a funerary context and which can be compared with the use of mythological motifs on Roman sarcophagi. Artemis is shown as a huntress but furthermore represented in the guise of Virtus, and indeed a dead lion lies at her feet; on sarcophagi, Virtus is frequently shown as accompanying a lion hunter or huntress. ${ }^{69}$ The story of Bellerophon is a further pointer to the heroic function of the iconography. ${ }^{70}$ This scene plays off the composition of the Artemis panel by depicting the slain Chimaera, lying on the ground. Bellerophon continued to be popular in Constantinople, where he is famously represented on the $10^{\text {th }}$. century Veroli casket, now in the Victoria \& Albert Museum. Circling around this central orbiculus, playful putti are represented as taking part in a variety of leisurely activities, including playing music, being crowned by wreaths, and riding a centaur. Among the different floral ornaments, we see below the Artemis panel, a trefoil which looks rather suspiciously similar to our red cruciform flower that Daphne holds in her hand. The main scenes are framed by Nilotic scenes on the clavi.

Zooming in now on the representation of Apollo and Daphne, the artisan has here tackled the difficult task of visualizing metamorphosis in action as Daphne is shown half-way into her transformation into a laurel tree. ${ }^{71}$ Indeed, the tree appears to be swallowing her, and her feet are already covered. This finds a close parallel in another Egyptian artefact, the ivory which is now in Ravenna. ${ }^{72}$ In contrast to the textile, Apollo is shown here with a lyre (thus emphasizing a less bellicose aspect of his identity), and although Daphne gestures towards him, she does not hold anything in her hand. On another textile fragment, now on the Zurich art market, we see a statu-

68 Guimet (cf. fn. 67), 18, and repeated in Santrot et al. (cf. fn. 34), 108.

69 For examples, see B. Andreae, Die antiken Sarkophagreliefs I. Die Sarkophage mit Darstellungen aus dem Menschenleben. 2. Die römischen Jagdsarkophage (Berlin 1980). See also Birk (cf. fn. 37), 107-114, 137-138.

70 Bellerophon in the Iliad: vi.155-203. For an example of the use of the myth of Bellorophon on a Roman sarcophagus, see Zanker and Ewald (cf. fn. 33), 301-304.

71 See also S. Woodford, Images of Myths in Classical Antiquity (Cambridge 2003), 165-166.

72 LIMC, Daphne 35. 
esque Apollo - and perhaps two representations of Daphne in different stages of the narrative; one of her metamorphosis and one of her running from Apollo, although this figure has also been interpreted as representing another nymph. ${ }^{73}$ In this example, we see how standard figures could be placed together to make up a story, even when only little effort has been made to show interaction between them. On a $7^{\text {th }}$ - to $9^{\text {th }}$-century tunic in the Abegg-Stiftung, a similar iconography may be recognized, but the figures are now depicted as dressed rather than nude. ${ }^{74}$ Furthermore, Daphne is depicted in Egyptian architectural sculpture, such as in an example from Herakleopolis Magna where the laurel tree looks rather less convincing than in the case of the Shawl of Sabina and where she is depicted on her own. ${ }^{75}$

This practice of isolating and juxtaposing single figures for different uses may explain why Apollo in the piece under discussion looks as if he is taken from a version of him killing the Niobids since he is shown reaching for his quiver in the standard iconography of a hunter - imagery that is also used in the case of the Atalante in the Abegg-Stiftung. This posture adds a certain irony to the story, in that in Ovid's Metamorphoses, Apollo lampoons Eros for handling big weapons and thus provokes his shooting by the arrow of love. But this posture has certainly also been chosen to make an iconographic link to the representation of Artemis, who is also portrayed on the textile with a bow. This juxtaposition comes through in the choice of colour as well; Apollo's bow is white, that of Artemis is, by contrast, black. Apollo's posture furthermore adds to the sense of (erotic) tension that is implicit in the scene; she reaches out to him, and he reaches to his quiver.

In comparison with these and other iconographic comparanda, the flower in Daphne's hand appears to be idiosyncratic, as in no other representations of the scene is she shown holding a similar object. Nor does the gesture resonate with any textual version of the story that I know of. This hints at an individual meaning which is difficult to reconstruct. Daphne may be appealing to Apollo, her father, or even evoking Zeus, as in Parthenius' version of the story, but we cannot be certain. ${ }^{76}$ In Parthenius' version, we are also told that Artemis taught Daphne how to shoot straight, thus creating a link between this panel and that showing Artemis and also a possible correlation between art and a particular text. The overall message of this piece of textile may then be to express various qualities of maidenhood that were appropriate for an unmarried girl. Furthermore, another fragment of the shawl that is now in Lyon apparently focuses on an aspect of ideal beauty. This piece shows an orbiculus, supported by two putti, that depicts Aphrodite's bath. ${ }^{77}$

73 LIMC, Daphne 40a. On the story of Daphne and its interpretation, see K. Dowden, Death and the Maiden. Girls’ Initiation Rites in Greek Mythology (London 1989), 174-179.

74 Stauffer (cf. fn. 65), 145-146; Schrenk (cf. fn. 3), 169-171, cat. no. 57.

75 LIMC, Daphne 4. Cairo, Coptic Museum 7061, dated to the $5^{\text {th }}$ or $6^{\text {th }}$ century.

76 Parthenius, Sufferings in Love, XV.

77 Rutschowscaya (cf. fn. 47), fig. 7. 
In answer to the question of whether the cruciform flower constitutes evidence for a Christian appropriation of the myth of Apollo and Daphne by means of the addition of a cross, I think that we should be very hesitant, in spite of the seemingly Christian finds that also were in the grave. In light of the idiosyncratic iconography that has been chosen for this particular textile, rather different meanings related to the wearer's identity rather than her religious affiliation may very well have been intended. Overall, the unusual iconography of the Shawl of Sabina may be explained by reference to license on behalf of the artist or the patron.

The continuity that these mythological images on Egyptian textiles attest to seems to be a subtle one which places the viewer at centre stage, allowing him or her to read different meanings into individual motifs, similar to how the Dionysiaca may have been read by both Christians and pagans, in spite of what appears, at least on the surface, to be a full-fledged pagan mythological narrative. Evidence, such as the newly discovered late antique house at Trimithis (Amheida) in the Dakhla Oasia, whose walls were decorated with mythological scenes and a rhetorical teacher's dipinto, certainly suggests that Greek literary tradition and education was alive and well into the fourth century, even beyond Alexandria and the Nile Valley. ${ }^{78}$ This means that we should not see the textiles as increasingly devoid of meaning, but rather as bearers of an iconographic tradition that helped to make sense of everyday life and the ways in which personhood was forged and represented in different media. The textile evidence suggests that this tradition was vital at least into the $6^{\text {th }}$ century. Do the mythological motifs then constitute Documents of Dying Paganism, to quote the title of one influential study? ${ }^{79}$ No, rather they attest to the complexity of religious change in Egypt. Recent work by Jitse Dijkstra on Philae has indeed shown just how complex the reality of pagan-Christian interaction was during this period. ${ }^{80}$ The mythological scenes on textiles are furthermore testament to a very powerful tradition in which conceptions of eschatology and other crucial aspects of life could be expressed through mythology which had already been appropriated within the Egyptian cultural canon. In this context, mythology functions as a habitus rather than as a religious system. ${ }^{81}$ By dressing themselves in myth, in life and for the afterlife, late antique Egyptians confronted the same sort of issues of representation and identity that are observed on contemporary funerary sculpture and in earlier Roman sarcophagi, thus linking their cultural and religious aspirations to the wider world of the Mediterranean.

78 R. Cribiore, P. Davoli, and S. Ratzan, “A Teacher's Dipinto from Trimithis (Dakhleh Oasis)”, JRA 21 (2008), 170 -191. See also A. Benaissa, “Greek Language, Education, and Literary Culture”, in: Oxford Handbook of Roman Egypt, edited by C. Riggs (Oxford 2012), 526-542.

79 P. Friedländer, Documents of Dying Paganism. Textiles of Late Antiquity in Washington, New York, and Leningrad (Berkeley 1945).

80 J. Dijkstra, Philae and the End of Ancient Egyptian Religion. A Regional Study of Religious Transformation (298-642 CE) (Leuven 2008).

81 Compare K. Bowes, “Christian Images in the Home”, AnTard 19 (2011), 171-190. 


\section{Epilogue}

When addressing the gradual disappearance of mythological motifs on Egyptian textiles it is often noted that from the $6^{\text {th }}$ century onwards, we witness an interesting development that most frequently has been characterized as a descent into form, stylized representations or even caricature, seemingly rendering figures and motifs increasingly devoid of meaning. Examples of this phenomenon can be found on a $7^{\text {th }}$ century wool tunic now in the Brooklyn Museum, the representation of Dionysos descends into heavily stylized ornament which is barely legible but still potentially meaningful (Fig. 20). ${ }^{82}$ Nereids and other mythological motifs lived on, although in a sometimes rather curious and increasingly abstract form. All of this makes it very difficult to define the limits of the use of mythology on Egyptian textiles, which it must be noted, co-existed with Christian motifs. This is a rather striking contrast to developments in other parts of the Mediterranean. For example, in a study of North African lamps, John Lund has shown that mythological motifs in this medium experienced a rapid decline in the first part of the $5^{\text {th }}$ century and were then entirely replaced by Christian ones. ${ }^{83}$ Arja Karivieri has similarly shown that this process occurred about 50 years later in the case of Athenian lamps, although in this instance the mythological motifs re-appeared in the $6^{\text {th }}$ century. ${ }^{84}$ This is testimony to the many regional variations and trajectories in the process of Christianization. Given the problems of chronology outlined earlier, our Egyptian textiles cannot be exposed to the same kinds of statistical analyses as lamps, but the enormous quantities of material still allow us to confront a question of considerable importance, namely the factors that were responsible for the prevalence of such motifs in the Egyptian context.

82 Brooklyn Museum, acc. no. 41.523, see Thompson (cf. fn. 1), 84-87, no. 37. Very similar piece in the Louvre: Bourguet (cf. fn. 18), 542, cat. no. H 115 (giving $11^{\text {th }}$ c. date).

83 J. Lund, "Motifs in Context: Christian Lamps", in: Late Antiquity. Art in Context, edited by J. Fleischer, J. Lund and M. Nielsen (Copenhagen 2001), 199-214.

84 A. Karivieri, "Mythological Subjects on Late Roman Lamps and the Persistence of Classical Tradition”, in: Late Antiquity. Art in Context, edited by J. Fleischer, J. Lund and M. Nielsen (Copenhagen 2001), 179-198. 


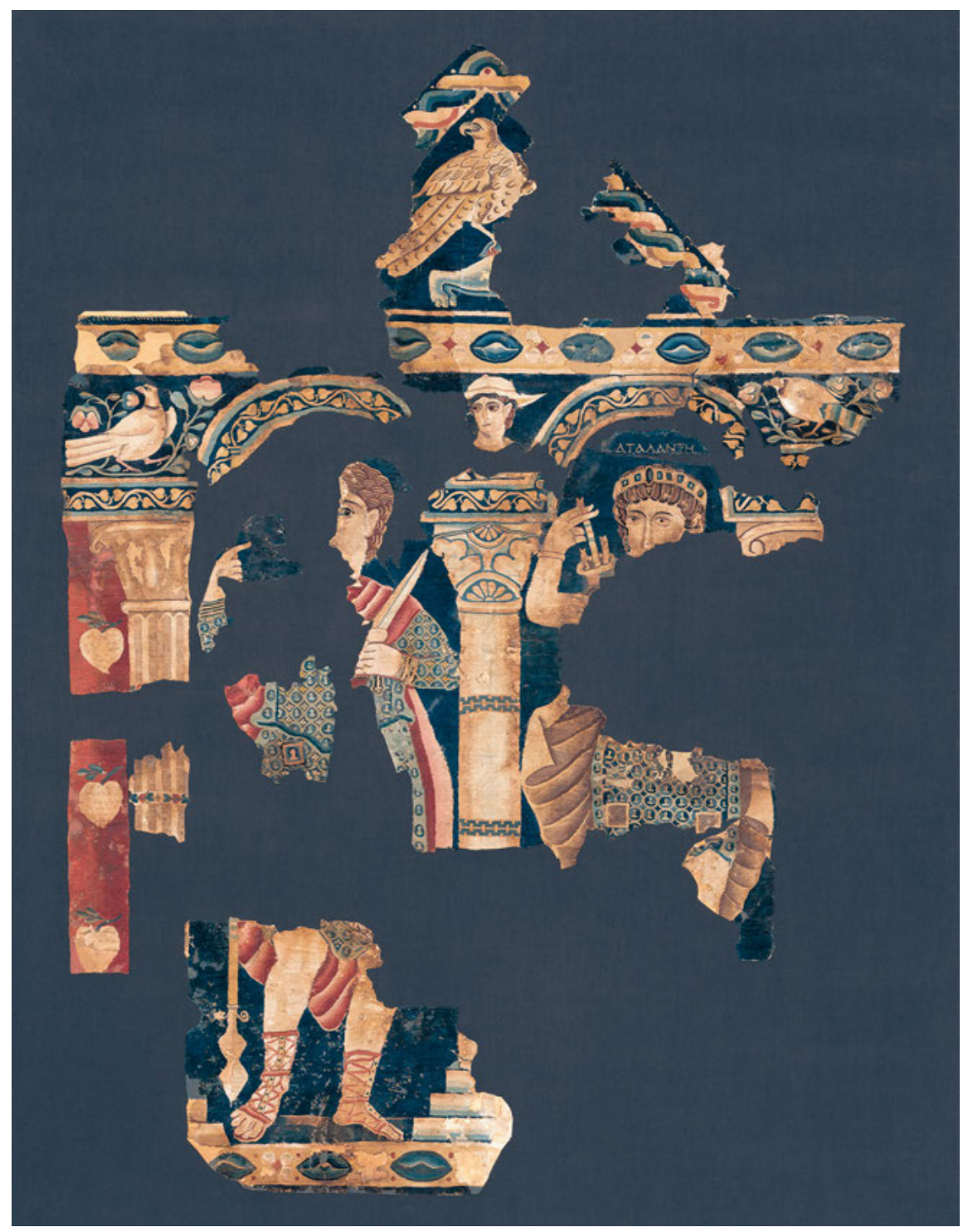

Fig. 1: Meleager and Atalante, Abegg-Stiftung, Riggisberg, inv. no. 1100 (৫ Abegg-Stiftung, CH-3132 Riggisberg, 2003, photo: Christoph von Viràg). 


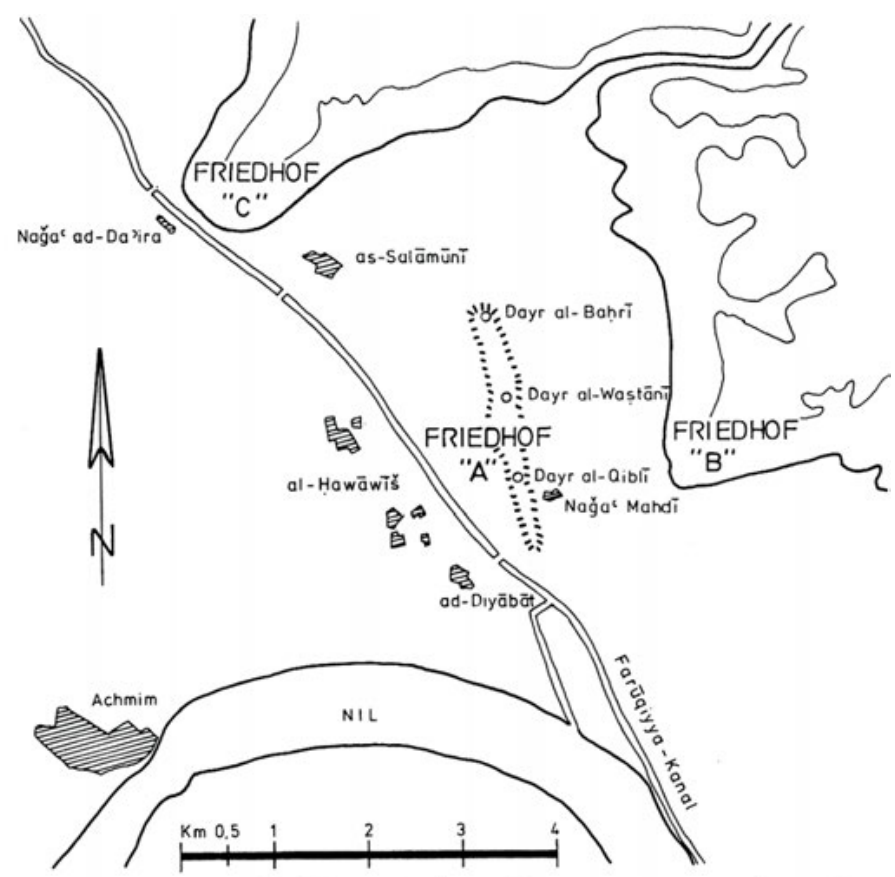

Abb. 14. Die Friedhofsbezirke der Achmimer Wüstennekropole $\mathrm{A}=$ al-Hawāwīš $-\mathrm{B}=(\mathrm{Bayt})$ al-Madīna ( $P M$ : el-Hawâwîsh $)$ $-\mathrm{C}=$ as-Salāmūn̄̄

Fig. 2: Map of cemeteries in the vicinity of Akhmim/Panopolis (from Kuhlmann [cf. fn. 5], 53, by permission of the author).

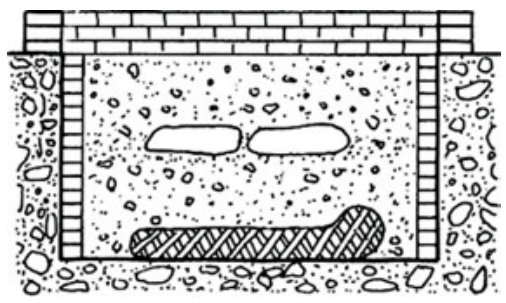

Fig. 3: Drawing of a Christian tomb from cemetery A (see Fig. 2) at Akhmim/Panopolis (from Kuhlmann [cf. fn. 5], 62 , by permission of the author). 


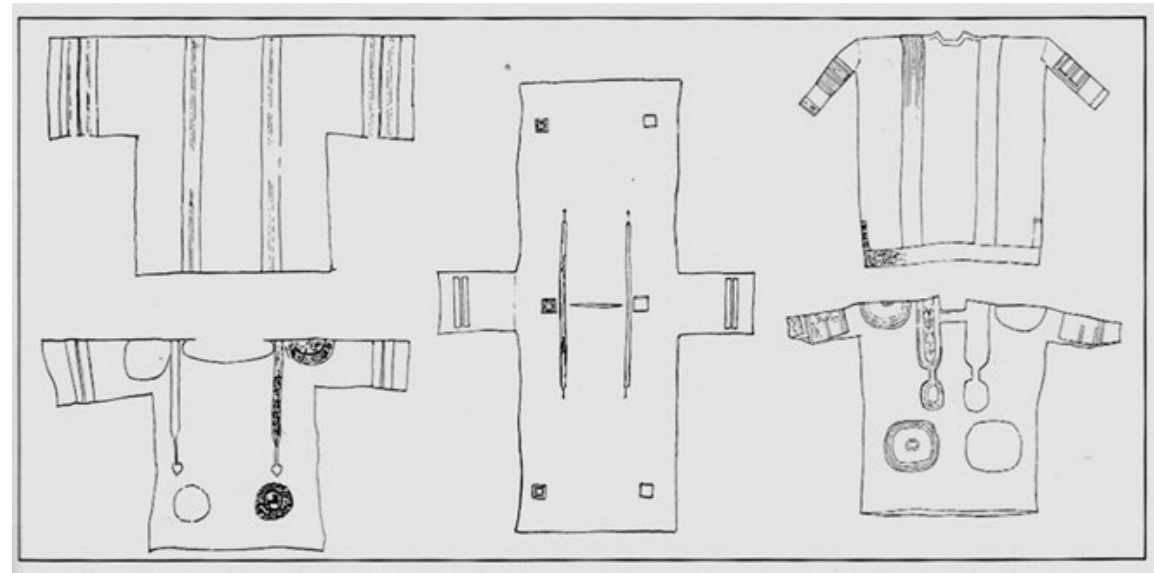

Fig. 4: Drawings of tunics in the Victoria \& Albert Museum, London (from A. Badawy, Coptic Art and Archaeology [Cambridge, MA 1978], 285, fig. 4.60, by permission of the publisher).

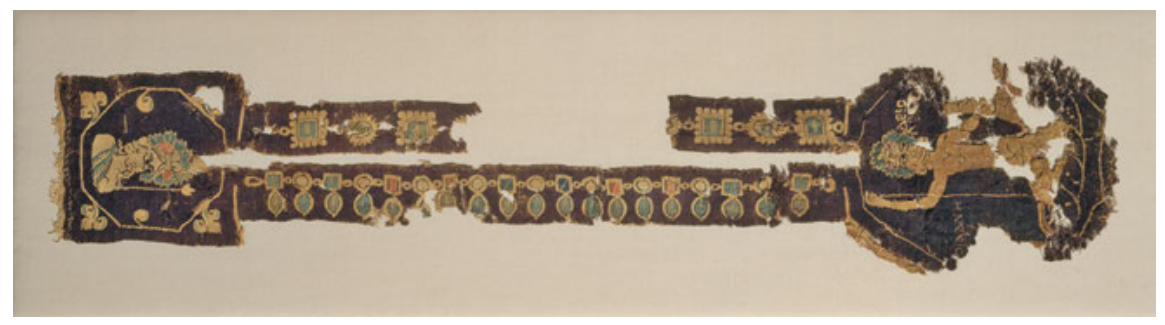

Fig. 5: Neck ornament from tunic, found in Egypt, probably $4^{\text {th }}$ century, Boston Museum of Fine Arts, Charles Potter Kling Fund 46.402 (photo @ Museum of Fine Arts, Boston).

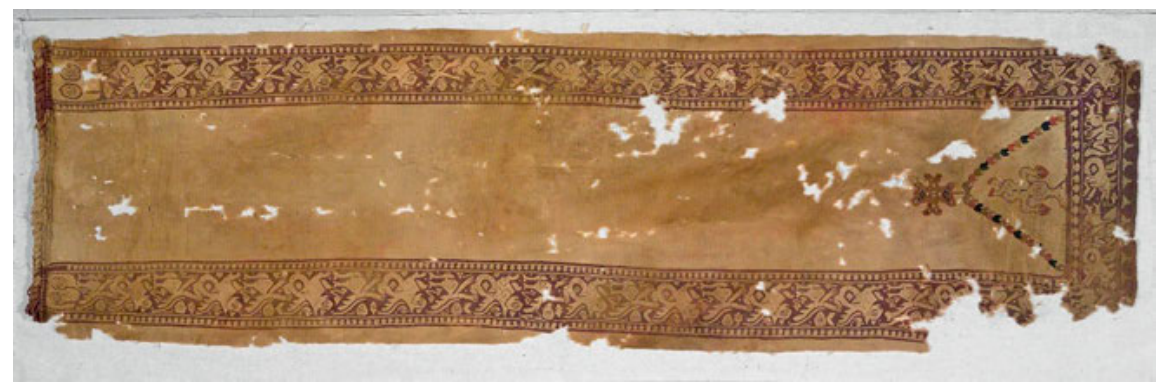

Fig. 6: Yellow tunic - front with marine motifs, $6^{\text {th }}$ century, wool, $33 \times 113 \mathrm{~cm}$, Brooklyn Museum, Charles Edwin Wilbour Fund, acc. no. 38.753 (Brooklyn Museum photograph 2005). 


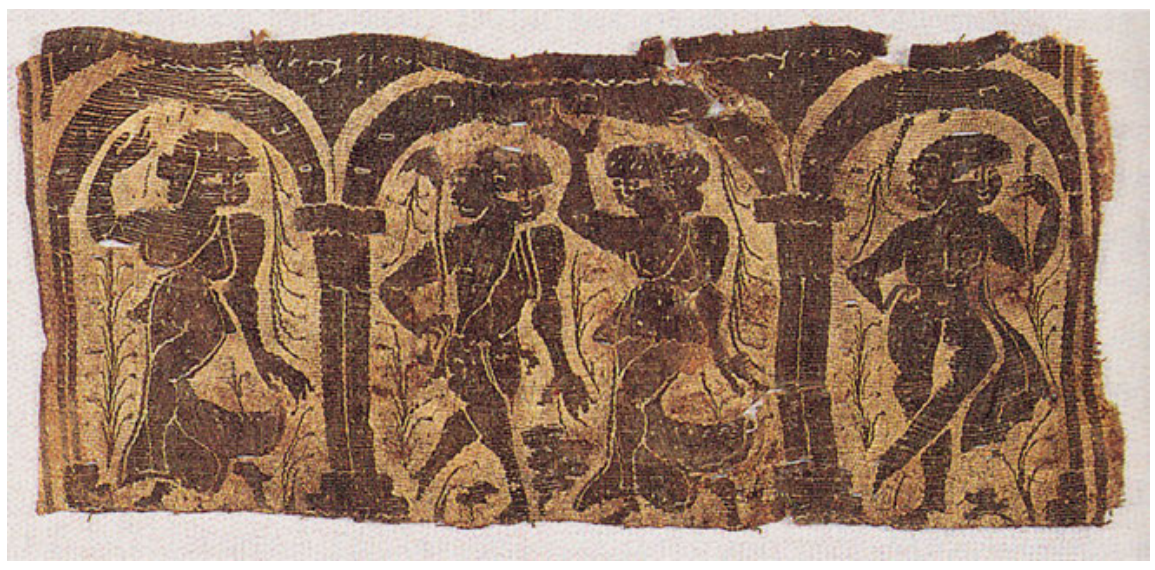

Fig. 7: Tunic panel with dancing figures, $4^{\text {th }}-6^{\text {th }}$ century, Röhsska Museet, Gothenburg, RKM 8-67 (from Erikson [cf. fn. 5], 106, reproduced by permission of the museum).
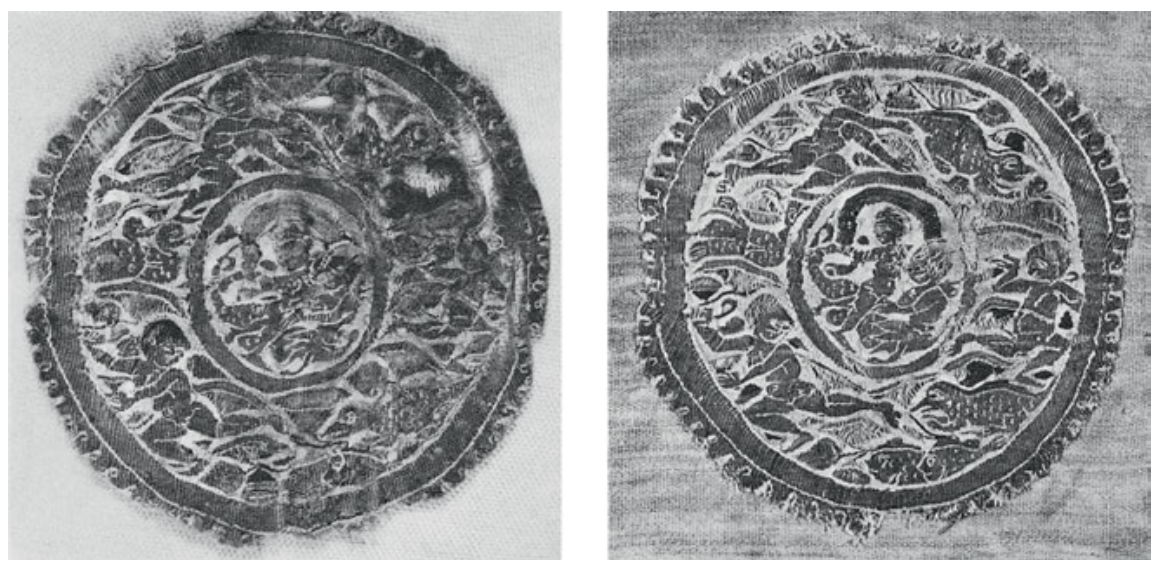

Fig. 8a-b: Pair of $6^{\text {th }}$-century medallions, now in the Louvre, inv. X 4339 \& X 4311 (from Bourguet [cf. fn. 18], 98). 


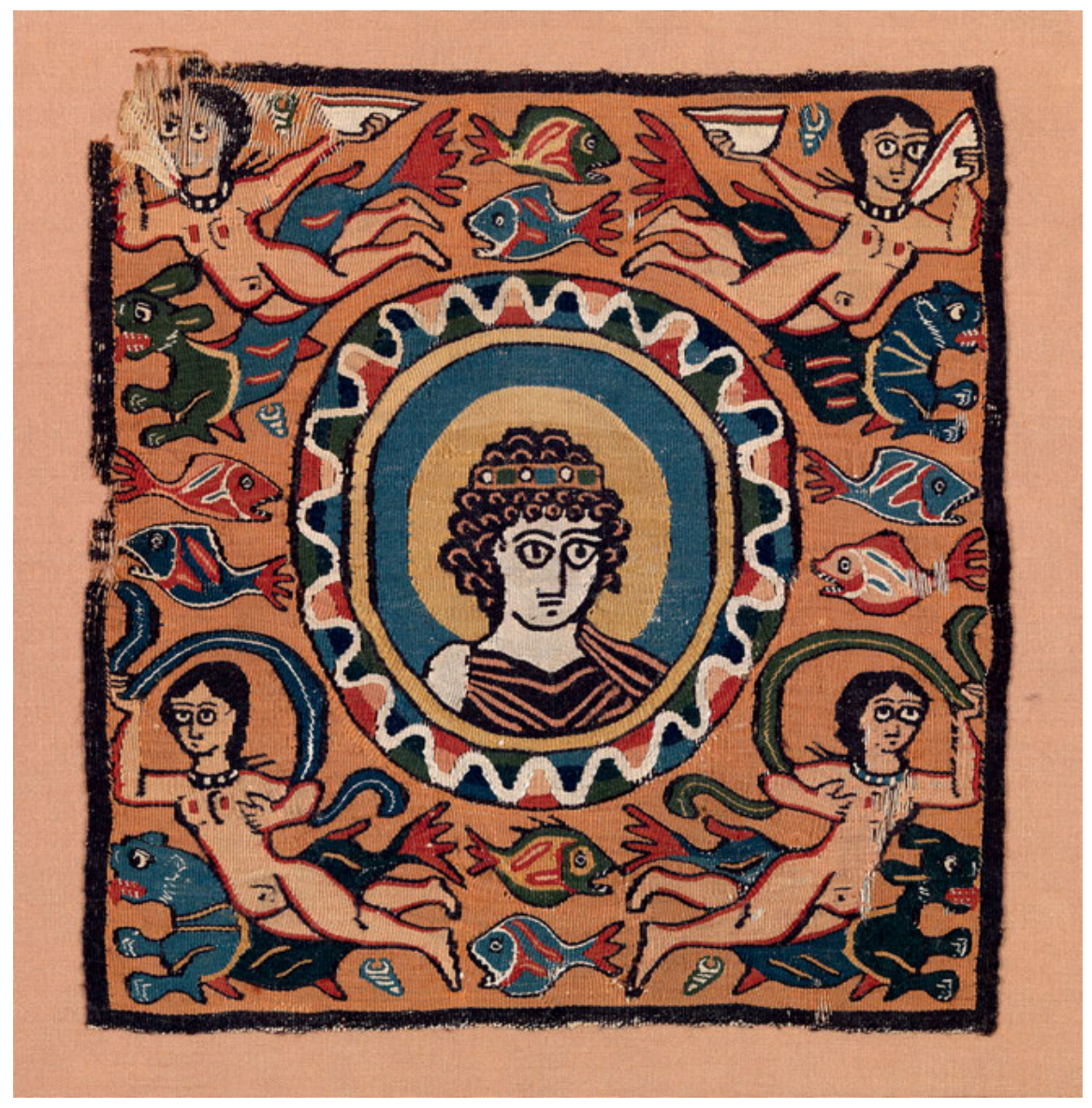

Fig. 9: Medallion portrait, now in the Louvre (๔ Musée du Louvre/Georges Poncet). 


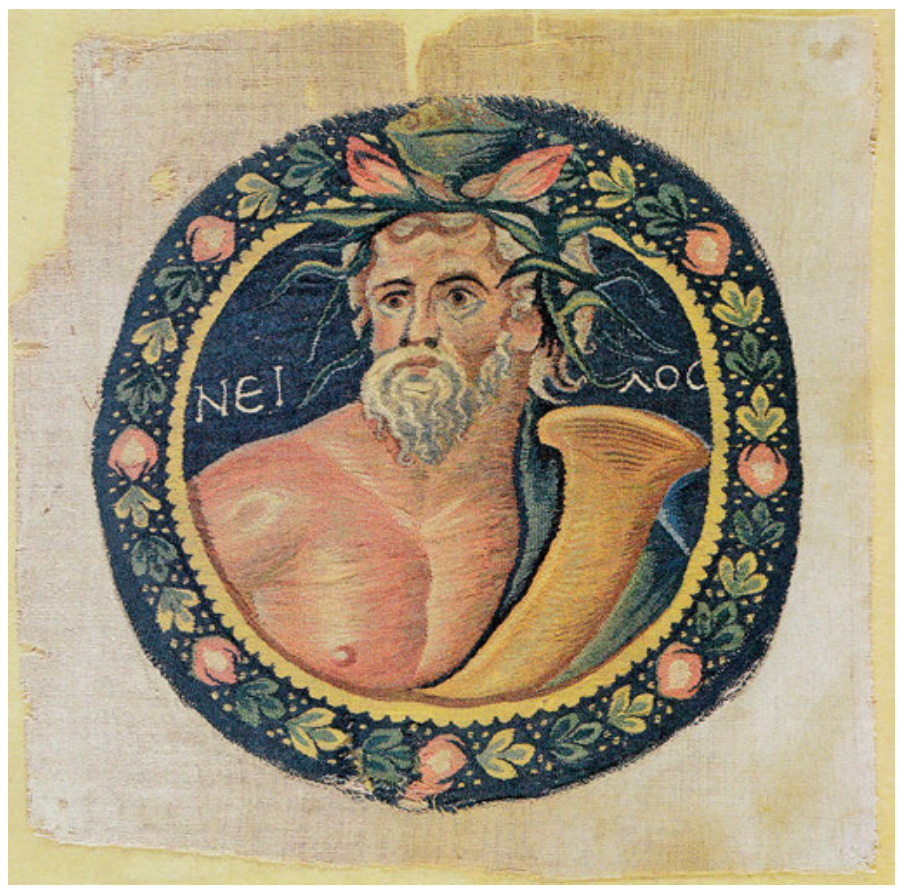

Fig. 10: Personification of the Nile, now in the Pushkin Museum, Moscow (from von Falck and Lichtwark [cf. fn. 35], 308).

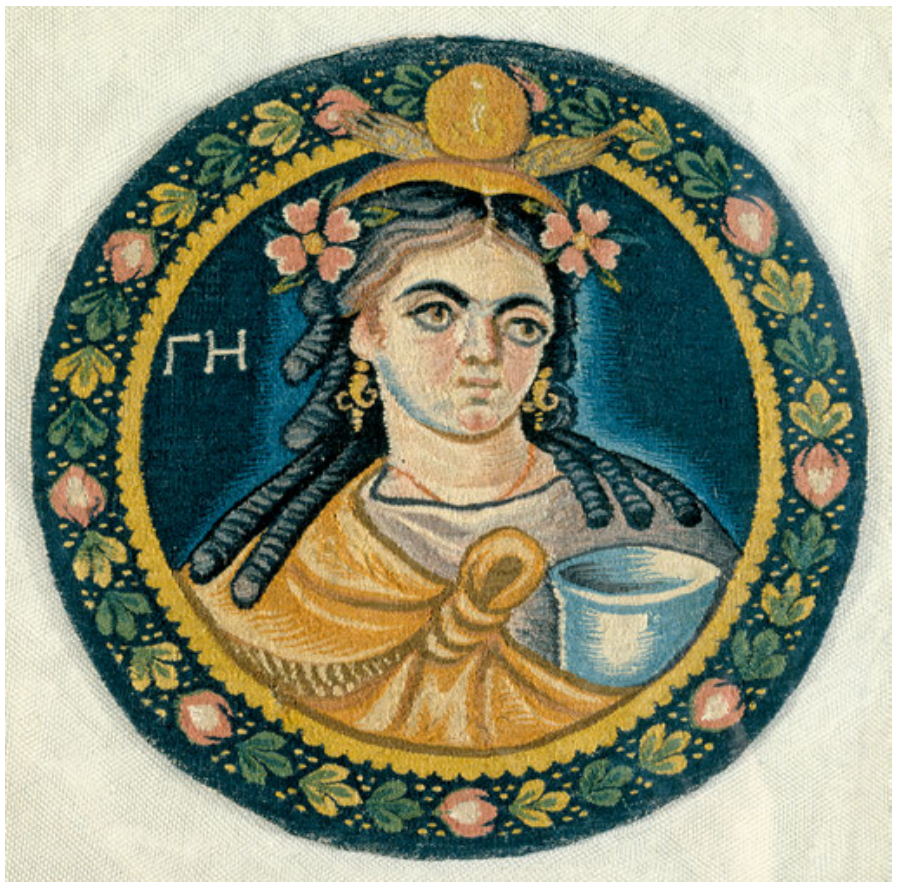

Fig. 11: Personification of $\mathrm{Ge}$, now in The State Hermitage Museum, St. Petersburg (photo (c) The State Hermitage Museum, photo by Svetlana Suetova). 


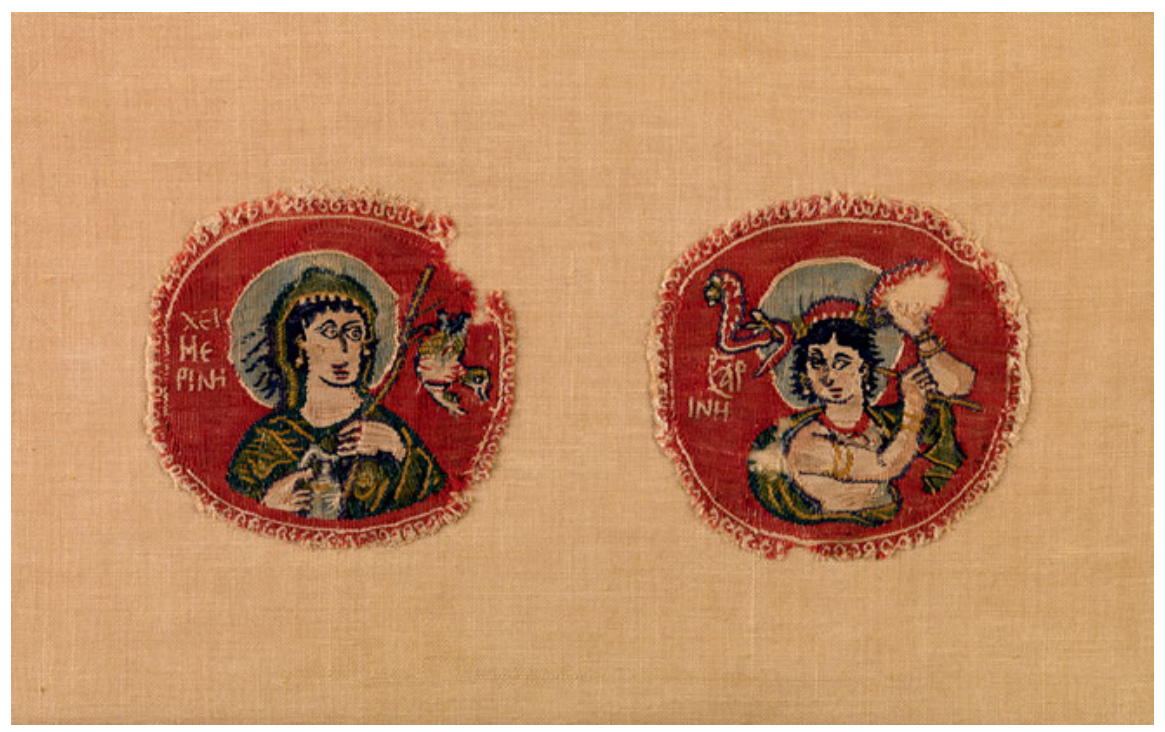

Fig. 12: Seasonal personifications on a tunic, now in the Louvre (from Rutschowscaya [cf. fn. 47], 119).

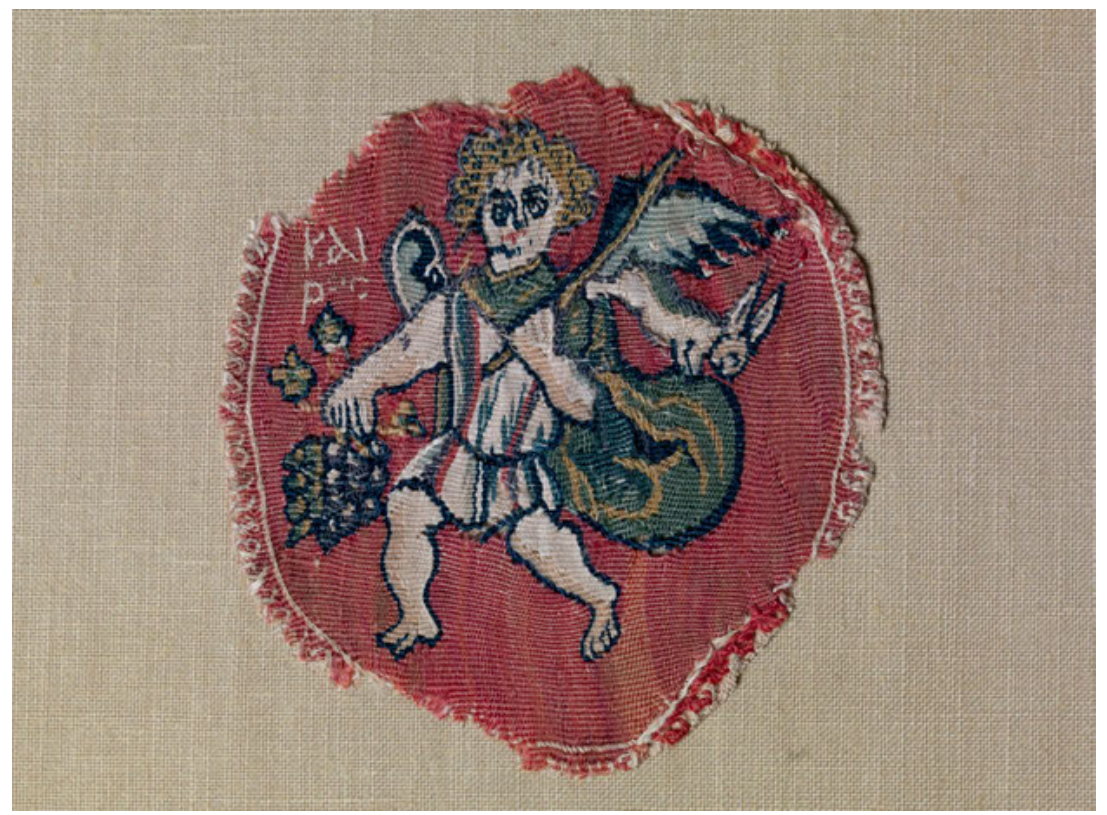

Fig. 13: Personification of Kairos, Musée departmental des Antiquités, Rouen, inv. 2002.0.14 (Photograph ( cg76 - Musée departmental des Antiquités - Rouen, cliché Yohann Deslandes). 


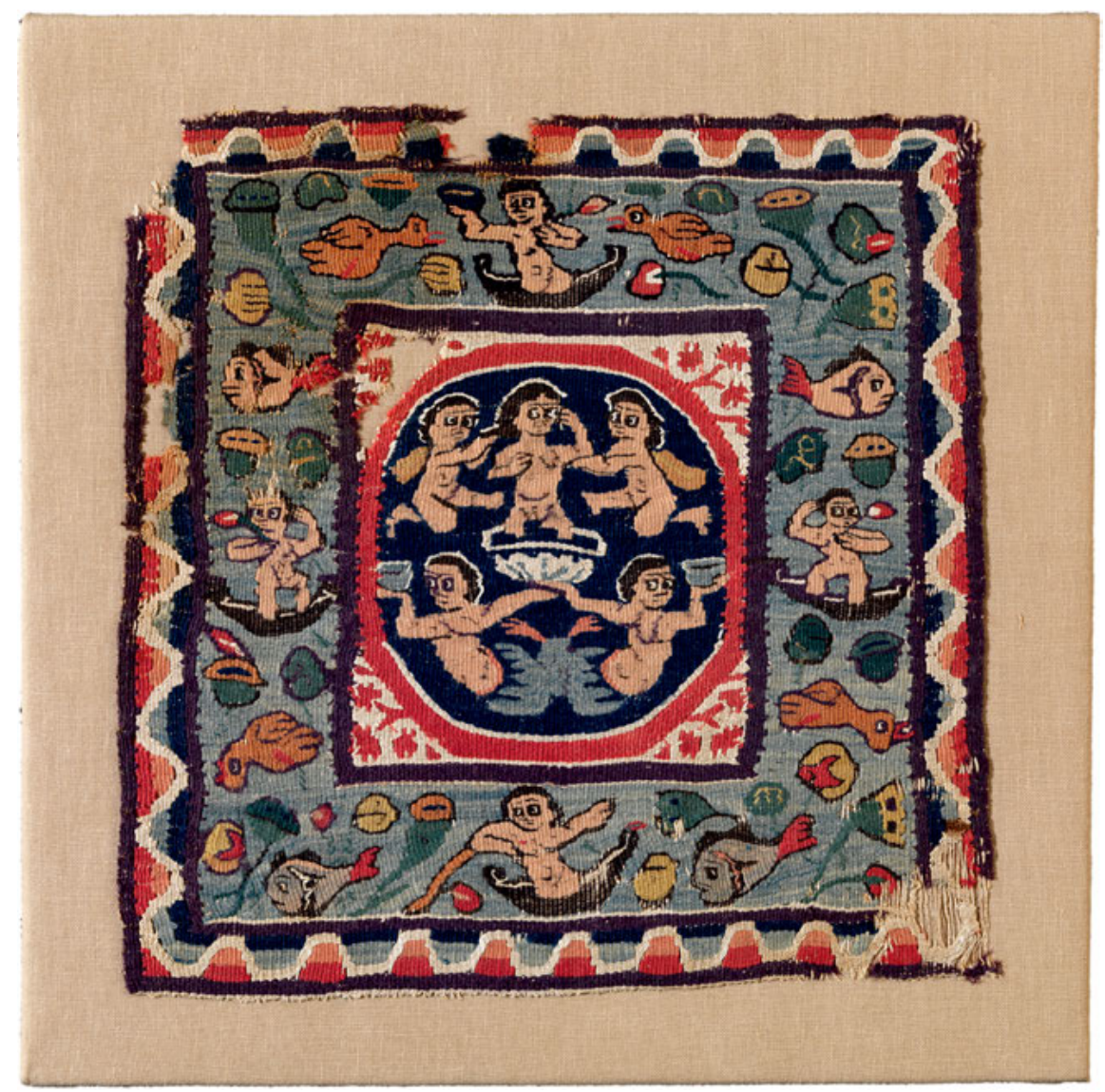

Fig. 14: Tabula with Nilotic scenes and the bathing Aphrodite, Louvre, inv. X 4151 (๑ Musée du Louvre/Georges Poncet). 


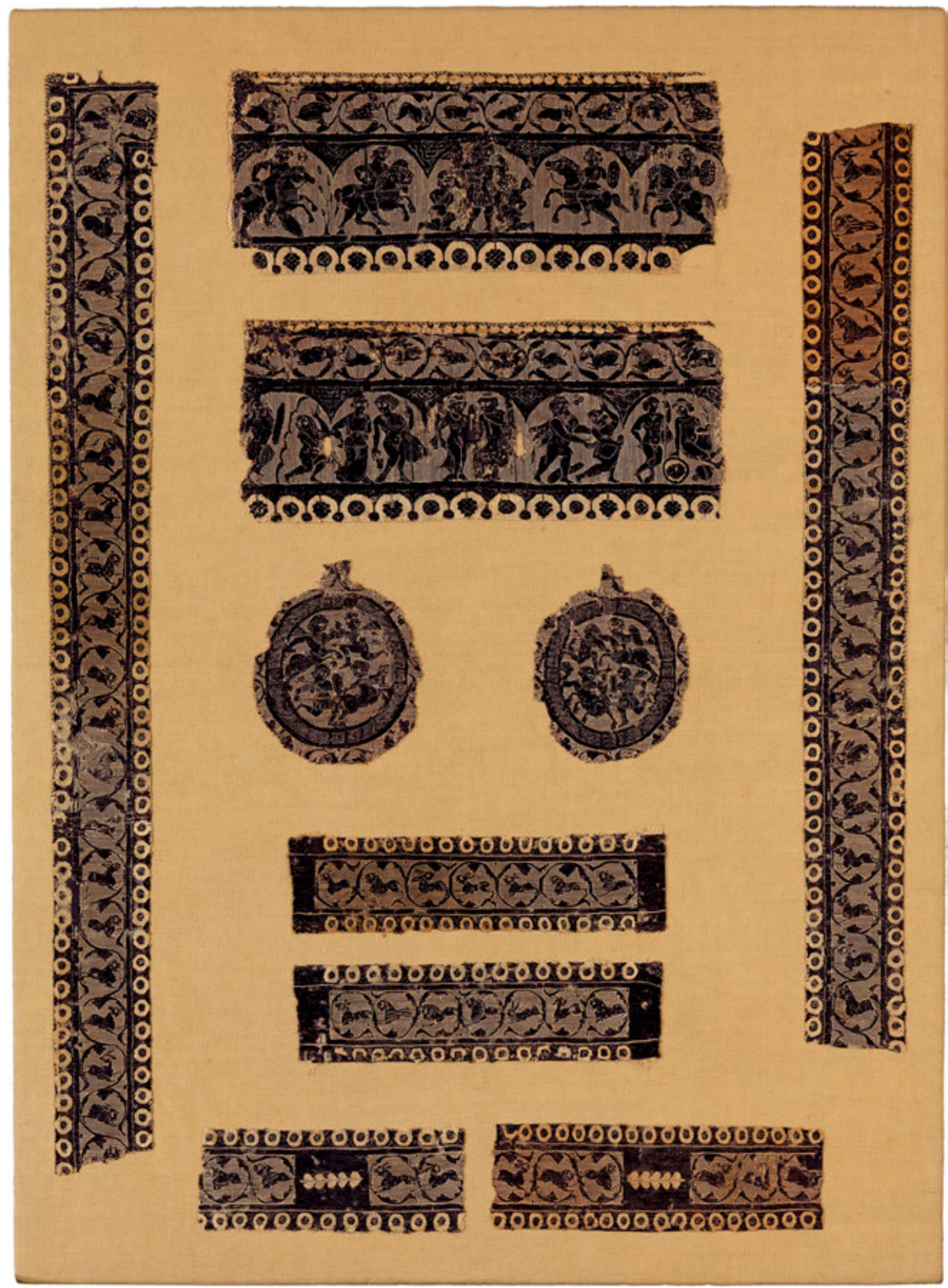

Fig. 15: Tunic in the Louvre, inv. E 29294 (৫ Musée du Louvre/Georges Poncet). 


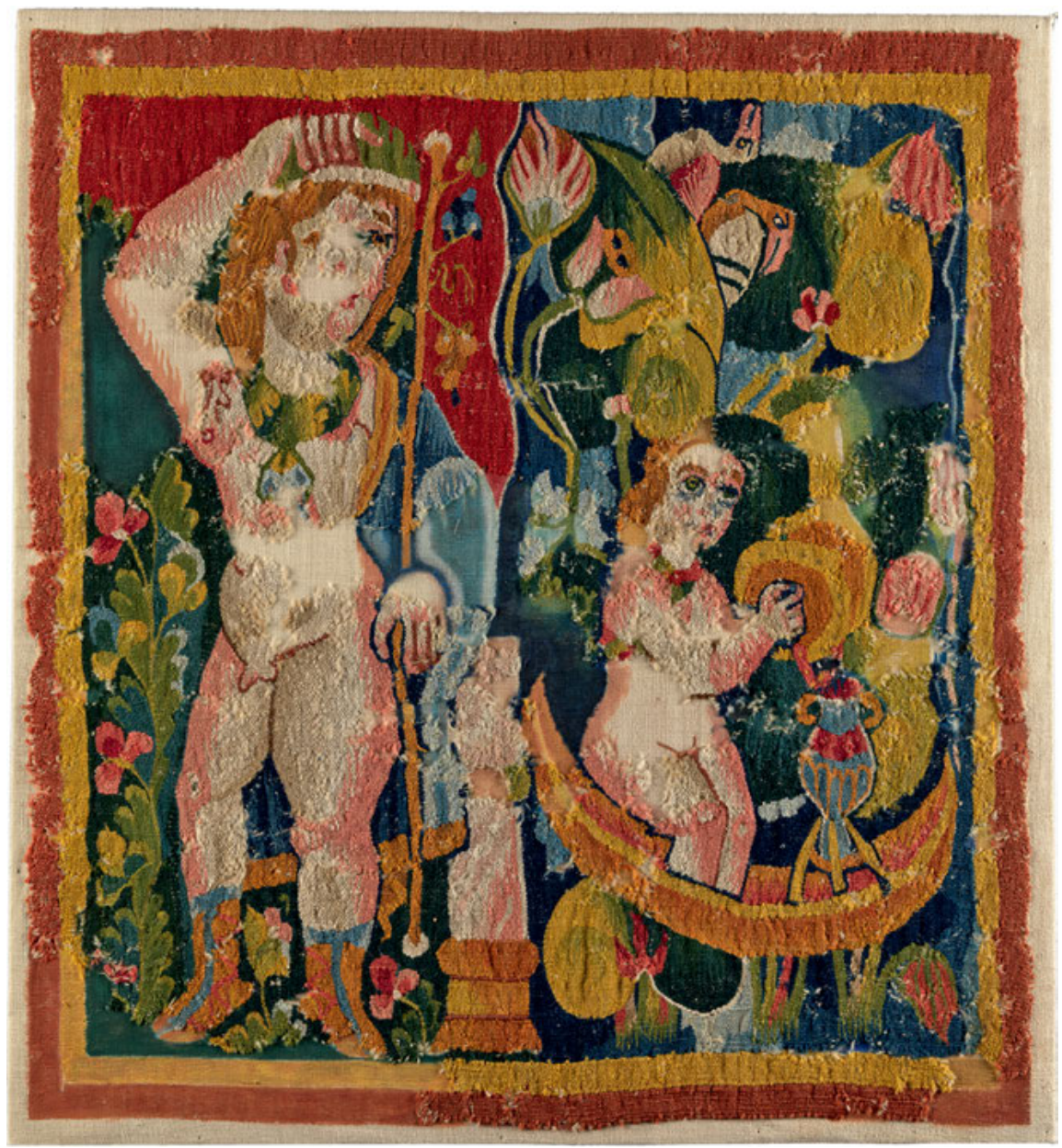

Fig. 16: Tabula showing Dionysos and reveller in a boat, now in the Louvre, inv. X 4792 (from Bourguet [cf. fn. 18], 25). 


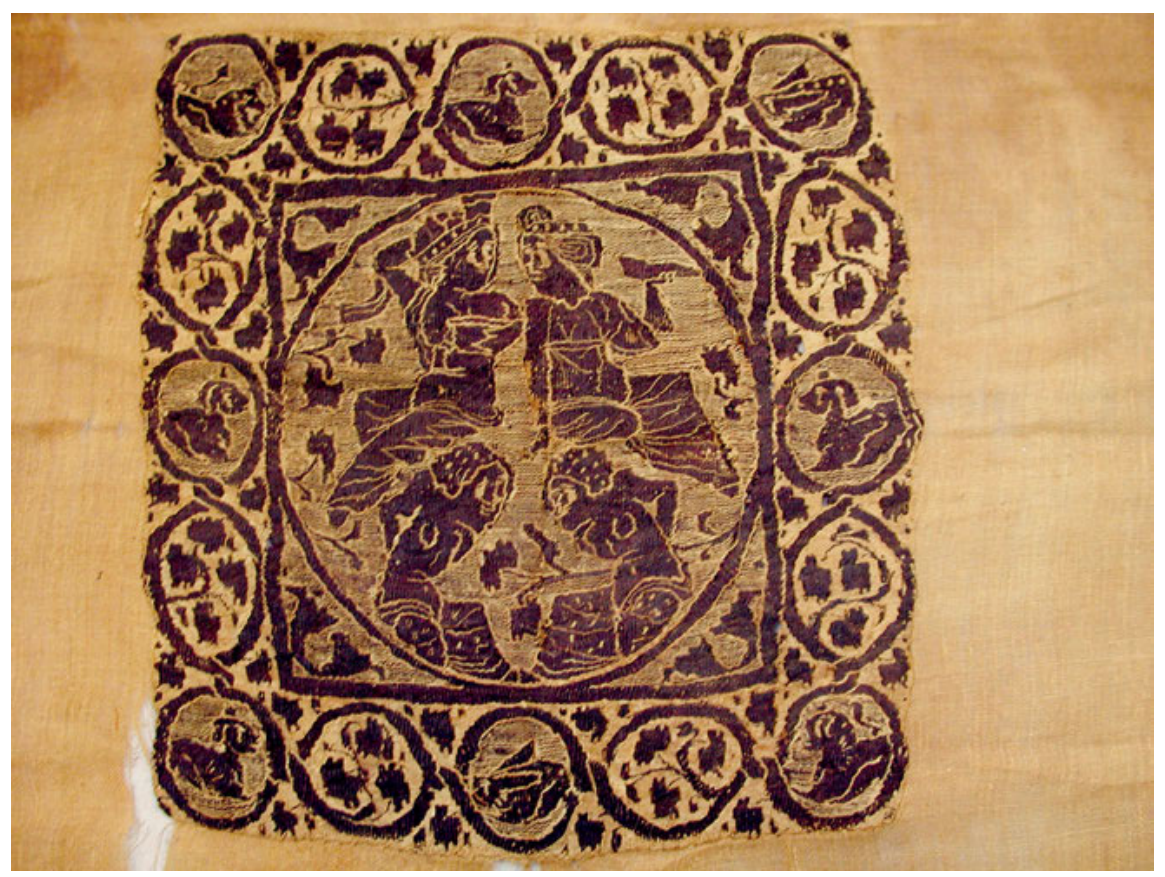

Fig. 17: Ornament from a tunic showing Dionysos and Ariadne, The Metropolitan Museum of Art, New York, Gift of Edward S. Harkness, 1926 (inv. 26.9.8) (Image (c) The Metropolitan Museum of Art). 


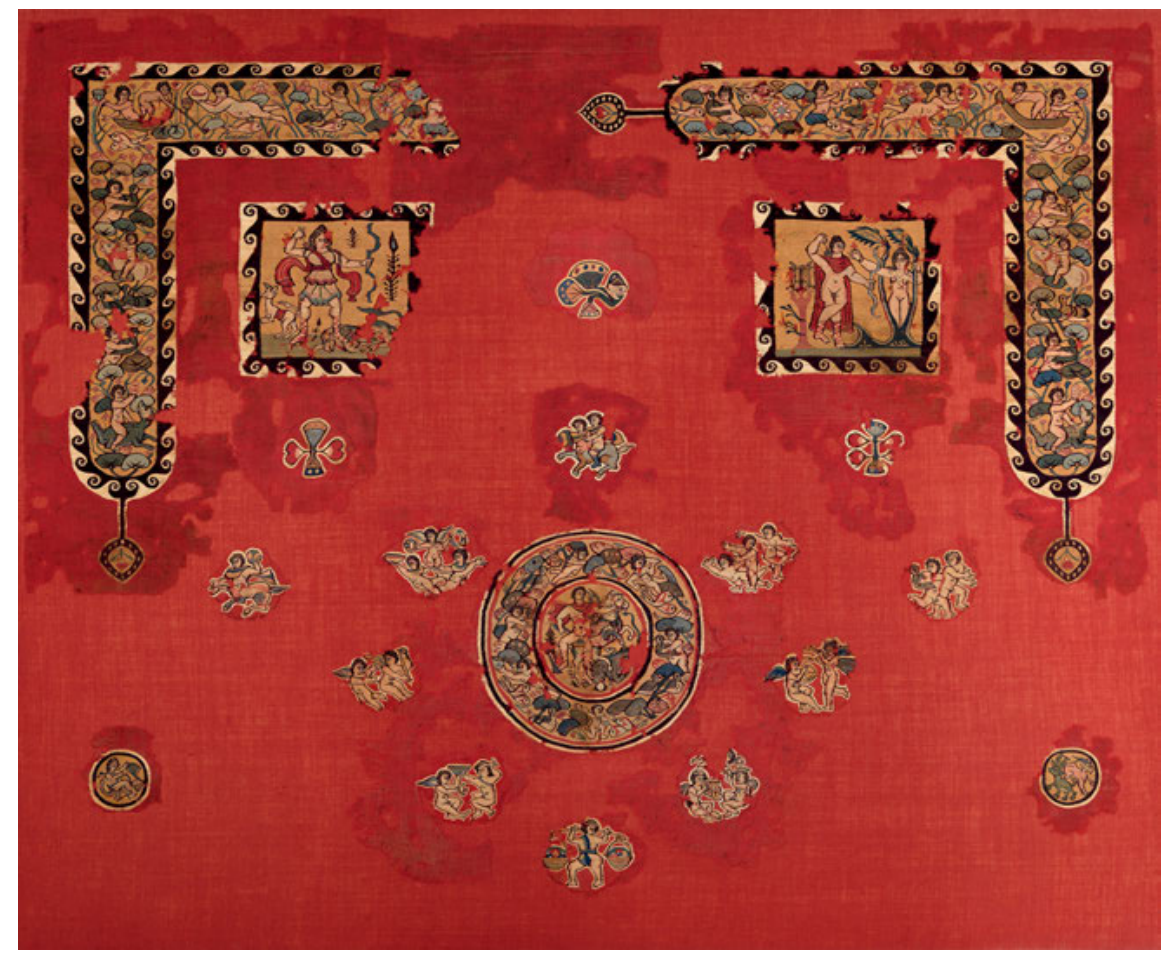

Fig. 18: The so-called "Shawl of Sabina", now in the Louvre (๑ Musée du Louvre/Georges Poncet). 

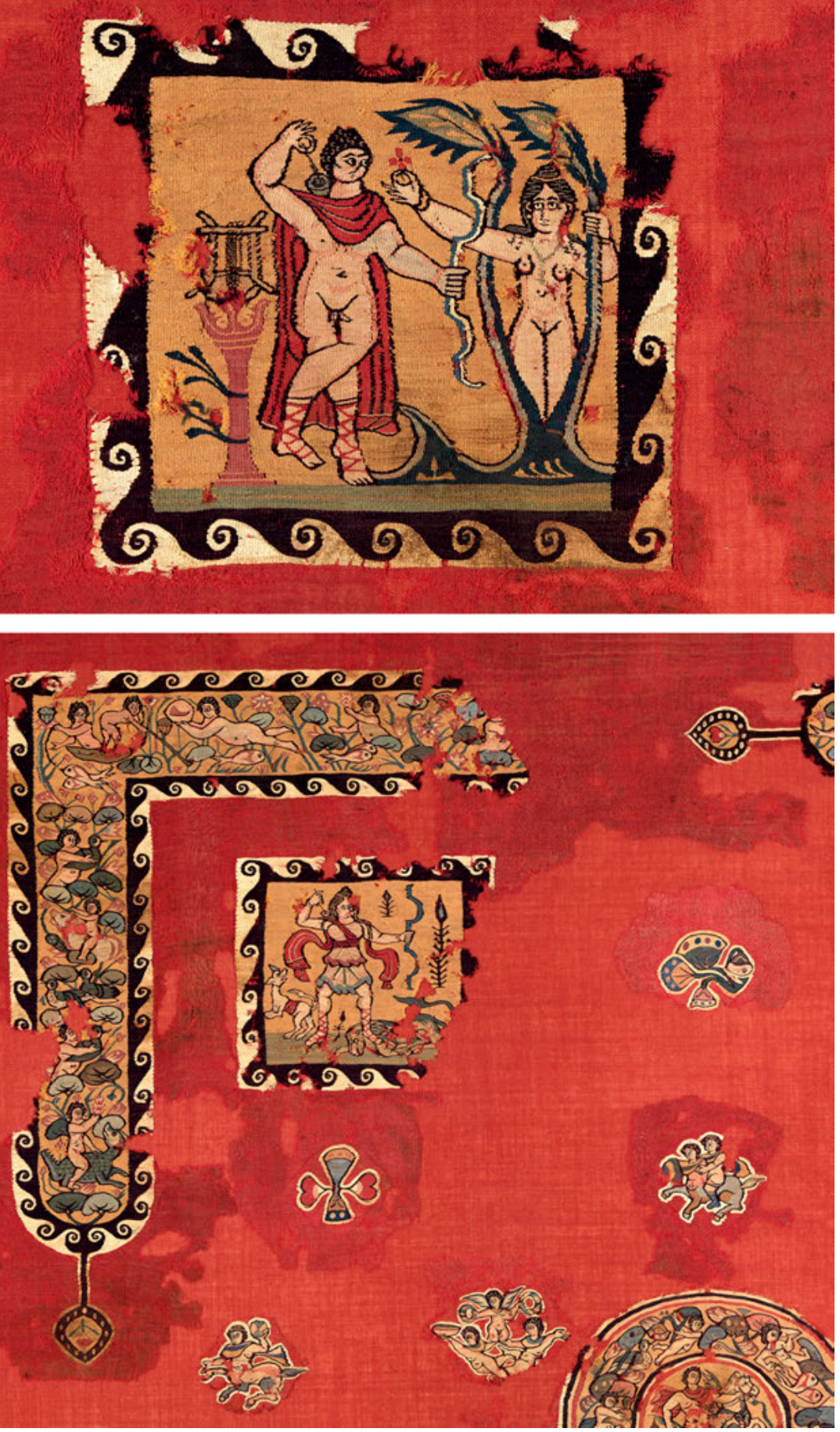

Fig. 19a-b: Depictions of Apollo, Daphne and Artemis on the "Shawl of Sabina" (๔ Musée du Louvre/Georges Poncet). 


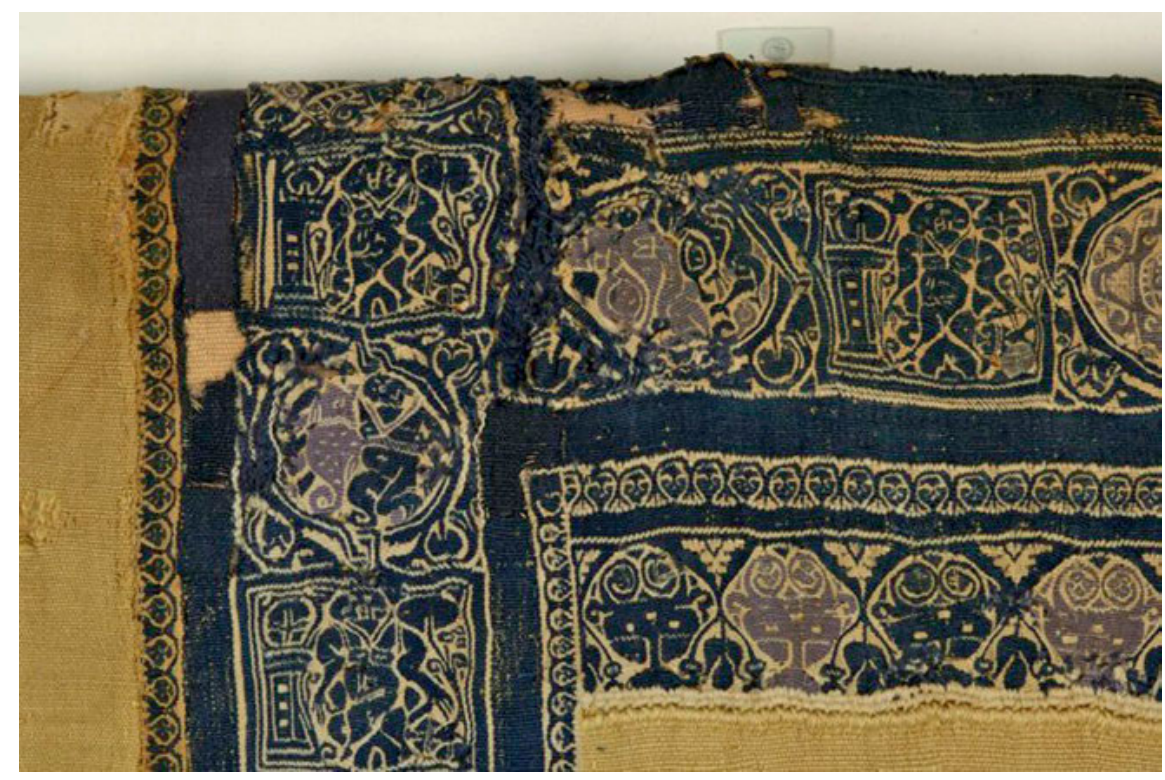

Fig. 20: Coptic wool tunic with mythological motifs, $7^{\text {th }}$ century, wool, $131.9 \times 190.5 \mathrm{~cm}$, Brooklyn Museum, Charles Edwin Wilbour Fund, acc. no. 41.523 (Brooklyn Museum photograph 2007). 


\section{Abstracts}

\section{Domenico Accorinti: Nonnus and the Myth. Pagan Antiquity from a Christian Perspective}

Nonnus of Panopolis (5th century), author of both the 'pagan' Dionysiaca, the largest poem known from antiquity with 21,286 lines in 48 books (more than the length of the Iliad and Odyssey combined), and a 'Christian' hexameter Paraphrase of St John's Gospel (3660 lines in 21 books), is no doubt the most representative poet of Greek Late Antiquity. He composed two works that seem to clash/opposing works, an epic mythological poem on Dionysus and a metrical rewriting of John's text. In the past, this was considered to be a sign for a likely conversion of a pagan author to Christianity. According to this view Nonnus would have written the Paraphrase after his conversion.

But recent scholarship has cleared up the conversion theory definitively - as well as the posteriority of the Paraphrase to the Dionysiaca - and generally acknowledges that Nonnus was a Christian. From this perspective, a valuable approach to the Egyptian poet should consist of a cross reading of both his works as evidence of a complex dialogue between the Classical and the Christian tradition in Late Antiquity.

After a summary of the various scholarly opinions concerning the religion of Nonnus and his use of mythology, this article deals with one of the most embarrassing - at least from a Christian point of view - episodes of the Dionysiaca: the treatment of Achille's and Penthesileia's love in Book 35 (1l. 21-78). Here Nonnus adjusts the famous instance of Achilles' necrophilia to an anonymous Indian, who takes part in the massacre of Bacchants described at the beginning of the Book (1l. 1-20). After killing one of Dionysus' followers with his spear, the Indian slayer falls in love with the Bacchant and would have had sexual intercourse with her dead body upon the ground, as Achilles did, had he not feared the orders of the king Deriades (1l. 27-30). Then the Indian soldier utters a pathetic monologue (1l. 37-77), that contains a list of various pagan healing methods, and in which the poet inserts the prosopopeia of the Bacchant (1l. 49b-53a).

Taking as a starting point the Appendix "De la virginité des Bacchantes", which the late Bernard Gerlaud added to his Budé edition of Books 33-34 of Nonnus' Dionysiaca, this essay suggests that Nonnus may have written this episode as a 'pagan' counterpart to the story of Drusiana and Callimachus in the apocryphal Acts of John $(63-86)$, where we are told of an attempted necrophilia and multiple resurrections.

Thus, the emphasis of Nonnus on terms related to the notion of life and eternity signifies that the central theme of the whole episode is the resurrection of the body after death. On the other hand, the occurrence of the Noli me tangere motif in the prosopopeia of the Bacchant leads us to think that the poet may have seen an analogy between the death of the Bacchant and the Passion of Christ. 


\section{Clifford Ando: Mythistory: The Pre-Roman Past in Latin Late Antiquity}

Historical writing in Latin Late Antiquity displays a new and widespread concern for the history of Italy before the foundation of Rome. The novelty of the moment is revealed both by the extent of the phenomenon and by its interest in the writing of systematic and internally coherent accounts (Section 2). Classical rehearsals of similar information convey specific data in response to exegetic or aetiological demands and show no concern for the coherence or some totality of their data (Section 3). Typical was rather their focus on myth, and especially synchronicities in myth, as a means to advance political claims in the cultural sphere (Section 4). Likewise, classical Roman historiography not only began its narratives with the foundation of cities but structured them around the institutions of poliadic life. This is true despite the persistence in public memory of the pre-Roman past of colonial sites founded de novo as Roman cities. (Section 5). Outliers to this scheme might include classical chronology, but the degree of its deviance is now hard to assess (Section 6). One possible explanation for this interest in a pre-Roman, non-poliadic Italy lies in the prestige status accorded in Late Antiquity to an ancient narrative of a pre-poliadic people, namely, the people of the Torah (Section 7).

\section{Sarah Bassett: “Curious Art”: Myth, Sculpture, and Christian Response in the World of Late Antiquity}

This essay examines Christian attitudes towards mythological sculpture, defined as the representations of gods and heroes, in the later Roman world. It begins with a description of early Christian objections to myth and sculpture, noting that such objections did not seem to carry much weight with the general populace as the use of sculpture in public and private contexts persisted. It continues by examining the ways in which mythological sculpture was used in public and private settings in the city of Constantinople over the course of the fourth, fifth, and sixth centuries. It observes an early fourth-century phase of sculptured installation in which mythological figures are used in a manner consistent with the long-standing habits of Greek and Roman tradition to create civic history, a practice that seems to ignore Christian unease with the questions of idolatry posed by sculpture. It then suggests that this early phase gives way to a later fourth- and fifth-century interest in accommodating mythological sculpture to Christian attitudes by viewing it in purely aesthetic terms as art. It understands this interest in reconciliation and compromise as consistent with the desire on the part of late ancient Christians to find a means to integrate the great cultural legacy of the classical world with new Christian teaching. Finally, it observes the decline of an interest in mythological sculpture in the sixth century, as new, primarily Christian, concerns come to shape late Roman cities. 


\section{Fabienne Jourdan: Orpheus and 'Orphism' in the Christian Literature (in Greek) of the First Five Centuries}

Contrary to the modern perception of the possible link between Orpheus and Christianity, the Christian writers of the first five centuries did not focus on Orpheus' travel into the underworld to compare it to Christ's descent into Hell. Neither did they consider Orphism as a kind of religion of the Book or a small sectarian group in competition with their Faith based on the Word at the heart of the Bible. For them as for the Pagans of their time, Orpheus was firstly the founder of the Mysteries and more generally of the Greek religion itself. Moreover, because of his Thracian origin, they considered him a Barbarian as they were themselves considered. This feature, together with the traditional journey to Egypt attributed to him, contributed to taking for granted that Orpheus was acquainted with the Ancient Wisdom and more precisely with the Mosaic doctrine. By the same token, the Jews had already ascribed to Orpheus a poem praising the One and Only God. The only thing the Christians had to do was appropriate these lines and use them for their own purposes to claim that the famous poet sang in agreement with their belief. Orpheus's marvelous song was the last feature they adopted to describe and enhance Christ's Word as a new and better Orphic song. The article shows in detail how they used these features of Orpheus and his Work in their polemics with the Pagans, sometimes to criticise this tradition and its followers (the Pagans, but also some "Heterodoxes"), sometimes to appropriate it and include it into their own discourse and their exhortations in favour of Christianity. In doing so, they outlined a portrait of Orpheus different from the one transmitted to us through the Middle Ages and the Renaissance where the picture of the Lover of Eurydice prevails.

\section{Troels Myrup Kristensen: Dressed in Myth: Mythology, Eschatology, and Performance on Late Antique Egyptian Textiles}

This paper explores the function of mythological imagery on late antique Egyptian textiles. Given that any study of this material is confronted with considerable methodological issues, it begins with an overview of the role and use of textiles decorated with figural images, as well as a discussion of the thorny issues of chronology and the reconstruction of the physical and visual environment in which the textiles were once an integral part. This first part provides important information on the viewing context in which the late antique textiles with mythological imagery functioned. It is furthermore argued that in order for this field of study to move forward, textiles must not be seen as exclusively decorative, daily-life objects; it is equally important to understand them as objects of performative display, self-representation, and as expressions of eschatological thinking within the funerary context. The second part focuses more explicitly on the use of mythology in late antique Egyptian textiles, and the interplay between art and text. The so-called "Shawl of Sabina", now in the Louvre and with fragments in other collections, is given special attention. 


\section{Winrich Löhr: Christian Bishops and Classical Mythology in Late Antiquity}

This paper analyzes the attitude of some Christian bishops to the myths of classical Greek and Roman Literature. The bishops' stance was articulated in the context of two debates: i) the debate about the conceptualization of pagan religion as theologia tripartita (the myths representing the theologia fabulosa) and ii) the debate about the Christian attitude to the traditional literary culture (paideia). It is shown that in both debates classical mythology was largely unproblematic for these bishops and offered no or few occasions for open conflict or controversy between them and educated pagans. There was a consensus in late antiquity among educated pagans and Christians that classical mythology was of little religious importance. Nevertheless, it remained - sanitised, secularised - part of the traditional paideia: An alternative Christian paideia that may have redefined the school curriculum was envisaged and discussed but not realised. Late antique Christian polemics against the public presence of Greek and Roman myths was largely confined to its representation in sculptures or on the theatrical stage.

\section{Mischa Meier: Heracles - Heraclius - Christ. Georgius Pisides and the kosmorhýstes}

This essay investigates the function of the Heracles-Heraclius references in the work of the poet and panegyric Georgius Pisides. Primarily on the basis of an analysis of the early poem In Heraclium ex Africa redeuntem (610/11), the panegyricus In Bonum Patricium (626), the Heraclias (since 628) and the Expeditio Persica (after 622), the special meaning of Heracles for the emperor as an example is shown. Apparently, the Heracles analogies provided a rather harmless way to associate the ruler with Christ. This went as far as Georgius Pisides creating word of his own invention with the term kosmorhýstes. It is derived from the New Testament verb rhýsesthai and refers directly to Jesus Christ. The associations to Heracles were not the only way for Heraclius to evoke a close bond to Christ. For this reason, the results of the analysis of Georgius are put into a further literary and historical context in the final part of this essay. On the one hand, the essay inquires after basic possibilities that the example of Heracles opened in the context of imperial representation in Late Antiquity. On the other hand, questions are asked about the reasons why Heraclius made such an effort to associate himself with Jesus Christ and why he presented himself as the "Saviour of the World" (kosmorhýstes).

\section{Jörg Rüpke: Shared and Contested History: The Chronograph of 354 and the Catacombe of the Via Latina}

The luxurious diary, known as the Chronograph of 354, is the subject matter of this study. In just one document there are mythological and historical narratives in text and image representation to be found. These were all identified as either exclusively "pagan" or "Christian". An analysis of the social position of both the code and its 
addressee and a detailed examination of its composition and content shed light upon the range and structure of knowledge expected of a young senator and also upon the role that religious questions and controversies played in his world. The result shows how especially historicised religion provided a frame for the orientation of a young member of the senatorial class, who was to be introduced to the fine lines beyond the flat terms such as "paganism" and "Christianity". Christian cults and traditions could be included in a framework, characterised by astrology, the ideas of gods and hundred-year-old Roman institutions. Distinguishing oneself strongly for example from Novatianists - and passing over apparent contradictions - Christianity and paganism - were part of an individual acquisition of religion.

\section{Christian Schäfer: "Seeming Extravagance”. Pagan and Christian Platonists about the Wondrousness of Myth}

The Platonism of the 3rd and 4th century is one of the intellectual centres in which the debate about myth and its meaning is most tangible. Based on an analysis of the philosophical explanation of myth in Sallustius (De dis et mundo III 1-3) this article elucidates how the "extravagance" and "digressiveness" of classical myths were interpreted in classical - pagan and Christian - Platonism. Further, it explains where the Platonist authors saw limits for the allegorisation of mythical material. Next to Sallustius' exegesis of myth the interpretations of Porphyry, emperor Julian, Celsus, Origen, and Augustine are examined in the essay.

\section{Claudia Schindler: Pagan Myths and Christian Rulers. Myths and Mythology in Claudian's Political Poems}

The question of Claudian's religious denomination has been discussed in scholarship intensively for some time. Next to the testimony of Augustine and Orosius, who deny the poet any association with Christianity, scholars point out the lack of explicit Christian references in the work of Claudian as an indication for his pagan orientation. Especially the numerous references to figures and events of GrecoRoman mythology found in Claudian's compositions seem to let ancient traditions live on continuously. On the other hand, this essay shows that Claudian's use of mythological examples is not as conform to traditions as first impressions might suggest. The ancient traditions of myth are functionalised by him in several ways. He places the protagonists of his poems in the roman literary and cultural tradition by using mythical names of peoples and locations so as to distinguish them as legitimate heirs of Roman reign. This argumentation couldn't have been made using Christian material. Direct comparison of the addressee of Claudians poems with mythical figures such as Hercules or Apollo profit from the fact that these figures are established in ancient tradition as keys in political discourse and are sanctioned by Christian argumentation. However, in Claudian's political poetry myth is also often the basis for a panegyrical exaggeration. Such panegyrical syncriseis are 
known to the recipients from both the pagan and the Christian traditions. The superiority of the late antique ruler in light of mythical figures contributes to the demontation of the ancient myth. Furthermore, Claudian underlines the fictionality of the myth over and over again and shows that the actions of his protagonists are true by comparison. Finally, one can observe that he disavows actions of the mythical heroes contrasted to those of the protagonists by unmasking the mythical actions as representations of the primitive and uncivilised earlier times.

\section{Ulrich Schmitzer: Sidonius Apollinaris - Unfertile Muse or the Renovation of Poetry on the Base of Mythology?}

The Gaulish aristocrat Sidonius Apollinaris was both a member of the political elite of the Western Roman Empire during the middle of the 5th century and deeply rooted in classical ancient education. For this reason, scholarship has seen in him until recently a representative of a devotion to old forms and formulas that had become a rhetorical gesture only. Sidonius himself seems to support this verdict by characterizing his poems to be unfertile (Musa sterilis). However, a closer look that is also free from resentment against late antique literature at especially the carmina shows that myth wins a new significance for Sidonius. Furthermore, as a productive piece of the pagan-ancient heritage it can be used for the development of a new form of literature in which the old dichotomies are overcome. Not anti-pagan rigorousness is the scale for this literate, but the integration of established elements that so contribute to the fame of the addressee into the Christian world of late antiquity. 


\section{Abkürzungen (Editionen, Zeitschriften, Reihen, Nachschlagewerke)}

\begin{tabular}{|c|c|}
\hline AASS & Acta Sanctorum \\
\hline $\mathrm{AB}$ & Analecta Bollandiana \\
\hline ACO & Acta conciliorum oecumenicorum \\
\hline $\mathrm{AE}$ & L’année épigraphique \\
\hline AHR & American Historical Review \\
\hline AJA & American Journal of Archaeology \\
\hline AJAH & American Journal of Ancient History \\
\hline $\mathrm{AJPh}$ & American Journal of Philology \\
\hline AJSLL & American Journal of Semitic Languages and Literatures \\
\hline AKG & Archiv für Kulturgeschichte \\
\hline AncSoc & Ancient Society \\
\hline ANRW & Aufstieg und Niedergang der römischen Welt \\
\hline AnTard & Antiquité tardive \\
\hline AntCl & L’antiquité classique \\
\hline $\mathrm{APF}$ & Archiv für Papyrusforschung \\
\hline BAR & British Archaeological Reports \\
\hline BASOR & Bulletin of the American Schools of Oriental Research \\
\hline BASP & Bulletin of the American Society of Papyrologists \\
\hline BBA & Berliner Byzantinistische Arbeiten \\
\hline BBS & Berliner Byzantinistische Studien \\
\hline BBKL & Biographisch-bibliographisches Kirchenlexikon \\
\hline $\mathrm{BCH}$ & Bulletin de correspondance héllenique \\
\hline $\mathrm{BF}$ & Byzantinische Forschungen \\
\hline BHAC & Bonner Historia-Augusta-Colloquium \\
\hline BHG & Bibliotheca Hagiographica Graeca \\
\hline BHL & Bibliotheca hagiographica Latina antiquae et mediae aetatis \\
\hline BJ & Bonner Jahrbücher \\
\hline BKV & Bibliothek der Kirchenväter \\
\hline BMGS & Byzantine and Modern Greek Studies \\
\hline $\mathrm{BS} / \mathrm{EB}$ & Byzantine Studies/Études byzantines \\
\hline BSOAS & Bulletin of the School of Oriental and African Studies \\
\hline BSOS & Bulletin of the School of Oriental Studies \\
\hline $\mathrm{BSl}$ & Byzantinoslavica \\
\hline Byz & Byzantion \\
\hline ByzBulg & Byzantinobulgarica \\
\hline $\mathrm{BZ}$ & Byzantinische Zeitschrift \\
\hline C. & Codex Iustinianus, ed. P. Krueger \\
\hline $\mathrm{CAH}$ & The Cambridge Ancient History \\
\hline CahArch & Cahiers archéologiques \\
\hline
\end{tabular}


CAVT

CC

CCSG

CCSL

CCCM

CFHB

CIG

CIL

CJ

CPG

$\mathrm{CPh}$

CPL

CPPM

CQ

CR

CRAI

CSHB

CSCO

CSEL

CTh

D.

DA

DACL

DHGE

DNP

DOP

DOS

DOT

EHR

FGrHist

FHG

FM

FMSt

GCS

GRBS

Gym

Hell

HdAW

$\mathrm{HSPh}$

HThR
Clavis apocryphorum Veteris Testamenti

Corpus christianorum

Corpus christianorum, series Graeca

Corpus christianorum, series Latina

Corpus Christianorum continuatio medievalis

Corpus fontium historiae byzantinae

Corpus Inscriptionum Graecarum

Corpus Inscriptionum Latinarum

Classical Journal

Clavis patrum Graecorum

Classical Philology

Clavis patrum Latinorum

Clavis patristica pseudepigraphorum medii aevi

Classical Quarterly

Classical Review

Comptes rendus des séances de l'Académie des inscriptions et belles-lettres

Corpus scriptorum historiae Byzantinae

Corpus scriptorum christianorum Orientalium

Corpus scriptorum ecclesiasticorum Latinorum

Codex Theodosianus

Digesta, ed. Th. Mommsen

Deutsches Archiv für Erforschung des Mittelalters

Dictionnaire d'archéologie chrétienne et de liturgie

Dictionnaire d'histoire et de géographie ecclésiastiques

Der neue Pauly

Dumbarton Oaks Papers

Dumbarton Oaks Studies

Dumbarton Oaks Texts

English Historical Review

Felix Jacoby (Hg.): Die Fragmente der griechischen Historiker. Leiden 1923-1958.

Fragmenta historicorum Graecorum, collegit, disposuit, notis et prolegomenis illustravit C. Mullerus, I-VI. Paris 1841/1870.

Fontes Minores

Frühmittelalterliche Studien

Die griechischen christlichen Schriftsteller

Greek, Roman and Byzantine Studies

Gymnasium

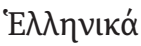

Handbuch der Altertumswissenschaft

Harvard Studies in Philology

Harvard Theological Review 


\begin{tabular}{|c|c|}
\hline $\mathrm{HZ}$ & Historische Zeitschrift \\
\hline I. & Institutiones, ed. P. Krueger \\
\hline IG & Inscriptiones Graecae \\
\hline ILS & Inscriptiones Latinae Selectae \\
\hline IstMitt & Istanbuler Mitteilungen \\
\hline JAOS & Journal of the American Oriental Society \\
\hline $\mathrm{JbAC}$ & Jahrbuch für Antike und Christentum \\
\hline JDAI & Jahrbuch des Deutschen Archäologischen Institutes \\
\hline JECS & Journal of Early Christian Studies \\
\hline JEH & Journal of Ecclesiastical History \\
\hline JHS & Journal of Hellenic Studies \\
\hline JÖAI & Jahrbuch des Österreichischen Archäologischen Instituts \\
\hline JÖB & Jahrbuch der Österreichischen Byzantinistik \\
\hline JÖBG & Jahrbuch der Österreichischen Byzantinischen Gesellschaft \\
\hline JRA & Journal of Roman Archaeology \\
\hline JRGZM & Jahrbuch des Römisch-Germanischen Zentralmuseums \\
\hline JRS & Journal of Roman Studies \\
\hline JS & Journal des Savants \\
\hline JThS & Journal of Theological Studies \\
\hline LACL & $\begin{array}{l}\text { Lexikon der antiken christlichen Literatur, hg. von Siegmar } \\
\text { Döpp und Wilhelm Geerlings. Freiburg/Basel/Wien }{ }^{3} 2002 .\end{array}$ \\
\hline LAW & Lexikon der Alten Welt \\
\hline LexMa & Lexikon des Mittelalters \\
\hline LIMC & Lexicon Iconographicum Mythologiae Classicae \\
\hline LThK & Lexikon für Theologie und Kirche \\
\hline $\operatorname{MDAI}(\mathrm{A})$ & $\begin{array}{l}\text { Mitteilungen des Deutschen Archäologischen Instituts, Athe- } \\
\text { nische Abteilung }\end{array}$ \\
\hline MDAI(R) & $\begin{array}{l}\text { Mitteilungen des Deutschen Archäologischen Instituts, Römi- } \\
\text { sche Abteilung }\end{array}$ \\
\hline MEFRA & Mélanges de l’École française de Rome: Antiquité \\
\hline MEFRM & $\begin{array}{l}\text { Mélanges de l’École française de Rome: Moyen âge - Temps } \\
\text { modernes }\end{array}$ \\
\hline MGH & Monumenta Germaniae Historica \\
\hline AA & Auctores antiquissimi \\
\hline Capit. & Capitularia \\
\hline Conc. & Concilia \\
\hline Epp. & Epistolae \\
\hline Poet. & Poetae Latini aevi Carolini \\
\hline SS & Scriptores \\
\hline SS rer. Lang. et It. & Scriptores rerum Langobardicarum et Italicarum \\
\hline SS rer. Merov. & Scriptores rerum Merovingicarum \\
\hline $\mathrm{MH}$ & Museum Helveticum \\
\hline
\end{tabular}


MIÖG

Mus

N.

PBE

PBSR

$\mathrm{PCPhS}$

PG

PIR

PL

PLRE

PmbZ

PO

P\&P

RA

RAC

$\mathrm{RB}$

$\mathrm{RbK}$

RE

REA

REArm

REAug

REB

REG

REL

RGA

RGG

$\mathrm{RH}$

RHE

RhM

RHR

$\mathrm{RPh}$

RQ

SC

SEG

SO

Spec

StP

StT

SubHag

TAM
Mitteilungen des Instituts für Österreichische Geschichtsforschung

Le Muséon

Novellae, edd. R. Schöll/W. Kroll

Prosopography of the Byzantine Empire

Papers of the British School at Rome

Proceedings of the Cambridge Philological Society

Patrologia Graeca

Prosopographia Imperii Romani

Patrologia Latina

Prosopography of the Later Roman Empire

Prosopographie der mittelbyzantinischen Zeit

Patrologia Orientalis

Past and Present

Revue archéologique

Reallexikon für Antike und Christentum

Revue bénédictine

Reallexikon zur byzantinischen Kunst

Pauly's Real-Encyclopaedie der classischen Altertumswissenschaft

Revue des études anciennes

Revue des études arméniennes

Revue des études augustiniennes

Revue des études byzantines

Revue des études grecques

Revue des études latines

Reallexikon der germanischen Altertumskunde

Religion in Geschichte und Gegenwart

Revue historique

Revue d'histoire ecclésiastique

Rheinisches Museum für Philologie

Revue de l'histoire des religions

Revue philologique

Römische Quartalschrift für christliche Altertumskunde und Kirchengeschichte

Sources chrétiennes

Supplementum epigraphicum Graecum

Symbolae Osloenses

Speculum

Studia Patristica

Studi e testi

Subsidia Hagiographica

Tituli Asiae Minoris 
TAPA

ThLL

ThLZ

ThQ

ThR

TIB

TRE

TRW

TU

VChr

VetChr

$\mathrm{VuF}$

WBS

WdF

WSt

WZKM

ZAC

ZKG

ZPE

ZRG germ. Abt.

ZRG kan. Abt.

ZRG rom. Abt.

ZThK
Transactions and Proceedings of the American Philological Association

Thesaurus Linguae Latinae

Theologische Literaturzeitung

Theologische Quartalschrift

Theologische Rundschau

Tabula Imperii Byzantini

Theologische Realenzyklopädie

Transformation of the Roman World

Texte und Untersuchungen zur Geschichte der altchristlichen

Literatur

Vigiliae Christianae

Vetera Christianorum

Vorträge und Forschungen

Wiener Byzantinistische Studien

Wege der Forschung

Wiener Studien

Wiener Zeitschrift für die Kunde des Morgenlandes

Zeitschrift für antikes Christentum

Zeitschrift für Kirchengeschichte

Zeitschrift für Papyrologie und Epigraphik

Zeitschrift der Savigny-Stiftung für Rechtsgeschichte, germanistische Abteilung

Zeitschrift der Savigny-Stiftung für Rechtsgeschichte, kanonistische Abteilung

Zeitschrift der Savigny-Stiftung für Rechtsgeschichte, romanistische Abteilung

Zeitschrift für Theologie und Kirche 



\section{Personenregister}

Die Anordnung der Namen erfolgt bei mythischen Figuren und Göttern nach deren griechischer Bezeichnung, bei römischen Amtsträgern nach deren römischer, bei bekannteren historischen Personen wird der heute (nach dem subjektiven Eindruck des Herausgebers) gebräuchliche Name verwendet, d.h. man findet Marcus Tullius Cicero unter Cicero.

\section{Antike Personen und mythische Figuren oder Götter}

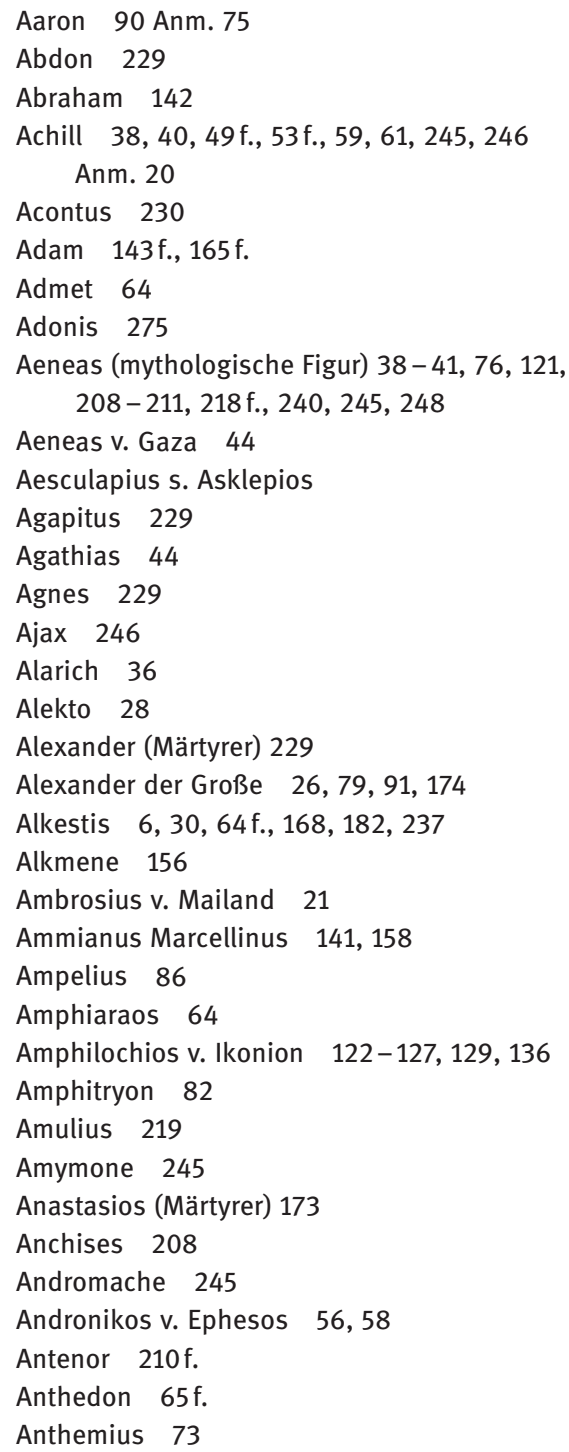

Aphrodite 54, 58, 60, 71, 77, 84, 90, 208, 240, $245 f ., 252-254,275,280$

Apollinaris v. Laodikeia d. Ä. 131-133

Apollinaris v. Laodikeia d. J. 131-133

Apollodoros 65

Apollon 4, 23, 27 f., 71, 85, 87, 89 f., 244

Anm. 15, 245, 278-281

Apollonios v. Rhodos 80

Araneola 89

Arcadius 25, 28, 188 Anm. 151, 242, 251, 257

Archilochos 215

Ares 54, 58, 60, 275

Arethusa 84, 111

Ariadne 269, 277

Ariston 230

Aristoteles 141, 216

Arktinos v. Milet 49

Arnobius 91, 204

Artemis 4, 27, 30, 68 Anm. 105, 71, 84, 240, $278-280$

Ascanius 208, 218

Asklepios 30 Anm. 62, 31, 62-64

Athanasios $110 \mathrm{f}$.

Athena 246, $252 \mathrm{f}$.

Athenagoras 158, 202, 239 f., 256, 260

Atlas 26,71

Auge 245,275

Augias 83, 182

Augustinus v. Hippo 19, 32, 41, 103, 106, $110-$ 113, 115, $118-121,129,136 \mathrm{f} ., 144$

Augustus $36-38$

Aurelius Victor 207

Ausonius v. Bordeaux 44, 73, 75-77, 83, 91

Avitus $72 \mathrm{f} ., 92$

Bacchus 71

Basileios v. Kaisarea 48, 122f., 125-127, 129, 136, $259 \mathrm{f}$. 
Bassus 229

Bathseba 189

Bellerophon 31, $278 \mathrm{f}$.

Belsazar 181

Boethius 26

Bonos 178f., 181, 183, 185

Briareus 135

Buddha 164

Bupalos v. Chios 252-254

Busiris 81

Cacus 82, 208

Caesar 37, 93

Caligula 232

Calocerus 229

Camillus 215

Carpoforus 229

Cassius Dio 218

Castor s. Dioskuren

Marcus Porcius Cato d. Ä. 88, 211f., 220

Marcus Porcius Cato d. J. 88

Publius Valerius Cato 88 Anm. 67

Catull 77-79, 142 Anm. 11

Catullinus 89

Cedrenus s. Kedrenos

Celsus s. Kelsos

Cerberus s. Kerberos

Chairemon 104 Anm. 31

Chalkomedeia 57f., 68 Anm. 105

Charon 276

Cheiron 51, 59

Chimäre 101

Chorikios v. Gaza 44

Chosroes II. 174, 180-186

Christus s. Jesus v. Nazareth

Chryses 245

Dion Chrysostomos 122, 189

Johannes Chrysostomos 48, 120

Cicero 75, 142 Anm. 11

Claudian 9f., 16, 19-42, 44, 58, $75 \mathrm{f}$.

Clavus 230

Clemens v. Alexandria $\quad 26,139,157,193 f .$, 196f., 199-206, 230

Ps.-Clemens v. Alexandria 195, 203

Commodus 11, 169, 190

Constantin I. 8, 27f., 157 Anm. 83, 168 Anm. 8, 169, 174, 184 Anm. 128, 190 f., 228, 242, 244, 248, 250f., 253, 258, 268 Anm. 18

Constantius II. 188 Anm. 151, 219

Coripp 27
Cornelius Nepos 78, 214f., 218, 220

Lucius Annaeus Cornutus 104 Anm. 31

Cosentius 89

Crescentianus 229

Cybele s. Kybele

Cyprian 230, 232

Cyriacus 229

Damasus 224, 236

Damian 27

Daphne 111, 113, 278-281

David 187-189, 193, 206

Demosthenes 174

Deriades 50

Diana s. Artemis

Dikaiarchos 216

Dido 121, 211, 240

Didymos 197, 203

Diocletian $229 \mathrm{f}$.

Diodor 116, 149, 218

Diomedes 83, 248

Furius Dionysius Filocalus 224, 226, 233, 236

Dionysos 6, 45-47, 50, 55 f., 63, 89, 193, 199 , 204 f., 269, 271, 273, 276 f., 282

Dioskuren 25-27, 65, 71

Dipoinos 252f., 254 Anm. 45

Dracontius 17, 44, 49

Drusiana 55-62

Ecdicius 89

Echo $275 \mathrm{f}$

Eleazar 149

Elisa 151 Anm. 58

Enkelados 135

Enkolpios 145

Ennius 71

Ephrem der Syrer 201

Epiktet 155

Epiphanios v. Salamis 55, 64 f., 67

Erinnyen 65

Eros 252-254, 280

Erymanthischer Eber 83

Eryx 81-83

Euagrios 191

Euander 76, 210

Eudocia 133

Euhemeros 116

Eurydike 193

Eurystheus 81, 178 
Eusebios v. Kaisarea 8, 27 f., 104 Anm. 31, 115-118, 146, 156, 157 Anm. 83, 168

Anm. 8, 194, 197, 235, 246 f., 250 f., 258

Eusebius (Märtyrer) 224

Eustathios v. Thessalonike 52

Euthion 85

Eutrop 23, 220

Eva $143 \mathrm{f} ., 165 \mathrm{f}$.

Fabianus 229

Faunus 71, 208

Faustus 89-91

Felicitas 230, 232

Felix 229, 236

Magnus Felix $77 \mathrm{f}$, 86, $88 \mathrm{f}$.

Filippus 229

Firmicius $204 \mathrm{f}$.

Flavius Josephus 149

Flora 119

Fortuna 235

Fortunata 141, 145

Fortunatus 23, 56, 58

Fredegar 168, 189

Fulgentius 17, 49

Gaius $216 \mathrm{f}$.

Ganymed 239

Georgios Pisides 167-192

Geryon 83

Giganten 25, 27, 135

Gildo 36

Glaukos 30,51, 59, 64-67, 71

Gorgonus 230

Gregor v. Nazianz 48, 123, 127, 134-136, 196

Gregor v. Nyssa 48, 161

Gyges 135

Harpyien $33 \mathrm{f}$.

Hekabe 246

Hektor $38 \mathrm{f}$.

Helena 246

Helenos 245, 246 Anm. 20

Helios 25f., 84, 109

Hera $71,80,84,105,211,218,246,252-254$, 260

Herakleios 11, 17, 167-192

Herakleios Konstantinos s. Konstantin III.

Herakleitos v. Ephesos 108, 197

Herakles 4, 11, 25-27, 29-31, 63f., 71, 8183, 84 Anm. 55, 149 f., 151 Anm. 58, 152 -
159, 160 Anm. 101, 167-192, 208, 237,

245-247, 257, 259 Anm. 59, 275

Herakliden $167 \mathrm{f}$.

Hercules s. Herakles

Herculii 25

Hermas 237

Hermes 47, 233, $274 \mathrm{f}$.

Herodot 239 Anm. 1

Hesiod 32, 115 Anm. 1, 121, 128, 130, 135, 215

Hesperiden 83, 182

Hiberia 89

Hieronymus 127, 143f., 206

Hippodame 81

Hippolyt 6, 30 f., 161-164, 230, 233

Homer 49, 54, 80, 110, 115 Anm. 1, 121-123, 125, 128-130, 133, 135 f., 140, 142, 145, 160 Anm. 101, 163, 174, 181, 197, 199, 215, 220, 259

Honorius 20, 25, $27 \mathrm{f} ., 36 \mathrm{f}$.

Horaz 75, 91 Anm. 82, 122

Hrotsvit v. Gandersheim 60

Hyacinthus 230

Hydra 82 f., 155, 174 f., 182, 184

Hyginus $65,212 \mathrm{f}$.

Hylas $80 \mathrm{f}$.

lanus 209f., 212-214, 216, 219, 220 Anm. 27

Ignatius v. Antiochia 162

Ikaros 69

Ionas 13 Anm. 27, 36

lovinianus 206

Isaak 142

Israel 90

Iulus 40

lunior 225

luno s. Hera

Iuppiter s. Zeus

Ixmaracdus 229

Jairus 151 Anm. 58

Jason 80

Jesaja 152 Anm. 64, 159

Jesus v. Nazareth 11, 47, 56, 60, 62f., 67-69, 111f., 115, 140, 142-148, 150, 153f., $156 \mathrm{f}$., 159, $162 \mathrm{f} ., 165,170,180,184,186,190$, $193,225,228-230,232,234-237$

Johannes $56,58,60,62,109,276 f$.

Joseph 31, 149 
Julian Apostata 10, 14 f., 15 Anm. 32, 87, 91, Macrobius 47, 210, 213f., 219, 234 94, 97, 107 f., 109, 128, 130-134, 235, 258, 301

Justin der Märtyrer $63,67,160,204,218$

Justinian 169 Anm. 16, $190 \mathrm{f}$.

Kadmos $35 \mathrm{f}$.

Kairos 252, 255, 260, 274

Kallikles 102

Kallimachos $56,58,78,92$

Kallist 164

Kassandra 246

Kaukasos 65

Kedrenos 252

Kelsos 103, 105f., 150, 201, 206

Kentaur 51, 59, 275

Kerberos $82 \mathrm{f} ., 182$

Kirke $29 \mathrm{f}$.

Kleonäischer Löwe 83

Klytaimnestra 37

Koiranos 64

Konstantin III. 175, 187

Kopeus 65

Kosmas 27

Kotos 135

Kreusa 245, 246 Anm. 20

Kronos 97, 210, 216

Kybele 71

Laktanz 39f., 91, 203

Laodameia 65

Largus 229

Latinus 208

Latona 27, 29, 81

Laurentius 229

Lausos 251-255, 257f., 260

Lazarus 66, 151 Anm. 58, 157, 277

Leontius 89

Leto 68 Anm. 105

Libanios 31, 53, 122 Anm. 28, 123, $127 \mathrm{f}$.

Liberius 236

Livius 224

Lucius Verus 158

Lukan 27, 36, 211

Lukas 130, 143 Anm. 17, 261

Lukian v. Samosata 156

Lukrez 142 Anm. 11

Johannes Lydos 47

Lykaios 84

Lysippos 252-255

Magnentius 225, 226 Anm. 25, 236

Maiorianus 73, 75 Anm. 25, 89

Johannes Malalas 47

Mallius Theodorus 22 Anm. 24

Marc Aurel 158

Marcia Helike 54

Maria Magdalena 68

Mars 33, 60, 71, 84

Marsyas 23f., 260

Martialis 229

Martianus Capella 47

Martina 172 Anm. 27, 189

Maurikios 167

Maximian $229 \mathrm{f}$.

Maximos v. Tyros 103

Memmia 229

Menander 249

Menelaos 246

Merkur 71, 156

Flavius Merobaudes 86

Messala 86

Caecilius Metellus 85 Anm. 58

Mezentius 218

Midas $23 \mathrm{f}$.

Minerva 23f., 33f., 71, 84, 89

Minos 29, 30 Anm. 62, 64-66

Miriam 90 Anm. 75

Morrheus 57f., 68 Anm. 105

Mose 142, 144, 149, 159 Anm. 96, 184

Anm. 128, 196, 199-201, 237

Mygdonia 56

Naïn 15 Anm. 58

Narkissos $275 \mathrm{f}$.

Nectarius v. Calama 119

Nero 232

Nessos $81 \mathrm{f}$.

Niceros 87

Nicostratus 230, 233

Niketas Choniates 257

Nil 273f., 276

Niobiden 6, 280

Noah 183

Nonnos v. Panopolis 10, 16, 44-69, 276

Novatus 233

Numitor 219 
Octavian s. Augustus

Odysseus 23, 84, 122, 139 f., 142, 153, 156, 160 Anm. 101, 161-164, 181, 246, 248, 259

Oikles 64

Oinone 246

Oite 82

Olybrius 25,27

Ommatius 89

Onomakritos 200

Orest 27 Anm. 49, 36-38

Origenes 31, 104-108, 150, 201f., 206

Orion 68 Anm. 105, 111

Orosius 19

Orpheus 11f., 90, 150, 156f., 193-206

Ovid 24, 65, 71, 75, 86 Anm. 60, 89, 113, 121, 275,280

Paian 51, 59

Palladas 44

Palladius 251

Pallas 38, 40, 90

Pan 71

Papanilla 73

Paris 84, 246, 248

Parthenus 229

Pasiphaë 65

Paulinus v. Nola 77, 86, 91

Paulus 148, 152, 158, 228 f., 232, 236

Paulus Diaconus 220

Pegasos 101, 278

Peisander v. Laranda 46

Peleus 89, 246, 248

Pelias 64

Pelops 64f., 81, 84

Penthesileia 49 f., 53 f., $58 \mathrm{f}$., 62

Peregrinus Proteus 4, 71, 158

Perpetua 229, 232

Persephone 84

Perseus 71, 84, 175

Petron $145 \mathrm{f}$.

Petrus 86, 145, 147, 228f., 232, 236

Phaeton 22, 25

Phanes 203

Phasis 80

Phidias 252f., 254 Anm. 45, 260

Philostrat 142, 151

Phoinix 87

Phokas 167, 172, 174-178, 182, 191

Phorkos 71
Phythagoras $89,129,150$

Picus $207 \mathrm{f}$.

Pius 233

Platon 10, 15, 93, 95, 99, 100-103, $106 \mathrm{f}$., 109, 110 Anm. 52, 129, 132f., 141

Plinius d. Ä.142 Anm. 11, 253

Plinius d. J. 75, 91 Anm. 82, 212

Plotin 104 Anm. 31

Plutarch v. Chaironeia 12, 96, 103 f., 107 Anm. 45, 125, 174, 209 f., $212 \mathrm{f}$.

Polemios 89

Pollux s. Dioskuren

Polybos 65

Polyeidos 30 f., 64-66

Polykarp v. Smyrna 11, 150, 154 f., 158-160

Polyklet 260

Polyxene 246

Pompeius Trogus $218 \mathrm{f}$.

Pomponius 216

Pontianus 229, 233

Porphyrios 62, 104 Anm. 31, 108-110, 117

Poseidon 65, 245

Postumius Silvius 208

Praetextatus 229

Praxiteles 252-254

Priamos 39

Priapus 85

Proba 27, 225

Probinus 25, 27

Prodikos $177 \mathrm{f}$., 190

Prohairesios 131

Prokopios v. Gaza 44

Prometheus 156

Promotus $38 \mathrm{f}$.

Protarchos v. Tralles 213

Protesilaos 65, 150

Protogonos 203

Protus 230

Prudentius 77, 256, 258, 260

Ptolemaios 212

Pyrrhos 246

Pythia 246

Python $27 \mathrm{f}$.

Quintus v. Smyrna 49

Quintilian 142 Anm. 11

Remus 246, 248, 250

Roma 77

Romulus $71,76,92,216,246,248,250$ 
Rufinus 23, 28

Ruricus 89

Sallust 211

Sal(l)ustios 10, 94-99, 108

Flavius Sallustius 94 Anm. 2

Saturninius Secundus Salustius 94 Anm. 2

Sarpedon 245

Saturn 71, 84, 207f., 212-214, 216, 218-220, 226

Saturninus 230

Satyr 51, 55, 71, 270

Schenute v. Atripe 45

Scipio 174

Sebastianus 229, 261

Secundus 229

Semnen 229

Sempronianus 230

Seneca 153, 154 Anm. 72, 158

Septimius Severus 242

Sergios 168, 172

Servius 210-212, $219 \mathrm{f}$.

Severinus 229

Severus 55

Sidonius Apollinaris $10,27,44,71-92$

Silanus 229

Silene 51

Silius Italicus 75

Sirenen 139, $162 \mathrm{f}$.

Sisyphos 65

Skylla $65,111,113,251$

Skyllis 252f., 254 Anm. 45

Sokrates (Kirchenhistoriker) 8, 131-134, 249

Anm. 33

Sokrates (Philosoph) 88, 102, 154

Sol s. Helios

Sozomenos 8, 131-134, 248, 249 Anm. 33

Statius 29, 75, 89, 142 Anm. 11

Stephanus 261

Stilicho 20, 28-41

Lucius Aurelius Avianus Symmachus 224

Quintus Aurelius Symmachus 75, 86, 223, 225

Synesios 44

Tacitus 91 Anm. 82, 145 Anm. 32

Tantalos $64 \mathrm{f} ., 84$

Tatian 55, 195, 197, 202, 239, 256, 260

Teiresias 65, 159 Anm. 95

Terenz 142

Tertia 56
Tertullian 91, 140, 143-145, 153, 156, 158, $239 \mathrm{f} ., 256,260$

Thales v. Milet 89

Thalia 79, 86

Thallos 218

Thekla 56

Theoderich II. 91, 92 Anm. 84

Theodoret v. Kyrrhos 62, 199, 203, 205

Theodoros Synkellos 188

Theodosius I. 20, 31, 36, 242, 244 Anm. 16, $250 \mathrm{f}$.

Theodosius II. 55, 242, 251

Theophanes 173 Anm. 37, 187

Theophilos v. Antiochia 63, 67

Theophrast 216

Theophylakt Simokates $167 \mathrm{f}$.

Thersites 53

Theseus 150, 277

Thetis $89,246,248$

Thomas 143, 151

Thukydides 239 Anm. 1

Thyestes 36, 84

Tiberius 232

Timotheos v. Athen 174, 230, 261

Tiphys $32 \mathrm{f}, \mathrm{g}$

Titanen 135

Tityos 68 Anm. 105

Trimalchio 145

Tullius Hostilius 215

Turnus 38,40

Tuscus 229

Tylos 66, 277

Typhon 101

Valentinian I. 251

Valentinus 223, 225, 226 Anm. 23, 234

Valerius Flaccus 34,80

Marcus Terentius Varro 118, 137, 217, 239

Publius Terentius Varro Atacinus 80

Venantius Fortunatus 23

Venus s. Aphrodite

Vergil 39f., 71, 74f., 77-79, 81, 92, 115

Anm. 1, 121, 136, 142 Anm. 11, 210-212, $218-220,225$

Vesta 84,248

Victorinus 131, 229

Virtus 279

Vitruv 142 Anm. 11

Vitalis 229

Vulcanus $39,71,84,208$ 
Xenokrates 104 Anm. 34

Xenon 214

Xenophanes v. Kolophon 15, 95

Xerxes 174,181

Xystus 229

\section{Nachantike Personen}

Accorinti, Domenico 10, 16

Ando, Clifford 12, 17

Assmann, Aleida 4

Assmann, Jan 4, 165

Auerbach, Erich 11,141-147, 150, 152, 156, 164-166

Balty, Janine 54

Basset, Sarah $8,12,15-17$

Benjamin, Walter 110

Betz, Hans Dieter 143, 150 f., 158 Anm. 88

Birt, Theodor 20

Blond, Georges 58

Blumenberg, Hans 1f., 4, 14

Bogner, Hans $45 \mathrm{f}$.

Bourdieu, Pierre 223

Bourguet, Pierre du 267

Bowersock, Glen 66, 278

Bracher, Karl Dieter 12

Cambell, Joseph 164

Cameron, Alan 19, 21, 45, 47, 76, 127, 133, 207, 210

Cancik, Hubert 158 f., 215

Certeau, Michael de 223

Chesterton, Gilbert K. 93

Christiansen, David 20

Christiansen, Peder G. 20

Chuvin, Pierre $47 \mathrm{f}$.

Daszewski, Wiktor A. $45 \mathrm{f}$.

Decker, Johannes 46

Demougeot, Émilienne 41

Dewar, Michael 37

Dijkstra, Jitse 281

Döpp, Siegmar 19, 29

Flasch, Kurt 102

Fuhrmann, Manfred $1,3,9,16,41$
Zagreus 193

Zeus $23,33,71,84,92,105,120,128,135$, 155, 203, 218, 239, 252 f., 260, 277, 280

Zonaras 251, 252 Anm. 41, 260 Anm. 61
Gayet, Albert 265f., 268, 275, 277

Gerlaud, Bernard 43, 55, 57f., $67 \mathrm{f}$.

Goulet, Richard 130

Gualandri, Isabella $28 \mathrm{f}$.

Heitsch, Ernst 101

Herzog, Reinhart 1

Huber, Irene 171

Iser, Wolfgang 1

Jauß, Hans Robert 1

Johnston, James-Howard 171

Jourdan, Fabienne 11

Kaldellis, Anthony 47

Karivieri, Arja 282

Kessler-Dimin, Elisabeth 46

Keydell, Rudolf $45 \mathrm{f}$., 48

Kleist, Heinrich v. 50

Koselleck, Reinhart 1

Krapinger, Gernot 75

Kresten, Otto 187

Kristensen, Troels Myrup 12,17

Lässig, Elisabeth 270

Leppin, Hartmut 69

Levy, Harry 20

Lewis, Clive S. $110 \mathrm{f}$.

Liebeschuetz, Wolfgang $46 \mathrm{f}$.

Livrea, Enrico 46

Löhr, Winrich 11, 15

Lucius, Ernst 160

Lugaresi, Leonardo $119 \mathrm{f}$.

Lund, John 282

Mann, Thomas 98

Markschies, Christoph 140

Marrou, Henri-Irénée 121, 131

Marx, Karl 156

Mazzarino, Santo 20 
Meier, Christian 1

Meier, Mischa 11, 17

Meyer, Emanuel 269

Nesselrath, Heinz-Günther 52, 154

Nietzsche, Friedrich 4

Nissen, Theodor 171

Oberg, Eberhard 123, $125 \mathrm{f}$.

Pépin, Jean 100

Piccardi, Daria Gigli 46

Piétri, Charles 236

Pound, Ezra 66

Prostmeier, Ferdinand R. 63

Pyykkö, Vappu 48

Rahner, Hugo 43

Riemschneider, Margarete 44

Rosen, Klaus $130 \mathrm{f}$.

Rousseau, Philip 126

Rüpke, Jörg 12, 17, 43, 209, 215

Rüpke, Ulrike 43
Salzman, Michele Renée 227 Anm. 28

Schäfer, Christian $10 \mathrm{f}$., 14

Schindler, Claudia 9f., 16, 75

Schmid, Wolfgang 20, 41

Schmitzer, Ulrich 10, 15, 17

Schneider, Carl 163

Shorrock, Robert 47f., 66

Simons, Roswitha 49

Snodgrass, Anthony 276

Spanoudakis, Konstantinos 69

Stern, Henri 227 Anm. 28

Stevens, Courtenay E. 74

Taubes, Jacob 1

Vian, Francis 46

Wallraff, Martin 133

Webb, Ruth 120, 129

Whitby, Mary 171, $174 \mathrm{f}$.

Willers, Dietrich 45

Wolter, Michael 149

Zanker, Paul 272

Zilling, Henrike Maria 11, 16, $189 \mathrm{f}$. 


\title{
Register der Orte, Länder und Völkerschaften
}

\author{
Ägypten 17, 55 Anm. 49, 56, 59, 200, 263 - \\ 282 \\ Akhmim 45, 265, $276 \mathrm{f}$. \\ Alba Longa 208f., 215, 218 \\ Alexandria 19, 21 Anm. 19, 56, 194, 235, 281 \\ Alpen 211 \\ Antinoopolis 265, 268, 272, 274-276, 278 \\ Antiochia am Orontes 128 Anm. 52 \\ Antiochia in Pisidien 172 \\ Apenninen 211 \\ Argos 84, 105, 260 \\ Arkadien 84 \\ Asia Minor s. Kleinasien \\ Athen 5, 17 Anm. 39, 126, 131 \\ Awaren 172, 177, 184 \\ Bagawat 267 \\ Bassariden 50 \\ Bastarner 38 \\ Bethesda 60 \\ Bethlehem 229 \\ Boier 215 \\ Bosporus 249 \\ Byzantion s. Konstantinopel \\ Camesene 213 \\ Campania 223 \\ Chryse 244 \\ Clermont 10,73 \\ Dakhla 270, 281 \\ Delphi 244, 246, 250 \\ Ephesos 244 \\ Eridianus s. Po \\ Fayum 268 Anm. 18, 270 \\ Gallien 23, 72f., 83, 92, 120, 211 (Gallia Cisal- \\ pina) \\ Gaugamela 79 \\ Germanen 121 \\ Getsemani 63 \\ Goten 22, 24, 29 f., 38 (Westgoten), 73 (West- \\ goten), 91f. (Westgoten) \\ Griechenland 14, 39, 215, 271 \\ Hades 51, 61, 182, 190, 193 \\ Hawara 268 Anm. 18 \\ Henna 84 \\ Herakleopolis Magna 280 \\ Hymettos 84 \\ Ilion s. Troja \\ Insubrer 215 \\ Italien 12 (Via Latina), 29, 207-216, 218, \\ 221f. (Via Latina), 230 (Via Aurelia), $237 \mathrm{f}$. \\ (Via Latina) \\ Ithaka 110, 153 \\ Janiculum 213 \\ Jerusalem 143 Anm. 17, 173, 186 f., 192 \\ Judäa 229 \\ Karanis 270 \\ Karthago 232 \\ Kelainai 23 \\ Kellis 270 \\ Kleinasien 24, 247, 271 \\ Knidos 253 \\ Konstantinopel $8,12,17,123,172,178,180$, \\ 184 f., 187f., 235, 241-251, 257f., 260 f., \\ 279 \\ Kreta 29,84 \\ Lampsakos 84 \\ Latium 84, 211 \\ Lavinium 208, 212, 218, 248 \\ Lindos $252 \mathrm{f}$. \\ Lipari 84 \\ Lykien 23 \\ Marathon 79 \\ Melpum 215 \\ Morija 142 \\ Mykene 36 \\ Nea-Paphos 45 \\ Nordafrika 9 Anm. 24, 17 Anm. 39, 233 (Afri- \\ ca), 235 (Africa), 247 \\ Numidia 223 \\ Oita 83,189 \\ Olymp 23
}


Olympia 252 f., 260

Palatin 76

Panopolis S. Akhmim

Paphos 84

Perser 172 f., 174 Anm. 45, 177, 182, 184-187, 191

Phäaken 123

Phrygien $23 \mathrm{f}$.

Po 22

Praeneste 212

Rhodos 84, 252

Rom 6 Anm. 16, 8, 12, 14, 17, 19, 20 (Forum Traiani) 26 f., 35 f., 39, 54, 72 f., 76, 92, 131, $145,158,164,190,207-210,212-216$, $218-220,228-233,235,244,246-251$, 271

Rotes Meer 237

Rubikon 211

Samos 84, 105, $252 \mathrm{f}$.

Sāsāniden 167, 173, 183
Senoner 215

Shahba-Philippopolis 54

Sinai 112, 149

Skythen 84

Styx 276

Symplegaden $32 \mathrm{f}$.

Tarsos 158

Tartaros 23, 29 f.,65

Terenouthis 276

Theben 35f., 84

Thermopylen 79

Thraker 84

Thymbra 84

Trier 235

Trimithis 281

Troja 12, 84, 208, 246, 248f., 251

Tyros 247

Vandalen 17

Veji 215

Venetia 211 